\title{
Regions at a Glance 2011
}

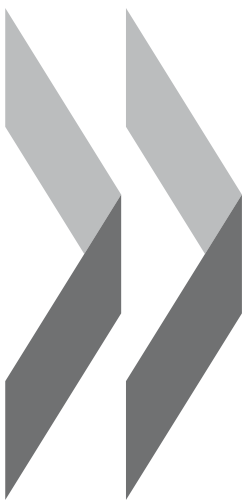

(6) 2
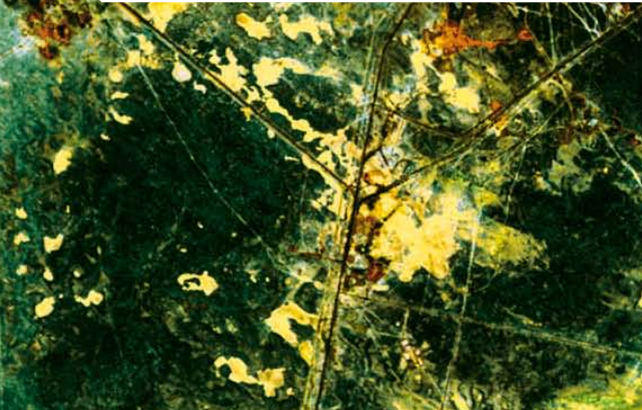

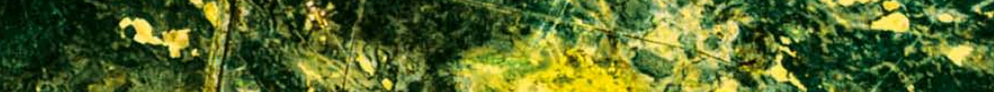

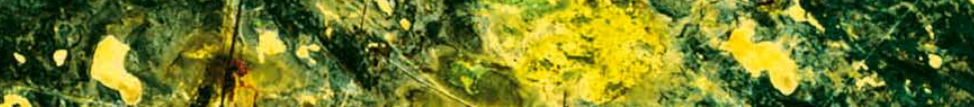

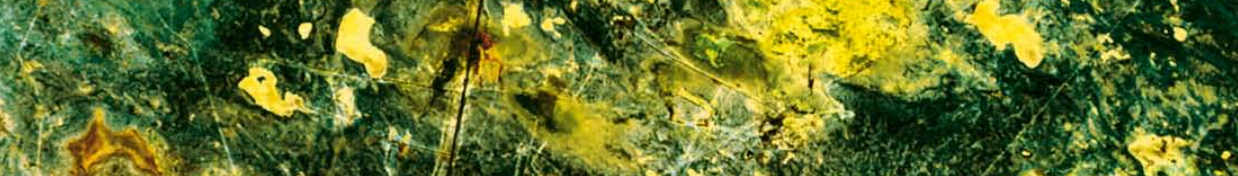
S.5.

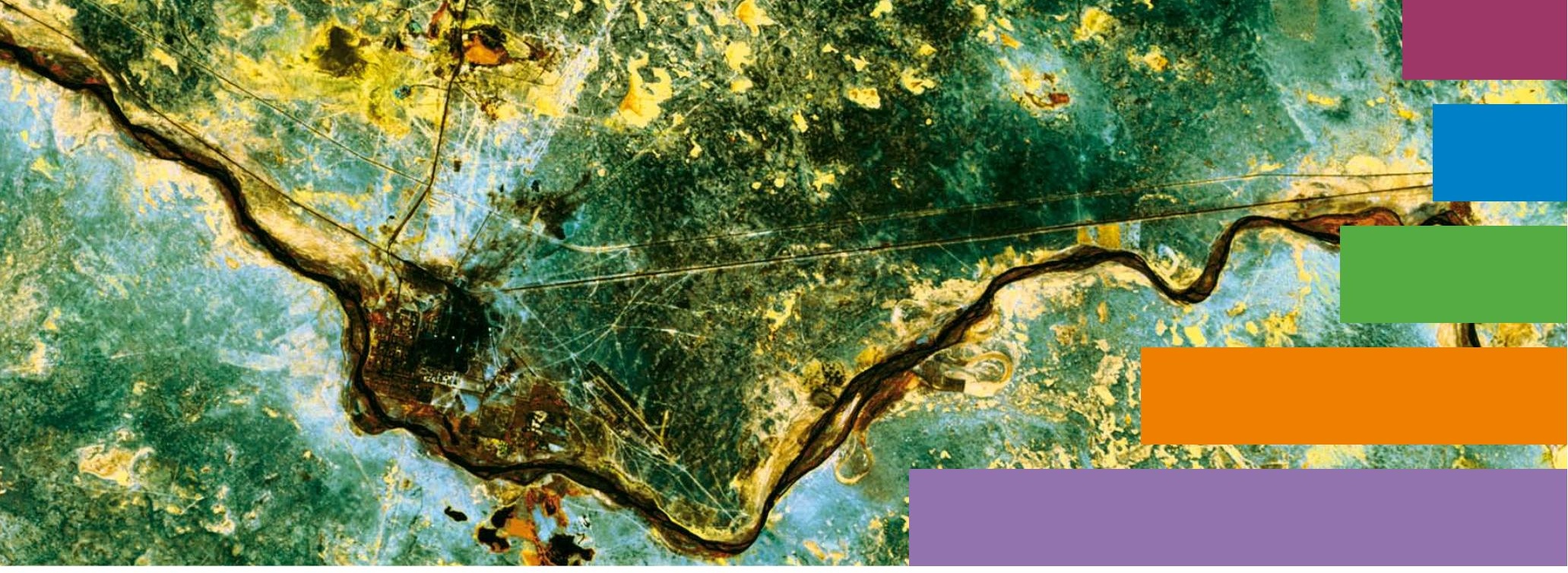

D.)
OECD 



\section{OECD Regions at a Glance}

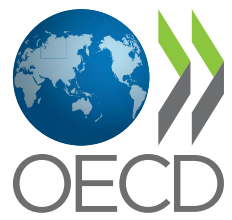


This work is published on the responsibility of the Secretary-General of the OECD. The opinions expressed and arguments employed herein do not necessarily reflect the official views of the Organisation or of the governments of its member countries.

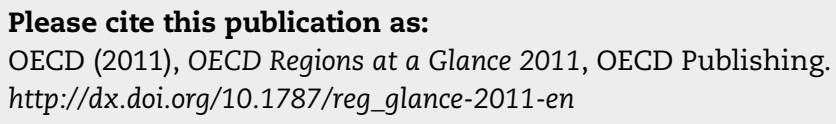

ISBN 978-92-64-10514-0 (print)

ISBN 978-92-64-10525-6 (PDF)

ISBN 978-92-64-10697-0 (HTML)

Series/Periodical:

ISSN 1999-0049 (print)

ISSN 1999-0057 (online)

\section{Photo credits:}

Cover illustration: @ InterNetwork Media/Photodisc/Getty Images.

Chapter 1: ๑ image100/Corbis/Inmagine ltd.

Chapter 2: ๑) Corbis/Inmagine ltd.

Chapter 3: ๑ Radius Images/Corbis.

Corrigenda to OECD publications may be found on line at: www.oecd.org/publishing/corrigenda.

Revised version, July 2011.

Details of revisions available at: $h t t p: / / w w w . o e c d . o r g /$ dataoecd/21/35/48464771.pdf.

(c) OECD 2011

You can copy, download or print OECD content for your own use, and you can include excerpts from OECD publications, databases and multimedia products in your own documents, presentations, blogs, websites and teaching materials, provided that suitable acknowledgment of OECD as source and copyright owner is given. All requests for public or commercial use and translation rights should be submitted to rights@oecd.org. Requests for permission to photocopy portions of this material for public or commercial use shall be addressed directly to the Copyright Clearance Center (CCC) at info@copyright.com or the Centre français d'exploitation du droit de copie (CFC) at contact@cfcopies.com. 


\section{Foreword}

G overnments need reliable and comparable data to underpin policies that promote regional growth. The OECD has developed a unique database of sub-national statistics that allow policymakers to analyse trends both domestically and across countries. The use of internationally comparable data has been a critical input in reforming the objectives and tools of regional development policy in OECD countries. By providing measures of regional performance and identifying factors that increase the competitive edge of a region and the well-being of its current and future population, OECD data has encouraged a shift from a subsidy-based, compensatory approach to regional policy to one that focuses on enhancing regional potential. OECD Regions at a Glance reflects continuous effort by the OECD Working Party on Territorial Indicators in collaboration with the OECD Secretariat to improve the evidence base at regional and local levels.

In line with OECD's broad based approach to policy - better policies for better lives - this fourth edition of OECD Regions at a Glance examines trends across an even wider range of policy fields demography and migration, economic growth, employment and productivity, knowledge-based activities, education, health care, income, environmental outputs and includes comparisons with regional development dynamics in emerging economies. The scope and time period covered by OECD Regions at a Glance give policy makers a tool to understand the contribution of each region to aggregate development, and clues as to how that contribution could be increased.

Disparities both across and within countries have widened in the aftermath of the 2008-09 economic crisis. This observation seems to suggest that in the interest of maintaining national growth levels, a differentiated approach is needed for different typologies of regions. As OECD countries search for a path to economic recovery that leads to more sustainable forms of development, sound statistics that encompass a richer definition of development and quality of life will be essential. The local availability of high-quality services, access to opportunity for marginal or vulnerable groups, the institutional capacity of sub-national governments, levels of civic participation are all relevant elements for more inclusive and sustainable policies that need to incorporate and be understood at the local level.

This new development model is mapped into the structure of this edition of OECD Regions at a Glance; within each section, a number of statistics showcase the contribution of regions to build stronger, fairer and cleaner economies. New measures of quality of life in regions are presented for the first time, such as, among others, income of households and regional disparities in the access of key public goods, estimates of air quality and carbon emissions in regions comparable across countries. The size of the regional difference in these measures points to the importance of improving the availability of sound information at detailed territorial levels to inform both the political debate and communities wanting to better understand the quality of life of the places they live in.

The development of internationally comparable indicators on environmental sustainability and social inclusion at regional and urban levels is still at the beginning and much needs to be done in the years to come. The OECD will continue to expand the use and integration of new sources of data and to explore areas where advancement in the conceptual framework is needed. For example, work is currently underway to produce internationally comparable estimates of carbon emissions of 
FOREWORD

metropolitan areas. This edition of OECD Regions at a Glance already shows that such progress is possible and suggests areas in which evidence and policy needs can be strenghtened.

OECD Regions at a Glance was coordinated by Monica Brezzi and prepared by Monica Brezzi, Mario Piacentini, Konstantin Rosin, Vicente Ruiz and Daniel Sanchez-Serra, under the responsibility of Joaquim Oliveira Martins, Head of the Regional Development Policy Division. Mauro Migotto contributed to the statistical data (innovation) required for the publication. Delegates of the OECD Working Party on Territorial Indicators (WPTI) offered guidance on the statistical tools to measure regional economies and commented on the draft.

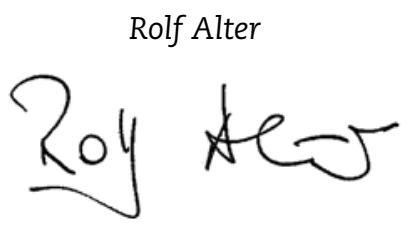

Director, Public Governance and Territorial Development Directorate

4

OECD REGIONS AT A GLANCE 2011 ○ OECD 2011 


\section{Table of Contents}

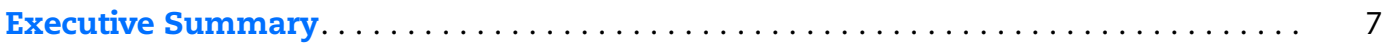

Interpreting OECD Regional Indicators $\ldots \ldots \ldots \ldots \ldots \ldots \ldots \ldots \ldots \ldots \ldots \ldots \ldots \ldots \ldots \ldots \ldots$

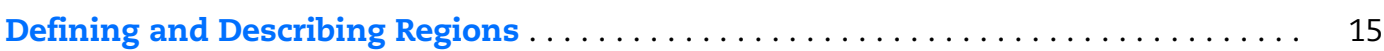

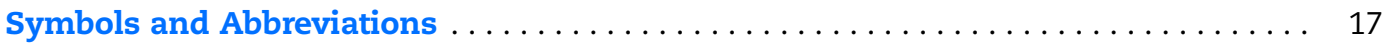

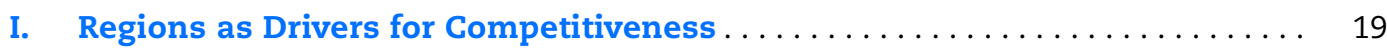

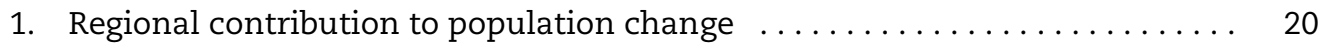

2. Distribution of population and regional typology $\ldots \ldots \ldots \ldots \ldots \ldots \ldots .22$

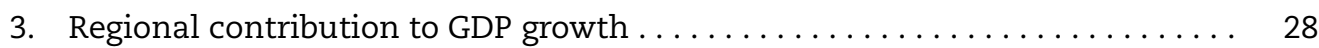

4. Regional contribution to change in employment $\ldots \ldots \ldots \ldots \ldots \ldots \ldots \ldots . \ldots \ldots$

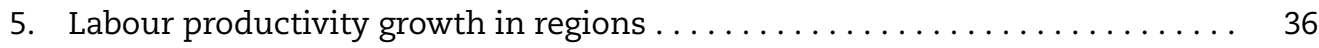

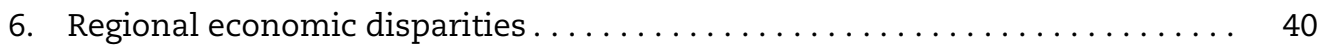

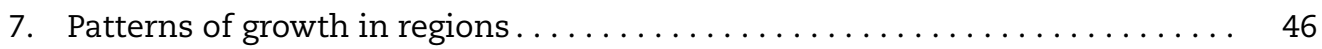

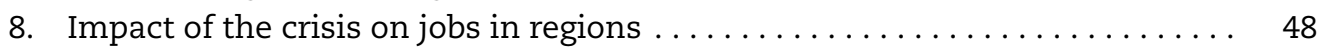

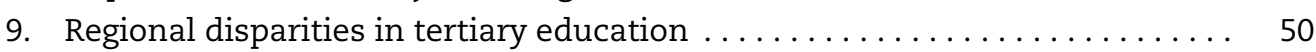

10. Skilled immigration in OECD regions ........................ 52

11. Regional specialisation and productivity growth across sectors . . . . . . 54

12. Regional specialisation in knowledge-oriented sectors . . . . . . . . . . 56

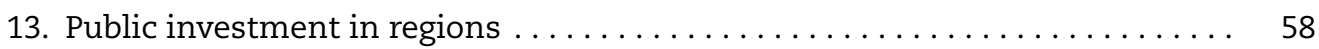

14. Research and development expenditure in regions $\ldots \ldots \ldots \ldots \ldots \ldots \ldots 62$

15. Public and business research and development expenditure .......... 64

16. Patents in regions and among different economic actors ........... 68

17. Regional patterns of co-patenting. .......................... 70

II. Inclusion and Equal Access to Quality Services in Regions . . . . . . . . 73

18. Regional disparities in household income .................. 74

19. Concentration of the elderly population in regions $\ldots \ldots \ldots \ldots \ldots \ldots$

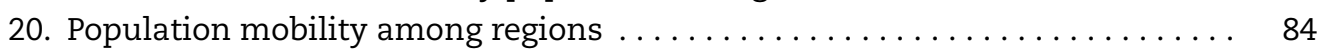

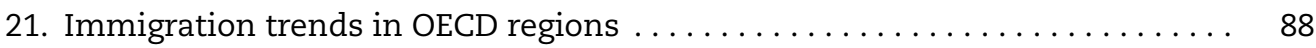

22. Regional disparities in unemployment. . . . . . . . . . . . . 90

23. Gender differences in employment opportunities ............... 96

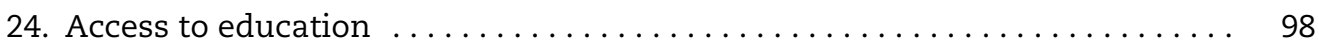

25. Access to health . . . . . . . . . . . . . . . . . . . . . . 100

26. Access to basic services in developing economies .................. 104 
III. Environmental Sustainability in Regions and Metropolitan Areas . . . . . . . . 107

27. The growth of urban land in OECD regions . . . . . . . . . . . . . . 108

28. Forests, natural vegetation and the carbon footprint of regions . . . . . 112

29. Carbon emissions and air quality in regions $\ldots \ldots \ldots \ldots \ldots \ldots$

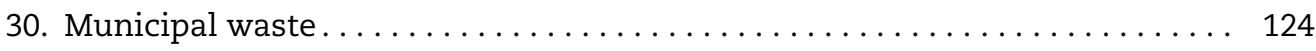

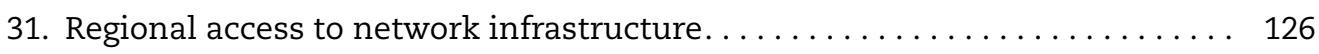

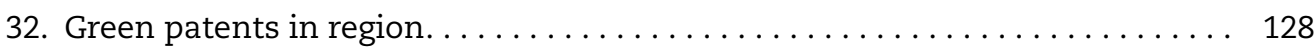

Annex A. Territorial grids and regional typology . . . . . . . . . . . . 131

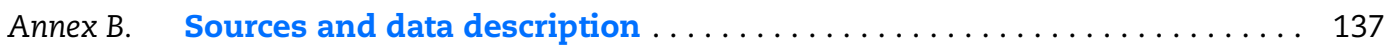

Annex C. Indexes and formulas. . . . . . . . . . . . . . . . . . . . 158

This book has...

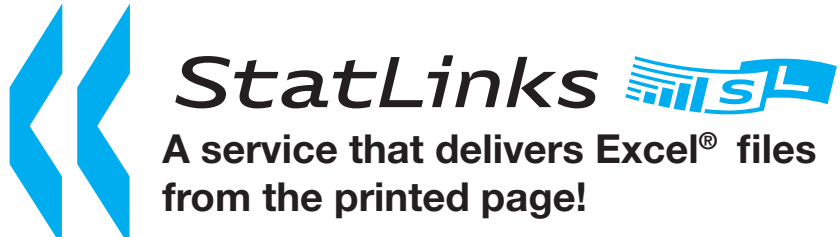

Look for the StatLinks at the bottom right-hand corner of the tables or graphs in this book. To download the matching Exce $^{\circledR}$ spreadsheet, just type the link into your Internet browser, starting with the $h t t p: / / d x_{\text {. }}$ loi.org prefix.

If you're reading the PDF e-book edition, and your PC is connected to the Internet, simply click on the link. You'll find StatLinks appearing in more OECD books. 


\section{Executive Summary}

I International comparisons of economies and societies tend to be undertaken the country level. Statistics on production capacities refer to gross domestic product (GDP) for example, while health and education levels tend similarly to be measured and debated in national terms. However, the differences between countries are often not as great as the disparities within them. In Chile, Poland, Portugal and Turkey, for example, the GDP per worker in the best performing region is more than three times higher than in the worst performing region. In several places, disparities have widened recently, as evidenced by the doubling of the difference in employment growth rate across OECD regions after the 2008-09 recession. Understanding the differences and similarities in regional economic structures is essential for designing effective strategies to resume and maintain aggregate growth. At the same time, statistical evidence specific to regional contexts can help strengthen the recovery of OECD countries by identifying potential and challenges of places to become engines of sustainable economic and social development.

OECD Regions at a Glance aims to make these differences across "places" apparent, and to unpack what they imply for national performance and individual welfare. It does so by providing region-by-region indicators that help to identify areas that are outperforming or lagging behind in their country, as well as the 34-country OECD area. Patterns of growth and the persistence of inequalities are analysed over time, and insights are provided on the relationships between the characteristics of regions and the outcomes they achieve.

This fourth issue of the OECD Regions at a Glance series is organised in three sections, showcasing the contribution of regions to build stronger, fairer and cleaner economies: I. Regions as drivers for competitiveness; II. Inclusion and equal access to services in regions; III. Environmental sustainability in regions and metropolitan areas. This edition includes a number of novelties compared with the previous issues. The analysis of regional competitiveness has been expanded to include measures of public investment in regions, regional connectivity in innovation activities and trends of skilled migrants. For the first time, regional indicators of carbon emissions, air quality, change in urban land and in forest cover, and access to network infrastructure have been produced to assess the environmental sustainability of regions. Statistics on labour mobility and immigration in OECD regions enrich the analysis of demographic trends. The territorial dimension of access to services is explored both for OECD countries (education, health and broadband access) and developing countries (water, sewage and electricity). Finally, regional statistics for emerging economies (Brazil, China, India, the Russian Federation and South Africa) are included for the first time. 


\section{Key findings}

Local factors matter for national sustained growth. Around $40 \%$ of OECD GDP, employment and population growth in the past 15 years are largely due to a small number of regions (the $10 \%$ top performing regions). The importance of economic agglomerations for growth is an established fact. However, data show that the pace of growth has slowed in many large metropolitan regions in OECD countries, while predominantly rural regions grew at a faster rate than predominantly urban regions in the past 15 years, narrowing the gap between urban and rural areas in some countries.

Increases in labour productivity have a more significant effect than changes in labour utilisation on the GDP per capita growth rate of OECD regions during 1995-2007. Differences in labour productivity growth among regions are invariably the result of multiple national and local factors, including labour-market policies and institutions as well as innovation and skills. For these reasons, national and regional governments are increasingly putting co-ordinated policies for education, skills and innovation in place.

Differences in the tertiary educational attainment of the labour force are greater among regions in the same country than across countries. The Czech Republic, France, Spain and the United States show the largest variation in tertiary educational attainment. For instance, in 2008, in West Virginia (United States) $16 \%$ of the labour force had completed tertiary education, while in the District of Columbia this value was $44 \%$. Highly skilled human capital is increasingly mobile. Regions boosting their human capital endowments are those capable of attracting and retaining highly skilled workers. Regional data on international migration show that regions already hosting a significant number of highly educated foreigners have an advantage in the global competition for talent, due to the decisive role of network effects.

Technology-based innovation is very concentrated in a few places. Around $10 \%$ of OECD regions account for one-third of the total OECD expenditure in research and development (R\&D) and more than half of patent applications. $R \& D$ and patenting are still concentrated in the top regions of knowledge-intensive OECD member countries (Japan, Germany, United States), having different technology specialisations (green technologies; biotechnology; and information and communication technology, for example). However, the last decade has witnessed the emergence of new regional top players. For example, Østjylland and Vestjylland (Denmark), Madrid and Barcelona (Spain) and Seoul and Gyeonggi-do (Korea) have appeared as hot spots in patenting on renewable energy. Improving collaboration to address global challenges is high on national agendas both in OECD countries and emerging economies: Shanghai (China) and Karnataka (India) have tripled the number of partners around the world with which they patent in green technologies in the last five years. Several regions are catching up with national leaders in high-tech manufacturing employment and knowledge-intensive sectors. Studying these regions can provide lessons on how to replicate a positive environment for business creation and technological upgrading.

The 2008-09 economic recession experienced by the OECD area has had a differentiated impact on the loss of jobs within OECD countries. Three-fourths of OECD regions that showed employment growth between 1999 and 2007 shifted to an employment decline between 2008 and 2009. All typologies of regions experienced on average a decline in employment. There are however important differences in the trajectories and it is useful to compare the pre-crisis growth profile of regions that managed to sustain employment growth during the recession ("resilient regions") with the one of regions that shifted from 
positive to negative total employment ("recession-hit regions"). Resilient regions experienced larger increases in their qualified human capital prior to the crisis, as well as in participation rates and in the productivity of business services, the public sector and agriculture.

Countries have responded to the economic crisis by taking measures to support business and employment and by improving conditions for long-term growth. Such structural policies emphasise the complementarities of efficiency, equity and environmental protection objectives. The long-term consequences of the crisis on families' living conditions and social mobility, as well as the degree of heterogeneity in policy responses, point to the need for statistics that go beyond the economic efficiency of a region to encompass economic and non-economic measures of the quality of life. Spatial differences in access to key public goods and in opportunities for families to invest in health and education have important, dynamic effects, since "fragile" regions can get trapped in downward spirals, and see their capacity to attract people and businesses shrinking over time.

Regional disparities in households' income are largest in Chile, Greece, Hungary, Israel, Italy and the Slovak Republic. Regions in these countries have also experienced structural difficulties in employing young adults (the youth unemployment rate in some regions was as high as 30\% in 2009) and women (less than half of women in working age were employed in 2009) and they display higher than average long-term unemployment (more than one-third of the unemployed in these regions have been out of the labour market for more than one year).

Income differentials only partially explain the quality of life in OECD regions. Disparities among regions in basic education attainment, health or natural resources are signalling the challenges of policies to overcome local disadvantages in many countries. Data show that students in city schools outperform rural areas by 20 points in the OECD PISA reading test, or the equivalent of almost one year of education, even after having taken into account the different socio-economic background of students. The ageadjusted mortality rate in regions of Canada, Portugal and the United States can be double that in other regions of the same country. In Chile, Italy, Korea and Mexico, the regional exposure to air pollution ranges from values below the World Health Organization's recommended levels of 10 micrograms of PM2.5 per cubic meter to more than 25 micrograms. Some provinces in China and states in India surpass a threshold of 60 micrograms of PM2.5 per cubic meter, a level proven to pose serious health risks.

For the first time, estimates of $\mathrm{CO}_{2}$ carbon emissions at the regional level comparable across countries are presented in this volume. In the Czech Republic, the Russian Federation, Spain, South Africa and the United States, $\mathrm{CO}_{2}$ carbon emissions in some regions are more than three times higher than the country average, highlighting the limited value of national figures to design policies to address climate change. Cities are hot-spots for carbon emissions, and work is currently underway to produce city-level estimates of the carbon efficiency of urban economies.

In sum, OECD Regions at a Glance provides a multidimensional and dynamic snapshot of how life is lived - and can be improved - from region to region in OECD countries and emerging economies. Gaps in data availability and geographical coverage, as well as the need to identify better indicators in certain areas, are highlighted in the publication, suggesting next steps to further improve our knowledge for evidence-based policy making. 



\section{Interpreting OECD Regional Indicators}

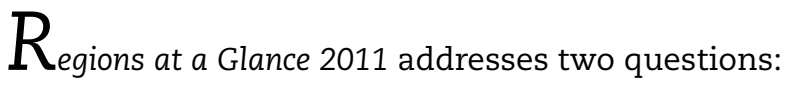

- What progress have OECD regions made towards more sustainable development, compared to the past and compared with other regions?

- Which factors drive the competitive edge of regions and what local resources could be better mobilised to increase national growth and people's well-being?

Addressing the first question can reveal the variety of regional economic structures and performance through a broad range of indicators. Given the multidimensionality of regional development, it is necessary to build sound information comparable across countries on economic, social and environmental outcomes.

Answering the second question can inform the design of effective strategies to improve the contribution of regions to aggregate performance and can suggest policy interventions unlocking complementarities among efficiency, equity and environmental sustainability. Clearly, this second question is more challenging to answer and regional statistics can provide only a partial assessment of the effects of policies. The publication Regional Outlook 2011 integrates the statistics presented in this edition of Regions at a Glance with analysis of institutional and policy determinants, going deeper into the assessment of causality links and policy evaluation.

The framework of Regions at a Glance is organised along two dimensions.

The first dimension reflects the OECD mission to encourage stronger, fairer and cleaner economies. The three main sections of the publication -1) Regions as drivers for competitiveness; 2) Inclusion and equal access to quality services in regions; and 3) Environmental sustainability in regions and metropolitan areas - present indicators showcasing the key role of regions to strengthen these three interconnected pillars of socio-economic development.

The second dimension highlights three perspectives that need to be integrated in order to develop a complete view of the evolution of regional economies:

- How are assets distributed across regions and how do they contribute to national growth? For example, only $10 \%$ of OECD regions are responsible for almost half of GDP growth and job creation in recent years.

- Do regional disparities tend to persist and what are the unused resources to be mobilised to maximise regions' competitive edge and well-being? For example, regional differences in unemployment rates within OECD countries have persistently been around two times higher than differences among OECD countries in the past 15 years.

- What are the common features that characterise OECD regions that have achieved a certain outcome? For example, the regions that managed to sustain positive employment during the economic recession are those which, more than the other regions, increased their qualified human capital and their participation in the labour market, and improved the productivity of traditional sectors in the previous period. 
This analytical approach which focuses simultaneously on distribution over space, persistence over time, and links between different characteristics/endowments, provides a solid foundation for evidence-based policy making.

The chapters of Regions at a Glance can be slotted into a summary matrix (framework) with the three dimensions of competitiveness, inclusion and sustainability in the columns and the three perspectives of concentration, persistence of disparities and characteristics of regions in the rows.

\section{Table 1. Framework for the chapters of Regions at a Glance}

\begin{tabular}{|c|c|c|c|}
\hline & Regions as drivers for competitiveness & $\begin{array}{l}\text { Inclusion and equal access to quality } \\
\text { services in regions }\end{array}$ & $\begin{array}{l}\text { Environmental sustainability in regions } \\
\text { and metropolitan areas }\end{array}$ \\
\hline $\begin{array}{l}\text { Concentration of resources } \\
\text { and contribution to growth }\end{array}$ & $\begin{array}{l}\text { 1. Regional contribution to population } \\
\text { change } \\
\text { 2. Distribution of population and regional } \\
\text { typology } \\
\text { 3. Regional contribution to growth } \\
\text { 4. Regional contribution to change } \\
\text { in employment } \\
\text { 12. Regional specialisation in knowledge- } \\
\text { oriented sectors } \\
\text { 10. Skilled immigration in OECD regions } \\
\text { 13. Public investment in regions } \\
\text { 14. Research and development } \\
\text { expenditure in regions } \\
\text { 16. Patents in regions and among } \\
\text { different economic actors }\end{array}$ & $\begin{array}{l}\text { 19. Concentration of elderly population } \\
\text { in regions } \\
\text { 21. Immigration trends in OECD regions }\end{array}$ & $\begin{array}{l}\text { 31. Regional access to network } \\
\text { infrastructure } \\
\text { 32. Green patents in regions }\end{array}$ \\
\hline $\begin{array}{l}\text { Regional disparities and mobilisation } \\
\text { of unused resources }\end{array}$ & $\begin{array}{l}\text { 6. Regional economic disparities } \\
\text { 9. Regional disparities in tertiary } \\
\text { education } \\
\text { 11. Regional specialisation and } \\
\text { productivity growth across sectors }\end{array}$ & $\begin{array}{l}\text { 18. Regional disparities in household } \\
\text { income } \\
\text { 22. Regional disparities in unemployment } \\
\text { 23. Gender differences in employment } \\
\text { opportunities } \\
\text { 24. Access to education } \\
\text { 25. Access to health }\end{array}$ & $\begin{array}{l}\text { 28. Forests, natural vegetation and } \\
\text { the carbon footprint of regions } \\
\text { 29. Carbon emissions and air quality } \\
\text { in regions } \\
\text { 30. Municipal waste }\end{array}$ \\
\hline $\begin{array}{l}\text { Characteristics of regions on common } \\
\text { outcomes }\end{array}$ & $\begin{array}{l}\text { 5. Labour productivity growth in regions } \\
\text { 7. Patterns of growth in regions } \\
\text { 8. Impact of the crisis on jobs in regions } \\
\text { 15. Public and business R\&D expenditure } \\
\text { 17. Regional patterns of co-patenting }\end{array}$ & $\begin{array}{l}\text { 20. Population mobility among regions } \\
\text { 26. Access to basic services in developing } \\
\text { economies }\end{array}$ & $\begin{array}{l}\text { 27. The growth of urban land in OECD } \\
\text { regions }\end{array}$ \\
\hline
\end{tabular}

The allocation of chapters to one or another cell in Table 1 is not always straightforward, as objectives may overlap or complementarities arise. For example, regional data on ageing populations provides information both on the competitiveness of regions in terms of future production and on social inclusion in terms of provision of specific services. Similarly, regional patent activities in green technologies measure the capacity of governments and industry to create new business values and at the same time proxy investment made to meet environmental improvements.

The dimension of characteristics of regions is a novelty in this publication and is explored by looking at correlations among different outcome and structural variables. Profiling regions to identify common characteristics in adaptability to changes and resilience to external shocks can serve as early evidence to identify complementarities among policy instruments at the regional level. It can be thus a useful tool to move towards integrated design of regional policies whose effects can be monitored over time.

\section{Choice of indicators}

OECD at a Glance 2011 includes 40 indicators selected from the OECD Regional Database, and presents around 12 indicators available at the sub-national level for the first 
time. What appears is a larger selection of sub-national statistics that refer to the economic structure and competitiveness compared to sub-national indicators of social inclusion and environmental conditions.

Sound data at sub-national level is often limited and difficult to compare across countries. The OECD will continue to pursue the development of regional indicators also in areas where considerable investment still needs to be made in conceptual work.

A regional perspective on the assessment of well-being of societies is necessary, since inequalities are not only among individuals but also across places where people live. Poor access to quality services in certain regions undermines the opportunities available to the inhabitants of these regions; and in turn reduces social mobility over time. However, only a few indicators are available at the regional level to assess inequality in access to services and measures of perceptions of quality of life are still lacking. A first attempt to improve the international comparison of regional quality of life is made here by presenting measures of household income by regions, regional inequalities in education and health and regional disparities in the access to essential services in emerging economies.

Statistics of environmental conditions and quality in cities and regions based on international standards are even scarcer. To start filling this gap, this publication presents new measures of land use, air quality, green gas emissions and urbanisation trends, produced taking advantage of the increasing availability of global datasets based on geographic information systems.

Small boxes point to comparability and measurement issues in the case of indicators presented for the first time for which an international standard has not been yet agreed. These measurement gaps aim at spurring discussion for future production of regional statistics by OECD countries to improve the evidence base for policy making.

For the first time, statistics for the four recent OECD member countries Chile, Estonia, Israel and Slovenia are included. Where available, data on Brazil, the People's Republic of China (China), India, the Russian Federation and South Africa are also included.

Finally, the main messages of this publication are also delivered with a selection of interactive graphs and maps on the OECD website www.oecd.org/gou/regional/ statisticsindicators. 



\section{Defining and Describing Regions}

\section{Territorial grids}

In any analytical study conducted at sub-national levels, the choice of the territorial unit is of prime importance. To address this issue, the OECD has classified two levels of geographic units within each member country (Table A.1 in Annex A). The higher level (Territorial level 2 [TL2]) consists of 362 larger regions while the lower level (Territorial level 3 [TL3]) is composed of 1794 smaller regions. All the territorial units are defined within national borders and in most of the cases correspond to administrative regions. Regions at the lower level (TL3) are contained within the higher level (TL2).*

This classification - which, for European countries, is largely consistent with the Eurostat classification - facilitates greater comparability of geographic units at the same territorial level. Indeed these two levels, which are officially established and relatively stable in all member countries, are used as a framework for implementing regional policies in most countries.

Due to limited data availability, labour-market indicators in Canada are presented for groups of TL3 regions. Since these groups are not part of the OECD official territorial grids, for the sake of simplicity they are labelled as non-official grids (NOGs) in this publication and compared with TL3 for the other countries (Table A.1 in Annex A).

The OECD has recently started to extend the regional classification to new member countries and emerging economies. More precisely TL2 regions have been identified and statistics collected in Chile, Estonia, Israel and Slovenia (new OECD members); Brazil, the Russian Federation, India, China and South Africa (the BRICS countries). The TL3 classification is now available only for Chile, Estonia and Slovenia (Table A.2 in Annex A).

\section{Regional typology}

A second important issue for the analysis of sub-national economies concerns the different "geography" of each geographic unit. For instance, in the United Kingdom one could question the relevance of comparing the highly urbanised area of London to the rural region of the Shetland Islands, despite the fact that both regions belong at the same territorial level. To take account of these differences, the OECD has established a regional typology according to which TL3 regions have been classified as predominantly urban (PU), predominantly rural (PR) and intermediate (IN). This typology, based on settlement patterns calculated on the percentage of population living in rural communities, enables meaningful comparisons between regions belonging to the same type and level (Table A.3 and Figures A.1 to A.4 in Annex A). The OECD regional typology is based on three criteria. The first criterion identifies rural communities according to population density. A community is defined as rural if its population density is below 150 inhabitants per square

* With the exception of United States. 
kilometre (500 inhabitants for Japan and Korea to account for the fact that the national population density exceeds 300 inhabitants per square kilometer). The second criterion classifies regions according to the percentage of population living in rural communities. Thus, a TL3 region is classified as:

- Predominantly rural (rural or PR), if more than $50 \%$ of its population lives in rural communities.

- Predominantly urban (urban or PU), if less than $15 \%$ of the population lives in rural communities.

- Intermediate (IN), if the share of population living in rural communities is between $15 \%$ and $50 \%$.

The third criterion is based on the size of the urban centres. Accordingly:

- A region that would be classified as rural on the basis of the general rule is classified as intermediate if it has a urban centre of more than 200000 inhabitants (500 000 for Japan) representing no less than $25 \%$ of the regional population.

- A region that would be classified as intermediate on the basis of the general rule is classified as predominantly urban if it has an urban centre of more than 500000 inhabitants ( 1 million for Japan) representing no less than $25 \%$ of the regional population.

The typology is calculated only for the lower territorial level (TL3). The dimension of TL2 regions is too large to allow for a categorisation into predominantly urban, intermediate or predominantly rural. For analytical purposes the percentage of population living in PU, IN, and PR is calculated for TL2 regions summing the population of TL3 regions by regional typology. For example the TL2 regions of Rhone-Alpes in France has $23 \%$ of its population living in TL3 regions classified as PU, 68\% of its population living in TL3 regions classified as IN and 9\% of its population living in TL3 regions classified as PR.

\section{Extended regional typology}

An extended regional typology has been adopted by the OECD and applied so far to Europe and North America. The new typology extends the methodology by distinguishing between rural regions that are located close to larger urban centres and those that are not. The result is a four-fold classification of TL3 regions into: predominantly urban (PU), intermediate regions (IN), predominantly rural regions close to a city (PRC) and predominantly rural remote regions (PRR). The distance from urban centres is measured by the driving time necessary to a certain share of the regional population to reach a large urban centre (with a population of at least 50000 people). The classification of TL3 regions in Europe and North America according to the extended typology is presented in Figure A.1 and A.2 of Annex A.

Due to lack of information on the road network and service areas, the extended typology has not been yet applied to Australia, Japan and Korea or to emerging economies. 


\section{Symbols and Abbreviations}

OECD\#

Sum of all OECD regions where regional data are available (\# number of countries included in the sum). It includes the four new member countries, Chile, Estonia, Israel and Slovenia, when data are available.

OECD\# average Average over OECD regions available (\# number of countries included in the average)

Total \# countries Sum of all regions where regional data are available, including emerging economies and BRICS countries

Country average Average value computed using regional data

Australia (TL2) TL2 regions of Australia

GDP Gross domestic product

HTM High-technology manufacturing

IN Intermediate (region)

KIS Knowledge-intensive services

LFS Labour force survey

NOG Non-official grid

PCT Patent Cooperation Treaty

PPP Purchasing power parity

PR Predominantly rural (region)

PRC Predominantly rural (region) close to a city

PRR Predominantly rural remote (region)

PU Predominantly urban (region)

R\&D Research and development

TL2 Territorial level 2

TL3

Territorial level 3

The cut-off date for data included in the publication was Febrary 2011. Due to the time lag of sub-national statistics, the last available year is generally 2009 for demographic and labour market data, 2007 for regional GDP and 2008 for the other statistics. 


\section{the

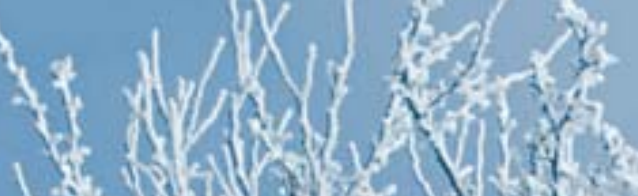

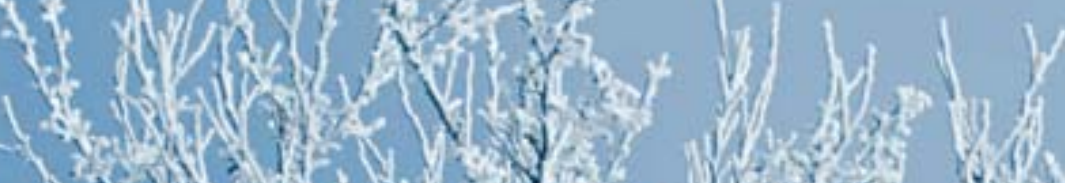

a

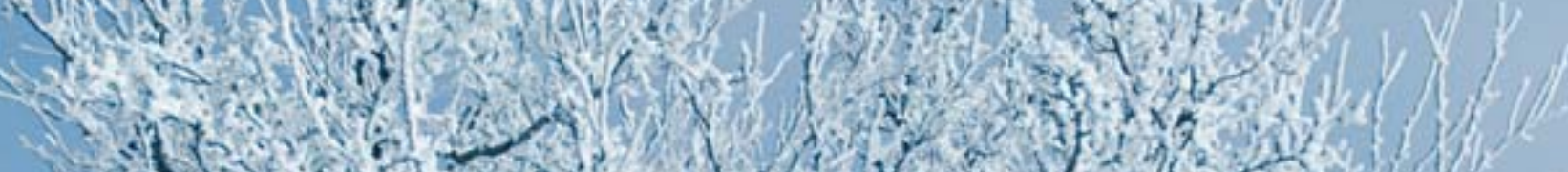

(1)

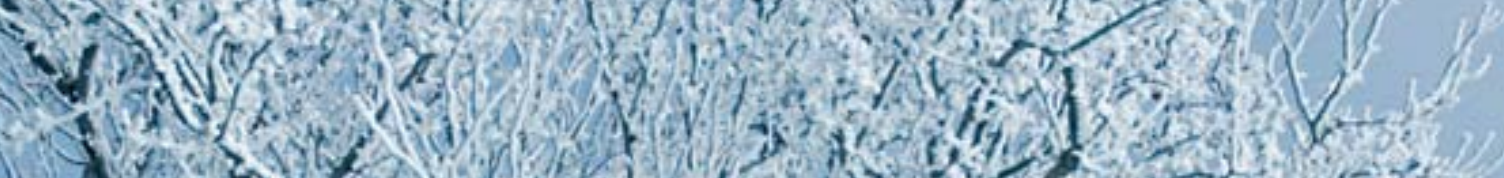

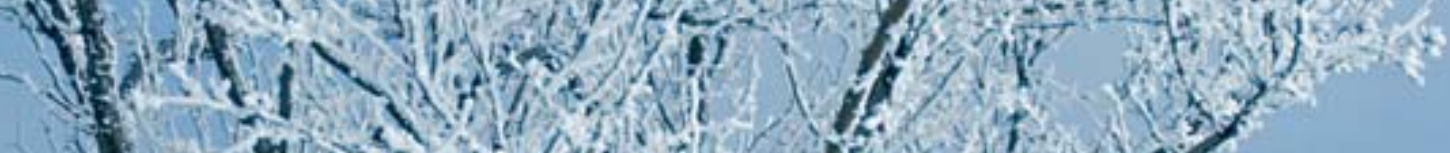

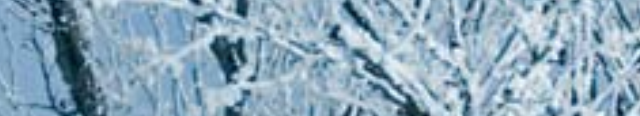

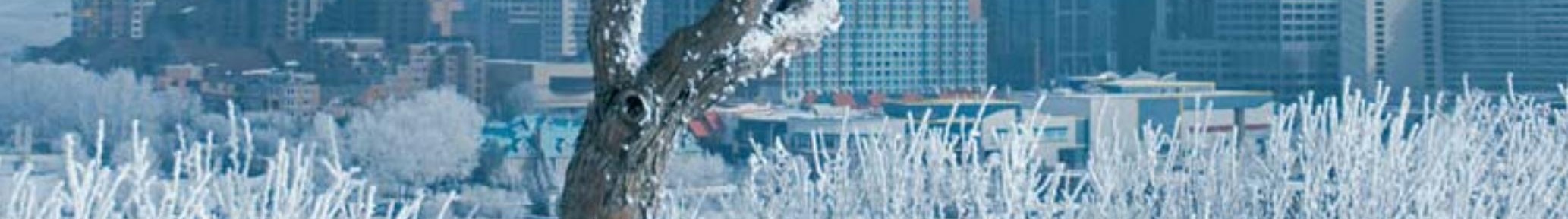
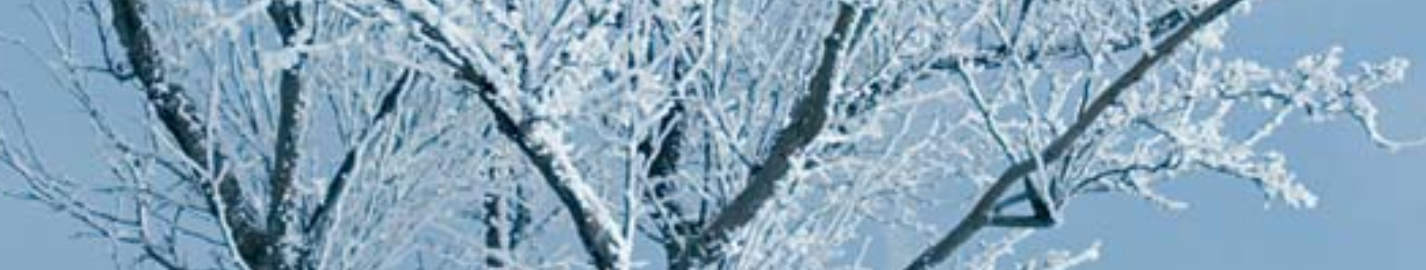


\section{REGIONS AS DRIVERS} FOR COMPETITIVENESS

1. Regional contribution to population change

2. Distribution of population and regional typology

3. Regional contribution to GDP growth

4. Regional contribution to change in employment

5. Labour productivity growth in regions

6. Regional economic disparities

7. Patterns of growth in regions

8. Impact of the crisis on jobs in regions

9. Regional disparities in tertiary education

10. Skilled immigration in OECD regions

11. Regional specialisation and productivity growth across sectors

12. Regional specialisation in knowledge-oriented sectors

13. Public investment in regions

14. Research and development expenditure in regions

15. Public and business R\&D expenditure

16. Patents in regions and among different economic actors

17. Regional patterns of co-patenting 
In $2009,10 \%$ of regions accounted for approximately $40 \%$ of the total population in OECD countries. The concentration of population was highest in Australia, Canada, Iceland and the United States, where differences in climatic and environmental conditions discourage human settlement in some areas (Figure 1.1).

During the past 14 years the population in OECD countries grew, on average, $0.8 \%$ per year, reaching 1.2 billion in 2009 . Over the same time period population growth in emerging economies (Brazil, China, India, Russian Federation and South Africa) was at around 1.1\% yearly. The largest TL2 region, the State of Uttar Pradesh in India, reached a population of over 190 million in 2009.

In OECD countries almost $65 \%$ of population growth is accounted for by just $10 \%$ of regions. The regional contribution to population growth is particularly concentrated in Canada, Korea and Australia (Figure 1.2).

Around $40 \%$ of OECD country populations live in the 90 large metropolitan regions (i.e. predominantly urban regions with a population of at least 1.5 million) and more than half of the national population in Korea and Japan (Figure 1.3).

In large metropolitan regions, population growth has been faster than the growth of the total OECD population (1.3 times higher), suggesting that migration, besides demographic dynamics, has increased the size of urban regions (see Chapters 20 and 21). Growth of population within countries, though, has varied. Compared to the national rate, the growth rate of population in large metropolitan regions has been particularly intense in Ireland, Turkey, New Zealand and Canada (Figure 1.4).

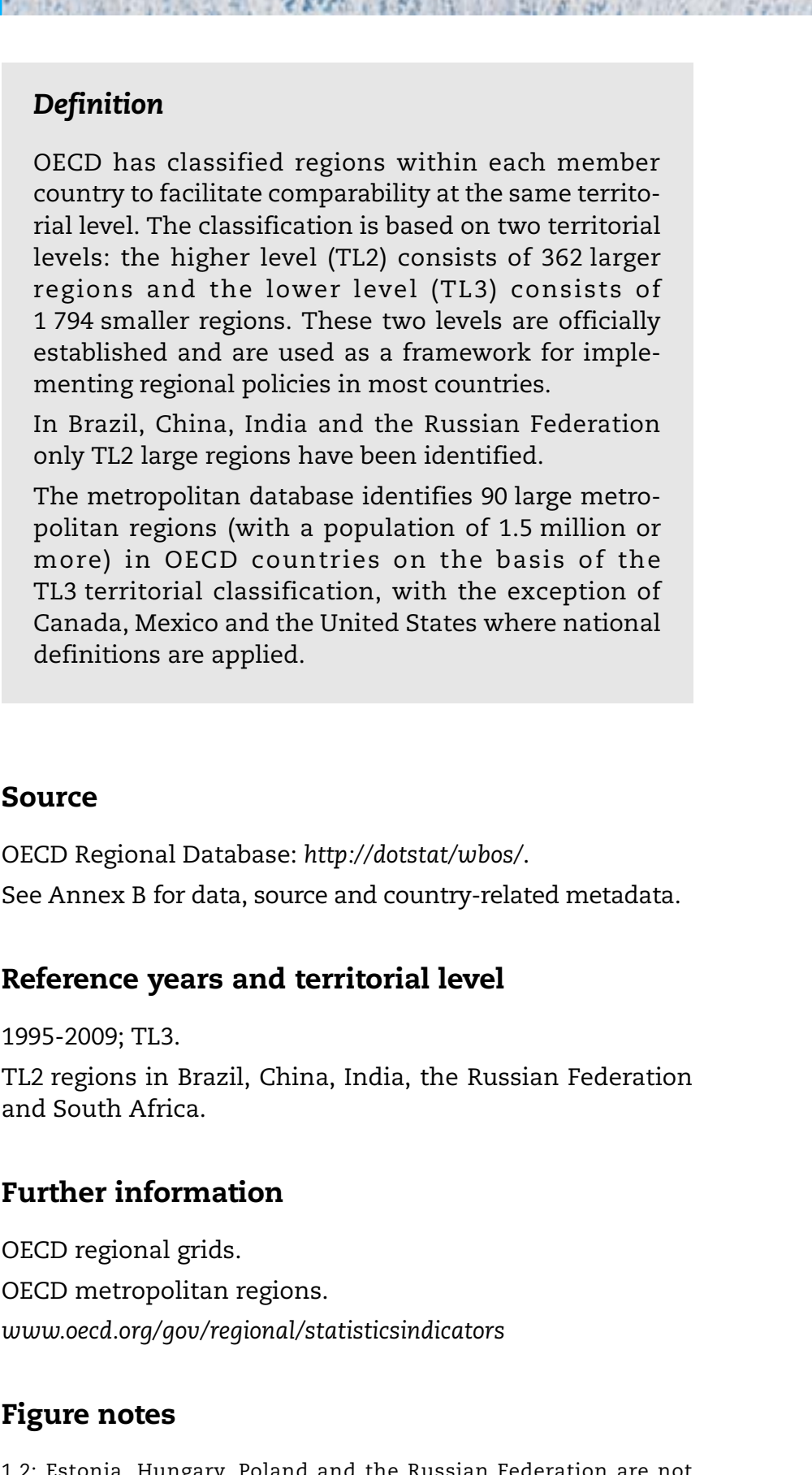

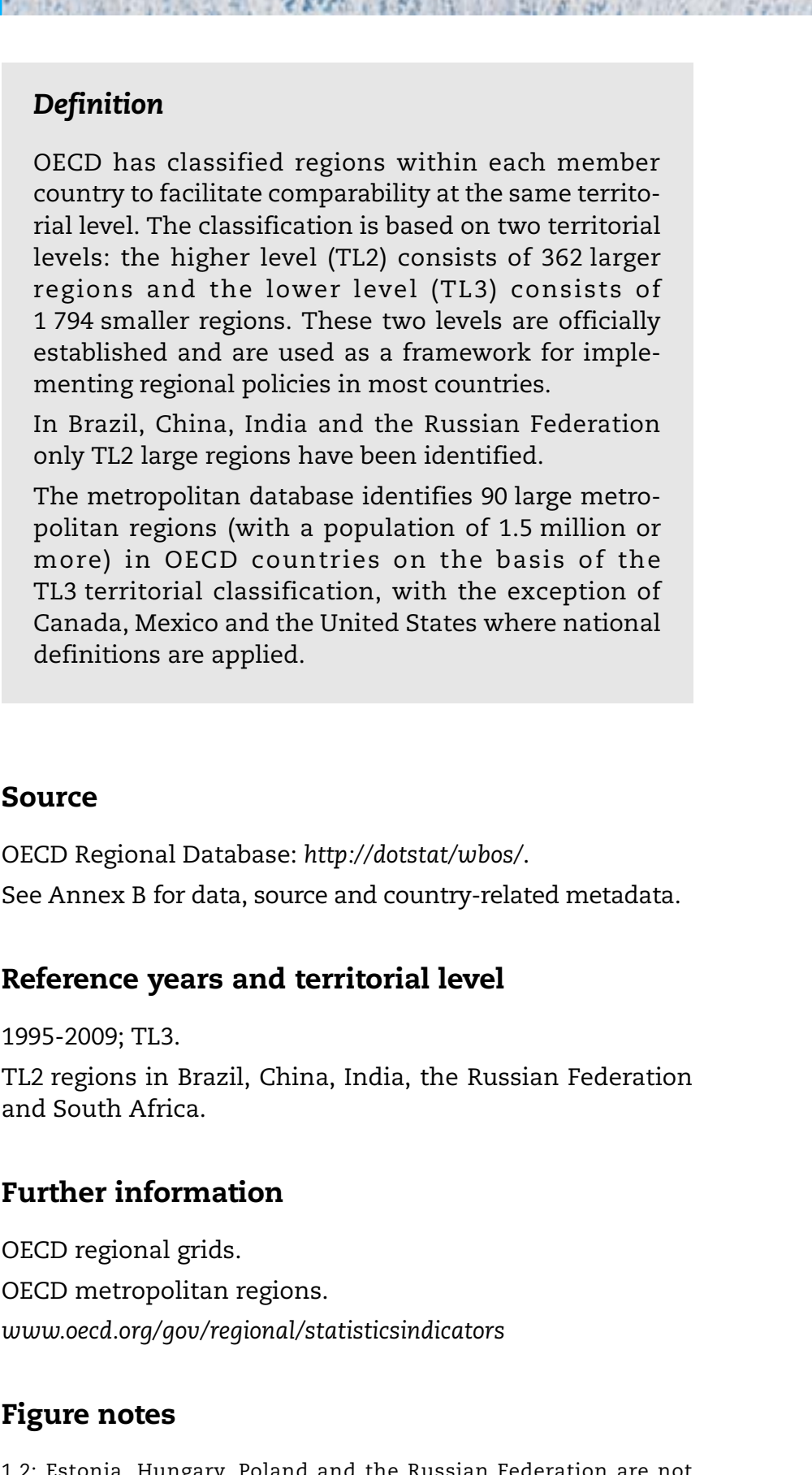

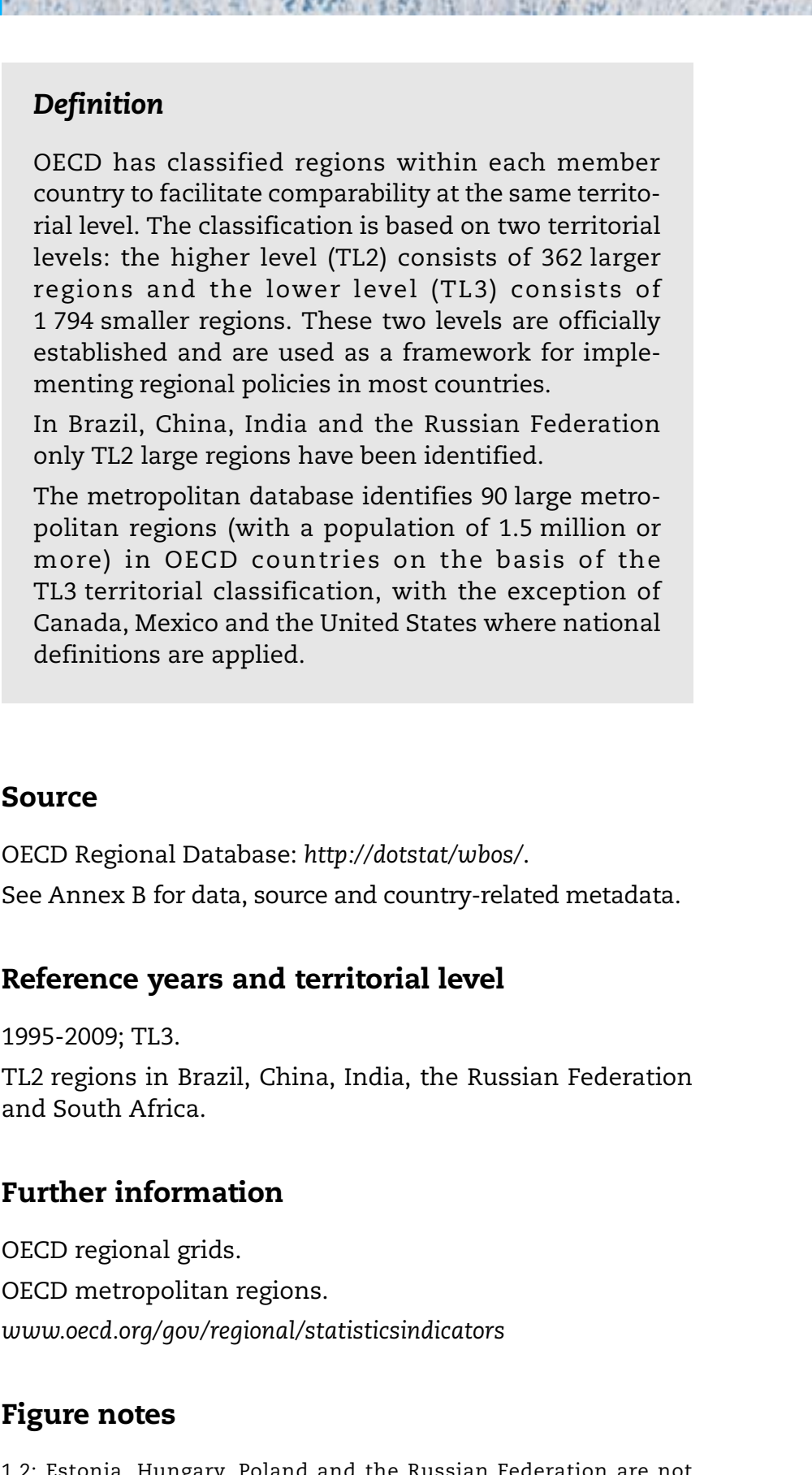

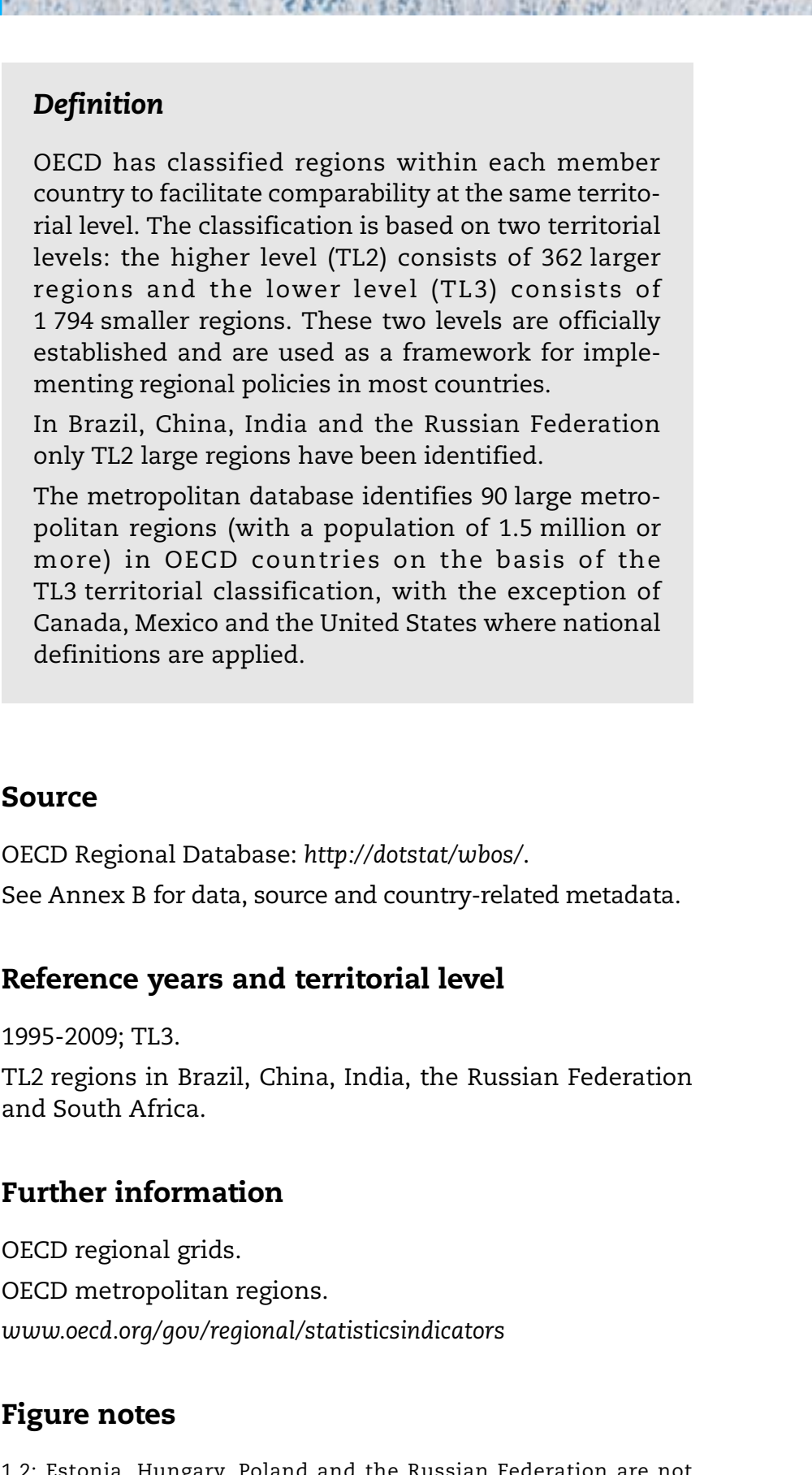

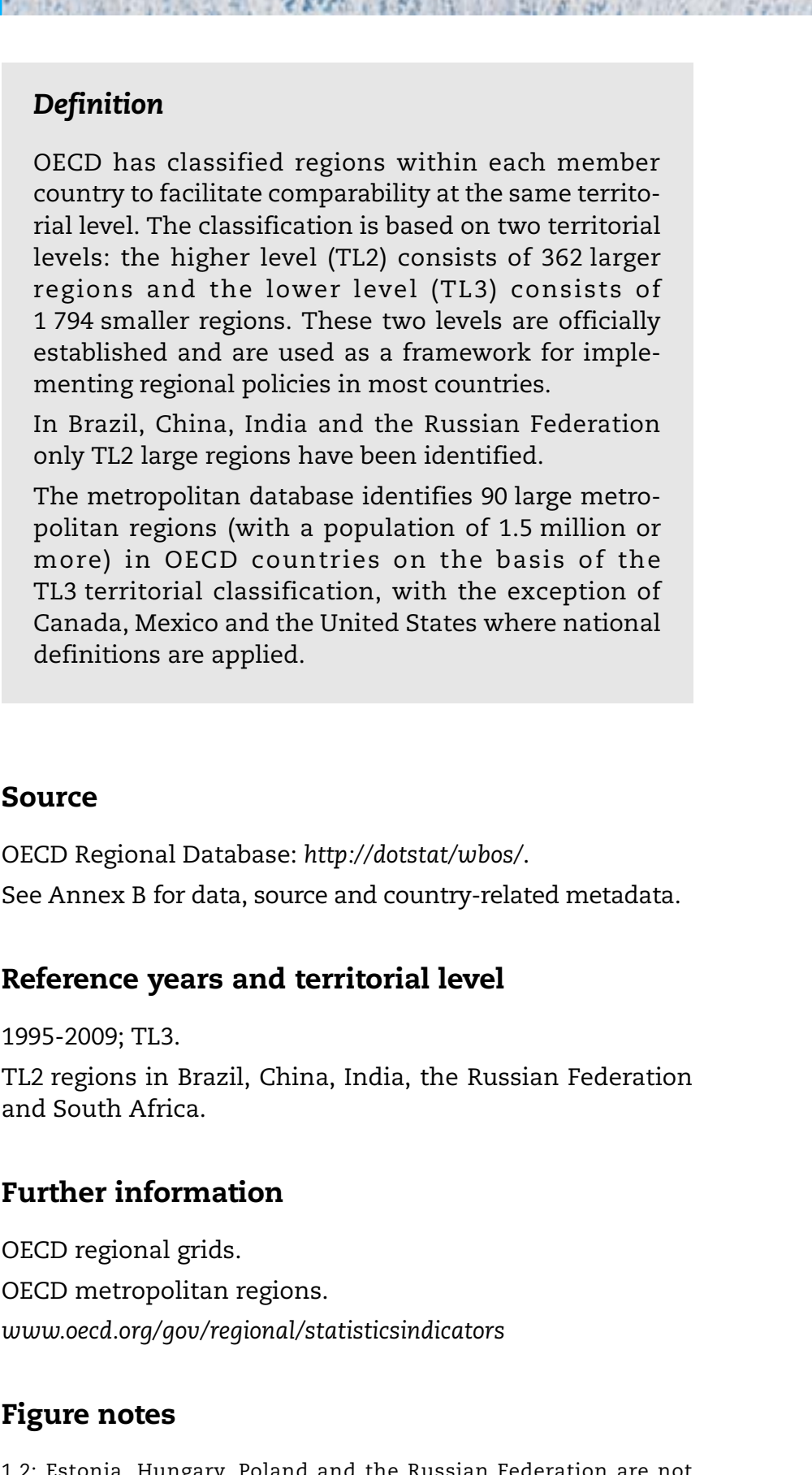

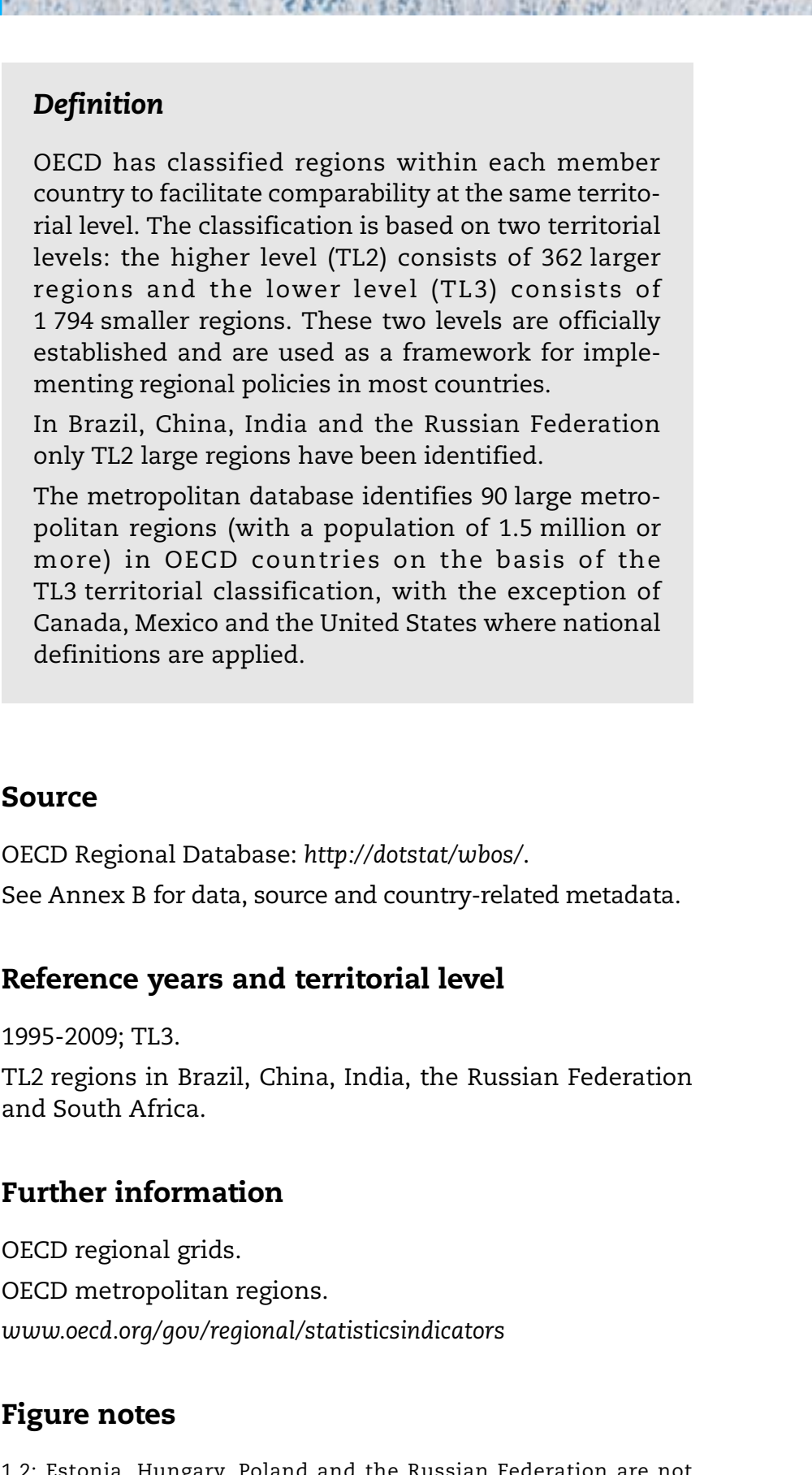

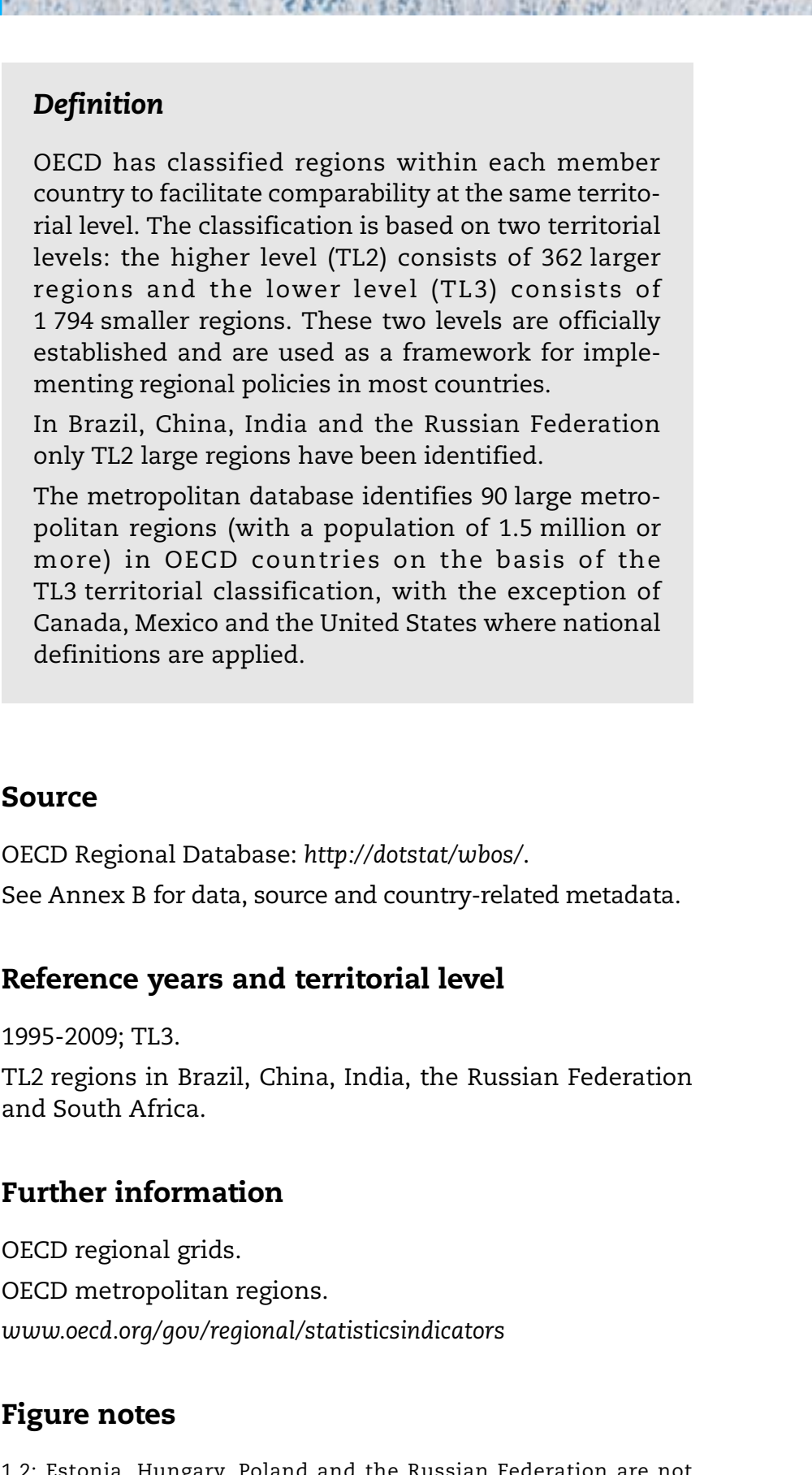

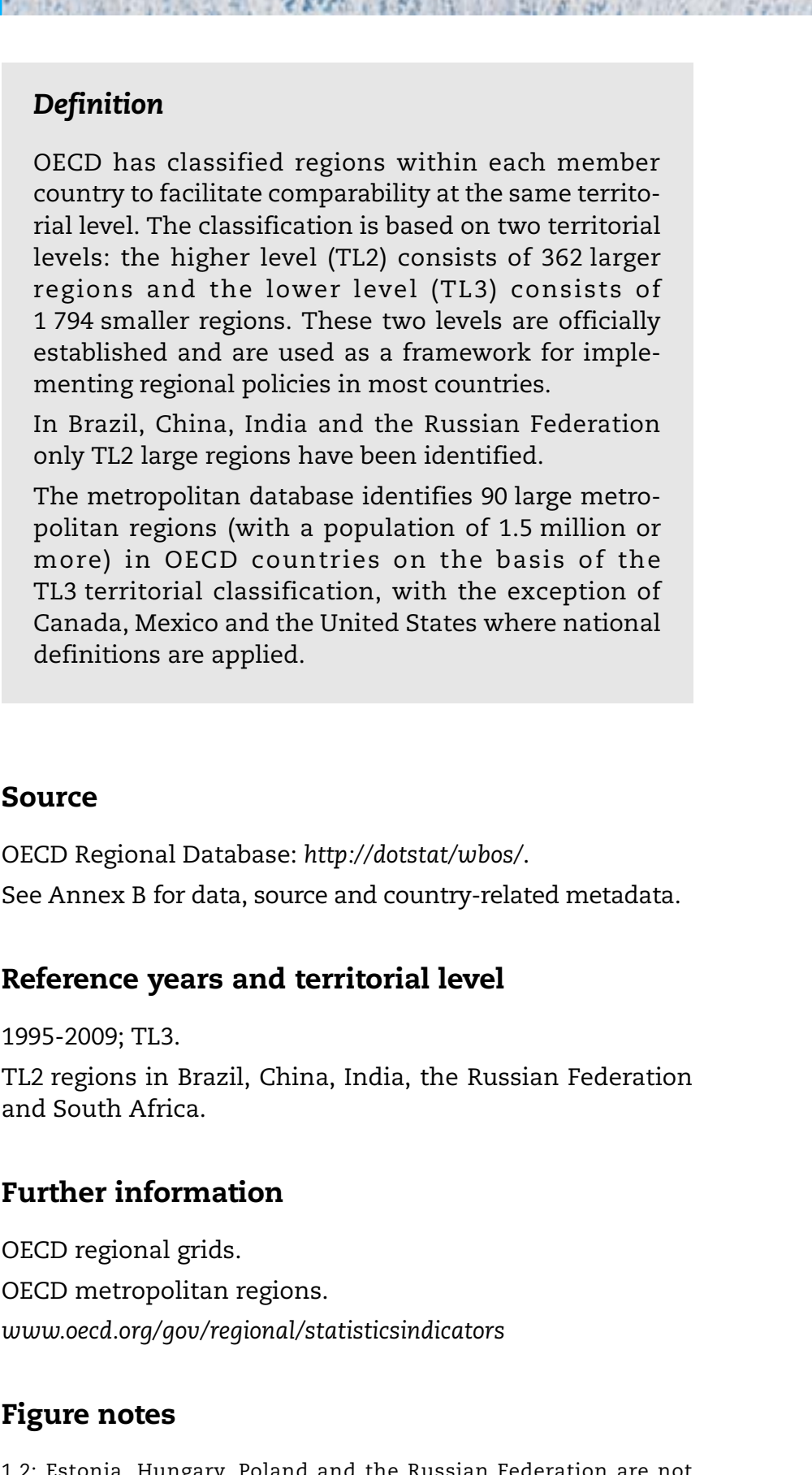

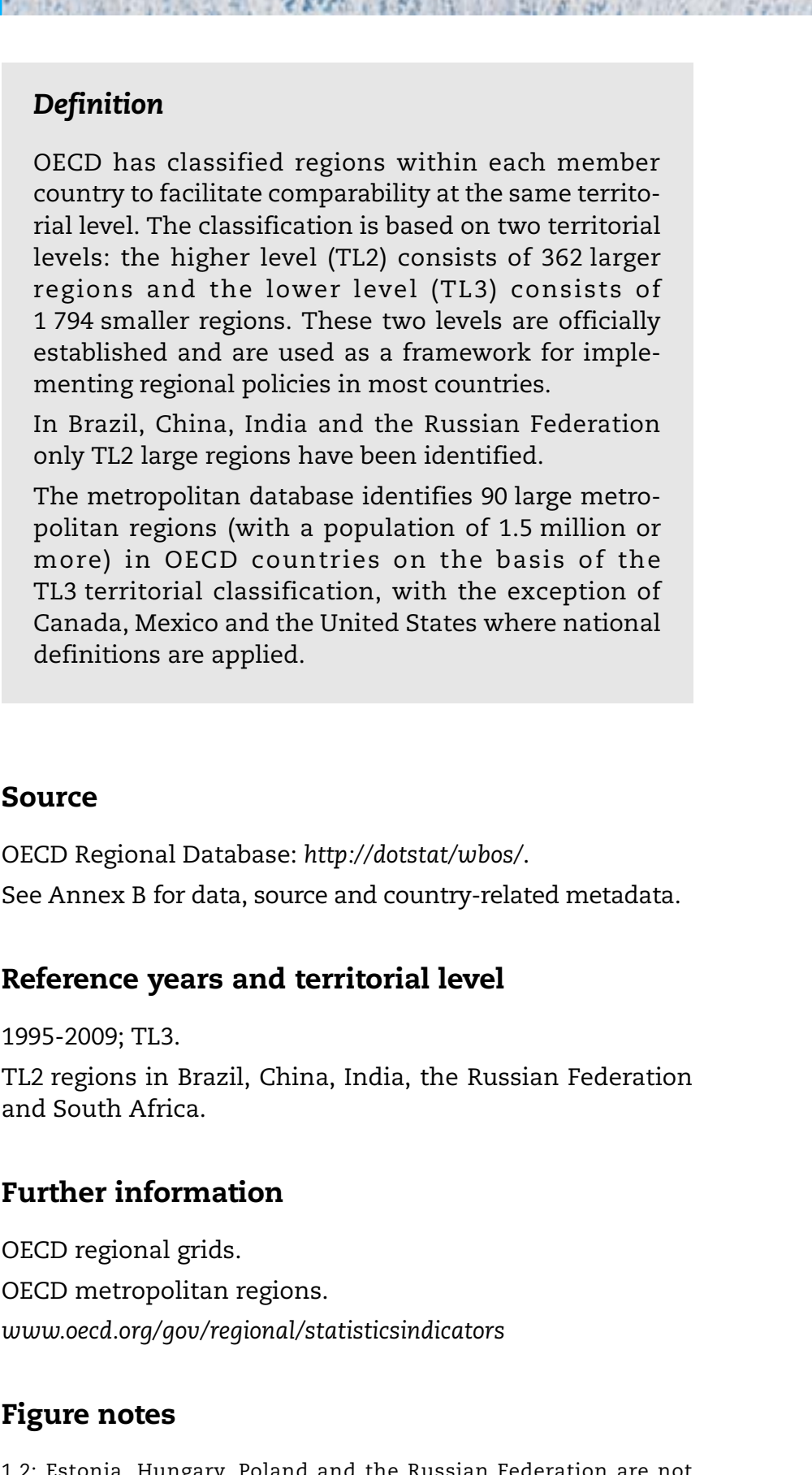

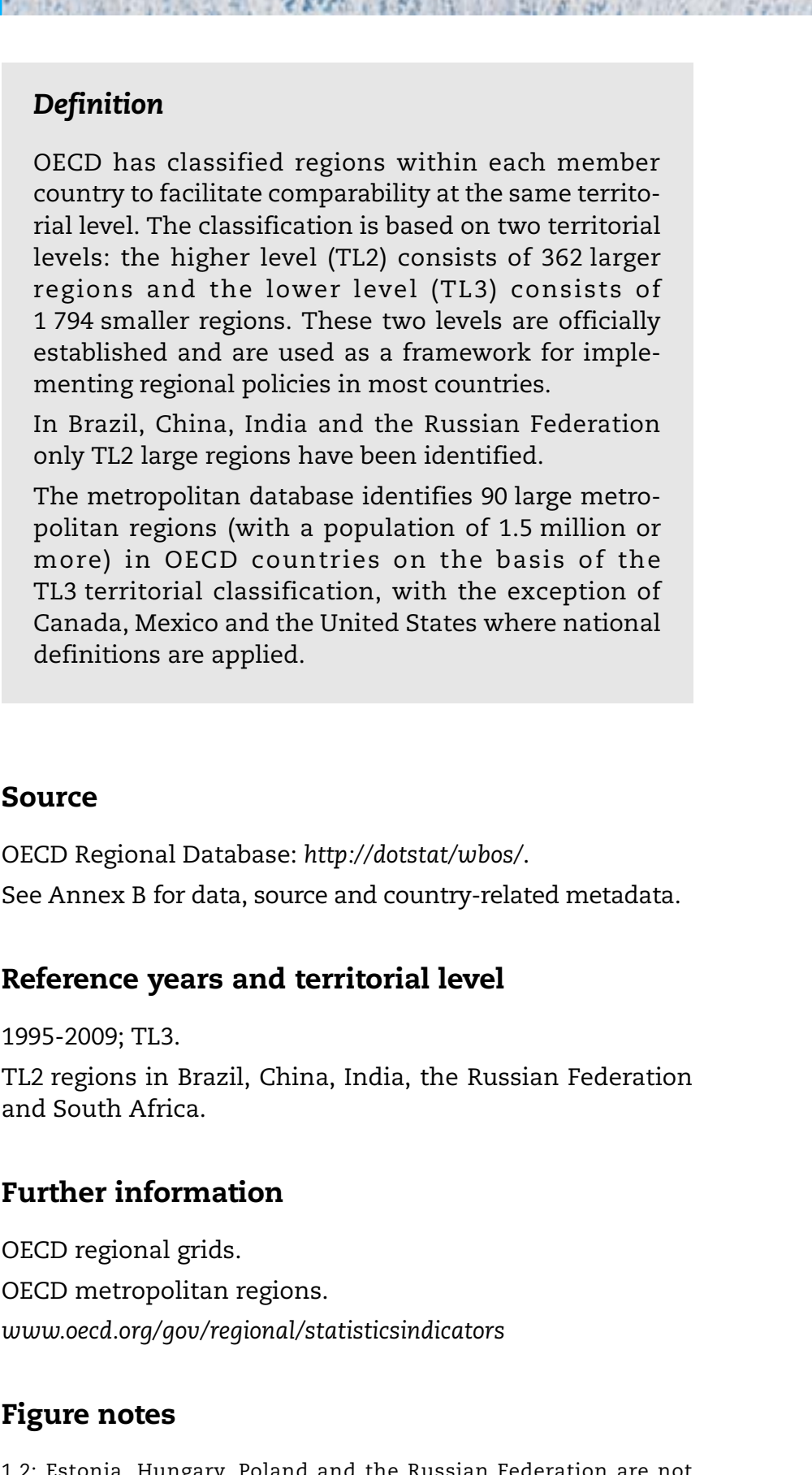

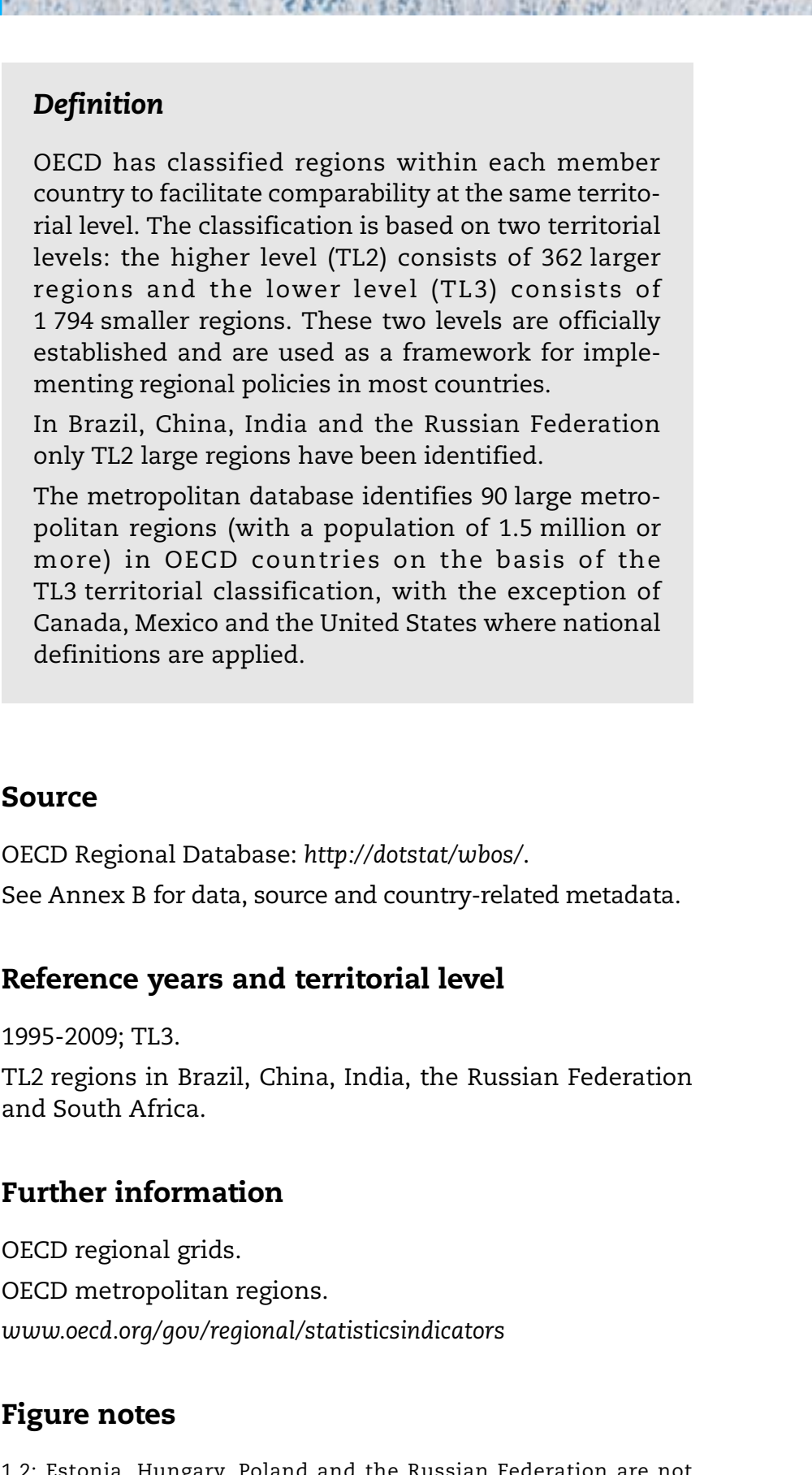

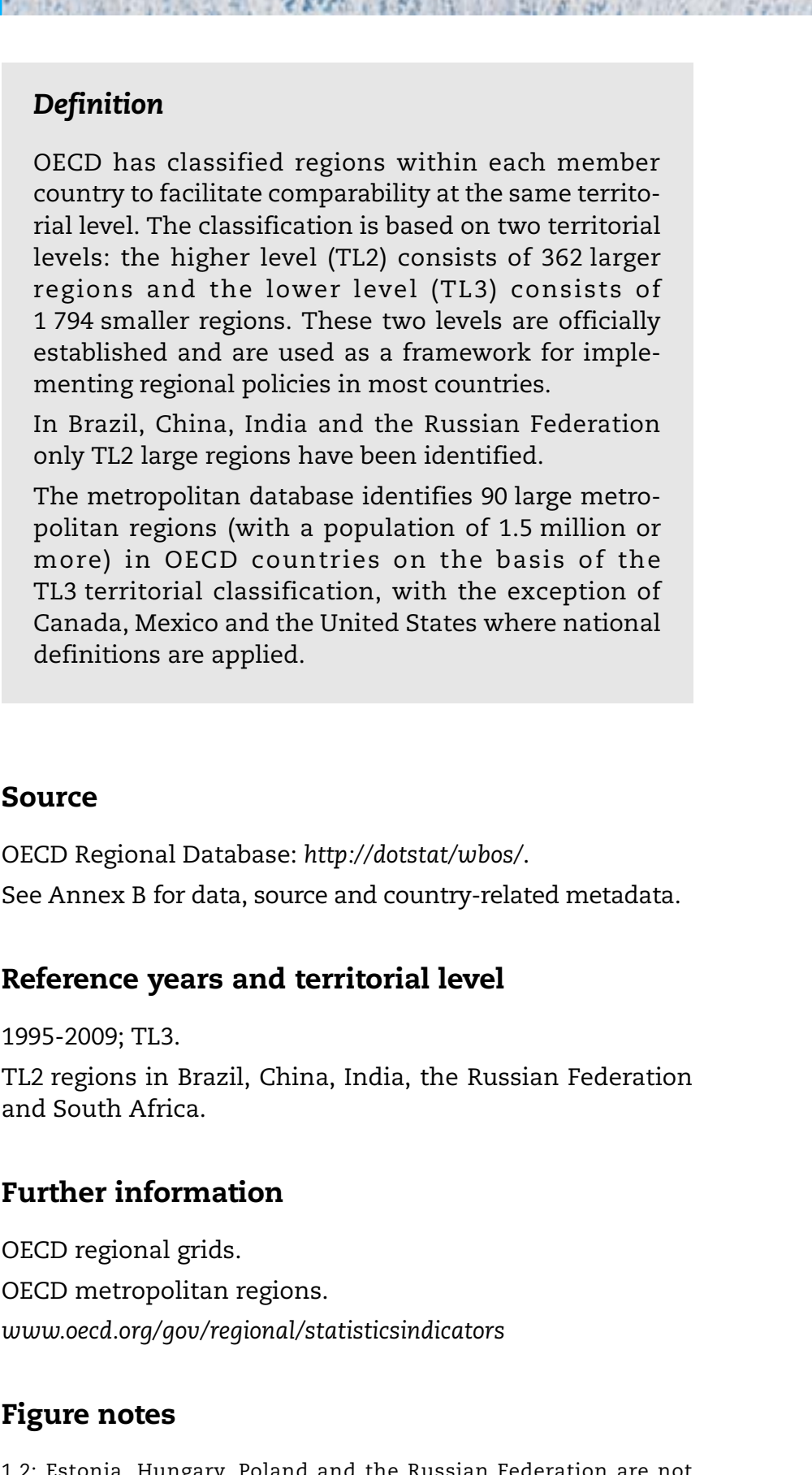

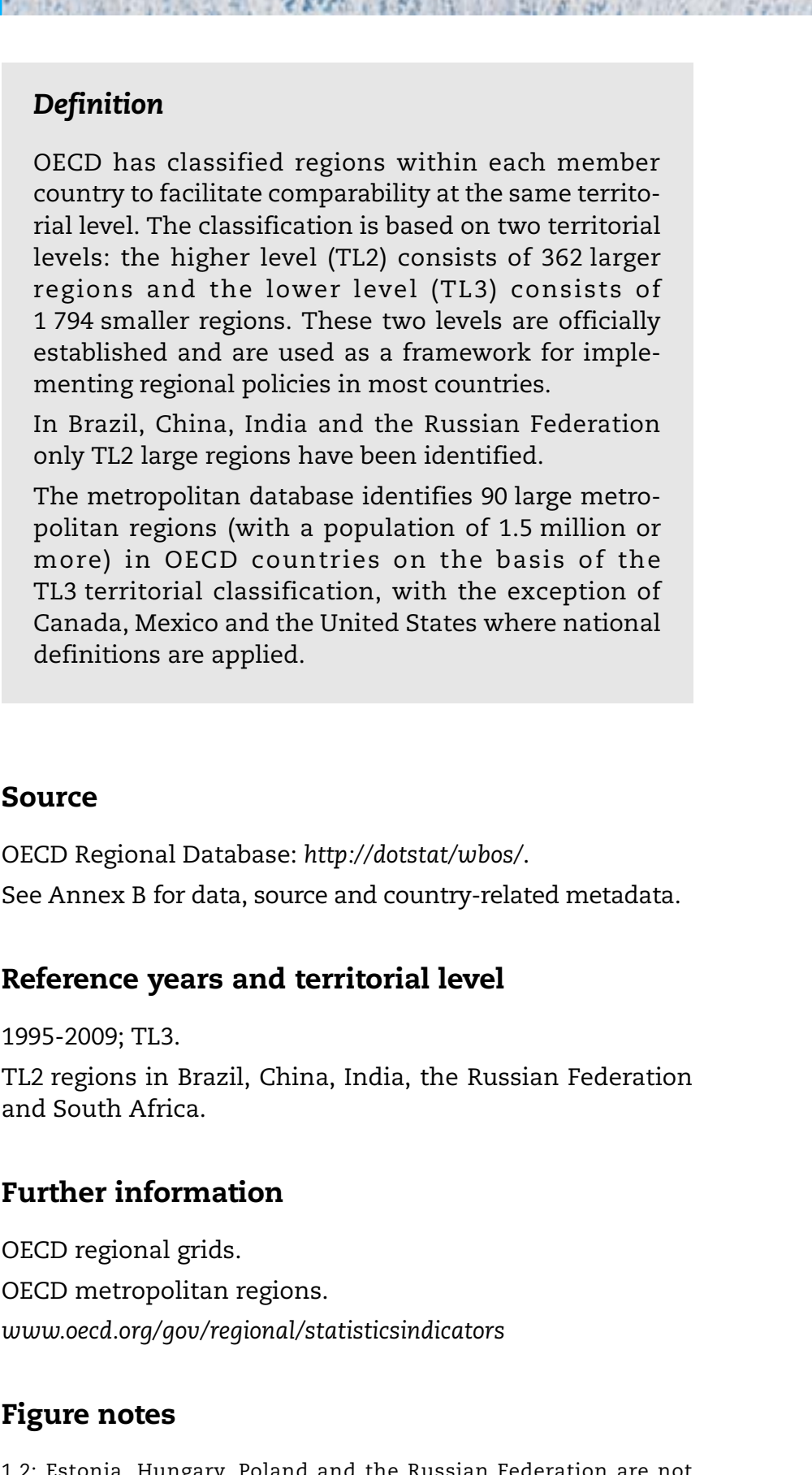

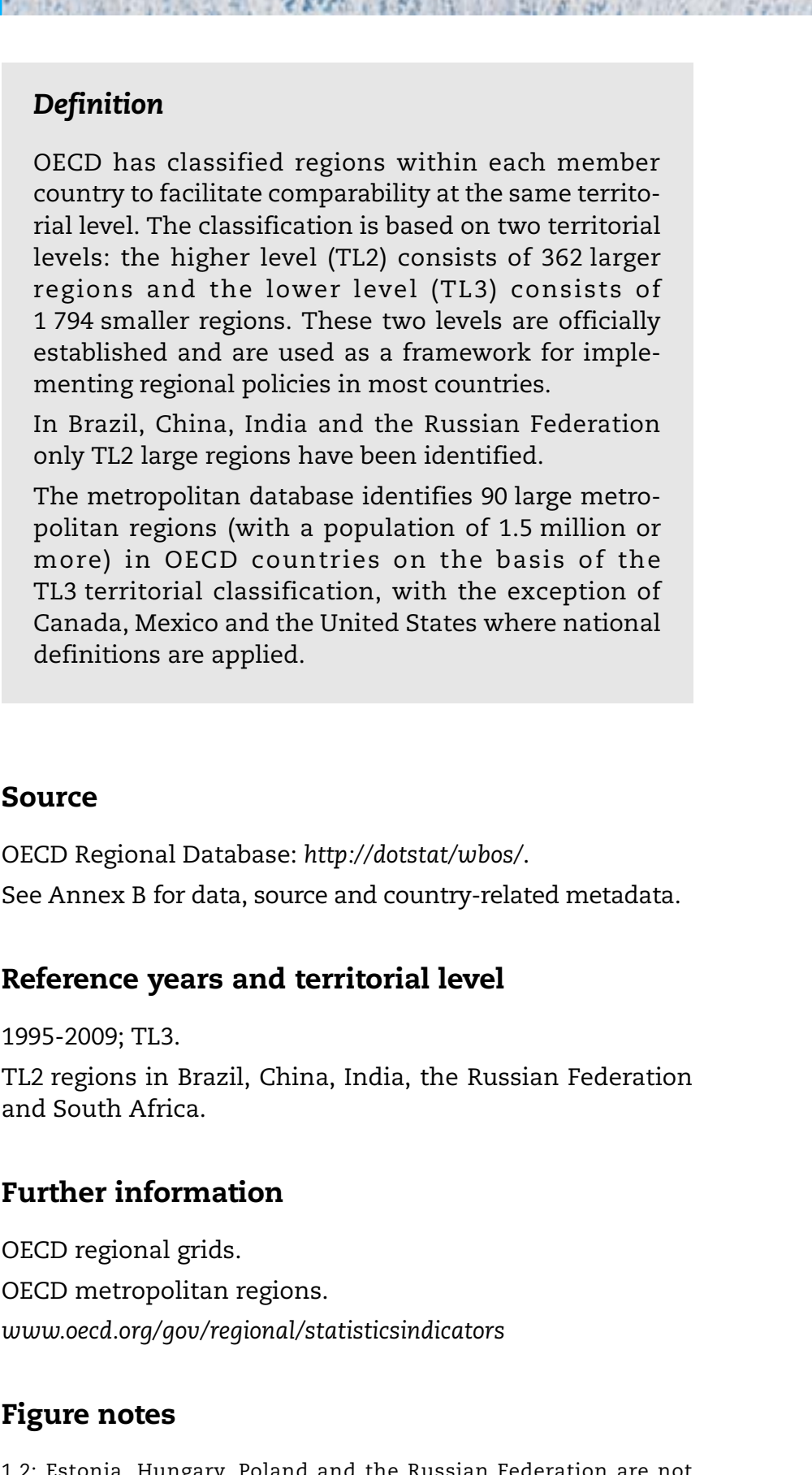

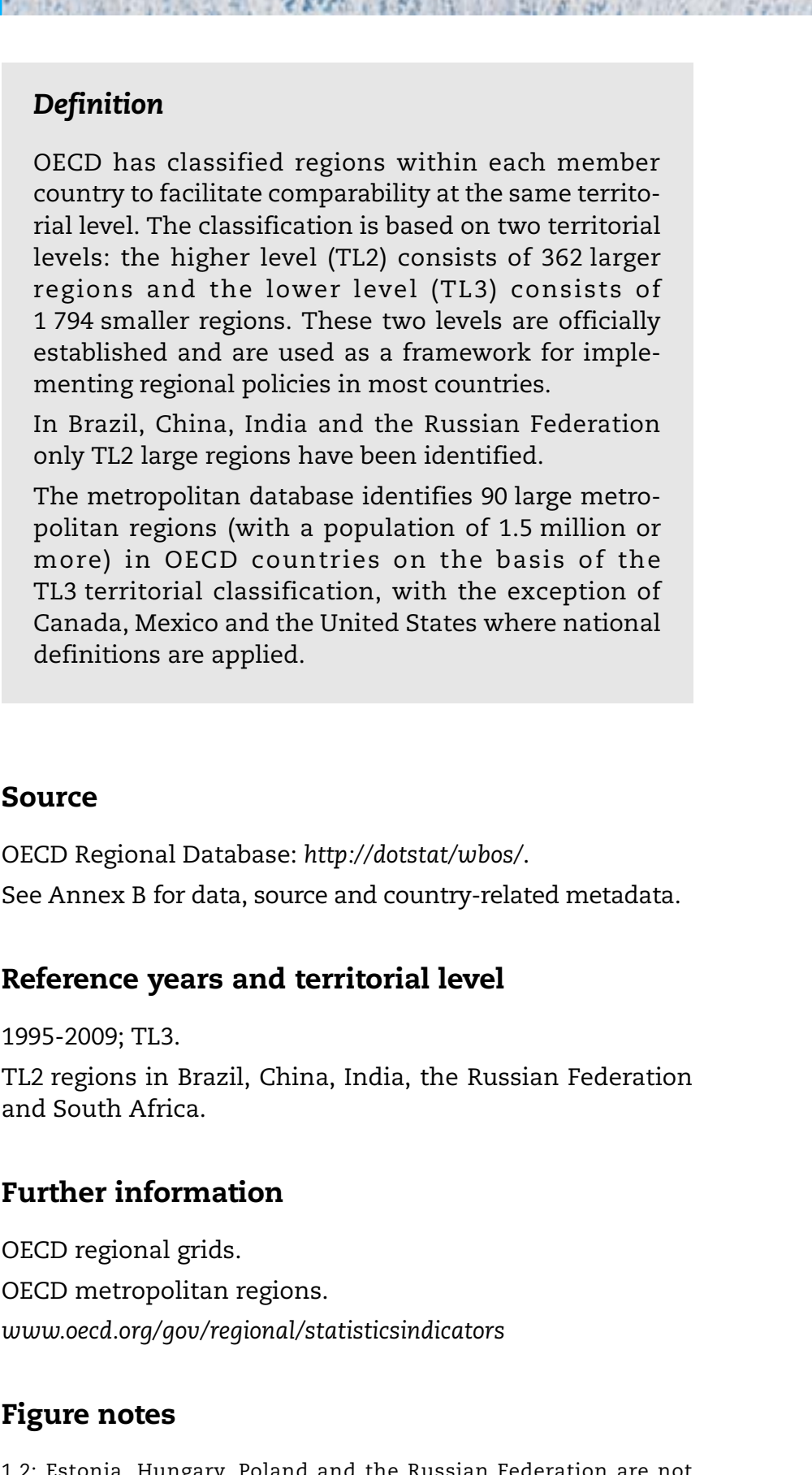

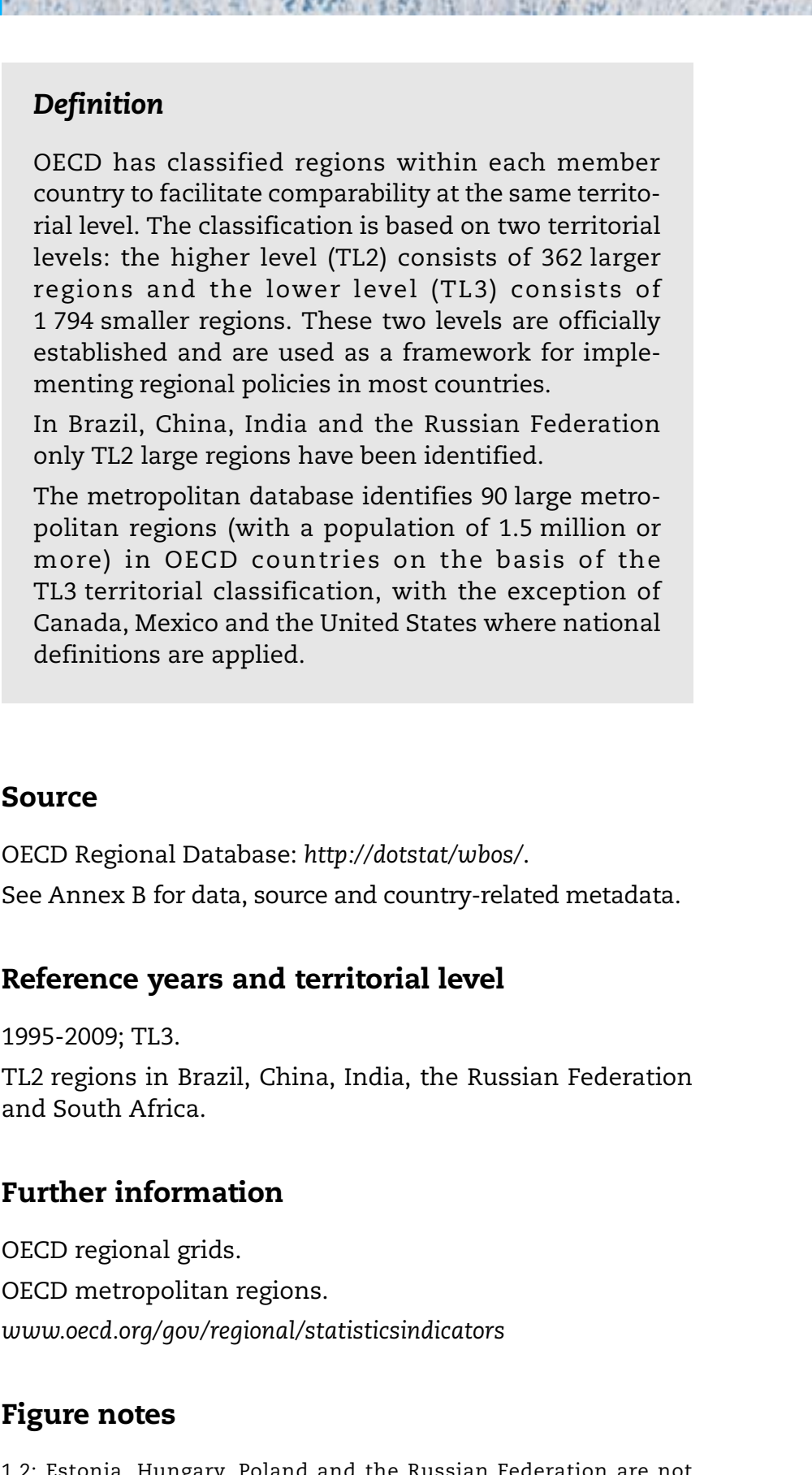

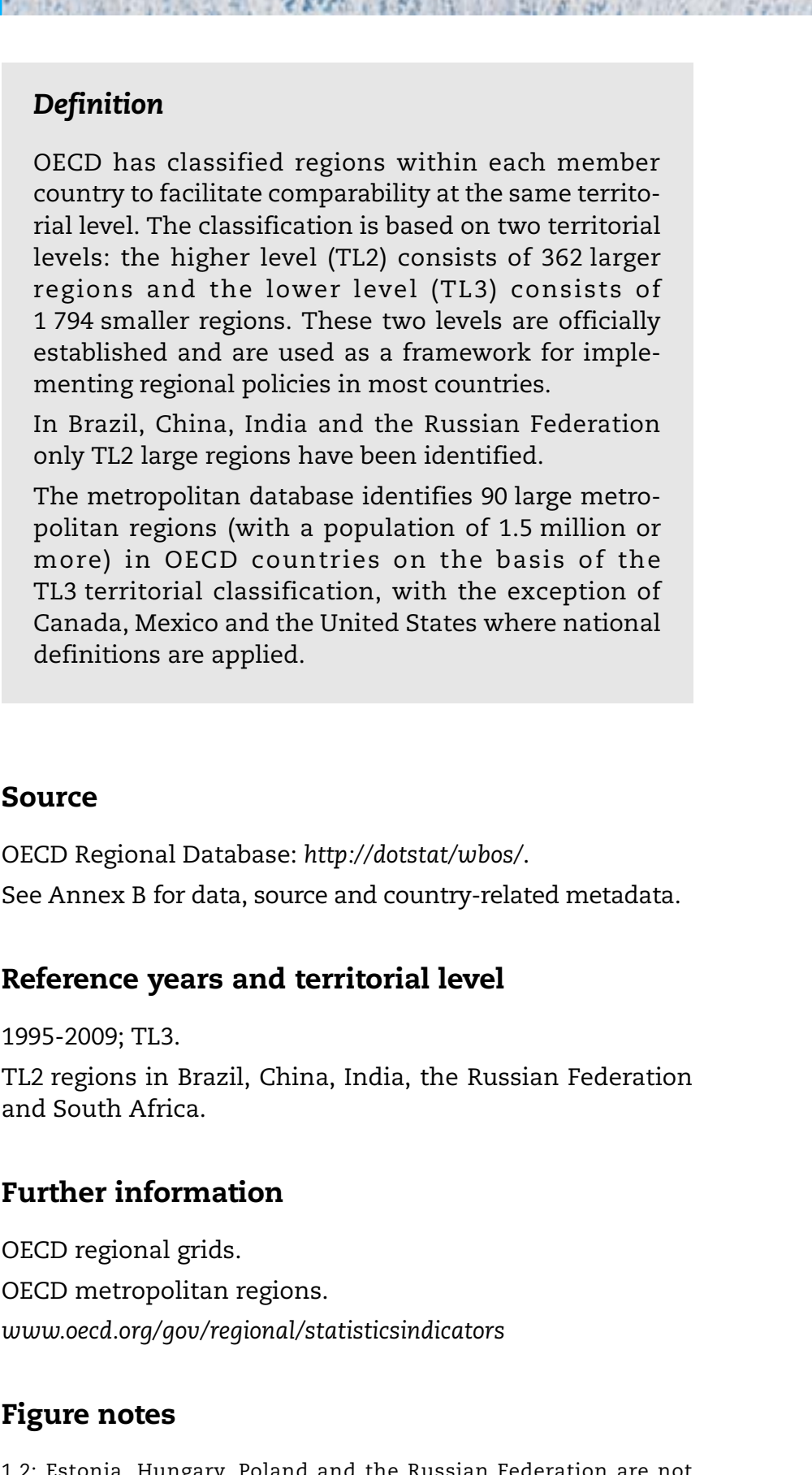

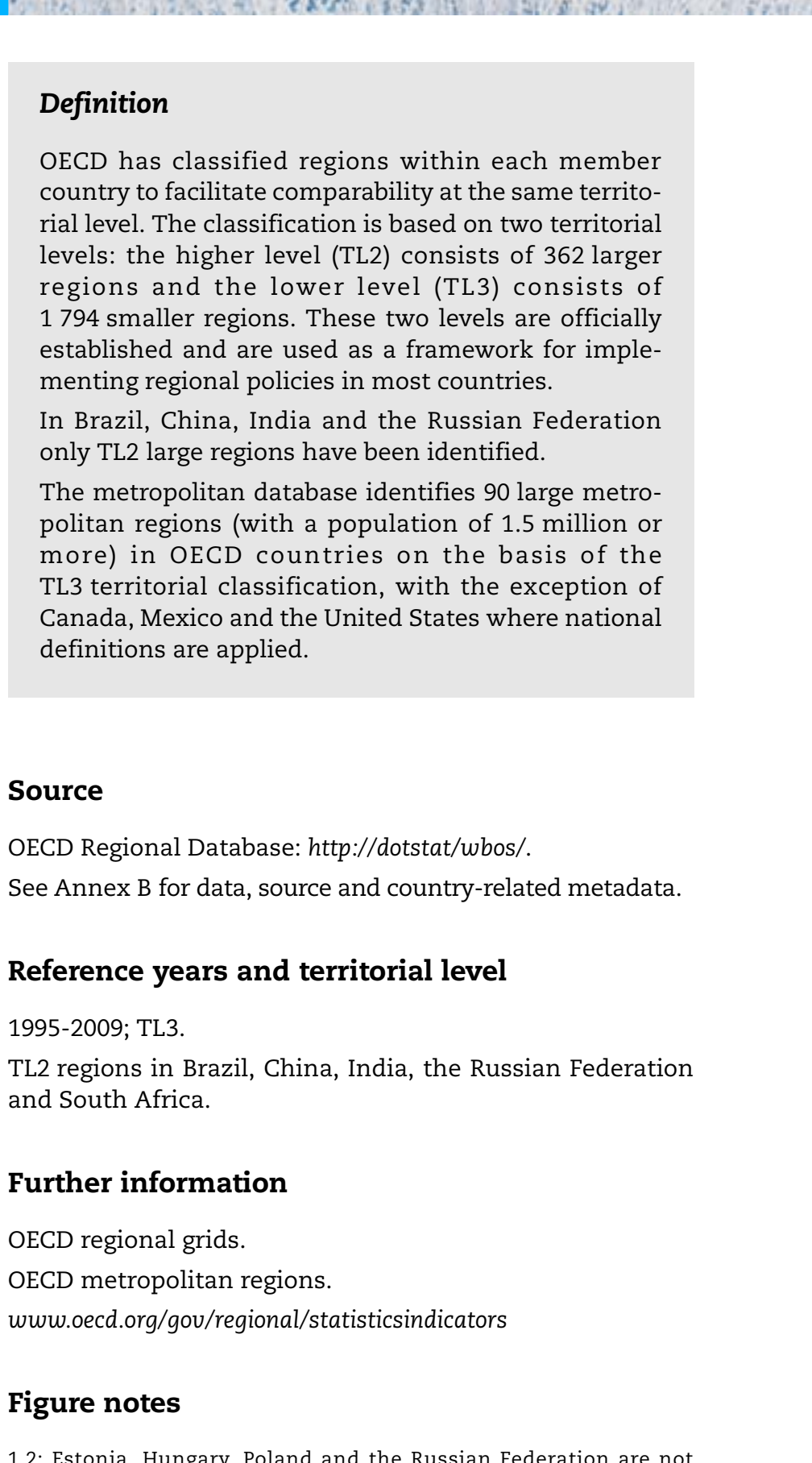

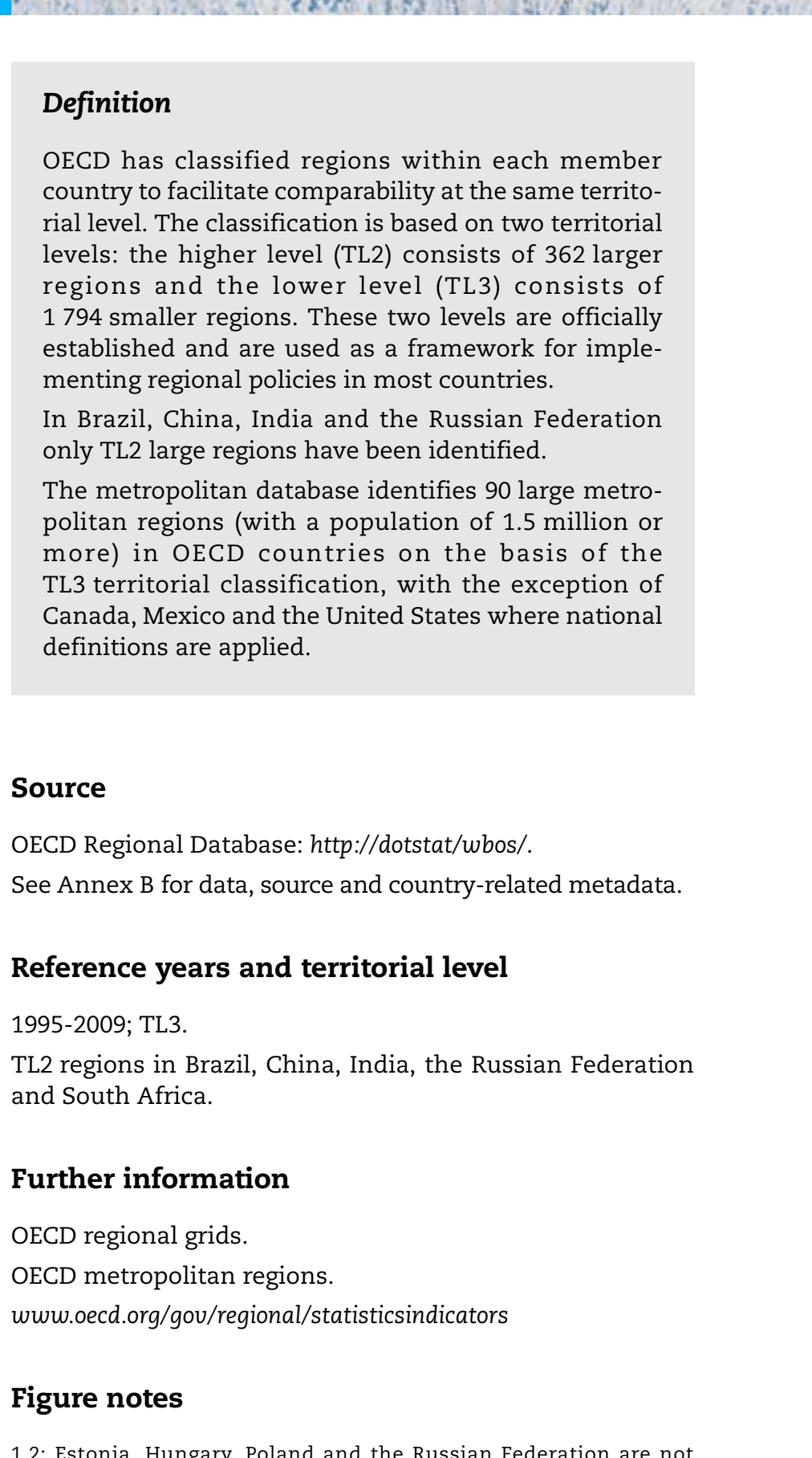

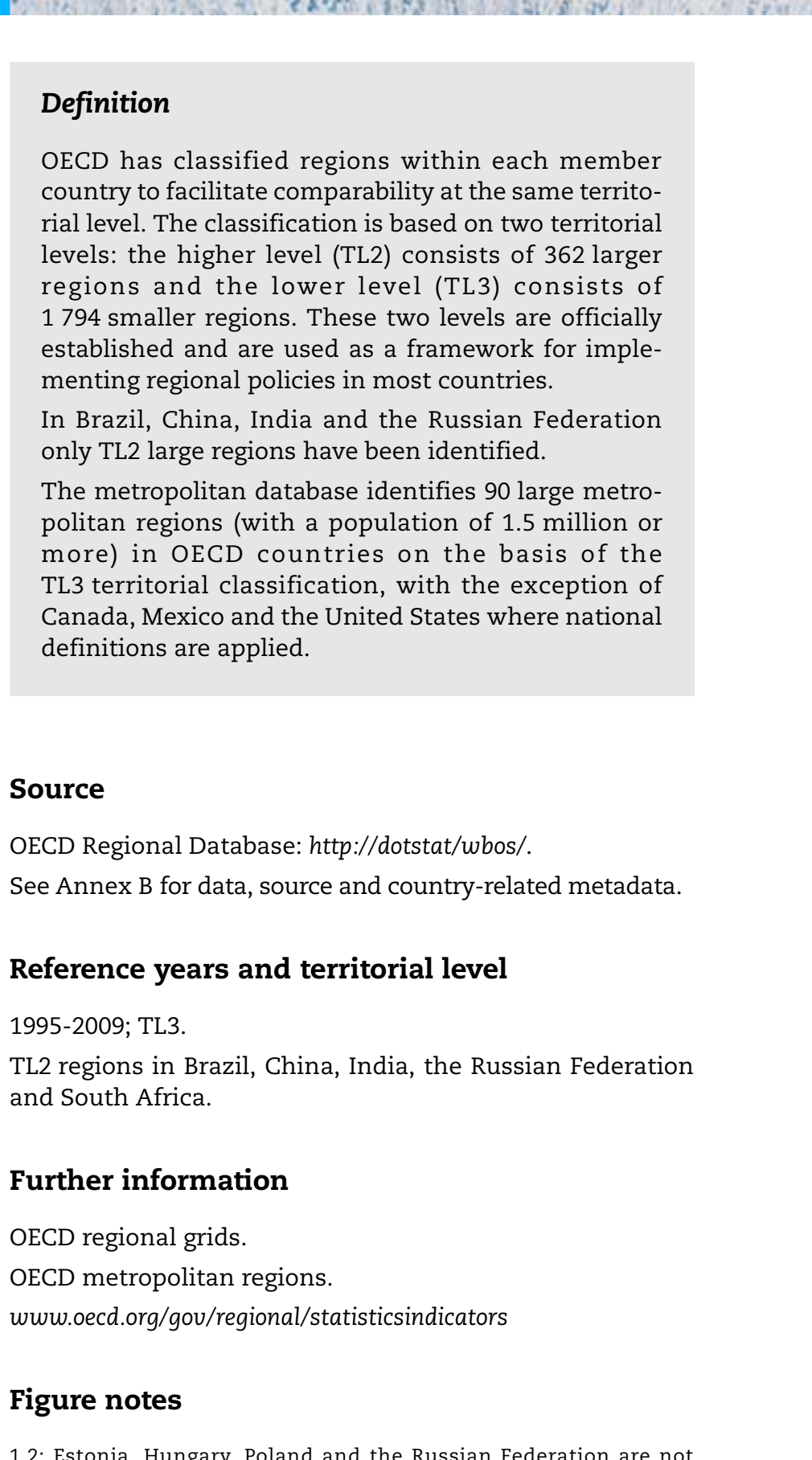

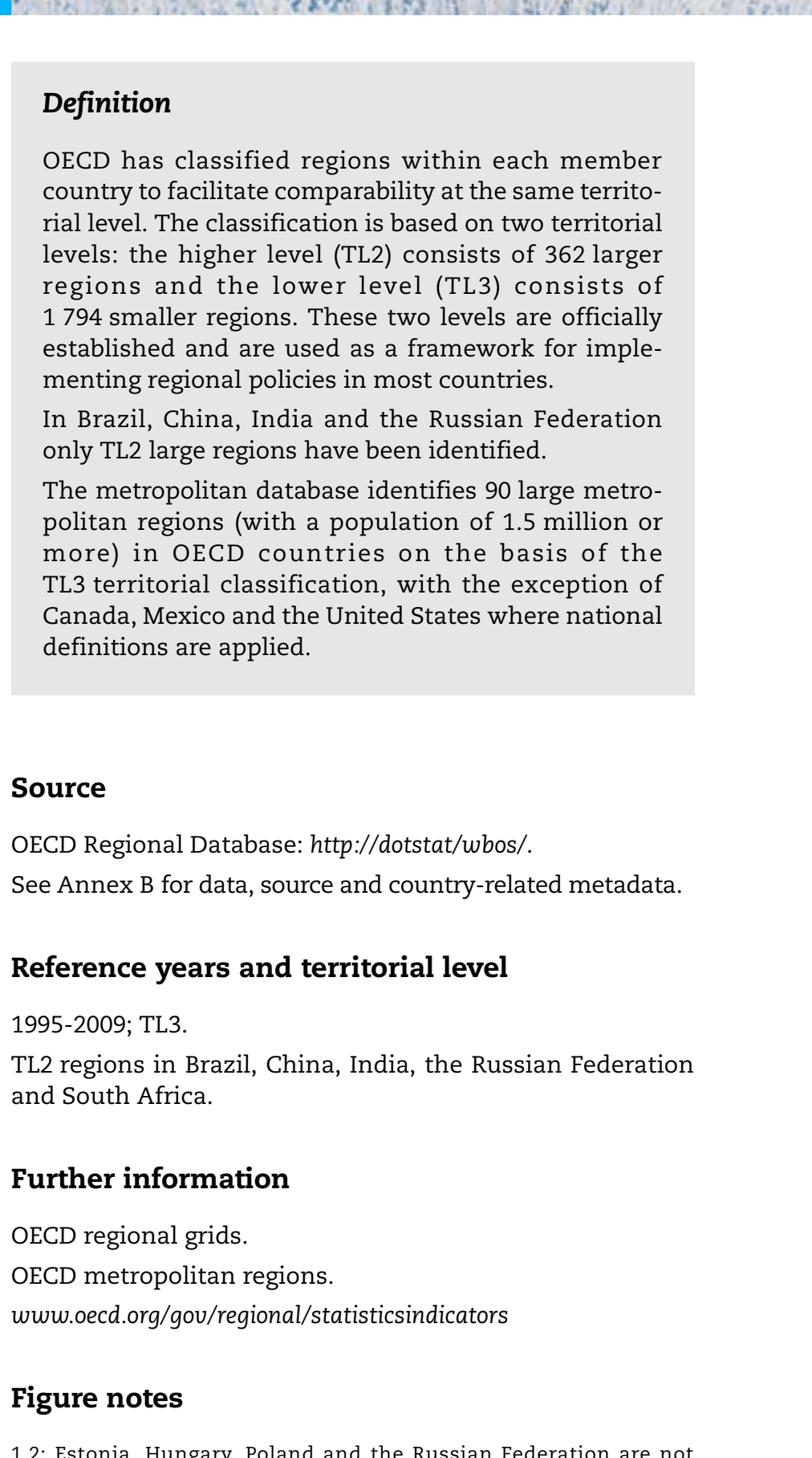

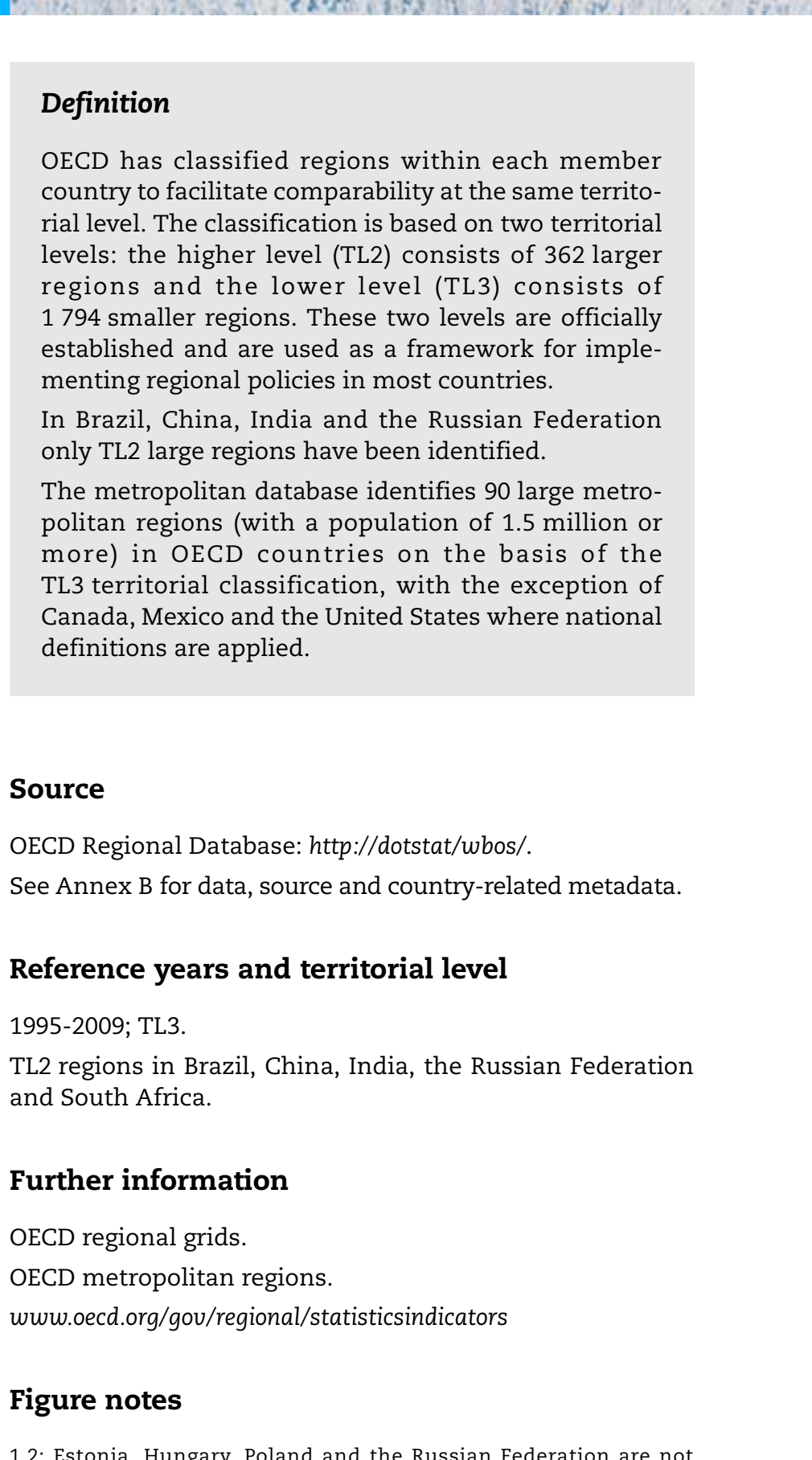

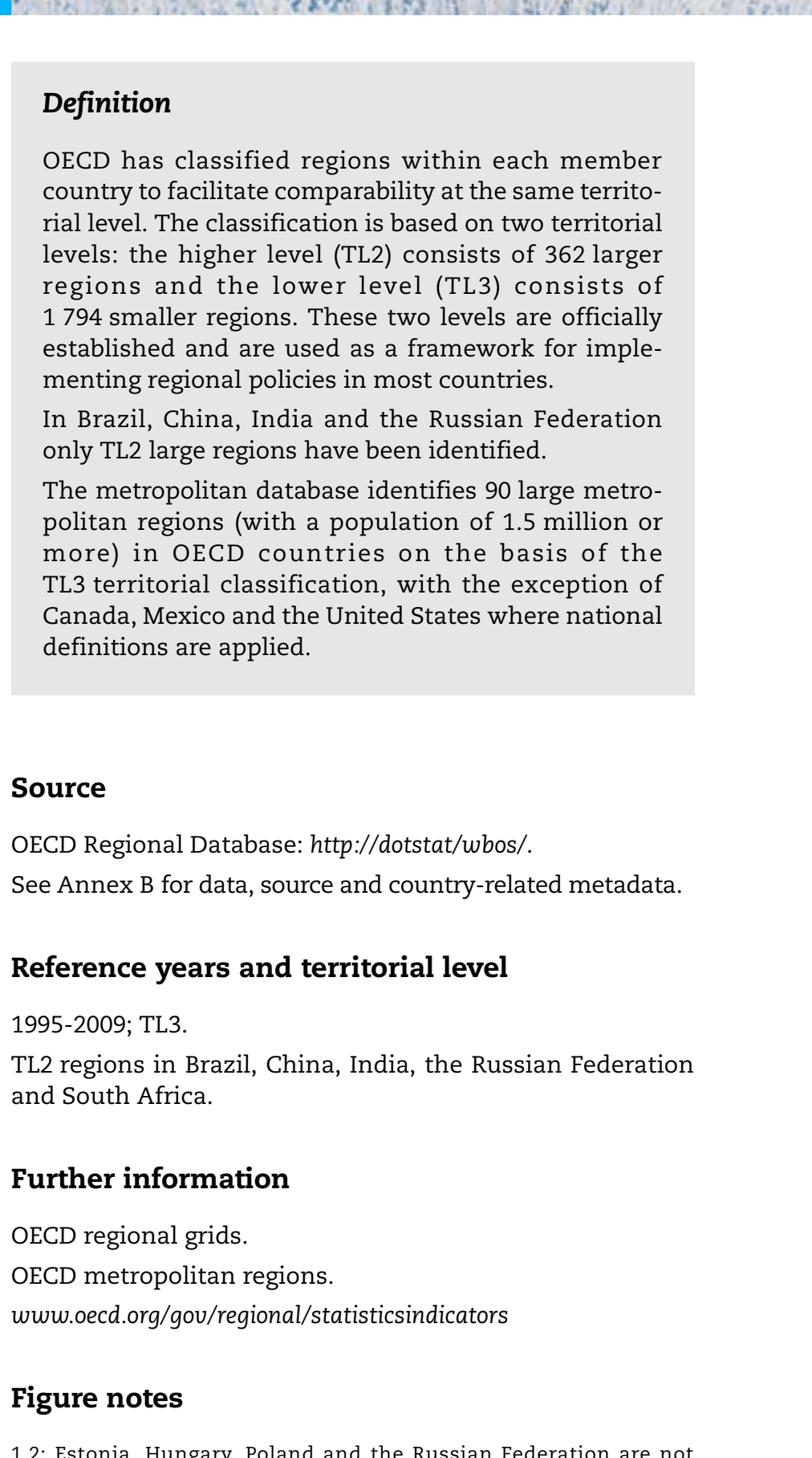

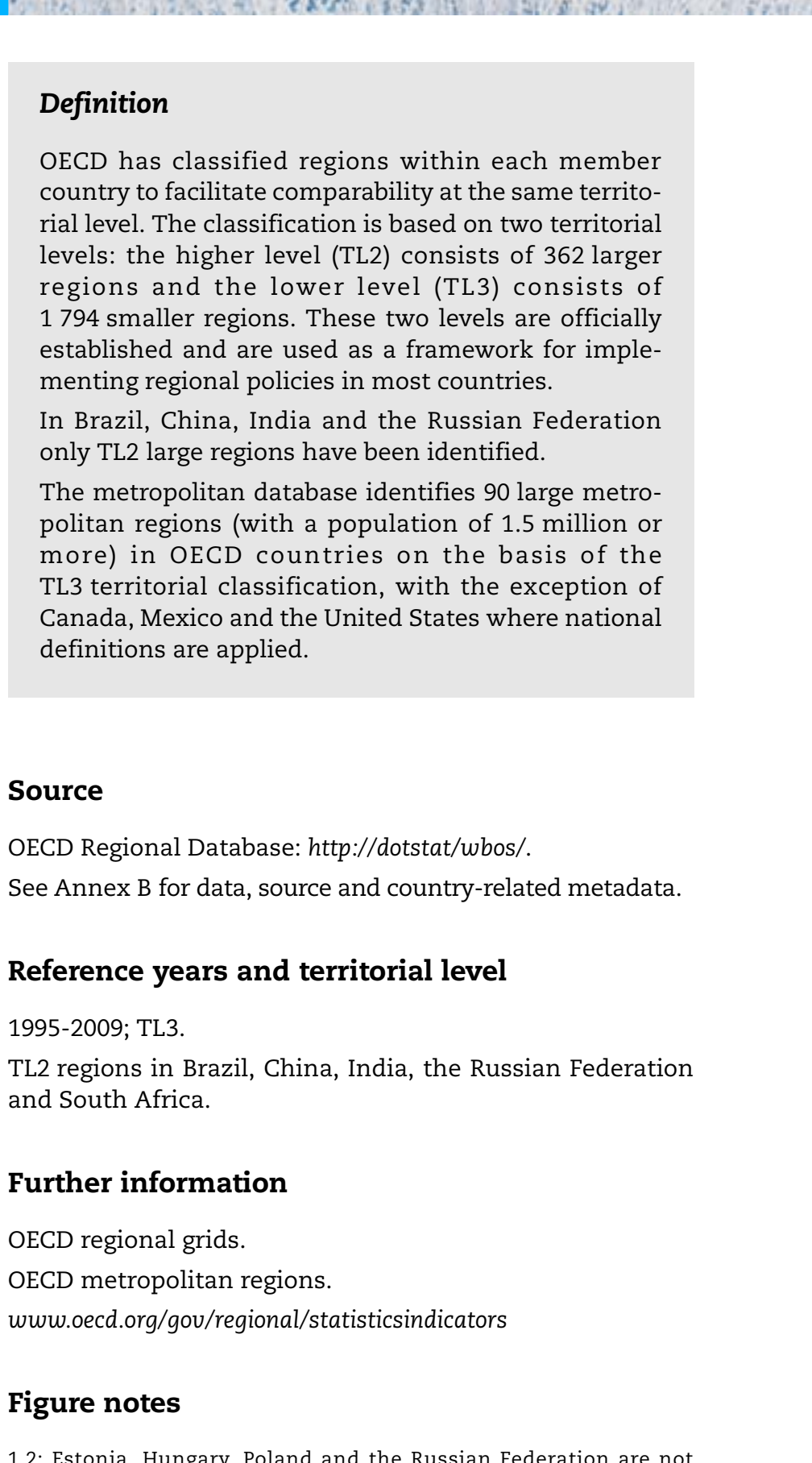

Definition
OECD has classified regions within each member
country to facilitate comparability at the same territo-
rial level. The classification is based on two territorial
levels: the higher level (TL2) consists of 362 larger
regions and the lower level (TL3) consists of
1 794 smaller regions. These two levels are officially
established and are used as a framework for imple-
menting regional policies in most countries.
In Brazil, China, India and the Russian Federation
only TL2 large regions have been identified.
The metropolitan database identifies 90 large metro-
politan regions (with a population of 1.5 million or
more) in OECD countries on the basis of the
TL3 territorial classification, with the exception of
Canada, Mexico and the United States where national
definitions are applied.
Figure notes
1.2. Estonia, Hungary, Poland and the Russian Federation are not
Further information
OECD regional grids.
OECD metropolitan regions.
www.oecd.org/gov/regional/statisticsindicators
Theference years and territorial level
and South Africa.
OECD Regional Database: http://dotstat/wbos/.
See Annex B for data, source and country-related metadata.
Thions in Brazil, China, India, the Russian Federation
The

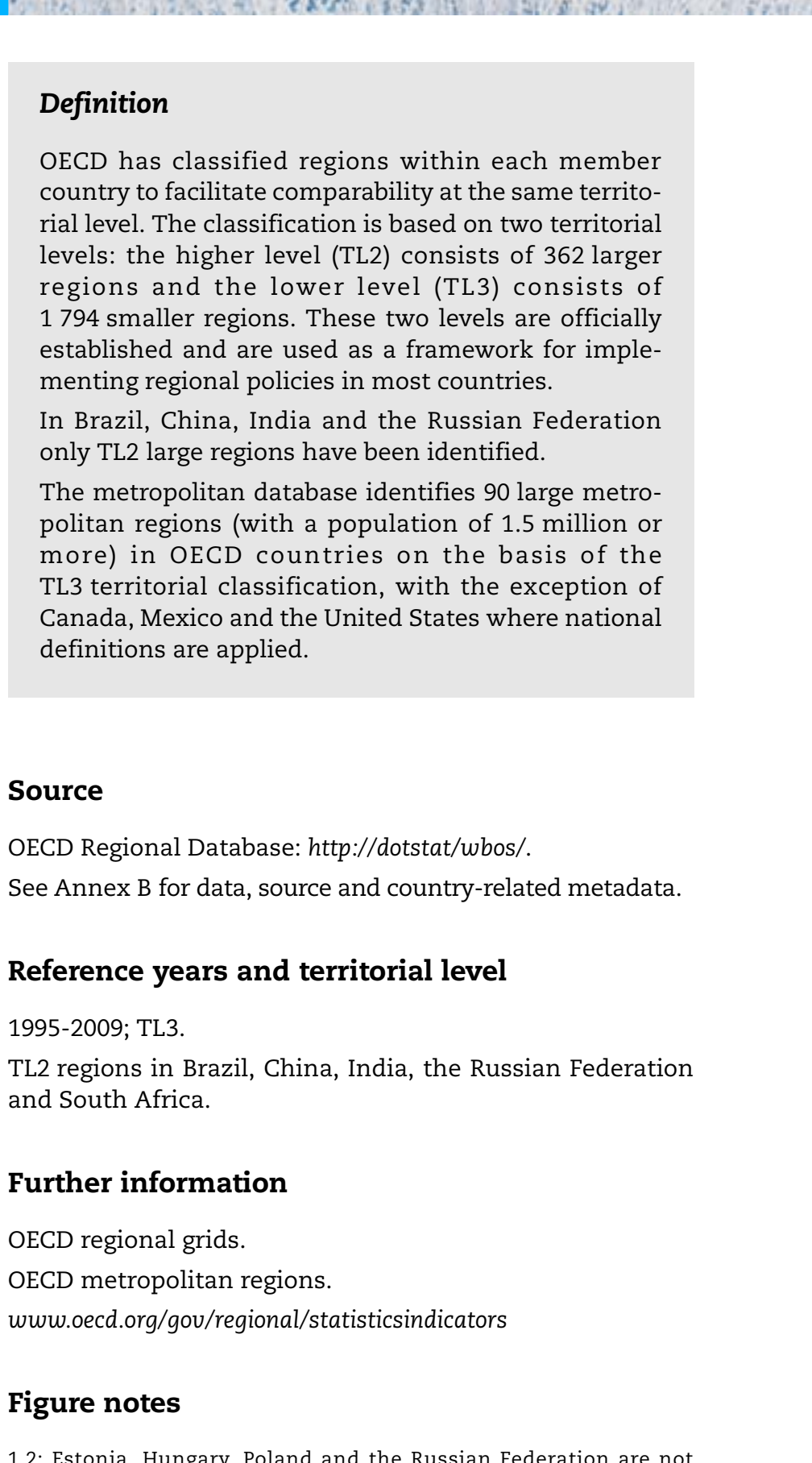

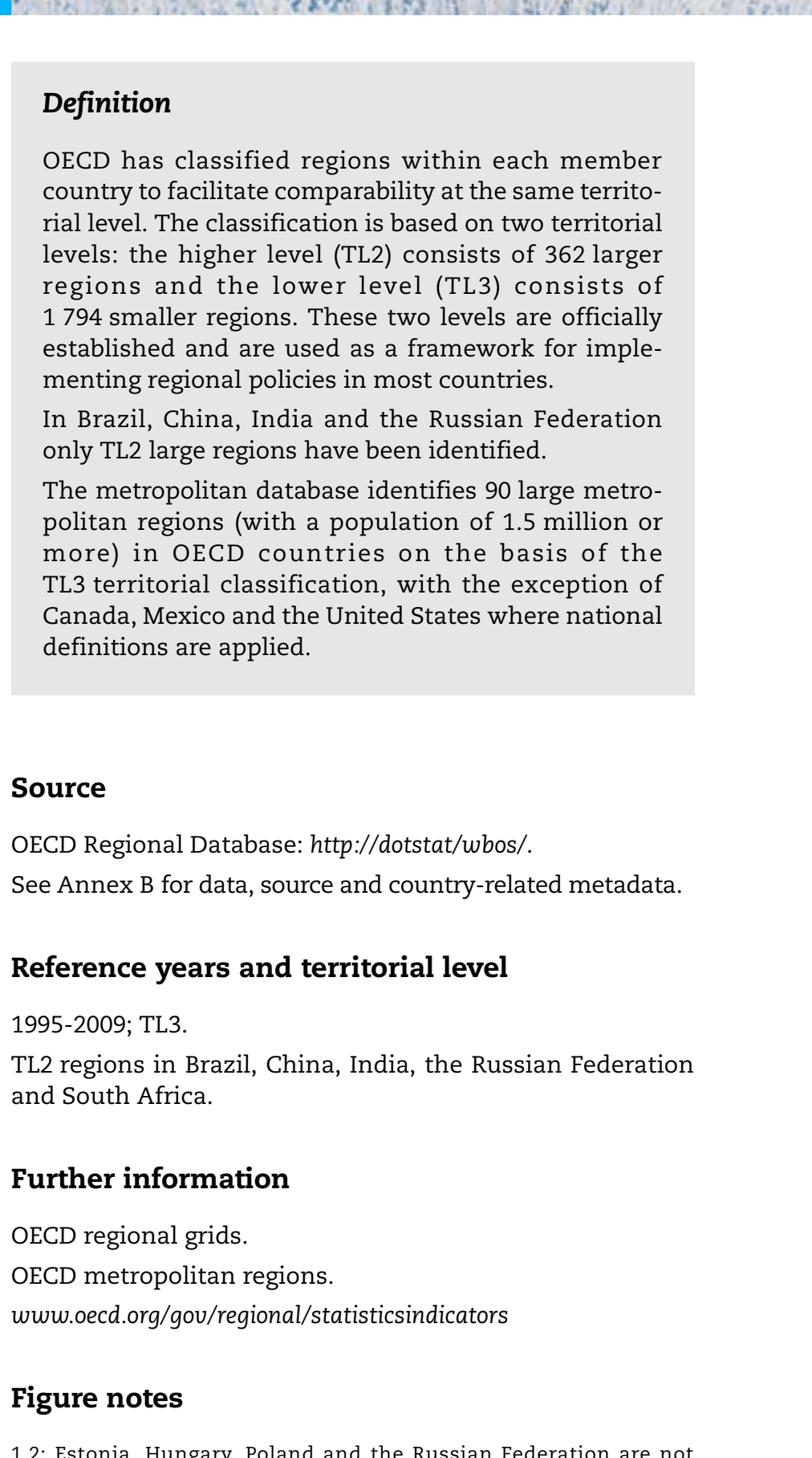

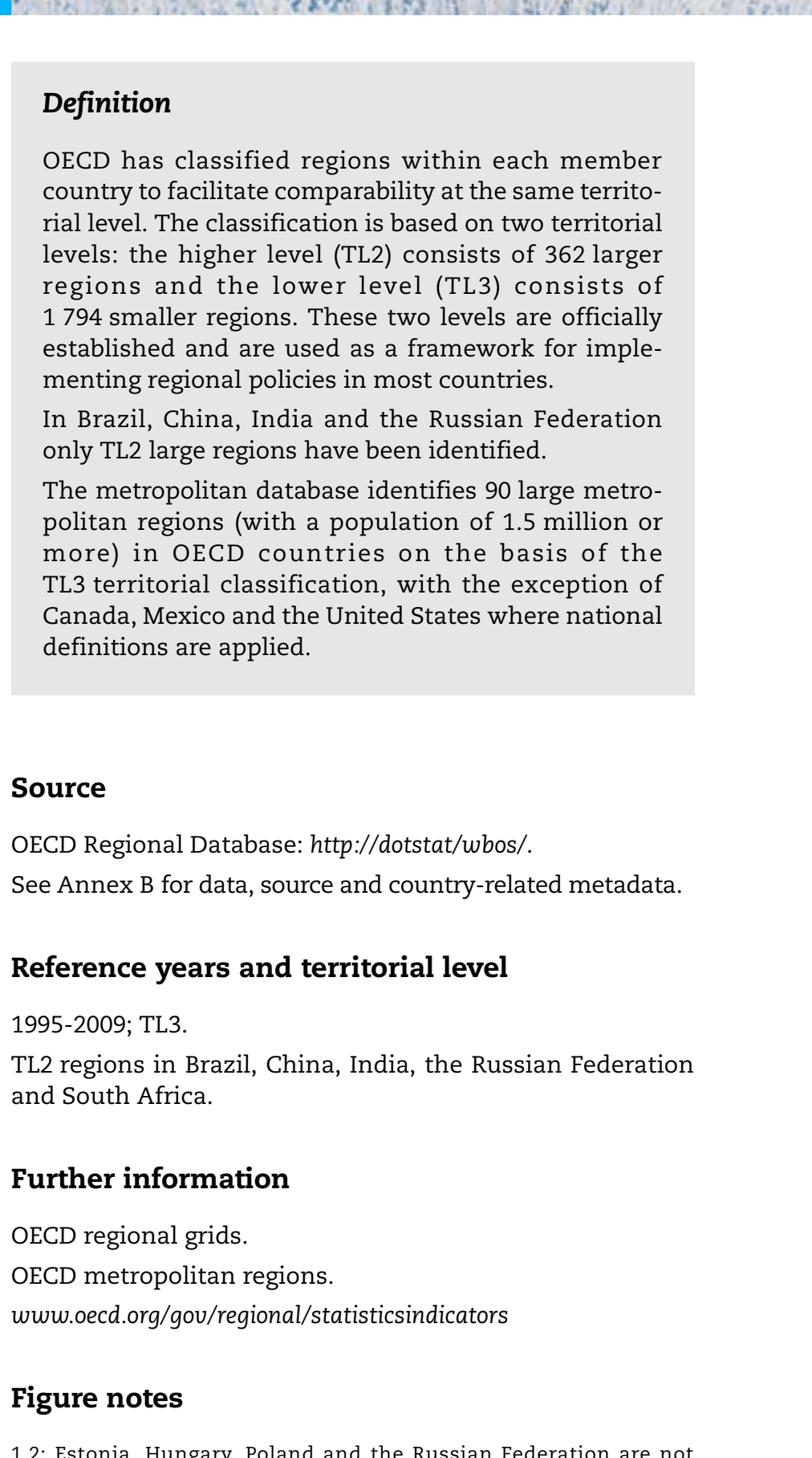

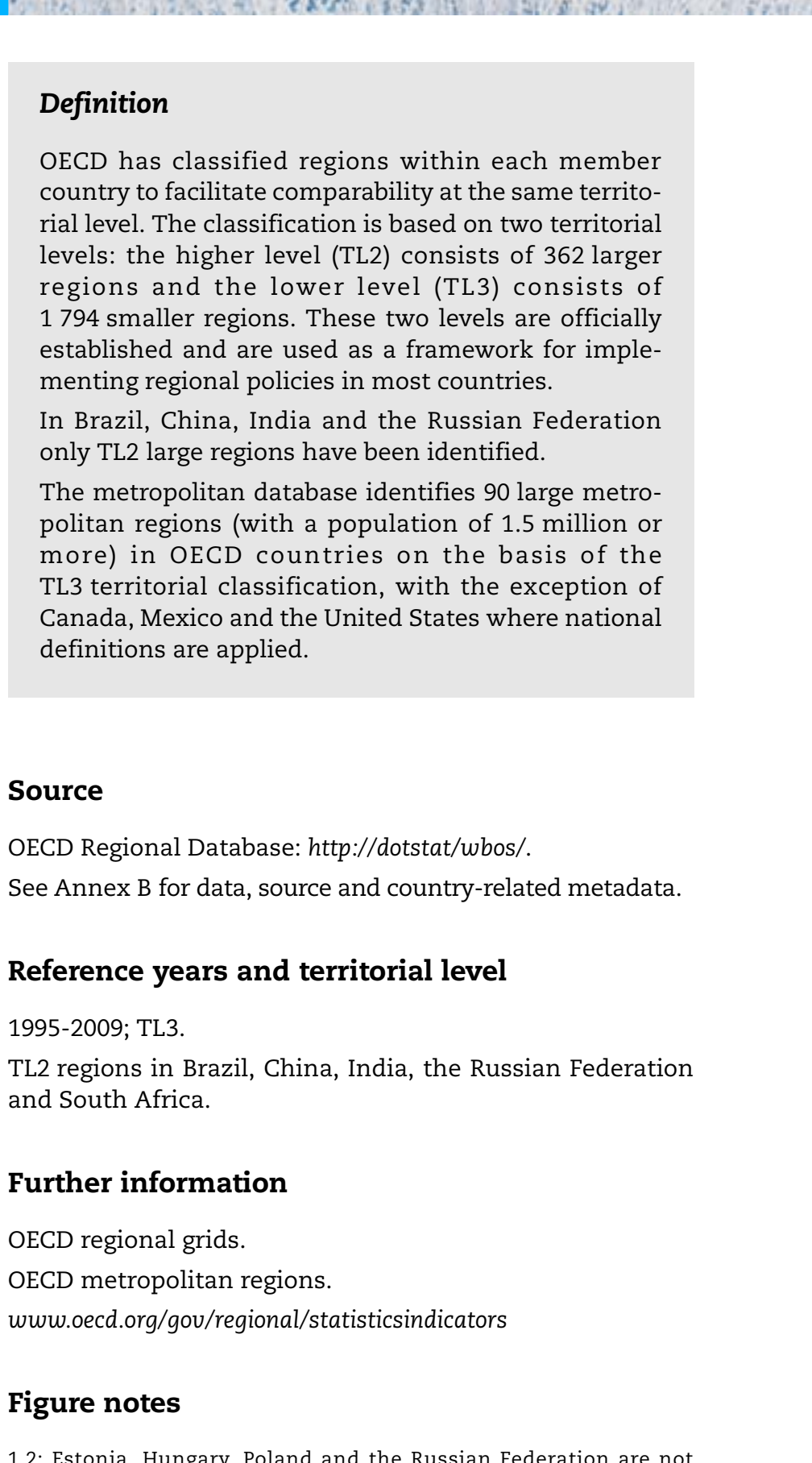

1.2: Estonia, Hungary, Poland and the Russian Federation are not included because of average decrease in population between 1995 and 2008. China is not included for lack of time series data.

1.3: The large metropolitan regions methodology has not been applied to Chile, Estonia, Israel and Slovenia. Luxembourg and Iceland don't have large metropolitan regions according to the OECD methodology.

1.4: Available years Belgium 2000-08; Denmark 2007-08; Germany 2005-08; Poland 2001-08. 


\section{REGIONAL CONTRIBUTION TO POPULATION CHANGE}

\subsection{Percent of the national population that lives in $10 \%$ of TL3 regions with the largest population, 1995 and 2009}

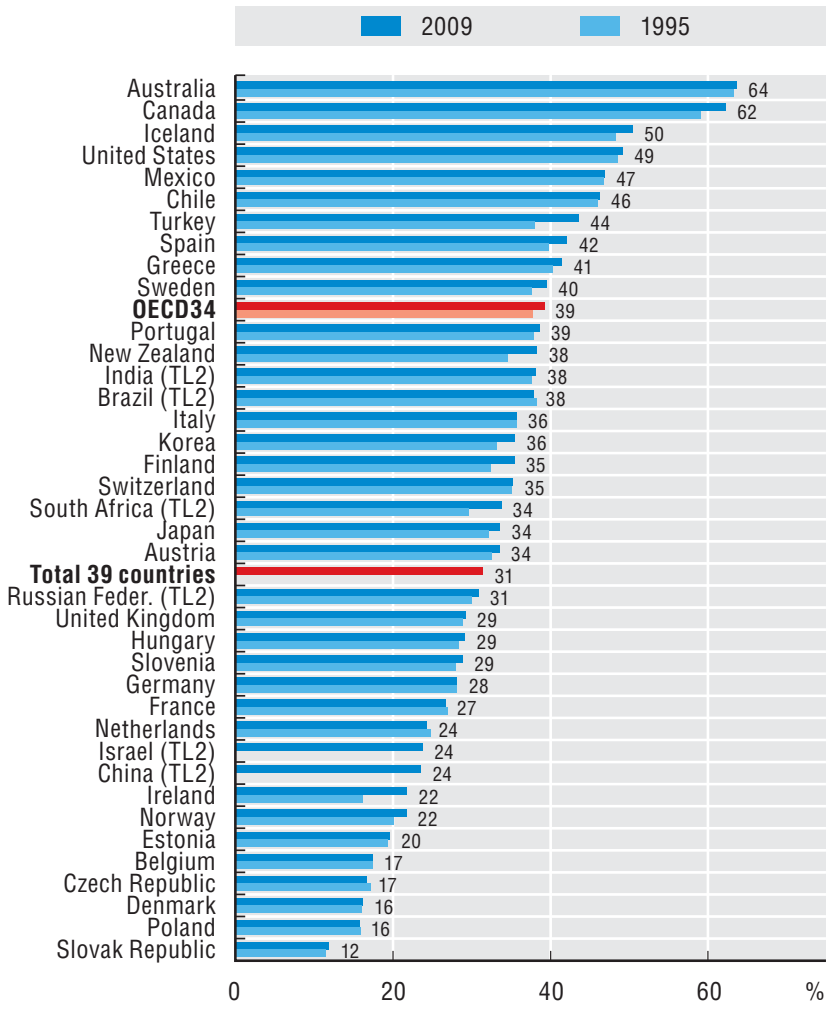

1.3. Percent of the national population living in large metropolitan regions, 2008

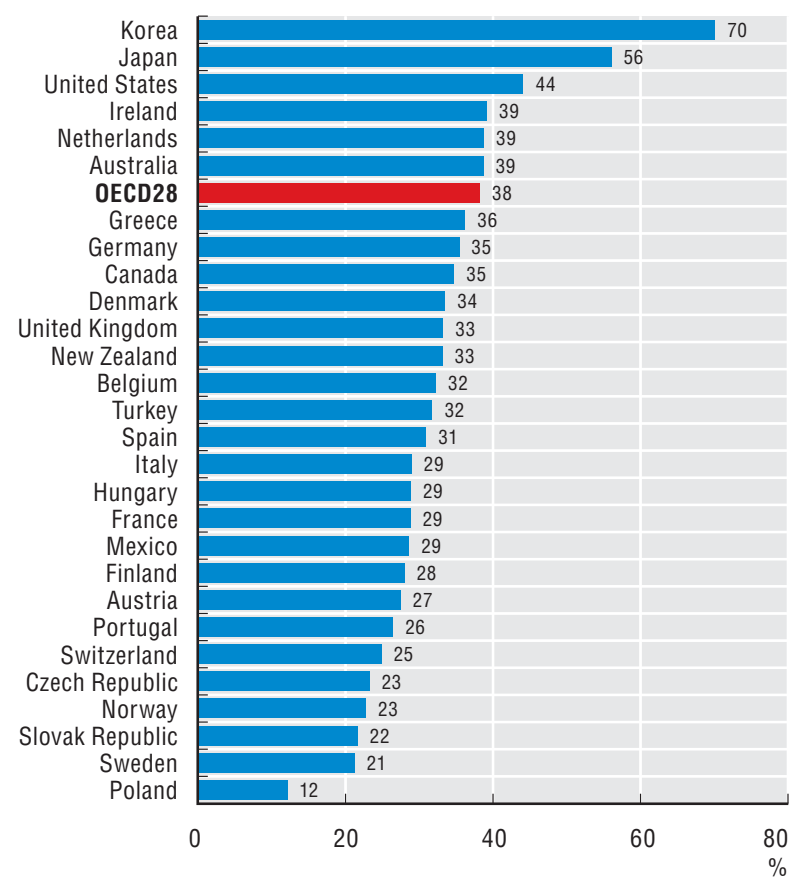

1.2. Percent of the national population growth contributed by the top $10 \%$ TL3 regions with the highest population growth, 1995-2009

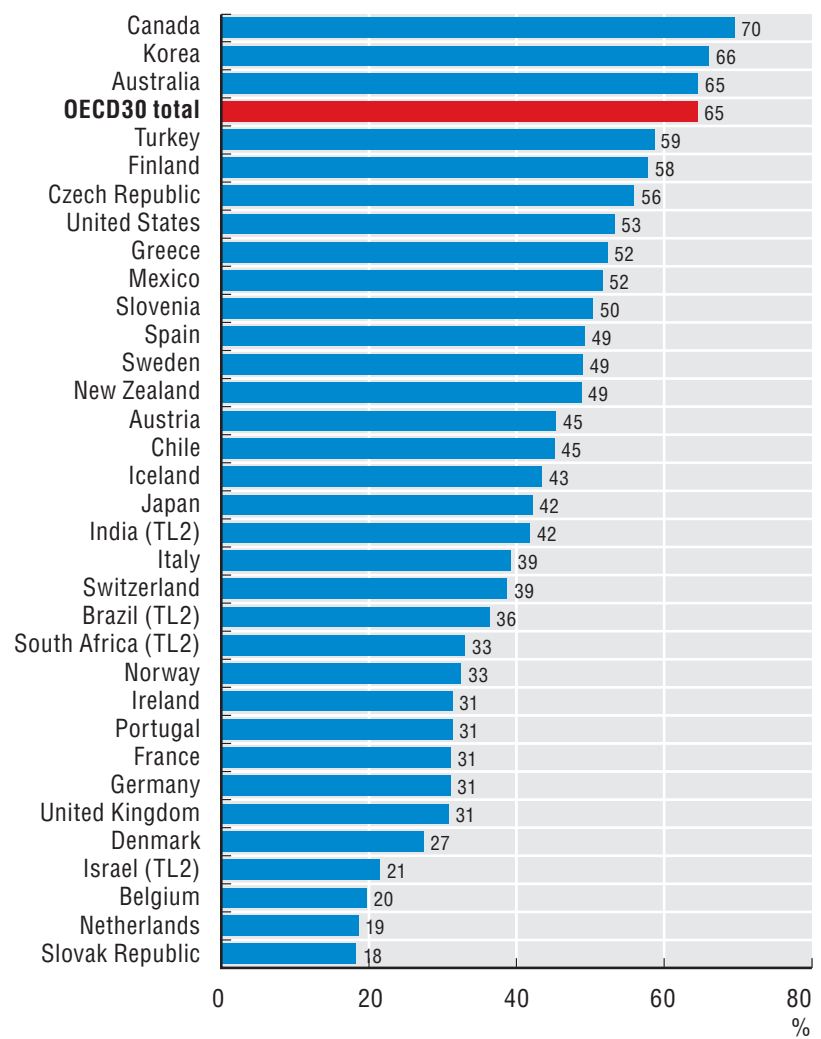

1.4. Annual change in the total population: metropolitan regions and country average, 1997-2008

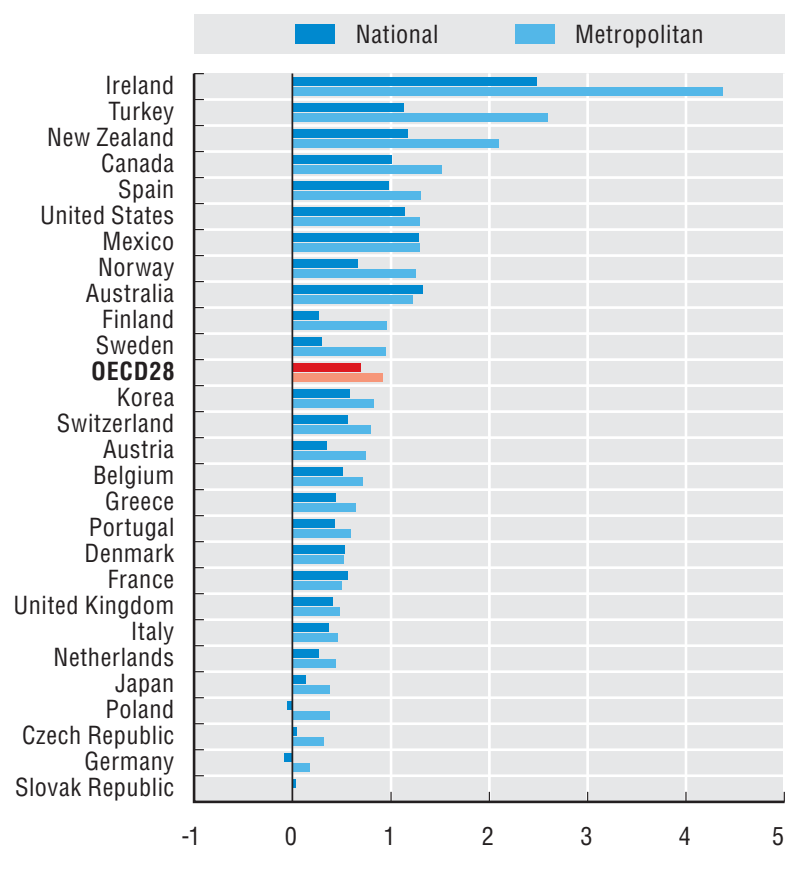

StatLink काजस http://dx.doi.org/10.1787/888932439368 
In 2009, almost half of the total OECD population (47\%) lived in predominantly urban regions, which accounted for less than $6 \%$ of the total area. More than $60 \%$ of the population lived in predominantly urban regions in the Netherlands, Belgium and the United Kingdom (Figure 2.1).

Predominantly rural regions accounted for one-fourth of total population and $80 \%$ of land area. In Ireland, Finland, Norway, Slovenia and Sweden the share of national population in rural regions was two times higher than the OECD average (Figure 2.1).

Rural regions in North America and European countries have been further classified as close to a large urban centre or remote. In Norway, Greece, Portugal, Switzerland and Canada more than half of the rural population lives in remote rural regions (Figure 2.2).

As expected, remote rural regions experienced outmigration. As a result, most of them display a net decrease of population and smaller population growth than any other type of regions in all countries, with the exception of Ireland (Figure 2.3).

On the other hand, the share of the population living in predominantly urban regions increased in 20 OECD countries and significantly in Ireland, Turkey, New Zealand, and Canada (more than three percentage points) in the past 14 years. In Korea, Hungary and the United Kingdom, intermediate regions have increased their share of population recently, while in the United States rural regions have gained weight in population (Figure 2.4).

In India the absolute number of new people who moved to urban regions between 2000 and 2009 was equal to all the OECD countries together (more than 50 million). The share of people living in urban regions in China has increased from less than 30\% in 1995 to around 45\% in 2009, corresponding to some 150 million new urban dwellers in just ten years from 2000 to 2009 (Figure 2.5).

\section{Definition}

OECD has established a regional typology to take into account geographical differences and enable meaningful comparisons between regions belonging to the same type. Regions have been classified as predominantly rural, intermediate and predominantly urban on the basis of the \% of population living in local rural units (see Annex A for the detailed methodology).

This typology has been refined by introducing a criterion of distance (driving time) to large urban centres. Thus a predominantly rural region is classified as remote rural region (PRR) if a certain percentage of the regional population needs more than a fixed time to reach a large urban centre; otherwise the rural region is classified as predominantly rural close to a city (PRC). The extended typology has been applied to North America and Europe (see Annex A for the detailed methodology).

\section{Source}

OECD Regional Database: http://dotstat/wbos/.

See Annex B for data, source and country-related metadata.

\section{Reference years and territorial level}

\section{5-2009; TL3.}

TL2 regions in Brazil, China, India, the Russian Federation and South Africa.

The extended OECD typology is applied only to North America and Europe.

\section{Further information}

OECD (2009), Regional typology: Updated statistics.

M. Brezzi, V. Ruiz and L. Dijkstra (2011), Refinement of the OECD regional typology: The economic performance of rural regions, OECD regional development Working Papers 2011/3.

www.oecd.org/gov/regional/statisticsindicators.

\section{Figure notes}

2.2: The extended typology is applied only to countries in Europe and North America

2.4: No predominantly urban regions in Iceland and Slovenia.

2.5: Measurement gap: OECD rural and urban typology and its extension to emerging economies: The OECD regional typology classifies small regions into predominantly rural, intermediate or urban according to the density of population in local communities and the presence of an urban centre. This methodology is here applied to Brazil (municipalities) and South Africa (sub-places). The share of urban population in South Africa according to the OECD definition is slightly lower than by the national definition (1996 Census of population, currently under revision by Statistics South Africa). For lack of data on population and area in small communities, the OECD typology is not applied to China and India and national definitions are used, which distinguish only between urban and rural populations (respectively Central Bureau of Statistics of China and Ministry of Statistics and Program Implementation of India).

Information on data for Israel: http://dx.doi.org/10.1787/888932315602. 
2.1. Distribution of population and area into predominantly urban (PU), intermediate (IN) and predominantly rural (PR) regions, 2009

Population

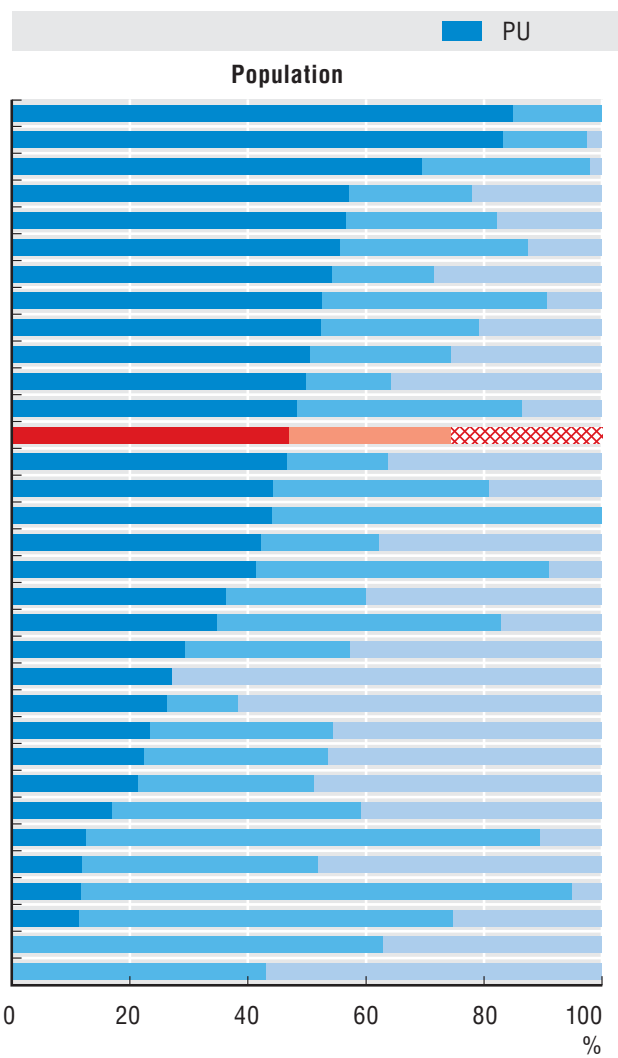

2.2. Percentage of the national population living in predominantly rural regions close to a city and predominantly remote rural, 2009

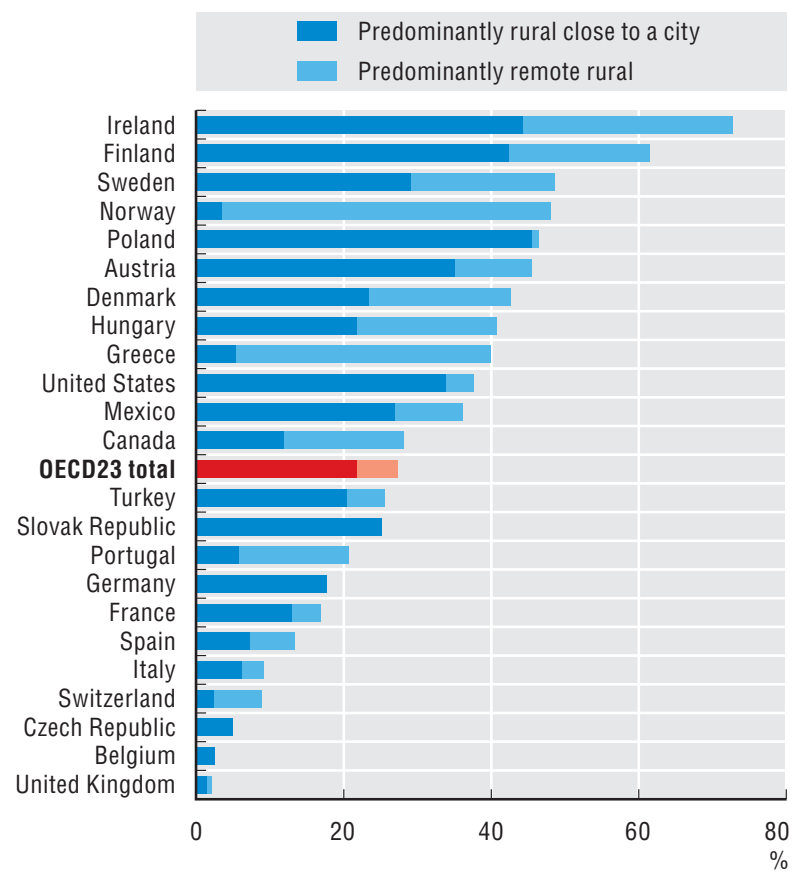

IN

Netherlands

Belgium

United Kingdom

Australia

Germany

Japan

Canada

Italy

Portugal

Turkey

Chile

Spain

OECD33

Mexico

Korea

New Zealand

United States

Switzerland

Greece

France

Denmark

Ireland

Finland

Austria

Poland

Sweden

Hungary

Estonia

Norway

Czech Republic

Slovak Republic

Iceland

Slovenia

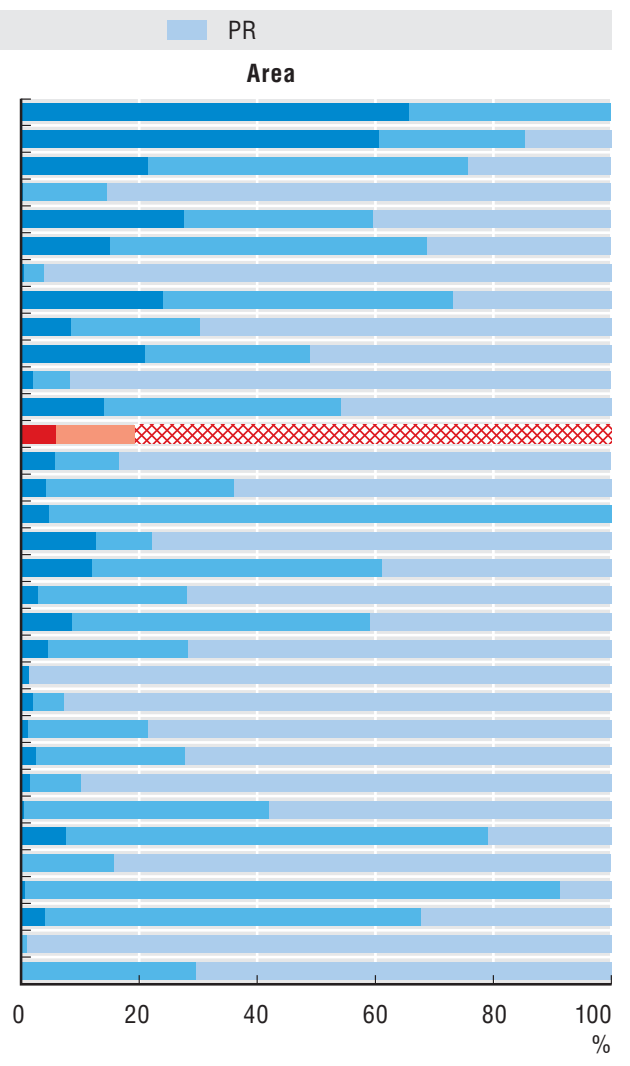

2.3. Annual growth rate of population in predominantly rural regions close to a city (PRC) and predominantly remote rural (PRR), 1995-2009

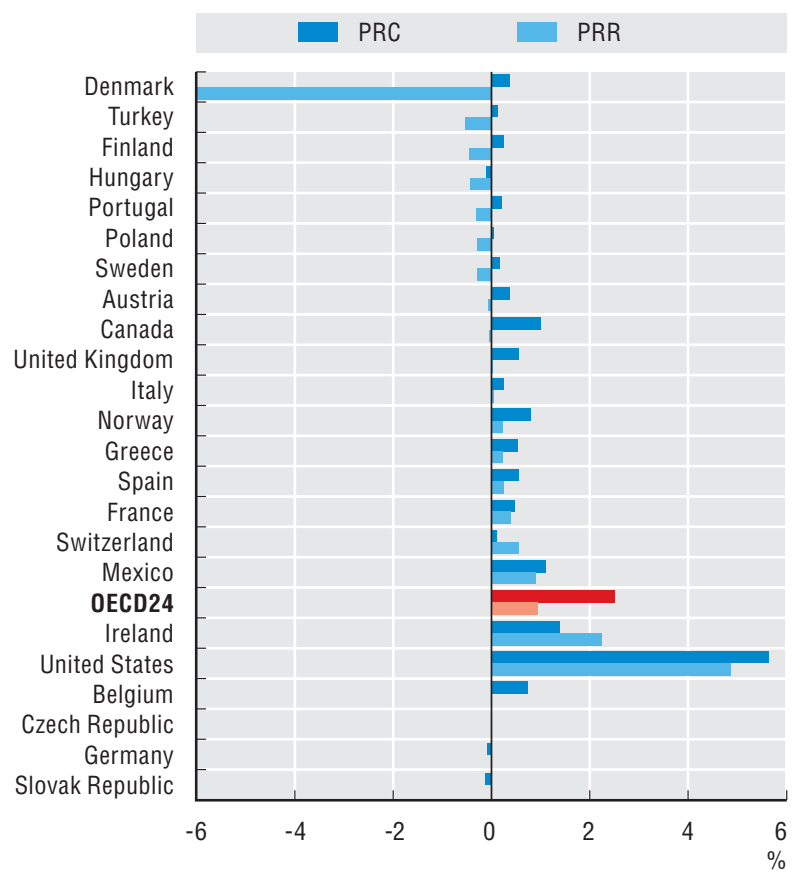

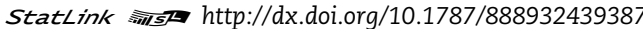




\section{DISTRIBUTION OF POPULATION AND REGIONAL TYPOLOGY}

2.4. Percentage point change in the share of population living in predominantly urban regions, 1995-2009

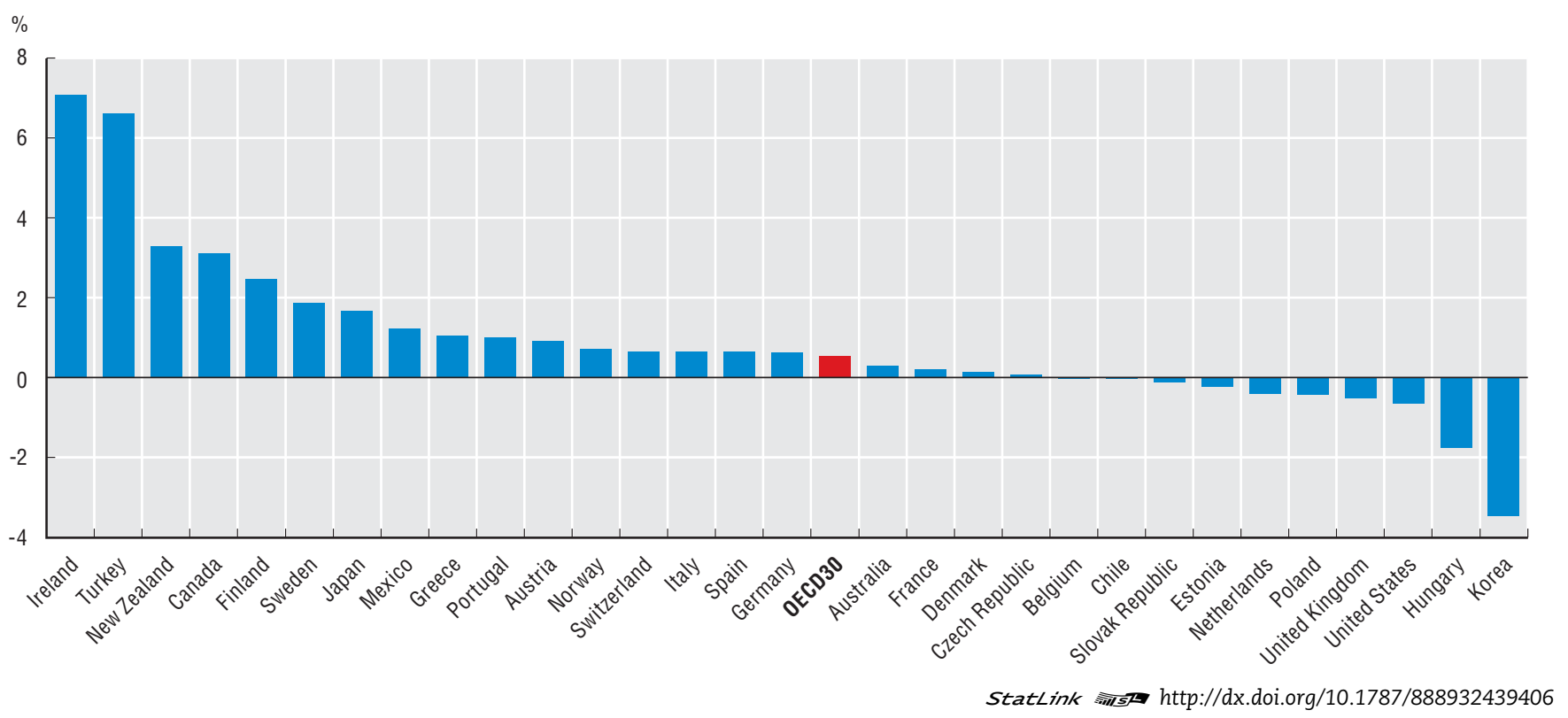

2.5. Share of population living in predominantly rural (PR), intermediate (IN) or predominantly urban regions (PU) in 2009 and millions of new urban dwellers: OECD countries, Brazil, South Africa, China and India, 2000-2009

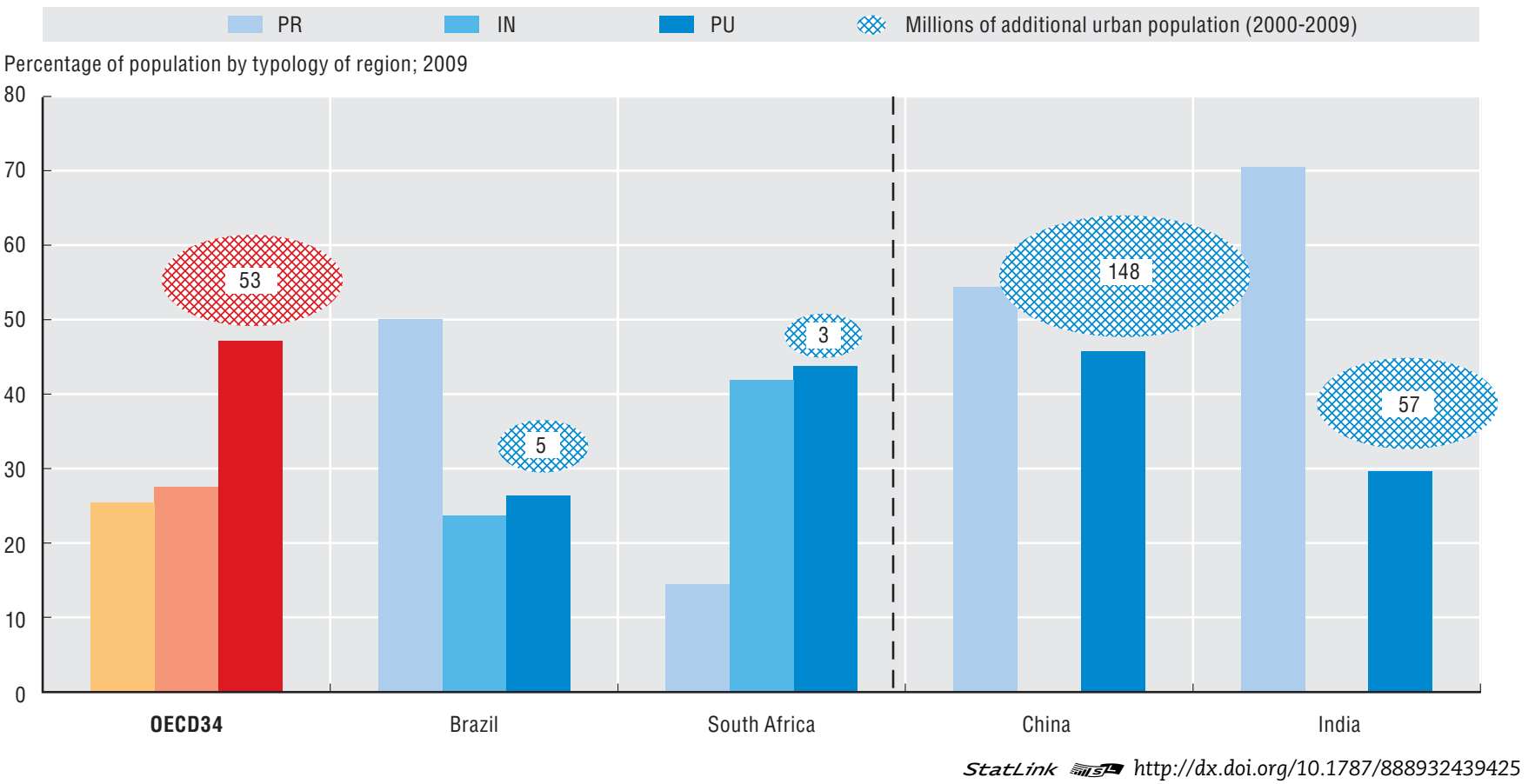




\section{DISTRIBUTION OF POPULATION AND REGIONAL TYPOLOGY}

2.6. Regional population density: Asia, Europe and Oceania, 2009

Inhabitants per square kilometer, TL3 regions

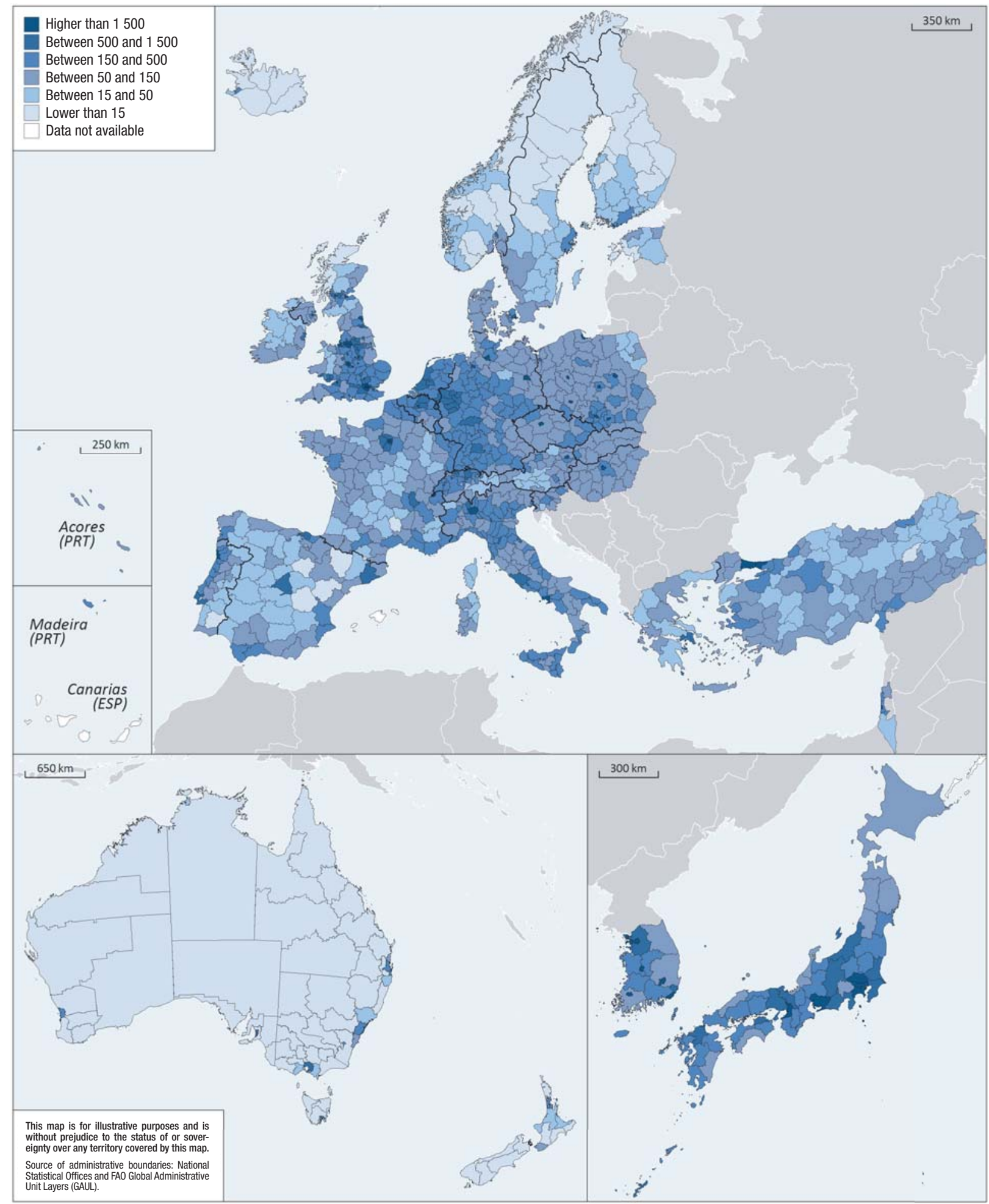

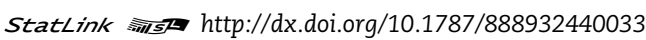




\section{DISTRIBUTION OF POPULATION AND REGIONAL TYPOLOGY}

\section{DISTRIBUTION OF POPULA}

\section{Xac nothen}

init

2.7. Regional population density: Americas, 2009

Inhabitants per square kilometer, TL3 regions

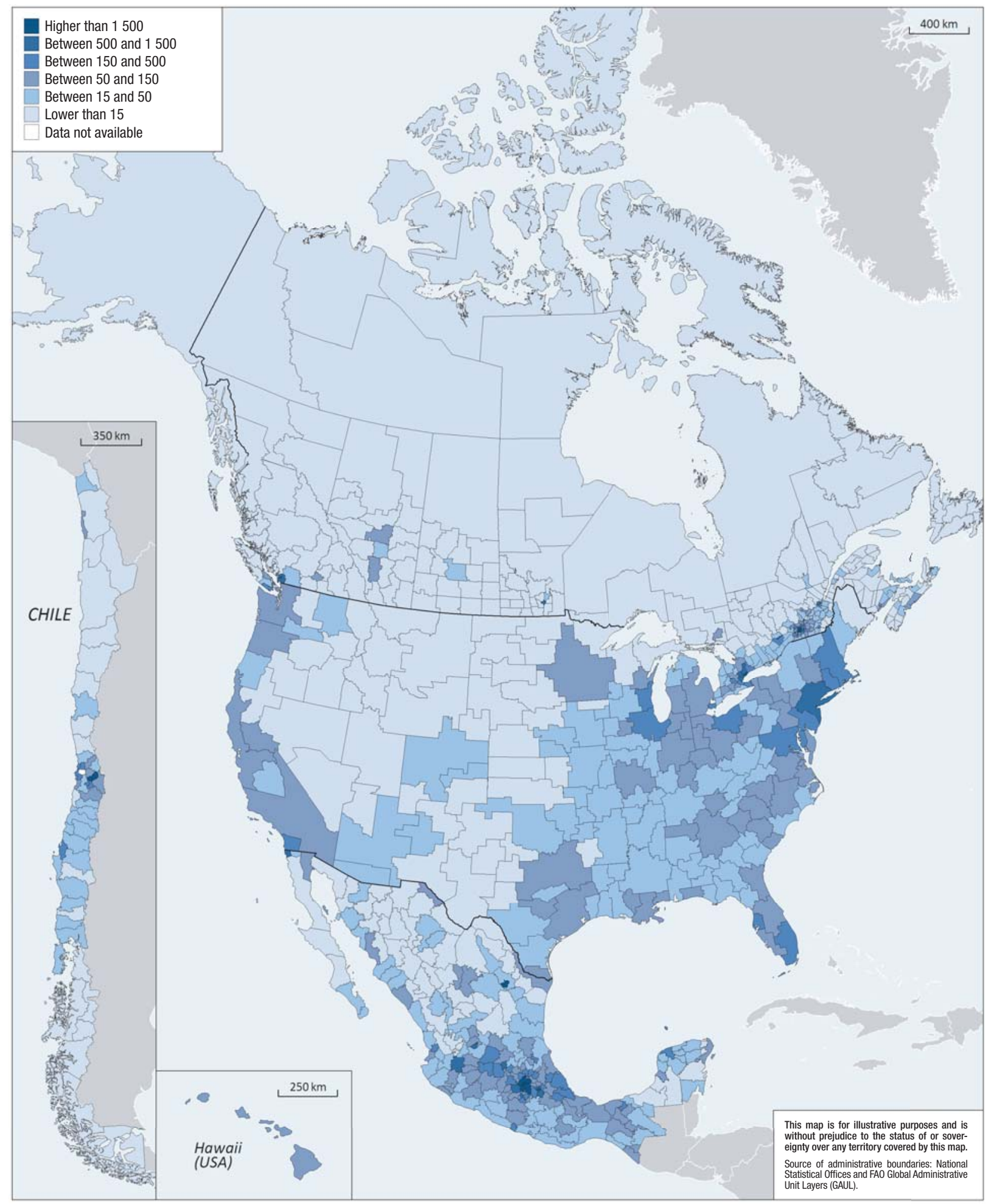

StatLink काIsL http://dx.doi.org/10.1787/888932440033 


\section{DISTRIBUTION OF POPULATION AND REGIONAL TYPOLOGY}

2.8. Regional population density: Emerging economies, 2009

Inhabitants per square kilometer, TL2 regions

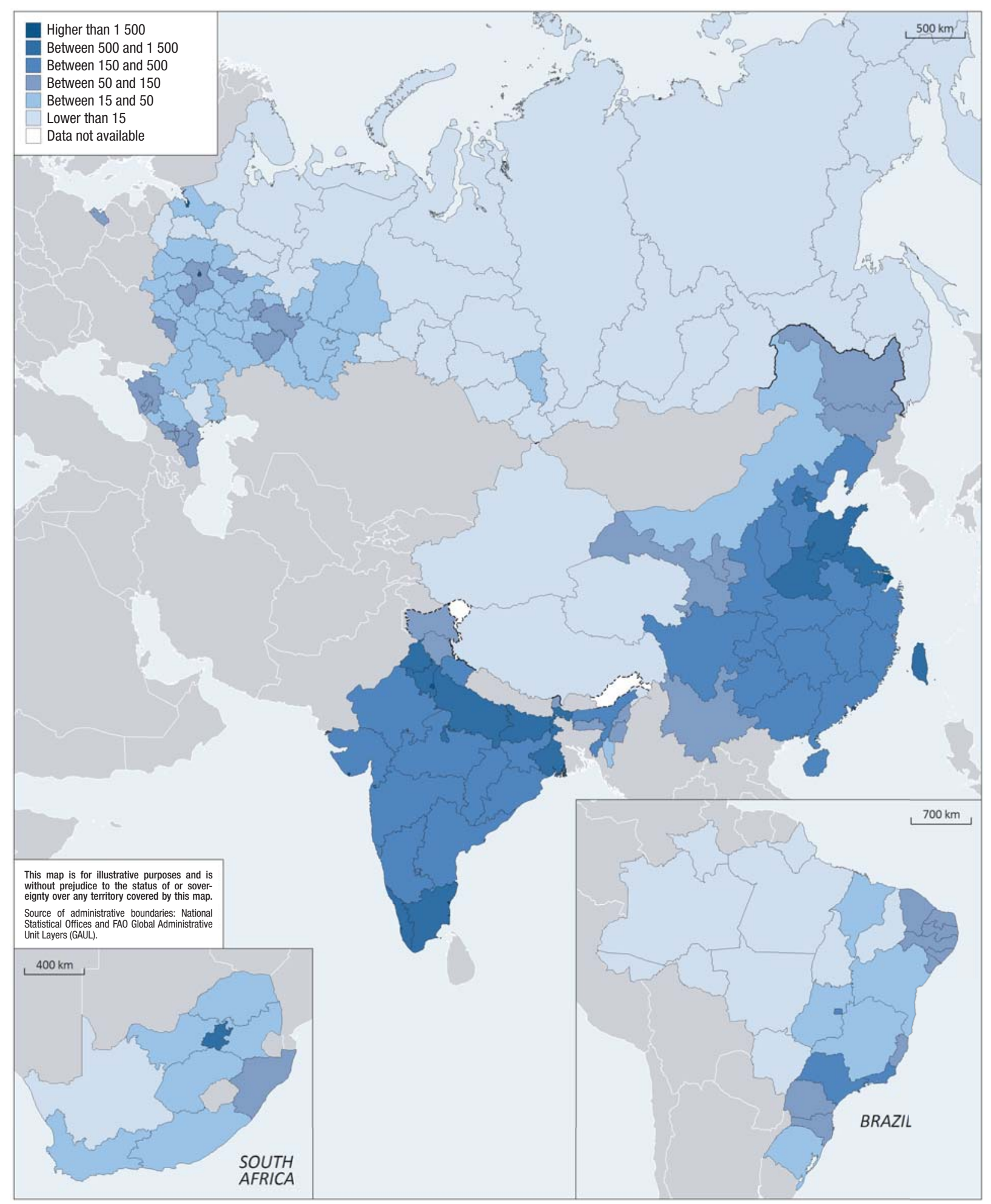

StatLink Aाs $h t$ ttp://dx.doi.org/10.1787/888932440033 
Local factors matter in achieving national sustained growth. In fact, $10 \%$ of OECD regions were responsible for $37 \%$ of OECD gross domestic product (GDP) in 2007. In Greece and Portugal the 10\% of regions with the highest output contributed half or more of the national GDP. Similarly, in countries such as the Russian Federation and Brazil contribution to national GDP was very regionally concentrated (Figure 3.1). On the other hand, GDP in Belgium, the Slovak Republic and the Netherlands was more evenly distributed among regions, with the $10 \%$ regions with the highest output accounting for no more than 25\% of total GDP.

GDP growth at the national level appears largely due to a small number of regions. On average, $40 \%$ of OECD growth was accounted for by just $10 \%$ of regions over the period 1995-2007 (Figure 3.2). At country level, the regional contribution to growth was very concentrated in Greece, Hungary, Sweden, Finland and Japan where the $10 \%$ of regions with highest GDP increase were responsible for more than half of the national growth in 1995-2007 (Figure 3.2).

Besides the regional contribution to national output growth, it is interesting to note which regions have been competitive, i.e. able to maintain or increase their growth rate. OECD countries have experienced different patterns of growth until 2007. Differences in regional GDP growth rates between the best and the worst performing regions were above five percentage points in almost half of the countries. The widest differences in GDP growth rates were in Mexico, Turkey, Greece and Poland. Japan and the Slovak Republic displayed a national growth rate higher than the OECD average and small regional variations (Figure 3.3). The emerging economies Russian Federation, China, India and Brazil, all displayed larger regional variance in their growth rates compared to OECD countries (Figure 3.3). For cross-country comparisons, it must be noted that regional GDP in emerging economies refer to TL2 large regions.

Regional GDP data are available with a time lag that does not allow for an analysis of whether the economic recession has changed the intra-country contribution to growth significantly. Preliminary evidence on the impact of the crisis on regional contribution to employment change is presented in Chapters 4 and 8.

Almost $70 \%$ of predominantly rural (PR) regions had a GDP per capita below the OECD average in 1995, as compared with only $30 \%$ of predominatly urban (PU) regions and $50 \%$ of intermediate (IN) regions. However, over the past 12 years the GDP growth rate in predominantly rural regions was on average higher than predominantly urban and intermediate regions (Figure 3.4). A large share of PR regions $(60 \%)$ grew at a rate higher than OECD average while only around $40 \%$ of urban or intermediate regions did. Despite this higher average growth of predominantly rural regions, the gap in GDP per capita between rural and urban regions has not narrowed significantly.

\section{Definition}

GDP is the standard measure of the value of the production activity (goods and services) of resident producer units. Regional GDP is measured according to the definition of the System of National Accounts (SNA). To make comparisons over time and across countries, it is expressed at constant prices (year 2000), using the OECD deflator and then it is converted into USD purchasing power parities (PPPs) to express each country's GDP in a common currency.

\section{Source}

OECD Regional Database: http://dotstat/wbos/.

OECD deflator and purchasing power parities $h$ ttp://dotstat/ wbos/.

See Annex B for data, source and country-related metadata.

\section{Reference years and territorial level}

1995-2007; TL3.

Australia, Canada, Chile, Mexico, Turkey and the United States TL2 regions.

Brazil, China, India, Russian Federation and South Africa TL2 regions.

Regional GDP is not available for Iceland, Israel and Switzerland.

New Zealand is excluded for lack of regional GDP after 2003.

\section{Figure notes}

3.1-3.4: Available years: Estonia 1996-2007; Norway 1997-2007; Poland 1999-2007; Turkey 2004-06; China 2004-07; India 2000-07; Russian Federation 2005-07.

3.4: Only countries where GDP is available for TL3 regions. 


\subsection{Percent of national GDP in the $10 \%$ TL3 regions with the largest GDP, 1995 and 2007}

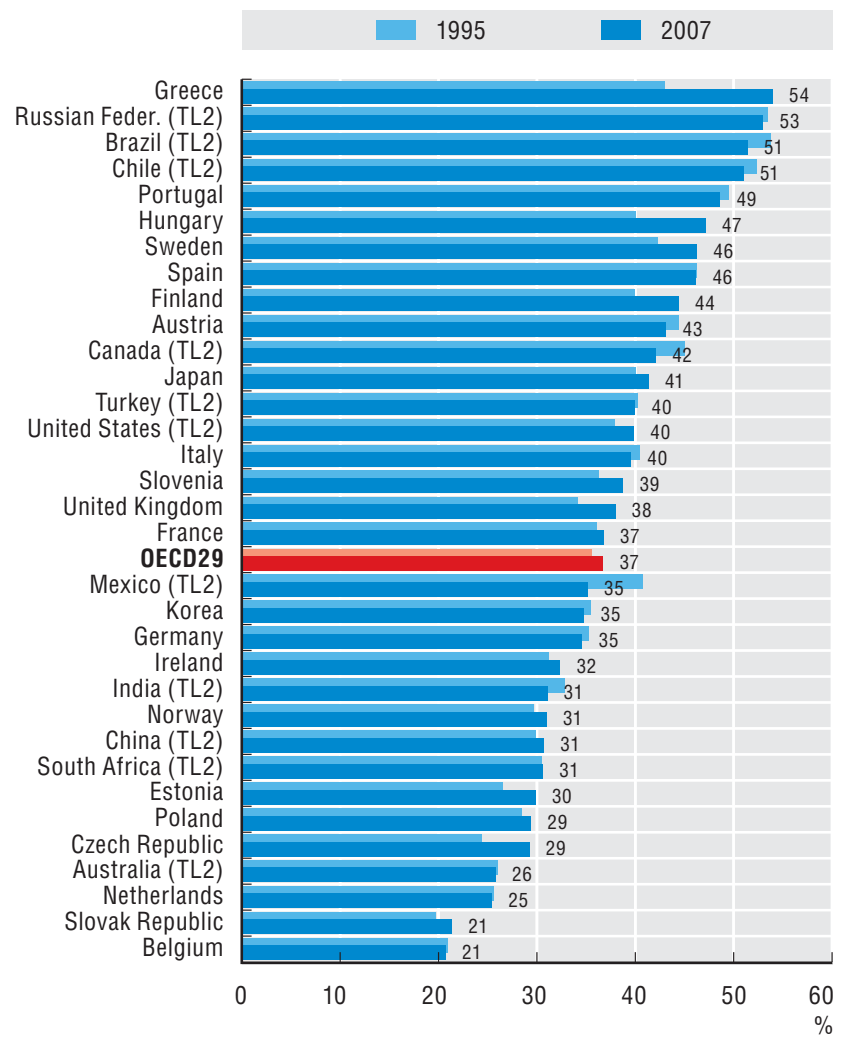

\subsection{Countries ranked by size of difference in TL3} regional annual GDP growth rates, 1995-2007

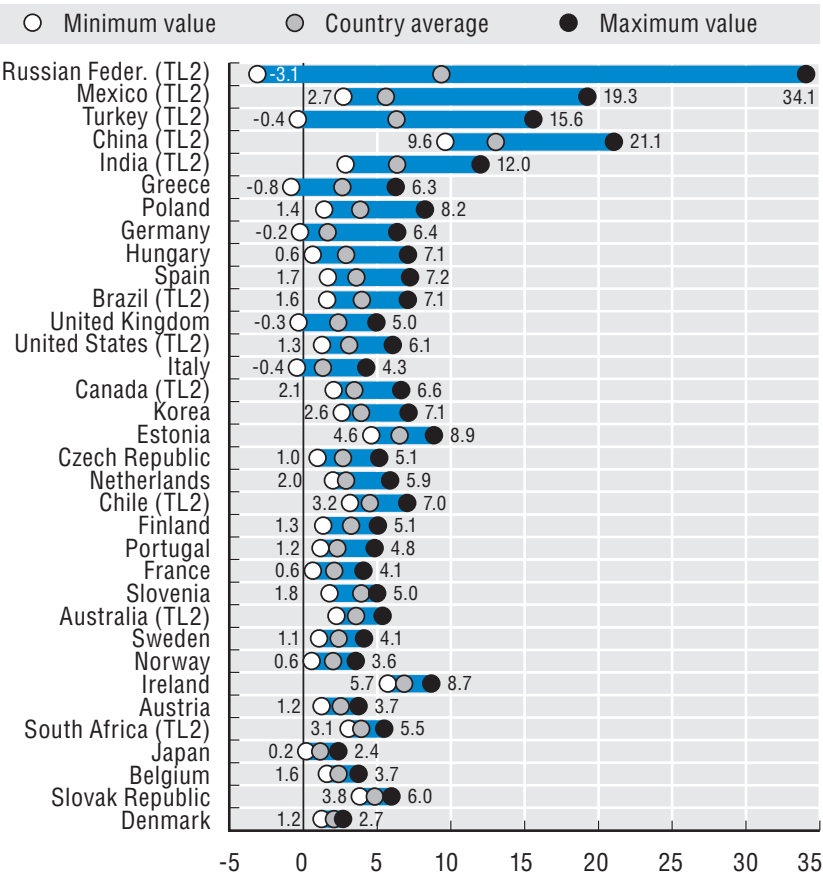

\subsection{Percent of national GDP growth contributed by the top $10 \%$ of TL3 regions, ranked by regional increase, 1995-2007}

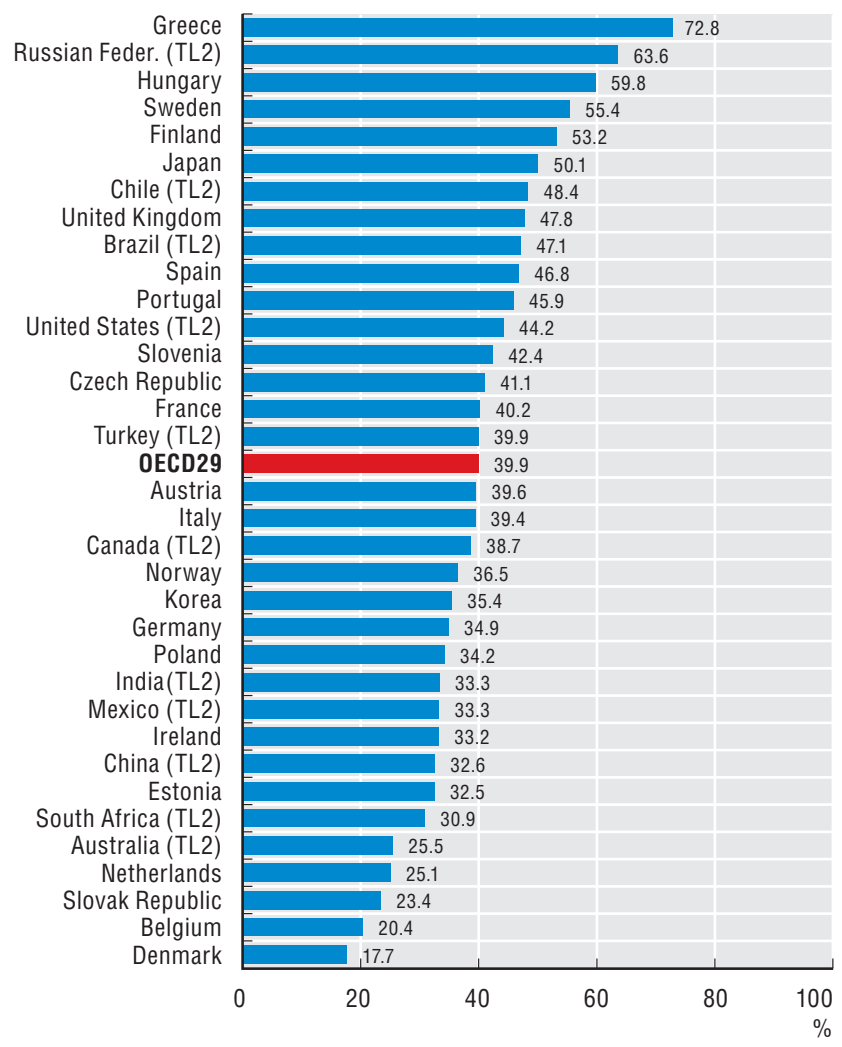

3.4. Percent of TL3 regions with GDP per capita below OECD average and GDP growth rate by typology of region, 1995-2007

\footnotetext{
\% of TL3 regions with GDP per capita below OECD average in 1995 $\diamond$ Yearly average GDP per capita growth rate
}

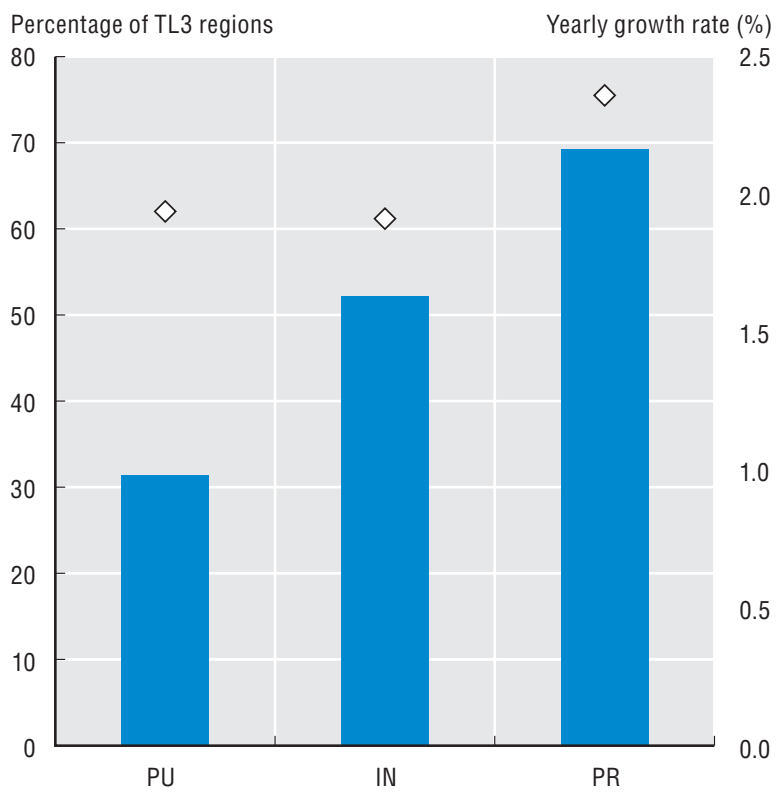

StatLink Aाst http://dx.doi.org/10.1787/888932439444 


\section{REGIONAL CONTRIBUTION TO GDP GROWTH}

3.5. Regional GDP growth: Asia and Oceania, 1995-2007

Average annual growth rate (constant 2000 USD PPP), TL3 regions

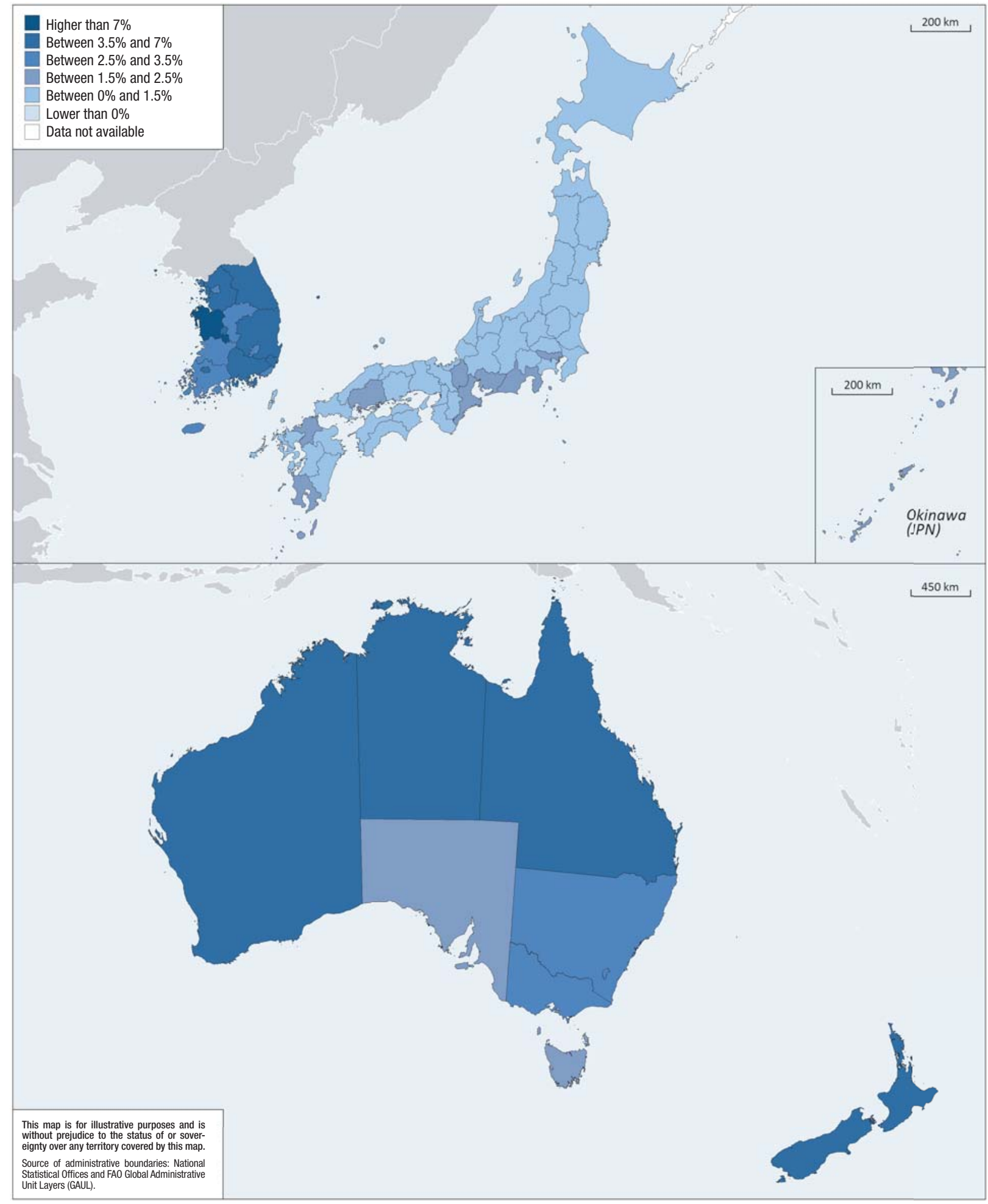

StatLink काIs $h t t p: / / d x . d o i . o r g / 10.1787 / 888932440052$ 
3.6. Regional GDP growth: Europe, 1995-2007

Average annual growth rate (constant 2000 USD PPP), TL3 regions

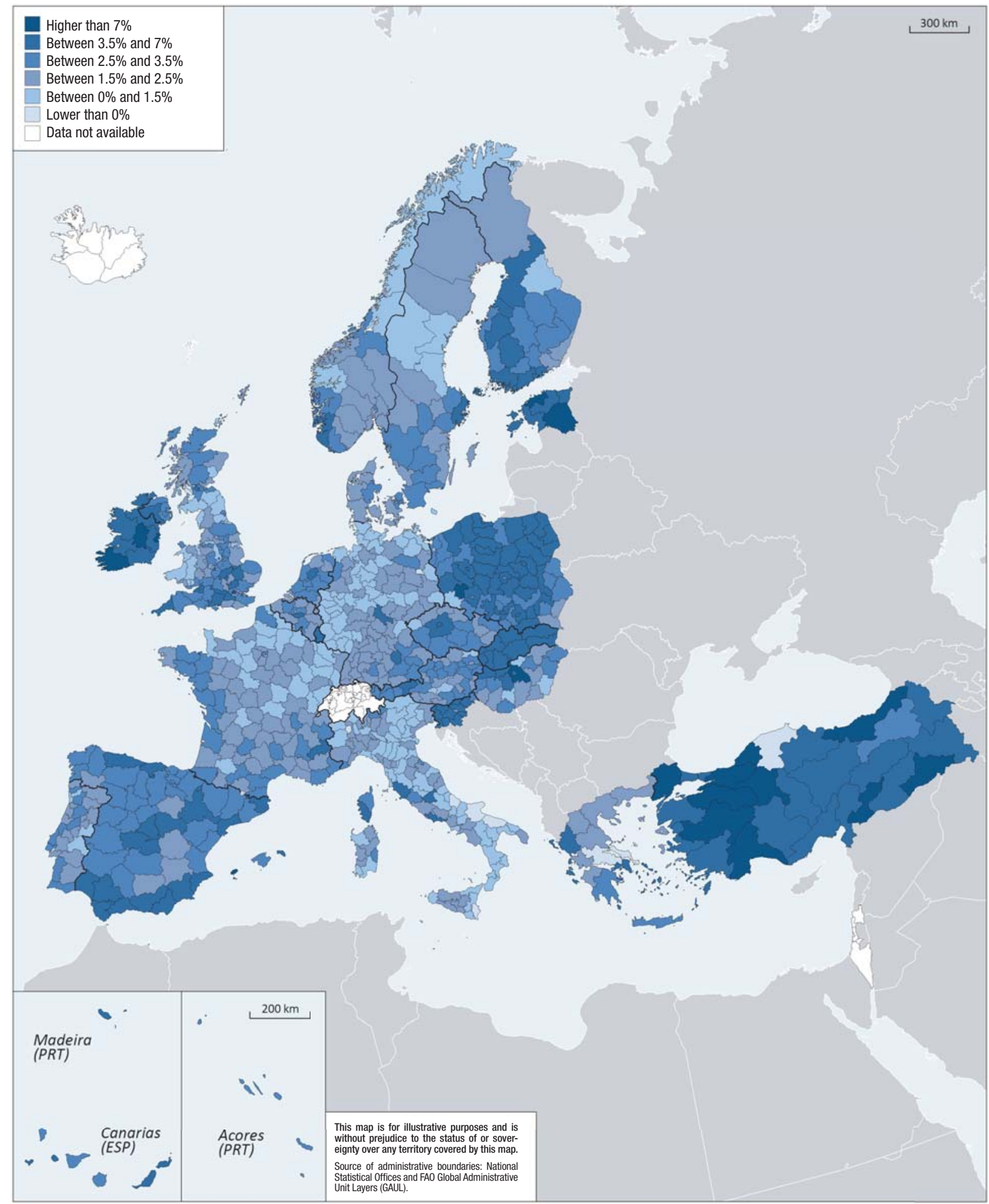

StatLink Aाs $h t$ ttp://dx.doi.org/10.1787/888932440052 


\section{REGIONAL CONTRIBUTION TO GDP GROWTH \\ 3. REGIONAL CONTRIBUTIONTO GDP GROWTH}

\section{Rikh}

3.7. Regional GDP growth: Americas, 1995-2007

Average annual growth rate (constant 2000 USD PPP), TL2 regions

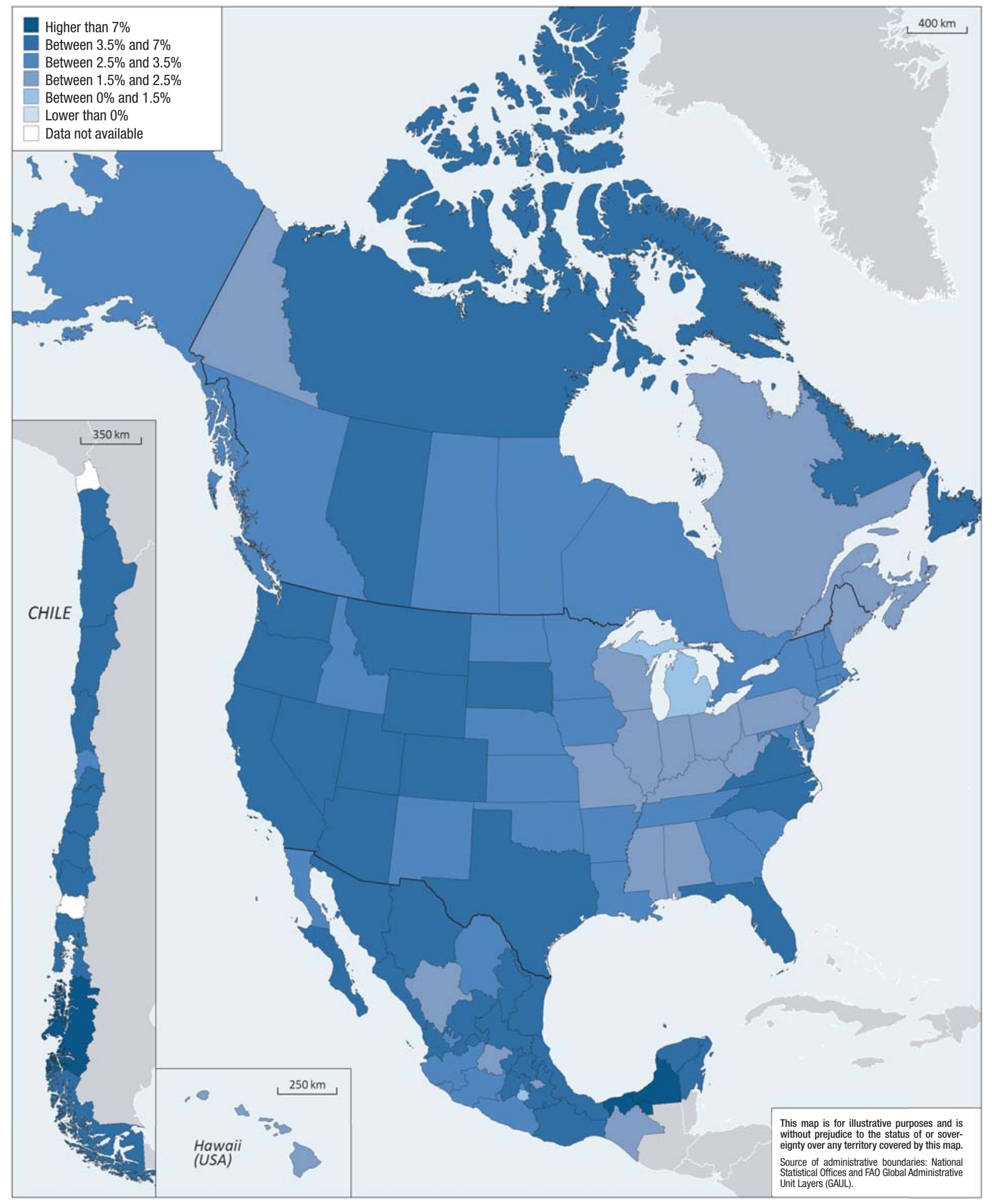

StatLink जाISL http://dx.doi.org/10.1787/888932440052 
3.8. Regional GDP growth: Emerging economies, 1995-2007

Average annual growth rate (constant 2000 USD PPP), TL2 regions

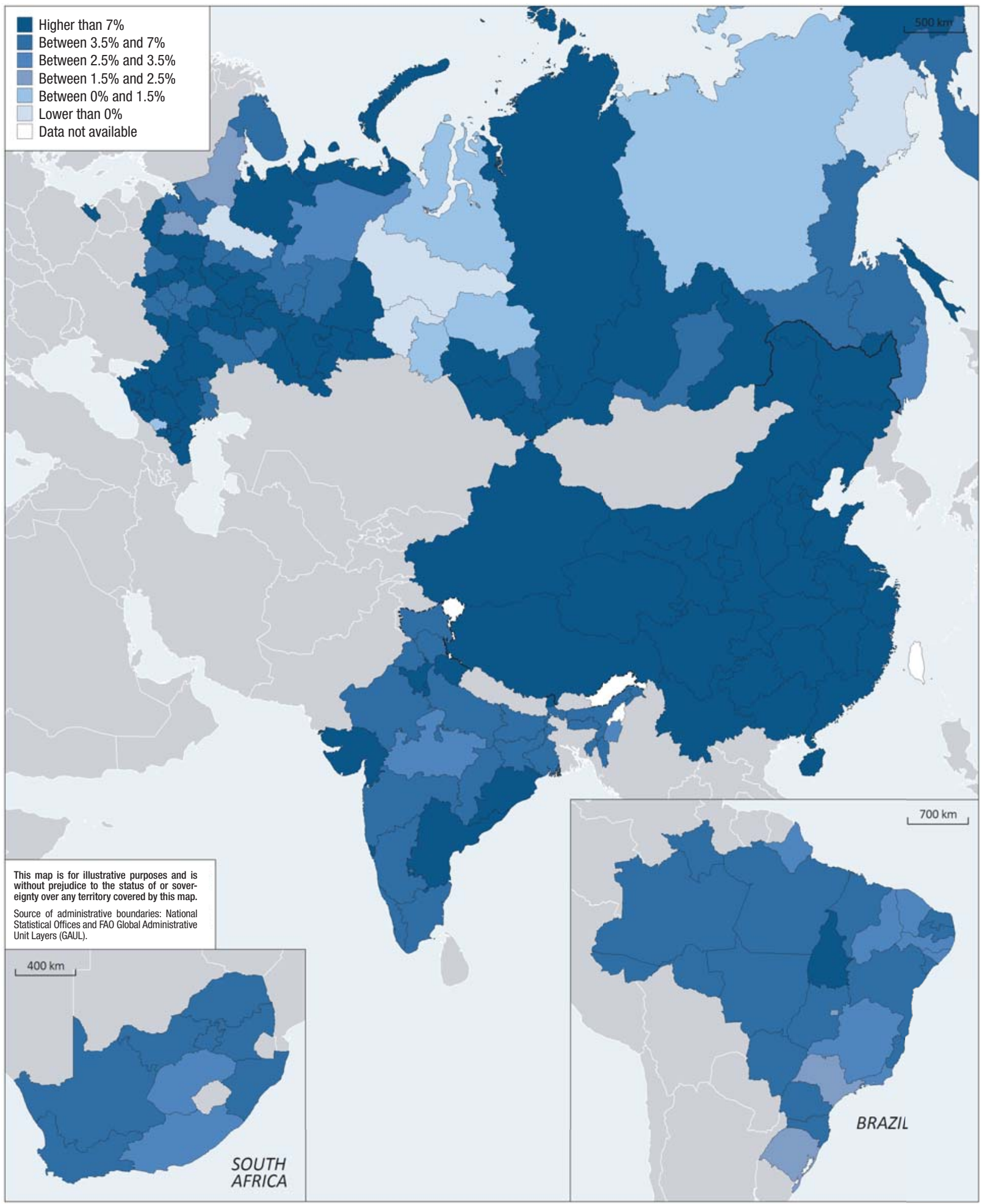

StatLink काIsL http://dx.doi.org/10.1787/888932440052 
A small number of regions drives employment creation at the national level. On average, $36 \%$ of overall employment creation in OECD countries between 1999 and 2009 was accounted for by just $10 \%$ of regions. The regional contribution to national employment creation was particularly concentrated in certain countries. In Sweden, the United States and Greece (among OECD countries) and South Africa, more than $60 \%$ of employment growth was spurred by $10 \%$ of regions (Figure 4.1).

The last two years have seen an increase in the regional concentration of employment creation in 20 of the 31 countries, resulting in higher differences in employment among regions (Figure 4.1).

The pattern was even more pronounced in decreases in employment. On average, $92 \%$ of job losses in OECD countries between 1999 and 2009 were concentrated in only 10\% of regions. In Spain, Finland and Italy all the net job losses occurred in $10 \%$ of regions. In the past two years, net job losses have been experienced by a larger number of regions (Figure 4.2).

Differences in employment growth within countries are larger than across countries. During 1999-2009, international differences in annual employment growth rates across OECD countries were as large as 2.9 percentage points, ranging from $-0.4 \%$ in Turkey to $2.5 \%$ in Spain.

Over the same period, differences in regional employment growth rates across regions were above three percentage points in almost half of the countries. The widest differences in regional employment growth rates are found in Sweden, Spain, the Russian Federation and Canada (Figure 4.3).

In the 24 countries considered, $44 \%$ of predominantly rural regions displayed an employment rate below the OECD average, while the corresponding figures are $52 \%$ and $62 \%$ respectively in predominantly urban and intermediate regions. However, job creation in predominantly rural regions was on average lower than in predominantly urban and intermediate regions between 1999 and 2009 (Figure 4.4). .

\section{Definition}

Employed persons are all persons who during the reference week worked at least one hour for pay or profit, or were temporarily absent from such work. Family workers are included.

The employment rate is defined as the ratio between total employment (place of residence) and population in the class age 15-64.

\section{Source}

OECD Regional Database: http://dotstat/wbos/.

See Annex B for data, source and country-related metadata.

\section{Reference years and territorial level}

1999-2009; TL3.

Australia, Chile, Iceland, Israel, Portugal, Switzerland and Turkey TL2.

Russian Federation and South Africa TL2 regions.

Canada Non Official Grids.

\section{Figure notes}

4.1-4.4: Denmark and Turkey are excluded for lack of data on comparable years. Available years: Czech Republic 2003-09; Finland and Norway 1999-2008; Mexico 2000-09; Switzerland 2001-09.

4.1: Only countries with average positive growth of employment over 1999-2009 are included. Hungary and Japan are excluded.

4.2: Only countries with regions displaying average net employment decline are included. Chile and Estonia no employment decline between 1999-2007.

Information on data for Israel: http://dx.doi.org/10.1787/888932315602. 
4.1. Percent of national employment increase contributed by the top $10 \%$ of $\mathrm{TL} 3$ regions, ranked by regional increase, 1999-2009

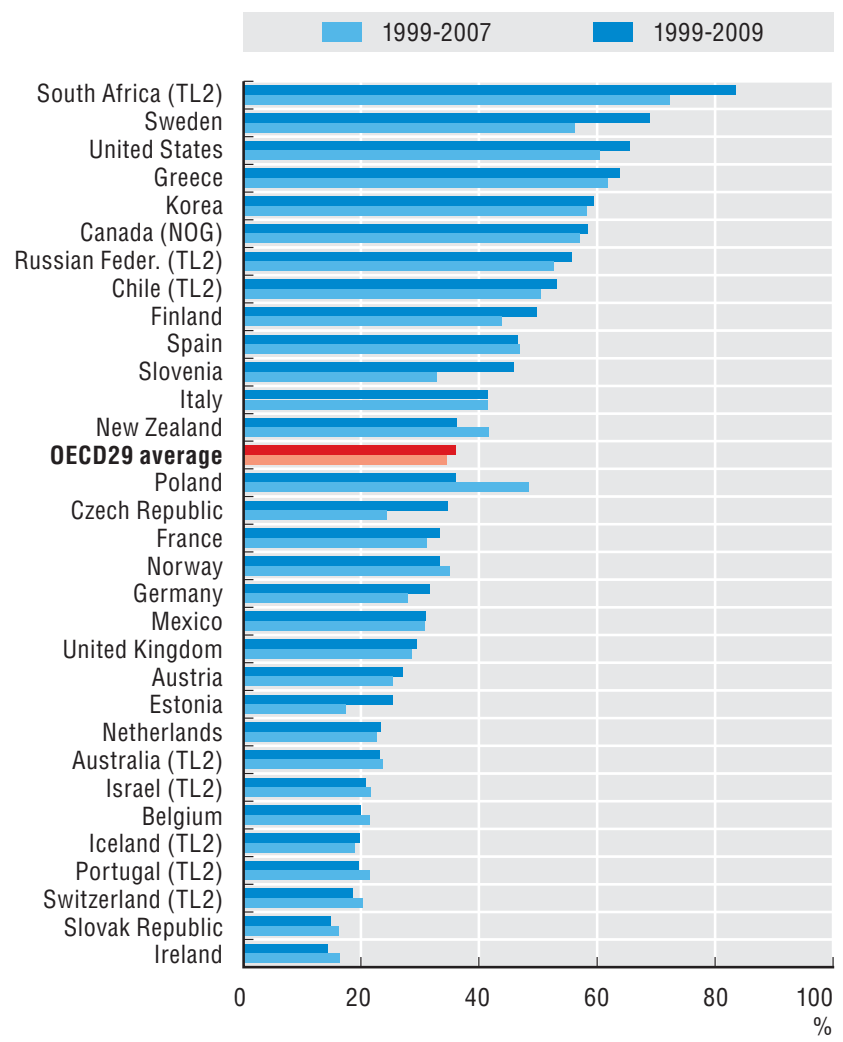

4.3. Countries ranked by size of difference in TL3 regional annual employment growth, 1999-2009

○ Minimum $\bigcirc$ Country average annual gr. of employment $\bullet$ Maximum

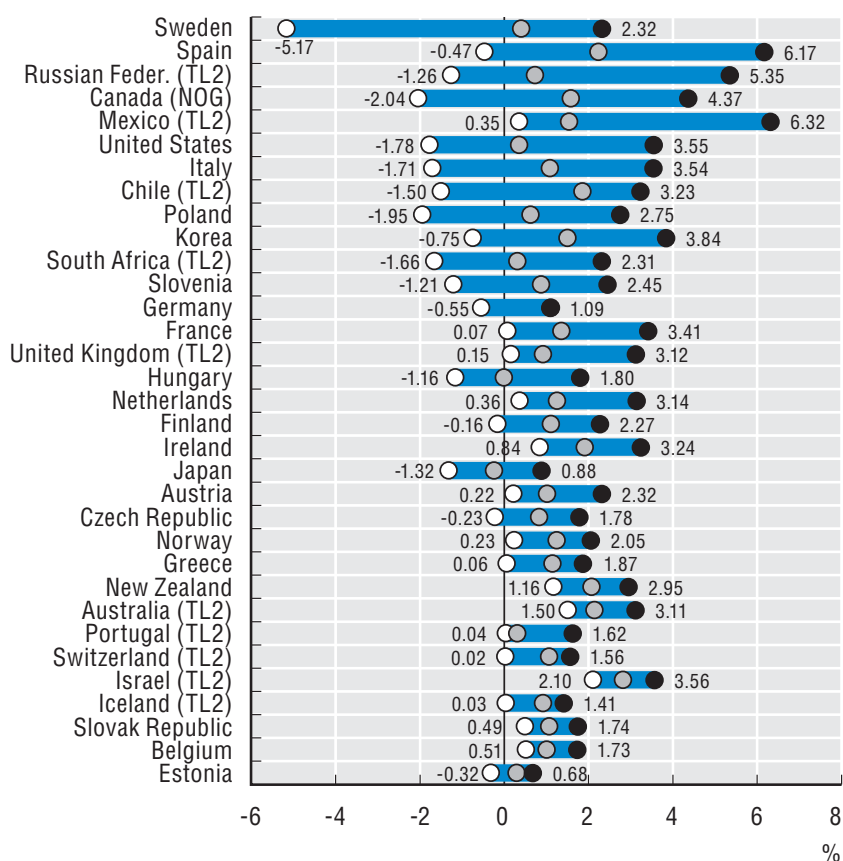

4.2. Percent of national employment decline due to $10 \%$ of TL3 regions, ranked by regional decrease, 1999-2009

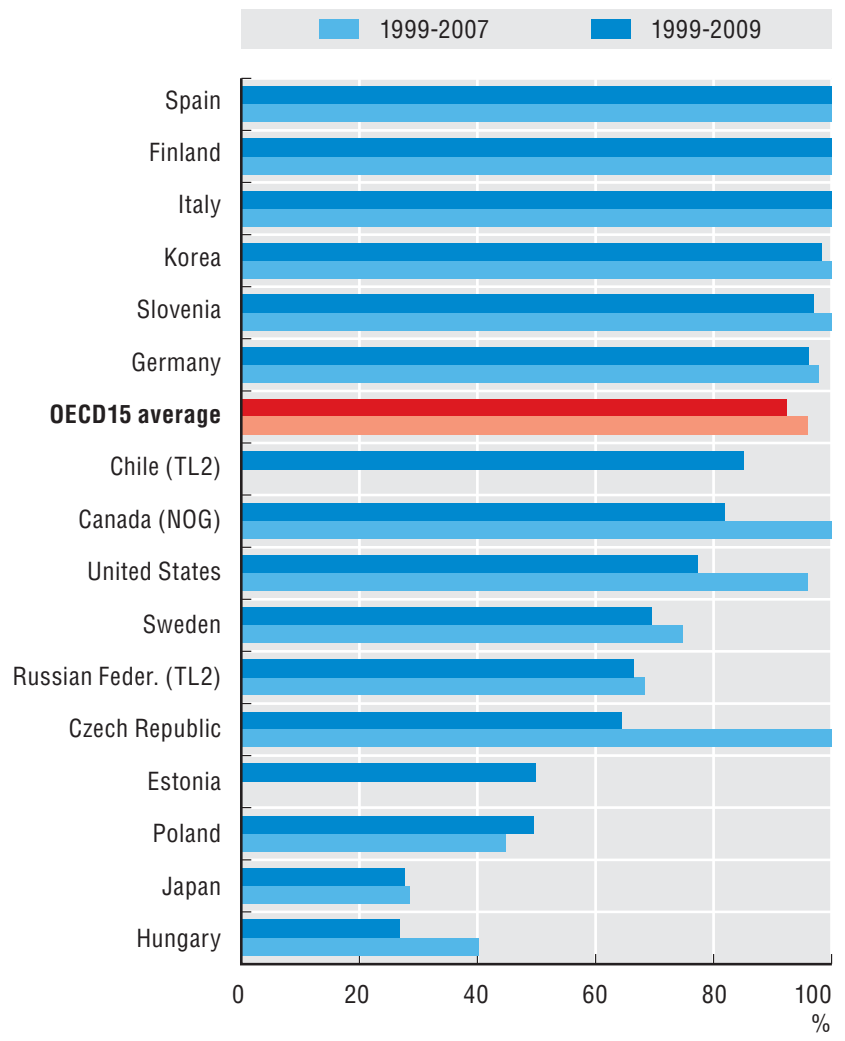

4.4. Percent of regions with an employment rate below OECD average and employment change by typology of region, 1999-2009

\% of regions with employment rate below the OECD average in 1999

$\diamond$ Yearly average employment growth 1999-2009

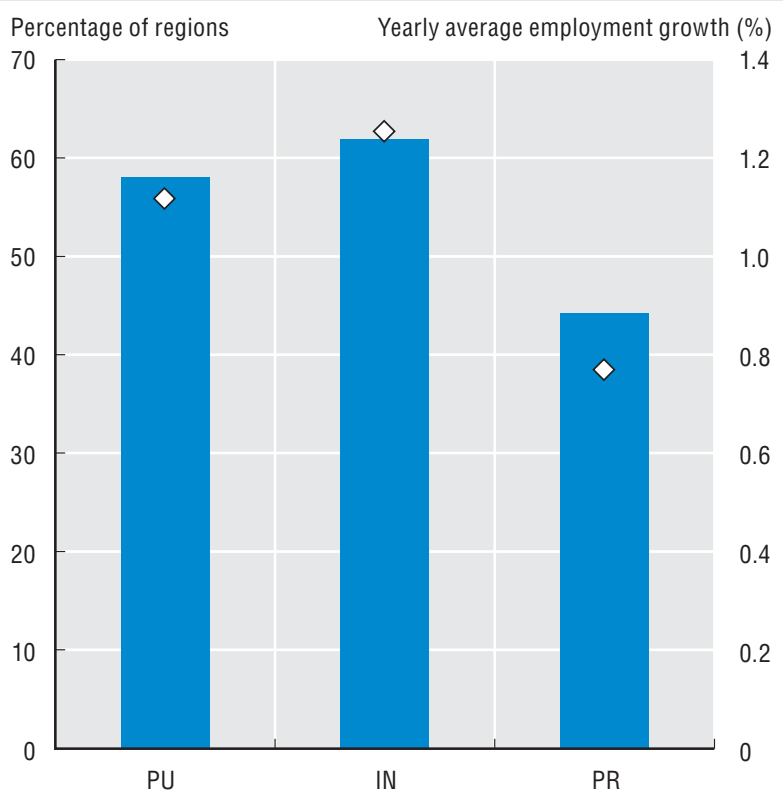

StatLink ताISt http://dx.doi.org/10.1787/888932439463 
Labour productivity growth is considered a key indicator to assess regional competitiveness and an essential driver of change in living standards. Regional living conditions are raised by continued gains in labour productivity, along with an increase in labour utilisation. In fact, only economies that manage to simultaneously sustain employment and productivity growth will increase their competitive edge and maintain it in the long run.

Growth in regional GDP per capita is broken down into the contribution of labour productivity growth (here measured as gross domestic product [GDP] per worker) and changes in labour utilisation (measured as the ratio between employment at place of work and population).

Among the 20 OECD regions with the highest GDP per capita growth rate during 1995-2007, labour productivity growth is a major determinant compared to changes in labour utilisation (Figure 5.1). In 17 of the 20 regions, labour productivity growth accounted for $70 \%$ or more of the rise in GDP per capita. In Prague (Czech Republic), Bratislava (Slovak Republic) and Magallanes (Chile), rates of labour utilisation declined (Figure 5.1).

The 20 regions with declining or the smallest GDP per capita growth rate during 1995-2007 were in four countries: the United States, Italy, Japan and Germany (Figure 5.2). Decline in the labour utilisation and an increase in productivity characterize Hokkaido (Japan), Berlin (Germany) and the seven US states. On the other hand, Schleswig-Holstein (Germany) and the ten Italian regions have seen a decrease in their productivity while labour utilisation increased (Figure 5.2).

Differences in labour productivity growth among regions are invariably the result of multiple national and local factors, including labour market policies and institutions as well as innovation and the adoption of new technologies. As such, differences in labour productivity growth among OECD regions are larger than among OECD countries (Figures 5.3 and 5.4).
Definition
GDP is the standard measure of the value of the pro-
duction activity (goods and services) of resident pro-
ducer units. Regional GDP is measured according to
the definition of the System of National Accounts
(SNA). To make comparisons over time and across
countries, it is expressed at constant prices (year 2000),
using the OECD deflator and then it is converted into
USD purchasing power parities (PPPs) to express each
country's GDP in a common currency.
Regional labour productivity is here measured as the
ratio of constant GDP in 2000 prices, to total employ-
ment where the latter is measured at place of work.
Labour utilisation is here measured as the ratio
between the total employment at place of work and
regional population.
In the decomposition of change in regional GDP per
capita, changes in labour utilisation may partially
depend on labour mobility if there is commuting on a
substantial scale in the region.
Further information
Figure notes
5.1: First available year for Canada, Chile, Ireland: 1996; United States:
www.oecd.org/statistics/productivity.
Reference years and territorial level
1995-2007; TL2.
Mexico and Turkey are not included for lack of regional
data on comparable years.
Regional GDP is not available for Iceland, Israel and
Switzerland.

Definition
GDP is the standard measure of the value of the pro-
duction activity (goods and services) of resident pro-
ducer units. Regional GDP is measured according to
the definition of the System of National Accounts
(SNA). To make comparisons over time and across
countries, it is expressed at constant prices (year 2000),
using the OECD deflator and then it is converted into
USD purchasing power parities (PPPs) to express each
country's GDP in a common currency.
Regional labour productivity is here measured as the
ratio of constant GDP in 2000 prices, to total employ-
ment where the latter is measured at place of work.
Labour utilisation is here measured as the ratio
between the total employment at place of work and
regional population.
In the decomposition of change in regional GDP per
capita, changes in labour utilisation may partially
depend on labour mobility if there is commuting on a
substantial scale in the region.
Further information
Figure notes
5.1: First available year for Canada, Chile, Ireland: 1996; United States:
www.oecd.org/statistics/productivity.
Reference years and territorial level
1995-2007; TL2.
Mexico and Turkey are not included for lack of regional
data on comparable years.
Regional GDP is not available for Iceland, Israel and
Switzerland.

Definition
GDP is the standard measure of the value of the pro-
duction activity (goods and services) of resident pro-
ducer units. Regional GDP is measured according to
the definition of the System of National Accounts
(SNA). To make comparisons over time and across
countries, it is expressed at constant prices (year 2000),
using the OECD deflator and then it is converted into
USD purchasing power parities (PPPs) to express each
country's GDP in a common currency.
Regional labour productivity is here measured as the
ratio of constant GDP in 2000 prices, to total employ-
ment where the latter is measured at place of work.
Labour utilisation is here measured as the ratio
between the total employment at place of work and
regional population.
In the decomposition of change in regional GDP per
capita, changes in labour utilisation may partially
depend on labour mobility if there is commuting on a
substantial scale in the region.
Further information
Figure notes
5.1: First available year for Canada, Chile, Ireland: 1996; United States:
www.oecd.org/statistics/productivity.
Reference years and territorial level
1995-2007; TL2.
Mexico and Turkey are not included for lack of regional
data on comparable years.
Regional GDP is not available for Iceland, Israel and
Switzerland.

Definition
GDP is the standard measure of the value of the pro-
duction activity (goods and services) of resident pro-
ducer units. Regional GDP is measured according to
the definition of the System of National Accounts
(SNA). To make comparisons over time and across
countries, it is expressed at constant prices (year 2000),
using the OECD deflator and then it is converted into
USD purchasing power parities (PPPs) to express each
country's GDP in a common currency.
Regional labour productivity is here measured as the
ratio of constant GDP in 2000 prices, to total employ-
ment where the latter is measured at place of work.
Labour utilisation is here measured as the ratio
between the total employment at place of work and
regional population.
In the decomposition of change in regional GDP per
capita, changes in labour utilisation may partially
depend on labour mobility if there is commuting on a
substantial scale in the region.
Further information
Figure notes
5.1: First available year for Canada, Chile, Ireland: 1996; United States:
www.oecd.org/statistics/productivity.
Reference years and territorial level
1995-2007; TL2.
Mexico and Turkey are not included for lack of regional
data on comparable years.
Regional GDP is not available for Iceland, Israel and
Switzerland.

Definition
GDP is the standard measure of the value of the pro-
duction activity (goods and services) of resident pro-
ducer units. Regional GDP is measured according to
the definition of the System of National Accounts
(SNA). To make comparisons over time and across
countries, it is expressed at constant prices (year 2000),
using the OECD deflator and then it is converted into
USD purchasing power parities (PPPs) to express each
country's GDP in a common currency.
Regional labour productivity is here measured as the
ratio of constant GDP in 2000 prices, to total employ-
ment where the latter is measured at place of work.
Labour utilisation is here measured as the ratio
between the total employment at place of work and
regional population.
In the decomposition of change in regional GDP per
capita, changes in labour utilisation may partially
depend on labour mobility if there is commuting on a
substantial scale in the region.
Further information
Figure notes
5.1: First available year for Canada, Chile, Ireland: 1996; United States:
www.oecd.org/statistics/productivity.
Reference years and territorial level
1995-2007; TL2.
Mexico and Turkey are not included for lack of regional
data on comparable years.
Regional GDP is not available for Iceland, Israel and
Switzerland.

Definition
GDP is the standard measure of the value of the pro-
duction activity (goods and services) of resident pro-
ducer units. Regional GDP is measured according to
the definition of the System of National Accounts
(SNA). To make comparisons over time and across
countries, it is expressed at constant prices (year 2000),
using the OECD deflator and then it is converted into
USD purchasing power parities (PPPs) to express each
country's GDP in a common currency.
Regional labour productivity is here measured as the
ratio of constant GDP in 2000 prices, to total employ-
ment where the latter is measured at place of work.
Labour utilisation is here measured as the ratio
between the total employment at place of work and
regional population.
In the decomposition of change in regional GDP per
capita, changes in labour utilisation may partially
depend on labour mobility if there is commuting on a
substantial scale in the region.
Further information
Figure notes
5.1: First available year for Canada, Chile, Ireland: 1996; United States:
www.oecd.org/statistics/productivity.
Reference years and territorial level
1995-2007; TL2.
Mexico and Turkey are not included for lack of regional
data on comparable years.
Regional GDP is not available for Iceland, Israel and
Switzerland.

Definition
GDP is the standard measure of the value of the pro-
duction activity (goods and services) of resident pro-
ducer units. Regional GDP is measured according to
the definition of the System of National Accounts
(SNA). To make comparisons over time and across
countries, it is expressed at constant prices (year 2000),
using the OECD deflator and then it is converted into
USD purchasing power parities (PPPs) to express each
country's GDP in a common currency.
Regional labour productivity is here measured as the
ratio of constant GDP in 2000 prices, to total employ-
ment where the latter is measured at place of work.
Labour utilisation is here measured as the ratio
between the total employment at place of work and
regional population.
In the decomposition of change in regional GDP per
capita, changes in labour utilisation may partially
depend on labour mobility if there is commuting on a
substantial scale in the region.
Further information
Figure notes
5.1: First available year for Canada, Chile, Ireland: 1996; United States:
www.oecd.org/statistics/productivity.
Reference years and territorial level
1995-2007; TL2.
Mexico and Turkey are not included for lack of regional
data on comparable years.
Regional GDP is not available for Iceland, Israel and
Switzerland.

Definition
GDP is the standard measure of the value of the pro-
duction activity (goods and services) of resident pro-
ducer units. Regional GDP is measured according to
the definition of the System of National Accounts
(SNA). To make comparisons over time and across
countries, it is expressed at constant prices (year 2000),
using the OECD deflator and then it is converted into
USD purchasing power parities (PPPs) to express each
country's GDP in a common currency.
Regional labour productivity is here measured as the
ratio of constant GDP in 2000 prices, to total employ-
ment where the latter is measured at place of work.
Labour utilisation is here measured as the ratio
between the total employment at place of work and
regional population.
In the decomposition of change in regional GDP per
capita, changes in labour utilisation may partially
depend on labour mobility if there is commuting on a
substantial scale in the region.
Further information
Figure notes
5.1: First available year for Canada, Chile, Ireland: 1996; United States:
www.oecd.org/statistics/productivity.
Reference years and territorial level
1995-2007; TL2.
Mexico and Turkey are not included for lack of regional
data on comparable years.
Regional GDP is not available for Iceland, Israel and
Switzerland.

Definition
GDP is the standard measure of the value of the pro-
duction activity (goods and services) of resident pro-
ducer units. Regional GDP is measured according to
the definition of the System of National Accounts
(SNA). To make comparisons over time and across
countries, it is expressed at constant prices (year 2000),
using the OECD deflator and then it is converted into
USD purchasing power parities (PPPs) to express each
country's GDP in a common currency.
Regional labour productivity is here measured as the
ratio of constant GDP in 2000 prices, to total employ-
ment where the latter is measured at place of work.
Labour utilisation is here measured as the ratio
between the total employment at place of work and
regional population.
In the decomposition of change in regional GDP per
capita, changes in labour utilisation may partially
depend on labour mobility if there is commuting on a
substantial scale in the region.
Further information
Figure notes
5.1: First available year for Canada, Chile, Ireland: 1996; United States:
www.oecd.org/statistics/productivity.
Reference years and territorial level
1995-2007; TL2.
Mexico and Turkey are not included for lack of regional
data on comparable years.
Regional GDP is not available for Iceland, Israel and
Switzerland.

Definition
GDP is the standard measure of the value of the pro-
duction activity (goods and services) of resident pro-
ducer units. Regional GDP is measured according to
the definition of the System of National Accounts
(SNA). To make comparisons over time and across
countries, it is expressed at constant prices (year 2000),
using the OECD deflator and then it is converted into
USD purchasing power parities (PPPs) to express each
country's GDP in a common currency.
Regional labour productivity is here measured as the
ratio of constant GDP in 2000 prices, to total employ-
ment where the latter is measured at place of work.
Labour utilisation is here measured as the ratio
between the total employment at place of work and
regional population.
In the decomposition of change in regional GDP per
capita, changes in labour utilisation may partially
depend on labour mobility if there is commuting on a
substantial scale in the region.
Further information
Figure notes
5.1: First available year for Canada, Chile, Ireland: 1996; United States:
www.oecd.org/statistics/productivity.
Reference years and territorial level
1995-2007; TL2.
Mexico and Turkey are not included for lack of regional
data on comparable years.
Regional GDP is not available for Iceland, Israel and
Switzerland.

Definition
GDP is the standard measure of the value of the pro-
duction activity (goods and services) of resident pro-
ducer units. Regional GDP is measured according to
the definition of the System of National Accounts
(SNA). To make comparisons over time and across
countries, it is expressed at constant prices (year 2000),
using the OECD deflator and then it is converted into
USD purchasing power parities (PPPs) to express each
country's GDP in a common currency.
Regional labour productivity is here measured as the
ratio of constant GDP in 2000 prices, to total employ-
ment where the latter is measured at place of work.
Labour utilisation is here measured as the ratio
between the total employment at place of work and
regional population.
In the decomposition of change in regional GDP per
capita, changes in labour utilisation may partially
depend on labour mobility if there is commuting on a
substantial scale in the region.
Further information
Figure notes
5.1: First available year for Canada, Chile, Ireland: 1996; United States:
www.oecd.org/statistics/productivity.
Reference years and territorial level
1995-2007; TL2.
Mexico and Turkey are not included for lack of regional
data on comparable years.
Regional GDP is not available for Iceland, Israel and
Switzerland.

Definition
GDP is the standard measure of the value of the pro-
duction activity (goods and services) of resident pro-
ducer units. Regional GDP is measured according to
the definition of the System of National Accounts
(SNA). To make comparisons over time and across
countries, it is expressed at constant prices (year 2000),
using the OECD deflator and then it is converted into
USD purchasing power parities (PPPs) to express each
country's GDP in a common currency.
Regional labour productivity is here measured as the
ratio of constant GDP in 2000 prices, to total employ-
ment where the latter is measured at place of work.
Labour utilisation is here measured as the ratio
between the total employment at place of work and
regional population.
In the decomposition of change in regional GDP per
capita, changes in labour utilisation may partially
depend on labour mobility if there is commuting on a
substantial scale in the region.
Further information
Figure notes
5.1: First available year for Canada, Chile, Ireland: 1996; United States:
www.oecd.org/statistics/productivity.
Reference years and territorial level
1995-2007; TL2.
Mexico and Turkey are not included for lack of regional
data on comparable years.
Regional GDP is not available for Iceland, Israel and
Switzerland.

Definition
GDP is the standard measure of the value of the pro-
duction activity (goods and services) of resident pro-
ducer units. Regional GDP is measured according to
the definition of the System of National Accounts
(SNA). To make comparisons over time and across
countries, it is expressed at constant prices (year 2000),
using the OECD deflator and then it is converted into
USD purchasing power parities (PPPs) to express each
country's GDP in a common currency.
Regional labour productivity is here measured as the
ratio of constant GDP in 2000 prices, to total employ-
ment where the latter is measured at place of work.
Labour utilisation is here measured as the ratio
between the total employment at place of work and
regional population.
In the decomposition of change in regional GDP per
capita, changes in labour utilisation may partially
depend on labour mobility if there is commuting on a
substantial scale in the region.
Further information
Figure notes
5.1: First available year for Canada, Chile, Ireland: 1996; United States:
www.oecd.org/statistics/productivity.
Reference years and territorial level
1995-2007; TL2.
Mexico and Turkey are not included for lack of regional
data on comparable years.
Regional GDP is not available for Iceland, Israel and
Switzerland.

Definition
GDP is the standard measure of the value of the pro-
duction activity (goods and services) of resident pro-
ducer units. Regional GDP is measured according to
the definition of the System of National Accounts
(SNA). To make comparisons over time and across
countries, it is expressed at constant prices (year 2000),
using the OECD deflator and then it is converted into
USD purchasing power parities (PPPs) to express each
country's GDP in a common currency.
Regional labour productivity is here measured as the
ratio of constant GDP in 2000 prices, to total employ-
ment where the latter is measured at place of work.
Labour utilisation is here measured as the ratio
between the total employment at place of work and
regional population.
In the decomposition of change in regional GDP per
capita, changes in labour utilisation may partially
depend on labour mobility if there is commuting on a
substantial scale in the region.
Further information
Figure notes
5.1: First available year for Canada, Chile, Ireland: 1996; United States:
www.oecd.org/statistics/productivity.
Reference years and territorial level
1995-2007; TL2.
Mexico and Turkey are not included for lack of regional
data on comparable years.
Regional GDP is not available for Iceland, Israel and
Switzerland.

Definition
GDP is the standard measure of the value of the pro-
duction activity (goods and services) of resident pro-
ducer units. Regional GDP is measured according to
the definition of the System of National Accounts
(SNA). To make comparisons over time and across
countries, it is expressed at constant prices (year 2000),
using the OECD deflator and then it is converted into
USD purchasing power parities (PPPs) to express each
country's GDP in a common currency.
Regional labour productivity is here measured as the
ratio of constant GDP in 2000 prices, to total employ-
ment where the latter is measured at place of work.
Labour utilisation is here measured as the ratio
between the total employment at place of work and
regional population.
In the decomposition of change in regional GDP per
capita, changes in labour utilisation may partially
depend on labour mobility if there is commuting on a
substantial scale in the region.
Further information
Figure notes
5.1: First available year for Canada, Chile, Ireland: 1996; United States:
www.oecd.org/statistics/productivity.
Reference years and territorial level
1995-2007; TL2.
Mexico and Turkey are not included for lack of regional
data on comparable years.
Regional GDP is not available for Iceland, Israel and
Switzerland.

Definition
GDP is the standard measure of the value of the pro-
duction activity (goods and services) of resident pro-
ducer units. Regional GDP is measured according to
the definition of the System of National Accounts
(SNA). To make comparisons over time and across
countries, it is expressed at constant prices (year 2000),
using the OECD deflator and then it is converted into
USD purchasing power parities (PPPs) to express each
country's GDP in a common currency.
Regional labour productivity is here measured as the
ratio of constant GDP in 2000 prices, to total employ-
ment where the latter is measured at place of work.
Labour utilisation is here measured as the ratio
between the total employment at place of work and
regional population.
In the decomposition of change in regional GDP per
capita, changes in labour utilisation may partially
depend on labour mobility if there is commuting on a
substantial scale in the region.
Further information
Figure notes
5.1: First available year for Canada, Chile, Ireland: 1996; United States:
www.oecd.org/statistics/productivity.
Reference years and territorial level
1995-2007; TL2.
Mexico and Turkey are not included for lack of regional
data on comparable years.
Regional GDP is not available for Iceland, Israel and
Switzerland.

Definition
GDP is the standard measure of the value of the pro-
duction activity (goods and services) of resident pro-
ducer units. Regional GDP is measured according to
the definition of the System of National Accounts
(SNA). To make comparisons over time and across
countries, it is expressed at constant prices (year 2000),
using the OECD deflator and then it is converted into
USD purchasing power parities (PPPs) to express each
country's GDP in a common currency.
Regional labour productivity is here measured as the
ratio of constant GDP in 2000 prices, to total employ-
ment where the latter is measured at place of work.
Labour utilisation is here measured as the ratio
between the total employment at place of work and
regional population.
In the decomposition of change in regional GDP per
capita, changes in labour utilisation may partially
depend on labour mobility if there is commuting on a
substantial scale in the region.
Further information
Figure notes
5.1: First available year for Canada, Chile, Ireland: 1996; United States:
www.oecd.org/statistics/productivity.
Reference years and territorial level
1995-2007; TL2.
Mexico and Turkey are not included for lack of regional
data on comparable years.
Regional GDP is not available for Iceland, Israel and
Switzerland.

Definition
GDP is the standard measure of the value of the pro-
duction activity (goods and services) of resident pro-
ducer units. Regional GDP is measured according to
the definition of the System of National Accounts
(SNA). To make comparisons over time and across
countries, it is expressed at constant prices (year 2000),
using the OECD deflator and then it is converted into
USD purchasing power parities (PPPs) to express each
country's GDP in a common currency.
Regional labour productivity is here measured as the
ratio of constant GDP in 2000 prices, to total employ-
ment where the latter is measured at place of work.
Labour utilisation is here measured as the ratio
between the total employment at place of work and
regional population.
In the decomposition of change in regional GDP per
capita, changes in labour utilisation may partially
depend on labour mobility if there is commuting on a
substantial scale in the region.
Further information
Figure notes
5.1: First available year for Canada, Chile, Ireland: 1996; United States:
www.oecd.org/statistics/productivity.
Reference years and territorial level
1995-2007; TL2.
Mexico and Turkey are not included for lack of regional
data on comparable years.
Regional GDP is not available for Iceland, Israel and
Switzerland.

Definition
GDP is the standard measure of the value of the pro-
duction activity (goods and services) of resident pro-
ducer units. Regional GDP is measured according to
the definition of the System of National Accounts
(SNA). To make comparisons over time and across
countries, it is expressed at constant prices (year 2000),
using the OECD deflator and then it is converted into
USD purchasing power parities (PPPs) to express each
country's GDP in a common currency.
Regional labour productivity is here measured as the
ratio of constant GDP in 2000 prices, to total employ-
ment where the latter is measured at place of work.
Labour utilisation is here measured as the ratio
between the total employment at place of work and
regional population.
In the decomposition of change in regional GDP per
capita, changes in labour utilisation may partially
depend on labour mobility if there is commuting on a
substantial scale in the region.
Further information
Figure notes
5.1: First available year for Canada, Chile, Ireland: 1996; United States:
www.oecd.org/statistics/productivity.
Reference years and territorial level
1995-2007; TL2.
Mexico and Turkey are not included for lack of regional
data on comparable years.
Regional GDP is not available for Iceland, Israel and
Switzerland.

Definition
GDP is the standard measure of the value of the pro-
duction activity (goods and services) of resident pro-
ducer units. Regional GDP is measured according to
the definition of the System of National Accounts
(SNA). To make comparisons over time and across
countries, it is expressed at constant prices (year 2000),
using the OECD deflator and then it is converted into
USD purchasing power parities (PPPs) to express each
country's GDP in a common currency.
Regional labour productivity is here measured as the
ratio of constant GDP in 2000 prices, to total employ-
ment where the latter is measured at place of work.
Labour utilisation is here measured as the ratio
between the total employment at place of work and
regional population.
In the decomposition of change in regional GDP per
capita, changes in labour utilisation may partially
depend on labour mobility if there is commuting on a
substantial scale in the region.
Further information
Figure notes
5.1: First available year for Canada, Chile, Ireland: 1996; United States:
www.oecd.org/statistics/productivity.
Reference years and territorial level
1995-2007; TL2.
Mexico and Turkey are not included for lack of regional
data on comparable years.
Regional GDP is not available for Iceland, Israel and
Switzerland.

Definition
GDP is the standard measure of the value of the pro-
duction activity (goods and services) of resident pro-
ducer units. Regional GDP is measured according to
the definition of the System of National Accounts
(SNA). To make comparisons over time and across
countries, it is expressed at constant prices (year 2000),
using the OECD deflator and then it is converted into
USD purchasing power parities (PPPs) to express each
country's GDP in a common currency.
Regional labour productivity is here measured as the
ratio of constant GDP in 2000 prices, to total employ-
ment where the latter is measured at place of work.
Labour utilisation is here measured as the ratio
between the total employment at place of work and
regional population.
In the decomposition of change in regional GDP per
capita, changes in labour utilisation may partially
depend on labour mobility if there is commuting on a
substantial scale in the region.
Figure notes
5.1: First available year for Canada, Chile, Ireland: 1996; United States:
OECD compendium of productivity indicators
www.oecd.org/statistics/productivity.
Reference years and territorial level
1995-2007; TL2.
Mexico and Turkey are not included for lack of regional
data on comparable years.
Regional GDP is not available for Iceland, Israel and
Switzerland.

Definition
GDP is the standard measure of the value of the pro-
duction activity (goods and services) of resident pro-
ducer units. Regional GDP is measured according to
the definition of the System of National Accounts
(SNA). To make comparisons over time and across
countries, it is expressed at constant prices (year 2000),
using the OECD deflator and then it is converted into
USD purchasing power parities (PPPs) to express each
country's GDP in a common currency.
Regional labour productivity is here measured as the
ratio of constant GDP in 2000 prices, to total employ-
ment where the latter is measured at place of work.
Labour utilisation is here measured as the ratio
between the total employment at place of work and
regional population.
In the decomposition of change in regional GDP per
capita, changes in labour utilisation may partially
depend on labour mobility if there is commuting on a
substantial scale in the region.
Figure notes
5.1: First available year for Canada, Chile, Ireland: 1996; United States:
Further information
OECD compendium of productivity in dicators
www.oecd.org/statistics/productivity.
Regional GDP is not available for Iceland, Israel and
Reference years and territorial level
1995-2007; TL2.
data on and Turkey are not included for lack of regional
Rico

Definition
GDP is the standard measure of the value of the pro-
duction activity (goods and services) of resident pro-
ducer units. Regional GDP is measured according to
the definition of the System of National Accounts
(SNA). To make comparisons over time and across
countries, it is expressed at constant prices (year 2000),
using the OECD deflator and then it is converted into
USD purchasing power parities (PPPs) to express each
country's GDP in a common currency.
Regional labour productivity is here measured as the
ratio of constant GDP in 2000 prices, to total employ-
ment where the latter is measured at place of work.
Labour utilisation is here measured as the ratio
between the total employment at place of work and
regional population.
In the decomposition of change in regional GDP per
capita, changes in labour utilisation may partially
depend on labour mobility if there is commuting on a
substantial scale in the region.
Figure notes
5.1: First available year for Canada, Chile, Ireland: 1996; United States:
Further information
OECD compendium of productivity in dicators
www.oecd.org/statistics/productivity.
Regional GDP is not available for Iceland, Israel and
Reference years and territorial level
1995-2007; TL2.
data on and Turkey are not included for lack of regional
Ritzerland.

Definition
GDP is the standard measure of the value of the pro-
duction activity (goods and services) of resident pro-
ducer units. Regional GDP is measured according to
the definition of the System of National Accounts
(SNA). To make comparisons over time and across
countries, it is expressed at constant prices (year 2000),
using the OECD deflator and then it is converted into
USD purchasing power parities (PPPs) to express each
country's GDP in a common currency.
Regional labour productivity is here measured as the
ratio of constant GDP in 2000 prices, to total employ-
ment where the latter is measured at place of work.
Labour utilisation is here measured as the ratio
between the total employment at place of work and
regional population.
In the decomposition of change in regional GDP per
capita, changes in labour utilisation may partially
depend on labour mobility if there is commuting on a
substantial scale in the region.
Figure notes
5.1: First available year for Canada, Chile, Ireland: 1996; United States:
Further information
OECD compendium of productivity in dicators
www.oecd.org/statistics/productivity.
Regional GDP is not available for Iceland, Israel and
Reference years and territorial level
1995-2007; TL2.
data on and Turkey are not included for lack of regional
Rico

Definition
GDP is the standard measure of the value of the pro-
duction activity (goods and services) of resident pro-
ducer units. Regional GDP is measured according to
the definition of the System of National Accounts
(SNA). To make comparisons over time and across
countries, it is expressed at constant prices (year 2000),
using the OECD deflator and then it is converted into
USD purchasing power parities (PPPs) to express each
country's GDP in a common currency.
Regional labour productivity is here measured as the
ratio of constant GDP in 2000 prices, to total employ-
ment where the latter is measured at place of work.
Labour utilisation is here measured as the ratio
between the total employment at place of work and
regional population.
In the decomposition of change in regional GDP per
capita, changes in labour utilisation may partially
depend on labour mobility if there is commuting on a
substantial scale in the region.
Figure notes
5.1: First available year for Canada, Chile, Ireland: 1996; United States:
Further information
OECD compendium of productivity in dicators
www.oecd.org/statistics/productivity.
Regional GDP is not available for Iceland, Israel and
Reference years and territorial level
1995-2007; TL2.
data on and Turkey are not included for lack of regional
Ritzerland.

Definition
GDP is the standard measure of the value of the pro-
duction activity (goods and services) of resident pro-
ducer units. Regional GDP is measured according to
the definition of the System of National Accounts
(SNA). To make comparisons over time and across
countries, it is expressed at constant prices (year 2000),
using the OECD deflator and then it is converted into
USD purchasing power parities (PPPs) to express each
country's GDP in a common currency.
Regional labour productivity is here measured as the
ratio of constant GDP in 2000 prices, to total employ-
ment where the latter is measured at place of work.
Labour utilisation is here measured as the ratio
between the total employment at place of work and
regional population.
In the decomposition of change in regional GDP per
capita, changes in labour utilisation may partially
depend on labour mobility if there is commuting on a
substantial scale in the region.
Figure notes
5.1: First available year for Canada, Chile, Ireland: 1996; United States:
Further information
OECD compendium of productivity in dicators
www.oecd.org/statistics/productivity.
Regional GDP is not available for Iceland, Israel and
Reference years and territorial level
1995-2007; TL2.
data on and Turkey are not included for lack of regional
Ritzerland.

Definition
GDP is the standard measure of the value of the pro-
duction activity (goods and services) of resident pro-
ducer units. Regional GDP is measured according to
the definition of the System of National Accounts
(SNA). To make comparisons over time and across
countries, it is expressed at constant prices (year 2000),
using the OECD deflator and then it is converted into
USD purchasing power parities (PPPs) to express each
country's GDP in a common currency.
Regional labour productivity is here measured as the
ratio of constant GDP in 2000 prices, to total employ-
ment where the latter is measured at place of work.
Labour utilisation is here measured as the ratio
between the total employment at place of work and
regional population.
In the decomposition of change in regional GDP per
capita, changes in labour utilisation may partially
depend on labour mobility if there is commuting on a
substantial scale in the region.
Figure notes
5.1: First available year for Canada, Chile, Ireland: 1996; United States:
OECD compendium of productivity indicators
www.oecd.org/statistics/productivity.
Reference years and territorial level
1995-2007; TL2.
Mexico and Turkey are not included for lack of regional
data on comparable years.
Regional GDP is not available for Iceland, Israel and
Switzerland.

Definition
GDP is the standard measure of the value of the pro-
duction activity (goods and services) of resident pro-
ducer units. Regional GDP is measured according to
the definition of the System of National Accounts
(SNA). To make comparisons over time and across
countries, it is expressed at constant prices (year 2000),
using the OECD deflator and then it is converted into
USD purchasing power parities (PPPs) to express each
country's GDP in a common currency.
Regional labour productivity is here measured as the
ratio of constant GDP in 2000 prices, to total employ-
ment where the latter is measured at place of work.
Labour utilisation is here measured as the ratio
between the total employment at place of work and
regional population.
In the decomposition of change in regional GDP per
capita, changes in labour utilisation may partially
depend on labour mobility if there is commuting on a
substantial scale in the region.
Figure notes
5.1: First available year for Canada, Chile, Ireland: 1996; United States:
Further information
OECD compendium of productivity in dicators
www.oecd.org/statistics/productivity.
Regional GDP is not available for Iceland, Israel and
Reference years and territorial level
1995-2007; TL2.
data on and Turkey are not included for lack of regional
Ritzerland.

Definition
GDP is the standard measure of the value of the pro-
duction activity (goods and services) of resident pro-
ducer units. Regional GDP is measured according to
the definition of the System of National Accounts
(SNA). To make comparisons over time and across
countries, it is expressed at constant prices (year 2000),
using the OECD deflator and then it is converted into
USD purchasing power parities (PPPs) to express each
country's GDP in a common currency.
Regional labour productivity is here measured as the
ratio of constant GDP in 2000 prices, to total employ-
ment where the latter is measured at place of work.
Labour utilisation is here measured as the ratio
between the total employment at place of work and
regional population.
In the decomposition of change in regional GDP per
capita, changes in labour utilisation may partially
depend on labour mobility if there is commuting on a
substantial scale in the region.
Further information
Figure notes
5.1: First available year for Canada, Chile, Ireland: 1996; United States:
www.oecd.org/statistics/productivity.
Reference years and territorial level
1995-2007; TL2.
Mexico and Turkey are not included for lack of regional
data on comparable years.
Regional GDP is not available for Iceland, Israel and
Switzerland.

Definition
GDP is the standard measure of the value of the pro-
duction activity (goods and services) of resident pro-
ducer units. Regional GDP is measured according to
the definition of the System of National Accounts
(SNA). To make comparisons over time and across
countries, it is expressed at constant prices (year 2000),
using the OECD deflator and then it is converted into
USD purchasing power parities (PPPs) to express each
country's GDP in a common currency.
Regional labour productivity is here measured as the
ratio of constant GDP in 2000 prices, to total employ-
ment where the latter is measured at place of work.
Labour utilisation is here measured as the ratio
between the total employment at place of work and
regional population.
In the decomposition of change in regional GDP per
capita, changes in labour utilisation may partially
depend on labour mobility if there is commuting on a
substantial scale in the region.
Figure notes
5.1: First available year for Canada, Chile, Ireland: 1996; United States:
Further information
OECD compendium of productivity indicators
www.oecd.org/statistics/productivity.
Reference years and territorial level
1995-2007; TL2.
Mexico and Turkey are not included for lack of regional
data on comparable years.
Switzerland.
RDP is not available for Iceland, Israel and
a

5.1: First available year for Canada, Chile, Ireland: 1996; United States: 2000.

5.2: First available year for Germany: 1996; United States: 2000.

\section{Source}

OECD Regional Database: $h$ ttp://dotstat/wbos/.

See Annex B for data, source and country-related metadata. 


\subsection{Contribution of labour productivity and labour utilisation to GDP per capita: Top 20 TL2 regions, ranked by GDP per capita growth rate, 1995-2007}

Growth in GDP per capita

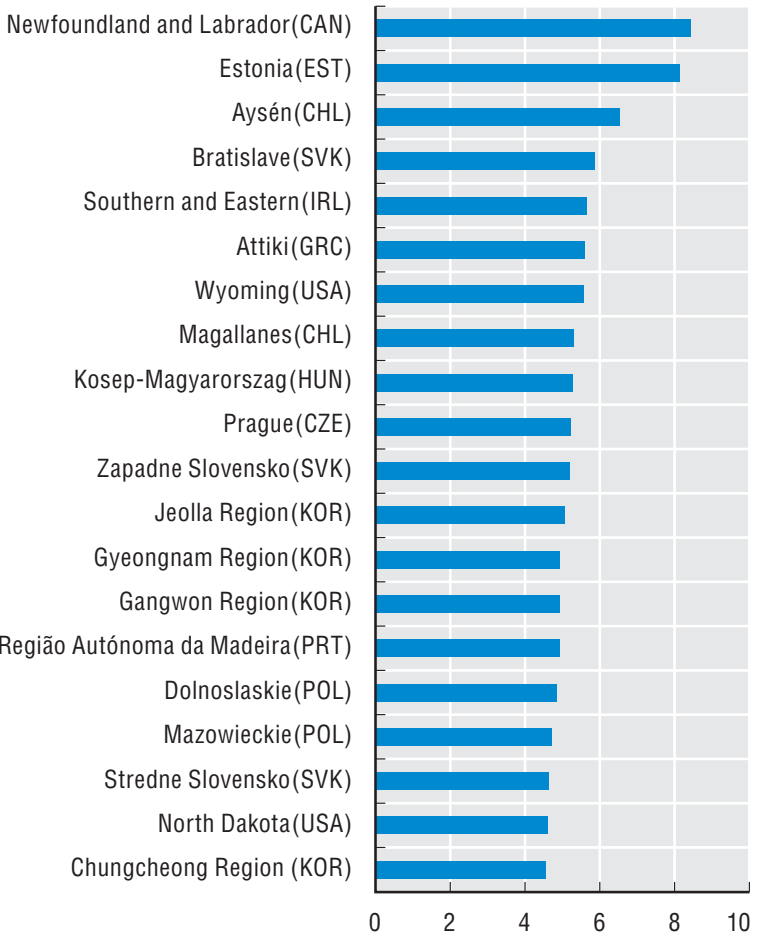

Growth in labour productivity

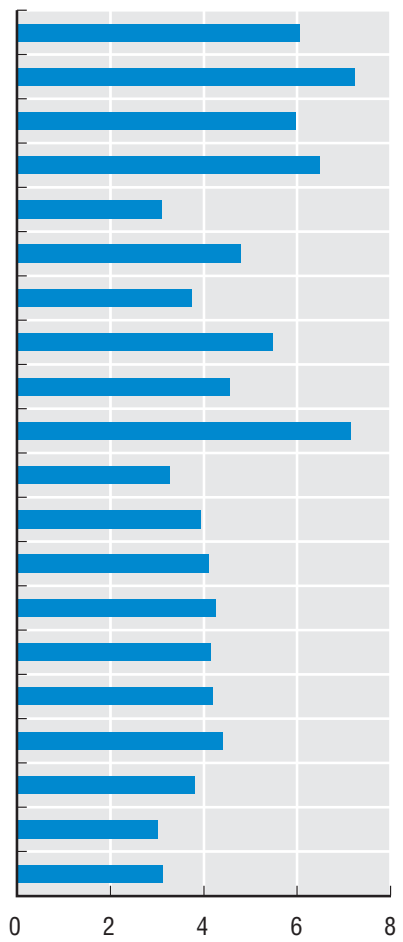

Growth in labour utilisation

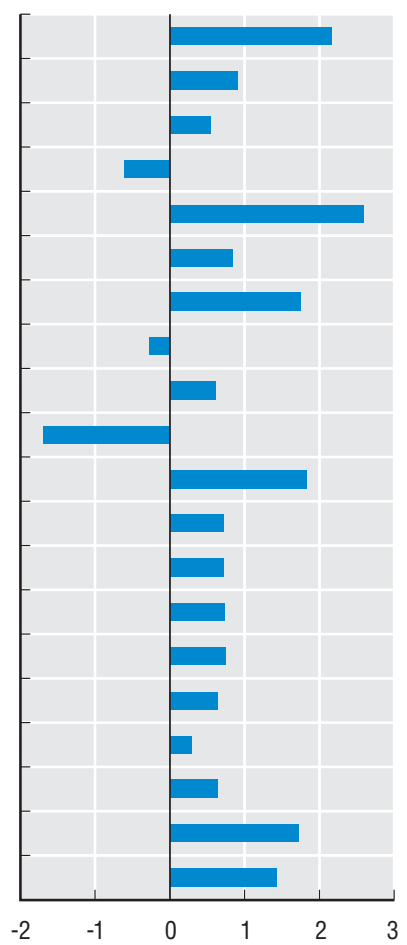

5.2. Contribution of labour productivity and labour utilisation to GDP per capita: Bottom 20 TL2 regions, ranked by GDP per capita growth rate, 1995-2007

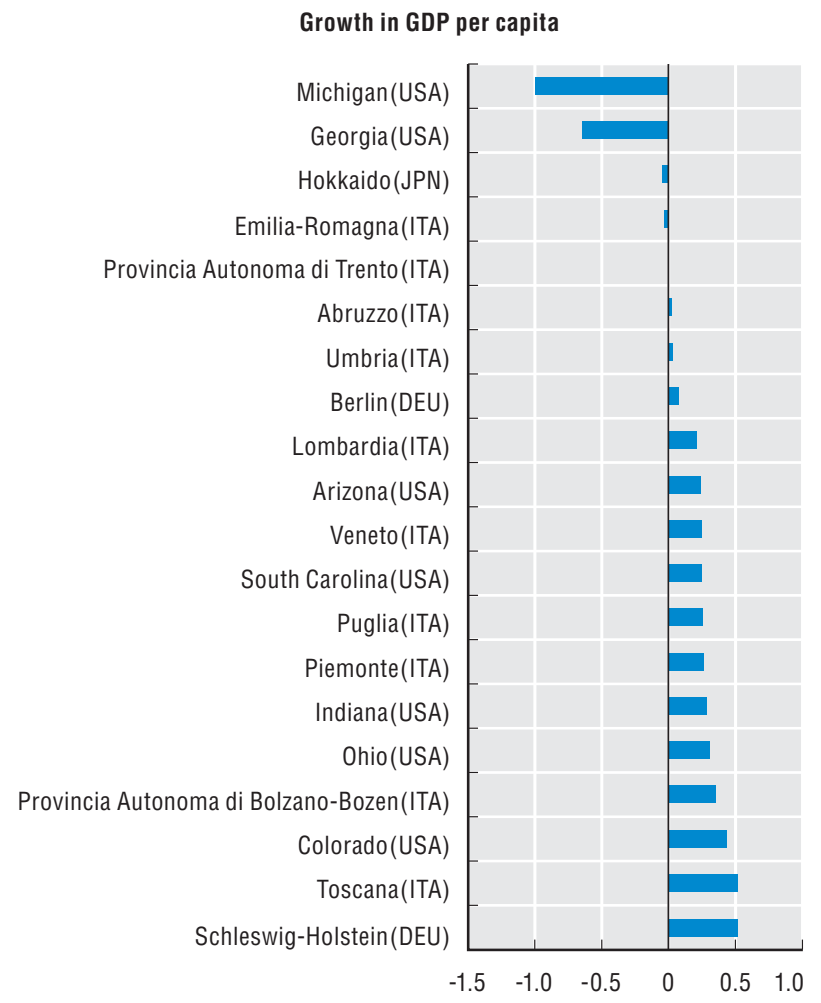

Growth in labour productivity

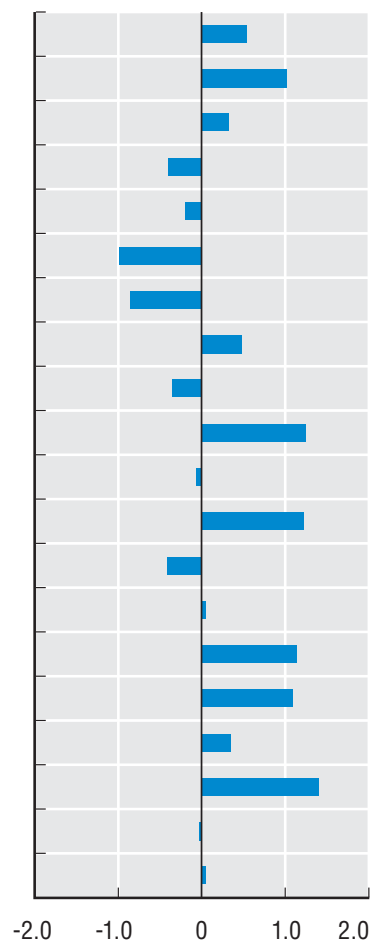

Growth in labour utilisation

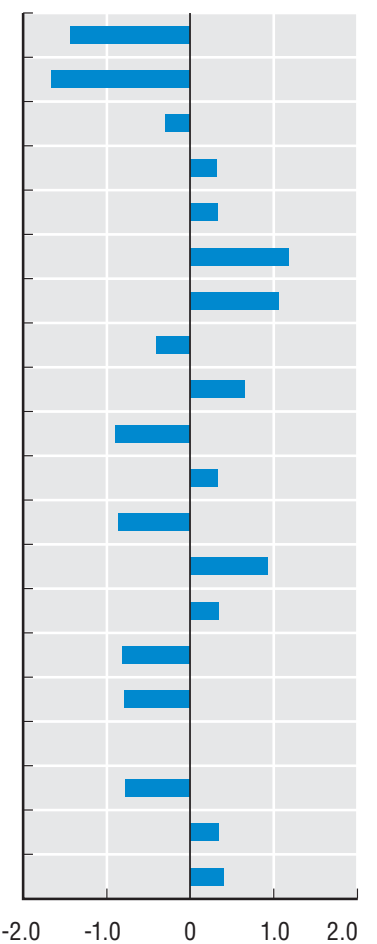

StatLink Ails http://dx.doi.org/10.1787/888932439482 


\section{LABOUR PRODUCTIVITY GROWTH IN REGIONS}

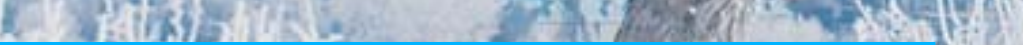

5.3. Annual growth of regional productivity: Asia, Europe and Oceania, 1995-2007

Growth in regional GDP per worker in constant 2000 USD (PPP), TL3 regions

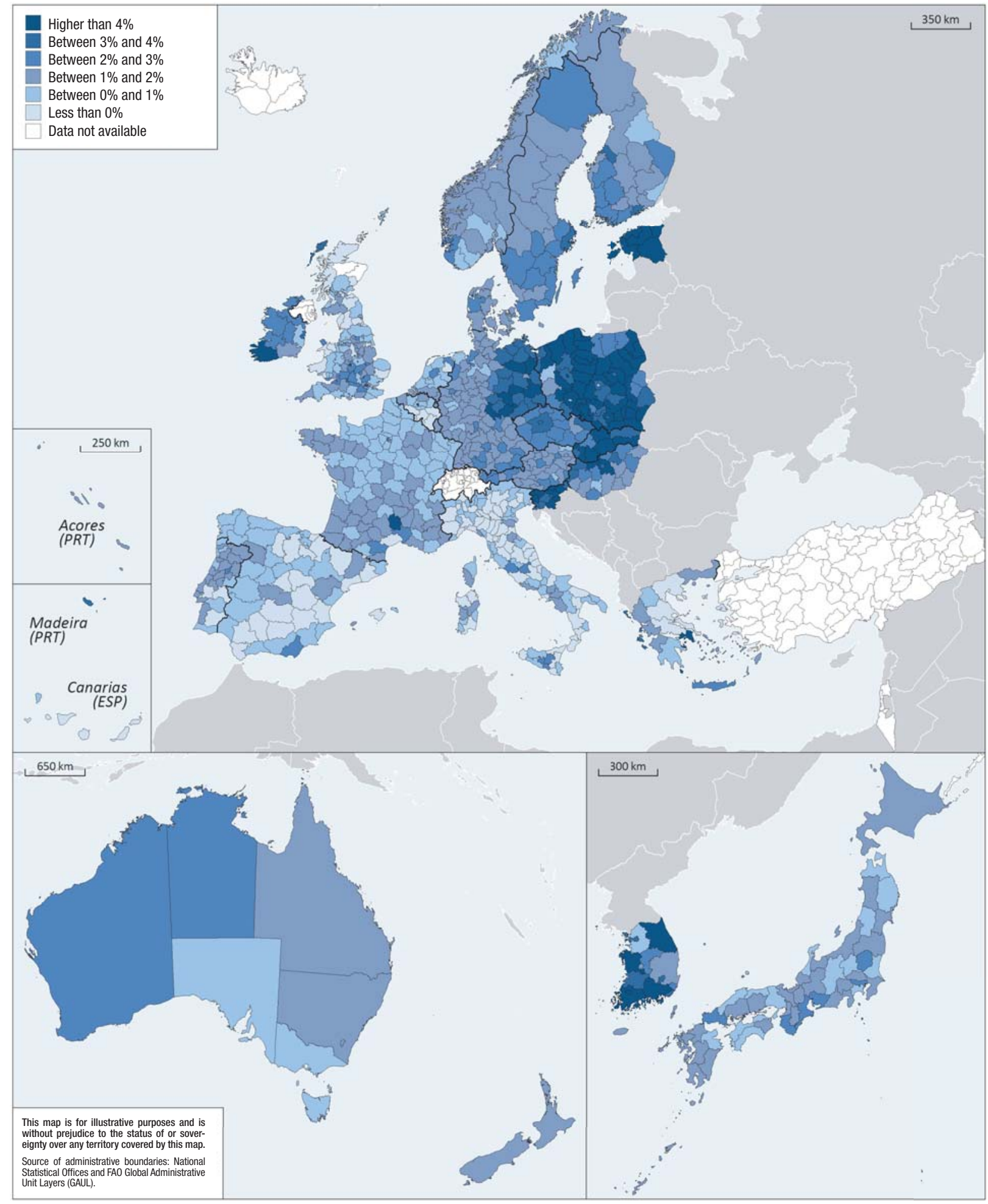

StatLink Aाsय $h t t p: / / d x . d o i . o r g / 10.1787 / 888932440071$ 
5.4. Annual growth of regional productivity: Americas, $1995-2007$

Growth in regional GDP per worker in constant 2000 USD (PPP), TL2 regions

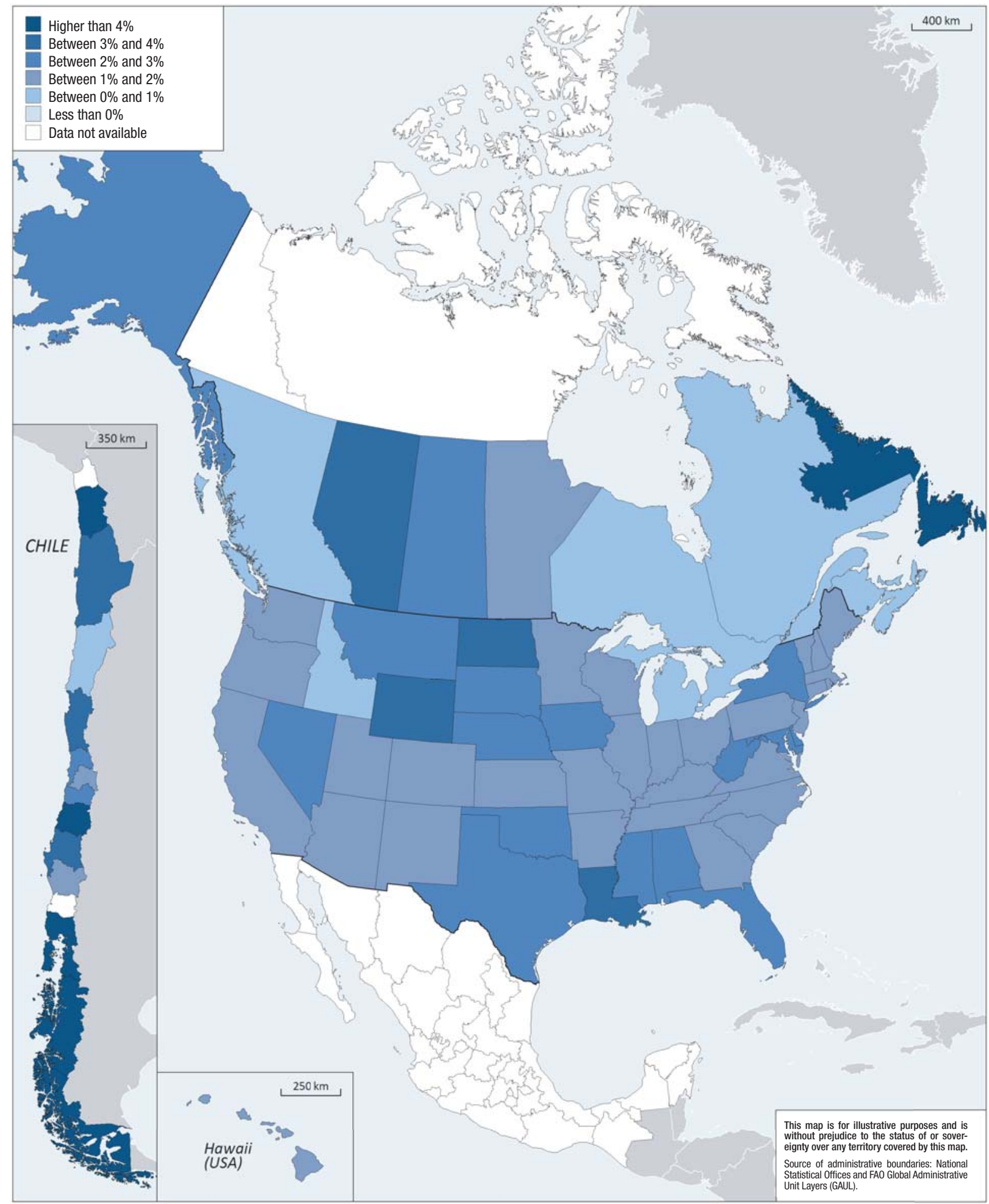

StatLink काIsL http://dx.doi.org/10.1787/888932440071 
Regional differences in gross domestic product (GDP) per capita within countries are often substantial and larger than among OECD countries. According to the Gini index, the emerging economies - China, the Russian Federation, India and Brazil - displayed the greatest disparity in GDP per capita in 2007 followed by Mexico, Chile, the Slovak Republic and Turkey among the OECD countries (Figure 6.1).

During 1995-2007 regional disparities increased in 19 out of 31 countries considered. Significant increases can be found in Mexico, Estonia, Hungary, Korea, Ireland and the Czech Republic (Figure 6.1).

For the large part, economic output differences are attributed to disparities in productivity and in the utilisation of the available labour force. Regional differences in labour productivity, here measured by the range in regional GDP per worker, were markedly high in Chile, France, Poland and Portugal, where some regions displayed productivity twice as high as the national value and some other regions had values lower than half of it (Figure 6.2).

The Gini index is a measure of inequality which assigns equal weight to each region of a country regardless of its size, while the number of people living in regions with low GDP per capita (under the national median), can provide an indication of the different economic implications of disparities within a country. For example, while the regional disparities as measured by the Gini index in GDP per capita are of the same magnitude in the Slovak Republic, Turkey and Estonia, the percentage of national population living in regions with low GDP per capita varies from almost $60 \%$ in the Slovak Republic to $23 \%$ in Estonia (Figure 6.3).

\section{Definition}

GDP is the standard measure of the value of the production activity (goods and services) of resident producer units. Regional GDP is measured according to the definition of the System of National Accounts (SNA). To make comparisons over time and across countries, it is expressed at constant prices (year 2000), using the OECD deflator and then it is converted into USD purchasing power parities (PPPs) to express each country's GDP in a common currency.

GDP per capita is calculated by dividing the GDP of a country or a region by its population.

GDP per worker is measured as the ratio of constant GDP in 2000 prices, to total employment where the latter is measured at place of work. This means that productivity and GDP per capita trends may diverge in regions if there is commuting on a substantial scale.

The Gini index is a measure of inequality among all regions of a given country (see Annex $C$ for the formula). The index takes on values between 0 and 1 , with zero interpreted as no disparity. It assigns equal weight to each region regardless of its size; therefore differences in the values of the index among countries may be partially due to differences in the average size of regions in each country.

\section{Source}

OECD Regional Database: http://dotstat/wbos/.

OECD deflator and purchasing power parities http://dotstat/wbos/.

See Annex B for data, source and country-related metadata.

\section{Reference years and territorial level}

1995-2007; TL3.

Australia, Canada, Chile, Mexico, Turkey and the United States TL2 regions.

Brazil, China, India, Russian Federation and South Africa TL2 regions.

Regional GDP is not available for Iceland, Israel and Switzerland.

New Zealand is excluded for lack of regional GDP after 2003.

\section{Figure notes}

6.1: Available years: Estonia 1996-2007; Norway 1997-2007; Poland 19992007; Turkey 2004-06; China 2008; India 2001-07; Russian Federation 2005-07.

6.3: Australia, Canada, Chile, China, Brazil, India, Mexico, Russian Federation, Turkey and United States TL2 regions. 


\section{REGIONAL ECONOMIC DISPARITIES}

6.1. Gini index of inequality of GDP per capita across TL3 regions, 1995 and 2007

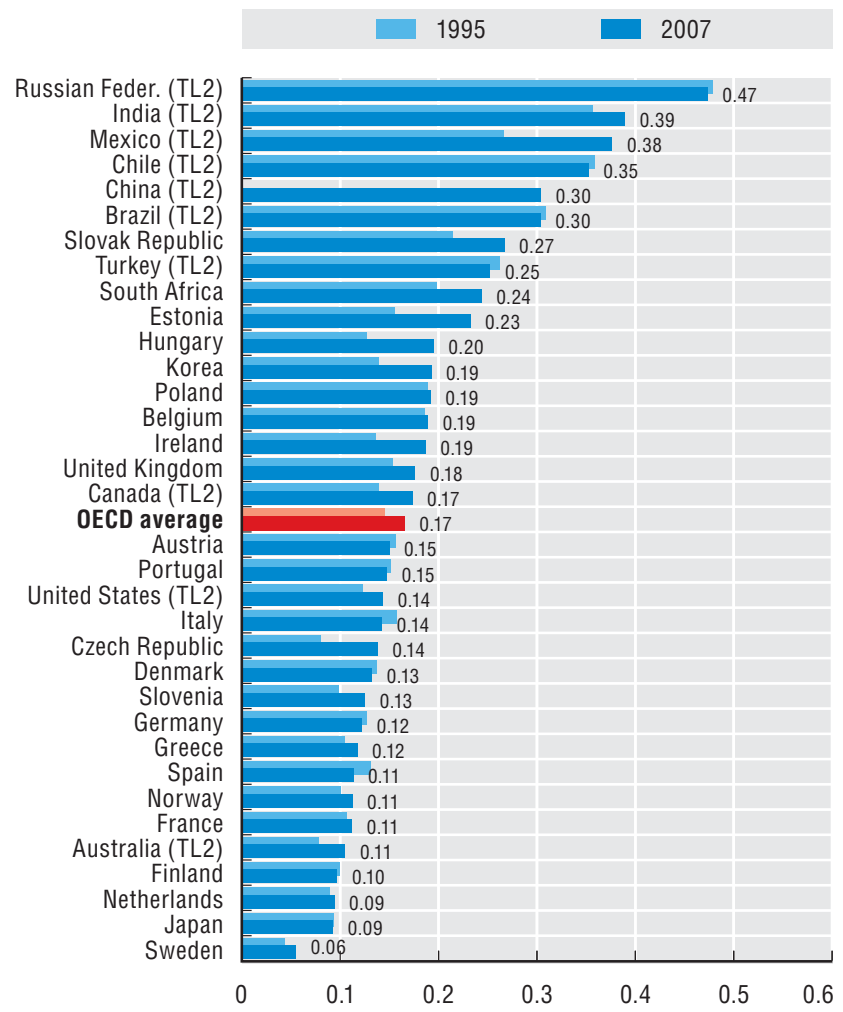

6.2. Range in TL3 regional GDP per worker (as a \% of national average), 2007
O Minimum value
- Maximum value

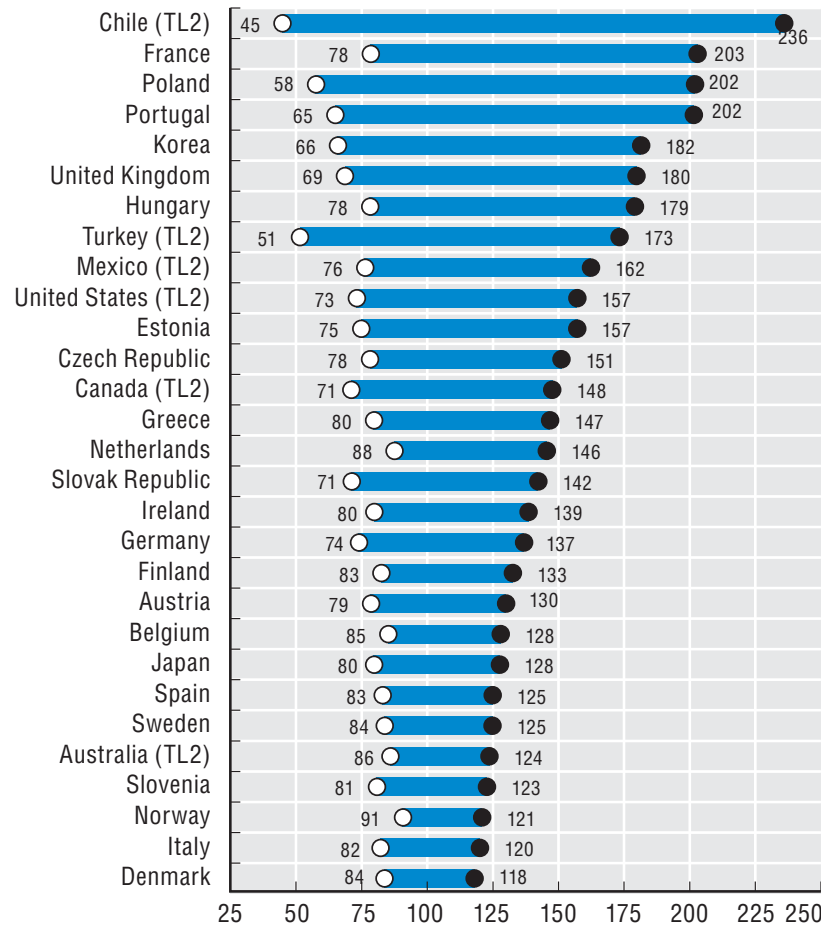

\subsection{Gini index of inequality of GDP per capita across TL3 regions and percentage of population in regions with GDP}

per capita under national median, 2007

\%POP living under median GDP per capita

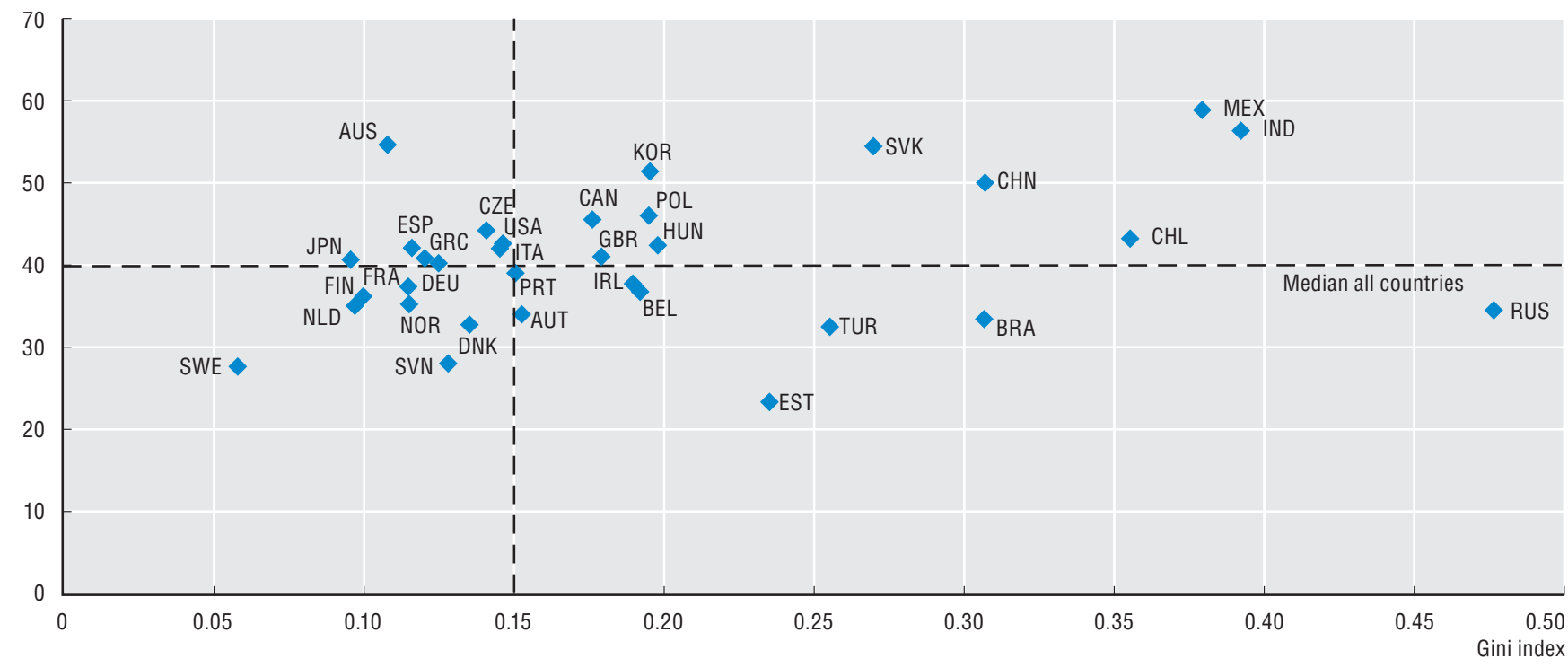




\section{REGIONAL ECONOMIC DISPARITIES}

6.4. Regional GDP per capita: Asia and Oceania, 2007

Constant 2000 USD (PPP) in thousands, TL3 regions

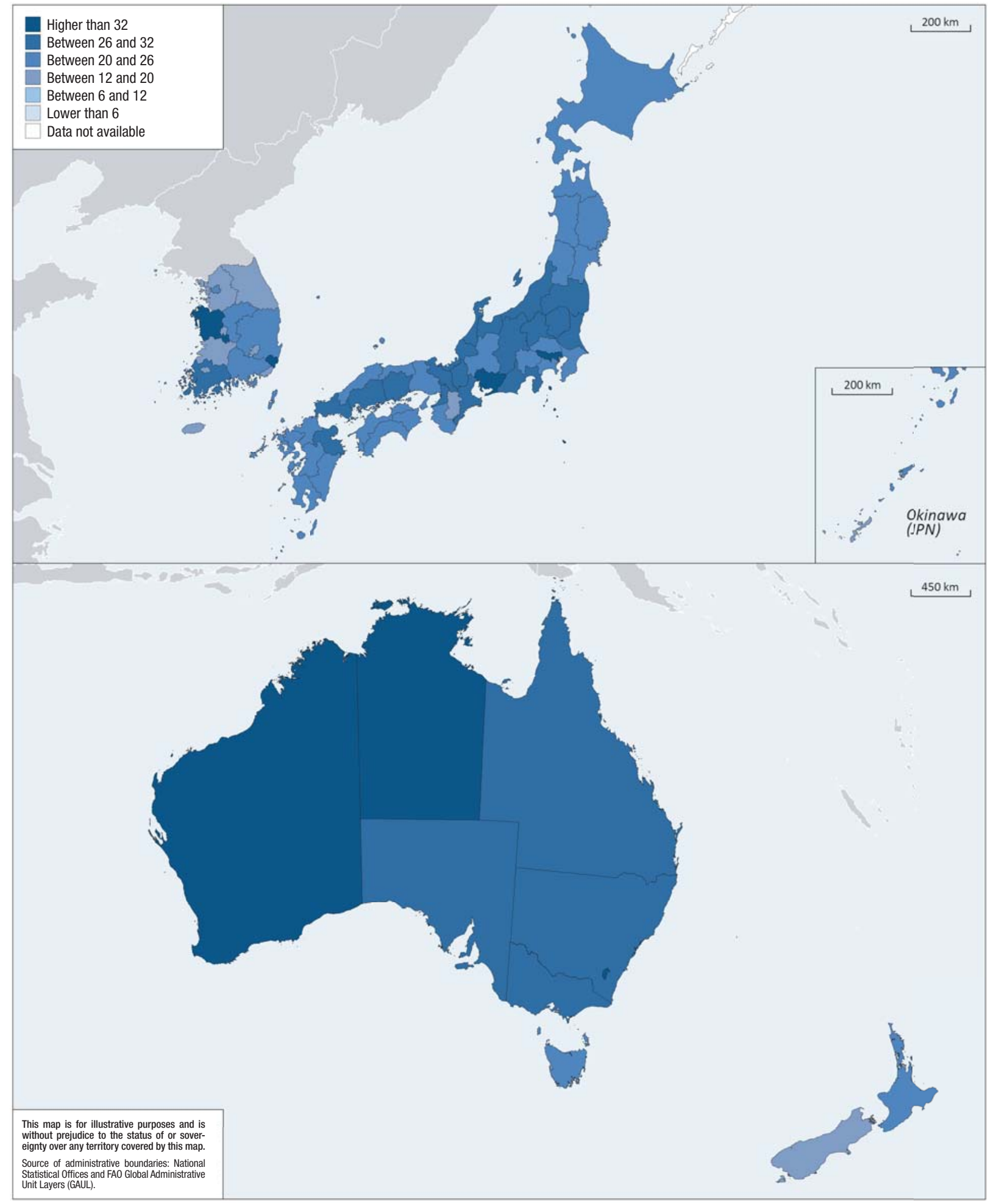

StatLink Aiाst http://dx.doi.org/10.1787/888932440090 


\section{REGIONAL ECONOMIC DISPARITIES}

6.5. Regional GDP per capita: Europe, 2007

Constant 2000 USD (PPP) in thousands, TL3 regions

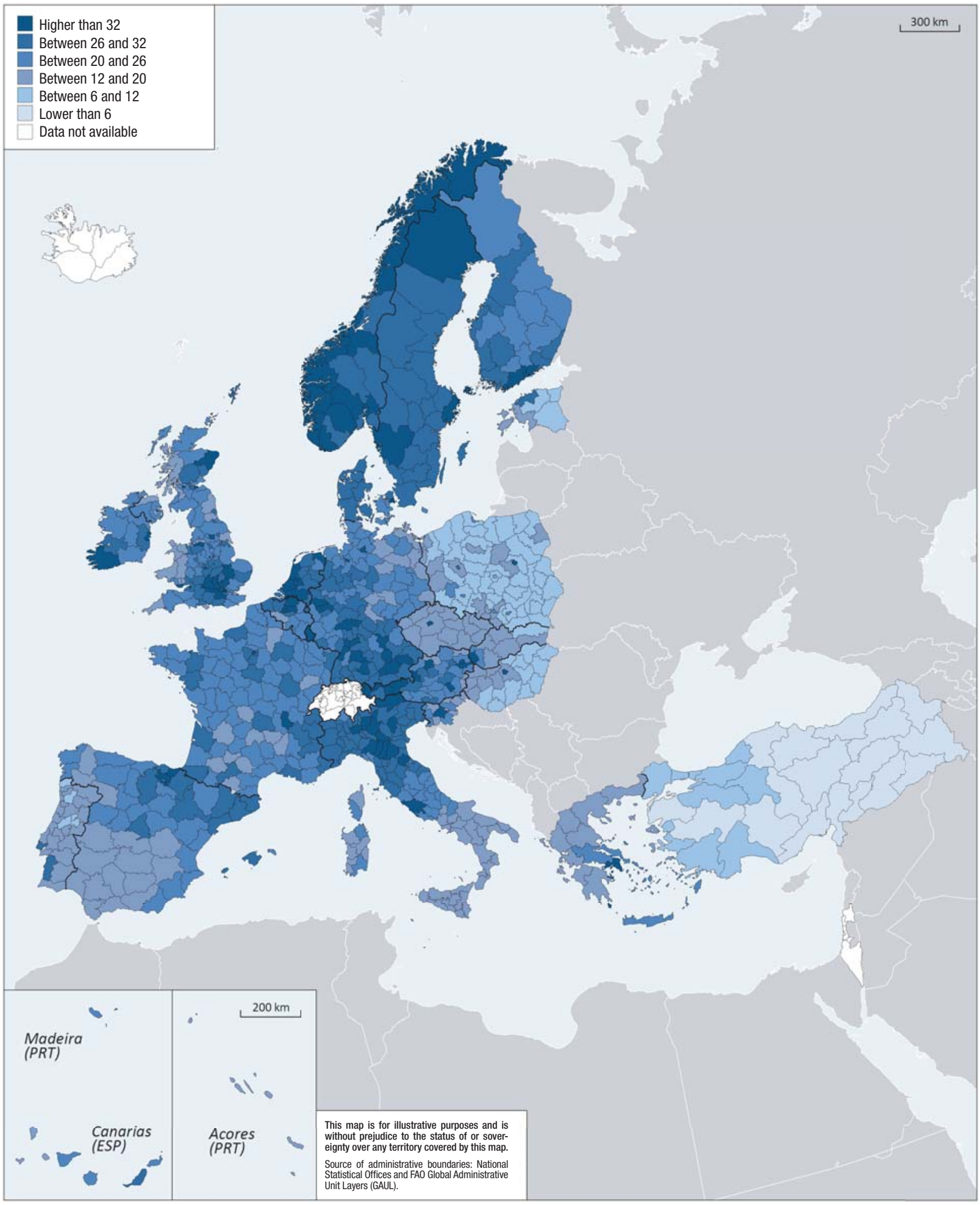

StatLink AilsL http://dx.doi.org/10.1787/888932440090 


\section{REGIONAL ECONOMIC DISPARITIES}

6.6. Regional GDP per capita: Americas, 2007

Constant 2000 USD (PPP) in thousands, TL2 regions

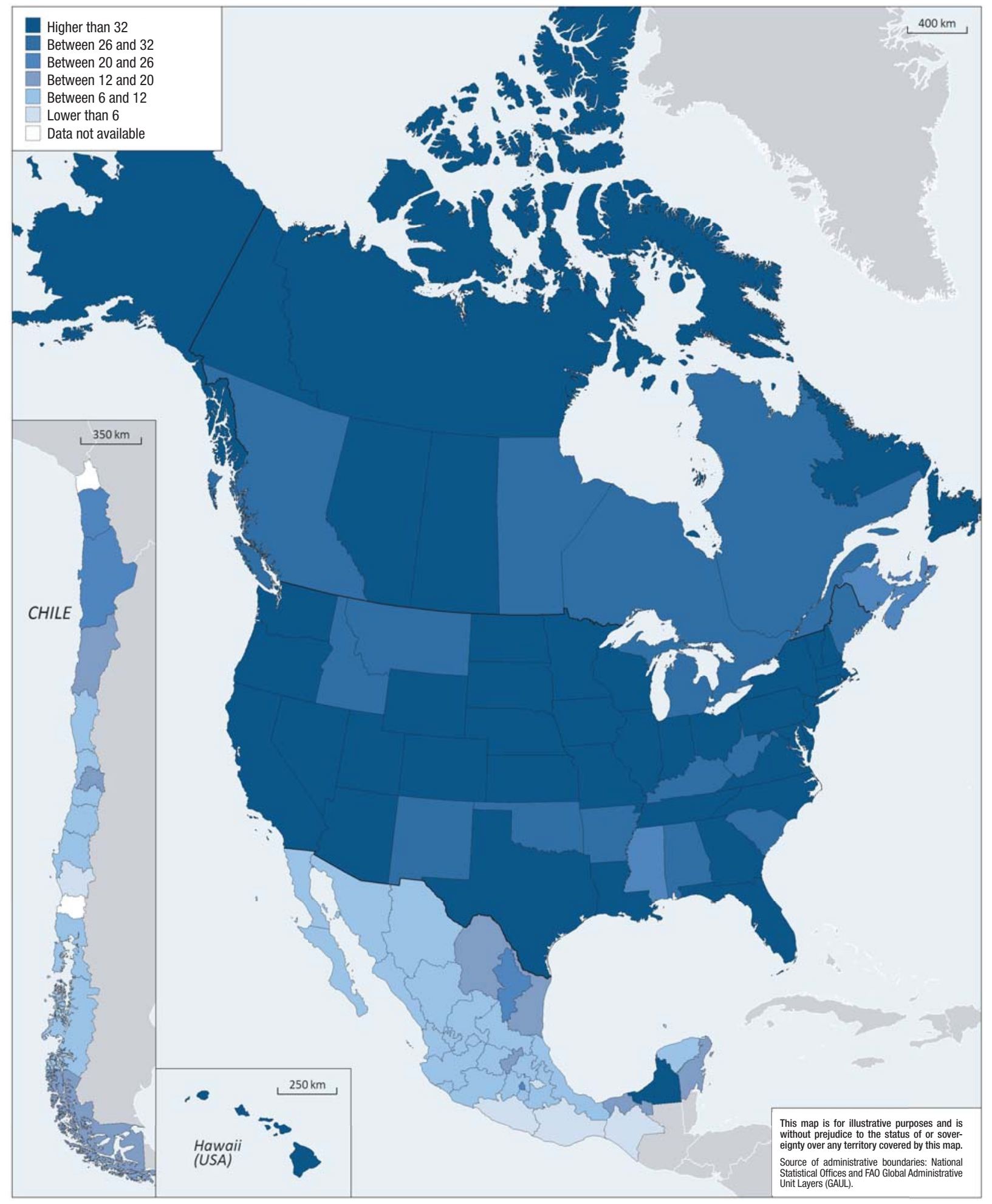

StatLink Aाs $h t$ ttp://dx.doi.org/10.1787/888932440090 


\section{REGIONAL ECONOMIC DISPARITIES}

6.7. Regional GDP per capita: Emerging economies, 2007

Constant 2000 USD (PPP) in thousands, TL2 regions

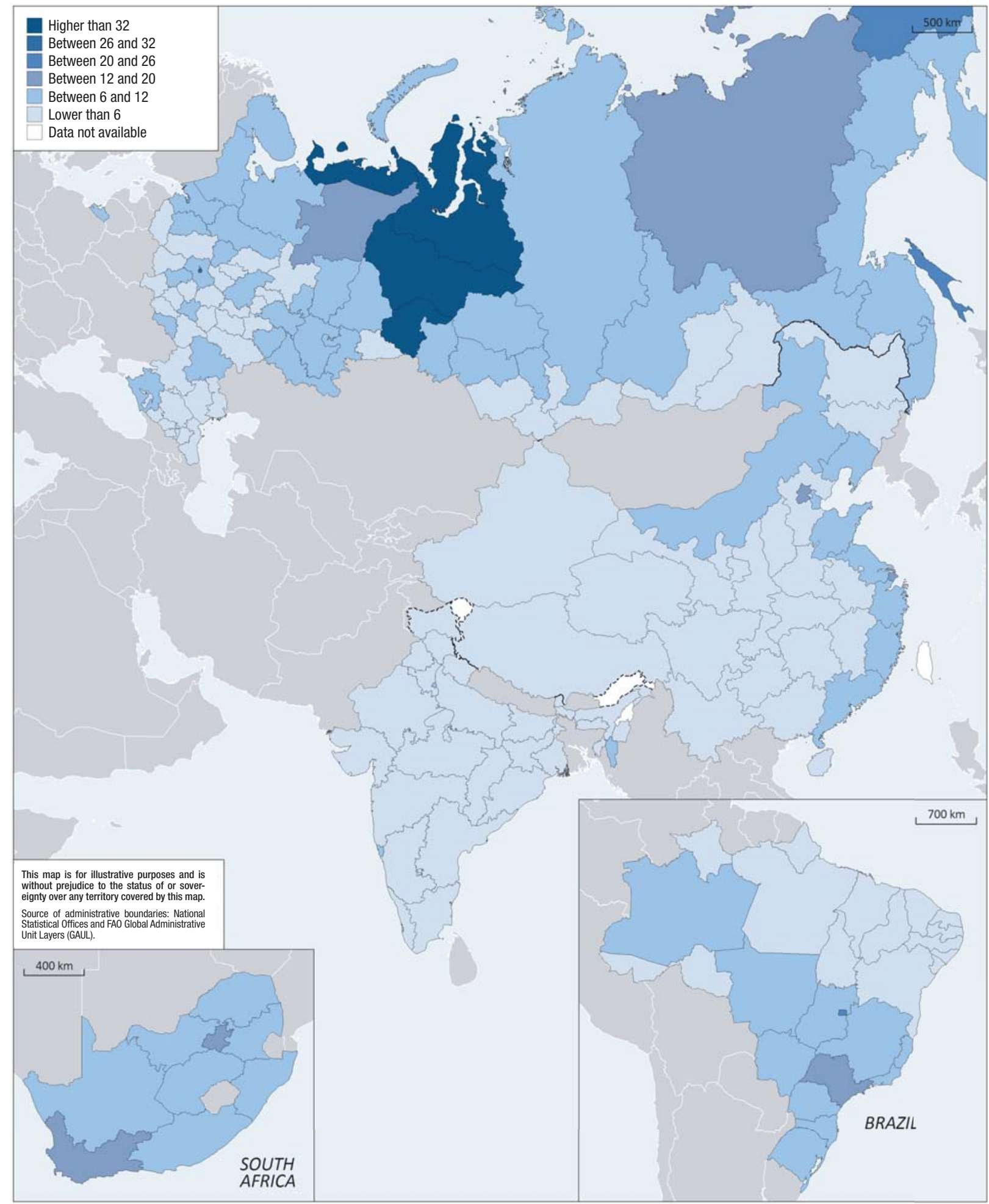

StatLink काIsL http://dx.doi.org/10.1787/888932440090 
Predominantly urban regions attract the largest share of economic activity. In 2007 , almost $60 \%$ of total gross domestic product (GDP) in OECD countries was produced in urban regions that account for less than half of the OECD population. Predominantly rural areas contributed $14 \%$ to overall GDP, even though in Ireland, Slovenia and in the Scandinavian countries the GDP produced by rural regions was above $40 \%$ of national GDP (Figure 7.1).

Large metropolitan regions in OECD countries are generally key drivers of growth.

The economic growth of the large metropolitan regions in Eastern Europe (Poland, the Czech Republic, Hungary, the Slovak Republic) and Greece was particularly strong compared to average national growth rates. In Austria, Australia, Canada, Ireland, Italy and Mexico, by contrast, the rate of growth in large metropolitan regions was below the national average (Figure 7.2).

Regional differences in GDP per capita are mainly explained by productivity differentials among regions. Labour productivity growth is therefore considered a key indicator to assess regional competitiveness. Among the 21 OECD countries considered (Europe, Japan and Korea), rural regions increased their labour productivity more than urban regions during 1995-2007 (1.7\% versus 1.2\%). Among rural regions, gains in productivity were greatest in rural regions close to cities (2\%), while remote rural regions grew at $1.3 \%$ (Figure 7.3 ). The largest productivity gains in rural rather than in urban regions were observed in Poland and the Slovak Republic, while the contrary was observed in Greece and Sweden (Figure 7.3).

Preliminary results suggest that the $20 \%$ of rural regions with highest productivity growth during 1995-2007 have gained in productivity by reducing the productivity gap between industry and agriculture $170 \%$ more than the average rural region, raising productivity in agriculture $20 \%$ more than the average rural region, and decreasing the share of employment in agriculture $50 \%$ more than the average rural region (Figure 7.4). More analysis is needed to understand whether the reduction in agricultural employment has been absorbed by other sectors, as the similar unemployment rates observed in the two groups seem to indicate (Figure 7.4).

\section{Source}

OECD Regional Database: http://dotstat/wbos/.

\section{Definition}

GDP is the standard measure of the value of the production activity (goods and services) of resident producer units. Regional GDP is measured according to the definition of the System of National Accounts (SNA). To make comparisons over time and across countries, it is expressed at constant prices (year 2000), using the OECD deflator and then it is converted into USD purchasing power parities (PPPs) to express each country's GDP in a common currency.

GDP per worker (labour productivity) is measured as the ratio of constant GDP in 2000 prices, to total employment where the latter is measured at place of work. This means that productivity and GDP per capita trends may diverge in regions if there is commuting on a substantial scale.

Large metropolitan regions (urban areas with a population of more than 1.5 million) are identified on the basis of TL3 urban regions, with the exception of Canada, Mexico and the United States where national definitions are applied.

OECD Metropolitan Database: http://dotstat/wbos/.

See Annex B for data, source and country-related metadata.

\section{Reference years and territorial level}

1995-2007; TL3.

Australia, Canada, Chile, Mexico and United States only TL2.

Regional GDP is not available for Iceland, Israel and Switzerland.

\section{Figure notes}

7.1: Available years: Turkey 2001 and New Zealand 2003.

7.2: Data refer to the OECD Metropolitan Database. No available data for Switzerland and Turkey. Available years: Japan 1997-2006, United States 2001-07; New Zealand 2000-03; Norway 1997-2007; Poland 1999-2007. GDP values in Canada refer to 2002-07 and are estimated using data on total income for census subdivisions from the Canada Revenue Agency Locality Code Statistics.

7.3-7.4: New Zealand is excluded for lack of regional GDP after 2003. 


\section{PATTERNS OF GROWTH IN REGIONS}

7.1. Distribution of GDP into predominantly urban (PU), intermediate (IN) and predominantly rural (PR) regions (TL3), 2007

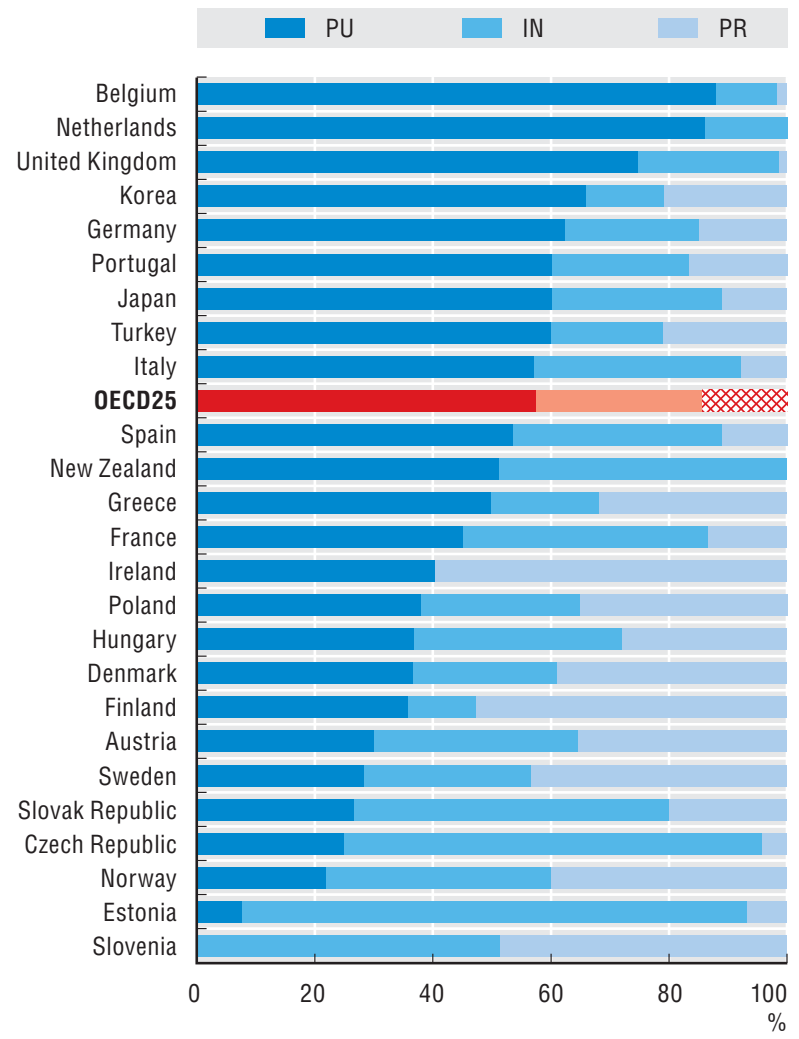

\subsection{Labour productivity growth by regional type,} 1995-2007

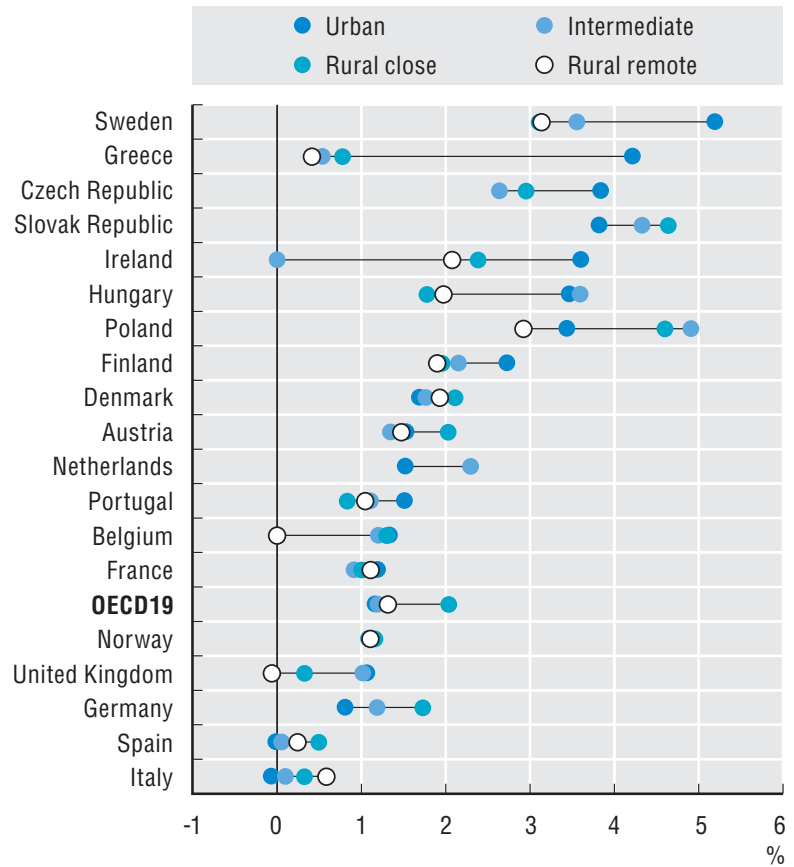

7.2. GDP growth rate in metropolitan regions, 1997-2007

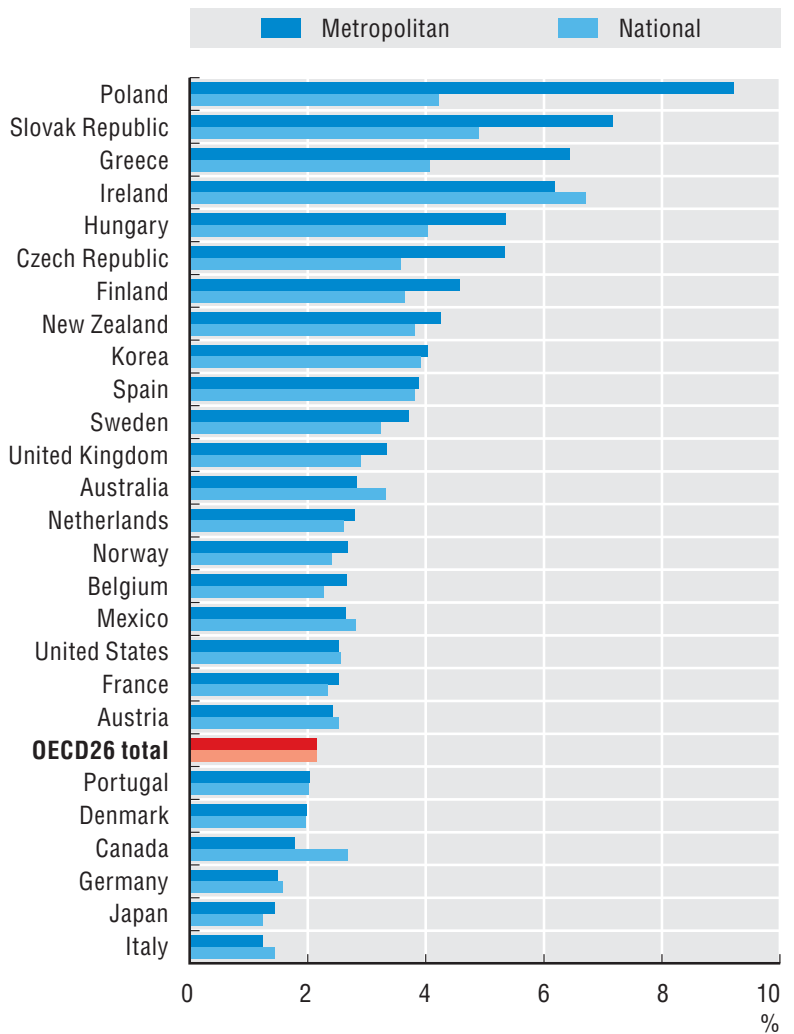

7.4. Characteristics of rural regions in the top $20 \%$ of productivity growth, 1995-2007

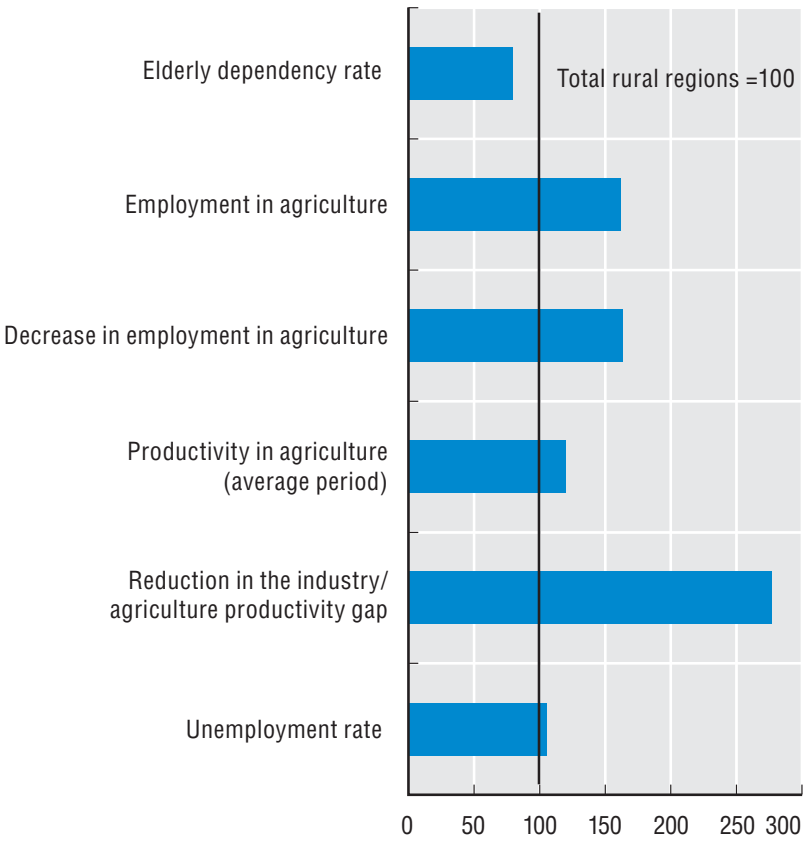

StatLink काISL http://dx.doi.org/10.1787/888932439520 
The economic recession has had a differentiated impact on the loss of jobs within OECD countries. Three-fourths of OECD regions that showed employment growth between 1999 and 2007 shifted to an employment decline between 2008 and 2009. Moreover, disparities in job losses have increased. In 1999-2007 the difference in employment growth in $75 \%$ of the regions was around 1.5 percentage points. This value doubled in 2008-09 (Figure 8.1A).

All typologies of regions experienced on average a decline in employment. There are however important differences among the different types of regions. Predominantly rural regions appear as those with more difficulty in creating jobs in 2008-09, displaying on average an employment change of $-2.4 \%$ (this value is $-1.6 \%$ in intermediate regions and $-1.7 \%$ in urban regions). However, predominantly urban regions display the largest variation in job losses compared to the previous period (8.1 B-D). This suggests that the resilience of urban regions to large economic shocks is extremely diverse within the OECD.

A simple way to quantify the impact of the crisis on the employment situation of different regions is to measure how many jobs it would be necessary to generate in order to return to the employment rate before the crisis. For example, in the United States 7.5 million jobs would be necessary to return to the employment rate of 2007. Around one-seventh of these new jobs would be needed in California alone, the state most hit by the crisis (Figure 8.2). In countries where the effects across regions have been more diverse, half or more of the employment gap could be filled by bringing back only one region to the employment rate before the crisis (this is the case in Chile, Finland, Ireland and Norway). Countries that on average managed to maintain employment rates equal to or higher than the pre-crisis level (such as Austria or Poland) would still benefit greatly from recovery in employment in the hardest hit regions.

It is useful to compare the pre-crisis growth profile of regions that managed to sustain employment growth during the recession ("resilient regions") with the one of regions that shifted from positive to negative total employment ("recession-hit regions"). Recession-hit regions experienced faster growth and faster reduction in unemployment from 1999 to 2007, suggesting the presence of structural fragilities in the growth path of this period. This same group of regions increased the share of employment in financial, real estate and business activities but not the productivity of the sector. Moreover, hard hit regions had larger inflows of young people, who were more exposed to job losses later. Before the crisis, resilient regions experienced larger increases in their qualified human capital, in participation rate, and in the productivity of the public sector and agriculture. An increased share of employment in the public sector also suggests higher protection from job losses in resilient regions (Figure 8.3).

\section{Definition}

Employed persons are all persons who during the reference week worked at least one hour for pay or profit, or were temporarily absent from such work. Family workers are included.

The job gaps in a region are estimated as the increase in employment required in 2009 to restore the ratio of employment and working age population to the 2007 value. The country's employment is computed as sum of regional values.

\section{Source}

OECD Regional Database: http://dotstat/wbos/.

See Annex B for data, source and country-related metadata.

\section{Reference years and territorial level}

1999-2009; TL3.

Australia, Chile, Iceland, Portugal, Switzerland and Turkey only TL2.

Canada non-official grids.

\section{Further information}

OECD (2010), OECD Employment Outlook 2010: Moving beyond the Jobs Crisis, OECD Publishing, DOI: 10.1787/ empl_outlook-2010-en. 
8.1. Yearly employment growth rate 1999-2007 and 2008-09: OECD regions, and by type of regions

A. Growth rate distribution
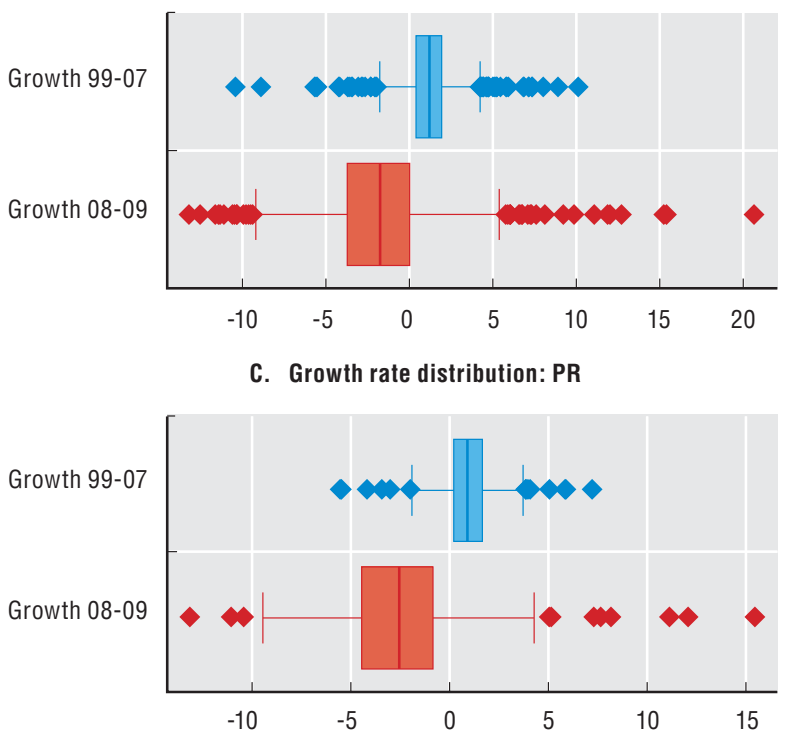

8.2. Estimated number of jobs needed to restore 2007 employment rate: Country average and region with largest loss

Number of estimated jobs in the country

Number of estimated jobs in the region with highest value

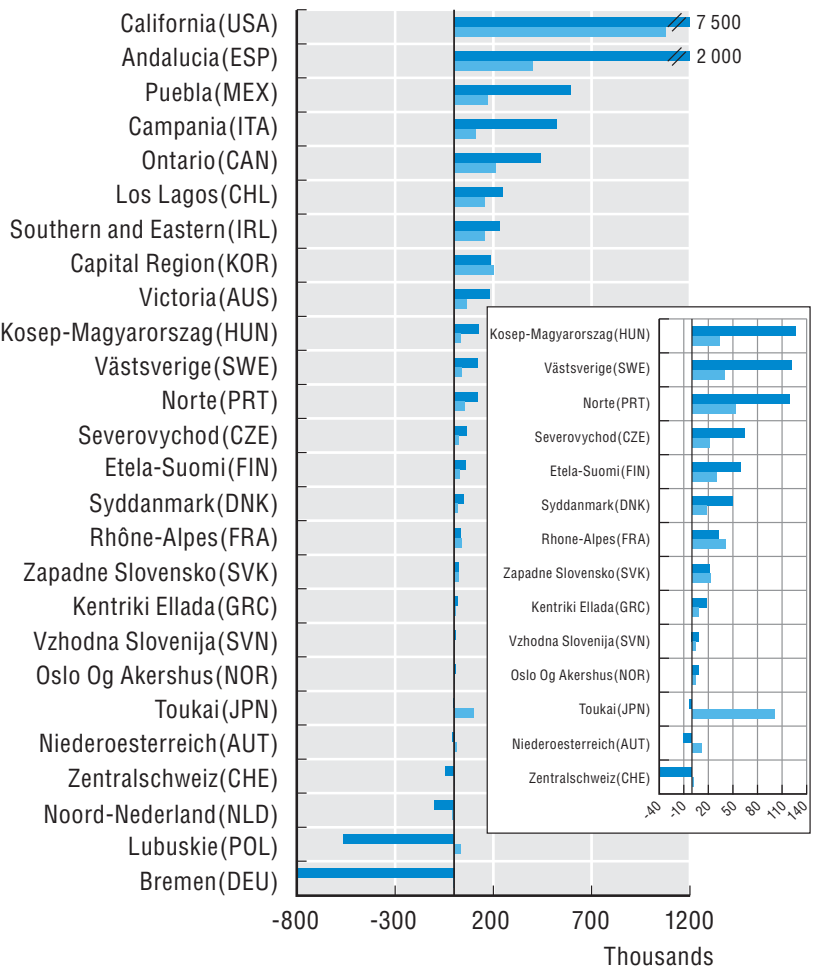

B. Growth rate distribution: PU

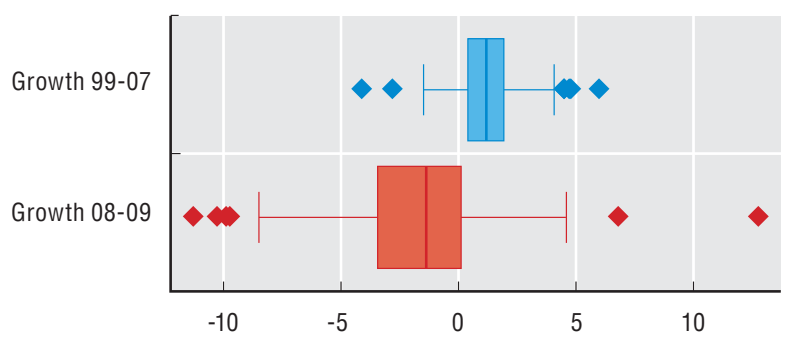

D. Growth rate distribution: IN

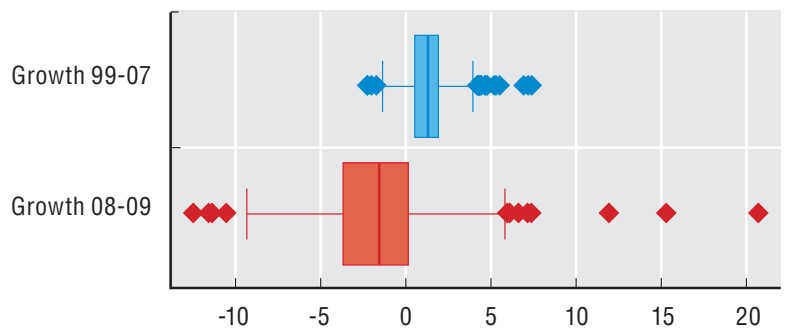

8.3. Annual growth rate of the selected variables 1999-2007, by regional employment change in 2008-09

Regions with negative employment change 2008-2009

Regions with positive employment change 2008-2009

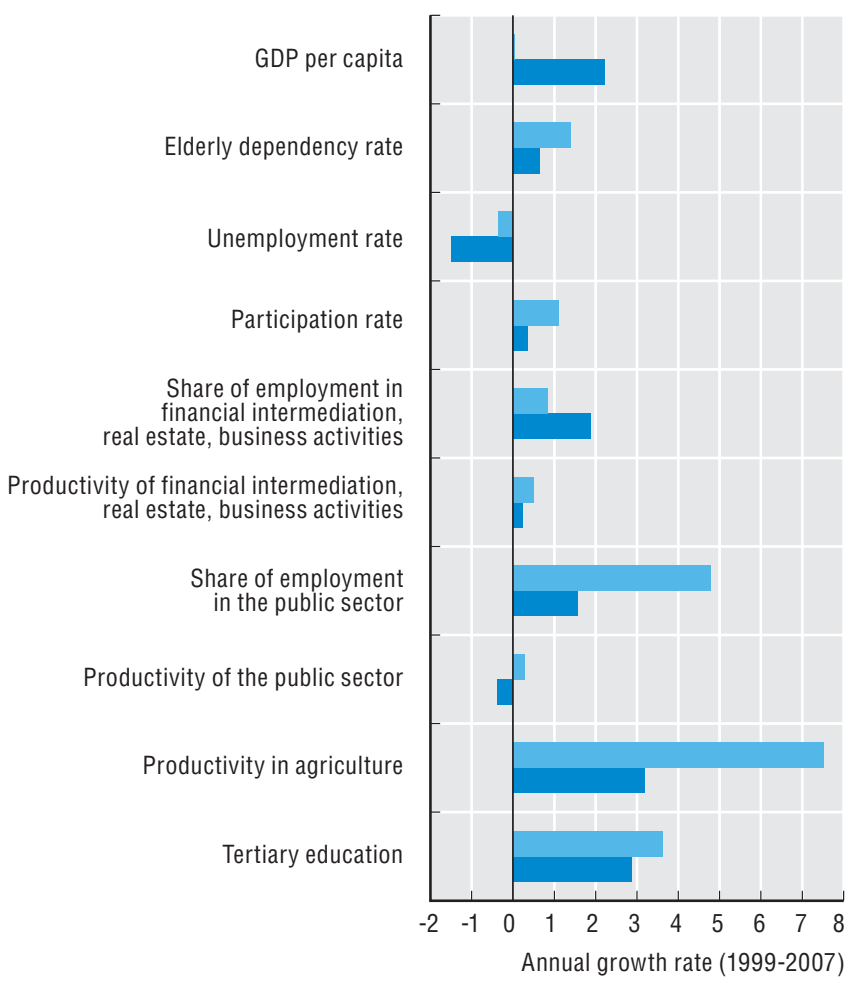

StatLink बiाsL http://dx.doi.org/10.1787/888932439539 
The quality of human capital is central to increasing productivity, as the ability to generate and make use of innovation depends, among other factors, on the skill level of the labour force. The proportion of the labour force with tertiary education is a common indicator for a region's capacity to produce and absorb innovation.

OECD countries show large differences in the tertiary educational attainment of their labour force. These differences hide even larger disparities among regions within the same country. The United States, France, Spain and the Czech Republic show the largest regional variation in tertiary educational attainment (Figure 9.1).

Concentration of a skilled labour force is also a major issue in countries with less regional dispersion; regional differences are often due to one populated region with a high share of skilled labour force and almost all the other regions below the country average (Figure 9.1).

The capital region is generally the region with the highest share of people with tertiary education (Figure 9.2). Ontario is the OECD region with the highest percentage of skilled labour force (56\%), followed by the Capital Territory in Australia, Pais Vasco in Spain and Oslo in Norway.

Predominantly urban regions have the highest percentage of labour force with tertiary educational attainment: in most countries higher educational attainment is positively correlated with the percentage of urban population and negatively correlated with the percentage of rural population (Figure 9.3).

Predominantly urban regions are also those with higher rates of students in tertiary education, which is a proxy of the geographical distribution of higher education institutions and a measure of a region's future stock of human capital. However, highly skilled human capital is increasingly mobile and the existence of differentials in the return to education between rural and urban areas can be a major incentive for individuals with advanced educational levels to migrate (see also Chapter 10). Such patterns call for policies that support training and human capital formation to respond to regional specificities.

As expected, there is a significant correlation between enrolments in tertiary education and employment in knowledge-intensive services (KIS) (Figure 9.4).

\section{Definition}

The labour force with advanced educational qualifications is defined as the labour force aged 15 and over that has completed tertiary educational programmes. Tertiary education includes both university qualifications and advanced professional programmes (ISCED 5 and 6).

The Spearman correlation coefficient measures the strength and direction of the relationship between two variables, in this case the labour force with advanced educational qualifications and the share of population in predominantly urban (PU), intermediate (IN) or predominantly rural (PR) regions. A value close to zero means no relationship (see Annex C for the formula).

\section{Source}

OECD Regional Database: http://stats.oecd.org/WBOS.

See Annex B for data, source and country-related metadata.

\section{Reference years and territorial level}

1999-2008; TL2.

Data for Iceland and Japan are not available at the regional level.

Data for Chile refer to tertiary educational attainment of population aged 15 and over.

\section{Further information}

OECD (2011), Regions and Innovation Policy, OECD Publishing. OECD (2010), The High Cost of Low Educational Performance: The Long-run Economic Impact of Improving PISA Outcomes, PISA, OECD Publishing, DOI: 10.1787/9789264077485-en.

OECD (2010), Education at a Glance 2010: OECD Indicators, OECD Publishing, DOI: 10.1787/eag-2010-en.

\section{Figure notes}

9.1-9.4: Available years: Australia 2005, Canada, Korea and New Zealand 2006, Chile and Switzerland 2007.

9.4: Spearman correlation with TL2 regional values. Only coefficient significant at 0.01 or 0.05 levels are shown. 
9.1. Range of labour force with tertiary educational attainment in TL2 regions, 2008

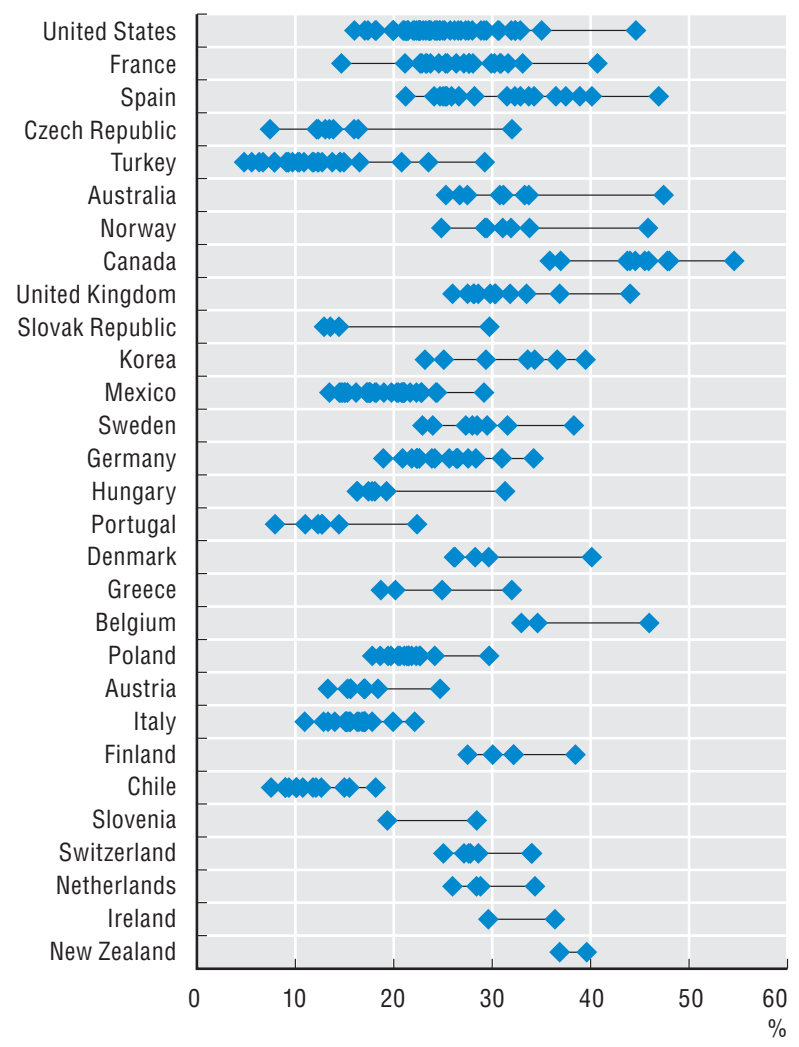

9.3. Correlation coefficient between the percentage of labour force with tertiary education and the population share by regional type, 2008 (TL2)

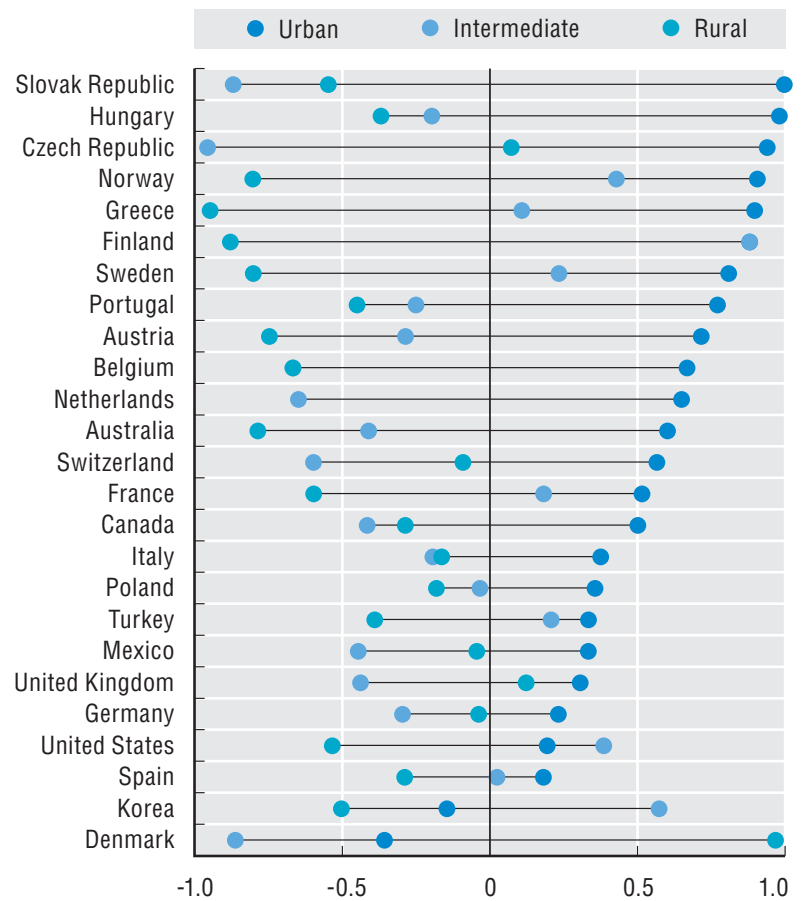

9.2. Top region within each country with the highest percentage of labour force with tertiary educational attainment compared to their country average, 2008 (TL2)

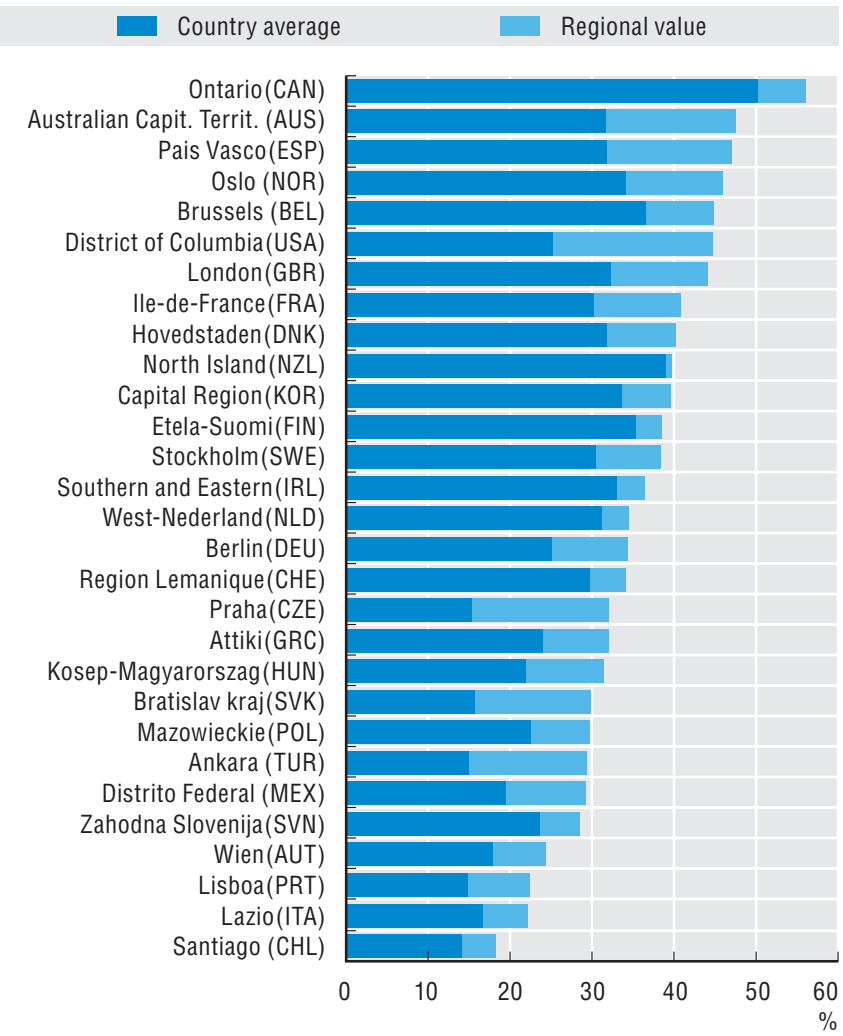

9.4. Correlation between $\%$ of students enrolled in tertiary education and \% of employed in KIS, TL2, total 2005-07

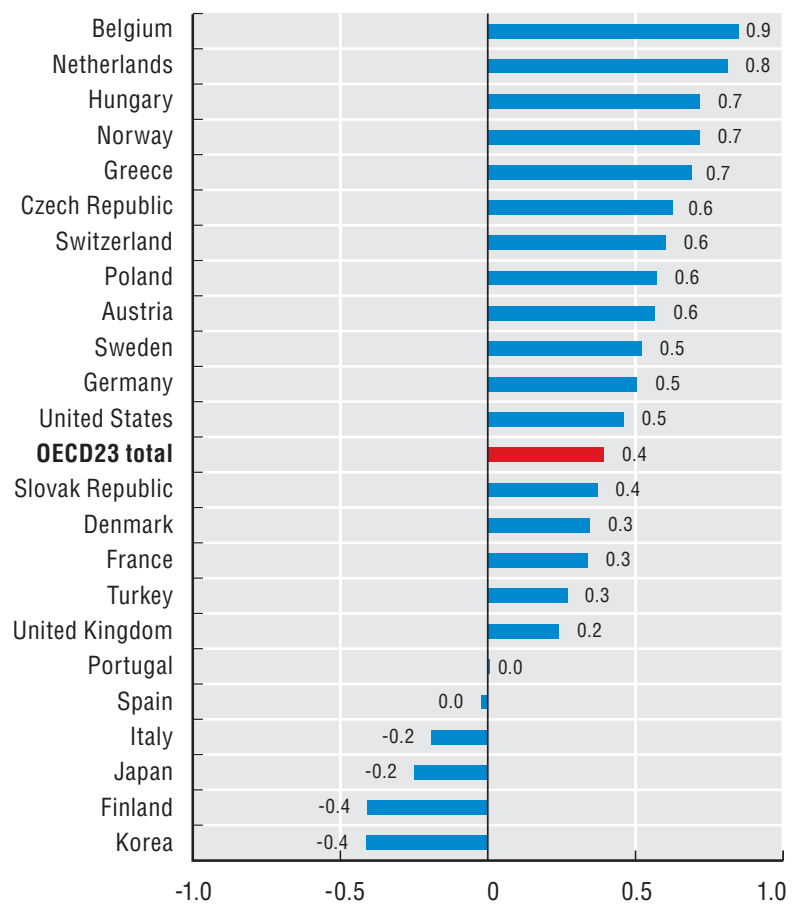

StatLink Aाsस http://dx.doi.org/10.1787/888932439558 
International migration is an important factor that contributes to demographic and human capital changes in many OECD regions. Information on the skill composition of migrants is important to understand its effects on local labour markets. Moreover, there is evidence that highly skilled migrants bring higher productivity, entrepreneurial assets and trading opportunities to host regions. The past decade has seen a substantial increase in the employment of immigrants with tertiary educational attainment, partly as a result of changes in migration policies to favour admission of highly qualified workers. Regional differences in the distribution of highly skilled foreign-born individuals across regions are particularly marked in Mexico, the United States, Spain, Canada and Germany (Figure 10.1). In Canada, the population of foreign-born individuals is on average highly educated. The result for Canada is partly explained by the large weight given to formal education in their immigration policies. Despite the large increases in recent inflows of low-skilled migrants from South America, Spanish regions have on average a similar proportion of highly skilled people compared to other Southern European countries such Italy and Portugal.

In absolute numbers, highly skilled foreign-born individuals contribute heavily to the human capital endowments of regions in the United States, Canada and Australia. Paris and London are other poles for skilled immigrants. Weighting these numbers by the size of the host region, the picture of represented regions is similar, even if their rank changes significantly. Ontario, London and British Columbia are the regions that benefit most from skilled migration, the tertiary educated, foreign-born population being over $15 \%$ of the surveyed labour force (Figure10.2).

Do foreign-born individuals increase the average education levels in host countries? The data show that this is the case in several OECD countries. In Ireland, Portugal, the Slovak Republic and the United Kingdom, the higher education level of the foreign-born individual with respect to the native-born is particularly evident. Higher rates of tertiary educated among natives are observed in Nordic countries that have traditionally hosted larger numbers of refugees. Of course, these estimates need to be interpreted with caution as non-registered migrants may be under-sampled in censuses and labour force surveys, and these migrants tend on average to have lower education rates (Figure 10.3).

An important issue is whether regions that host highly educated migrants have competitive advantages in the competition for global talents. It is interesting to note that the correlation between skilled recent immigrants (having lived in the region for less than five years) and skilled established migrants (with more than four years of residence in the region) is much higher than the one between skilled recent and unskilled established immigrants
(Figure 10.4 for African migrants, similar findings hold for other origin groups). This might be explained by network effects that are specific to the highly skilled (e.g. skilled immigrants passing information on job openings or creating jobs for other skilled migrants). This suggests that it will be more difficult to boost skill endowments through immigration for those regions that are not traditional destinations for skilled immigration. A tighter co-ordination of migration policies and regional development policies might be needed to "take advantage" of migration as a lever for skill upgrading.

\section{Definition}

Skilled migrants are defined as the number of foreignborn labour force with completed ISCED 5-6 education levels, residing in the region in 2005.

Recent migrants are defined as persons who arrived in the country within the previous five years. Established migrants are those having resided in the country for five years or more.

\section{Source}

OECD Database on Immigrants (DIOC) and OECD Regional Database: $h$ ttp://stats.oecd.org/WBOS.

See Annex B for data, source and country-related metadata.

\section{Reference years and territorial level}

2005-06; TL2 and TL3. Data on immigrants by region are not available in Chile, Czech Republic, Iceland, Israel, Japan, Korea, Poland, Slovenia and Turkey.

\section{Further information}

OECD (2010), International Migration Outlook 2010, OECD Publishing. DOI: 10.1787/migr_outlook-2009-en.

OECD (2010), "Determinants of localisation of recent immigrants across OECD regions", www.oecd.org/dataoecd/61/ 49/45344744.pdf.

\section{Figure notes}

10.3: Country values are computed by aggregating TL2 regional values. 


\subsection{TL2 regional range in skilled migrants as \% of total immigrants, 2005}

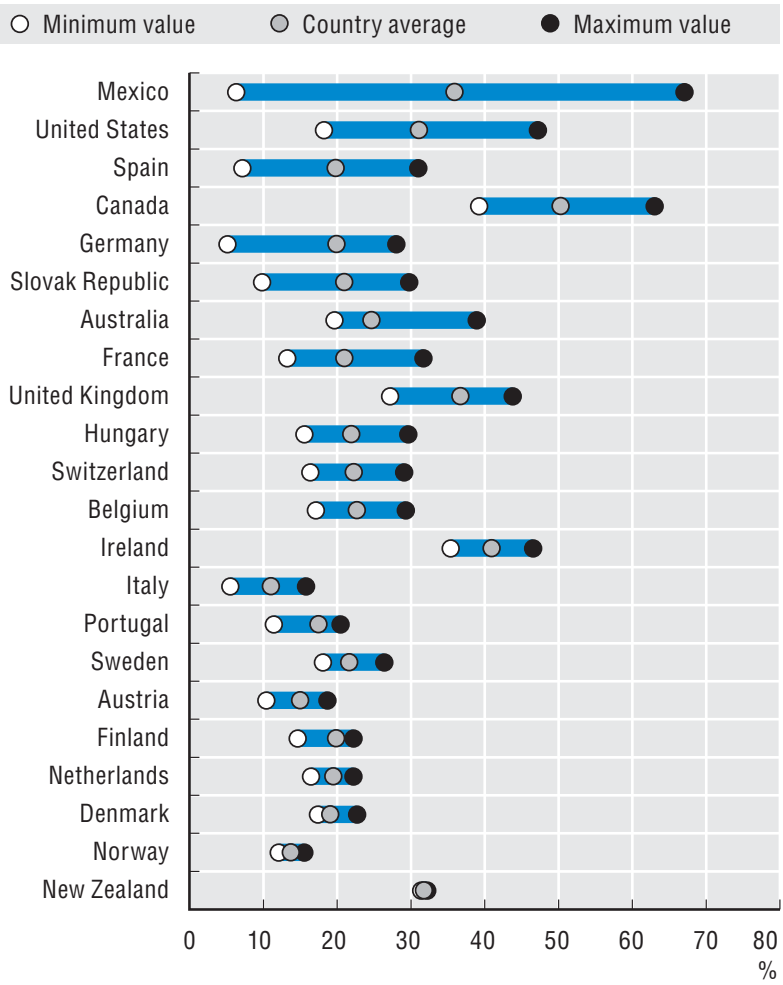

10.3. Share of labour force with tertiary education attainment, by place of birth, 2005

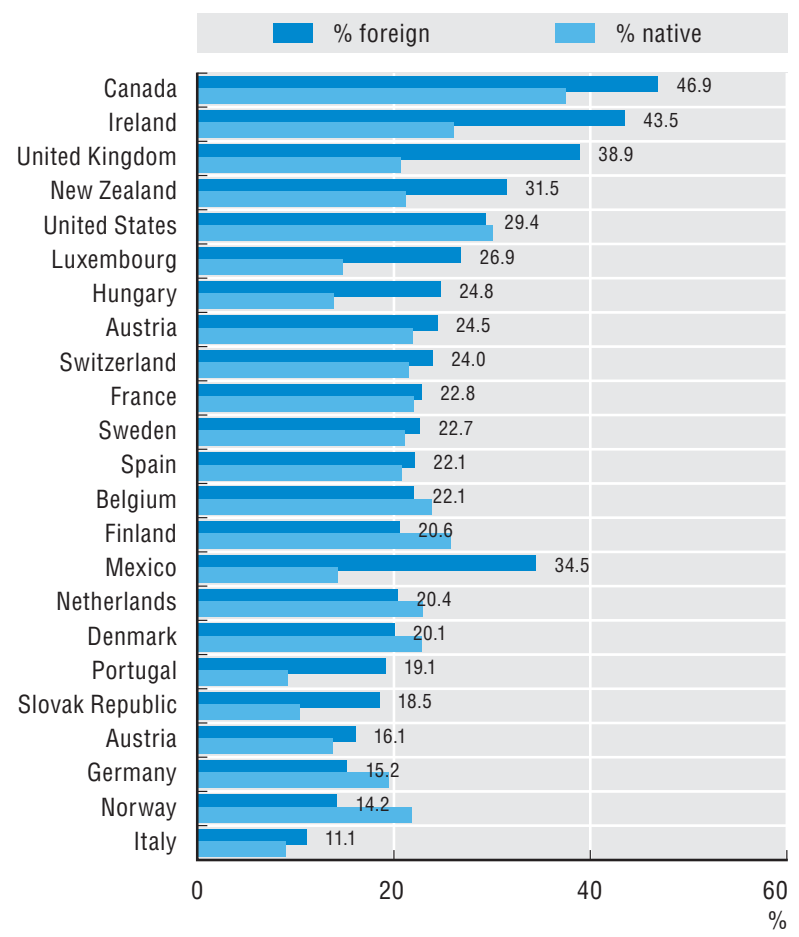

10.2. Top 20 TL2 regions of skilled immigrants, 2005

\begin{tabular}{lr|lc}
\hline $\begin{array}{l}\text { Rank by number of highly } \\
\text { skilled immigrants }\end{array}$ & $\begin{array}{c}\text { Skilled } \\
\text { immigrants }\end{array}$ & $\begin{array}{l}\text { Rank by highly skilled } \\
\text { immigrants as \% } \\
\text { of labour force }\end{array}$ & $\begin{array}{c}\text { Skilled } \\
\text { immigrants } \\
\text { as \% of labour } \\
\text { force }\end{array}$ \\
\hline California & 2628162 & Ontario & 15.50 \\
Ontario & 1499035 & British Columbia & 15.30 \\
New York & 1341895 & London & 15.30 \\
Florida & 1060243 & Australian Capital Territory & 11.90 \\
London & 932560 & Bruxelles/Brussels & 10.10 \\
Texas & 752027 & Luxembourg & 10.00 \\
New Jersey & 632125 & New South Wales & 9.40 \\
Illinois & 510517 & California & 9.30 \\
British Columbia & 509985 & New Jersey & 9.10 \\
Ile De France & 494161 & Western Australia & 9.10 \\
New South Wales & 483865 & Alberta & 9.00 \\
Quebec & 371120 & Region Lemanique & 8.90 \\
Virginia & 332904 & North Island & 8.70 \\
Victoria & 329221 & New York & 8.60 \\
Massachusetts & 327303 & Victoria & 8.40 \\
Nordrhein-Westfalen & 307732 & Florida & 7.20 \\
South East & 300485 & District Of Columbia & 7.10 \\
Maryland & 298746 & Hawaii & 6.80 \\
Bayern & 263096 & Maryland & 6.70 \\
Georgia & 258200 & Yukon Territory & 6.30 \\
\hline & & &
\end{tabular}

10.4. The specificity of network effects to education groups, immigrants of African origin, TL2, 2005

Network effects: skilled recent and skilled established African immigrants

Skilled recent migrants

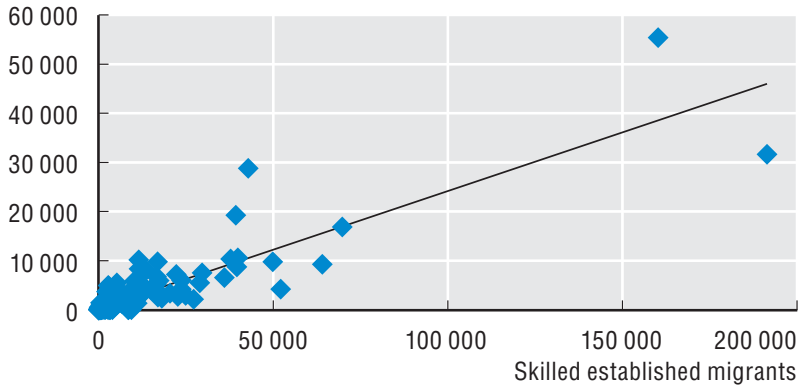

Network effects: skilled recent and unskilled established African immigrants

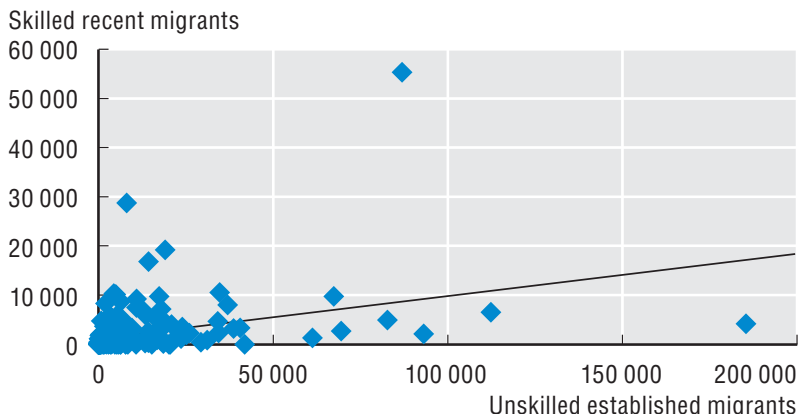

StatLink जiाsय $h t t p: / / d x . d o i . o r g / 10.1787 / 888932439577$ 
While deeply rooted in local history, geography, institutions and social capital, the production structure of regions keeps evolving over time as a result of both macroeconomic changes and economic policies at the national or subnational level.

The primary sector (agriculture, fishing and forestry), is still an important employer in many regions. The countries with the largest employment shares in the agricultural, forestry and fishery sector are Turkey, Greece, Korea and Portugal among OECD countries, the Russian Federation and South Africa among emerging economies. All these countries display a large interregional variation in agricultural employment, with few regions still highly specialised in primary activities. One such highly specialised region is Agri in Turkey, where $70 \%$ of the labour force is employed in the primary sector (Figure 11.1). Most countries have large differences in the shares of employment in mining, manufacturing and utilities (electricity, gas and water). Four countries in Eastern Europe - the Czech Republic, the Slovak Republic, Hungary and Slovenia - had markedly higher shares of employment in this sector in 2008. The region of Bursa in Turkey has a specialisation in this sector only matched by Severovychod, in the Czech Republic (Figure 11.1). Both agriculture and manufacturing have lost relative importance with respect to the service sector in the last decade. Focusing on a limited number of occupations in the very diverse service sector (financial intermediation, real estate, renting and business activities), most countries have regional "outliers", where the share of service jobs is much above the national average. The regions of Zurich (Switzerland), London (United Kingdom) and Northern Cape (South Africa) are such "service centers" hosting important shares of employment in these rapidly evolving sectors (Figure 11.1).

Both as a result of redistribution of employment shares and of actual capacity increases, productivity dynamics have been markedly different across agriculture, manufacturing and service sectors. Differences in productivity changes have also been marked within countries, contributing largely to regional convergence or divergence. In the agricultural sector, the productivity growth between 1995 and 2007 in leading regions (those with gross domestic product [GDP] per capita above the national average in 1995) has been significantly higher than in lagged behind regions (GDP per capita below average in 1995) in the Czech Republic and Poland. Lagged behind regions performed significantly better in the agricultural sector, in Belgium and Norway in particular. In the manufacturing sector, there are more countries where regions lagging behind in 1995 had relatively lower productivity gains. This is the case in particular in Belgium, Spain and Greece, where the productivity growth of lagged regions was less than half than the one leading. This lower dynamism of regions starting at lower levels of GDP per capita is even more evident in the service sector, where very few countries (Germany, the Netherlands and Italy), saw a relative increase in the productivity of lagged behind regions (Figure 11.2).

\section{Definition}

Industries are defined according to the International Standard Industrial Classification (ISIC) Rev. 3.1. Industry size is defined by the total number of employed in that industry. Regional data on gross value added (GVA) and employment are available aggregated in six sectors (see Annex B).

Productivity by sector is defined as the GVA in the sector divided by the number of employees in the sector in the region. It is expressed in average yearly growth rates over available years.

\section{Source}

OECD Regional Database: http://dotstat/wbos/.

See Annex B for data, source and country-related metadata.

\section{Reference years and territorial level}

1995-2008; TL2.

Canada and Mexico regional GVA by industry not available.

\section{Figure notes}

11.1: Chile and Mexico are not included (latest available year respectively 2005 and 2004).

11.2: Leading (lagged behind) regions are defined as those with GDP per capita in 1995 above (below) national average GDP per capita. Data for Japan not used due to changes in industrial classifications over the period. Available years: Korea 2004-07, Netherlands and United Kingdom 1999-2007, Norway 1997-2007, Poland 1998-2007, United States 2000-07, Germany, Slovenia 1996-2007, Chile 1996-2005. 


\section{REGIONAL SPECIALISATION AND PRODUCTIVITY GROWTH ACROSS SECTORS}

\subsection{TL2 regional range of employment share (as a \% of regional total employment)}

in selected industries, 2008

O Minimum value

Agriculture, forestry, fishing and hunting

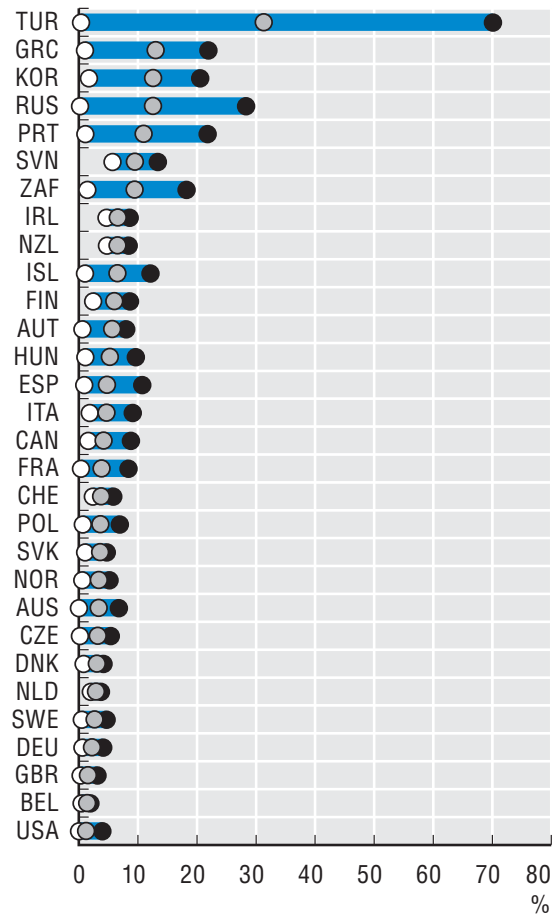

O Country average

Mining, manufacturing and utilities

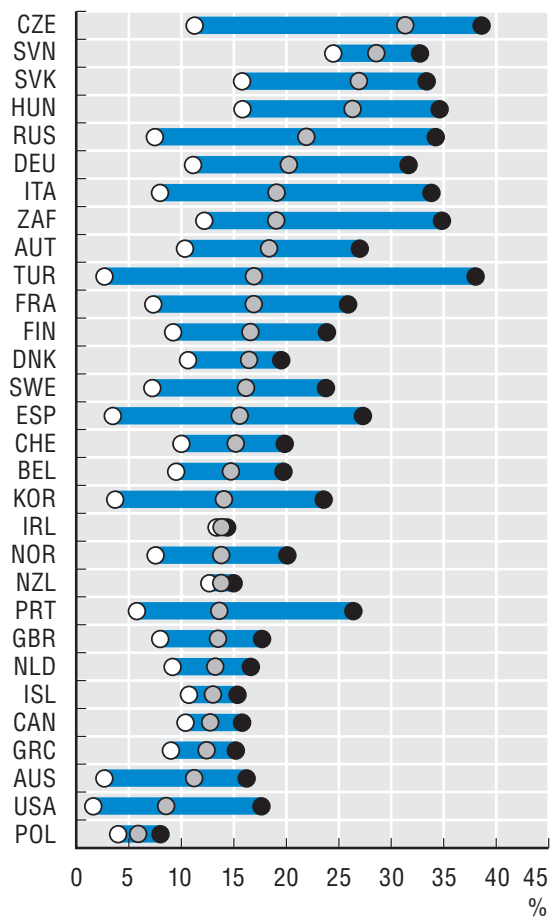

- Maximum value

Financial intermediation, real estate renting and business

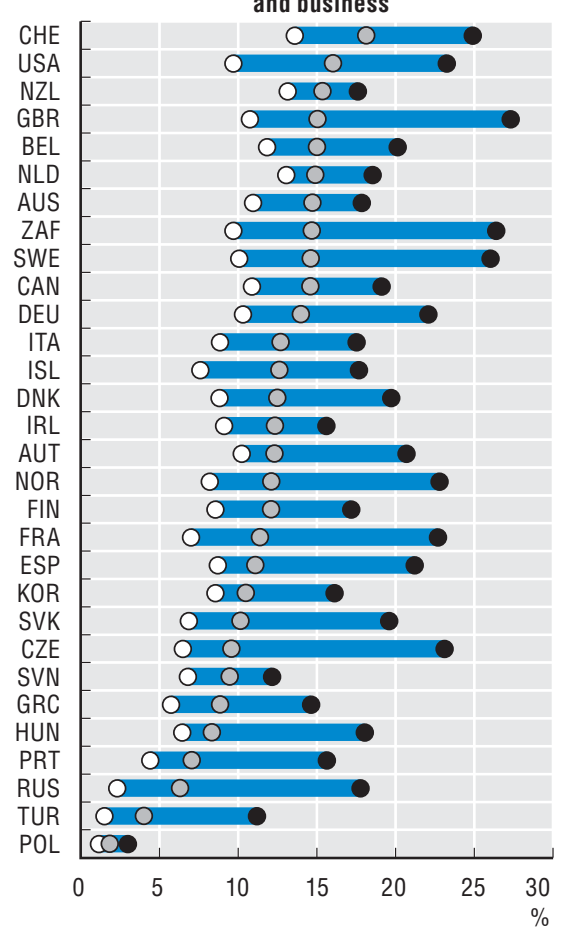

11.2. Annual rate of productivity growth in selected industries in 1995-2007, by regional economic performance in 1995, TL2

Lagged behind regions

Agriculture, forestry, fishing and hunting

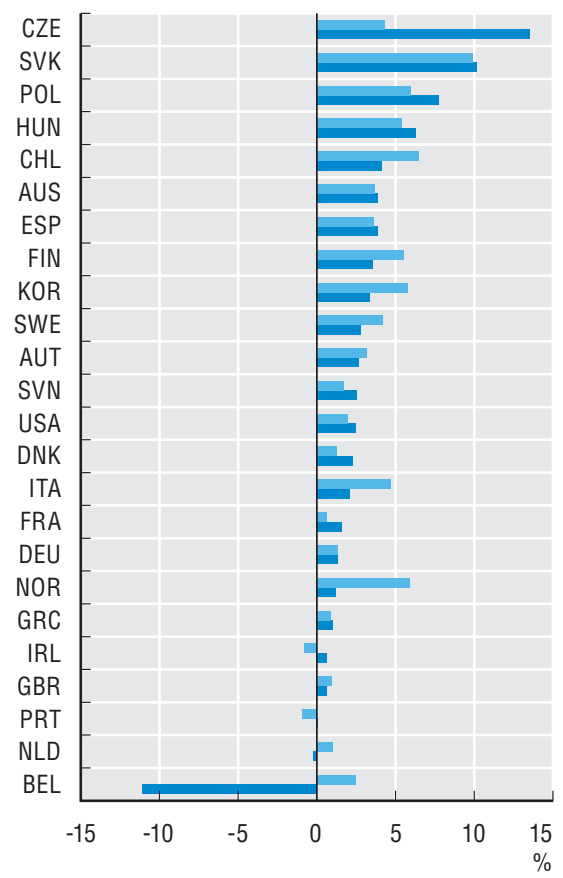

Mining, manufacturing and utilities

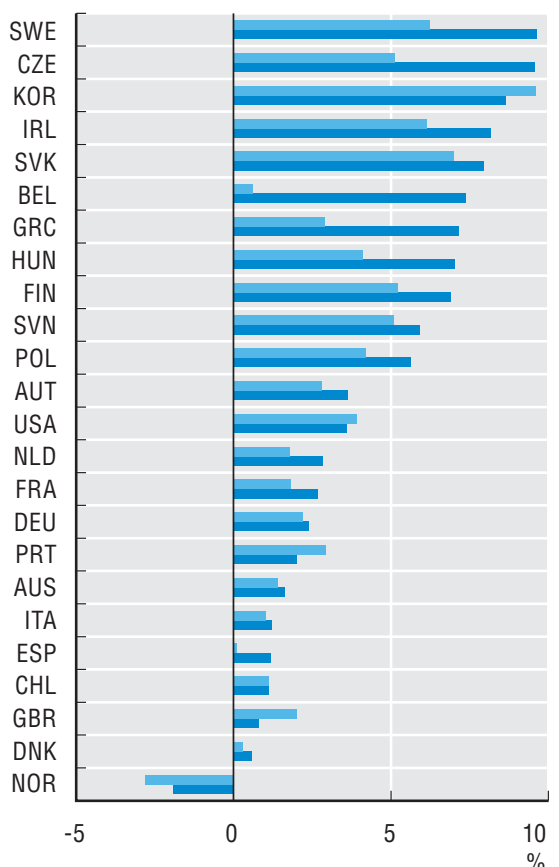

Financial intermediation, real estate renting and business

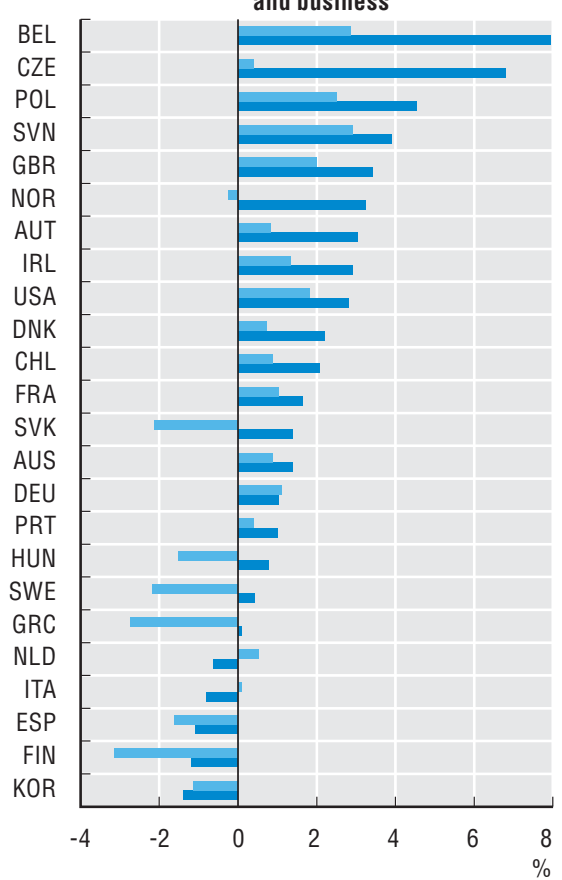


Knowledge-oriented sectors receive a great deal of attention due to their association with innovative products, new production processes and their impact on productivity growth and international competitiveness.

Individuals employed in knowledge-oriented sectors are often in research and development (R\&D) positions, increasing scientific knowledge and using it to develop products and production processes; others apply technology in other activities, including the design of equipment, computer applications; marketing; quality management. All these activities are classified into two groups: high-tech manufacturing (HTM) and knowledge-intensive services (KIS).

High-tech manufacturing and knowledge-intensive services have a tendency to be concentrated in certain regions since investments, infrastructure, and physical and human capital, tend to be geographically clustered. In several countries one region appears to be leading in the share of knowledge-oriented employment. Baden Wuerttemberg in Germany is the region with the highest rate of employment in HTM, almost ten points higher than the country average (Figure 12.1).

The regions with the highest share of employment in KIS are almost all capital regions where the bulk of public administrations and services tend to be concentrated. Stockholm has the highest rate of KIS followed by London. Particularly low is the KIS employment in the Korean Capital region and in Ankara, around 24\% (Figure 12.2).

Regional catching-up processes are taking place in hightech manufacturing employment and new regional hubs have been emerging in the past ten years. With the exception of Zuid Netherland in the Netherlands, Lansi Suomi in Finland and Vzhodna Slovenija in Slovenia, regions increasing their specialisation in HTM faster over time are not showing the highest percentage of HTM in levels in 2008 (Figure 12.3).

About half of the fast-specialising regions are still more specialised in total manufacturing than in high-tech manufacturing (Figure 12.3). Comparative analysis could help identify which policies can accelerate this transition from traditional manufacturing into more technology-intensive manufacturing.

\section{Definition}

Employment in knowledge-oriented sectors is defined as employment in high-technology manufacturing sectors and knowledge-intensive services.

Employment in high-technology manufacturing sectors corresponds to the following ISIC Divisions/Groups/ Classes: 2423 Manufacture of pharmaceuticals, medicinal chemicals and botanical products, 30 Manufacture of office machinery and computers, 32 Manufacture of radio, television and communication equipment and apparatus, 33 Manufacture of medical, precision and optical instruments, watches and clocks, 353 Manufacture of aircraft and spacecraft. It is to be noted that these classes included both hightech and medium high-tech manufacturing activities.

Employment in knowledge-intensive services includes employment in the following ISIC divisions: 61 Water transport, 62 Air transport, 64 Post and telecommunications, 65 Financial intermediation, except insurance and pension funding, 66 Insurance and pension funding, except compulsory social security, 67 Activities auxiliary to financial intermediation, 70 Real estate activities, 71 Renting of machinery and equipment without operator and of personal and household goods, 72 Computer and related activities, 73 Research and development, 74 Other business activities, 80 Education, 85 Health and social work and 92 Recreational, cultural and sporting activities.

A region's degree of specialisation in an industry is measured according to the Balassa-Hoover index which is computed as the ratio between the weight of an industry in a region and the weight of the same industry in the country. Values of the index above 1 reflect a specialisation higher than the national average.

\section{Source}

OECD Regional Database: http://dotstat/wbos/.

See Annex B for data, source and country-related metadata.

\section{Reference years and territorial level}

1995-2008; TL2.

No regional data available in Australia, Iceland, Mexico and New Zealand.

\section{Figure notes}

12.1-12.2: Latest available year: Japan 2006, Poland, Sweden and Slovak Republic 2007.

12.2: No regional data available on KIS employment in Korea. 


\section{REGIONAL SPECIALISATION IN KNOWLEDGE-ORIENTED SECTORS}

12.1. Regions with the highest share of high-tech manufacturing employment, 2008

Country average

Regional high-tech manufacturing employment (\% of total employment)

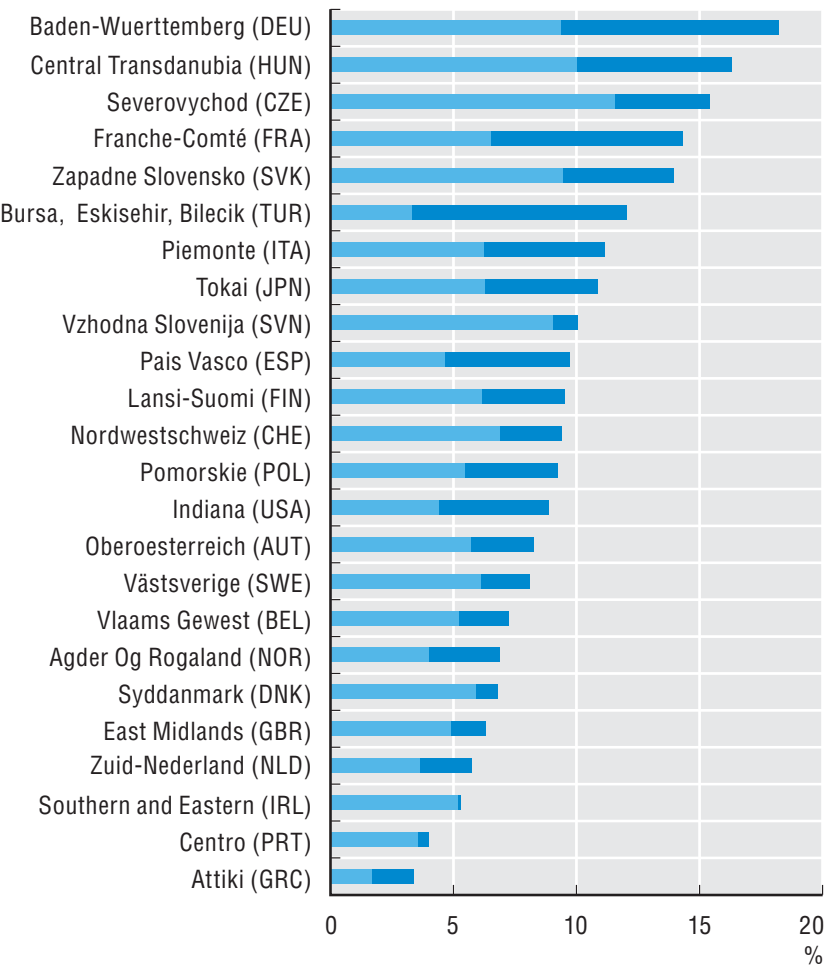

\subsection{Regions with the highest share of knowledge- intensive services employment, 2008}

Country average

Regional knowledge intensive services employment (\% of total employment)

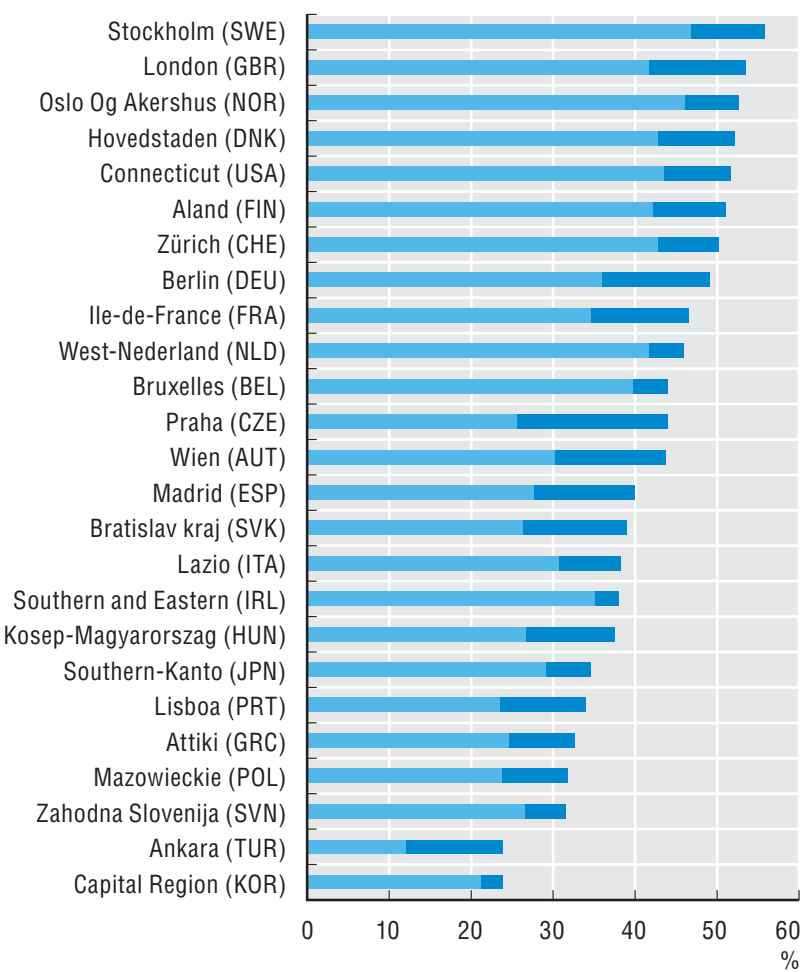

12.3. Specialisation index in 2008 of the region with the largest increase in specialisation in HTM from 1995 to 2008

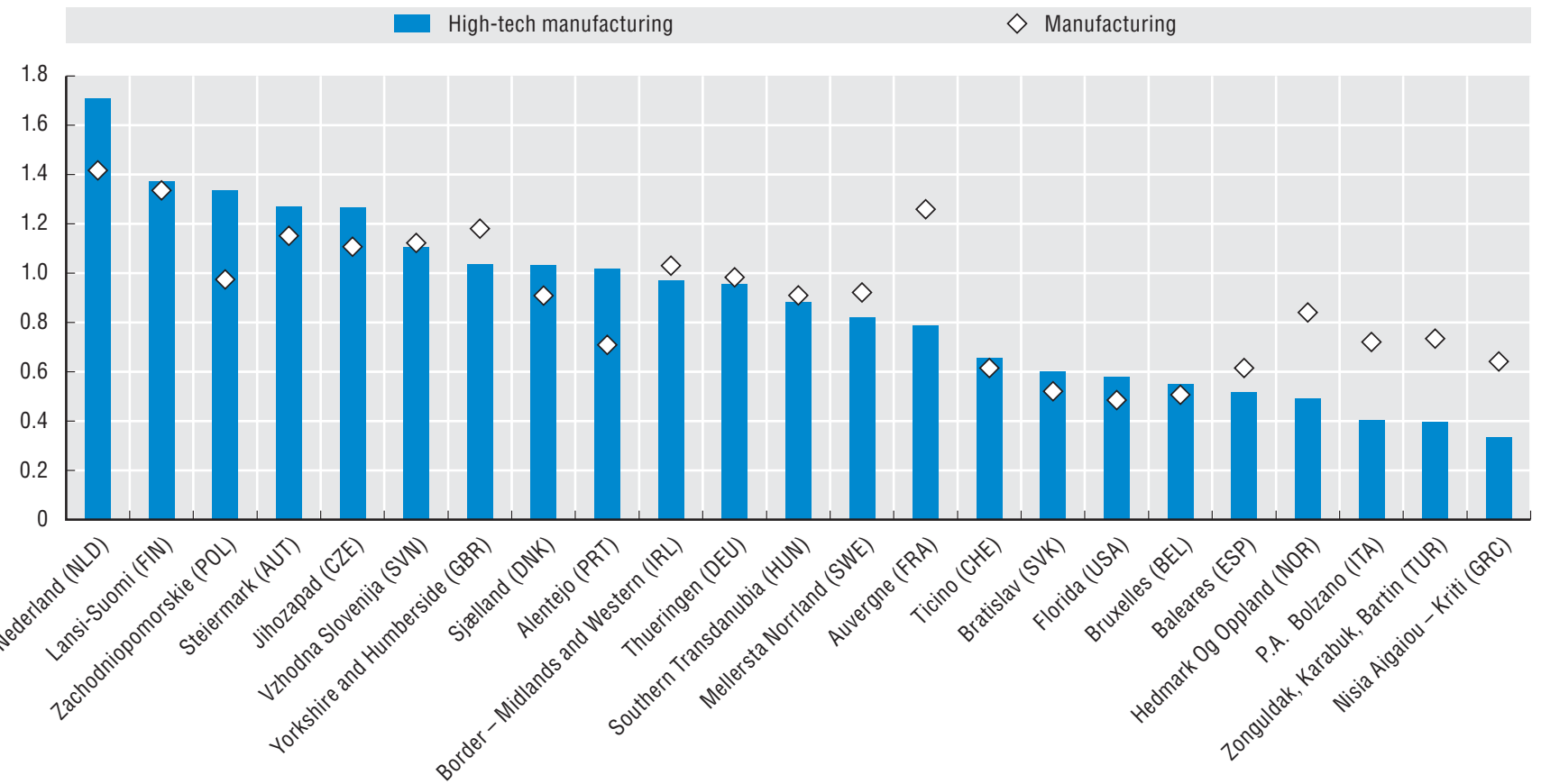

StatLink Aाs $h t$ ttp://dx.doi.org/10.1787/888932439615 
Sub-national governments have an important role in public investment: on average, around half of the total public investment in OECD countries is carried out by sub-national governements. This share is as high as two-thirds in some federal and regionalised countries such as Canada, Australia, Austria, Switzerland, Belgium and Germany (Figure 13.1).

The value of public investment in the economy of OECD countries has not varied greatly in the past 20 years, settling at around $12 \%$ of gross domestic product (GDP). However, the volatility of public investment (here measured as the yearly change in the ratio of gross fixed capital formation to GDP) has been higher for sub-national governments than for the general government, at least until the the end of the 1990s when the process of devolution was intensified in most OECD countries. The relative stability of the value of public investment for sub-national governments suggests that the shift of responsibilites from central to sub-national governments in most recent years has not been accompanied by increased resources (Figure 13.2).

In 2009 sub-national governments' public investment equalled $2.3 \%$ of OECD GDP. Spain, Korea, Canada and Poland have the highest shares of sub-national capital spending on GDP, while Greece and Israel have the lowest (Figure 13.3).

Countries look for effectiveness in public spending by customising expenditure according to regional challenges and potential. However, regional breakdowns of national capital expenditure are limited in OECD countries and are difficult to compare. Preliminary results show that differences in public investment within countries are large, both when considering the total public investment in a certain region (such as in Italy or Canada) and when considering public investment carried out only by sub-national governments (such as in Spain) (Figure 13.4).

The amount of public investment per person varies greatly among regions in the same country. The regions with the highest values of public investment are those with a high degree of administrative autonomy, such as in Australia and Italy (Australian Capital Territory and Valle d'Aosta and Bolzano in Italy), or those with specific geographic features, such as in Canada, Sweden and the United States, or those lagging behind, such as in Germany (Figures 13.5-13.7).

\section{Source}

OECD General Governments Accounts and OECD Regional Database: $h t t p: / / d o t s t a t / w b o s /$.

See Annex B for data, source and country-related metadata.

\section{Reference years and territorial level}

1980-2009 national economic accounts.

2001-08; TL2 regional accounts.

Data on public investment in TL2 regions are available for Australia, Canada, Czech Republic, Finland, Germany, Italy, Japan, Mexico, Norway, Spain, Sweden, Switzerland, United Kingdom and United States.

\section{Definition}

Expenditure data on general government at country level are derived from the OECD National Accounts, harmonised according to the System of National Accounts (SNA93).

The general government sector of the SNA93 is comprised of central government, state (when applicable) and local government, and social security. The subnational level of government is here defined as the sum of the two sub-sectors state and local government.

Public investment is here defined as the sum of gross fixed capital formation (GFCF) and capital transfers payable to business or households. GFCF is measured by the total value of a producer's acquisitions, less disposals, of fixed assets during the accounting period plus certain additions to the value of non- produced assets (such as subsoil assets or major improvements in the quantity, quality or productivity of land) realised by the productive activity of institutional units. Capital transfers consist of those involving transfers of ownership of fixed assets; transfers of funds linked to, or conditional upon, acquisition of disposal of fixed assets; or cancellation, without any counterparts being received in return, of liabilities by creditors.

The regional breakdowns of countries' public expenditure are not harmonised. Therefore, cross-country comparability is limited.

The total public investment in TL2 regions carried out by all levels of government is available for Australia, Canada, Finland, Hungary, Italy, Japan, Mexico, Sweden and the United Kingdom.

In the Czech Republic, Germany, Norway, Spain, Switzerland and the United States data refer to the public investment carried out by sub-national governments. A regional breakdown of the central government's public investment is missing. See Annex B for details.

\section{Further information}

OECD (2009), "Regional prioritisation of investment strategies for economic recovery: What information is necessary?".

OECD (2011), "Making the most of public investment in a tight fiscal environment: multi-level governance lessons from the crisis".

\section{Figure notes}

13.1. and 13.3: Australia only GFCF; Chile data not available. Information on data for Israel: http://dx.doi.org/10.1787/888932315602. 


\section{PUBLIC INVESTMENT IN REGIONS}

13.1. Sub-national governments' public investment as a share of general government, 2009

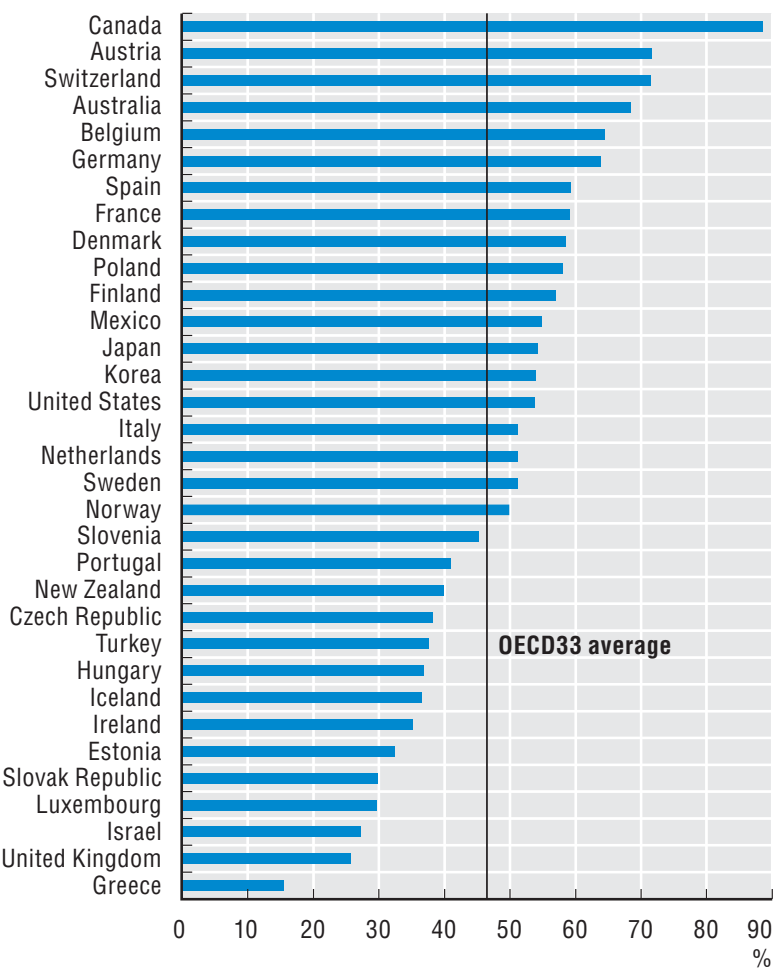

13.3. Sub-national governments' public investment (\% of GDP), 2009

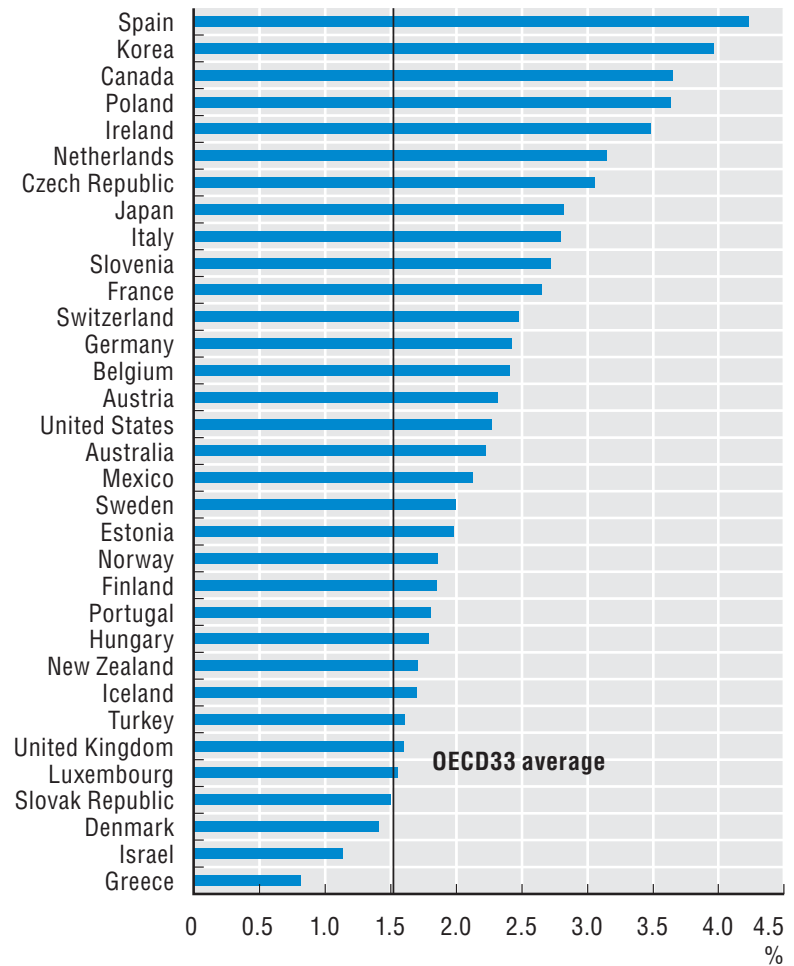

13.2. Yearly change in gross fixed capital formation as a $\%$ of GDP, OECD average

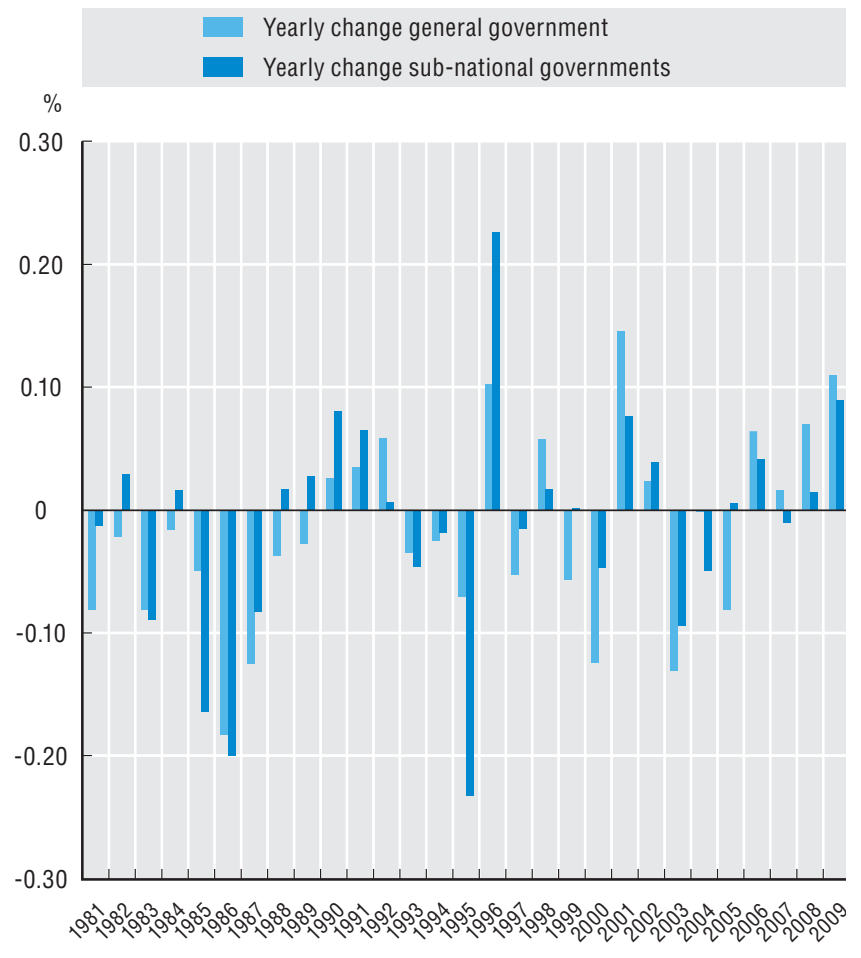

13.4. Public investment in regions (\% of GDP), TL2 regions (dots), 2006-08

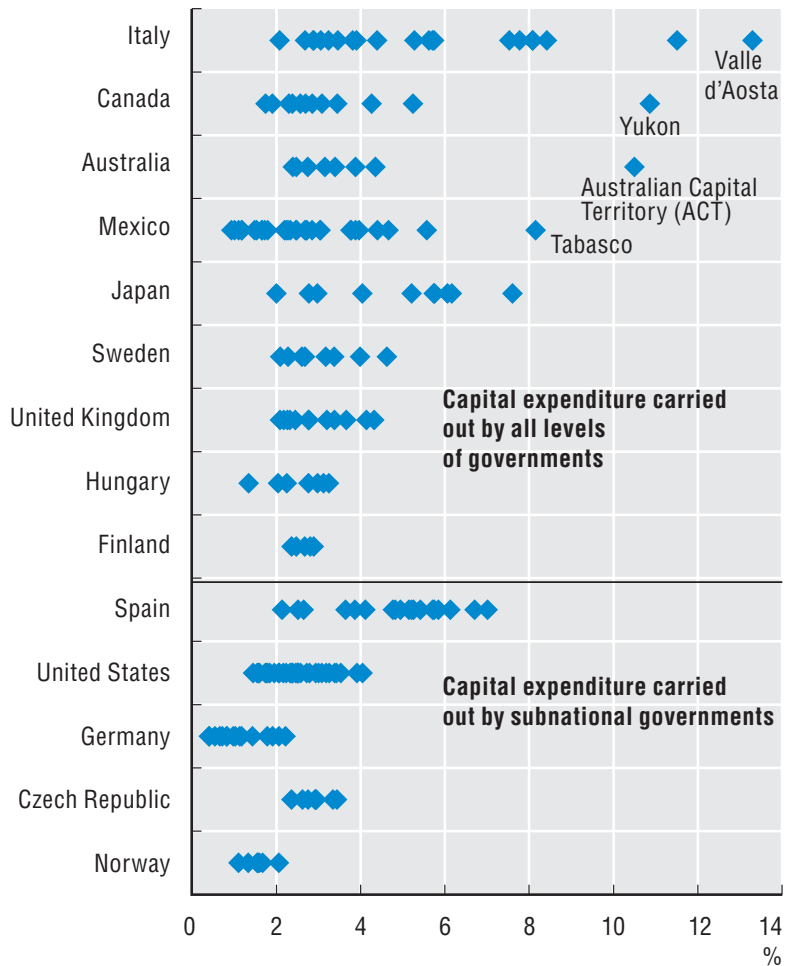

StatLink ants http://dx.doi.org/10.1787/888932439634 


\section{PUBLIC INVESTMENT IN REGIONS}

13.5. Public investment per capita: Asia, Europe and Oceania, 2006-08

Country value $=100$, TL2 regions, average 2006-08

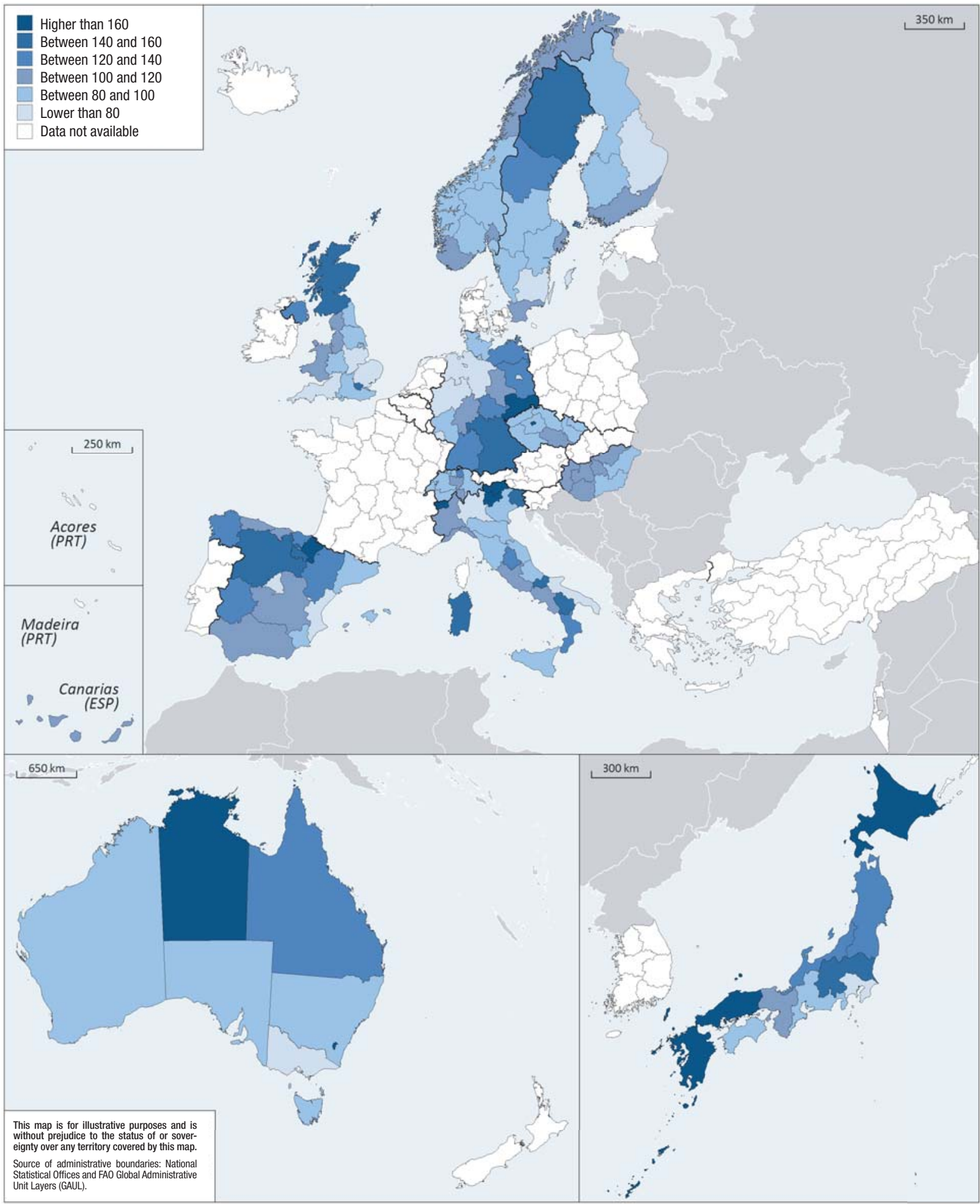

StatLink काIsL http://dx.doi.org/10.1787/888932440109 
13.6. Public investment per capita: Americas, 2006-08

Country value $=100$, TL2 regions, average 2006-08

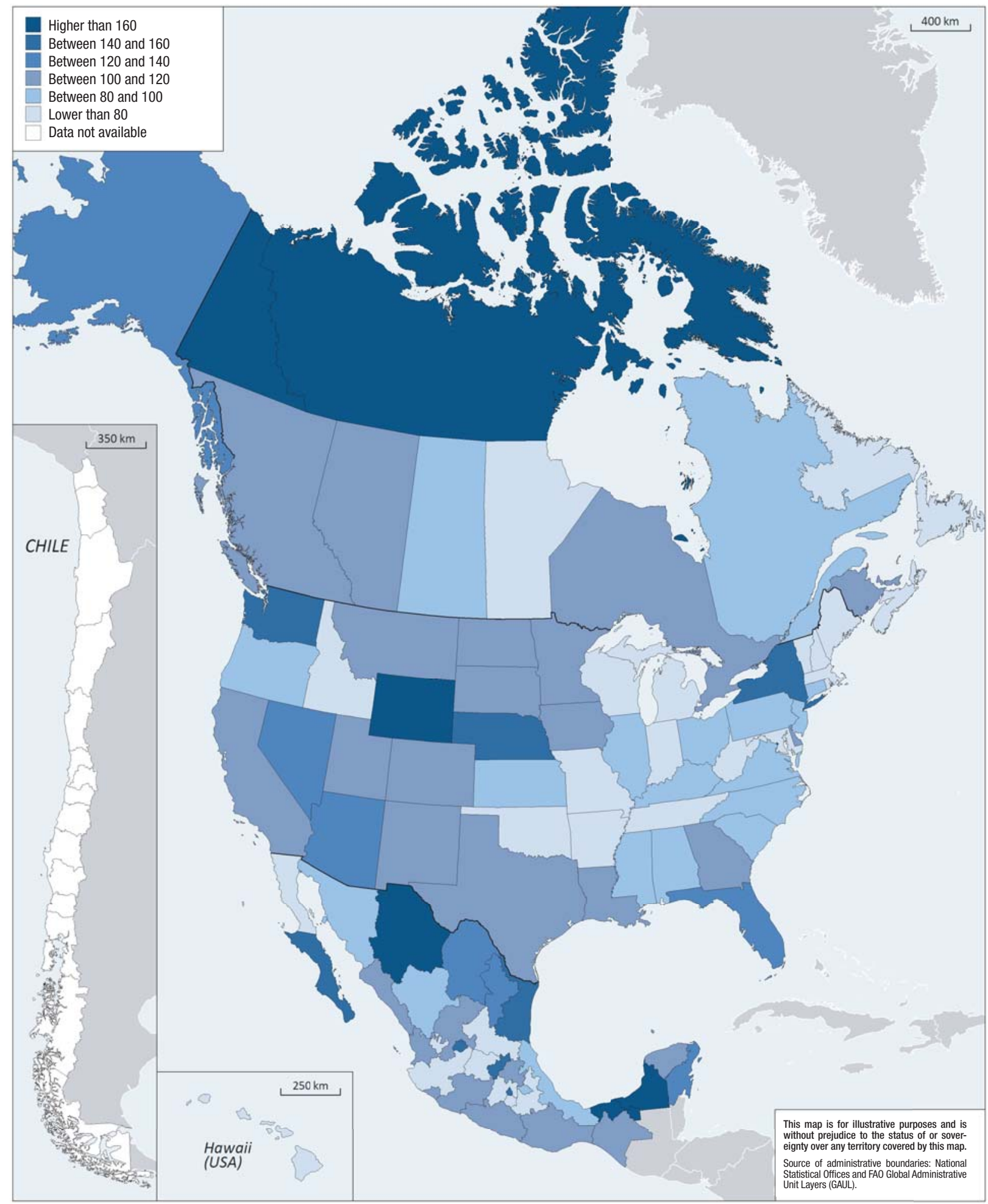

StatLink बाजर http://dx.doi.org/10.1787/888932440109 
Expenditures and personnel employed in research and development (R\&D) are common proxies for innovation activities in regions. According to the Frascati Manual, R\&D is defined as a "creative work undertaken on a systematic basis in order to increase the stock of knowledge of man, culture and society, and the use of this stock of knowledge to devise new applications."

Expenditure in R\&D is highly concentrated in a group of major global players, due also to different R\&D efforts in different economic sectors. In 2007, around one-third of total R\&D expenditure in OECD countries was performed by just $10 \%$ of regions. Large regional concentration of $R \& D$ is found both in countries with high R\&D intensity, such as the United States, Korea and France and in countries with low R\&D expenditure, such as Poland, Spain and Hungary (Figure 14.1). Therefore, within country dispersion in regions $R \& D$ effort is not a positive or negative feature per se; it needs to be evaluated along with aggregate national performance and the specificity of the country in question.

The share of a country's $R \& D$ expenditure carried out by just a single region ranges between $80 \%$ in Ireland to $21 \%$ in Italy (Figure 14.2). In the past seven years the share of $R \& D$ expenditure carried out by the top performing region has increased mostly in Eastern England (United Kingdom), Bratislava (Slovak Republic) and Prague (Czech Republic) (Figure 14.2).

In 2007, R\&D intensity, i.e. R\&D expenditures as a percentage of gross domestic product (GDP), was on average about $2.3 \%$ in OECD. Within country differences in R\&D intensity are larger than among countries (Figure 14.3). The United States, Finland, Denmark and Sweden show the largest regional disparities in $R \& D$ intensity across TL2 regions. In the United States, the states of New Mexico and Massachusetts devote more than 7\% of their GDP to $R \& D$, while the state of Wyoming devotes only $0.4 \%$. Regional R\&D hot spots have emerged in countries that are not the most R\&D-intensive, such as South Netherlands and Trøndelag in Norway. These two regions have more than double their respective country average $R \& D$ intensity (Figure 14.3).

Similarly, regional differences in the share of employment in $R \& D$, i.e. all persons employed directly in R\&D activities, such as researchers, technicians and support staff, are the largest in the Czech Republic and Austria, where, respectively, in the regions of Prague and Wien there are more than 40 persons per thousand employed in $R \& D$, two times higher than the country average. In most countries, the capital region has the highest rate of employed in $R \& D$ (Figure 14.4).

\section{Definition}

Gross domestic expenditure on R\&D is the total intramural expenditure on R\&D performed in the region or country during a given period (see the Frascati Manual, Section 6.7.1 and Section 6.6). Intramural expenditures are all expenditures for R\&D performed within a statistical unit or sector of the economy during a specific period, whatever the source of funds (see the Frascati Manual, Section 6.2).

R\&D personnel includes all persons employed directly in R\&D activities such as researchers as well as those providing direct services such as R\&D managers, administrators, and clerical staff. Data are expressed in headcounts.

$R \& D$ intensity is defined as the ratio between $R \& D$ expenditure and GDP.

\section{Source}

OECD Regional Database: http://dotstat/wbos/.

See Annex B for data, source and country-related metadata.

\section{Reference years and territorial level}

1995-2007; TL2

Data for Chile, Iceland, Japan, Mexico, New Zealand, Switzerland and Turkey are not available at the regional level. In addition, R\&D personnel data are not available for Australia and the United States.

\section{Further information}

OECD (2011), Regions and Innovation Policy, OECD Publishing. OECD (2009), OECD Science, Technology and Industry Scoreboard 2009, OECD Publishing, DOI: 10.1787/ sti_scoreboard-2009-en.

OECD (2002), Frascati Manual 2002: Proposed Standard Practice for Surveys on Research and Experimental Development, The Measurement of Scientific and Technological Activities, OECD, DOI: 10.1787/9789264199040-en.

\section{Figure notes}

14.1-14.3: Latest available year: France 2004, Greece 2005, Canada 2006. 
14.1. Percent of national R\&D expenditure in the $10 \%$ TL2 regions with the largest R\&D expenditure, 2007

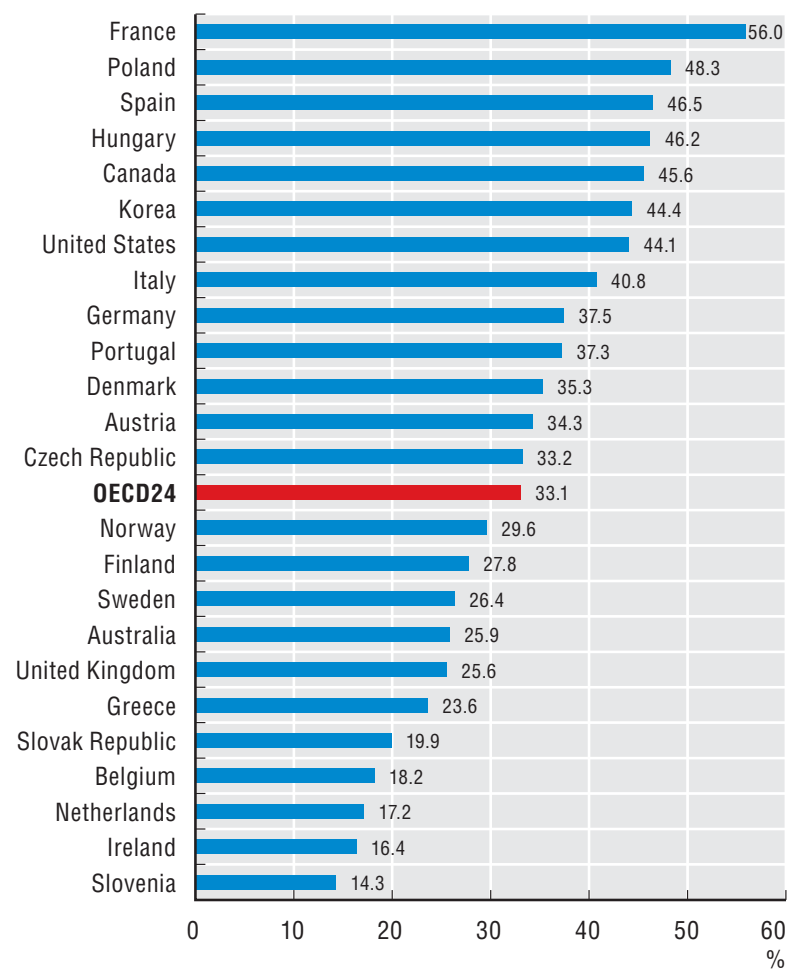

14.3. Range of TL2 regional R\&D intensity, 2007

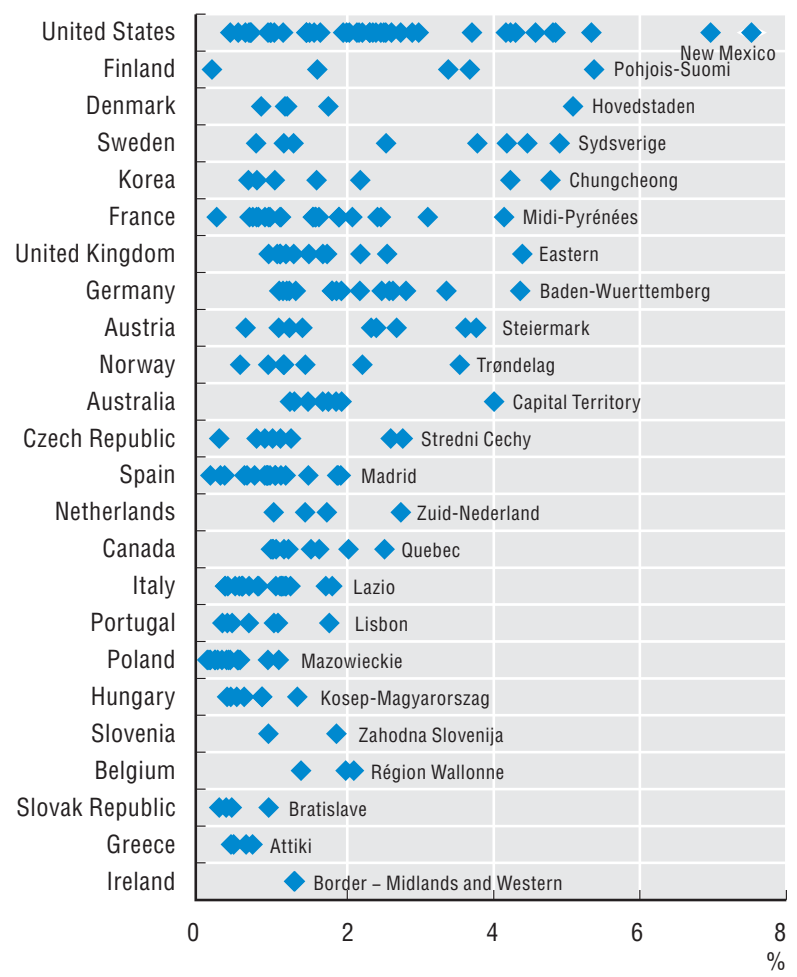

14.2. Percent of R\&D expenditure in the TL2 regions with the largest R\&D expenditure over country value, 2000 and 2007

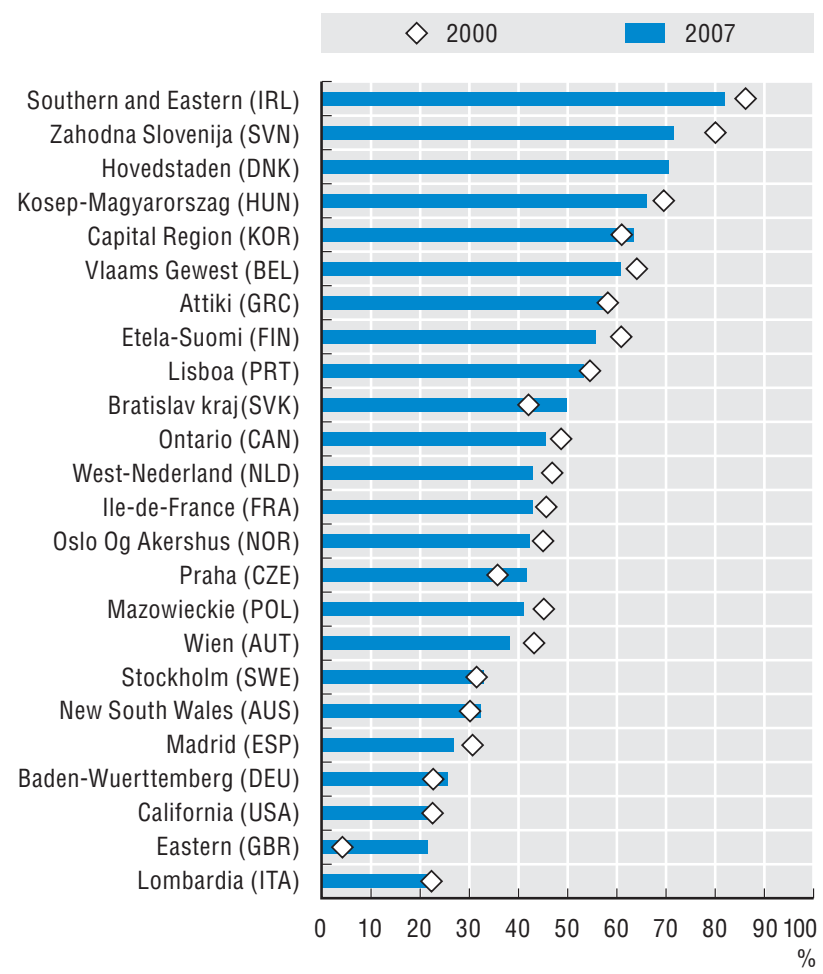

14.4. Range of TL2 regional R\&D personnel
per 1000 employees, 2007

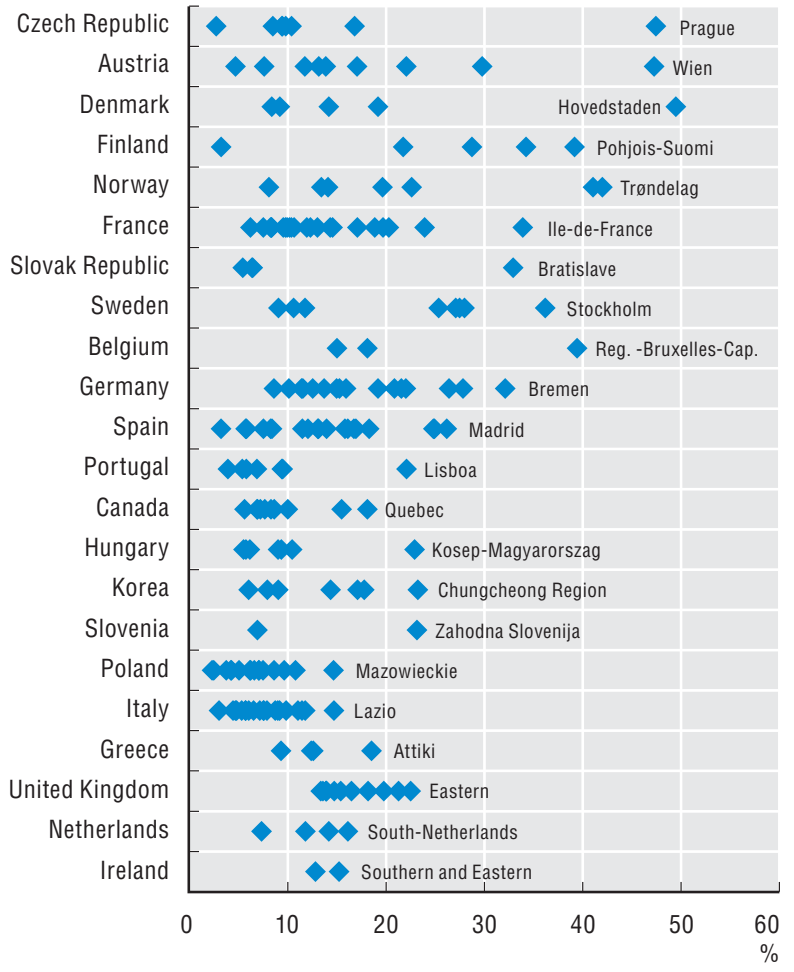

StatLink ला1s http://dx.doi.org/10.1787/888932439653 
The gross domestic expenditure in research and development (R\&D) is usually broken down among four sectors of performance: business enterprise, government, higher education and private non-profit. In general, R\&D performed by the business sector accounts for the largest part of R\&D activities. In $2007 \mathrm{R} \& \mathrm{D}$ performed by the business sector was close to $70 \%$ of total R\&D in OECD countries. At the same time governments can play an important role in fostering investment in R\&D; and most basic research is performed in universities and public research organisations.

Differences in the share of R\&D expenditure performed by the business and by the public (government and higher education) sectors can be very different both in countries with high R\&D intensity (total R\&D expenditure as a per cent of gross domestic product [GDP]) and in those that are less R\&D-intensive (Figures 15.5 and 15.6).

The ratio between the business R\&D expenditure (BERD) and the value added of industry was quite varied among OECD countries in 2007. Regional differences were the widest in the United States, Denmark, Finland and Sweden (Figure 15.1).

Evidence shows that for the OECD area as a whole, R\&D tends to display larger variations than GDP over the business cycle (OECD STI Scoreboard 2009). This suggests that a drop in regional GDP due to the economic crisis could result in an even larger decrease in R\&D expenditures of regions. This decrease is likely to affect countries differently, depending on the resilience of regions within countries. Responsiveness of business R\&D expenditure to the business cycle seems the strongest in Portugal, Spain and Finland. On the other hand, in Belgium, the United Kingdom, the Netherlands and the United States the elasticity of business R\&D expenditure to regional GDP is the lowest among the countries considered; this result suggests that these countries have been able to maintain their level of R\&D expenditure over the business cycle (Figure 15.2).

Top performing regions in business R\&D intensity can differ from the country average values as high as 2.5 percentage

\section{Source}

OECD Regional Database: http://dotstat/wbos/.

See Annex B for data, source and country-related metadata.

\section{Reference years and territorial level}

1995-2007; TL2.

Data for Chile, Iceland, Japan, Mexico, New Zealand, Switzerland and Turkey are not available at the regional level.

Australia regional data are available only for business R\&D expenditure.

\section{Further information}

OECD (2011), Regions and Innovation Policy, OECD Publishing.

OECD (2010), Measuring Innovation: A New Perspective, OECD Publishing, DOI: 10.1787/9789264059474-en.

OECD (2009), OECD Science, Technology and Industry Scoreboard 2009, OECD Publishing, DOI: 10.1787/ sti_scoreboard-2009-en. points; such is the case for Massachusetts (United States) and Eastern England (United Kingdom). But also in countries that are less R\&D-intensive, the gap between the top performing region and other regions can be high, such as in Stredni Cechy in the Czech Republic and Trøndelag in Norway (Figure 15.3). $R \& D$ expenditure performed by the public sector was around $0.6 \%$ of GDP in OECD countries. In most countries, the regions with largest $R \& D$ intensity performed by the public sector are usually capital regions, where public research centres are located. (Figure 15.4)

\section{Definition}

Gross domestic expenditure on R\&D is the total intramural expenditure on R\&D performed in the region or country during a given period (see the Frascati Manual, Section 6.7.1 and Section 6.6). Intramural expenditures are all expenditures for R\&D performed within a statistical unit or sector of the economy during a specific period, whatever the source of funds (see the Frascati Manual, Section 6.2).

The gross domestic expenditure in R\&D is disaggregated in four sectors: business enterprise, government, higher education and private non-profit.

$R \& D$ intensity is defined as the ratio between $R \& D$ expenditure and GDP.

Responsiveness of business $R \& D$ expenditure is measured as the estimated elasticity of BERD to GDP. The estimation is based on a country regression of the natural log of business R\&D on one year lagged GDP with regional fixed effects.

In the maps, a regional $R \& D$ intensity is defined as strong (weak) if it is above (below) the OECD median; the share of business R\&D expenditure is labelled as private (public) if it's above (below) the OECD median share.

\section{Figure notes}

15.1-15.4: Latest available year: France 2004, Greece 2005, Canada 2006.

15.2: The coefficient measures the expected increment in BERD for 1 point increment in GDP.

15.3-15.4: R\&D intensity is equal to R\&D expenditure as a \% of GDP. No regional data available for public R\&D expenditure in the Netherlands.

15.5-15.6: Regions are classified as strong (or weak) if their R\&D intensity is above (below) the OECD median value; and private (public) if the share of BERD on total R\&D expenditure is above (below) the OECD median value.

Information on data for Israel: http://dx.doi.org/10.1787/888932315602. 
15.1. Range of TL2 regional business R\&D expenditure as \% of value added in industry, 2007

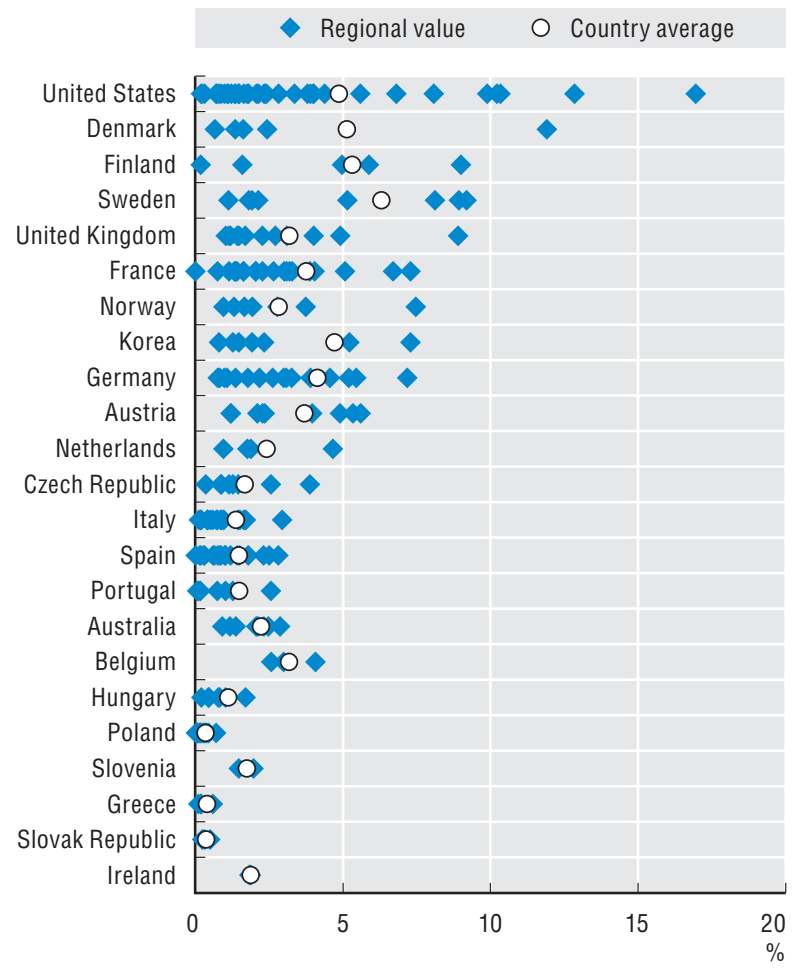

15.3. Regions with the highest business R\&D intensity, compared to the country average, 2007

Business R\&D intensity in 2007

$\diamond$ Country (business) R\&D intensity in 2007

Massachusetts (USA)

Pohjois-Suomi (FIN)

Hovedstaden (DNK)

Sydsverige (SWE)

Eastern (GBR)

Capital Region (KOR)

Baden-Wuerttemberg (DEU)

Steiermark (AUT)

Midi-Pyrénées (FRA)

Stredni Cechy (CZE)

Zuid-Nederland (NLD)

Trøndelag (NOR)

Région Wallonne (BEL)

Pais Vasco (ESP)

Western Australia (AUS) Quebec (CAN)

Piemonte (ITA)

Lisboa (PRT)

Zahodna Slovenija (SVN)

Border - Midlands and Western (IRL) Kosep-Magyarorszag (HUN)

Zapadne Slovensko (SVK)

Mazowieckie (POL) Attiki (GRC)

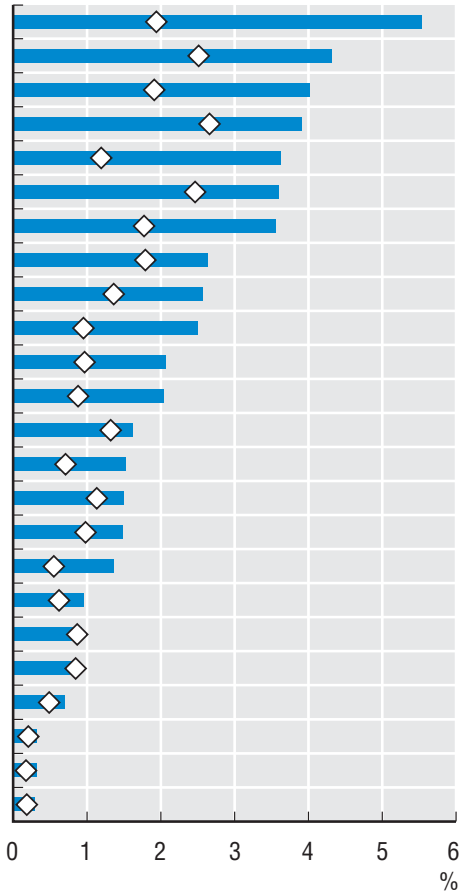

15.2. Percentage increase in business R\&D expenditure for $1 \%$ increase in GDP, 1995-2007

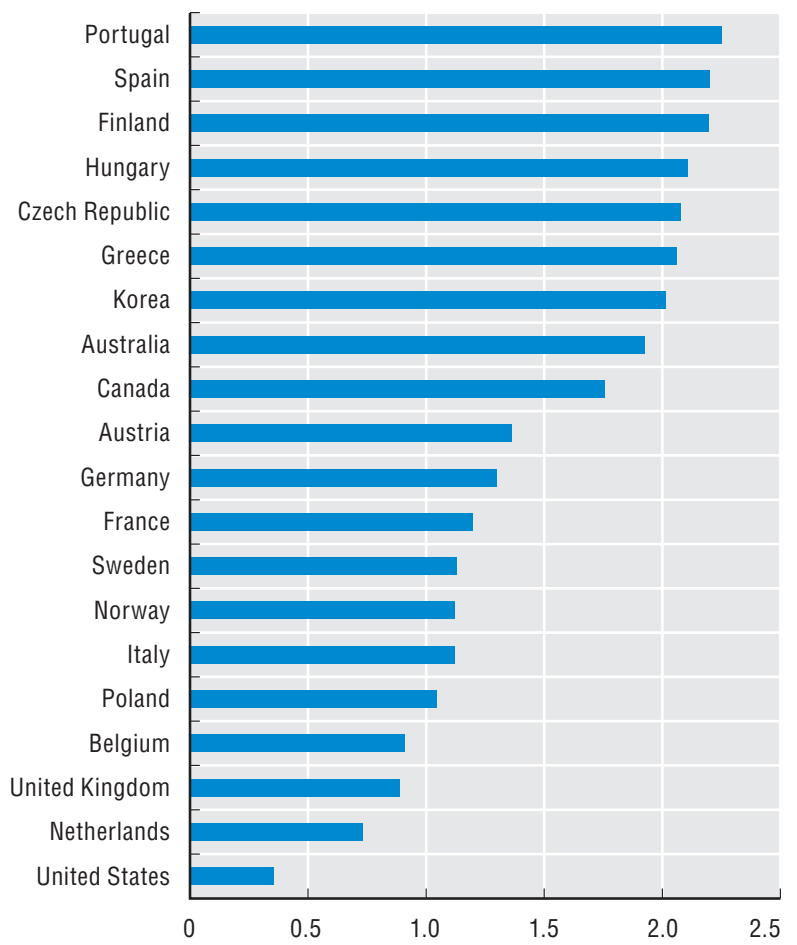

15.4. Regions with the highest public R\&D intensity, compared to the country average, 2007

Public R\&D intensity in 2007

$\diamond$ Country (public) R\&D intensity in 2007

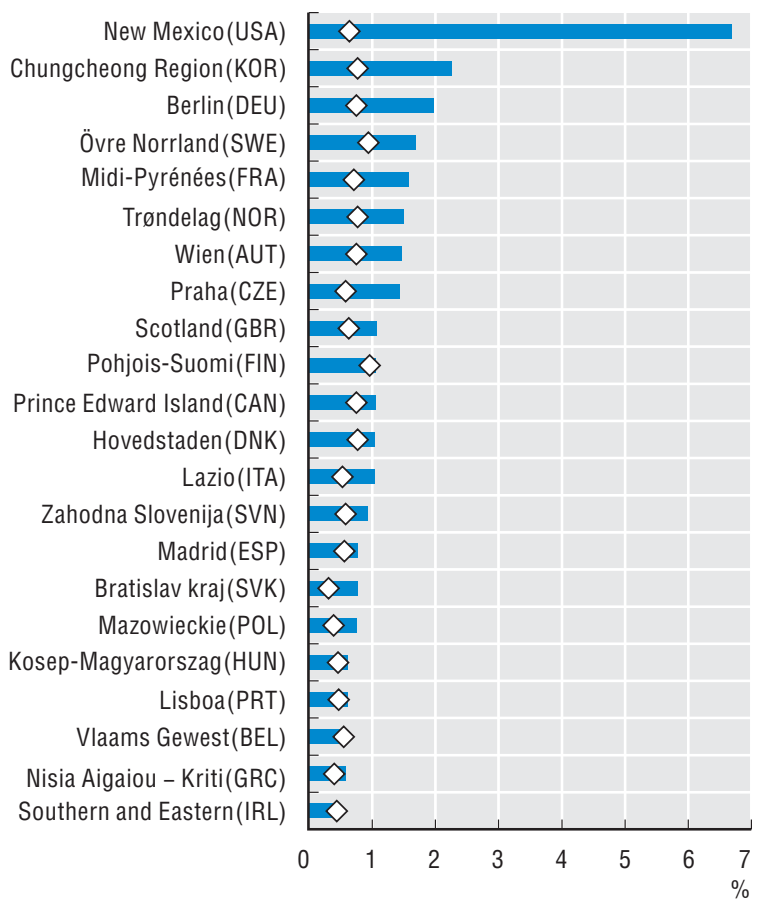

StatLink AाIS $h t t p: / / d x . d o i . o r g / 10.1787 / 888932439672$ 


\section{PUBLIC AND BUSINESS RESEARCH AND DEVELOPMENT EXPENDITURE}

\section{antit 20}

15.5. Regional R\&D intensity and share of business R\&D: Asia, Europe and Oceania, 2007

TL2 regions

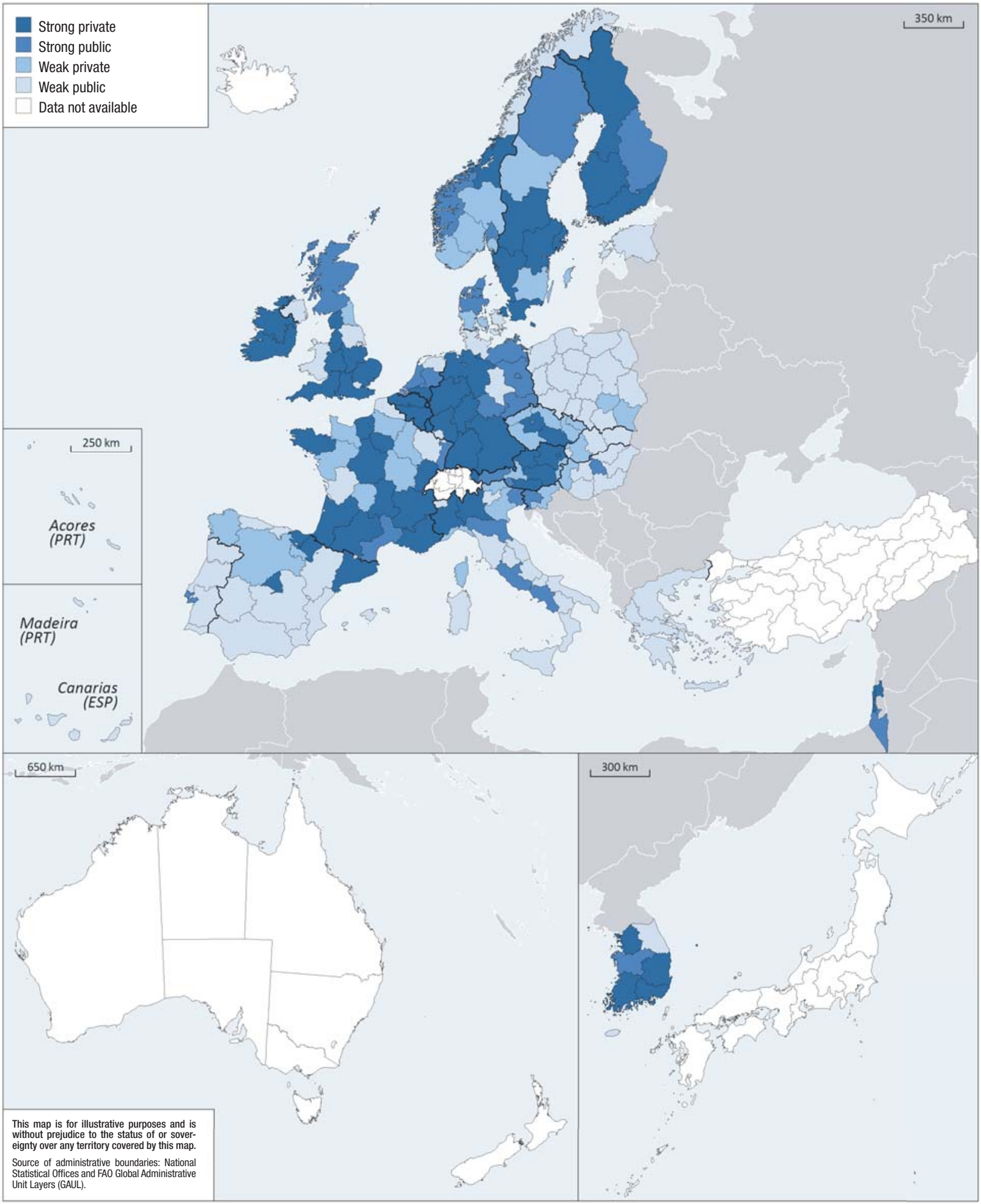

StatLink तiाs $h$ ttp://dx.doi.org/10.1787/888932440128 


\section{PUBLIC AND BUSINESS RESEARCH AND DEVELOPMENT EXPENDITURE}

15.6. Regional R\&D intensity and share of business R\&D: Americas, 2007

TL2 regions

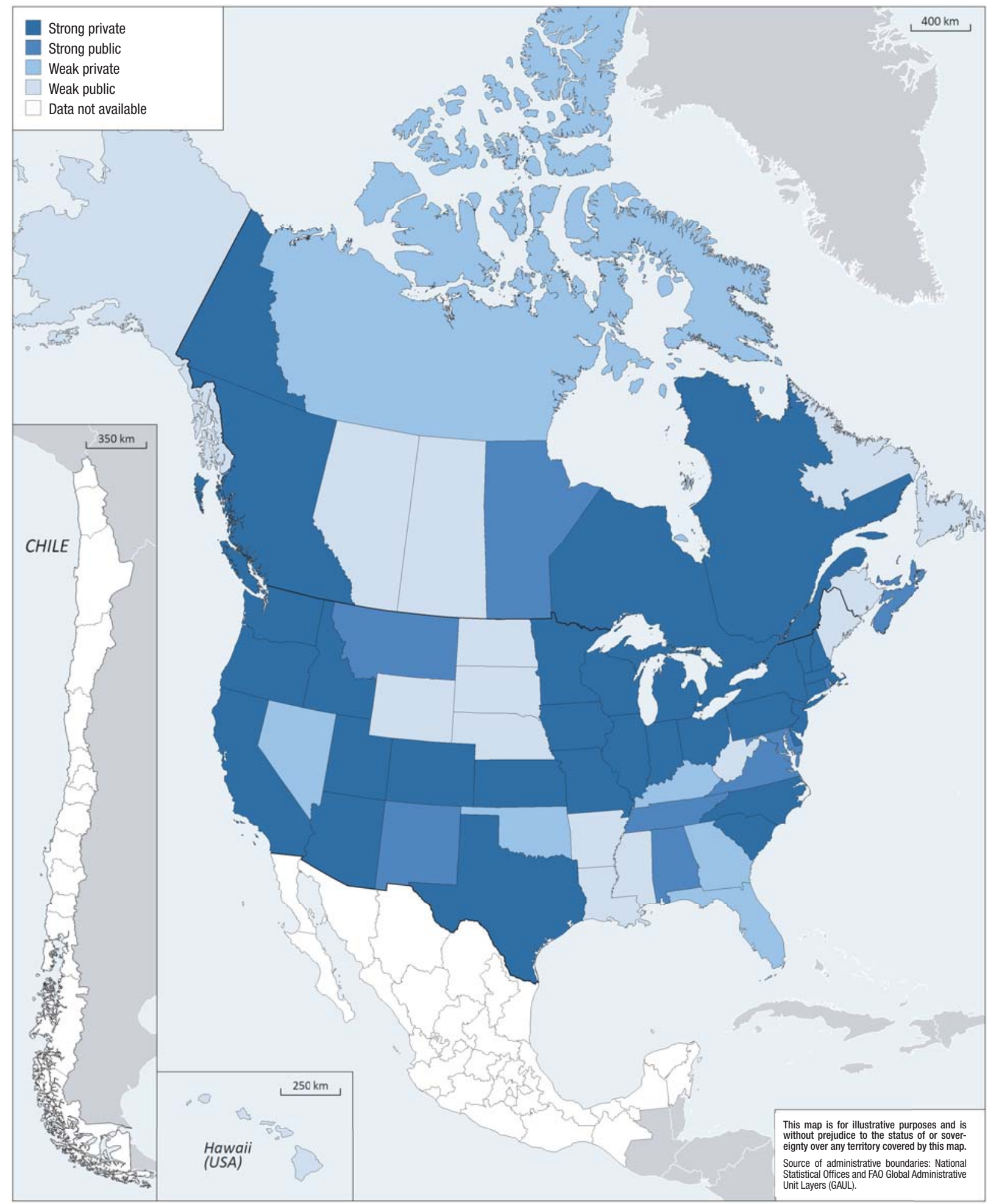

StatLink Aाs $h t$ ttp://dx.doi.org/10.1787/888932440128 
Patent applications can be used as an indicator of inventive activity. Patents are one of the mechanisms used to appropriate the results of investments in intangibles. They are a good proxy of innovation efforts; however, patenting activity is strongly associated with sectoral patterns, since some economic sectors (i.e. pharmaceuticals and electronics) tend to show higher patenting trends due to the type of innovative activity than other sectors (i.e. textiles or other low-tech sectors). The analysis of regional patenting helps assess the spatial distribution of inventive activity, not only between countries, but within countries.

Patent applications are concentrated in few countries, and in a small number of regions within each country. In 2007, $55 \%$ of all patent applications in OECD countries were recorded by $10 \%$ of regions. The geographic concentration of patents is related both to the different input needed for patent generation (e.g. investments, infrastructure, human capital) and to the sectoral concentration of industries (Figure 16.1). High concentration of patents is observed both in countries with large number of patents and in countries with a limited number.

Among the leading countries in patents per million inhabitants, regional disparities are the highest in the Netherlands, the United Kingdom and Korea because of a single top performing region. The United States, Japan, Germany, France and Switzerland have more regions patenting. Regional variation is generally low in the countries with a limited number of patents per million inhabitants, with the exception of Iceland (Figure 16.2).

Technology transfer of public research (universities, hospitals and government research centres) to industry is an important element of national and regional innovation policy. Among the countries that patent the most - the United States, Japan, Germany - around $40 \%$ of the collaboration between non-business and business actors happens in the same region and $40 \%$ among regions in the same country. On the contrary in Estonia, Turkey, the Slovak Republic and Finland business and non-business collaborations are mostly carried out beyond national boundaries (Figure 16.3). In China most of the business and public collaboration occur within national borders, while in India collaboration with foreign countries accounts for $30 \%$ of the copatenting among different actors.

\section{Definition}

A patent is an exclusive right granted for an invention, which is a product or a process with industrial applicability that provides, in general, a new way of doing something, or offers a new technical solution to a problem ("inventive step"). A patent provides protection for the invention to the owner of the patent. The protection is granted for a limited period, generally 20 years.

Data refer overall patent applications to Patent Cooperation Treaty (PCT) applications.

Patent documents report the inventors (where the invention takes place), as well as the applicants (owners), along with their addresses and country of residence. Patent counts are based on the inventor's region of residence and fractional counts. If on the patent document are registered two or more inventors, the patent is classified as a co-patent.

A co-patent is classified as a collaboration between business (companies) and non-business organisations (government, universities or hospitals) when there is at least one business applicant and at least one public applicant. The co-patents so classified are successively assigned to the region(s) of residence/ work of the co-inventors. Co-patents involving only individuals are not classified as business-non business collaboration. This has to be taken into account in the results, since in some countries the weight of individuals' applicants is quite high.

\section{Source}

OECD REGPAT Database http://dotstat/wbos/.

See Annex B for data, source and country-related metadata.

\section{Reference years and territorial level}

1995-2007; TL2 and TL3. 


\section{PATENTS IN REGIONS AND AMONG DIFFERENT ECONOMIC ACTORS}

16.1. Percent of patent applications in the $10 \%$ of TL3 regions with the highest concentration of patents, average 2005-07

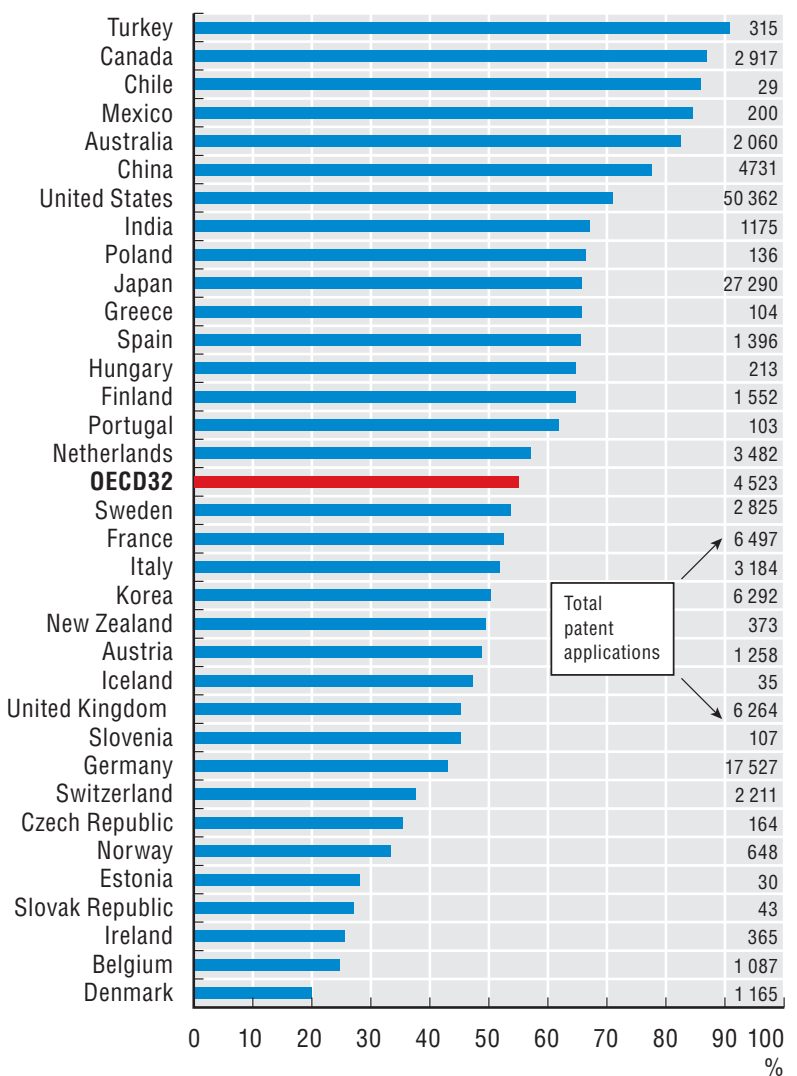

16.2. Range in TL3 regional patent applications per million population, 2005-07

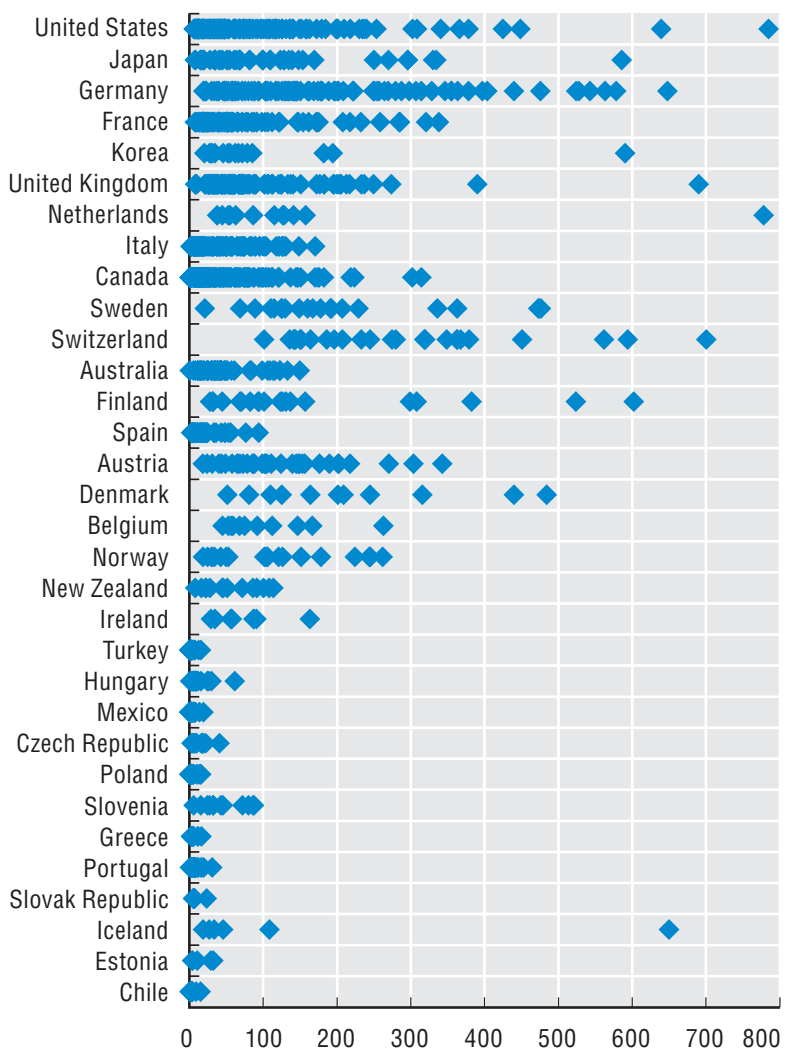

16.3. Share of collaboration between business and public (co-patenting with at least one business and one public applicant) over total co-patenting, by location of applicants, 2005-07

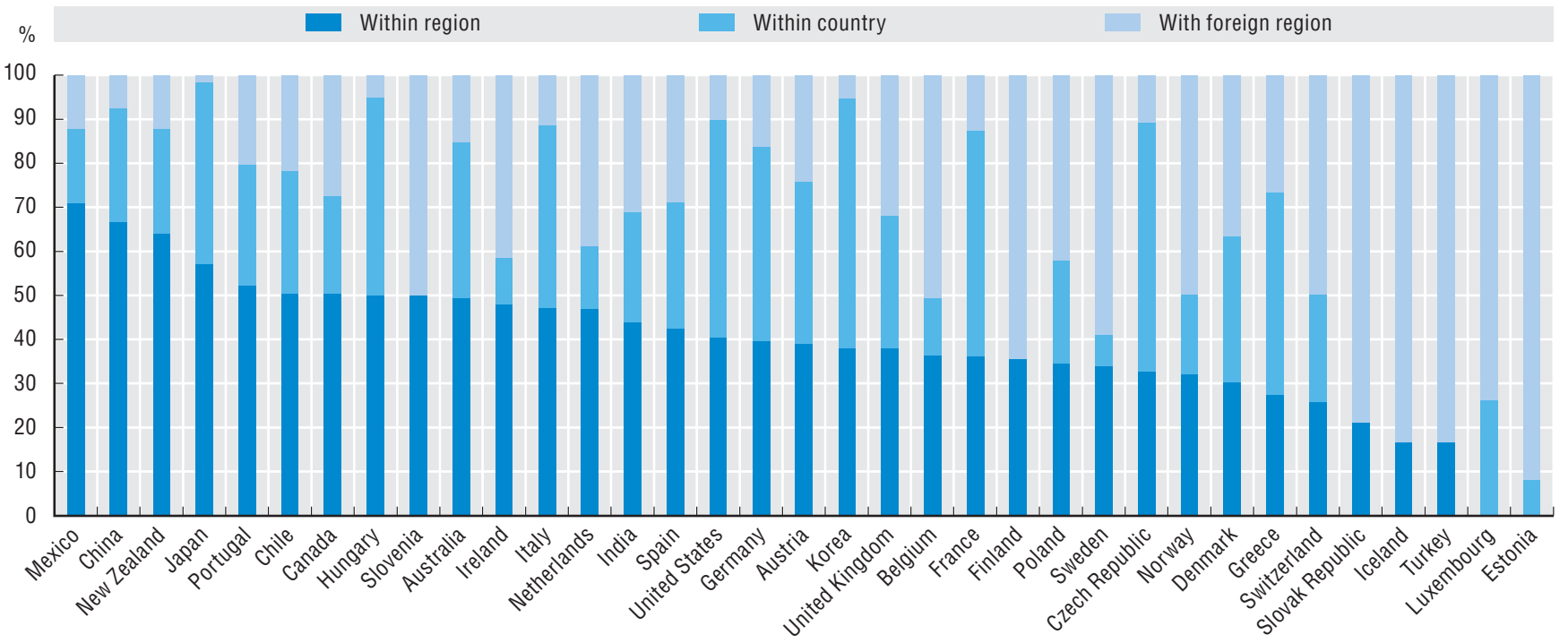


The percentage of regional patent applications with coinventors from another region, whether or not they belong to the same country, is an indicator of co-operation activity in innovation between localities.

More than $60 \%$ of patents in OECD countries are applied for by two or more inventors. The share of co-patenting on the total Patent Cooperation Treaty (PCT) applications can be high for patenting leaders (such as the United States), residual actors (such as Slovenia and Hungary) and emerging economies (India) (Figure 17.1).

The propensity to co-patent with co-inventor(s) from the same TL3 region (average $46 \%$ ) is higher than with coinventor(s) from the same country (average $33 \%$ ) and from foreign regions (average 21\%). Turkey, China and Japan show the highest propensity to co-patent within the same region. Japan, Korea, and the United States show the lowest propensity to co-patent outside national borders. Those countries play the role of global patenting hubs. By contrast, the Slovak Republic, Chile and Greece - which have a low level of patenting activities - and Switzerland and Belgium seem more oriented toward international cooperation rather than national (Figure 17.2).

Among the $10 \%$ regions that patent the most, different patterns of collaboration emerge. The top patenting regions in Belgium, France, Canada and the United Kingdom are relatively more connected with other foreign hubs. American States and Chungheong region (Korea) have a relatively lower share of foreign collaborations even if they are strongly connected with other hubs. The top ranking regions in Asian countries show lower propensity to patent collaborations and foreign co-inventors than the other regions (Figure 17.3).

\section{Source}

OECD REGPAT Database http://dotstat/wbos/.

See Annex B for data, source and country-related metadata.

\section{Definition}

A patent is an exclusive right granted for an invention, which is a product or a process with industrial applicability that provides, in general, a new way of doing something, or offers a new technical solution to a problem ("inventive step"). A patent provides protection for the invention to the owner of the patent. The protection is granted for a limited period, generally 20 years.

Data refer to overall patent applications to PCT applications.

Patent documents report the inventors (where the invention takes place), as well as the applicants (owners), along with their addresses and country of residence. Patent counts are based on the inventor's region of residence and fractional counts. If on the patent document are registered two or more inventors, the patent is classified as a co-patent.

The number of foreign co-inventors is defined as the number of co-inventors that reside/work in a TL region outside national borders.

\section{Reference years and territorial level}

1995-2007; TL3 and TL2.

\section{Figure notes}

17.2: Average by country of distribution of co-inventors by location (TL3 regions). 
17.1. Patent applications with co-inventors as a $\%$ of PCT patents, 2005-07

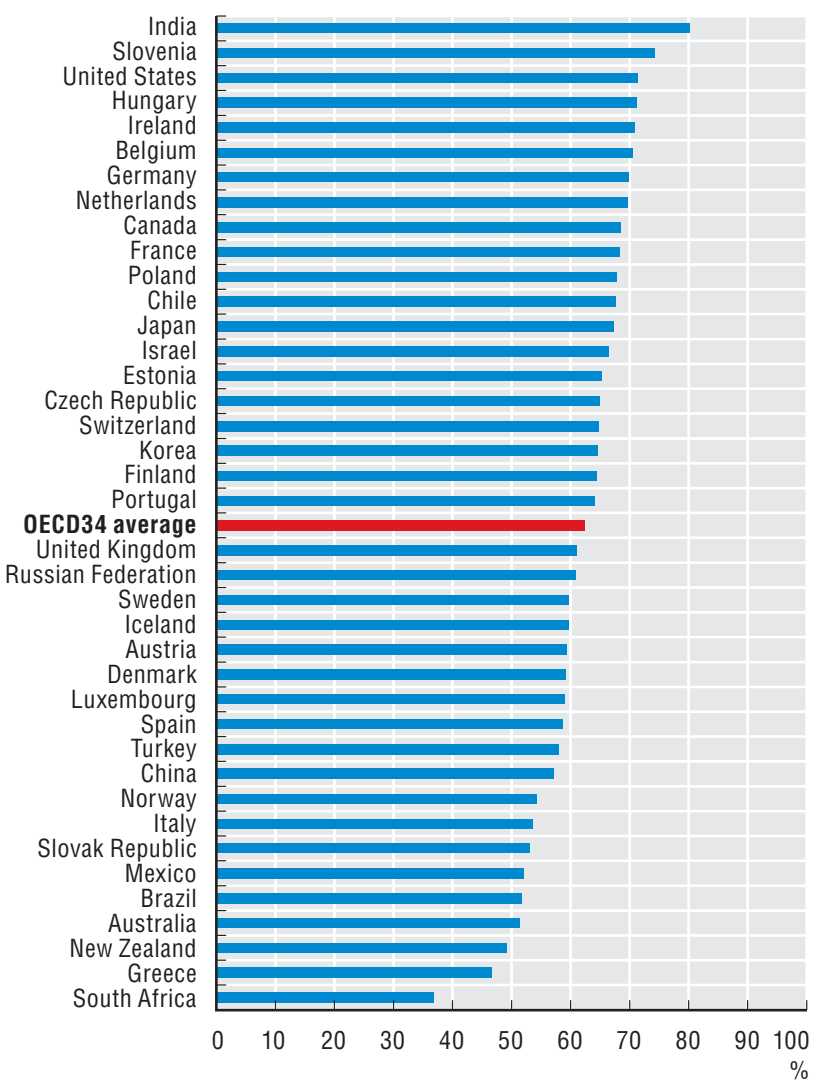

\subsection{Share of collaborations in patents, by location of co-inventors, TL3 regions, 2005-07}

Within region Within country Foreign region

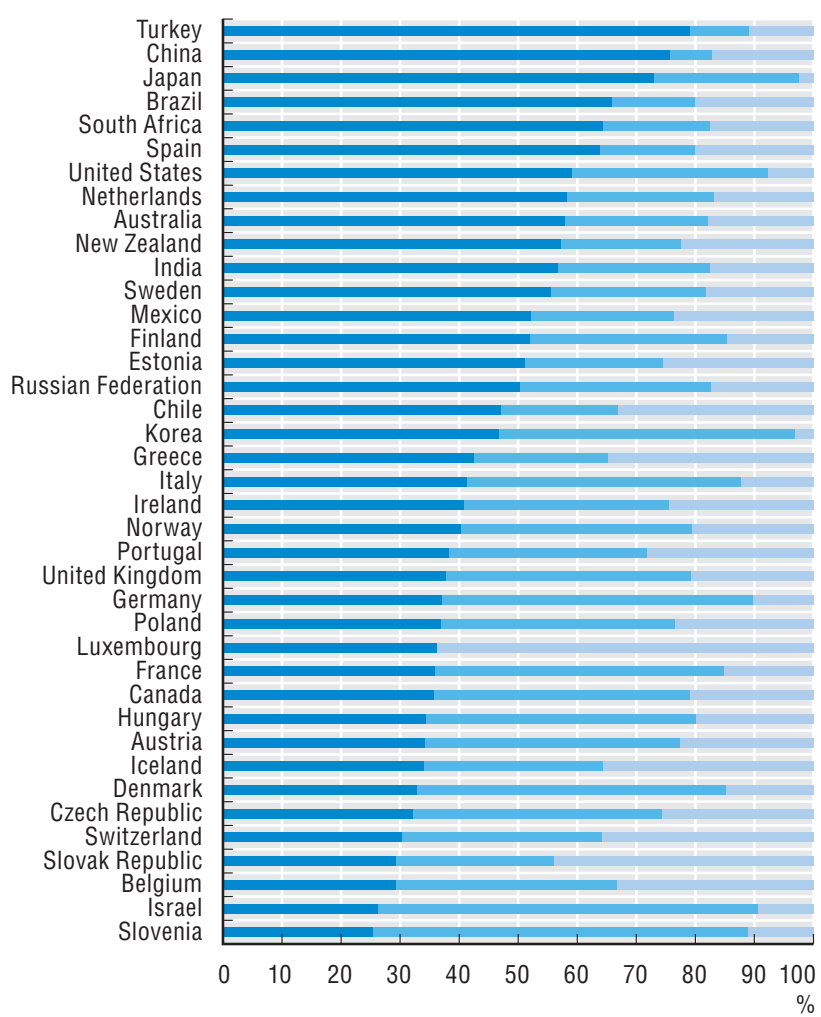

\subsection{Share of co-patents (X-axis) and share of foreign collaborations ( $\mathrm{Y}$-axis) in the $10 \%$ regions with the highest patent applications, 2005-07}

Share of foreign collaborations on total collaborations (\%)

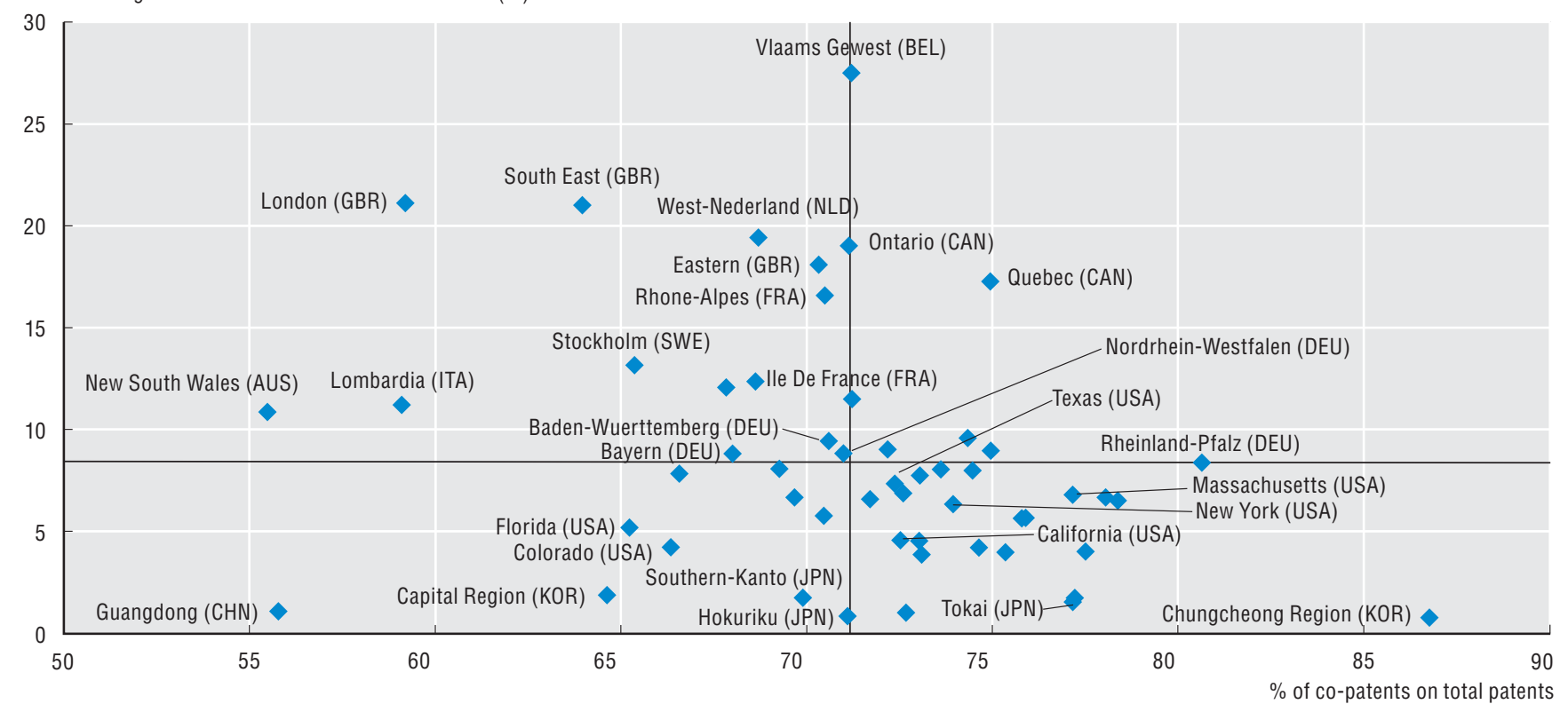



The disposable income of households can be seen as the maximum amount that a unit can afford to spend on consumption goods or services without having to reduce its financial or non-financial assets or by increasing its liabilities. As such, it is a better indicator of the material well-being of citizens than gross domestic product (GDP) per inhabitant. Regions where net commuter flows are high may display a very high GDP per capita which does not translate into a correspondingly high income for their inhabitants (the most notable case is London in the United Kingdom).

Regional income per capita disparities within countries are generally smaller than GDP per capita disparities. Still, in 2007 per capita income in the District of Colombia (United States) was $80 \%$ higher than the country median income and in the bottom income state, Mississippi, per capita income was roughly equivalent to the income of the median American in 1995. Similarly, in Chile, the Slovak Republic, Australia, Canada and Hungary, inhabitants in the top income region were $40 \%$ richer than the median citizen (Figure 18.1).

In the decade prior to 2007 , household income growth has occurred with large regional variation both in countries displaying sustained growth, such as Hungary and the Slovak Republic and in countries with limited income growth, such as Chile and Germany (Figure 18.2).

While the regional range measures the distance between the richest and the poorest regions in a country, the Gini index of household disposable income provides a measure of disparities among all regions. According to this index, the Slovak Republic, Italy, Chile and Greece were the OECD countries with the highest inequalities in 2007. Among them, inequalities have grown in the Slovak Republic and Greece between 1995 and 2007. From 1996 to 2007 inequalities have decreased the most in Chile, New Zealand and Finland (Figure 18.3).

A comparison between the regional household disposable income and the primary income (income generated primarily by market transactions) provides a measure of the levelling role of state intervention. Current transfers to households significantly reduce the difference between the highest and lowest regional values; sizable effects on the relative income level of regions (ratio between disposable income and primary income larger than 1), are found mostly in West Virginia, Tennessee, Mississippi and Kentucky (United States); Lubelskie and Swietokrzyskie (Poland); and Calabria (Italy) (Figures 18.4-18.6).

\section{Source}

OECD Regional Database: http://dotstat/wbos/.

OECD National Final Consumption Expenditure of Households.

See Annex B for data, source and country-related metadata.

\section{Reference years and territorial level}

1996-2007; TL2.

Regional data are not available in Iceland, Korea, Mexico, Portugal, Switzerland and Turkey.

\section{Definition}

The primary income of private households is defined as the income generated directly from market transactions, i.e. the purchase and sale of factors of production and goods. These include in particular the compensation of employees. Private households can also receive income on assets (interest, dividends and rents) and from operating surplus and self-employment. Interest and rents payable are recorded as negative items for households.

The disposable income of private households is derived from the balance of primary income by adding all current transfers from the government, except social transfers in kind and subtracting current transfers from the households such as income taxes, regular taxes on wealth, regular inter-household cash transfers and social contributions.

To make comparisons over time and across countries, regional disposable income is expressed at constant prices (year 2000), computing the deflator from the OECD national final consumption expenditure of households in current and constant prices; then it is converted into USD purchasing power parities (PPPs) for private consumption to express each country's income in a common currency.

The Gini index is a measure of inequality among all regions of a given country (see Annex $C$ for the formula). The index takes on values between 0 and 1 , with zero interpreted as no disparity. It assigns equal weight to each region regardless of its size; therefore differences in the values of the index among countries may be partially due to differences in the average size of regions in each country.

\section{Figure notes}

18.1: As a \% of country median disposable income per capita.

18.1-18.3: Disposable income in constant (2000) PPP USD. Chile latest available year 2006. First available year New Zealand 1998, Denmark and Hungary 2000.

18.3: Measurement gap: Regional disposable income in OECD countries: The disposable income of households does not take into account social transfer in kind to households. A preferable measure of material condition of households at regional level could be the adjusted disposable income which additionally reallocates income from government and non-profit institutions serving the households, through expenditure on individual goods and services such as health, education and social housing (in-kind expenditure). Interregional disparities of adjusted household income could shed a light on possible areas of social exclusion, material deprivation and lack of access to essential services.

18.5: No regional primary income available in Mexico

Information on data for Israel: $h t t p: / / d x . d o i . o r g / 10.1787 / 888932315602$. 
18.1. TL2 regional range in household income per capita, as a \% of income in the country's median region, 2007

O Minimum value

O Maximum value

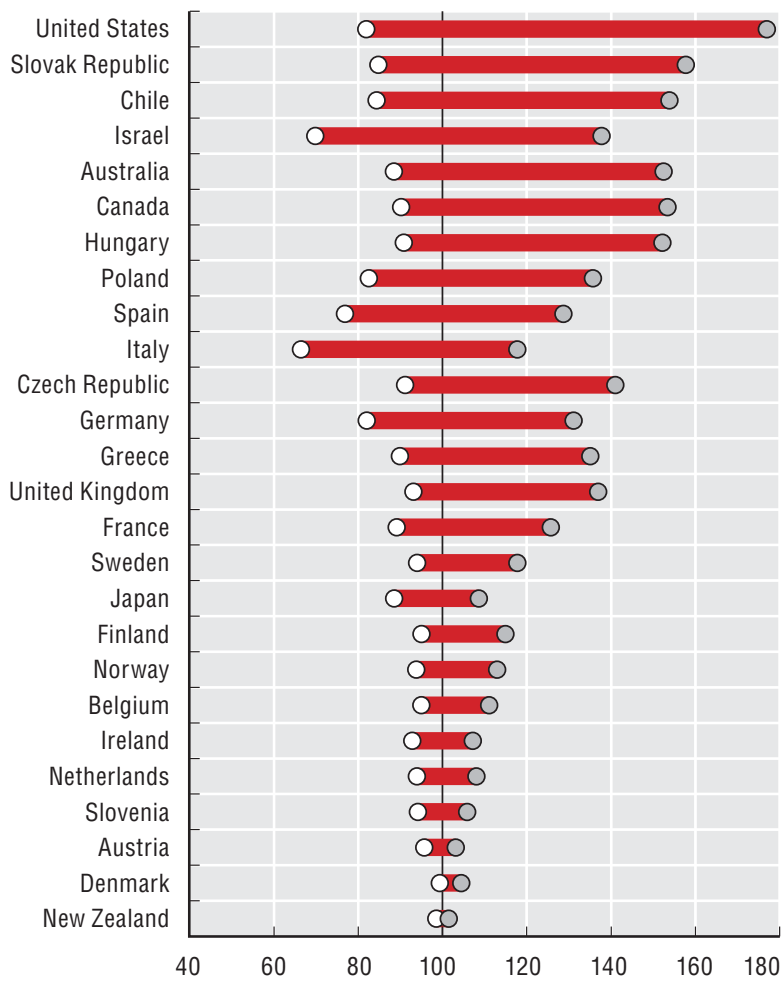

18.2. Countries ranked by size of difference in TL2 regional annual household income growth, 1996-2007

$\bigcirc$ Minimum value $\bigcirc$ Country average Maximum value

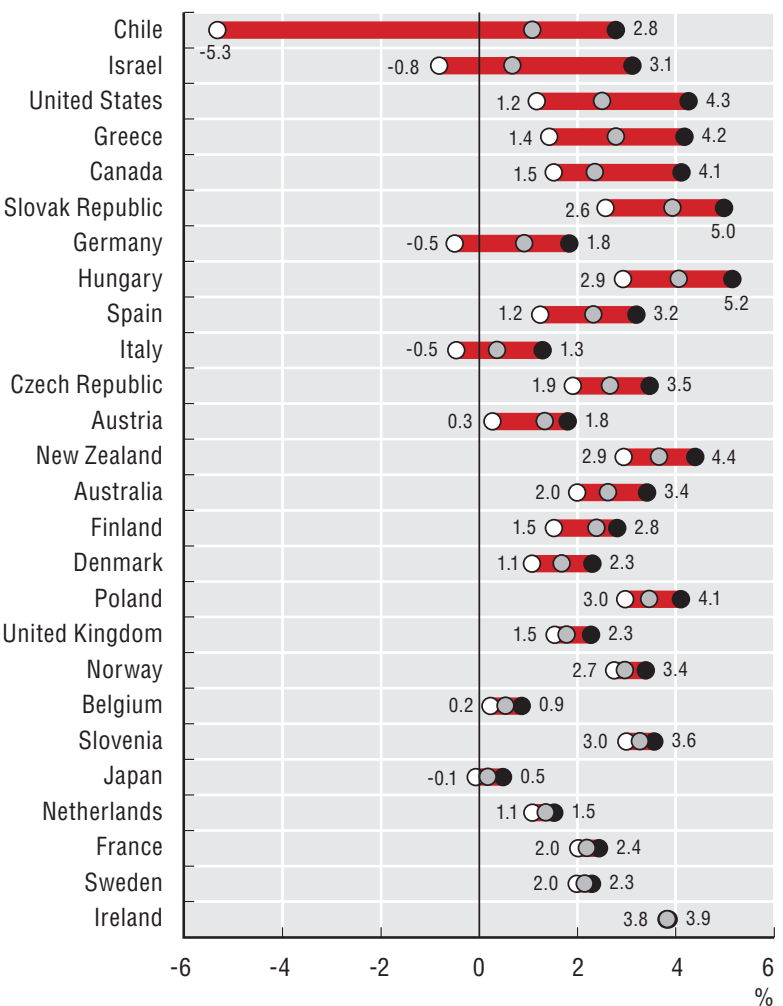

18.3. Gini index of TL2 regional disposable income, 1996 and 2007

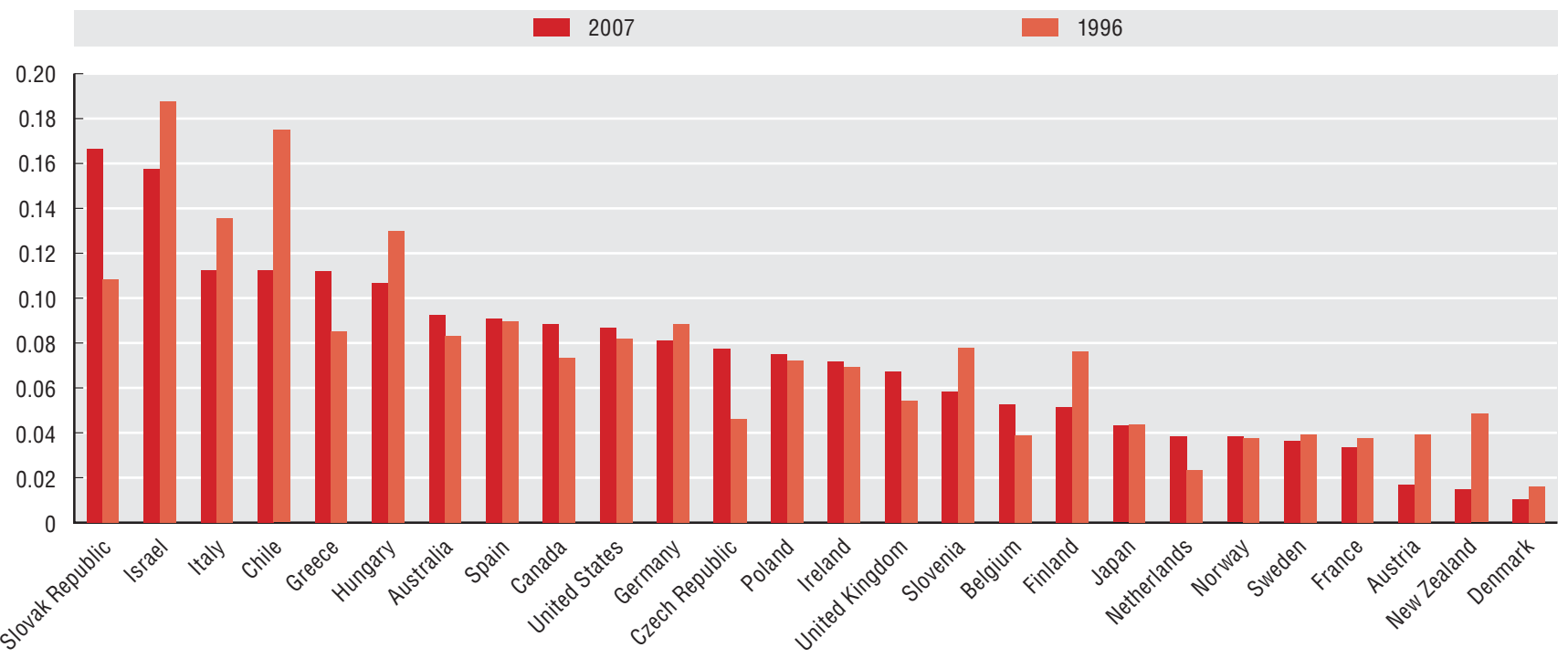




\section{REGIONAL DISPARITIES IN HOUSEHOLD INCOME}

18.4. Regional disposable income of private households as a \% of primary income: Asia, Europe and Oceania, 2007 TL2 regions

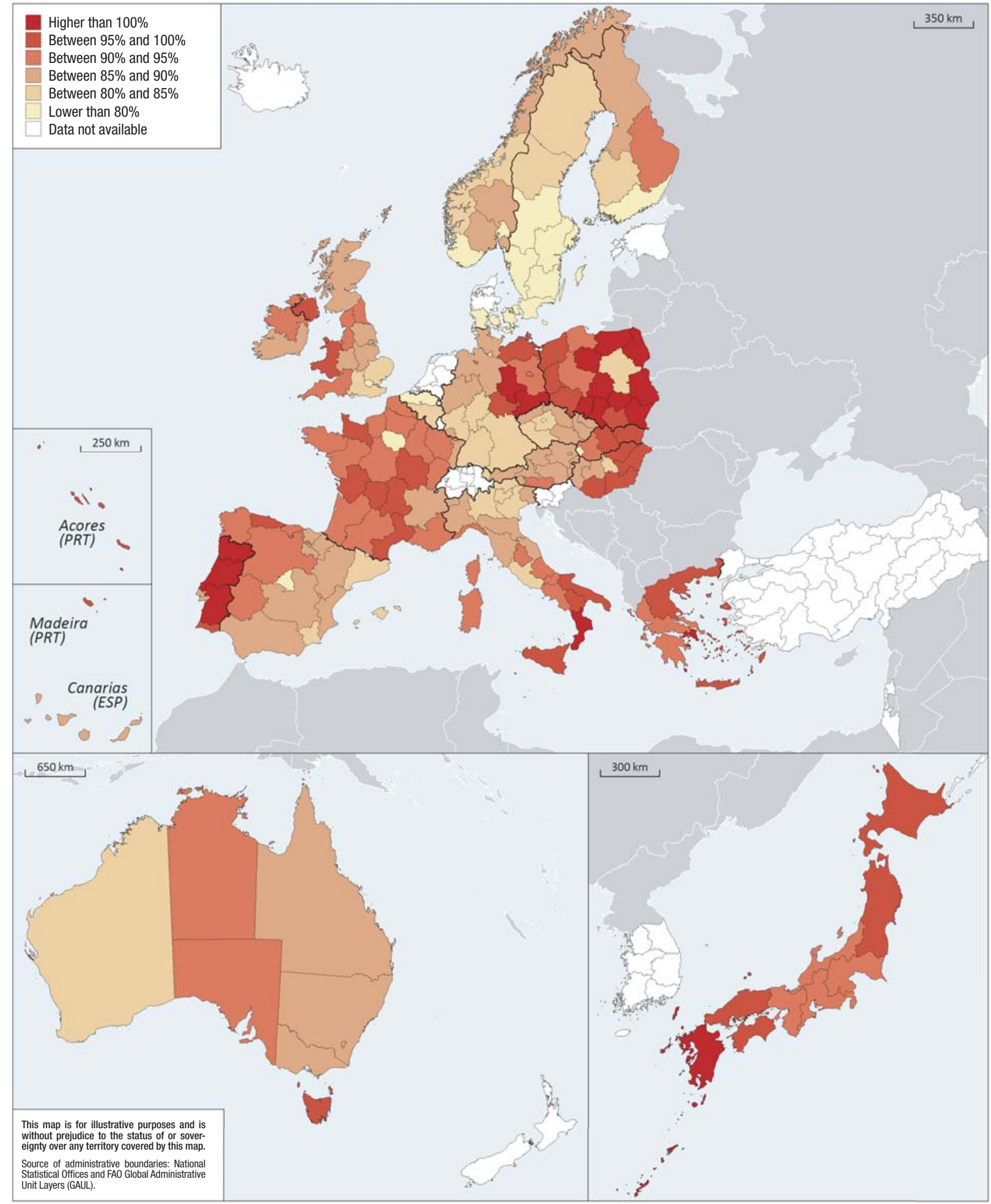

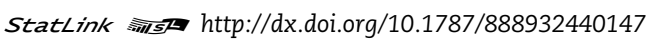


18.5. Regional disposable income of private households as a \% of primary income: Americas, 2007 TL2 regions

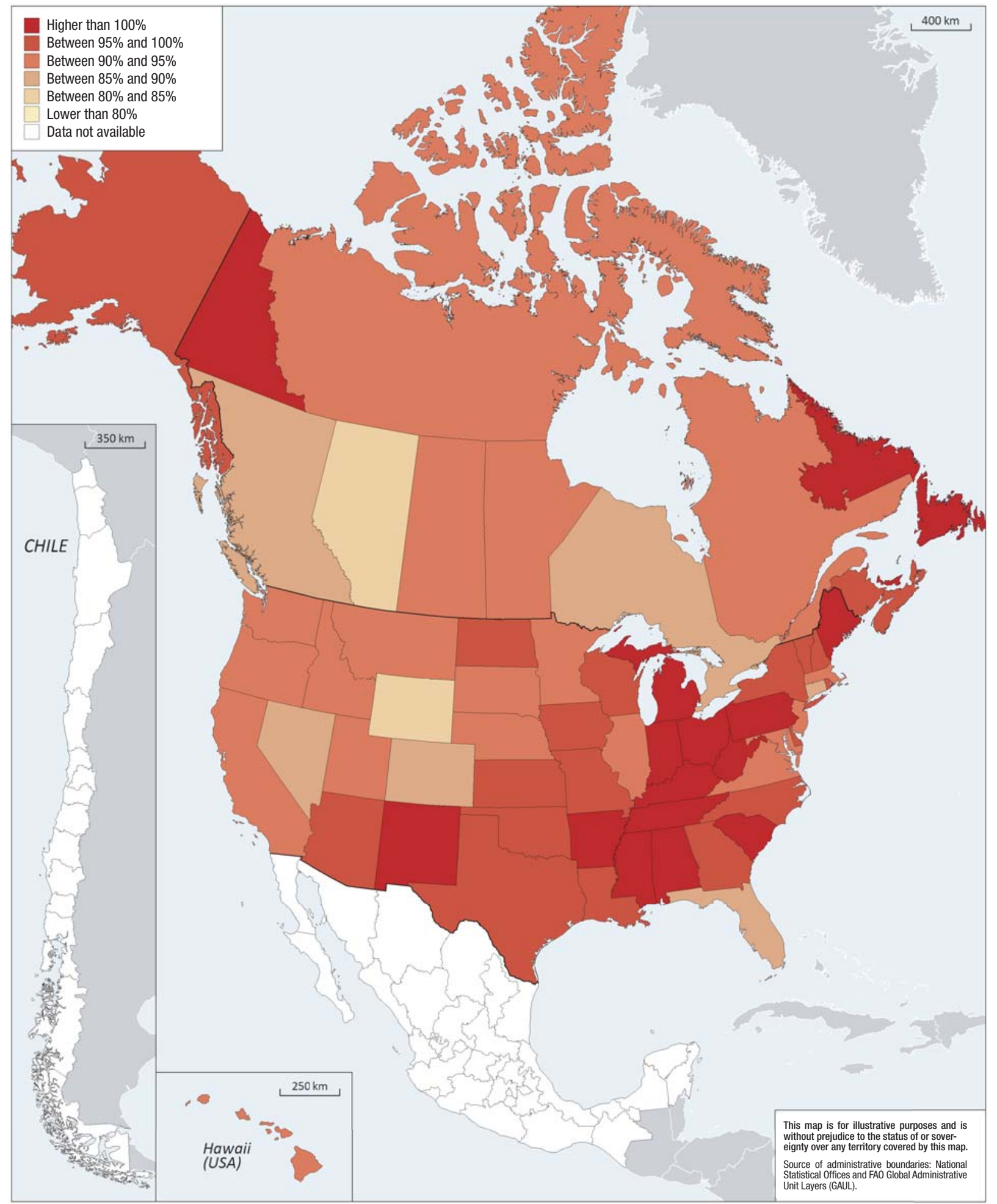

StatLink ताIsय $h t t p: / / d x . d o i . o r g / 10.1787 / 888932440147$ 
In most OECD countries the population is ageing. Due to higher life expectancy and low fertility rates, the elderly population (those aged 65 years and over), accounts for $14 \%$ of OECD population in 2008. The proportion of elderly population is remarkably lower in the emerging economies (Brazil, China, India, and South Africa) and Mexico and Turkey (Figure 19.1).

The elderly population in OECD countries has increased more than 1.5 times faster than the total population between 1995 and 2008. The rate of ageing within a country can be quite different, as an increase in the geographic concentration of the elderly may arise from inward migration of the elderly or by ageing "in place" because the younger generations have moved out of the regions (Figure 19.2).

The ratio of the elderly to the working age population, the elderly dependency rate, is steadily growing in OECD countries. The elderly dependency rate gives an indication of the balance between the economically active and the retired population. In 2008 this ratio was around $22 \%$ in OECD countries, with substantial differences between countries (34\% in Japan versus $9 \%$ in Mexico). Differences among regions within the same countries were also large. The higher the regional elderly dependency rate, the higher the challenges faced by regions in generating wealth and sufficient resources to provide for the needs of the population. Concerns may arise on the financial self-sufficiency of these regions to generate taxes to pay for these services (Figure 19.3).

In 2008, the elderly dependency rate across OECD regions was higher in intermediate and rural regions than in urban ones, with the only exceptions being Belgium, Chile, the Czech Republic, Estonia, Hungary and Poland. This general pattern was more pronounced in certain countries, like Portugal, France, Japan, Spain and Korea (Figure 19.3). Besides the elderly dependency rate, the absolute number of elderly people in a certain region may allow economies of scale in the provision of certain services, in particular health care and personal services. Only 25\% of the OECD elderly population lived in rural regions in 2008; with more of the elderly residing in urban regions (46\%). As such, rural regions are more likely to face the challenge of ageing due to higher elderly dependency rates and lower elderly population.
Within countries, the elderly population seems to be more concentrated in "peripheral" regions in Korea, Portugal, France, New Zealand, Japan and Ireland. On the contrary, in Poland, Belgium, Slovak Republic and Hungary the share of the elderly population seems to be higher where the population is more concentrated, generally urban regions (Figures 19.5-19.7).

\section{Definition}

The regional elderly population is the regional population of 65 years of age and over.

The elderly dependency rate is defined as the ratio between the elderly population and the working age (15-64 years) population.

\section{Source}

OECD Regional Database: http://dotstat/wbos/.

See Annex B for data, source and country-related metadata.

\section{Reference years and territorial level}

1995-2008; TL3.

TL2 regions in Brazil, Chile, China, India, the Russian Federation and South Africa.

\section{Further information}

Territorial grids and regional typology (Annex A). www.oecd.org/gov/regional/statisticsindicators

\section{Figure notes}

19.1-19.2: Latest available year: Germany 2007. First available year: Australia 1996, Denmark 2006, Iceland 1997, Poland 2000, Slovak Republic 1996.

Information on data for Israel: $h t t p: / / d x . d o i . o r g / 10.1787 / 888932315602$. 


\section{CONCENTRATION OF THE ELDERLY POPULATION IN REGIONS}

19.1. Elderly population as a $\%$ of the total population, 1995 and 2008

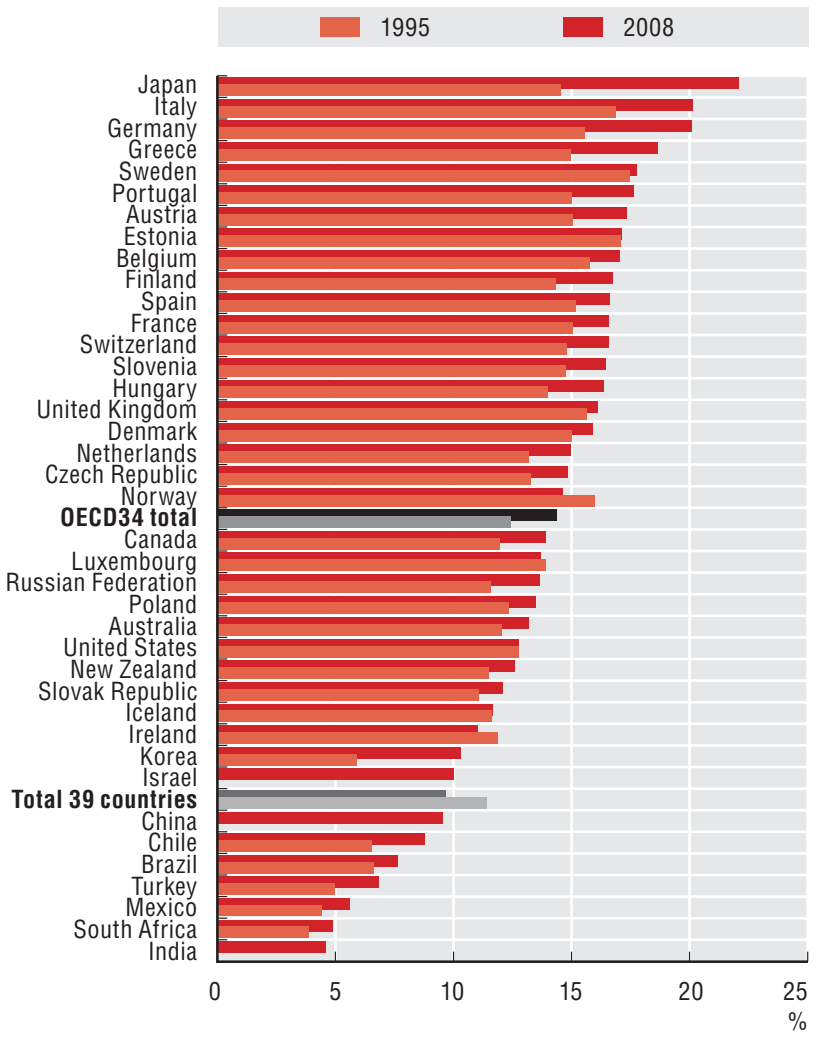

19.3. Elderly dependency rate: Country average and in predominantly urban and predominantly rural regions, 2008

$\bigcirc$ Urban regions $\bigcirc$ Elderly dependency rate $\quad$ Rural regions

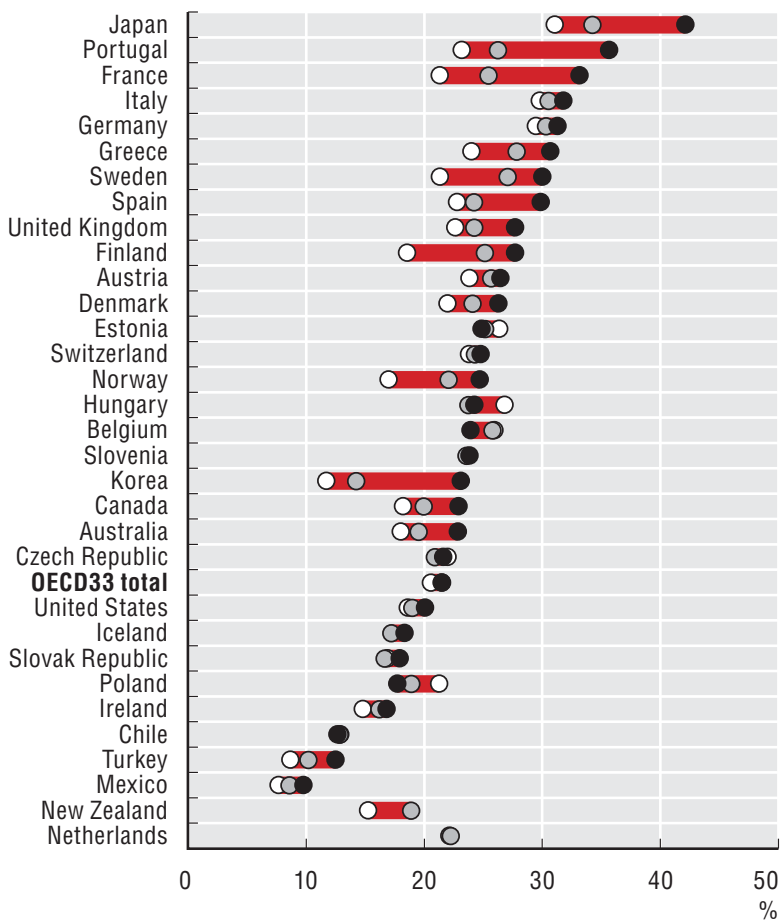

19.2. Yearly growth of regional elderly population, 1995-2008

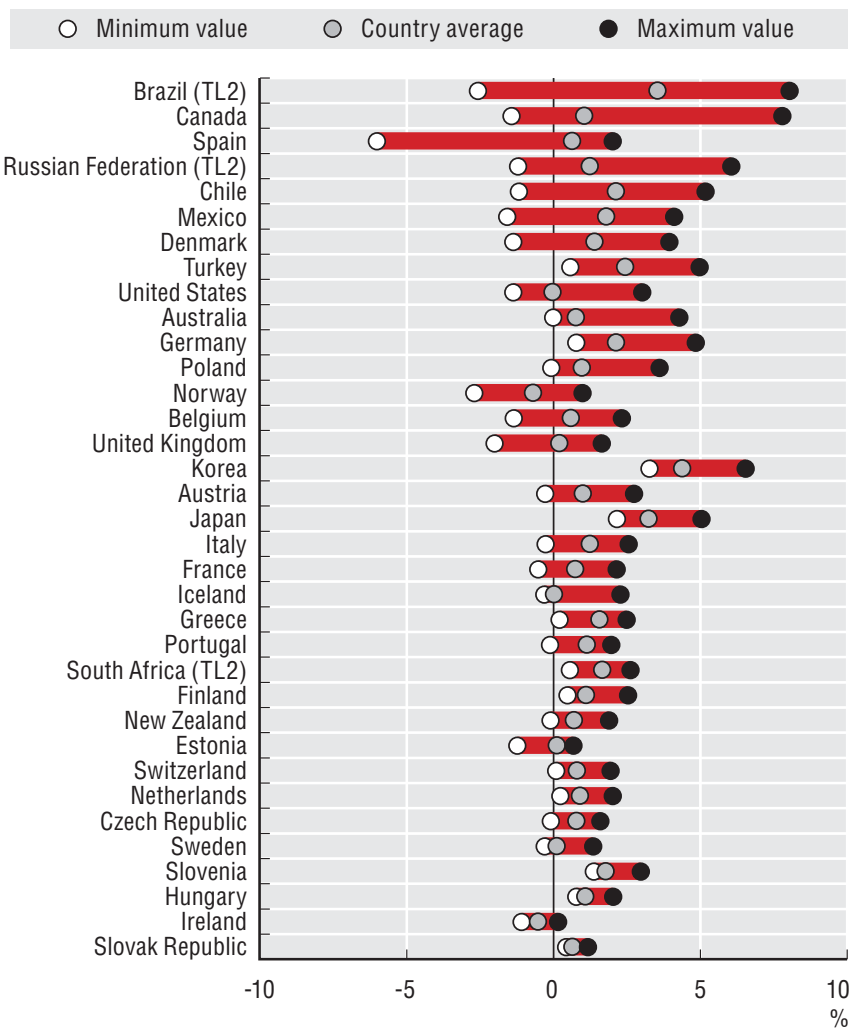

19.4. Distribution of the elderly population in predominantly urban (PU), intermediate (IN) and predominantly rural (PR) regions, 2008

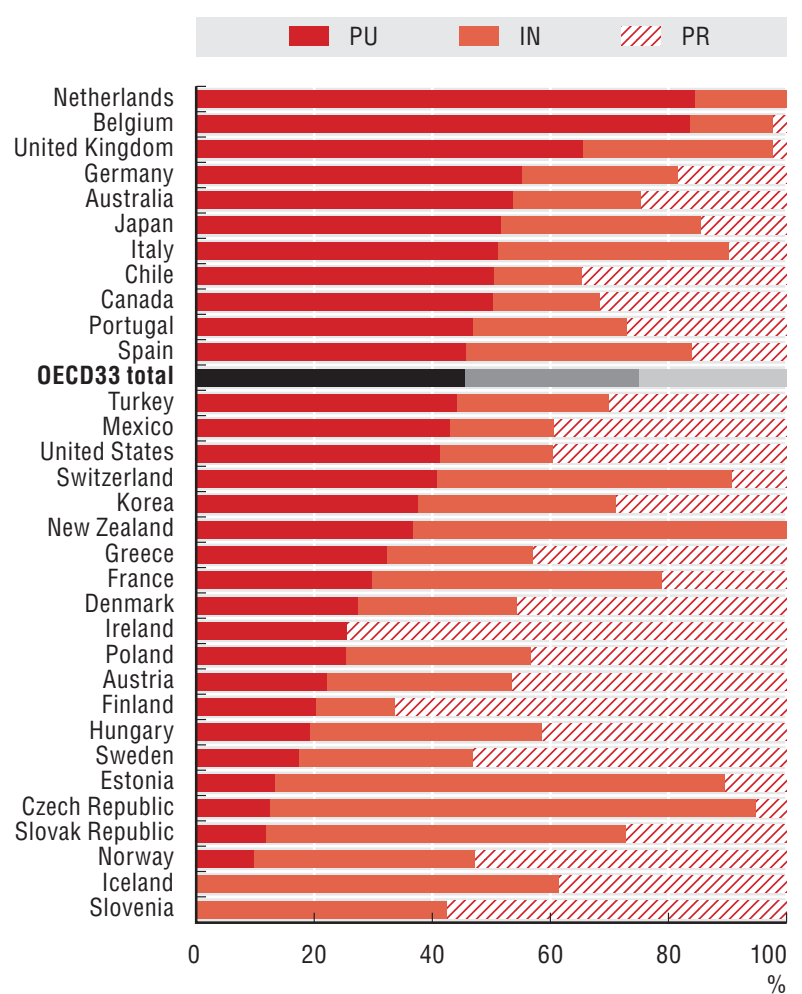

StatLink तiाst $h t t p: / / d x . d o i . o r g / 10.1787 / 888932439748$ 
19.5. Regional elderly dependency rate: Asia and Oceania, 2008

Ratio between elderly population and working age population, TL3 regions

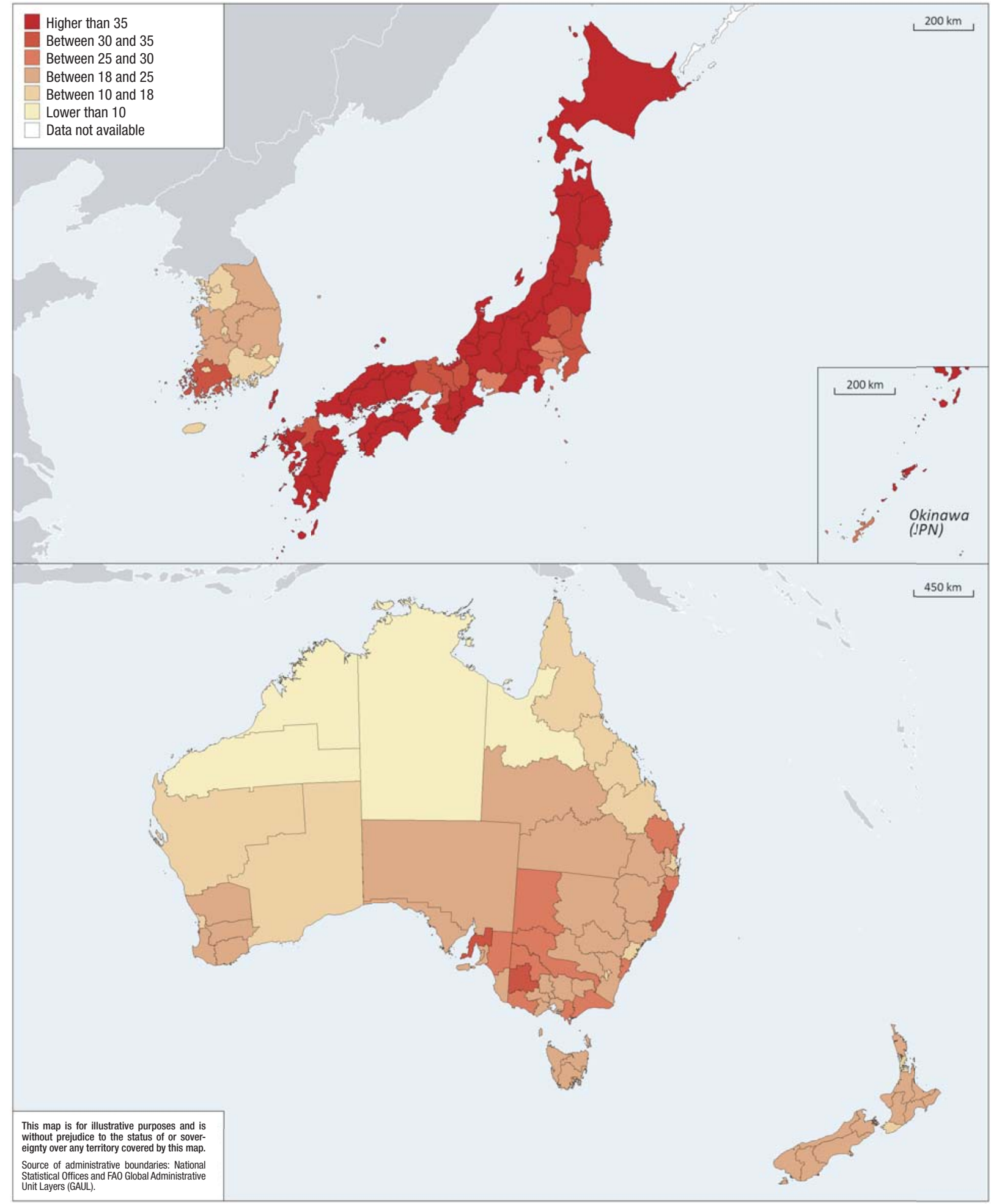

StatLink AाsL http://dx.doi.org/10.1787/888932440166 
19.6. Regional elderly dependency rate: Europe, 2008

Ratio between elderly population and working age population, TL3 regions

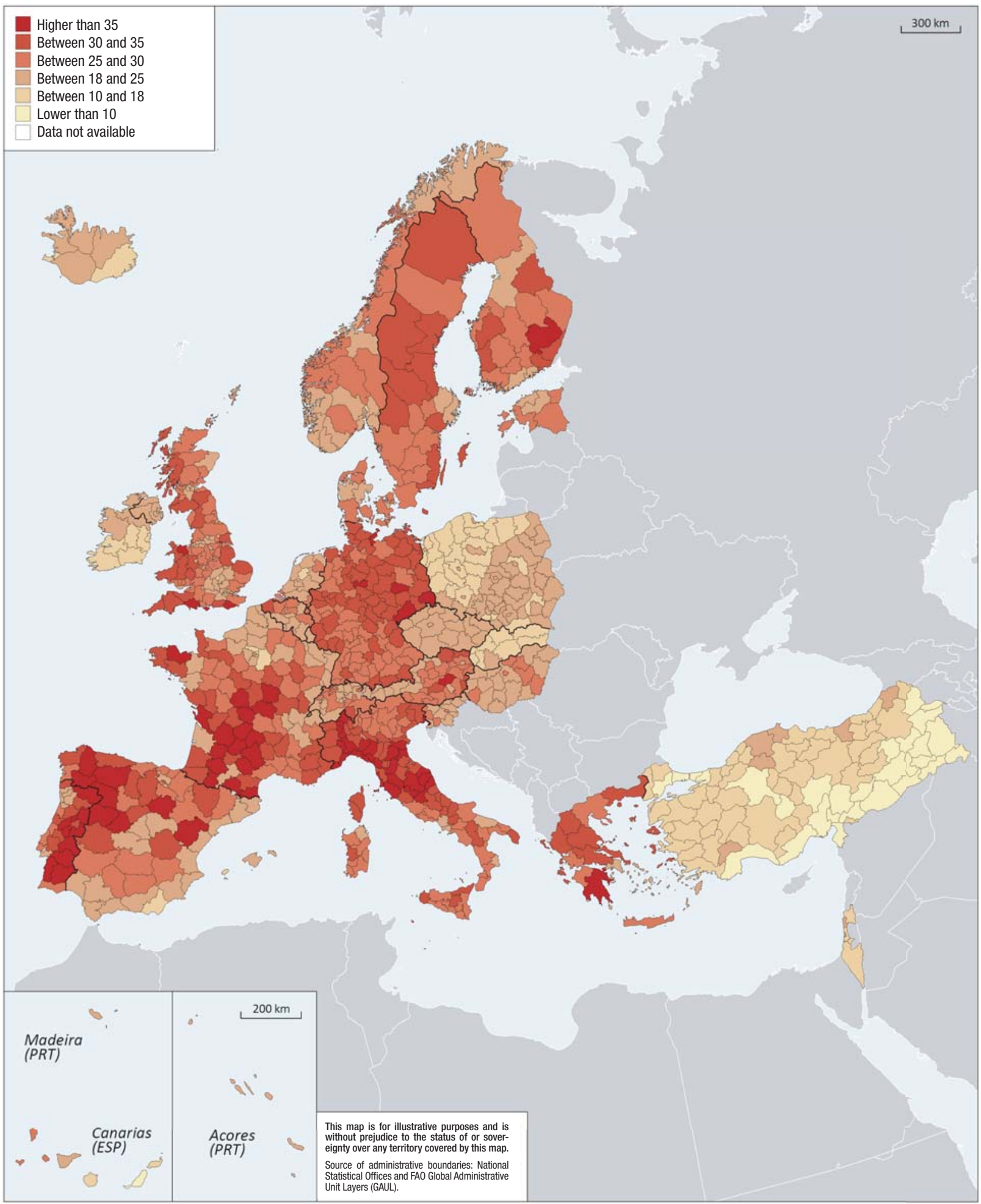

StatLink तiाst $h t t p: / / d x . d o i . o r g / 10.1787 / 888932440166$ 
19.7. Regional elderly dependency rate: Americas, 2008

Ratio between elderly population and working age population, TL3 regions

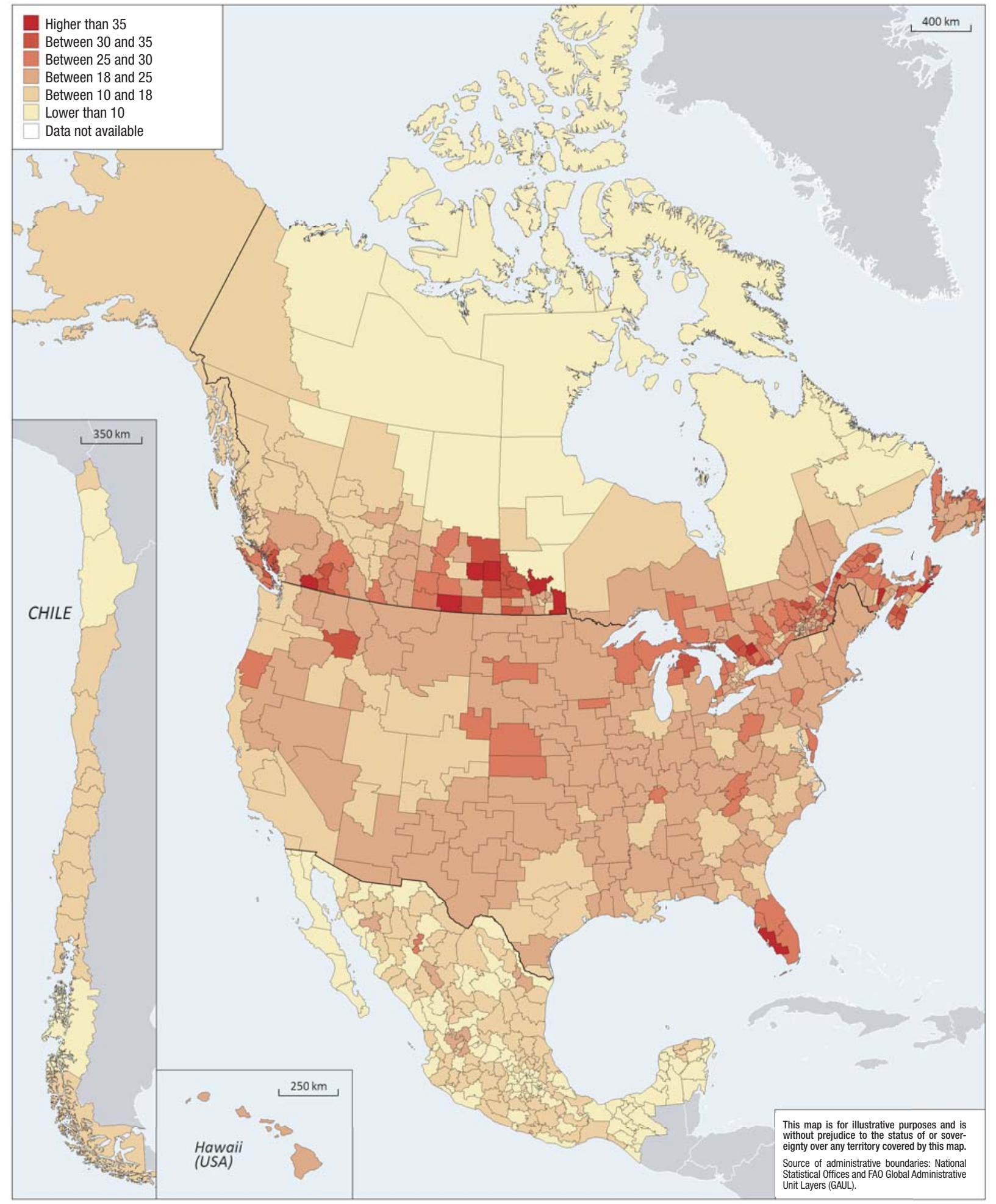

StatLink Aाs $h t$ ttp://dx.doi.org/10.1787/888932440166 
19.8. Regional elderly dependency rate: Emerging economies, 2008

Ratio between elderly population and working age population, TL2 regions

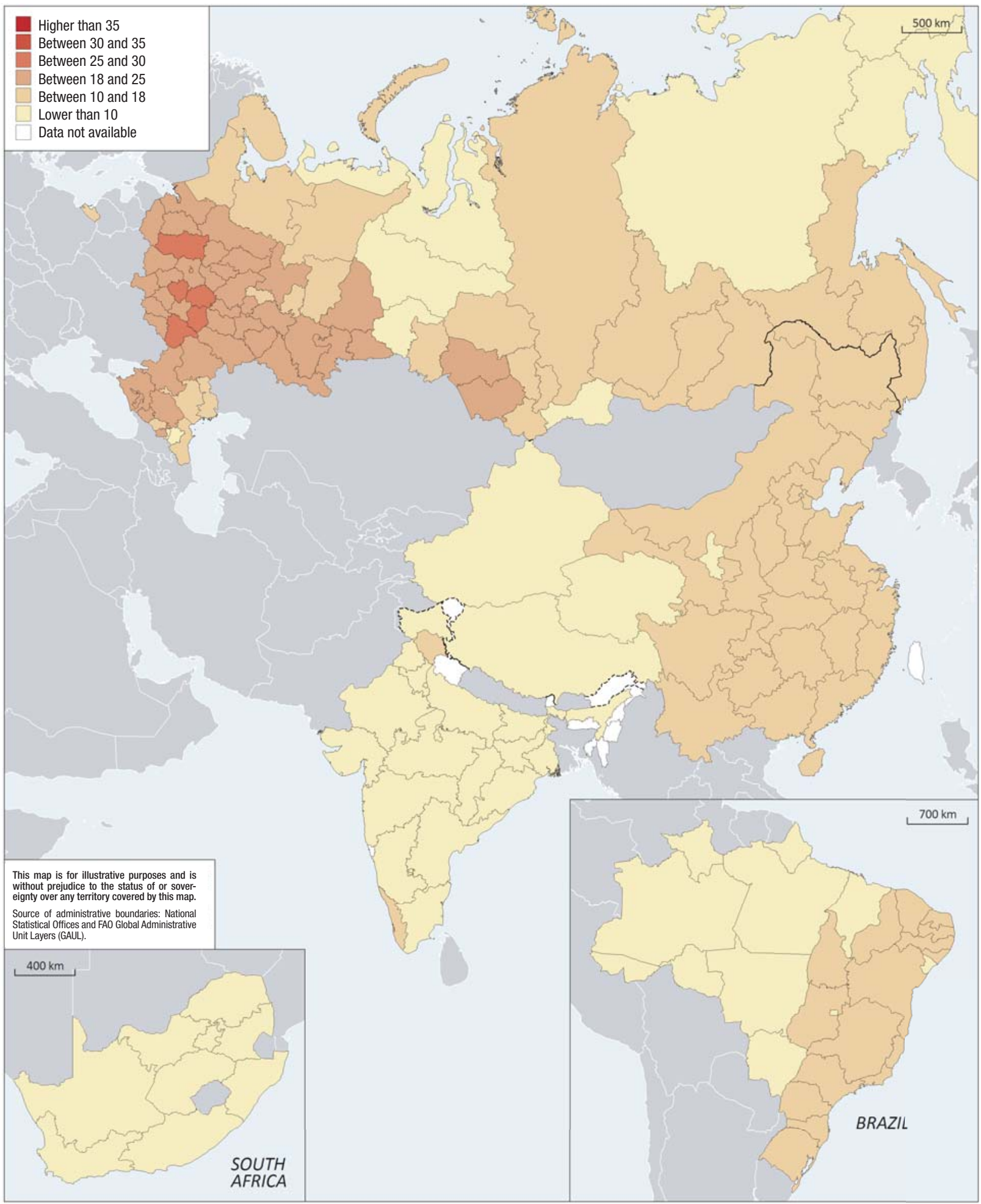

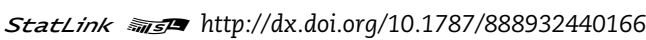


Interregional mobility within countries is an important component of the change in the demographic structure, indicating whether the ageing of certain areas is reinforced by outflows of the working age population.

Mobility between rural and urban regions of a country is quite varied: on aggregate, $60 \%$ of rural regions display net negative flows versus $50 \%$ of predominantly urban or intermediate regions. In the Czech Republic, Denmark and Japan all rural regions display net outflows of population. Rural regions in Japan will bear the largest share of the future decrease in population because of the already high incidence of elderly population reinforced by out-migration of young people. In contrast, in France, Korea and Switzerland more than $70 \%$ of predominantly urban regions have experienced net negative flows of population (Figure 20.1).

Distance to markets and services seems to be a stronger predictor of out-mobility than mere population density: in 12 out of the 13 countries considered, more remote rural regions - i.e. regions which are far in driving distance from urban agglomerations - are more likely to display net negative flows than predominantly rural regions. The exception of France is due to the recent positive mobility towards the western and southern TL3 regions (Figure 20.2).

Around $37 \%$ of OECD regions have experienced persistent out-migration in the last 15 years (i.e. they display net negative flows for at least $80 \%$ of the years observed in the data). These regions are characterised by a higher share of employment in agriculture and lower productivity in the same sector, a very low productivity of the public sector, a higher unemployment rate and lower gross domestic product (GDP) per capita. Net out-migration causes these regions to become "older". In addition, net out-migration has been towards higher population density regions (Figure 20.3).

Predominantly urban regions are the recipient of young migrants (those aged 16-24 years). In the United Kingdom, Switzerland and Norway more than $80 \%$ of young migrants move to urban regions. The mobility of young adults - onethird of the total internal mobility - is essentially a migration from rural to urban regions where higher education facilities and more diverse job opportunities can be found. The urban regions of Seoul (Korea), Madrid and Zaragoza (Spain) as well as urban regions in Switzerland and the United Kingdom attract young migrants, at the same time reporting negative net internal migration. However, thanks to international migration the total population continues to grow. The urban regions in the south of Italy, in contrast, are losing their young population and are seeing a decline in total population (Figure 20.4).

\section{Definition}

Data refer to yearly flows of population from one TL3 region to another TL3 region. Outflows are represented as the number of persons who left the region the previous year to reside in another region of the country, while inflows are represented as the number of new residents in the region coming from another region of the country.

The net interregional flow is defined as the difference between inflows and outflows in a region. A net negative flow represents a loss of population due to migration in that year.

A region is said to experience persistent out-migration in a certain period if it shows net out-migration for at least $80 \%$ of the years considered.

Young migrants are those aged between 18 and 24 .

\section{Source}

OECD Regional Database: http://dotstat/wbos/.

See Annex B for data, source and country-related metadata.

\section{Reference years and territorial level}

1996-2008; TL3.

Australia and Mexico TL2.

Data for Belgium, Chile, Estonia, Greece, Ireland, Iceland, Israel, New Zealand and Slovenia are not available at regional level.

\section{Further information}

Territorial grids and regional typology (Annex A)

www.oecd.org/gou/regional/statisticsindicators

M. Brezzi and M. Piacientini (2011), "Labour mobility and development dynamics in OECD regions", Regional Development Working Papers 2011/04.

\section{Figure notes}

20.1-20.3: Latest available year: Canada, Germany and Italy 2007, France 2006 and Portugal 2001 (Census data).

20.1: Australia and Mexico are not included because data are at TL2 level.

20.2: The Czech Republic, Germany, the Netherlands and the Slovak Republic do not have predominantly remote rural regions.

20.3: Total regions $=100$. For lack of time series on comparable years the Czech Republic, Denmark, Portugal and Turkey are not included.

20.3-20.5-20.6: Regions are classified as "persistent out-migration" if they experienced net negative flows for at least $80 \%$ of the years observed; as "prevalent out-migration" if they fall in the range $50-80 \%$ of the years observed; "intermittent out-migration" if between $20-50 \%$ of the years observed; "rare out-migration" if less than $20 \%$ of the years observed.

20.4: Portugal 2001 


\section{POPULATION MOBILITY AMONG REGIONS}

20.1. Share of TL3 regions with net negative flows by typology of regions, 2008

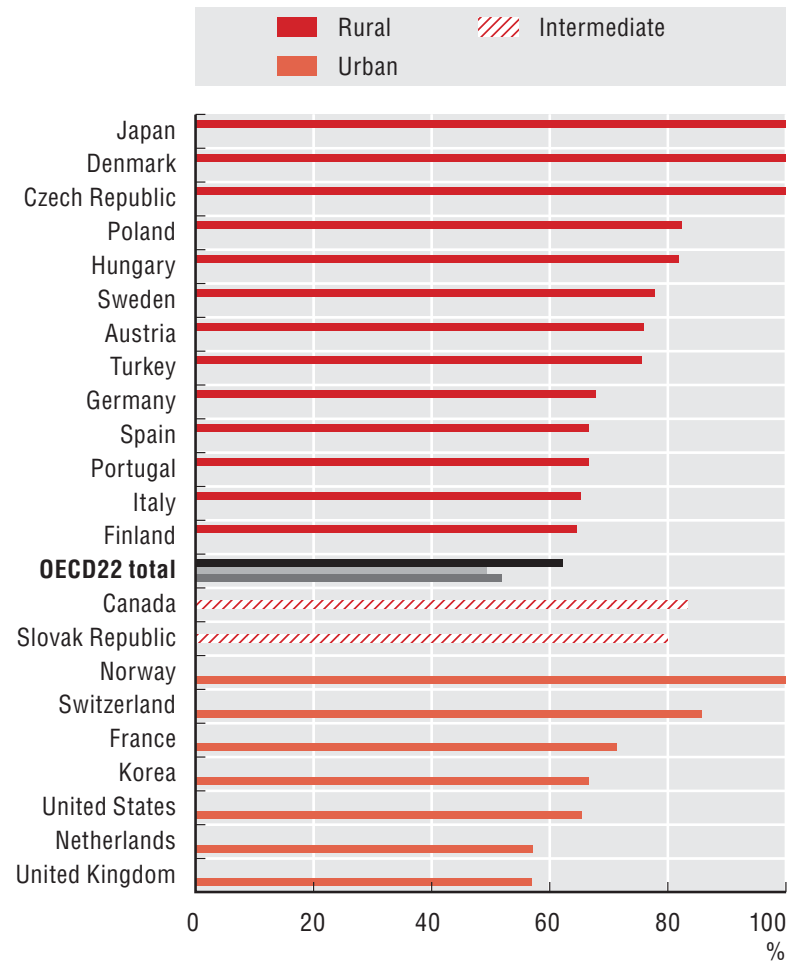

20.3. Regional characteristics by degree of persistent loss of population, 1996-2008 (average for all regions $=100$ )

Rare out-migration

Prevalent out-migration

Share of employment of the public sector

Labour productivity of the public sector

Unemployment rate

GDP per capita (USD)

Labour productivity of agriculture

Share of employment in agriculture

Pop. density

$\%$ of old population

Share of rural regions

Share of urban regions

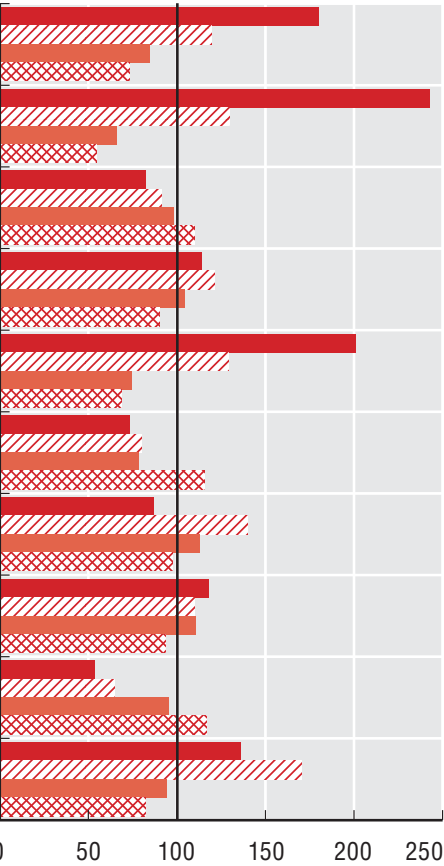

20.2. Percentage of TL3 remote rural regions with net negative flows of population, last 3 available years

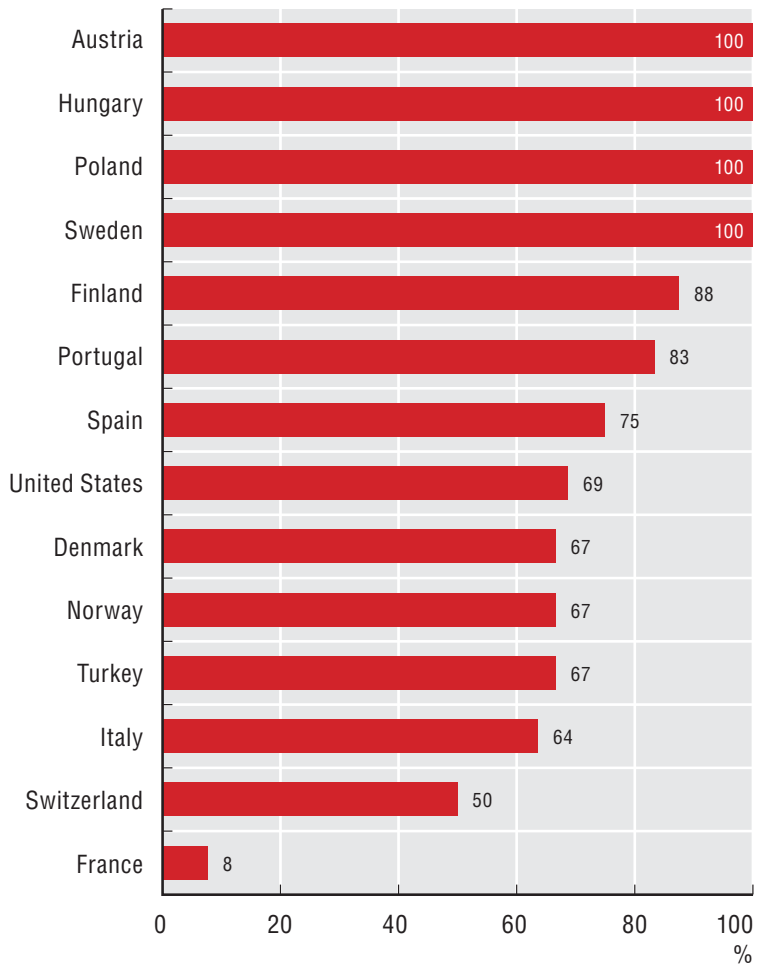

20.4. Young immigrants in large urban regions as a $\%$ of young immigrants in the country, 1996 and 2008

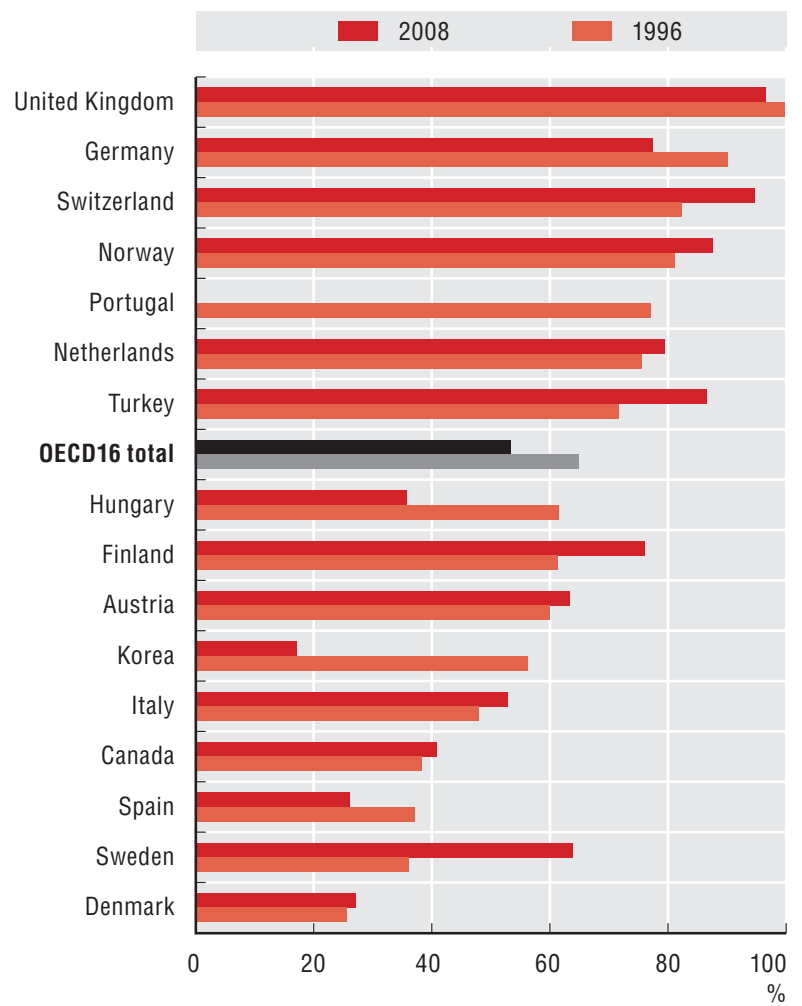

StatLink गाISட http://dx.doi.org/10.1787/888932439767 
20.5. Net interregional flows of population: Asia, Europe and Oceania, 1995-2008 TL3 regions

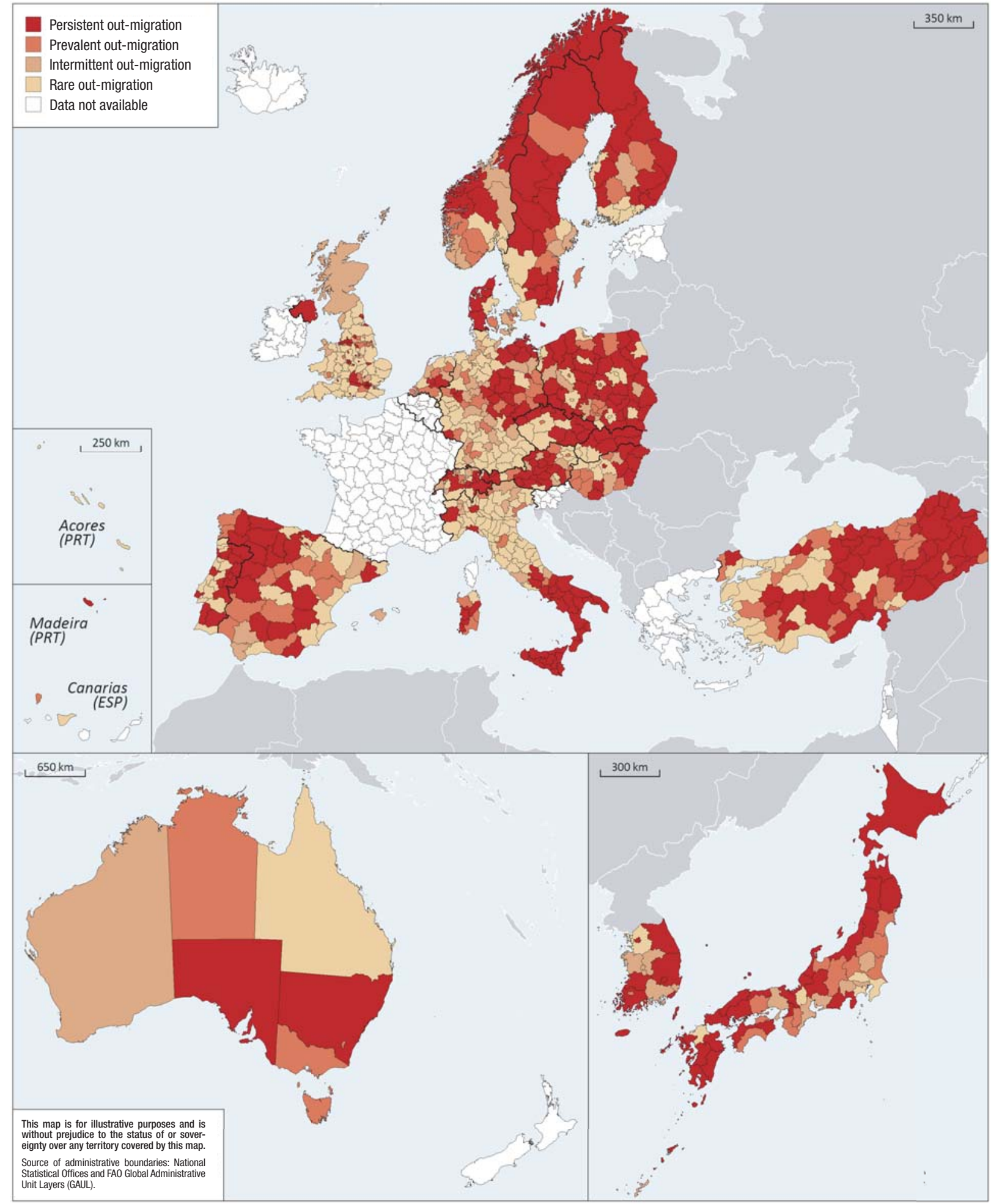

StatLink काIs $h t t p: / / d x . d o i . o r g / 10.1787 / 888932440185$ 


\section{POPULATION MOBILITY AMONG REGIONS}

20.6. Net interregional flows of population: Americas, 1995-2008

TL3 regions

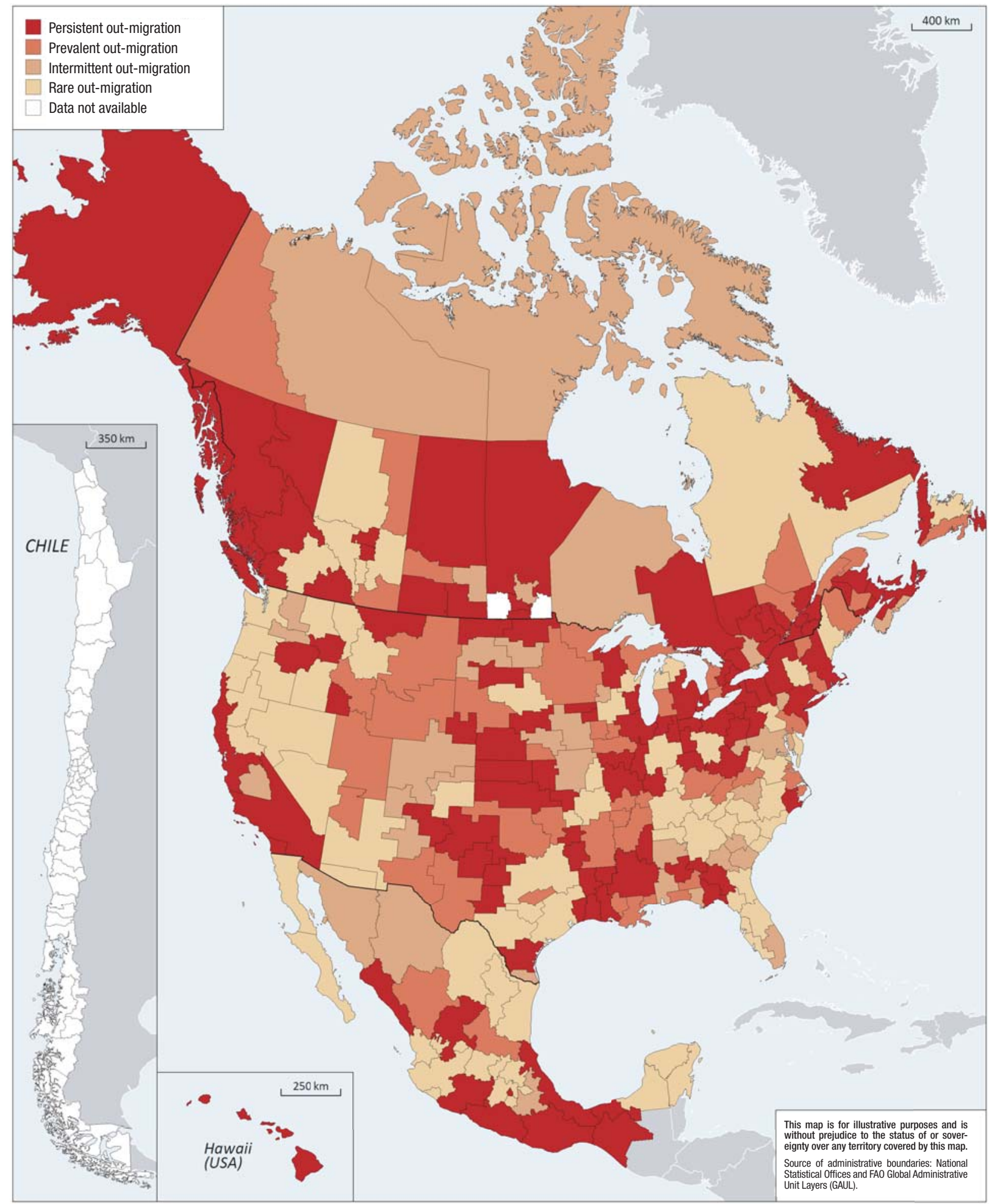

StatLink Aiाsस http://dx.doi.org/10.1787/888932440185 
California, New York, Texas and Florida in the United States had the highest foreign-born population among OECD regions in 2005 (more than 3.6 million each). California hosts more immigrants than any OECD country and the state of New York would rank fifth, after Canada, Australia, the United Kingdom and France, if compared to OECD countries. The stock of immigrants accounts for more than one-third of the total population in some TL2 regions in Australia, Canada and Switzerland, as well as in London (United Kingdom).

Immigrants are more concentrated than the native population in certain regions, although there are large variations across countries. The density index of immigrant population shows that in many countries the density of the immigrant population is at least 1.5 higher in capital regions than in any other region. In Italy, Spain, Switzerland and the United States, in contrast, the presence of immigrants tends to be spread across a relatively large number of regions, comprising both metropolitan areas and mediumsized cities (Figure 21.1).

International migration trends have both intensified and diversified in terms of countries and regions of destination; recent migration trends have been marked by a rapid increase in inflows, notably in southern European countries, the United Kingdom and Ireland in the context of the European Union (EU) enlargement. In four Spanish regions recent migrants represent more than $7 \%$ of the total population and the same four regions are among the top 20 TL2 regions in absolute value of recent migrants. London emerges as a major region for recent immigrants: more than $13 \%$ of the population were recent migrants and with a density index four times higher than the rest of the country (Table 21.2).

Two opposite effects contribute to explaining the changes or the persistence in the regional distribution of immigrants. On the one hand, network effects tend to generate inertia in the settlement choices of recent immigrants; on the other hand, specific policies and regional economic development may contribute to channelling new migrants towards new regions. Figure 21.3 shows a strong correlation between the percentage of recent and established migrants among the Asian-born community (similar results are found among the African- and Oceania-born and to a lesser extent for Latin-American migrants). The network effect is not identifiable in the case of European migrants. Because of the EU enlargement in 2004 new migration channels emerged from new EU member states to regions that were not hosting many migrants before the enlargement.

\section{Definition}

The stock of immigrants in a region is defined as the number of foreign-born population residing in the region in 2005. Recent migrants are defined as persons who arrived in the country within the previous five years.

The density index of the immigrant population in a region is given by the ratio between the share of immigrants in the region over total immigrants and the share of regional population over total population. The index is higher than 1 when immigrants are over-represented in a region (compared to the national average).

\section{Source}

OECD Database on Immigrants (DIOC) and OECD Regional Database.

See Annex B for data, source and country-related metadata.

\section{Reference years and territorial level}

2005-06; TL2 and TL3.

Data on immigrants by region are not available in Chile, the Czech Republic, Iceland, Japan, Korea, Poland and Turkey.

\section{Further information}

OECD (2009), International Migration Outlook 2009, OECD Publishing. DOI: 10.1787/migr_outlook-2009-en.

OECD (2010), "Determinants of localisation of recent immigrants across OECD regions", www.oecd.org/dataoecd/61/ 49/45344744.pdf. 


\section{IMMIGRATION TRENDS IN OECD REGIONS}

21.1. Density index of the immigrant population, 2005

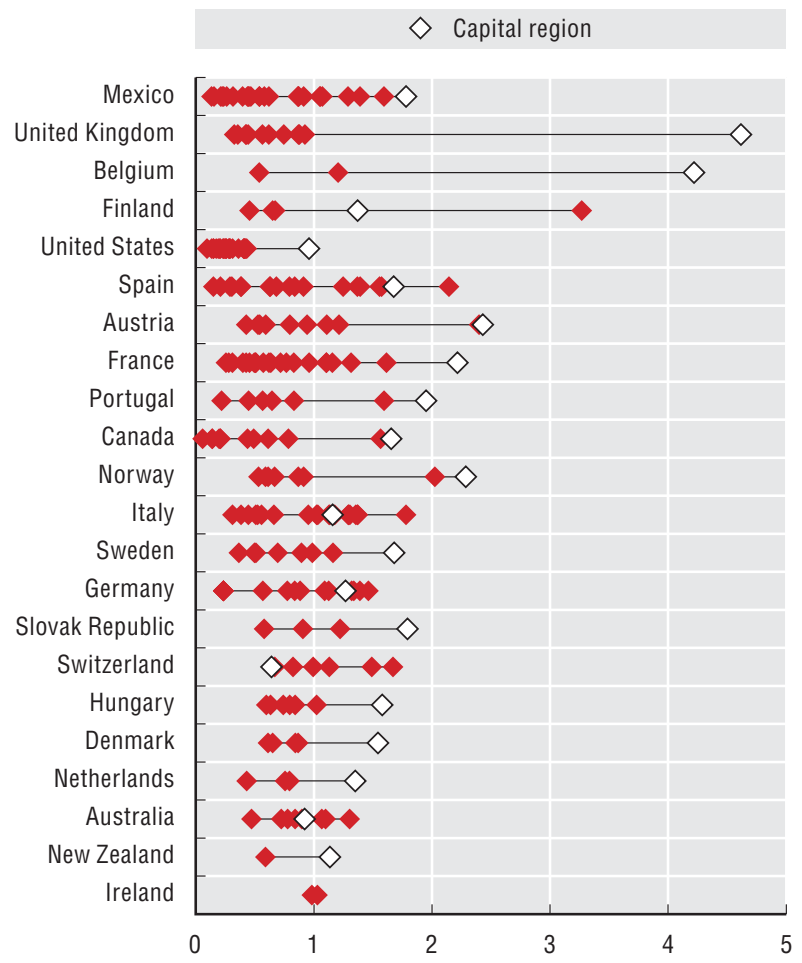

21.2. Top 20 TL2 regions in terms of recent immigrants, 2005

\begin{tabular}{lr|lr}
\hline \multicolumn{2}{l|}{ Rank by number of recent migrants } & $\begin{array}{l}\text { \% population of the region that is recent } \\
\text { immigrant }\end{array}$ \\
\hline USA - California & 1206993 & BEL - Reg -Bruxelles-Cap & 13.1 \\
GBR - London & 795159 & GBR - London & 13.1 \\
USA - Florida & 594924 & ESP - Murcia & 9.5 \\
USA - Texas & 588990 & ESP - Baleares & 9.4 \\
USA - New York & 552552 & ESP - Comunidad Valenciana & 8.8 \\
CAN - Ontario & 464865 & ESP - Madrid & 8.8 \\
ESP - Madrid & 435013 & NZL - North Island & 8.3 \\
ESP - Cataluna & 410406 & ESP - Rioja & 7.4 \\
ESP - Comunidad Valenciana & 339421 & CHE - Region Lemanique & 7.3 \\
USA - New Jersey & 270102 & ESP - Cataluna & 7.1 \\
USA - Illinois & 255878 & LUX - Luxembourg & 6.7 \\
FRA - Ile De France & 239206 & ESP - Canarias & 6.3 \\
GBR - South East & 237578 & AUT - Wien & 6.2 \\
ESP - Andalucia & 229289 & ESP - Navarra & 5.6 \\
NDL - West-Nederland & 224355 & CHE - Zürich & 5.5 \\
DEU - Nordrhein-Westfalen & 216854 & NZL - South Island & 5.2 \\
AUS - New South Wales & 214612 & ESP - Aragon & 5.2 \\
NZL - North Island & 197496 & IRL - Southern And Eastern & 5.0 \\
USA - Georgia & 191683 & CAN - Ontario & 4.7 \\
USA - Arizona & 178263 & CHE - Ticino & 4.7 \\
\hline & & &
\end{tabular}

\subsection{Share of recent and established migrants as a \% of TL3 regional population, 2005}

Network effects - Asian-born population

Recent migrants (\% of regional population)

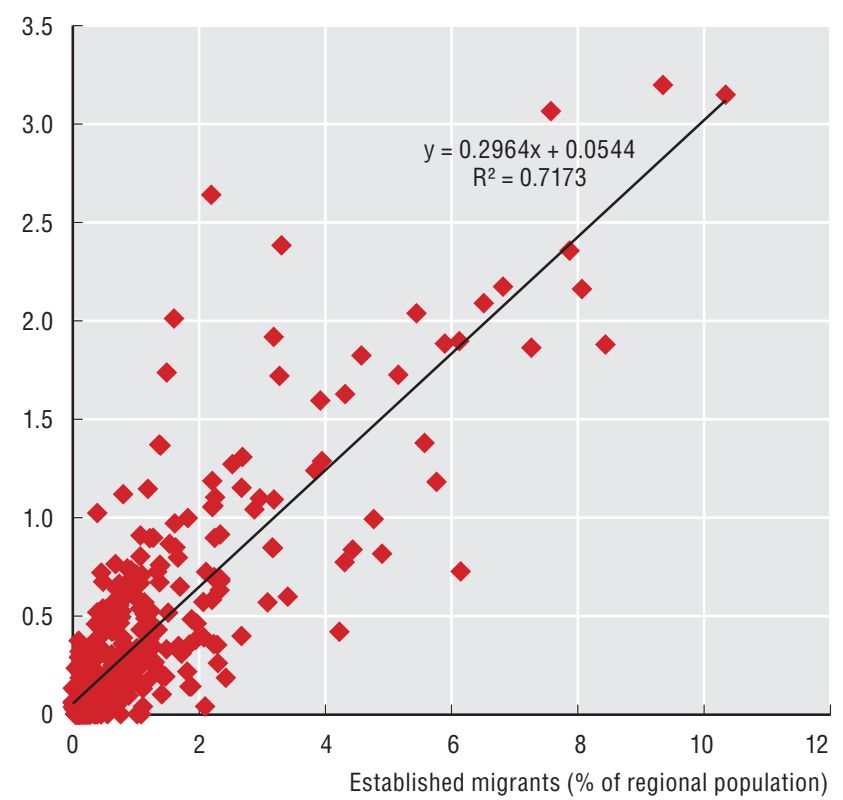

Network effects - European-born population

Recent migrants (\% of regional population)

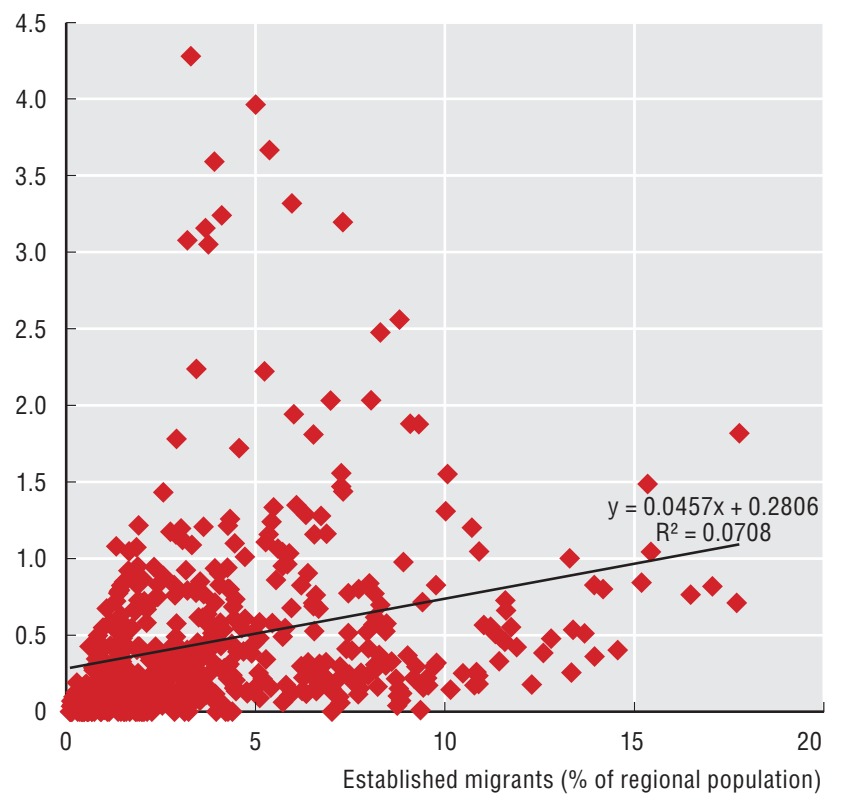

StatLink AाISL http://dx.doi.org/10.1787/888932439786 
Unemployment has soared in OECD countries in recent years, from $5.6 \%$ in 2007 to $8.3 \%$ in 2009 . Recent OECD analysis suggests a further rise in the past two years. In 2009, regional differences in unemployment rates within OECD countries were almost two times higher (28 percentage points) than differences among OECD countries (15 percentage points).

Regional disparities in unemployment were already high before the economic crisis in countries such as Canada, Germany, Italy, Spain and the Slovak Republic. Overall the economic downturn has aggravated problems of the most fragile regions. The Gini index gives a measure of differences in unemployment rates among all regions in a country. According to this measure Belgium, Germany, Italy and the Slovak Republic displayed the highest inequalities among OECD countries. Large regional differences were also found in China and the Russian Federation (Figure 22.1).

Young people have been hit hardest by the economic crisis: youth employment fell by $8 \%$ between the end of 2008 and the end of 2009, nearly four times the decline in overall employment. Unemployment among young people in OECD countries was high at 16.7\% in 2009.

Youth unemployment is of particular concern in Italy, France, the Slovak Republic, Turkey, Poland and Spain, where regional differences are high and some regions display a youth unemployment rate over 30\% (Figure 22.2). These regions display also higher than average early leavers from education and training, suggesting that specific policies to improve the employability of these people through training and apprenticeship are needed.

Among the unemployed, the long-term unemployed (i.e. those who have been unemployed for 12 months or more) are of particular concern to policy makers both for their impact on social cohesion and because those individuals become increasingly unattractive to employers. The regional long-term unemployment is, therefore, an indicator of labour-market rigidity. Moreover, it highlights areas with individuals whose inadequate skills prevent them from getting a job.

In almost $40 \%$ of the regions considered one out of three unemployed was out of the labour market for more than a year (Figure 22.3).

Similarly, the long-term unemployment rate showed large regional variations not only in dual economies such as Italy or Germany, but also in Spain, the Slovak Republic, Belgium, Turkey and Hungary (Figure 22.4).

\section{Definition}

Unemployed persons are defined as those who are without work, who are available for work and have taken active steps to find work in the last four weeks. The unemployment rate is defined as the ratio between unemployed persons and labour force, where the latter is composed of unemployed and employed persons.

The youth unemployment rate is defined as the ratio between the unemployed persons aged between 15 and 24 and the labour force in the same age class.

The long-term unemployment rate is defined as the ratio of those unemployed for 12 months or more out of the total labour force.

The incidence of long-term unemployment is defined as the ratio between long-term unemployed and total unemployed.

The Gini index is a measure of inequality among all regions of a given country (see Annex $\mathrm{C}$ for the formula). The index takes on values between 0 and 1 , with zero interpreted as no disparity. It assigns equal weight to each region regardless of its size; therefore differences in the values of the index among countries may be partially due to differences in the average size of regions in each country.

\section{Source}

OECD Regional Database: http://dotstat/wbos/.

See Annex B for data, source and country-related metadata.

\section{Reference years and territorial level}

1999-2009; TL3.

Australia, Chile, Iceland, Portugal, Switzerland and Turkey only TL2. Canada non-official grids.

Data on long-term unemployment and youth unemployment are available only at TL2 level.

\section{Further information}

OECD (2010), Off to a Good Start? Jobs for Youth, OECD Publishing, DOI: 10.1787/9789264096127-en.

\section{Figure notes}

Information on data for Israel: http://dx.doi.org/10.1787/888932315602. 22.7: Chile and Mexico TL2; Canada NOG. 
22.1. Gini index of TL3 regional unemployment rates, 1999 and 2009

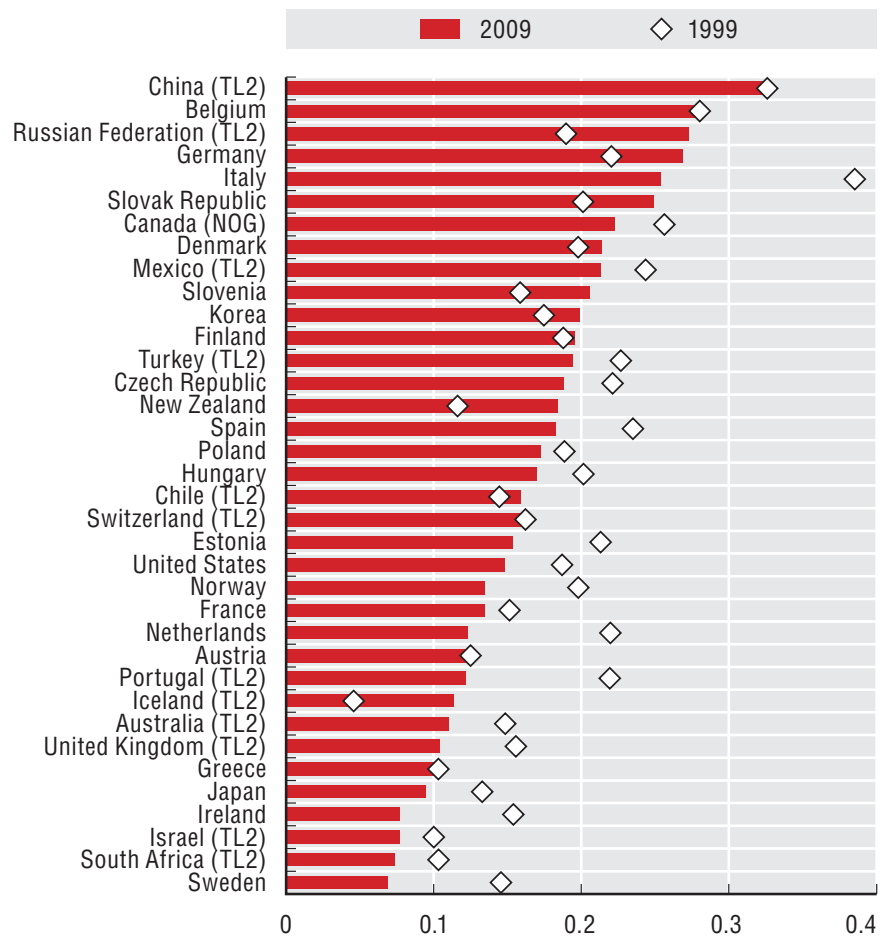

22.3. TL2 regional incidence of long-term unemployment as a \% of total unemployment, 2009

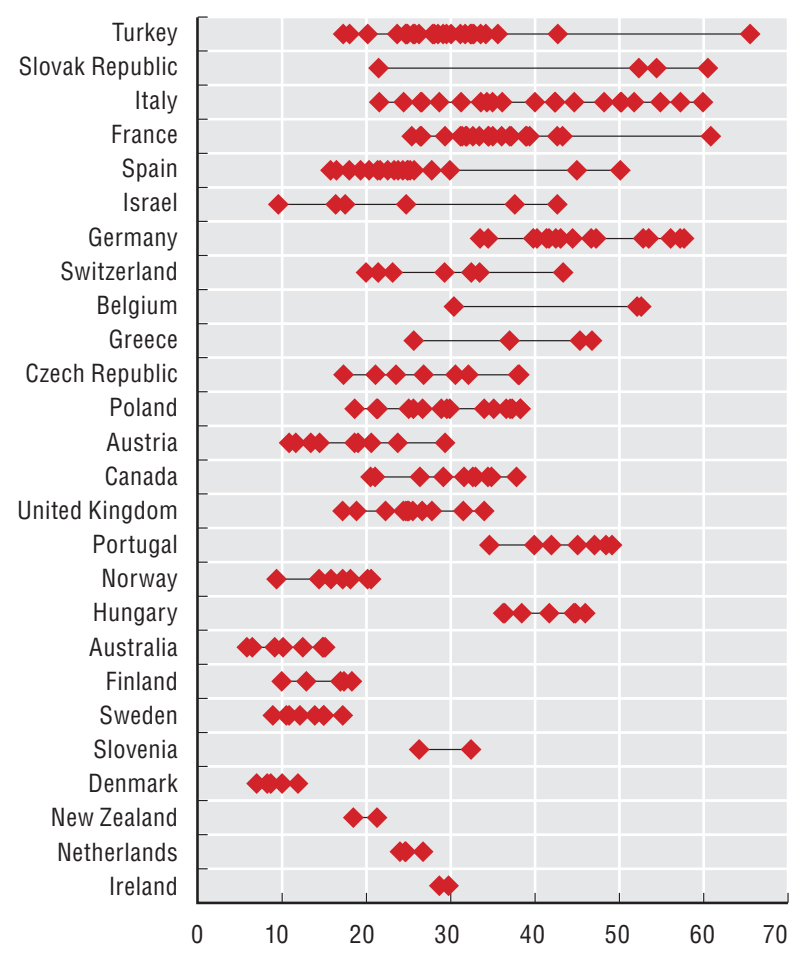

22.2. TL2 regional variation in the youth unemployment rate, 2009

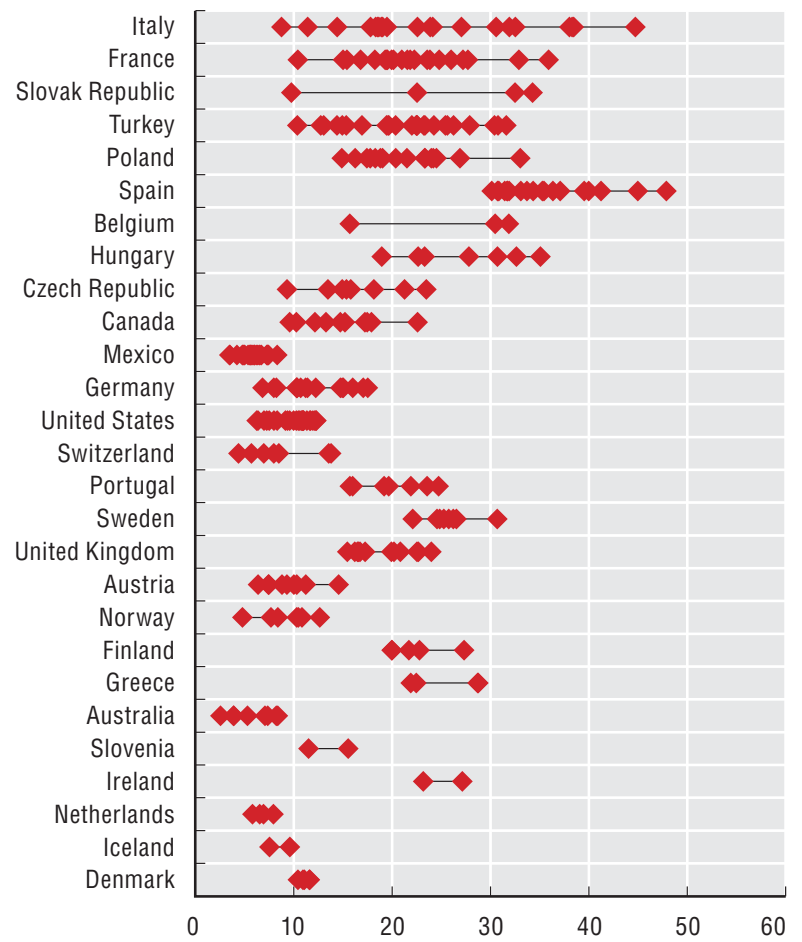

22.4. TL2 regional variation in long-term unemployment rates, 2009

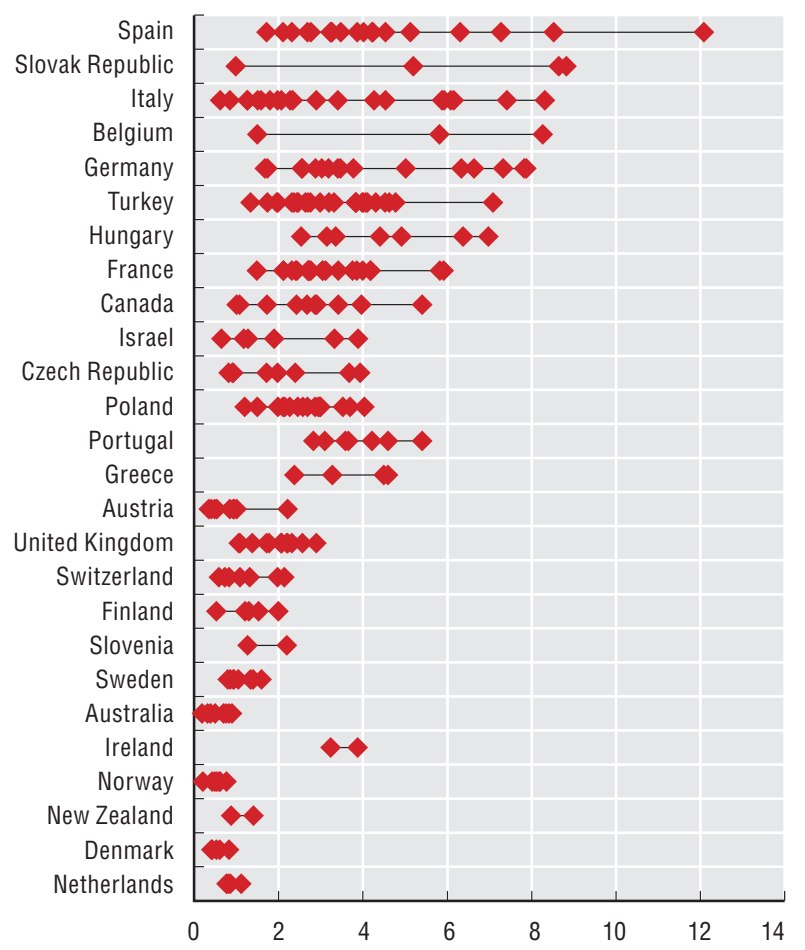

StatLink AाsL http://dx.doi.org/10.1787/888932439805 
22.5. Regional unemployment rates: Asia and Oceania, 2009

TL3 regions

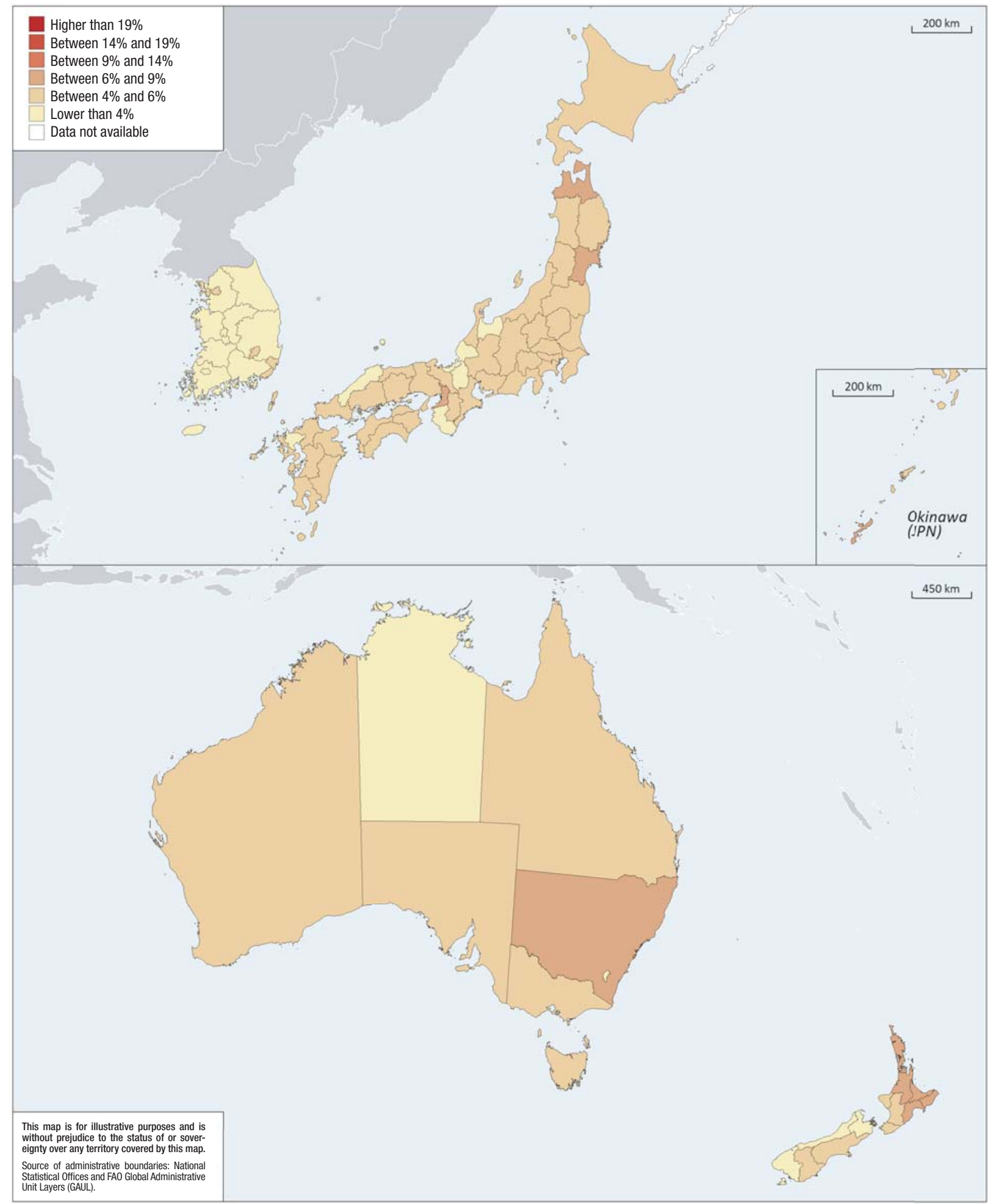

StatLink जाISL http://dx.doi.org/10.1787/888932440204 
22.6. Regional unemployment rates: Europe, 2009

TL3 regions

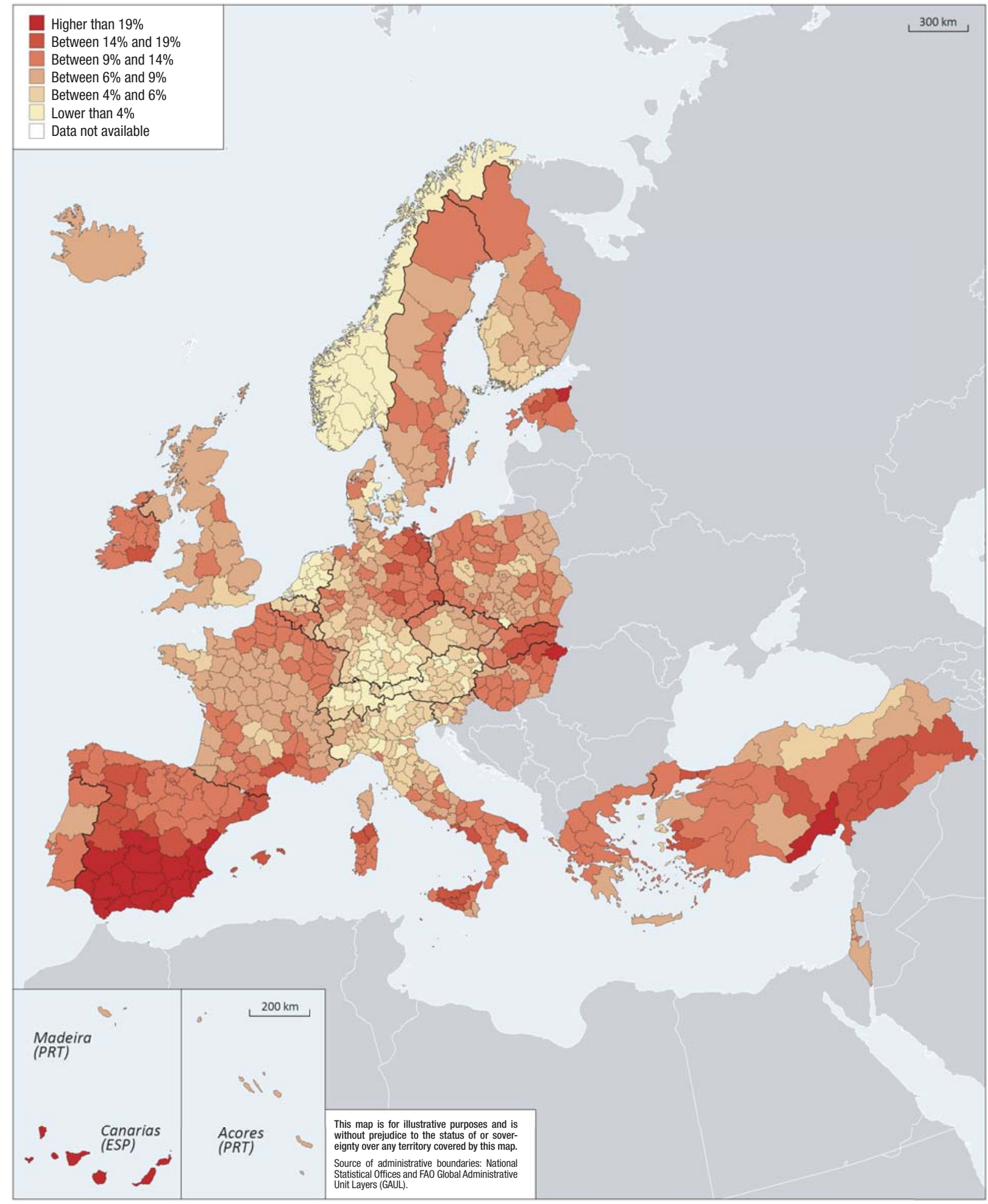

StatLink AाISL $h t t p: / / d x . d o i . o r g / 10.1787 / 888932440204$ 
22.7. Regional unemployment rates: Americas, 2009

TL3 regions

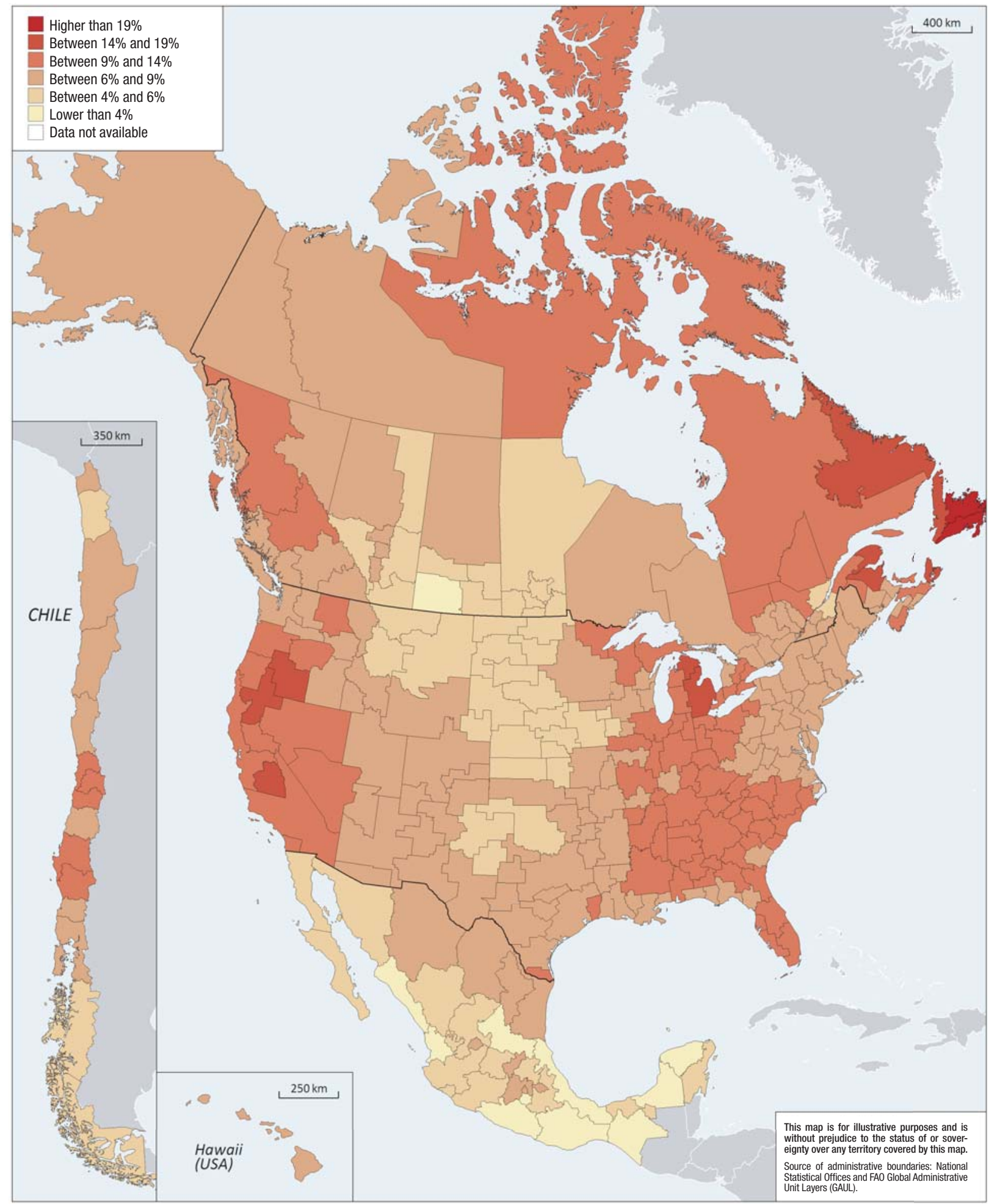

StatLink Aाs $h t$ ttp://dx.doi.org/10.1787/888932440204 


\section{REGIONAL DISPARITIES IN UNEMPLOYMENT}

22.8. Regional unemployment rates: Emerging economies, 2009

TL2 regions

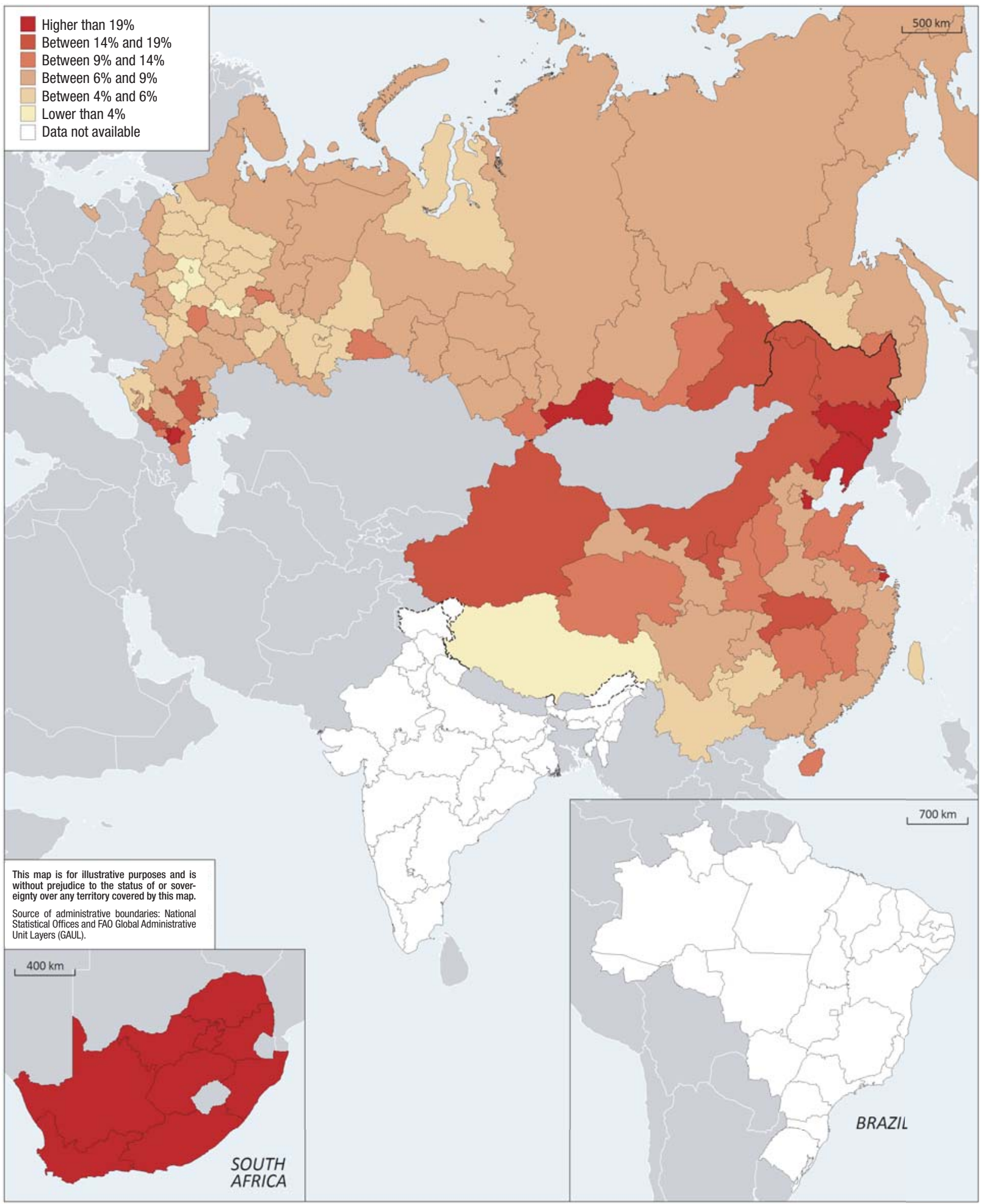

StatLink Aiाst $h t t p: / / d x . d o i . o r g / 10.1787 / 888932440204$ 
About $61 \%$ of all women in OECD countries were in the labour force, compared with $80 \%$ of all men in 2009. Broadening access to women to the labour market would require a mix of policies, including equal access to higher education and training; measures to reconcile family and work life; and tools to strengthen gender equality in the workplace.

Regional differences in male and female participation rates were above 20 percentage points in Turkey, Italy, Mexico, Korea and Poland. In Poland and Mexico these differences are due to particularly low female labour-force participation in predominantly rural regions. In Italy, Korea and Turkey the difference between male and female participation rates is often marked in predominantly urban regions, such as Istanbul in Turkey and Incheon in Korea, and in medium-sized urban areas in Italy (Figure 23.1). Regional differences in female participation rates suggest that the availability and use of services to reconcile family and work life (i.e. child care and day care facilities, parental leaves and tax/benefit policies to families) are also quite diverse within countries.

There is a smaller participation of women than men in the labour force in countries with low participation rates and high geographical disparities, such as Turkey, Poland and Italy (Figure 23.2). Regional disparities in participation rates, measured here by the Gini index, have generally decreased from 1999 to 2009 due to an increase of labourforce participation in less advantaged regions, such as in Greece, France, Portugal and the United Kingdom. The Gini index showed the greatest decline in Ireland, thanks to an increased labour force in the regions with low participation rates up to 2007, but also due to a steep reduction of the labour-force participation in Dublin in 2009-10. Regional inequalities in participation rates increased most in Iceland, Italy and New Zealand, where labour-force participation increased more in the regions with higher participation rates (Figure 23.2).

The female employment rate steadily increased in OECD countries up to 2007 , when it reached $57.2 \%$ and then declined to $56.7 \%$ in 2009 as a result of the job losses following the economic recession. However, in around $25 \%$ of OECD regions, less than one out of two women was employed in 2009. Regional differences in female employment were the largest in Italy, Spain, the United States, France, Portugal, Mexico and the Slovak Republic (Figure 23.3).
Employment rates are generally higher for workers with tertiary qualifications and differences in employment rates between males and females are wider among less educated groups (OECD Education at a Glance 2010). The correlation between high educational achievement and female employment at regional level could be tested only using the regional educational attainment of the total labour force; in this case, 17 out of the 23 countries considered showed a positive linear association (Figure 23.4).

\section{Definition}

Employed persons are all persons who during the reference week worked at least one hour for pay or profit, or were temporarily absent from such work. Family workers are included.

The female employment rate is calculated as the ratio between female employment and female working age population (aged 15- 64 years).

The participation rate is the ratio of the labour force to the working age population. The labour force is defined as the sum of employed and unemployed people.

\section{Source}

OECD Regional Database: http://dotstat/wbos/.

See Annex B for data, source and country-related metadata.

\section{Reference years and territorial level}

1999-2009; TL3.

Australia, Canada, France, Mexico, Portugal, Switzerland, Turkey, United Kingdom and United States female participation rates only TL2.

\section{Figure notes}

23.3: No regional data in Turkey. 
23.1. Differences between female and male participation rates, TL3 regional minimum and maximum values, 2009

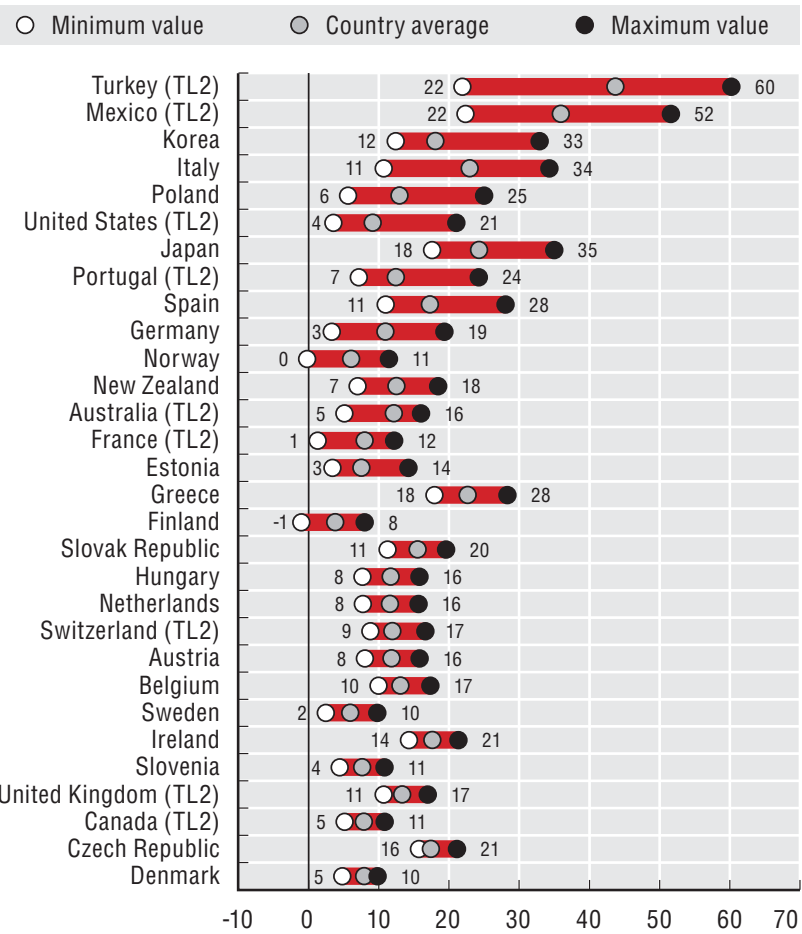

23.3. Countries ranked by size of difference in TL2 regional female employment rate, 2009

$\bigcirc$ Minimum $\quad \bigcirc$ Country average female employment rate

- Maximum

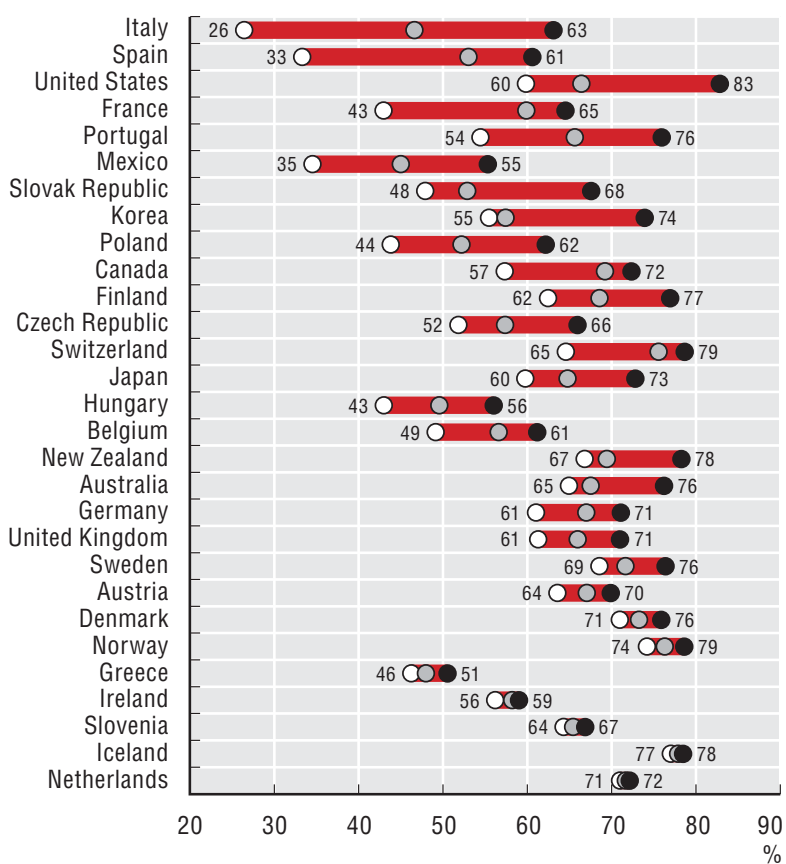

23.2. Gini index of TL3 regional participation rates, 1999 and 2009

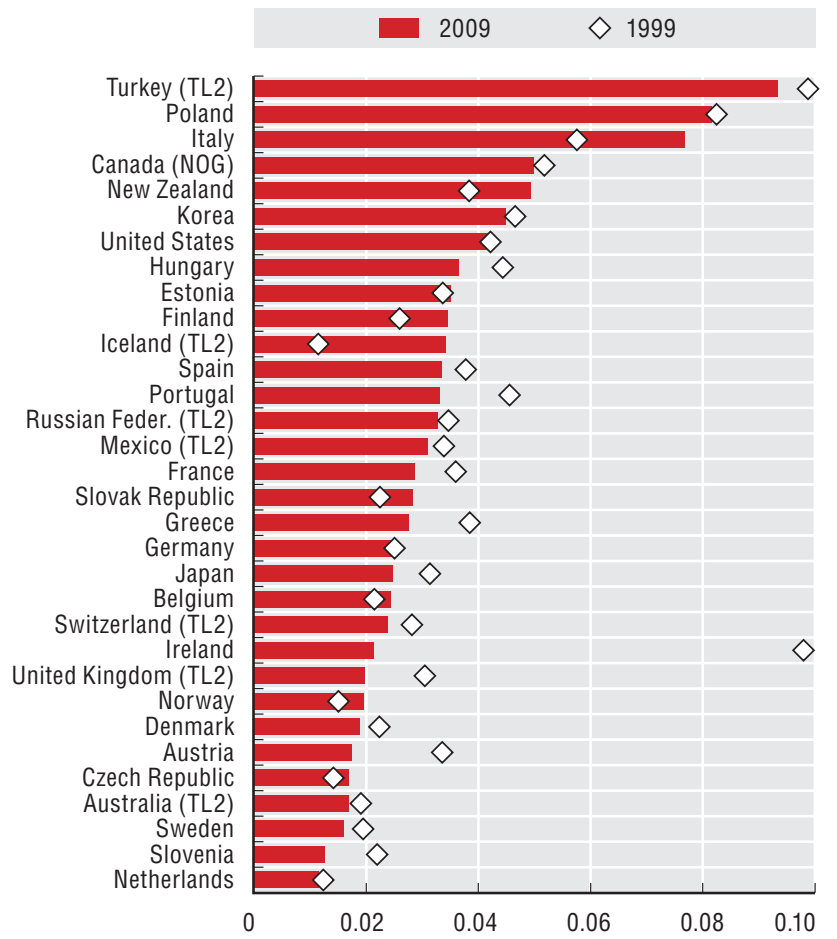

23.4. Pearson correlation between female employment rate and higher educational attainment, 2008

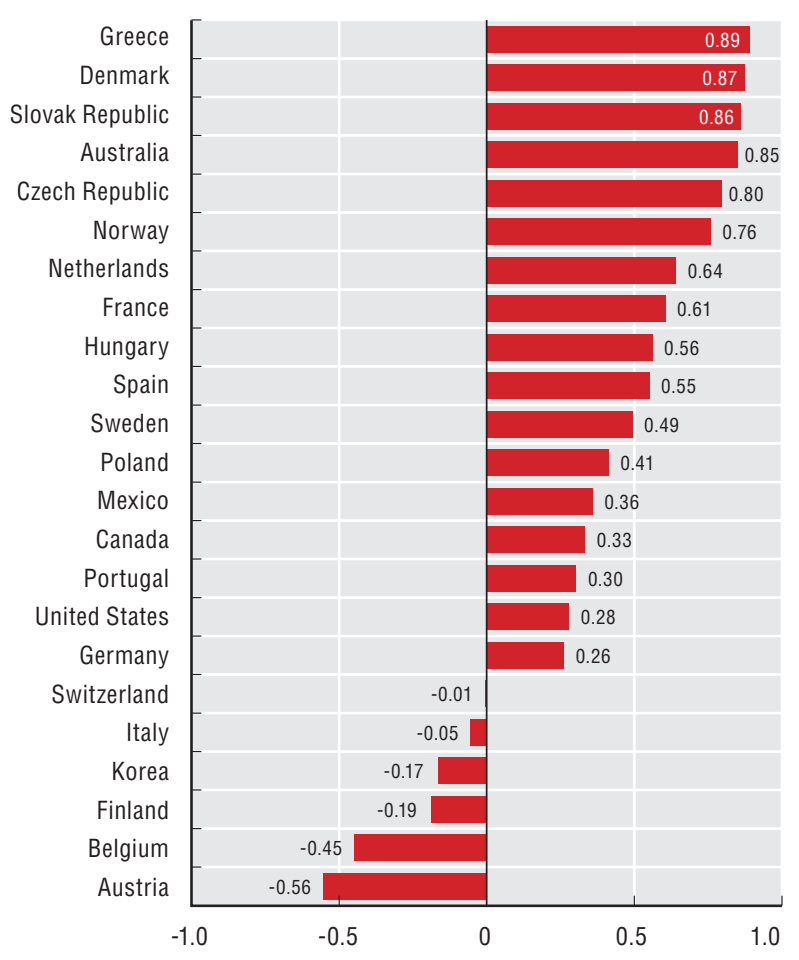

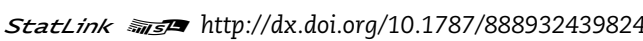


Education provides individuals with knowledge and competencies to participate effectively in society and to break the cycle of disadvantage. Still, in 2008 one-fourth of the OECD population had only a basic education and in most of the regions in Mexico and Portugal, and in some regions in Chile and Spain, this proportion was as high as $50 \%$.

Large regional differences in education attainment within a country are generally found in countries with a high proportion of adults with only basic education attainment. This is the case of France, Greece, Mexico, Portugal and Spain. However, in Germany, Korea and the United States the share of population with only basic education is lower than the OECD average, but regional differences are higher (Figure 24.1).

In the knowledge-based economy the demand for skills is increasing and a high school diploma has become the minimum level to participate in the job market. On average, $80 \%$ of an age cohort in 2008 is estimated to complete upper secondary education in OECD countries (Education at a Glance 2010). However, the number of young adults (aged 18-24) who have not completed upper secondary education and are not enrolled in training - the early school leavers is high in some countries such as, Portugal, Spain and Turkey. Opportunities within countries also seem to be very different: the difference between regions in the share of early school leavers is high in Italy, Greece and the United Kingdom, besides Portugal, Spain and Turkey (Figure 24.2).

Regional inequalities in education attainment persist also for higher levels of education; the most in Canada (mostly due to the unequal distribution of population in the country), Chile, Portugal and Finland. The Gini index of regional labour force with at least upper education has decreased only in half of the OECD countries over the past ten years (Figure 24.3).

Educational attainment and graduation rates alone do not capture the quality of educational outcomes. Monitoring the outcomes of education in different regions can give insight of where/ how to intervene. Countries that have undertaken the OECD PISA survey at the regional level show that regional disparities in learning outcomes also persist in unitary educational systems (OECD PISA 2009 Results: Annex B2 - Results for regions within countries). Even when taking into account the different socio-economic backgrounds of students, the location of schools still matter: in the OECD area, students in city schools outperform rural areas by more than 20 score points, or the equivalent of almost one year of education (Figure 24.4).

\section{Source}

OECD Regional Database: http://stats.oecd.org/WBOS.

See Annex B for data, source and country-related metadata.

OECD PISA www.oecd.org/edu/pisa/2009.

Early school leavers - Eurostat LFS.

\section{Definition}

The educational attainment rate is defined as the proportion of labour force with a certain level of education. The international standard classification for education (ISCED 97) is used to define the levels of education. Pre-primary, primary and lower secondary education comprises the 3 lowest ISCED levels: 0, 1 and 2. For simplicity, here it is referred as basic education (or lower secondary education). Upper secondary education comprises ISCED levels 3-4, while tertiary education levels 5-6.

The population aged 18-24 that has at most attained a lower secondary diploma and is not following any training is defined as early school leavers.

The Gini index is a measure of inequality among all regions of a given country (see Annex $C$ for the formula). The index takes on values between 0 and 1 , with zero interpreted as no disparity. It assigns equal weight to each region regardless of its size; therefore differences in the value of the index among countries may be partially due to differences in the average size of regions in each country.

The OECD Programme for International Student Assessment (PISA) assesses 15-year-old students' ability to use their knowledge and skills.

\section{Reference years and territorial level}

1999-2008; TL2.

Data for Iceland and Japan are not available at the regional level. In Turkey data available only for secondary education.

Data for Chile refer to tertiary educational attainment of population aged 15 and more.

\section{Further information}

OECD (2010), Education at a Glance 2010: OECD Indicators, OECD Publishing, DOI: 10.1787/eag-2010-en.

OECD (2010), PISA 2009 Results: Overcoming Social Background: Equity in Learning Opportunities and Outcomes (Volume II), PISA, OECD Publishing, DOI: 10.1787/9789264091504-en.

\section{Figure notes}

24.1: Countries ranked by average share of population with only basic education.

24.2: Only European countries (source own computations from Eurostat data). Range computed on available regional data.

24.4 Source OECD PISA 2009 Database, Table II.2.6.

Information on data for Israel: $h t t p: / / d x . d o i . o r g / 10.1787 / 888932315602$. 
24.1. Range in TL2 regional education attainment: labour force with only basic education, 2008

$\bigcirc$ Minimum value $\bigcirc$ Country average Maximum value

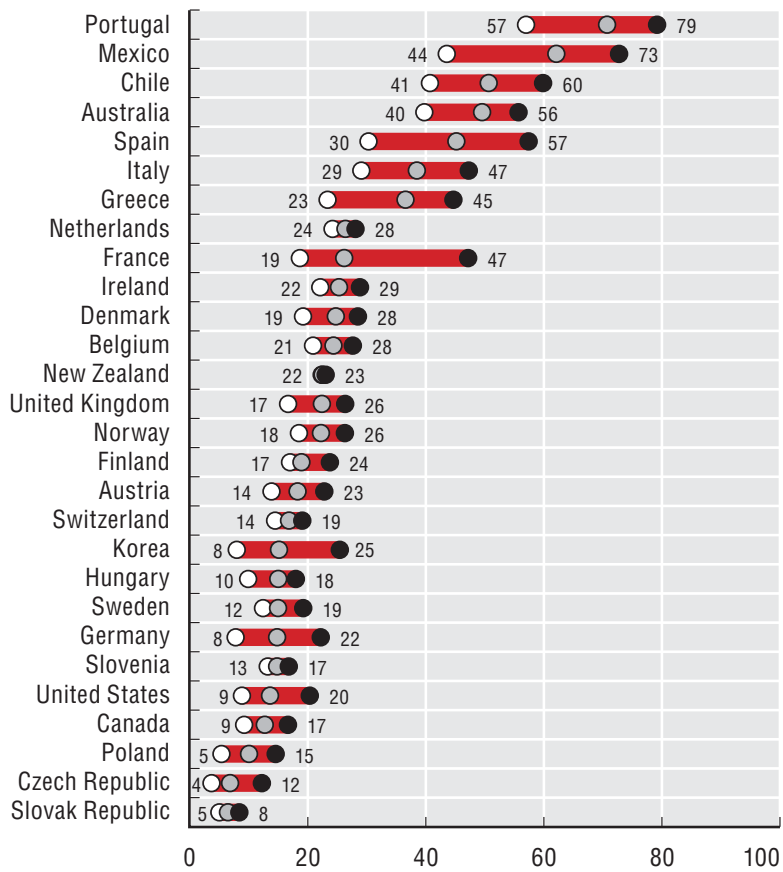

24.3. Gini index of TL2 regional labour force with at least upper secondary education, 1999 and 2008

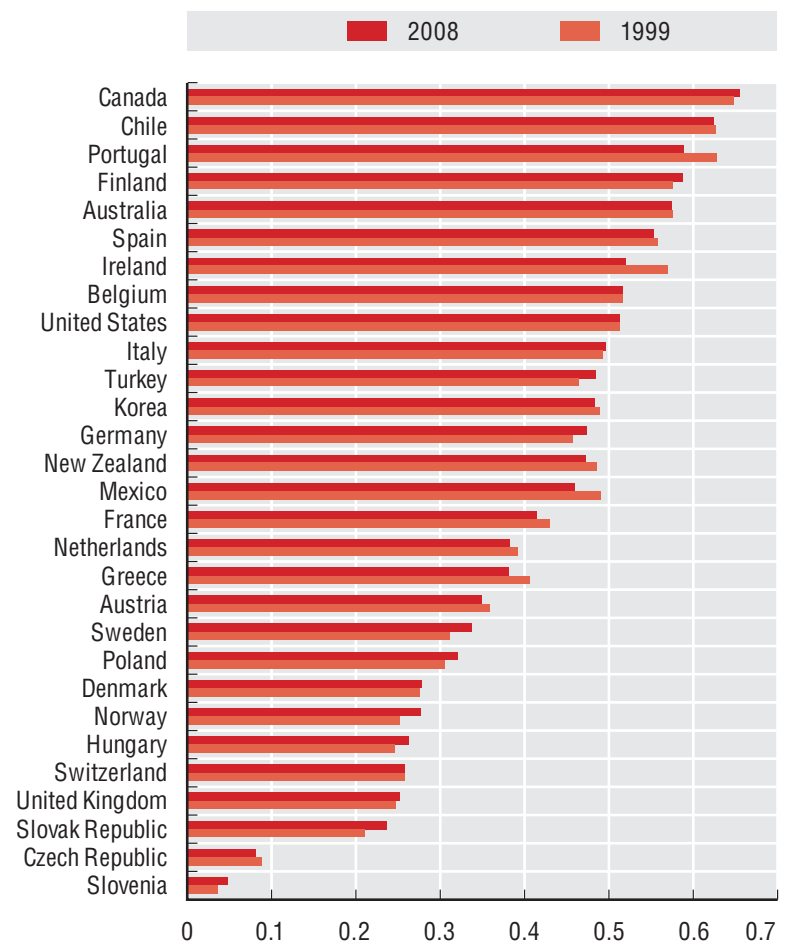

24.2. Regional range of early school leavers, TL2, 2009

$\bigcirc$ Minimum value $\quad \bigcirc$ Country average Maximum value

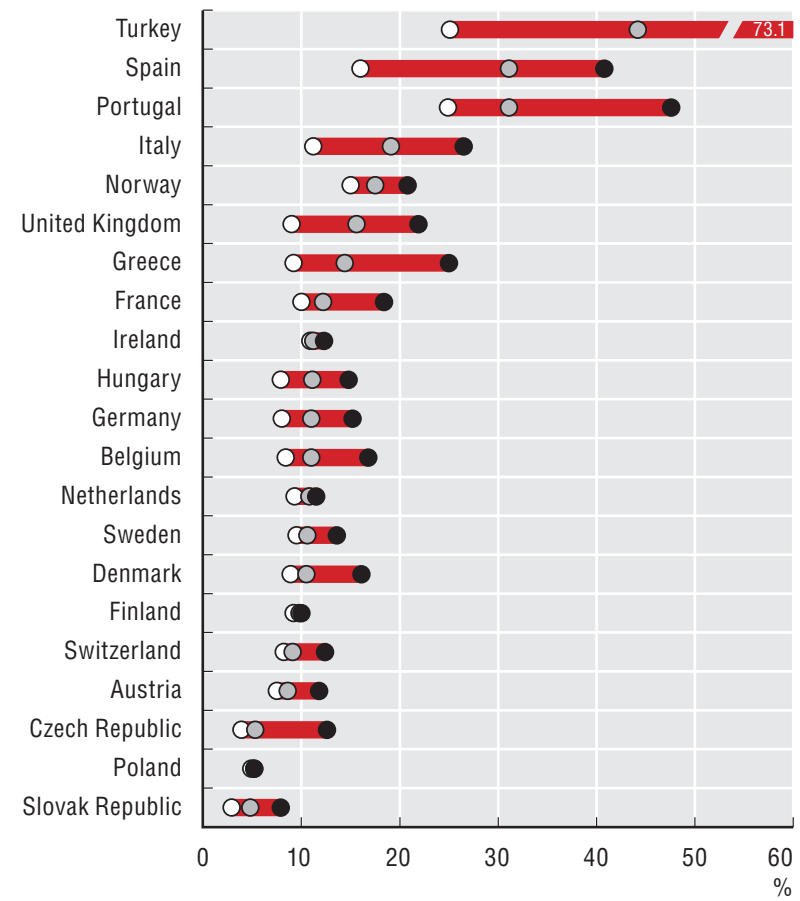

24.4. Score point difference in reading performance associated with being in a city school or rural school, after adjusting for socio-economic background, 2009

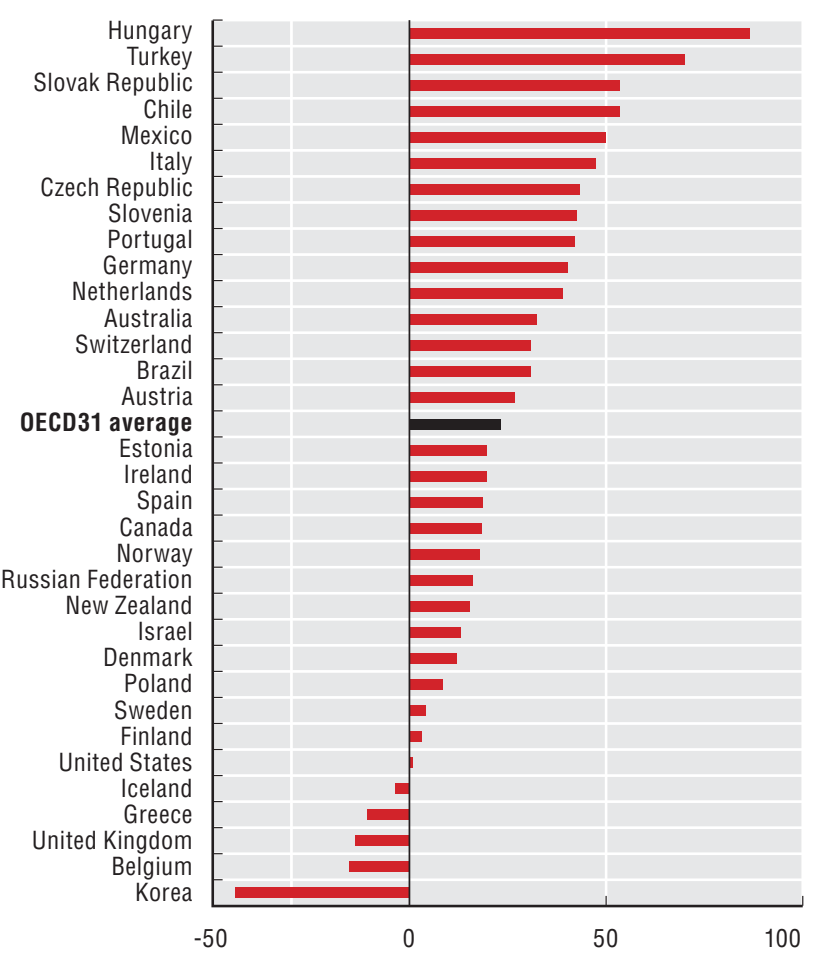

StatLink तiाst $h t t p: / / d x . d o i . o r g / 10.1787 / 888932439843$ 
The delivery of safe, high-quality medical services requires among other things an adequate number of doctors. Even though other components of health systems (such as nurse practitioners and tele-health technology) can substitute for doctors, the variation in the number of doctors reflects differences in the design and territorial management of the health system.

Disparities in the number of doctors among regions within the same country provide an indication of the accessibility of health services and can signal areas needing an increase in access to health care. In 2008, the regional variation in the number of physicians was the widest in the United States, Italy and the Czech Republic among OECD countries and in the Russian Federation. In these countries the large variation is due to one or two agglomerated regions that have a high density of practising physicians, because they were centres for specialised medical services, compared to other regions. In the United States, the District of Columbia has a physician density three times higher than the country average; Lazio (Italy) and the region of Prague (Czech Republic) have a density of doctors almost two times higher than their country average. A more balanced regional distribution in the number of physicians is observed in New Zealand, Korea and Japan (Figure 25.1).

As expected, the density of physicians is greater in regions with a prevalence of urban population due to the concentration of higher order services (such as surgery and specialised practitioners) in metropolitan centres. A positive correlation between the number of physicians and the share of population in urban regions is found in 16 out of 24 countries. The highest values are observed in the Slovak Republic, the Czech Republic and Greece (Figure 25.2). A limited number of physicians in rural regions, as in Greece, Portugal, Sweden and Austria, may lead to delayed treatment, larger distances travelled and higher costs for care.

The mortality rate is a common indicator of a population's health status. When comparing values across countries and regions, mortality rates are adjusted for age, which is a primary factor of mortality. The resulting age-adjusted mortality rates eliminate difference across regions that are solely due to a population's age profile. Regional differences in age-adjusted mortality rates within countries were the widest in Canada, Portugal, the United States and the United Kingdom (Figure 25.3). In 2008, the regions Região Autónoma Dos Açores (Portugal), Northwest Territories and Nunavut (Canada) and Mississippi and West Virginia (United States) had an age-adjusted mortality rate that was at least $20 \%$ higher than their country average (Figures 25.5 and 25.6)

In most countries, regional disparities both in the number of doctors per capita and in the mortality rates are positively associated with high disparities in household income, suggesting different opportunities in the access (both in terms of cost and distance) to health services. For instance, this is the case of the United States which shows the highest ratio between the richest and poorest states as well as the highest ratio between the state with the highest and lowest density of doctors. However, in other countries such as Norway, Austria and Denmark relatively low regional income disparities are accompanied by high regional disparities in health status and services (Figure 25.4).

\section{Definition}

The number of physicians is the number of general practitioners and specialists actively practicing medicine in a region during the year, in both public and private institutions.

Age-adjusted mortality rates eliminate the difference in mortality rates due to a population's age profile and are comparable across countries and regions. Age-adjusted mortality rates are calculated by applying the age-specific death rates of one region to the age distribution of a standard population. In this case the population by five years age class, averaged over all OECD regions.

The Spearman correlation coefficient measures the strength and direction of the relationship between two variables, in this case the number of doctors and the share of population in predominantly urban (PU), intermediate (IN) or predominantly rural (PR) regions. A value close to zero means no relationship (see Annex $\mathrm{C}$ for the formula).

\section{Source}

OECD Regional Database: http://stats.oecd.org/WBOS.

See Annex B for data, source and country-related metadata.

\section{Reference years and territorial level}

2008; TL2.

Japan and the Netherlands 2004; Portugal and Turkey 2009; Iceland and Switzerland 2002; the United Kingdom 2000.

No regional data are available on physicians in Ireland and Finland. 
25.1. Range in TL2 regional number of physicians per 1000 inhabitants, 2008

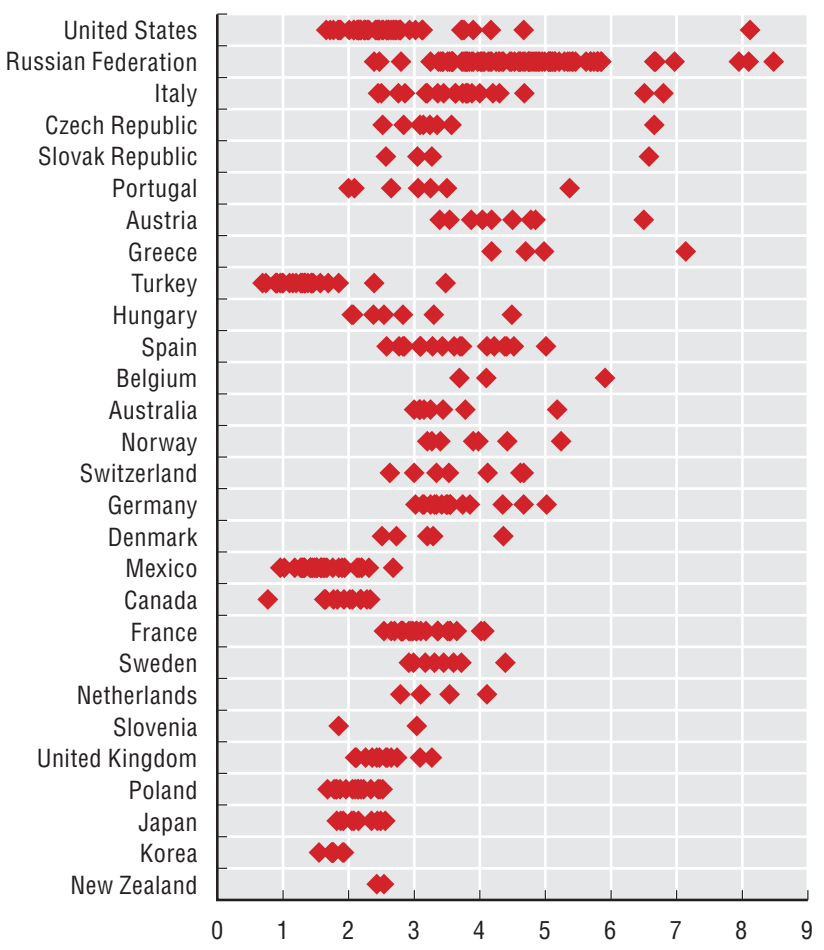

25.3. Range in TL2 regional age adjusted mortality rates, number of deaths per 1000 inhabitants, 2008

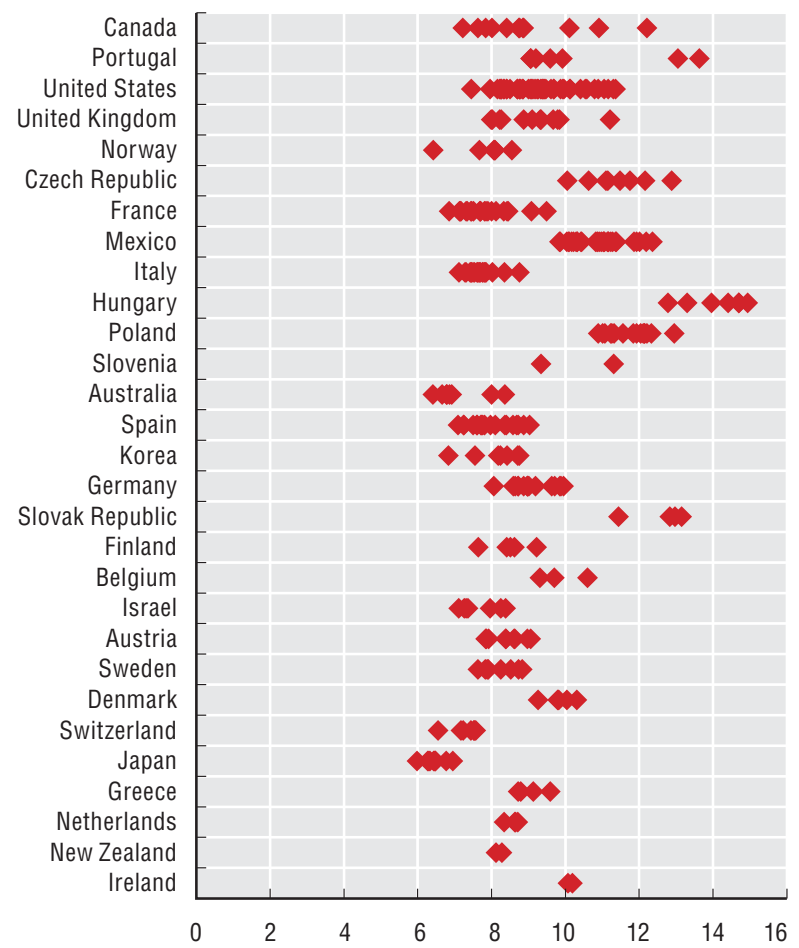

25.2. Spearman correlation coefficient between the regional physician density and population share by regional type, 2008 (TL2)

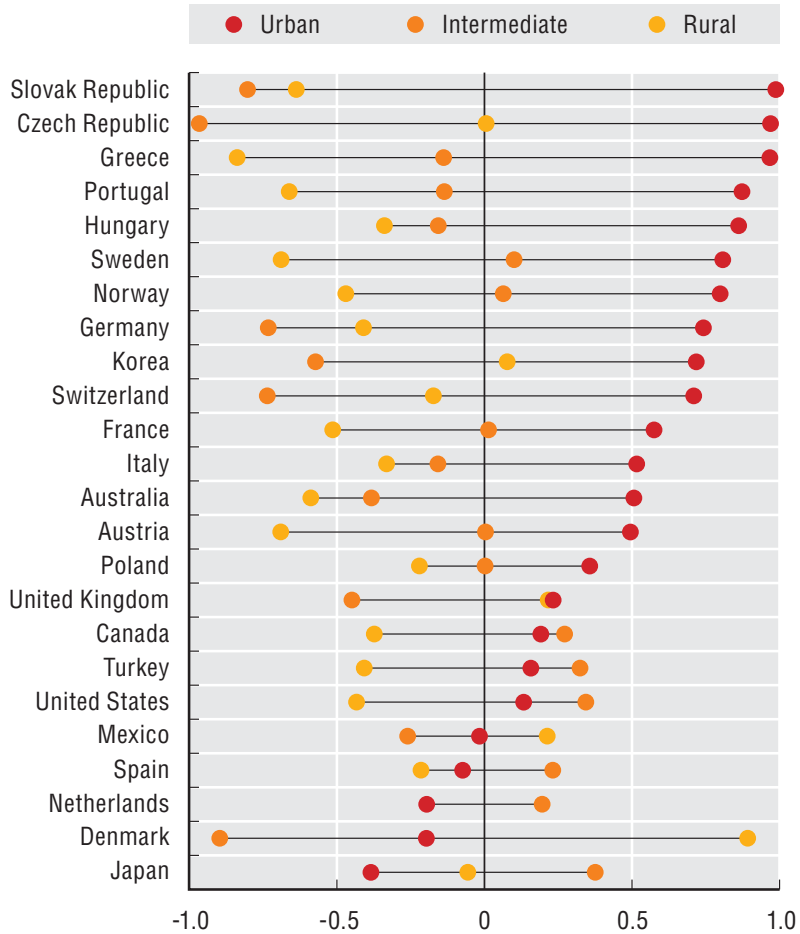

25.4. Ratio between the largest and smallest TL2 regional values: household income, age-adjusted mortality rate density of physicians and basic education, 2007

Household income $\quad$ labour force with only basic education
Physicians density $\quad$ IV//. Age adjusted mortality rate

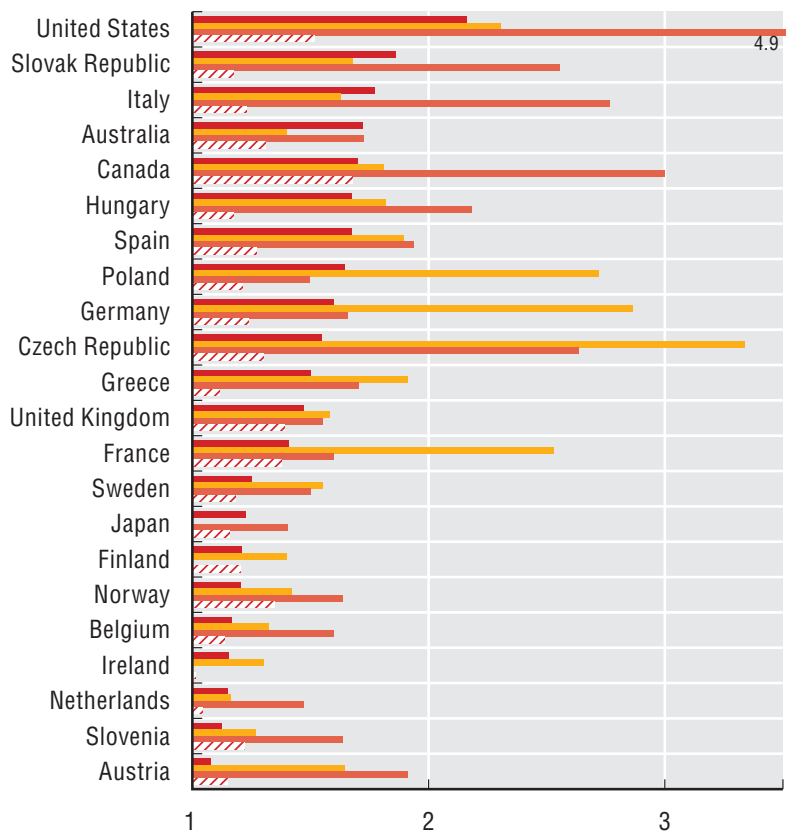

StatLink गाISL http://dx.doi.org/10.1787/888932439862 
25.5. Regional age-adjusted mortality rates: Asia, Europe and Oceania, 2008

$\%$ of country average, TL2 regions

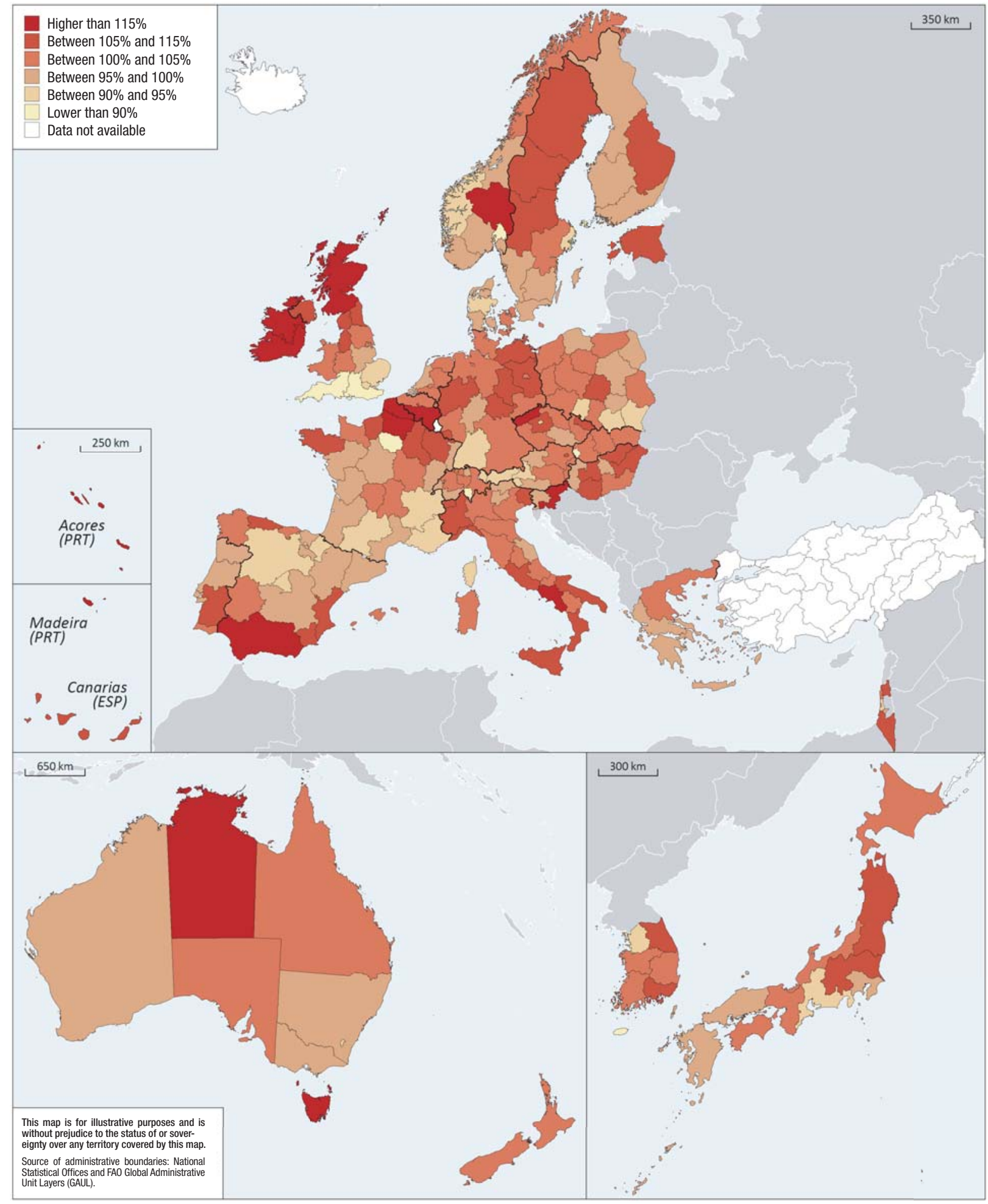

StatLink बiाsए http://dx.doi.org/10.1787/888932440223 
25.6. Regional age-adjusted mortality rates: Americas, 2008

$\%$ of country average, TL2 regions

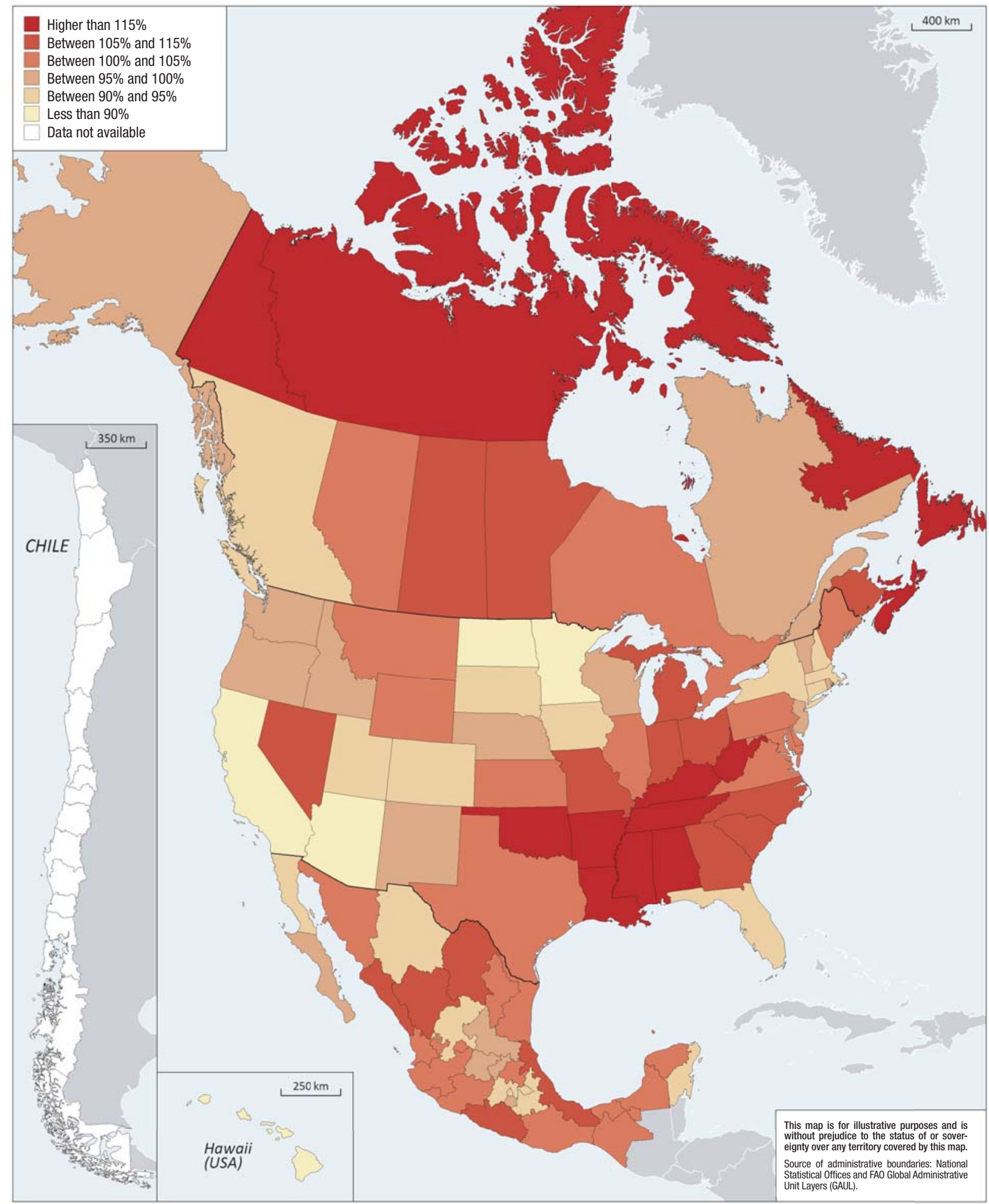

StatLink Aाs $h t$ ttp://dx.doi.org/10.1787/888932440223 
Quality-of-life differentials across and within regions are largely explained by the local availability of public services. Large segments of the world population still lack access to basic public goods, such as piped water or sewage facilities because they live in places that are historically underserved, too geographically isolated, and economically marginal. Poor access to services is also a key dimension of poverty in slums and in the peripheries of large cities.

Regional disparities in access to piped water are sizable in emerging economies with high economic growth such as Brazil and India as well as in Latin American developing countries with different histories of economic performance and decentralisation (Figure 26.1). In 2009, while almost $100 \%$ of the population in the state of Chandigarh (India) had access to a water supply network, almost $70 \%$ of the population in the state of Lakshadweep did not. Similar differences are found in Colombia, Panama and Brazil (Figure 26.1).

Data on utilities disaggregated according to a harmonised definition of rural and urban areas are still not available. This hinders international comparability. However, using national definitions, it is possible to observe that rural areas still lag significantly behind urban areas. This is particularly the case in Bolivia, Colombia, Venezuela and Peru, where access of rural households to piped water is less than half that of urban households (Figure 26.2).

Investments in facilities outside national nodal centers have narrowed regional differences in access to basic services in the past decade. When comparing the percentage of the population covered by the service across two census rounds, marked relative improvements in regions with the lowest rates of access to piped water are observed in Venezuela, Costa Rica, Chile and South Africa. In regions that were lagging behind the most, access to the electricity network grew faster than the national average. With the exception of Chile, instead, there is no evidence of catching-up of regions with low access to sewage facilities (Figure 26.3). Technological change and innovation in service delivery can accelerate the convergence of regions that benefit less from high-quality public services. A notable case is the one of the telephone. The availability of a fixedline telephone has been decreasing both at the national level and in regions with the lowest access, due to a substitution with other communication technologies. In Atacama (Chile), the percentage of households owning a cellular phone increased from $0.3 \%$ in 1992 to $43 \%$ in 2002; in Limpopo (South Africa), from 5\% in 1997 to 62\% in 2007 (Figure 26.3).

\section{Definition}

Access to water is defined as the percentage of households with piped (running) water.

Access to sewage is the percentage of households with access to a sewage system or public septic tank.

Access to electricity is the percentage of households using electricity for lighting.

Access to telephone is the percentage of households with a fixed-line telephone in the dwelling.

Urban and rural households are classified according to whether the household was located in a place designated as urban or rural in national censuses.

\section{Source}

Census Microdata from Minnesota Population Center. Integrated Public Use Microdata Series (IPUMS) for all countries but India. The 2009 data on water for India are from the National Sample Survey “Office's Report No. 535: Housing Condition and Amenities in India". The 2009 data on water for Brazil and for Chile are respectively from IBGE, Household Survey and from MIDEPLAN, Socioeconomic Characterization Survey. 2008 data on water for Argentina are from National Company of Hydraulic and Sewerage Works (ENOHSA). Data for Chile, Brazil, Peru, Argentina and Colombia used in Figure 26.1 were provided to the OECD by ECLAC-UN.

See Annex B for data, source and country-related metadata.

\section{Figure notes}

26.1: Data refer to full sample (from census or regionally representative surveys) for Argentina, Brazil, Colombia, India, Peru and South Africa. For all the other countries they are estimates from $10 \%$ census sample microdata.

26.2: Data are disaggregated according to the national definition of urban-rural status. 
26.1. Regional range in access to piped water, latest available years

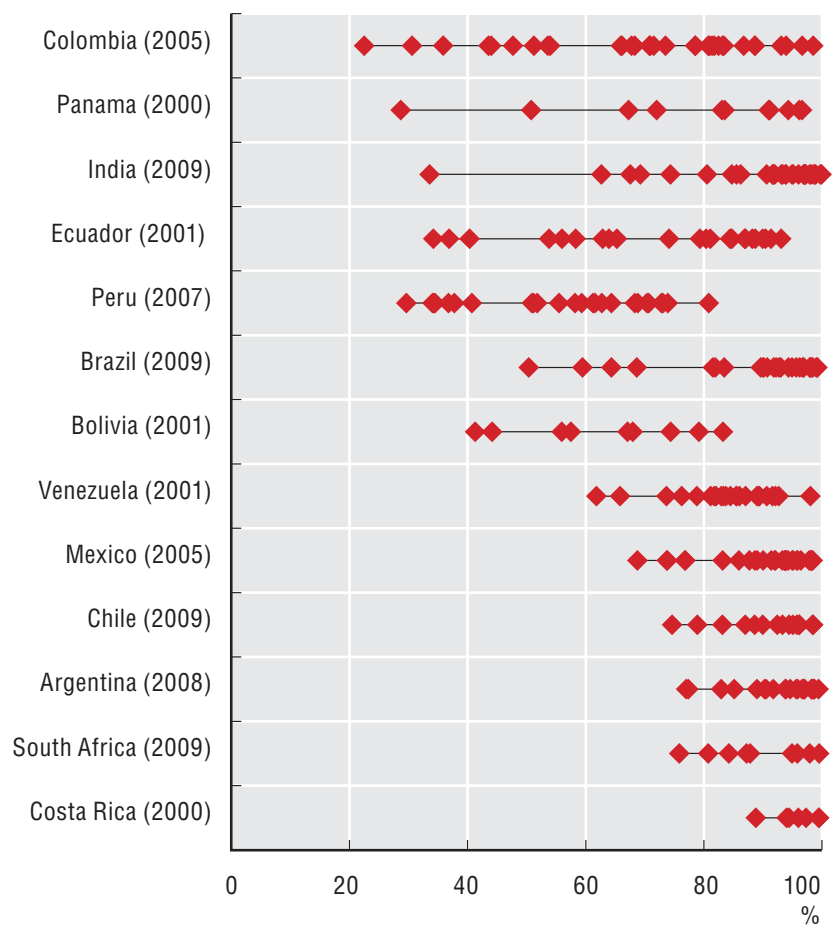

26.2. Access to piped water in rural and urban households, latest available years

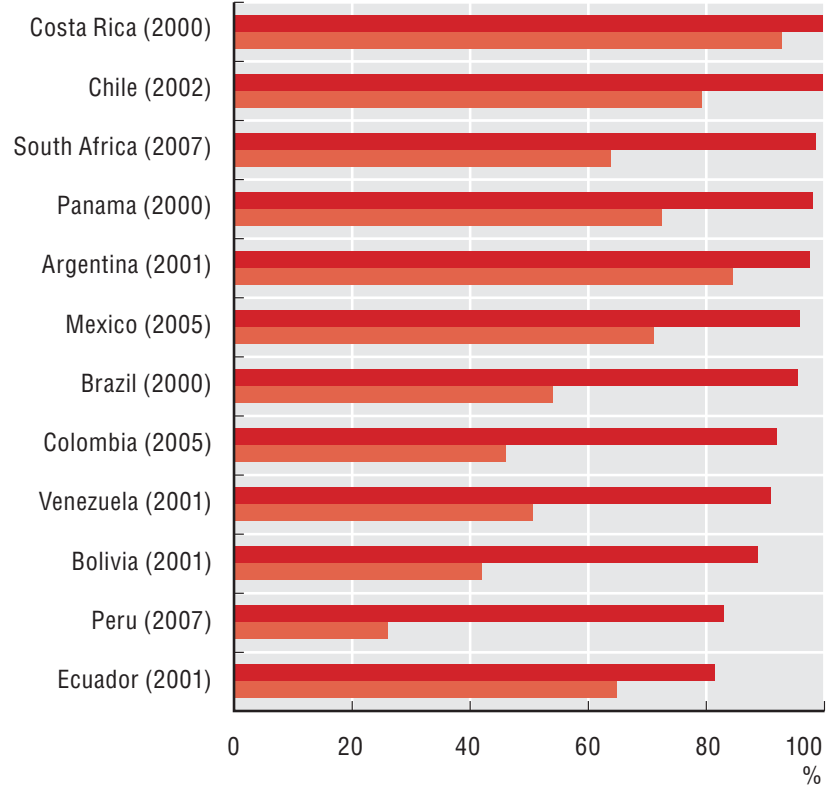

26.3. Change in the percentage of households with access to piped water, sewage, electricity and fixed telephone, circa 2000 and 2008
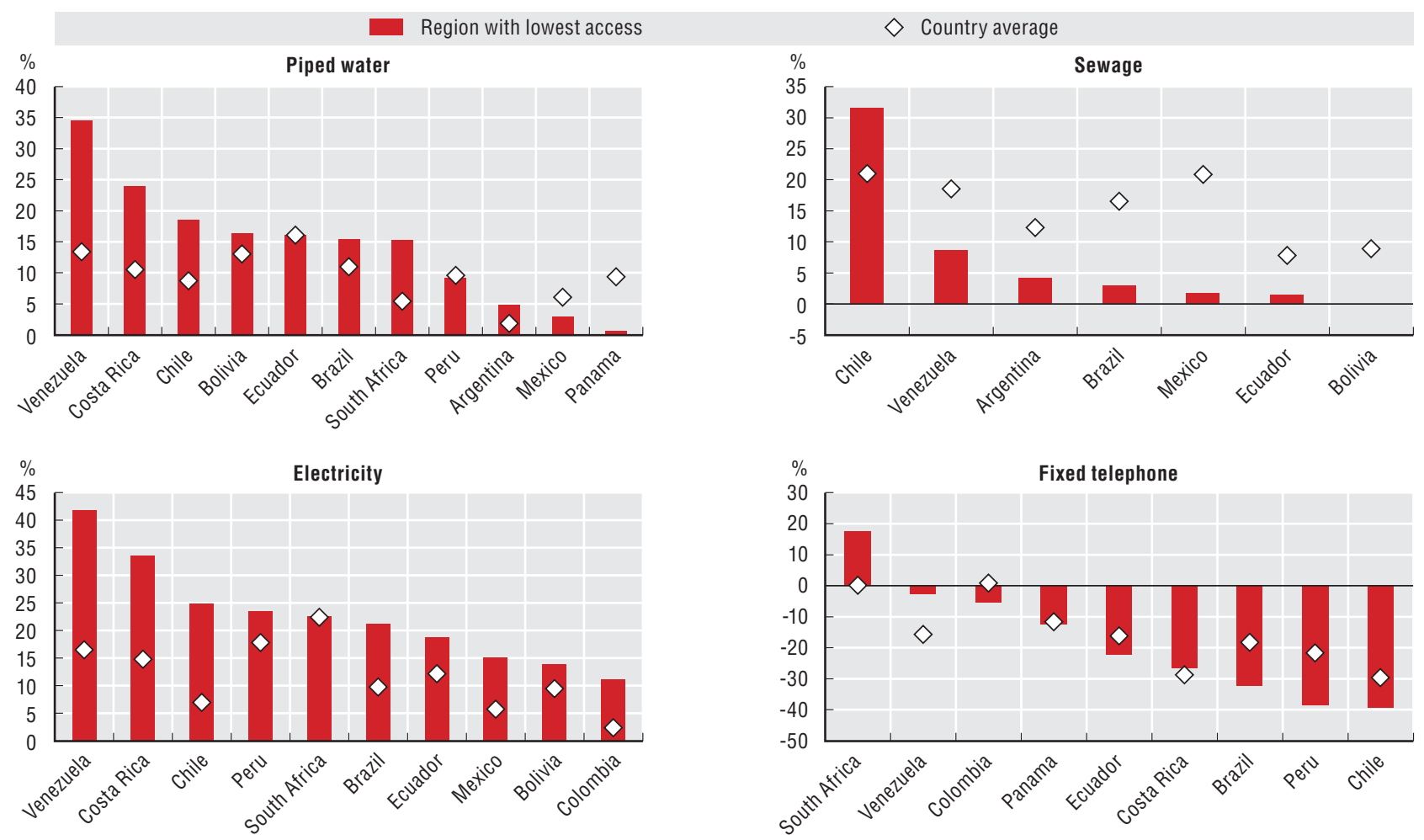

StatLink काts http://dx.doi.org/10.1787/888932439881 
(1) (1)

trat

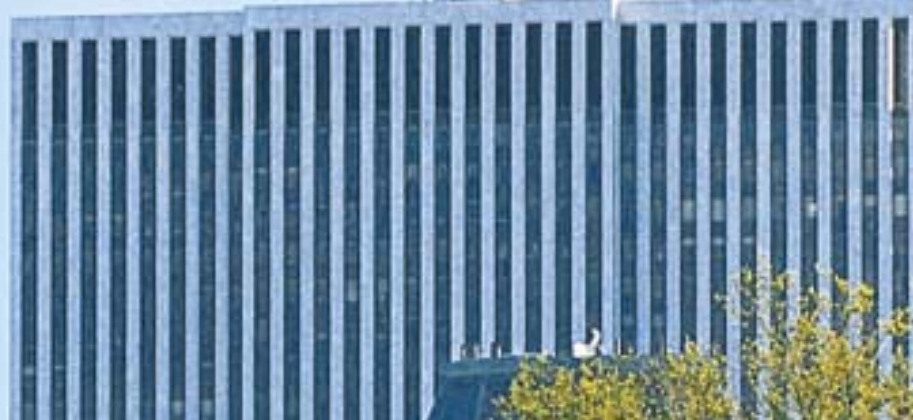

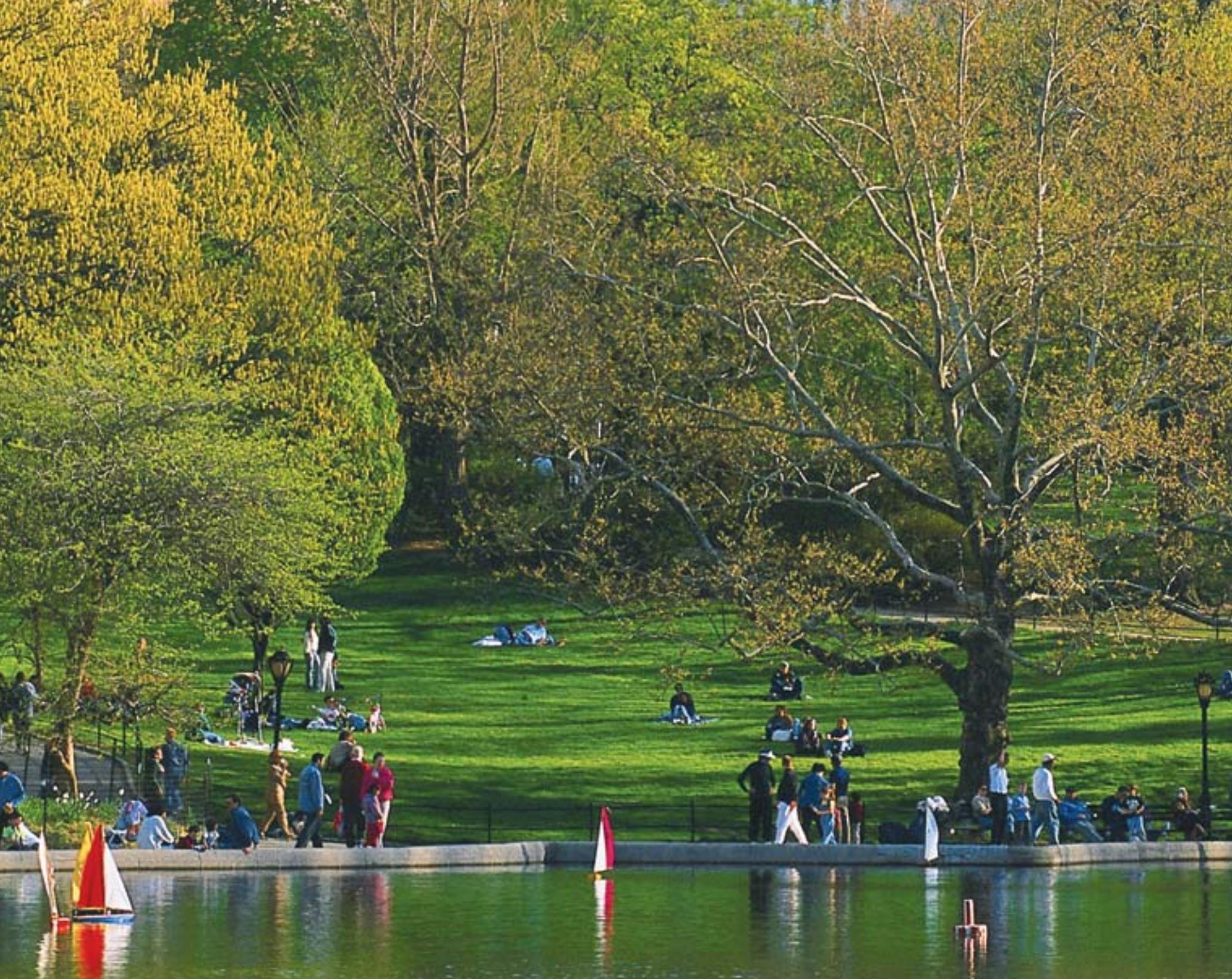




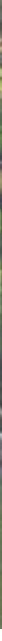

\section{ENVIRONMENTAL SUSTAINABILITY IN REGIONS AND METROPOLITAN AREAS}

27. The growth of urban land in OECD regions

28. Forests, natural vegetation and the carbon footprint of regions

29. Carbon emissions and air quality in regions

30. Municipal waste

31. Regional access to network infrastructure

32. Green patents in regions 
Monitoring changes in land cover is crucial to understanding how urbanisation impacts the natural environment. Detailed spatial information on these changes can help identify which areas have been exposed to larger urban pressure, guiding targeted policy interventions where this expansion threatens the quality of the landscape or bio-diversity. In 2001, urban land ranged from very low levels in sparsely populated countries (less than $0.1 \%$ of the national territory in Iceland and Canada) to significant levels in densely inhabited ones (more than 10\% in Belgium and the Netherlands) (Figure 27.1). Emerging economies had generally low-intermediate levels of their territory covered by artificial surfaces (from $0.5 \%$ in Brazil to $1 \%$ in India).

There are very large differences in the extent of growth in urban land both across and within OECD countries. Slightly more than $25 \%$ of the regions in Europe experienced very limited growth in urban surfaces between 2000 and 2006. These regions account on average for $32 \%$ of the European territory (Figure 27.2). Almost 9\% of the European regions saw their urban land grow by more than $10 \%$ over the same period. These regions are very concentrated in those countries, Spain, Ireland and Portugal, that experienced large fluctuations in housing market. Patterns in Japan and the United States are quite different, partly as a result of the different characteristics of the land cover data available to monitor dynamics. In Japan, the majority of the regions experienced large increases in urban land between 1997 and 2006, while in the United States most of the regions experienced intermediate rates of urban land growth (Figure 27.2). In the United States, relatively lower rates of transition to urban use of land are partly explained by the densification of those areas classified as sparse or "open" urban spaces (thus many transitions occur within the urban class).

Those countries that have experienced the largest overall changes in urban land (Japan, Spain, Portugal and Ireland) generally also show greater interregional differences in these changes (Figure 27.3). Large interregional variations are also observed in countries with lower regional peaks, such as Turkey, France and the Netherlands. Small regions with large cities such as Tokyo, Budapest or Wien have much lower urban growth than their hinterland region surroundings, because they are already densely built-up.

What is the origin of this land that becomes urban? Again, differences across countries are very marked. While in the Czech Republic, Germany, Denmark and the Slovak Republic the majority of new urban land was converted from agriculture, in Slovenia, Norway and Finland new urban land comes primarily from forests. Large relative conversions of other natural vegetation (e.g. grass-land, shrubs) can be observed in regions of Austria and the United States (Figure 27.4).

\section{Definition}

Growth in urban land is defined as the ratio between the net change of urban areas (i.e. the newly formed areas of urban class minus areas that changed from urban to another class) and the total area of urban class at the beginning of the observed period. It is expressed in average yearly growth rates. Urban class is defined as artificial land with built-up cover or urban use. It includes, for example, residential and non-residential buildings, major roads and railways and also open urban areas like parks and sport facilities.

\section{Source}

MODIS MCD12Q1 for land cover.

Corine Land Cover 2000-06 (Europe); National Land Cover Dataset (NLCD) United States; Japan National Land Service Information data.

See Annex B for references, details on, and differences across, the datasets.

\section{Reference years and territorial level}

2000-2006; TL3.

In Japan the changes are calculated for the period between 1997 and 2006. Other countries are excluded due to current unavailability of land cover datasets suited to monitor changes over time.

\section{Figure notes}

27.2: For Japan, the time interval considered is 1997-2006. Low growth regions are defined as regions with lower than $0.1 \%$ of urban land growth, moderate growth regions as those regions with urban land growth between $0.1 \%$ and $1 \%$; high growth regions are those with annual urban land growth higher than $1 \%$. Relative size is calculated as the area of the regions in the urban growth class divided by the total national area.

27.3: For Japan, the time interval considered is 1997-2006.

27.4: The different land cover classes in the three datasets have been harmonised in six classes. "Other vegetation" includes grasslands, sparsely vegetated lands and other non-forest natural vegetation classes. 


\subsection{Percentage of country surface covered by urban land, 2001}

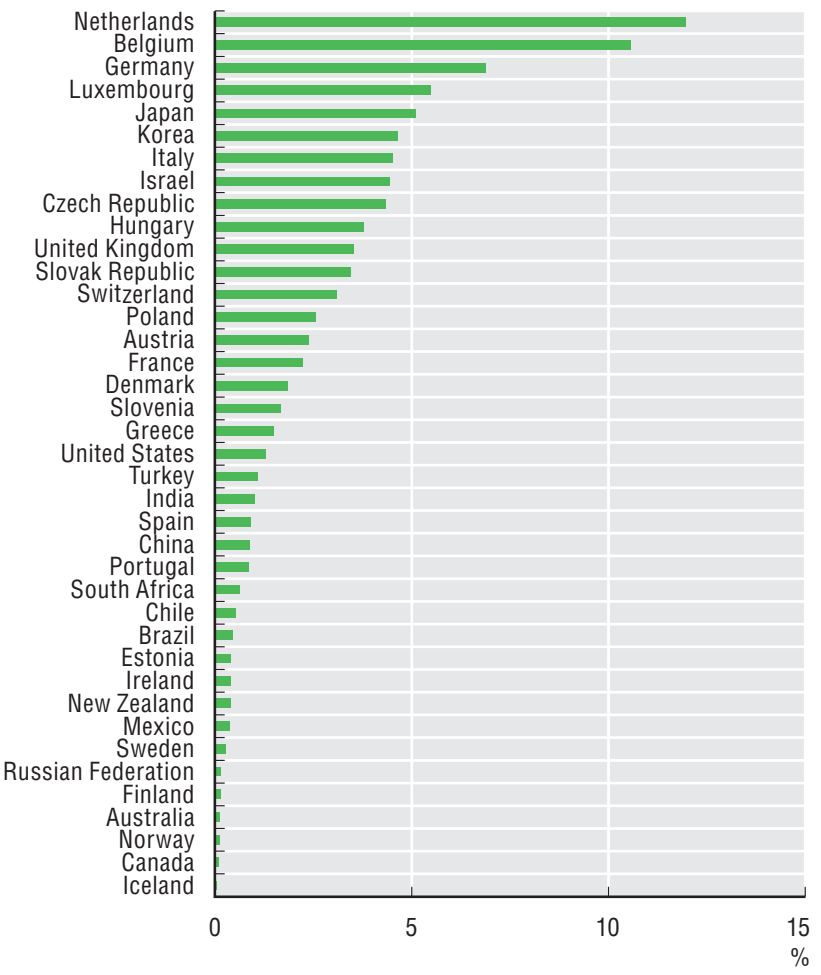

27.3. Regional range of growth in urban land, 2000-06

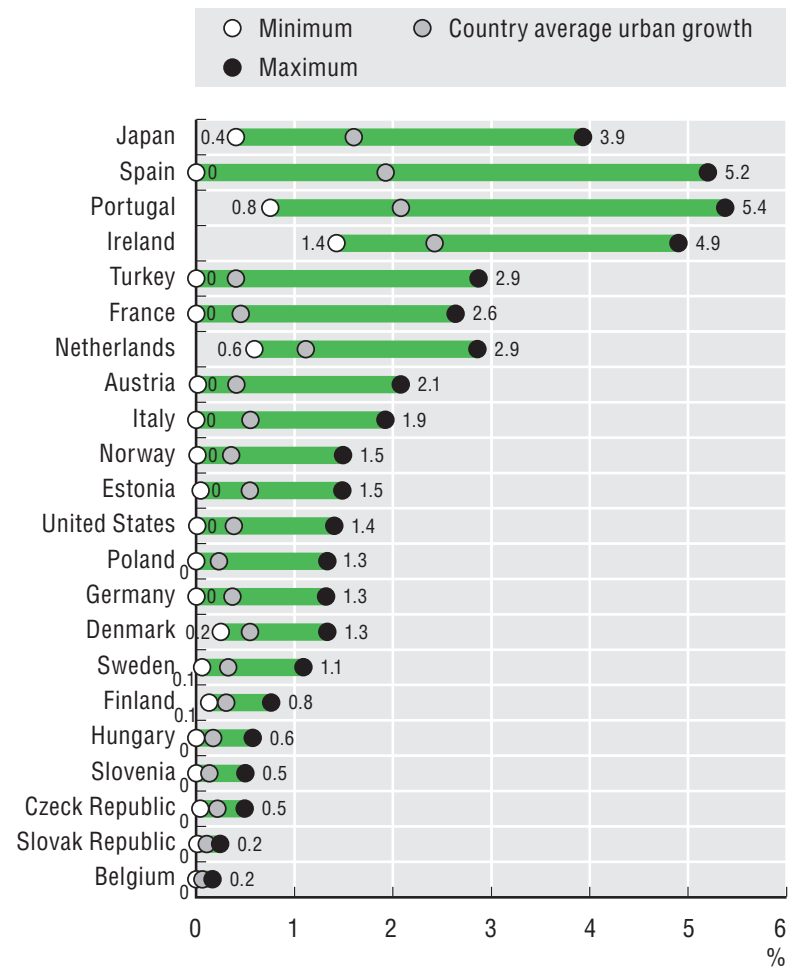

27.2. Percent of country surface covered by regions with low, moderate or large growth of urban land, 2000-06

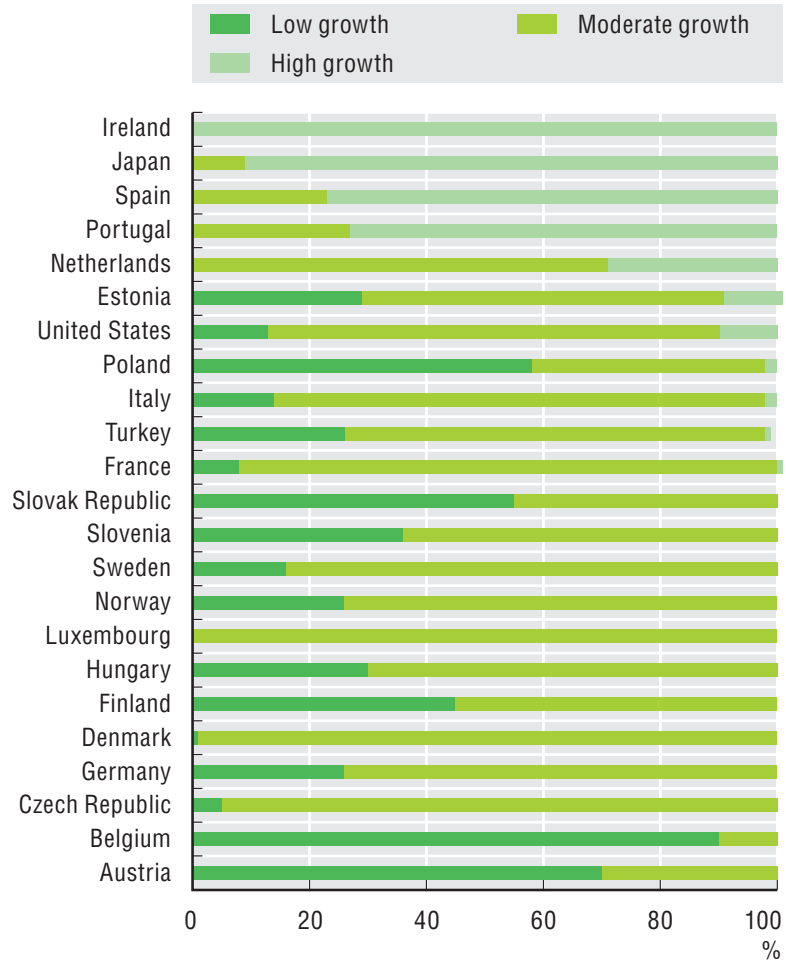

27.4 Share of urban land converted from agriculture, forest and other vegetation, 2000-06

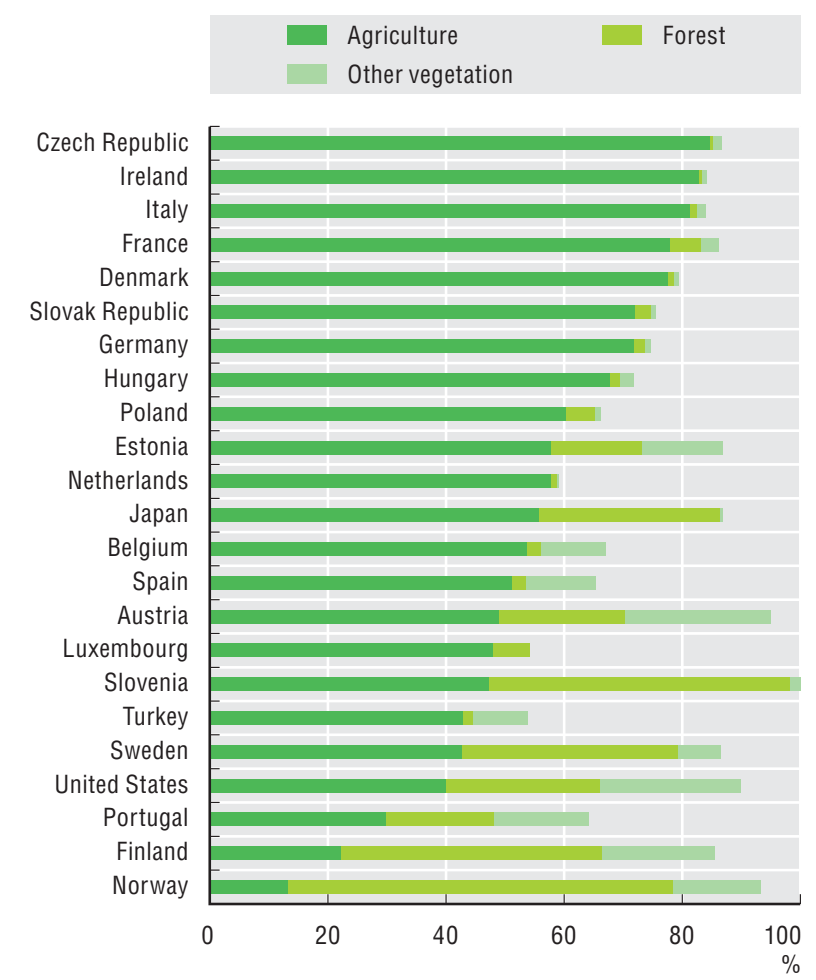

StatLink जाISL http://dx.doi.org/10.1787/888932439900 


\section{THE GROWTH OF URBAN LAND IN OECD REGIONS}

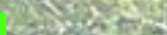

27.5. Growth of urban land: Europe, 2000-06

Average annual growth, TL3 regions

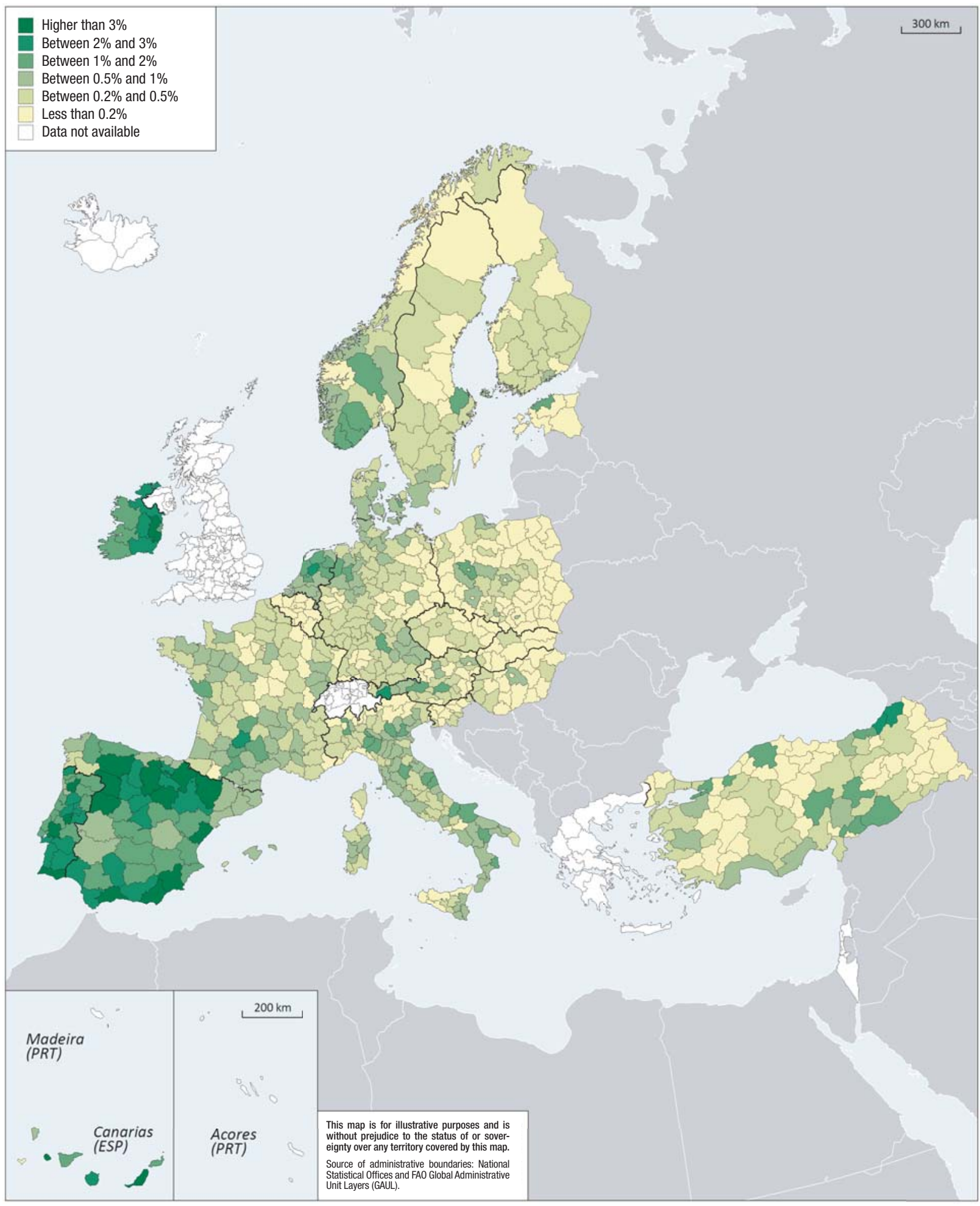

StatLink काज़ http://dx.doi.org/10.1787/888932440242 


\section{THE GROWTH OF URBAN LAND IN OECD REGIONS}

27.6. Growth of urban land: Japan and United States, 2000-06

Average annual growth, TL3 regions

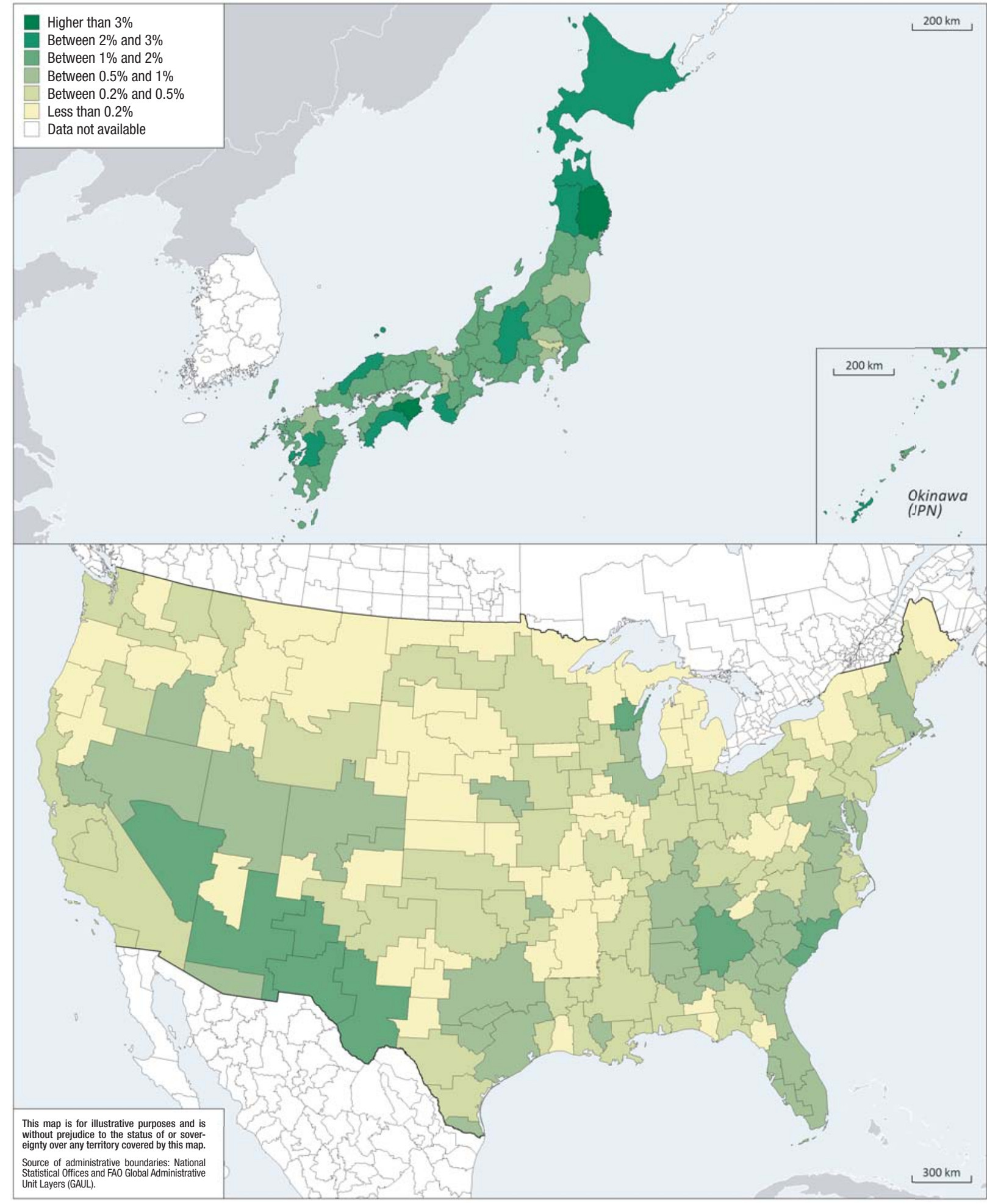

StatLink लाडs http://dx.doi.org/10.1787/888932440242 
Forests are strategic assets for sustainable development and for climate change mitigation. Besides being essential for biodiversity and the environment, they fulfil other functions for society, providing employment opportunities as well as recreational value. A significant fraction of the land of OECD countries is covered by forests. There are however large differences across and within countries. Among the countries with the largest interregional variation, the United States, Canada, Chile, Mexico and Norway in the OECD - and Brazil and the Russian Federation among emerging economies - display regions with more than $80 \%$ of the land covered by forests (Figure 28.1). At the same time, in all these countries with the exception of Norway, more than one region has less than $10 \%$ of forested land. Given these large regional differences, it is very important to put in place co-ordinated policies for forest conservation at the national, regional and local level.

Significant changes in the extent of forest and natural vegetation have occurred in several OECD countries (Figure 28.2). Some countries have registered relatively larger gains than losses in land covered by vegetation, partly as a result of agricultural abandonment. This is the case in Hungary, Ireland and the Netherlands. Relative large losses in natural vegetation are observed in Portugal and Spain, as well as in Japan (for which the change is measured from 1997 to 2006). In most countries, these changes have been concentrated in space. In fact, the regions with the largest changes in natural vegetation within countries have registered either losses (e.g. Oost-Vlandereen in Belgium, Lausitz-Spreewaldl in Germany, Baixo Alentejo in Portugal) or gains (e.g. Szabolcs-Szatmár-Bereg in Hungary, Sydjylland in Denmark, Drenthe in the Netherlands) several folds higher than the national average (Figure 28.2). Countries tend to differ significantly in the destination use of the land taken away from forests and natural vegetation. If in some countries urbanisation was the main pressure behind natural vegetation losses (Austria and Norway), in other countries (Spain, Finland, Portugal and Turkey) a great fraction of the lost vegetation transited to agricultural use (Figure 28.3).

Converting natural landscapes to developed areas has relevant implications for the carbon footprints of regions and countries, since plants absorb carbon dioxide $\left(\mathrm{CO}_{2}\right)$ in the process of photosynthesis. Through the modelling of remote-sensing data, it is possible to quantify how photosyntetic production, (measured by net primary productivity [NPP]), contributes in terms of reductions of carbon in the atmosphere. Regions in Portugal, India and New Zealand have on average very large values per square metre of NPP, meaning that they contribute significantly to absorbing the carbon generated by human activity (Figure 28.4). Differences in the regional distribution of vegetation types, sunlight, water and temperature translate into very large dif- ferences in the contribution of places to carbon absorption (Figures 28.5-28.9). Targeted allocation of resources to protect these local reserves thus makes sense, not only for landscape preservation, but for the global objective of climate change mitigation.

\section{Definition}

The percentage of regional land covered by forests is computed as the land classified in the categories 1 to 5 in the International Geosphere Biosphere Programme (IGBP) over total regional land.

Gains and losses of forest and natural vegetation are respectively the hectares transiting to and from forest and natural vegetation classes, over total forest and natural vegetation hectares in the starting year.

NPP measures the amount of carbon stored by the landscape through the production of biomass, excluding the one used for plant respiration, expressed in grams of carbon/ $\mathrm{m}^{2} /$ year.

\section{Source}

MODIS MCD12Q1 for \% of forest cover in 2008.

Corine Land Cover 2000-06 (Europe); National Land Cover Dataset (NLCD) United States; Japan NLSI data for natural vegetation changes.

Average 2000 to 2006 yearly NPP from Improved MOD17 by Zhao and Running (2010).

See Annex B for references, details on, and differences across, the datasets.

\section{Reference years and territorial level}

2008; TL2 for \% of forest cover.

Average 2000-06; TL2 for NPP.

2000 to 2006; TL3 for changes in Europe and the United States. In Japan the changes are calculated for the period between 1997 and 2006.

\section{Figure notes}

28.1-28.6: The statistical data for Israel are supplied by and under the responsibility of the relevant Israeli authorities. The use of such data by the OECD is without prejudice to the status of the Golan Heights, East Jerusalem and Israeli settlements in the West.

Information on data for Israel: http://dx.doi.org/10.1787/888932315602. 
28.1. Percentage of TL2 regional land covered by forests, 2008

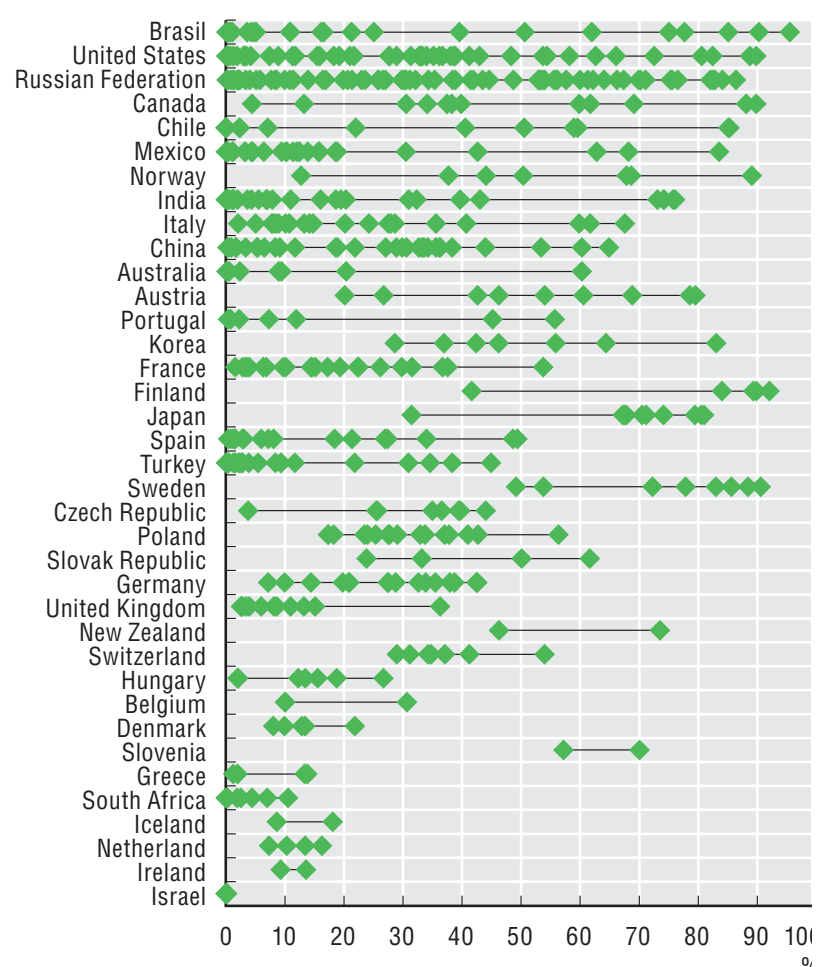

28.3. Destination use of land originally covered by forest and natural vegetation, 2000-06

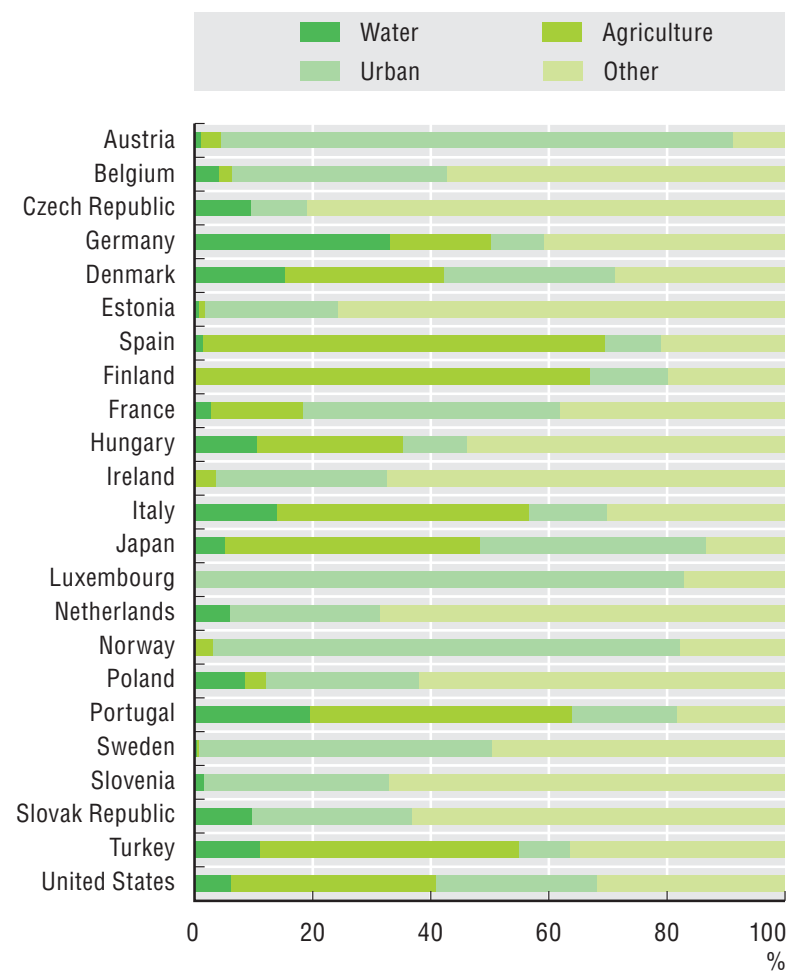

28.2. Gains and losses of forests and natural vegetation, by country and TL3 region with the largest transition, as a $\%$ of total change, $2000-06$

$\%$ loss of forest and vegetation $\quad \%$ gain in forest and vegetation

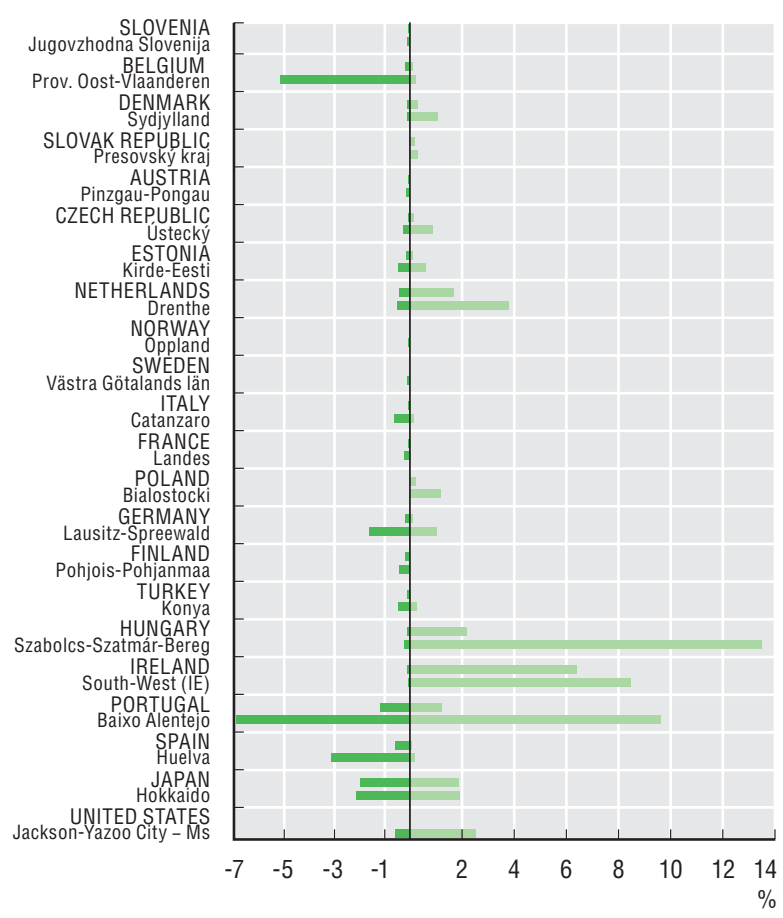

28.4. TL2 regional range in carbon absorption through biomass production (NPP as grams of carbon per square metre), average 2000-06

$\bigcirc$ Minimum value $\bigcirc$ Country average NPP Maximum value

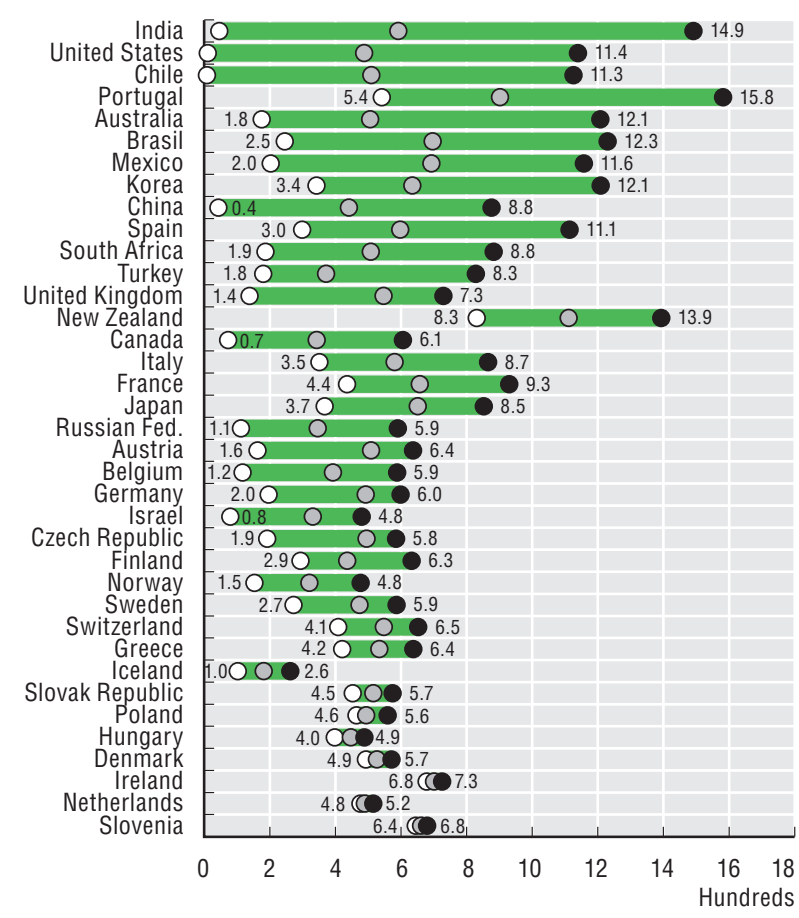

StatLink तiाs http://dx.doi.org/10.1787/888932439919 
28. FORESTS, NATURAL VEGETATION AND THE CARBON FOOTPRINT OF REGIONS

28.5. Regional range in carbon absorption through biomass production (NPP measured as grams of carbon per square metre): Asia and Oceania, 2000-06

TL2 regions, average 2000-06

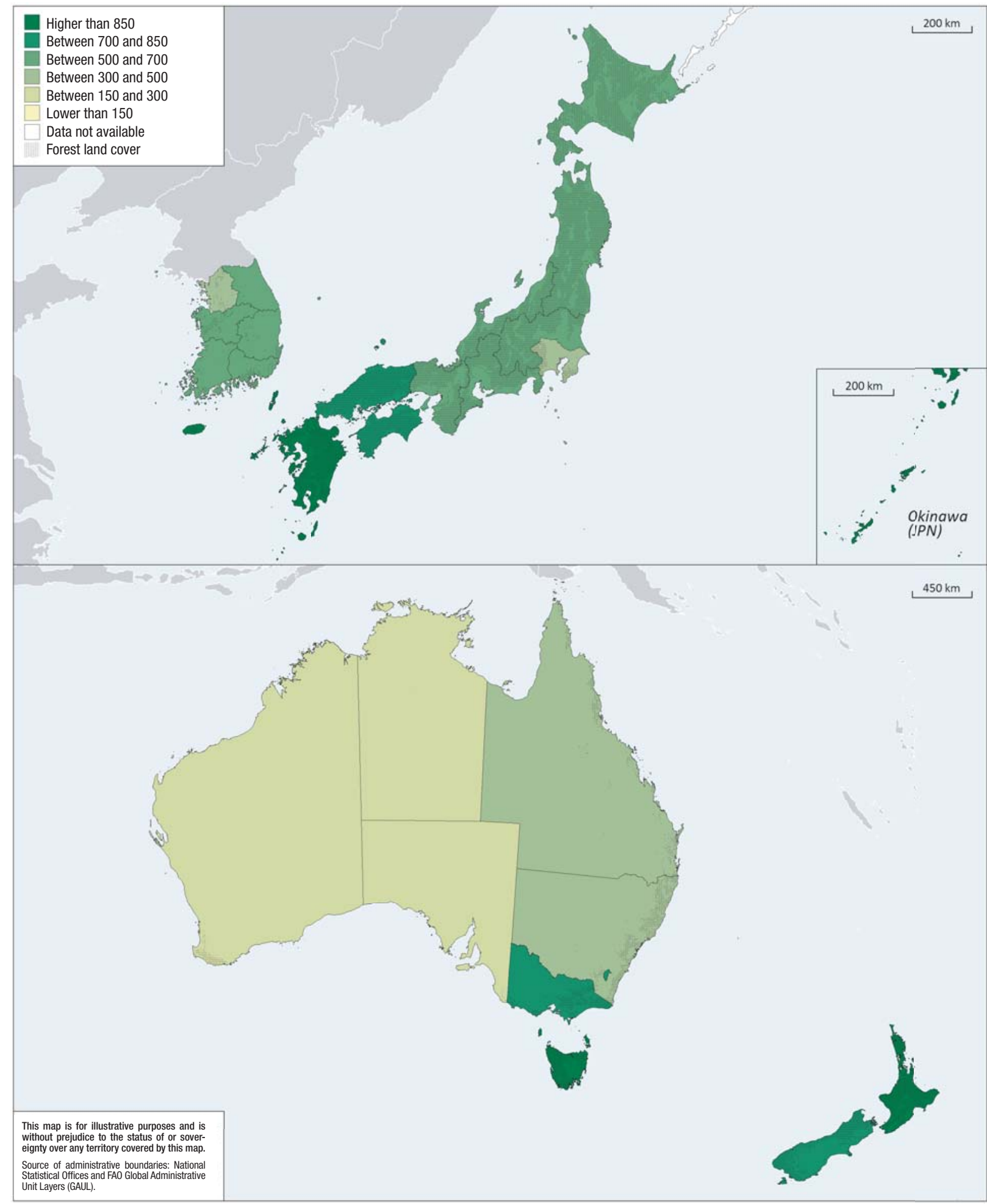

StatLink त्ञाSस $h t t p: / / d x . d o i . o r g / 10.1787 / 888932440261$ 
28.6. Regional range in carbon absorption through biomass production (NPP measured as grams of carbon per square metre): Europe, 2000-06

TL2 regions, average 2000-2006

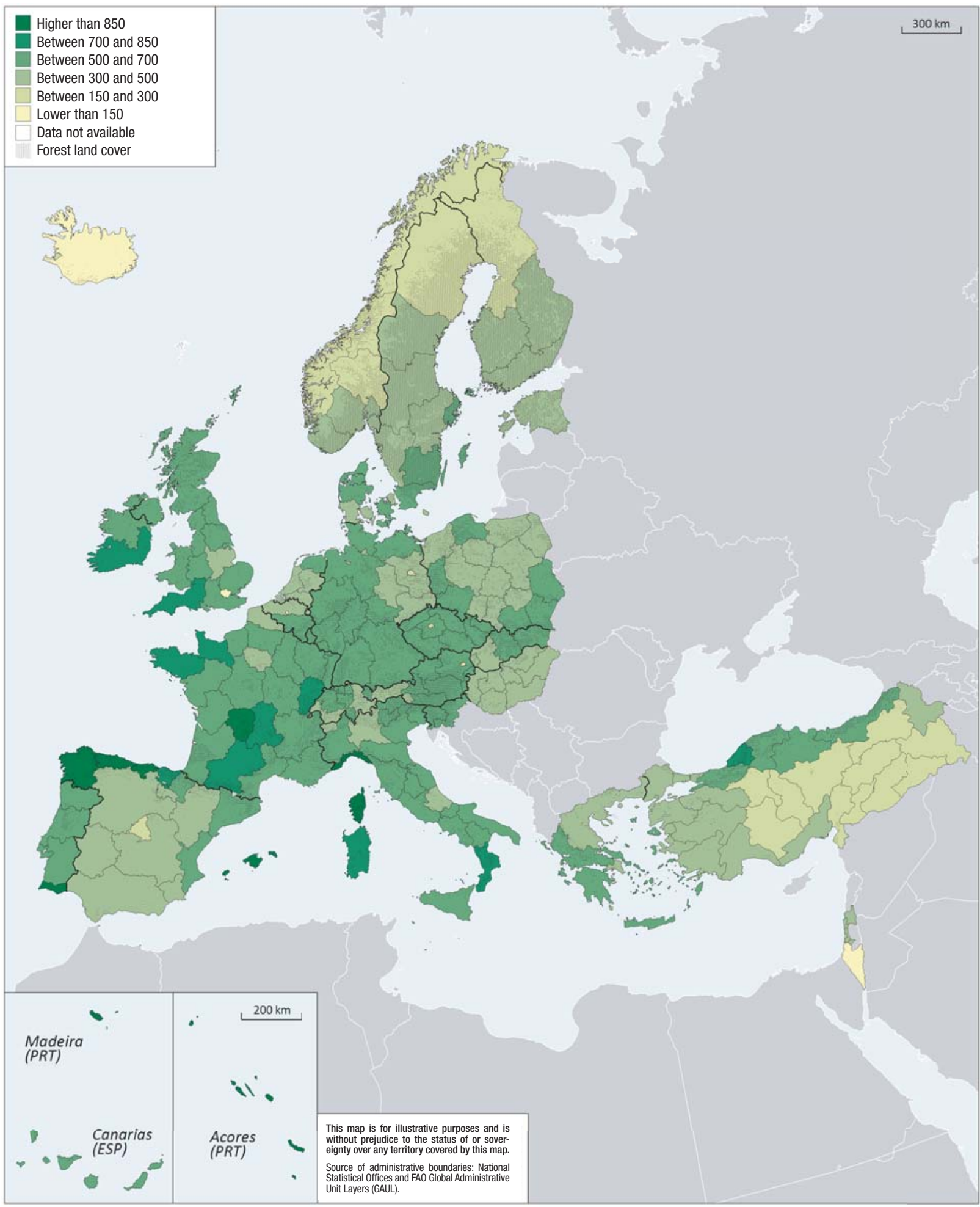

StatLink ताIst http://dx.doi.org/10.1787/888932440261 
28.7. Regional range in carbon absorption through biomass production (NPP measured as grams of carbon per square metre): Americas, 2000-06

TL2 regions, average2000-2006

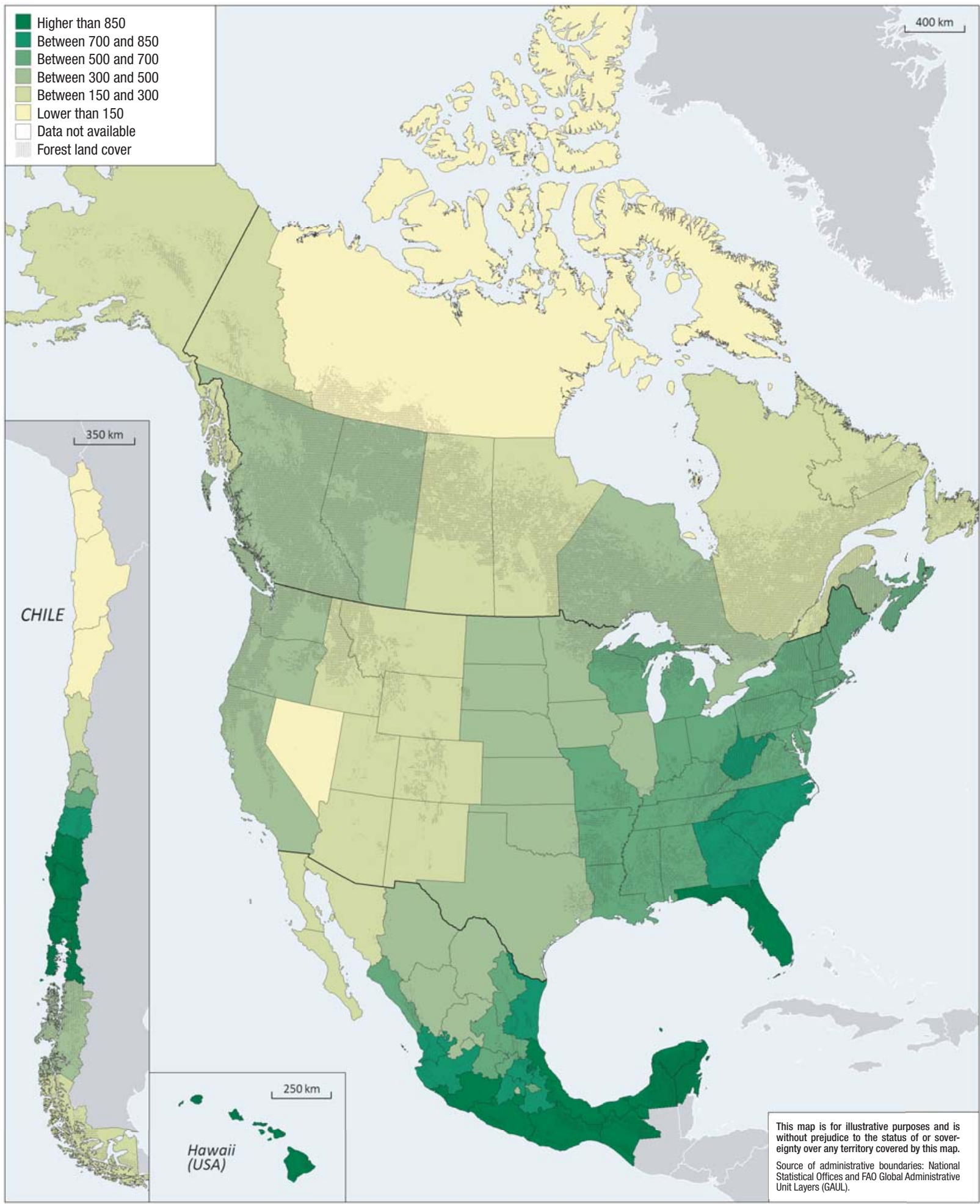

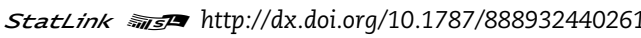




\section{FORESTS, NATURAL VEGETATION AND THE CARBON FOOTPRINT OF REGIONS}

28.8. Regional range in carbon absorption through biomass production (NPP measured as grams of carbon per square metre): Emerging economies, 2000-06

TL2 regions, average 2000-06

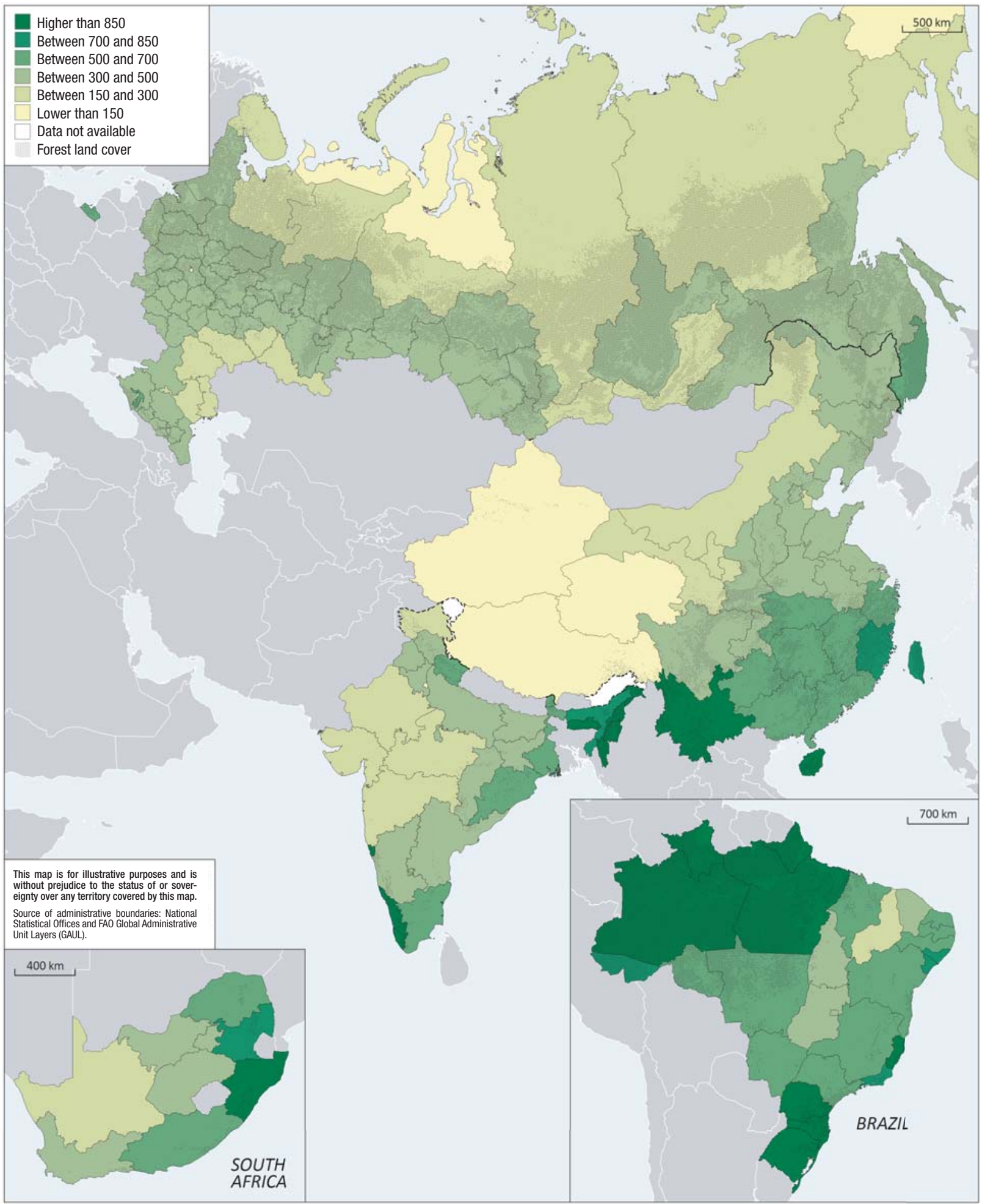

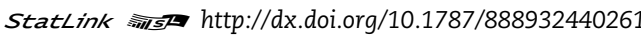


The urgency of the climate change challenge requires a rapid, sustained, and effective transition to lower carbon regional economies. Apart from necessary reduction in greenhouse gases, there is also a need to cut emissions of other pollutants like toxic gases or fine particles that can severely threaten people's health. Regional and city-level policies have a key role to play in this transition.

A look at interregional disparities gives a first rationale for spatially targeted interventions. In fact, it is possible to observe large disparities in carbon dioxide $\left(\mathrm{CO}_{2}\right)$ per capita produced in different regions. Regions with the highest levels of emissions per capita are located in the United States, the Czech Republic and Canada. For Canada, this result is largely explained by the low levels of population in these regions. Similarly, relative low population explains in part the very high levels observed in Wyoming (United States). The significant degree of geographical concentration of $\mathrm{CO}_{2}$ emissions per capita is evident in several countries, where some regions have a value more than double than the country average (Figure 29.1).

A positive correlation is found between levels of regional gross domestic product (GDP) and emissions, but there are significant differences in the "carbon intensity" of production across regions. In fact, when looking at the ratio of GDP over $\mathrm{CO}_{2}$, it is clear that the production of some regions is much more efficient, in terms of embodied $\mathrm{CO}_{2}$, than the national average (Figure 29.2). This is particularly evident in Turkey, the United States and Mexico and in the Russian Federation and Brazil among emerging economies. In general, the regions with the highest GDP/CO 2 host the national capital (where service-intensive industries are concentrated). However, this is not always the case (for example, Bolzano in Italy or Shikogu in Japan). Relatively low values of $\mathrm{GDP} / \mathrm{CO}_{2}$ indicate a potential for decoupling emissions from the economic growth of the region (Figure 29.2).

Internationally comparable measures of air quality in regions can be derived from satellite-based measurement of particulate matter finer than 2.5 micrometers (PM 2.5), which can cause cardiovascular and other diseases when inhaled. While these estimates can be less precise than ground-based measurement, they have the clear advantage of being available for the large areas of the globe that are still without air monitoring stations. By overlaying these data on fine particulate matter with data on population distribution at circa $1 \mathrm{~km}$ resolution, it is possible to conclude that large fractions of the world population breathe air whose pollution exceeds the World Health Organization's recommended level of 10 micrograms of PM 2.5 per cubic meter (Figure 29.3). It is important to emphasise that the measured PM 2.5 concentration comes from both natural and human sources, the fraction imputable to human activity varying significantly among regions. This notwithstanding, the share of people living in areas with health-damaging levels of pollution is worryingly high in several countries (particularly in China, India and Italy).
There are large regional variations in the extent of population exposure to high levels of particulate matters. Regional peaks are clear in China, Italy, India, Mexico and Chile (Figure 29.4).

\section{Definition}

$\mathrm{CO}_{2}$ regional emissions are imputed from national emission data allocated to grids of circa $10 \mathrm{~km} \times 10 \mathrm{~km}$ square. It includes emissions from all sources with the exception of air transport, international aviation and shipping.

Population exposure to air pollution is calculated by taking the weighted average value of PM2.5 for the grid cells present in each region, with the weight given by the estimated population count in each cell.

\section{Source}

$\mathrm{CO}_{2}$ emissions: EDGAR spatial emission datasets, JRC, available at http://edgar.jrc.ec.europa.eu/.

Satellite-Derived Surface PM2.5 map derived by Van Donkelaar et al. (2010), available at http://fizz.phys.dal.ca/ atmos/g47.swf.

LandScan 2009 for population estimates.

See Annex B for references and details on datasets and indicators' definitions.

\section{Reference years and territorial level}

2005; TL2 for $\mathrm{CO}_{2}$ regional emissions.

Average 2001-06; TL2 for PM 2.5 values.

\section{Figure notes}

Information on data for Israel: $h t t p: / / d x$.doi.org/10.1787/888932315602.

29.3, 29.4: Measurement gap: Internationally comparable measures of urban carbon emissions: While it is increasingly clear that urban areas emanate a growing percentage of the world carbon emissions, we still lack statistics suited for global comparison and monitoring of the carbon footprints of cities. Even if many cities around the world have started collecting inventories of their carbon emissions, differences in the methodologies (techniques, input data, sources included) used to compute total $\mathrm{CO}_{2}$ or $\mathrm{SO}_{2}$ make any comparison of their performance very difficult. Another problem is that cities "delimit" themselves in different ways, so that inventories in different countries can refer to a very narrow (the core municipality) or a very extended (the functional area of influence) definition of city. While supporting international efforts to harmonise urban carbon inventory, the OECD is also using estimates for small geographic units, derived from national data downscaled through the use of spatial datasets. Time-varying statistics for large and medium-sized cities in the OECD are obtained by applying these estimates to urban areas that are defined through a harmonised methodology. 
29.1. TL2 regional range in $\mathrm{CO}_{2}$ emissions per capita, 2005

$\bigcirc$ Minimum value $\bigcirc$ Country average $\mathrm{CO}_{2} \quad$ Maximum value

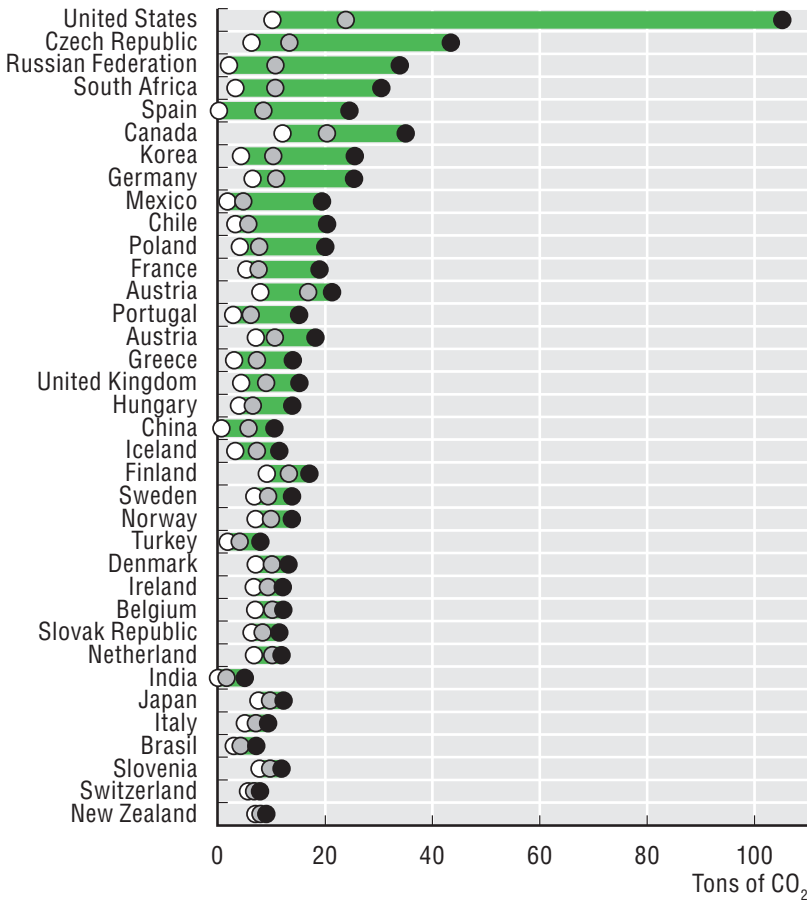

29.3. Population exposed to air pollution, by WHO PM2.5 thresholds, average 2001-06

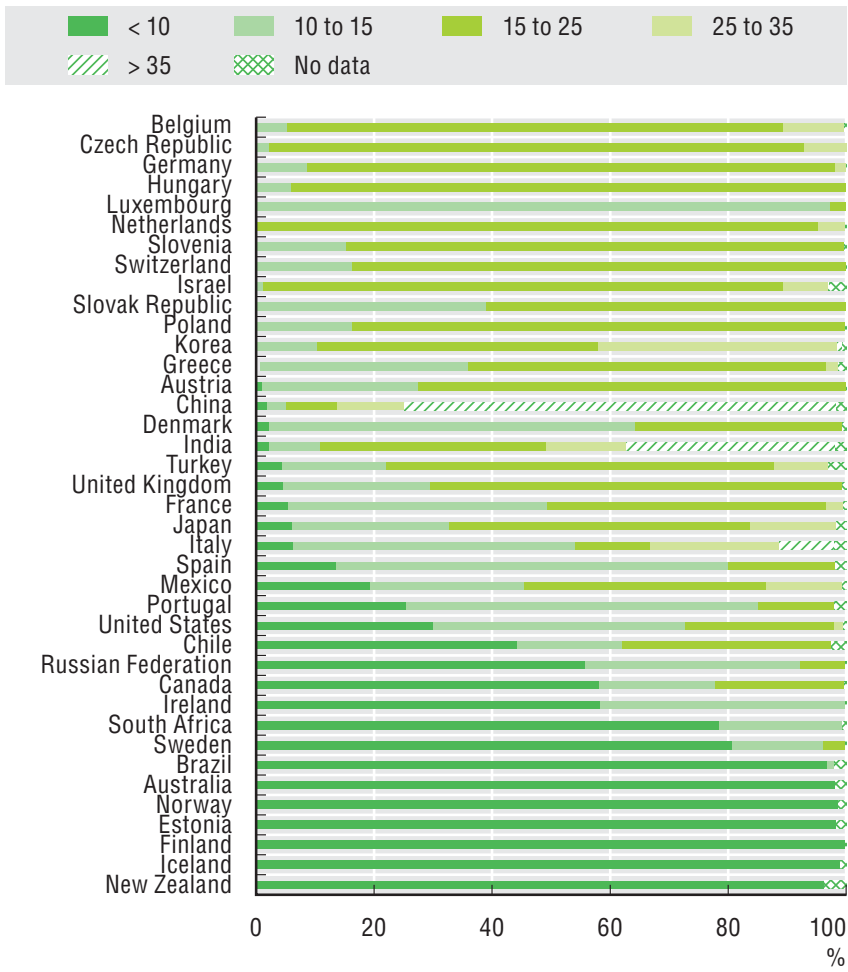

\subsection{TL2 region with highest GDP to $\mathrm{CO}_{2}$ ratio and country average, 2005}

Highest regional value

$\diamond$ Country average

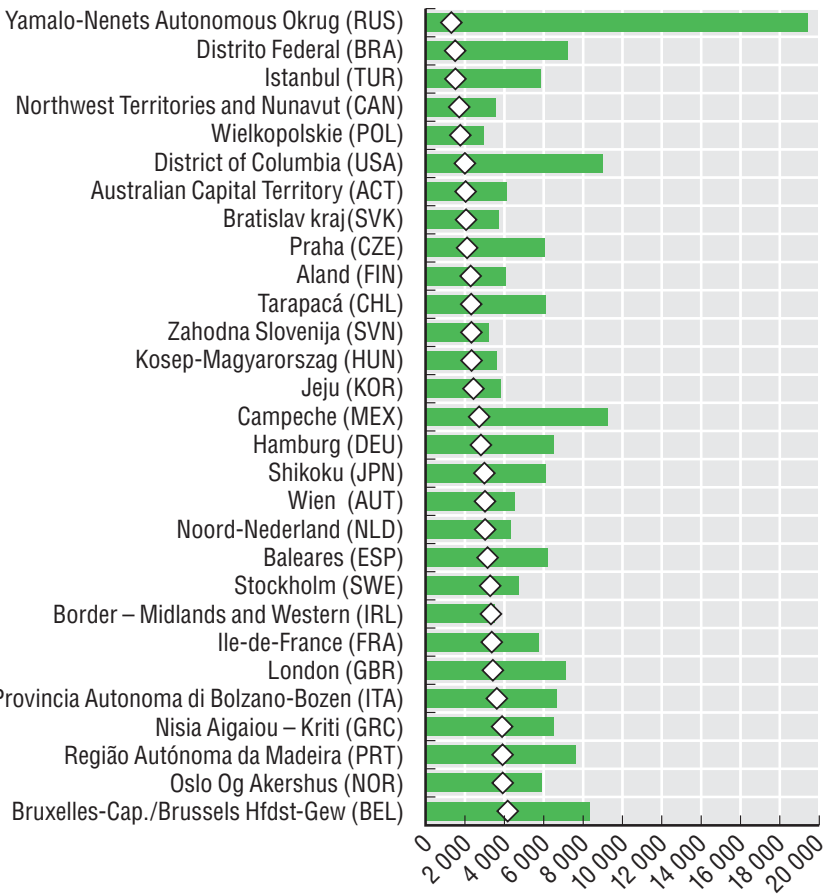

29.4. TL2 regional range of population exposure to air pollution, average 2001-06
Minimum value
Average exposure
- Maximum value

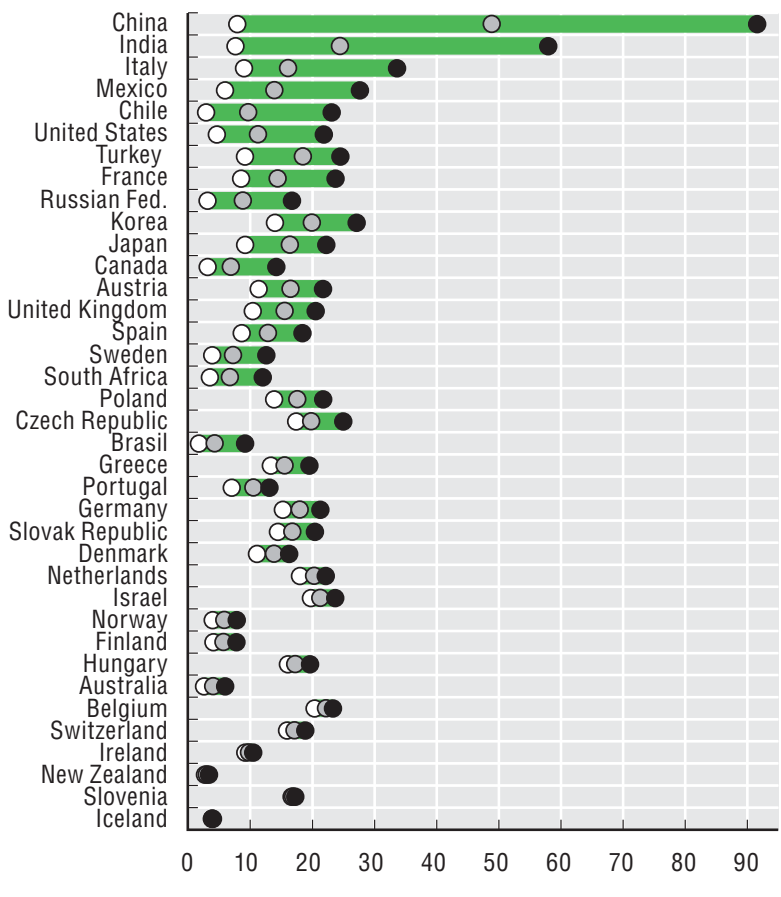

StatLink क्गाडस http://dx.doi.org/10.1787/888932439938 
29.5. Regional population exposure to air pollution, by WHO PM2.5 thresholds: Asia and Oceania, 2001-06 TL2 regions, average 2001-06

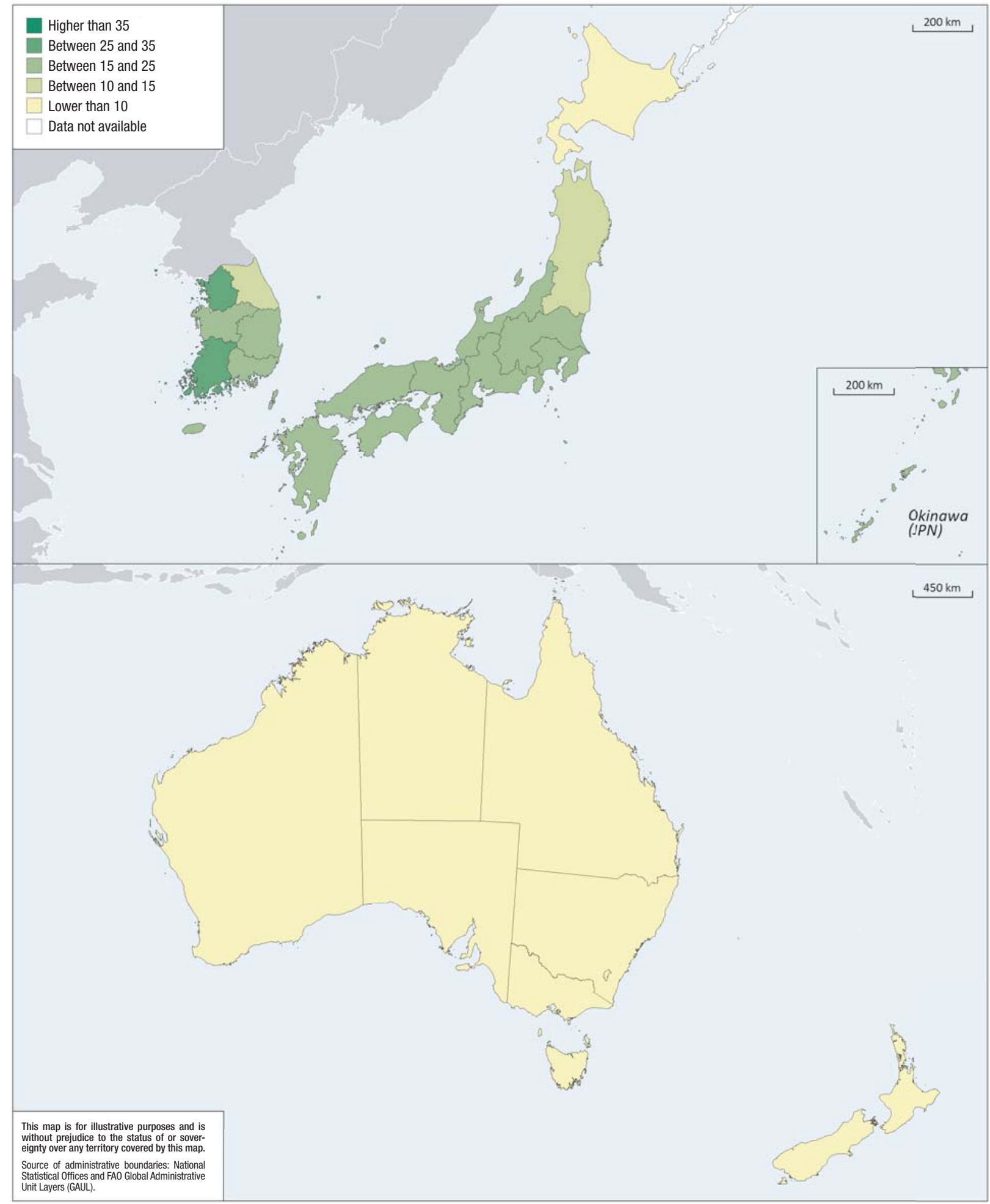

StatLink त्ञाS $h$ ttp://dx.doi.org/10.1787/888932440280 


\section{CARBON EMISSIONS AND AIR QUALITY IN REGIONS}

29.6. Regional population exposure to air pollution, by WHO PM2.5 thresholds: Europe, 2001-06 TL2 regions, average 2001-06

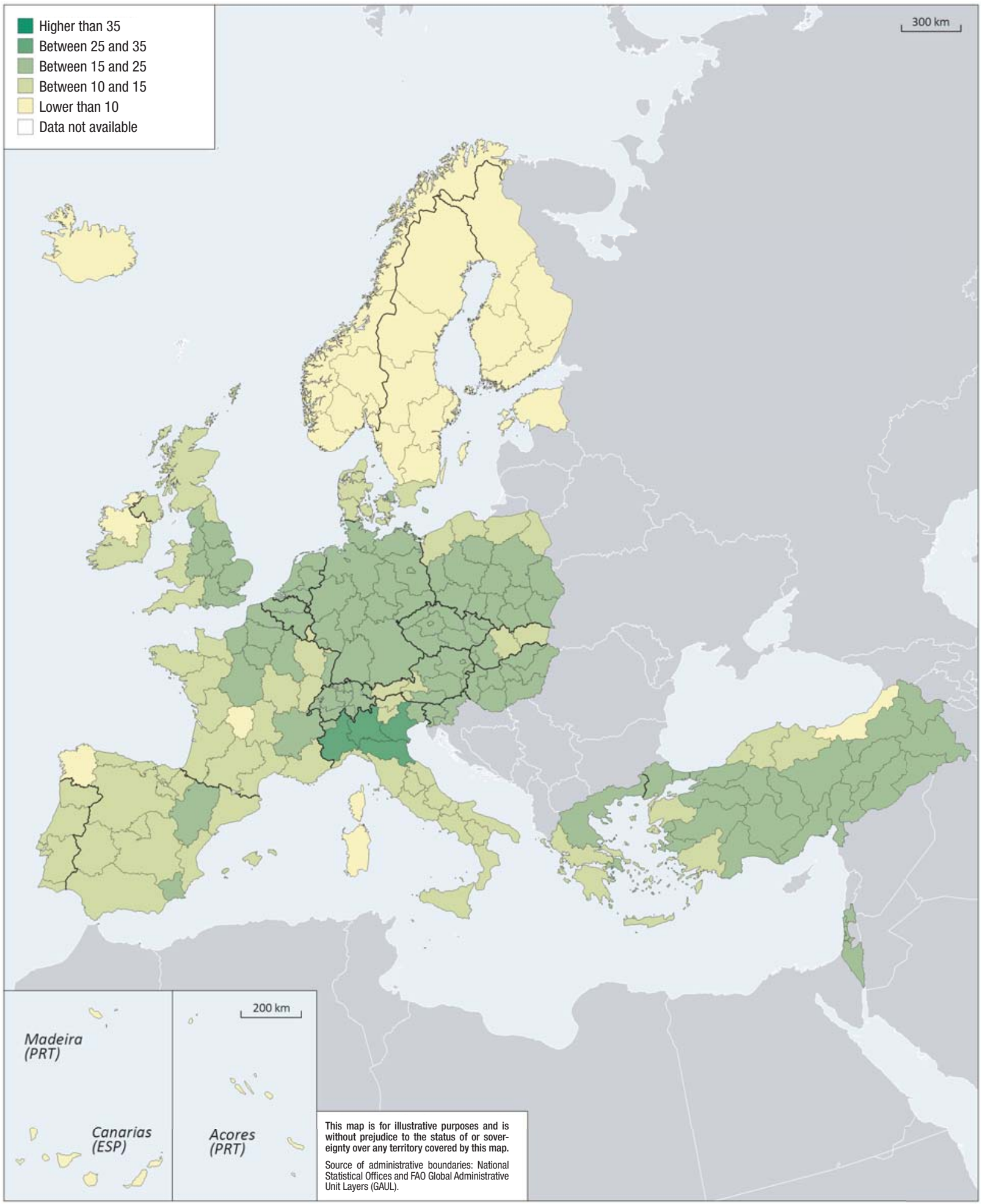

StatLink काIsL http://dx.doi.org/10.1787/888932440280 


\section{CARBON EMISSIONS AND AIR QUALITY IN REGIONS}

29.7. Regional population exposure to air pollution, by WHO PM2.5 thresholds: Americas, 2001-06

TL2 regions, average 2001-06

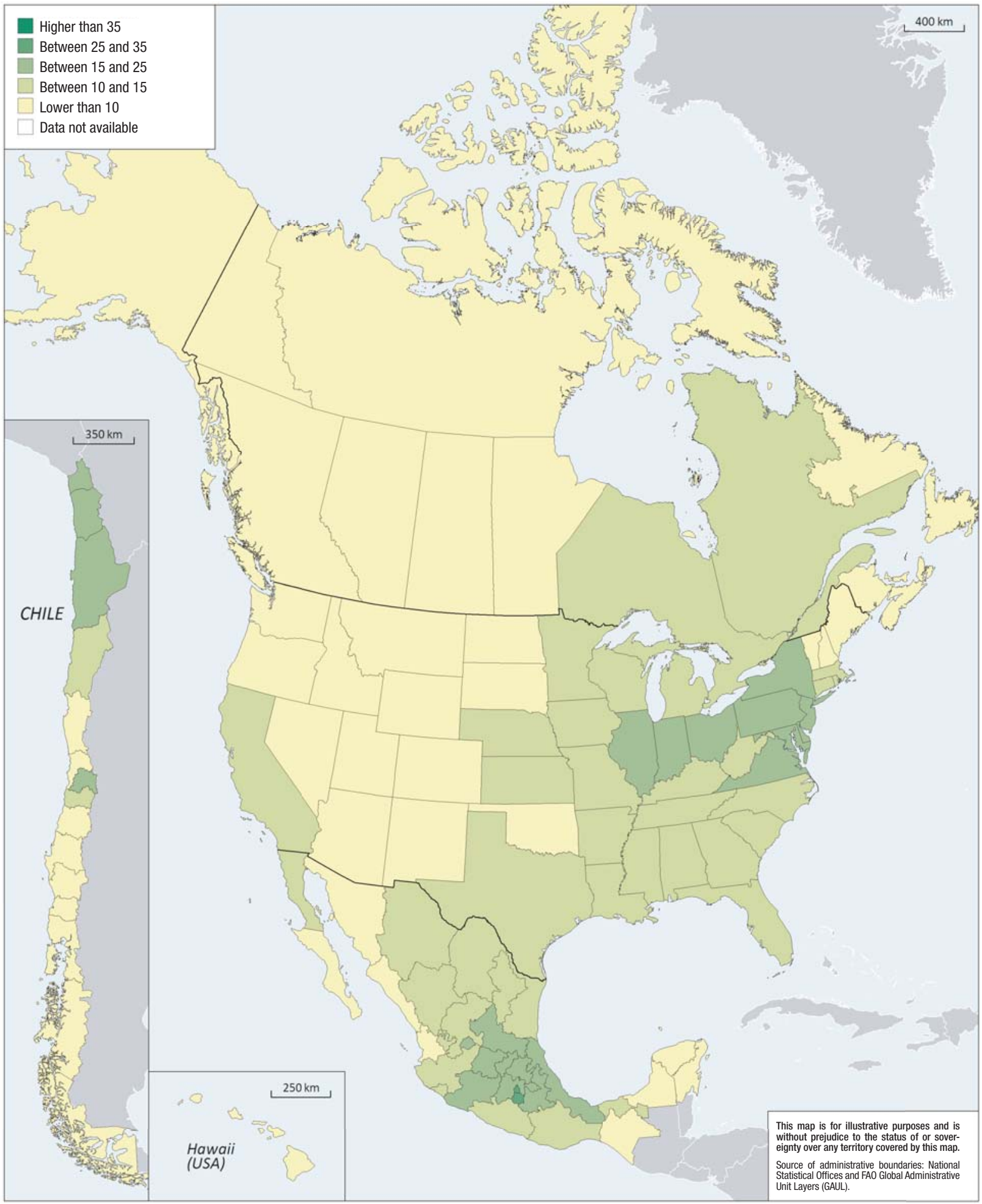

StatLink Aाs 


\section{CARBON EMISSIONS AND AIR QUALITY IN REGIONS}

29.8. Regional population exposure to air pollution, by WHO PM2.5 thresholds: Emerging economies, 2001-06 TL2 regions, average 2001-06

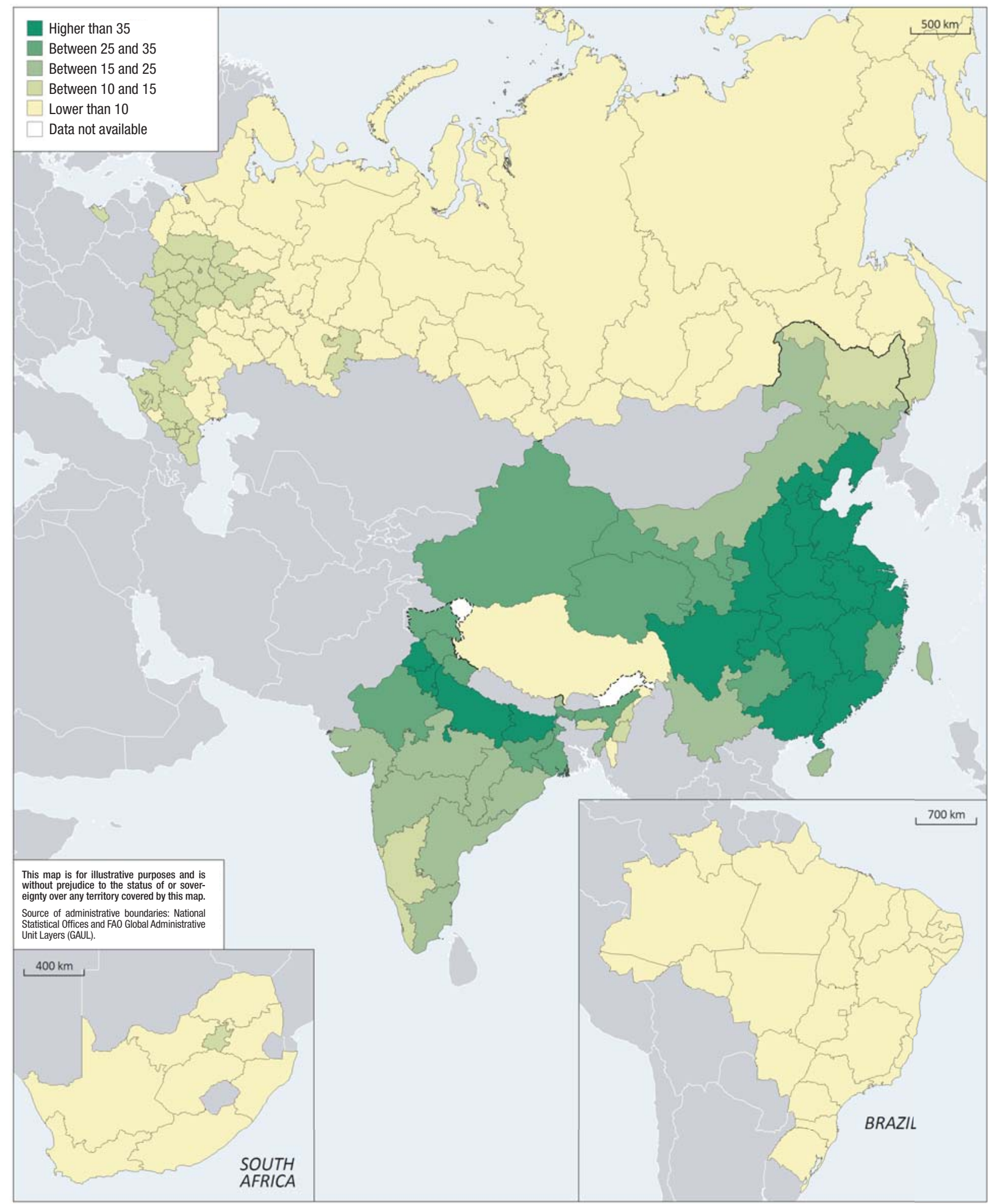


Waste management has potential impacts on human health and ecosystems. However, there are also concerns about the treatment and disposal capacity of existing facilities, and on the location and social acceptance of new facilities. The economic, environmental and social impact of waste is relevant in regions also because waste disposal is usually managed at the local level. Many OECD countries have strengthened measures for waste minimisation, recycling, product life cycle management and extended producer responsibility.

The amount of municipal waste generated gives an approximation of the potential pressure on the environment, and the economic cost for management and treatment. Studies show that municipal waste can represent more than one third of the public sector's financial efforts to abate and control pollution.

In 2008, OECD countries municipal waste production varied from 833 kilograms per inhabitant in Denmark to 306 kilograms in the Czech Republic (Figure 30.1). The different amount depends on the level and pattern of consumption, the rate of urbanisation, lifestyle and also on national waste management practices. Between 1995 and 2008, the municipal waste generated decreased the most in New Zealand, Slovenia, Israel, Japan and Germany. These data have to be interpreted with great caution since they may be biased by changes in the methodology for collecting the information. Nevertheless they give an indication of the level and trend of municipal waste production in these countries.

When looking at regional data, the volume of municipal waste per inhabitant varies significantly among regions within and across countries. In 2008, from the whole sample of countries considered, the Russian Federation is the one with the highest disparities. The municipal waste per capita in the region of Volgograd represents $11 \%$ of the country average, while in the region of Kostroma this value is more than two times higher. Within the group of OECD countries, Germany had the highest regional variation. Indeed, the region of Sachsen-Anhalt had a municipal waste per capita almost two times higher than the national average, while the region of Berlin only accounted for $43 \%$ of the country average (Figure 30.2).

Differences in the local management of waste, as well as in citizens' environmental behaviour within countries, explain the large regional disparities in recycling rates. These disparities are particularly marked in Germany and Italy (Figure 30.3).

Outperforming regions can be found both in countries with high rates of recycling (the region of Trier in Germany, where almost all the waste is recycled), and in countries where recycling is less common (Pomorskie in Poland, where $20 \%$ of the waste gets recycled, two times higher than the national average) (Figure 30.3).

\section{Definition}

Municipal waste is generally defined as the total waste collected by or on behalf of municipalities. It includes waste from households, commerce, institutions and small business, yard and garden; the definition excludes municipal waste from construction and demolition and municipal sewage.

Recycling rates are calculated as the \% of municipal waste that undergoes material or other forms of recycling (including composting).

\section{Source}

National data: OECD Environmental Statistics.

OECD Regional Database http://dotstat/wbos/.

Eurostat and Istat for regional data on waste recycled.

See Annex B for data, source and country related metadata.

The sum of collected regional data on waste does not always match the OECD national data.

\section{Reference years and territorial level}

2008; TL2.

Latest available year for Australia 2003; France 2004; Canada and Spain 2006; Hungary, Korea and Russia 2007.

No regional data are available for Chile, Switzerland, Denmark, Finland, Iceland, Slovenia, Sweden, New Zealand, and the United States.

\section{Further information}

OECD Key environmental indicators (2008).

\section{Figure notes}

Information on data for Israel: $h$ ttp://dx.doi.org/10.1787/888932315602.

30.3: Belgium and the Netherlands data are at TL3 level; Germany and United Kingdom data for 39 and 37, respectively, nationally defined regions. Austria, Norway and United Kingdom data refer to 2009. 

Infrastructure is the foundation of regional development and has been the target of significant investment through regional policy in the past years. Regional competitiveness is affected by infrastructure endowment, such as transport or telecommunication networks which, together with investment in human capital and innovation, can improve the access to markets, increase the connectivity of regions and provide services more efficiently.

Distance to markets and services can be approximated by the time needed to reach an urban centre (larger than 50000 inhabitants). Similar to most continental western European countries, in Mexico and the United States more than $70 \%$ of population is distributed within a 30 minutes driving distance from an urban centre. However, in the case of Scandinavian countries, Greece and Canada, at least one-fifth of population live in remote areas (Figure 31.1).

Regional disparities in the density of the road network can be used not only to account for different patterns of regional capital investment, but also for the capacity of regions to exchange goods and services. Nevertheless, despite the economic benefits provided by a well connected system of roads, there is increasing concern on the negative environmental effects caused by a higher flow of motor vehicles to the wellbeing of the population.

While most of the regions in continental Europe seem to benefit from a more homogenous network density, large differences are found in the United States and Norway, where the regions District of Columbia and Oslo have network densities that are more than 20 times higher than the national average (Figure 31.2).

Besides the physical access, high-speed ICT network is a key factor of the facility to adopt new technologies and provide services to remote areas. Regional differences in the percentage of households with broadband access are marked both in countries with a high ICT penetration, such as Canada, the United States and Australia and countries with low average values such as the Czech Republic, Greece, Spain and Italy (Figure 31.3).

A significant amount of the regional difference in the access to broadband can be attributed to agglomeration economies, and more precisely to the difference in urban and rural settlements. As expected, households in rural regions have a limited access to broadband. All the countries, except for Denmark and the Slovak Republic show a positive correlation between the access to broadband and the level of urbanization, (Figure 31.4).

\section{Definition}

The road network density of a region is defined as the ratio between the total kilometres of roads divided by the total area of the region (Km2). In the case of Europe, the road networks accounts for all motorways. For Canada, Mexico and the United States the road network takes only into account roads classified as highways. In the case of Chile, the road network is composed by all pavement primary roads.

Broadband access accounts for the number of broadband lines provided by operators in the country. This includes business and residential lines, with residential making up the vast majority. For clarification, the high-capacity leased line to a business counts as one subscription. Subscriber data does not count the number of business employees who may use that connection.

The Spearman correlation coefficient measures the strength and direction of the relationship between two variables, in this case the broad band access and the share of population in predominantly rural (PU), intermediate (IN) or predominantly rural (PR) regions. A value close to zero means no relationship (see Annex 3 for formula).

\section{Source}

OECD Regional database http://dotstat/wbos/.

See Annex B for data, source and country related metadata.

\section{Reference years and territorial level}

2009; TL2.

Road network density: No regional data available for Israel, Japan, Korea, Australia and New Zealand.

Broadband Access: No regional data available for Canada, Chile, France, Iceland, Israel, Mexico, New Zealand, Poland and Turkey.

\section{Figure notes}

31.2: Network density is expressed as $\mathrm{km}$ of road network by $100 \mathrm{~km}^{2}$. The country value is equal to 1 . 
31.1. \% of population living less than 30 minutes and more than 90 minutes away from an urban centre, 2009

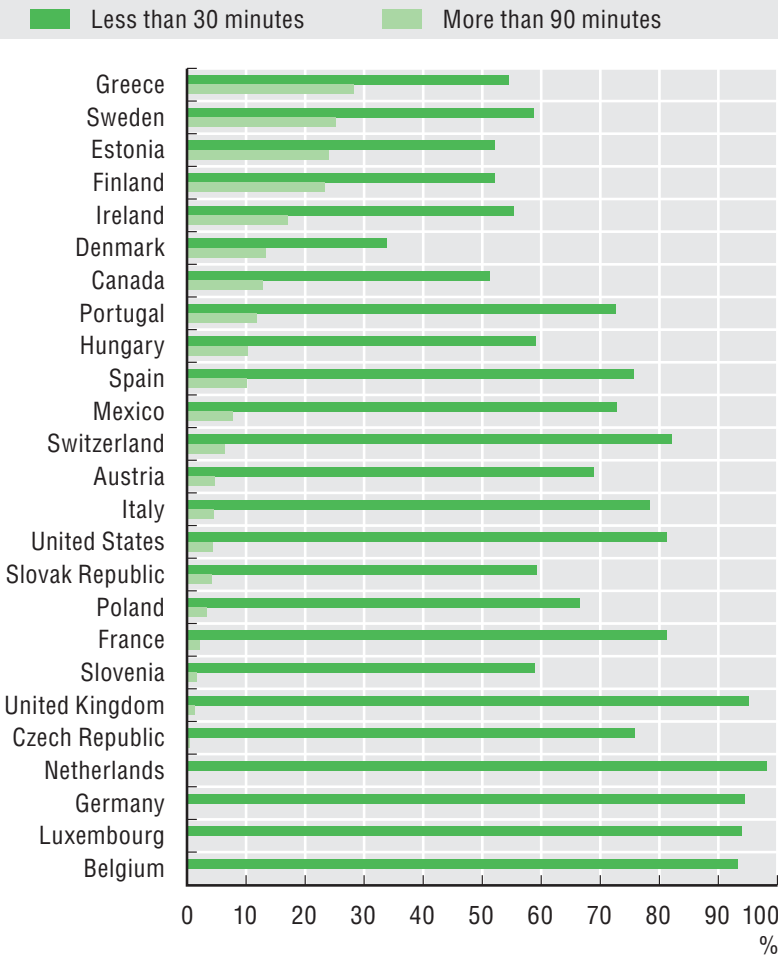

\subsection{TL2 regional range in households with broadband} access, 2009

O Country average

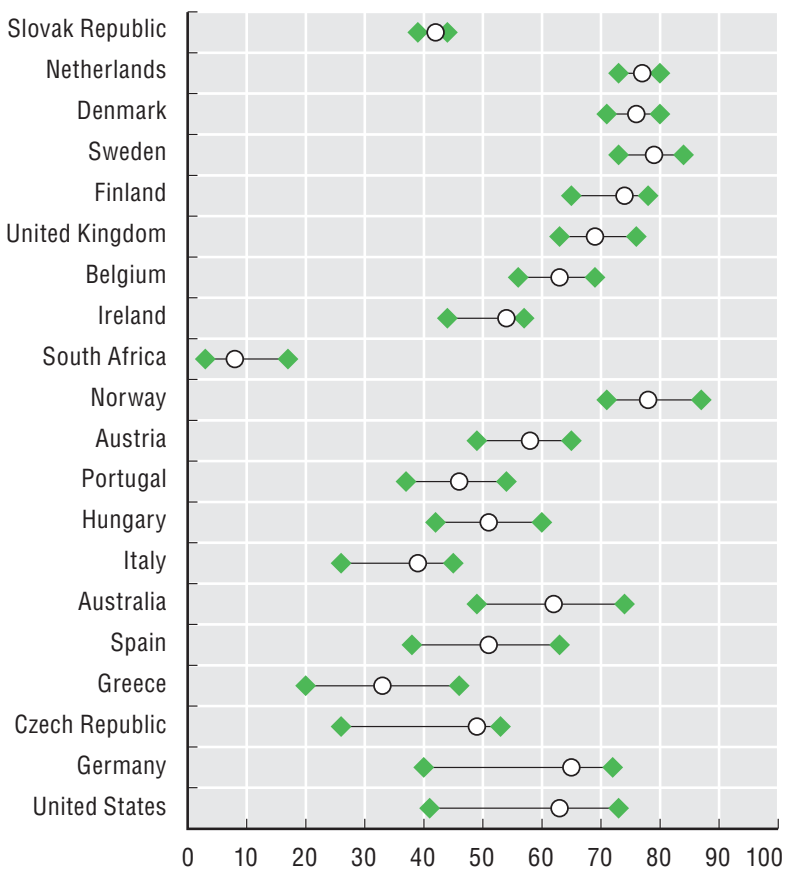

31.2. TL2 regional range of network density, 2009

Minimum

Maximum

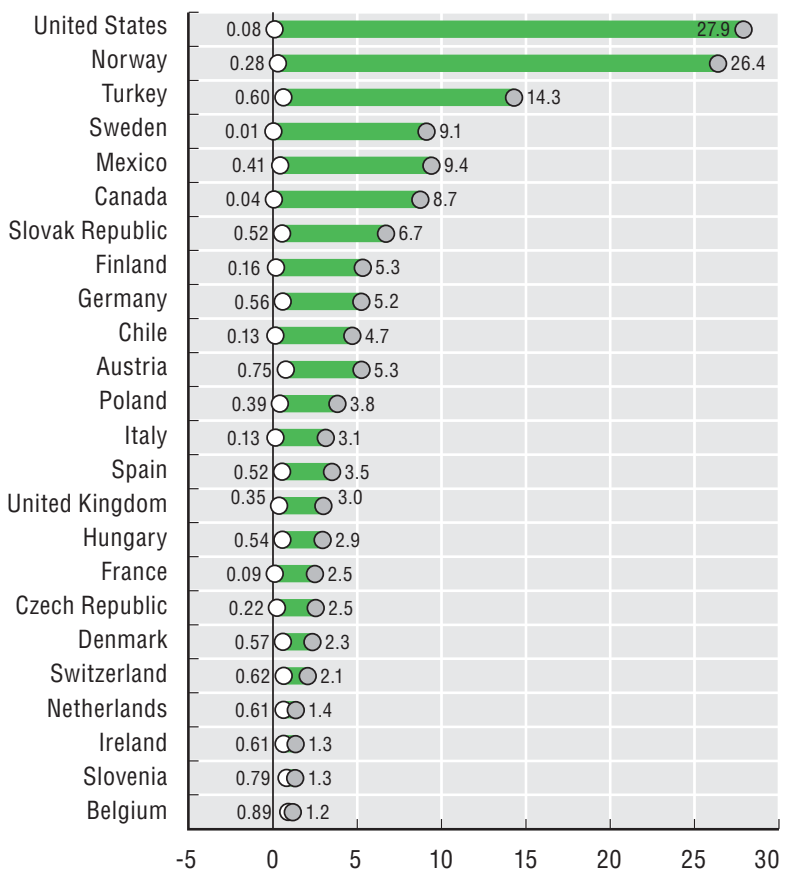

31.4. Spearman correlation coefficient between households with broadband access and share of population by regional type, TL2, 2009
- Urban
- Intermediate
- Rural

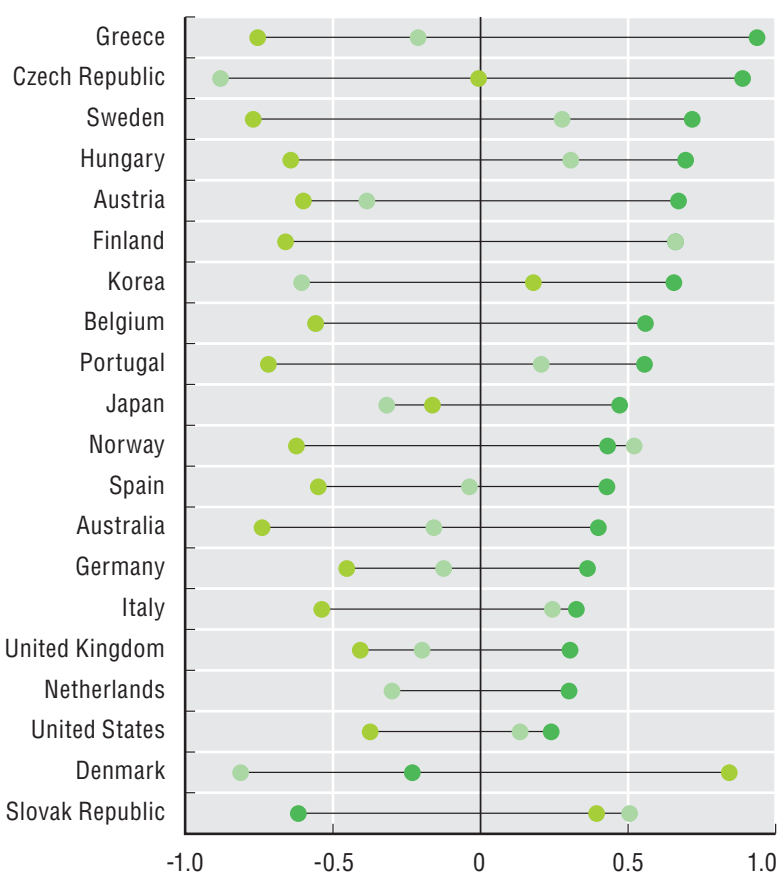

StatLink जiाsय http://dx.doi.org/10.1787/888932440014 
Innovation in mitigation technology is a means to address climate change. The patenting activity of regions in green technology provides a measure of the efforts and pace of innovation. Japan and the United States display the top performing regions in number of patents in new sectors, such as green technologies, biotechnologies and nanotechnologies. The number of patents in biotechnologies is higher and patenting activities less recent than in green and nanotechnologies. Among the top performing regions in green patenting, Aichi and Tokyo (Japan) have emerged most recently (Figure 32.1).

A limited number of regions have appeared as hot spots in patenting on renewable energy. In some cases, like $\emptyset$ stjylland and Vestjylland (Denmark), Madrid and Barcelona (Spain) and Seoul and Gyeonggi-do (Korea), despite limited patenting activity on renewable energy at the country level. These regions can provide an indication of how to replicate a positive environment for business innovation (Figure 32.2).

Patent activities in green technologies have become a more collaborative process, as the increase in the number of partners in most recent years show (Figure 32.3). SouthernKanto, Hokuriku and Tokai (Japan), Baden-Wuerttemberg and Bayern (Germany) and California (United States) are the leading regions in green parenting and have uncreased their collaborations with other regions between 3 and 20 times. New regions are becoming hubs in global co-invention networks. The Capital region and Chungcheong (Korea) have 37 times more collaborations with other regions than ten years ago. Guangdong (China) passed from 1 collaboration to more than 100 (Figure 32.3).

Universities account for $5 \%$ of total patent applications in green technologies. This share is close to the average of most technologies, with the exception of biotechnology where universities account for $23 \%$ of patent applications. There is a high and statistically significant correlation in business and university patenting activity across regions, suggesting that universities may be important partners for industrial research and development (R\&D) (Figure 32.4).

\section{Definition}

A patent is an exclusive right granted for an invention, which is a product or a process with industrial applicability that provides, in general, a new way of doing something, or offers a new technical solution to a problem ("inventive step"). A patent provides protection for the invention to the owner of the patent. The protection is granted for a limited period, generally 20 years.

Data refer to overall patent applications to Patent Cooperation Treaty (PCT) applications.

Patent documents report the inventors (where the invention takes place), as well as the applicants (owners), along with their addresses and country of residence. Patent counts are based on the inventor's region of residence and fractional counts. If on the patent document are registered two or more inventors, the patent is classified as a co-patent.

A co-patent is classified as a collaboration between business (companies) and non-business organisations (government, universities or hospitals) when there is at least one business applicant and at least one public applicant. The co-patents so classified are successively assigned to the region(s) of residence/ work of the co-inventors. Co-patents involving only individuals are not classified as business-non business collaboration. This has to be taken into account in the results, since in some countries the weight of individuals' applicants is quite high. The co-location statistics is the Spearman rank correlation between the number of patents in TL3 regions with a university applicant and the number of patents with nonuniversity applicants (individuals and companies).

Green patents include those in waste management, air and water pollution reduction, renewable energies, hybrid/electric car technologies and energy efficiency in lighting and building.

\section{Source}

OECD REGPAT Database http://dotstat/wbos/.

For classifications of green and renewable energy patents, see www.oecd.org/environment/innovation/indicator.

See Annex B for data, source and country related metadata.

\section{Reference years and territorial level}

1995-2007; TL3.

\section{Figure notes}

32.3: Ratio between the number of co-patents in green technologies in 2007 and in 1995

32.4: * significant at $1 \%$ level. 
32.1. Patents in biotech, green and nanotech of the top five patenting TL3 regions in 2005-07 and their values in 1995-1997

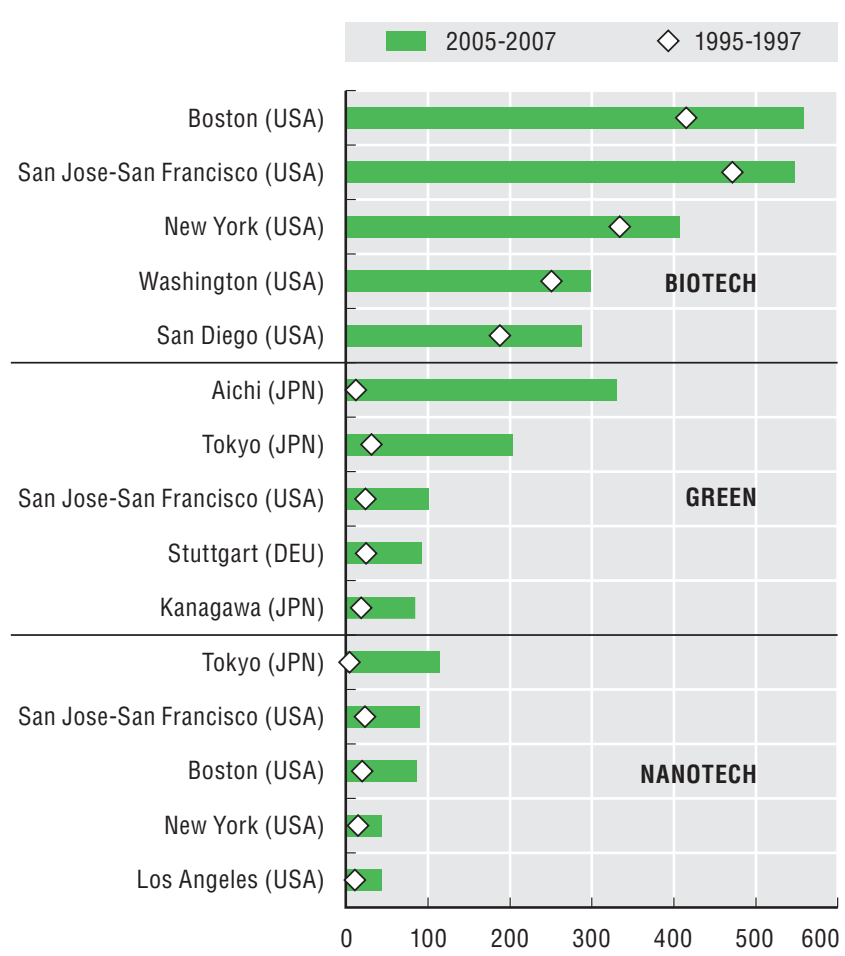

32.3. Increase in collaboration among regions, top 25 green patenting (TL2) regions, 1995-2007

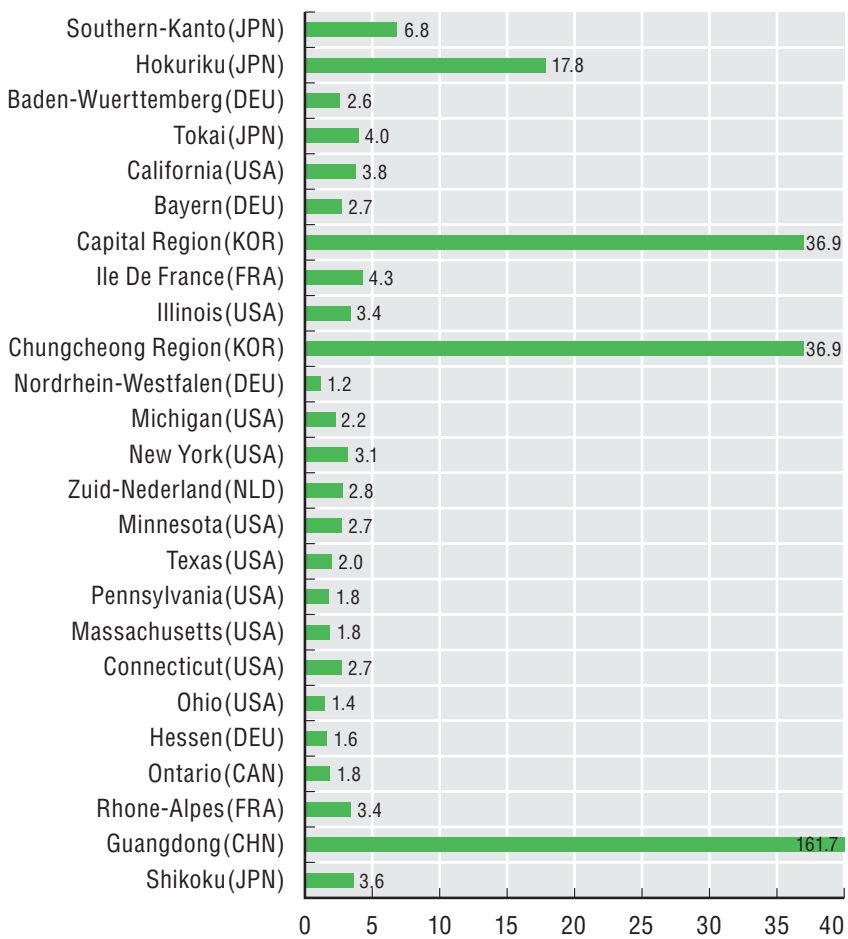

32.2. Patents in renewable energy in the top 20 patenting TL3 regions as a \% of the country's renewable energy patents, 2005-07

Regional share on country's renewable
$\diamond$ Country share on total patents in renewable energy

San Jose-San Francisco (USA) Østjylland(DNK) Tokyo(JPN)

Los Angeles (USA) Boston (USA) Vestjylland(DNK) Seoul(KOR)

Osaka(JPN) Navarra(ESP) München(DEU) Gyeonggi-do(KOR) Sydjylland(DNK) New York (USA)

Sydney (AUS)

Nagasaki(JPN)

Philadelphia (USA) Madrid(ESP)

Barcelona (ESP)

Washington (USA) Südlicher Oberrhein(DEU)

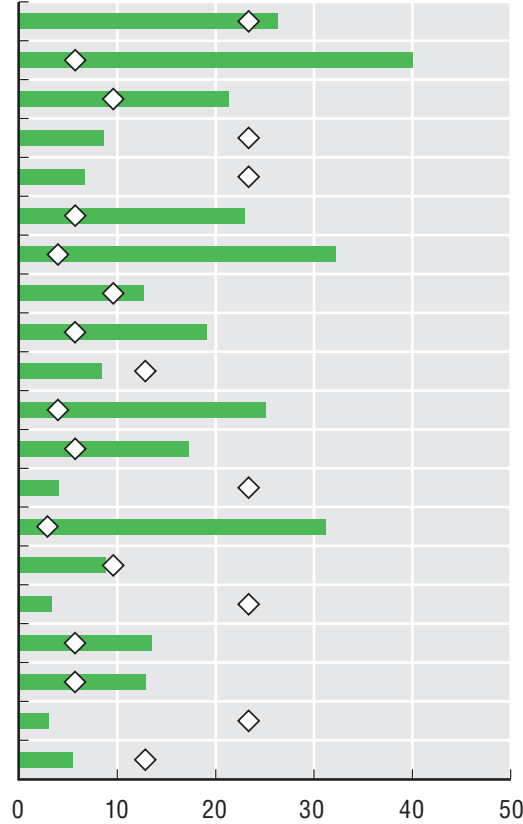

32.4. Contribution of universities to patent applications in green technologies and co-location of university-business applications, 2005-07

\begin{tabular}{|c|c|c|}
\hline & All TL3 regions (\%) & Top innovators quintile (\%) \\
\hline \multicolumn{3}{|l|}{ Green technologies } \\
\hline $\begin{array}{l}\text { Share of universities } \\
\text { applicants }\end{array}$ & 5 & 5 \\
\hline $\begin{array}{l}\text { Colocation university and } \\
\text { business }\end{array}$ & 33 & 26 \\
\hline \multicolumn{3}{|l|}{ All technologies } \\
\hline $\begin{array}{l}\text { Share of universities } \\
\text { applicants }\end{array}$ & 6 & 7 \\
\hline $\begin{array}{l}\text { Colocation university and } \\
\text { business }\end{array}$ & 65 & 34 \\
\hline
\end{tabular}





\section{Territorial grids and regional typology}

\section{Table A.1. Territorial grid of OECD member countries}

\begin{tabular}{|c|c|c|c|}
\hline Region & Territorial levels 2 & Territorial levels 3 & Non-official grid (NOG) \\
\hline Australia & States/territories (8) & Statistical divisions (60) & - \\
\hline Austria & Bundesländer (9) & Gruppen von Politischen Bezirken (35) & - \\
\hline Belgium & Régions (3) & Provinces (11) & - \\
\hline Canada & Provinces and territories (12) & Census divisions (288) & LFS, Economic areas (71) \\
\hline Chile & Regions (15) & Provincias (54) & \\
\hline Czech Republic & Oblasti (8) & Kraje (14) & - \\
\hline Denmark & Regioner (5) & Landsdeler (11) & - \\
\hline Estonia & Region (1) & Groups of maakond (5) & - \\
\hline Finland & Suuralueet (5) & Maakunnat (20) & - \\
\hline France & Régions (22) & Départements (96) & - \\
\hline Germany & Länder (16) & Spatial planning regions (96) & - \\
\hline Greece & Groups of development regions (4) & Development regions (13) & - \\
\hline Hungary & Planning statistical regions (7) & Counties+Budapest (20) & - \\
\hline Iceland & Regions (2) & Landsvaedi (8) & - \\
\hline Ireland & Groups regional authority regions (2) & Regional authority regions (8) & - \\
\hline Israel & 7 Districts & & - \\
\hline Italy & Regioni (21) & Province (107) & - \\
\hline Japan & Groups of prefectures (10) & Prefectures (47) & - \\
\hline Korea & Regions (7) & Special city, metropolitan area and province (16) & - \\
\hline Luxembourg & State (1) & State $(1)$ & - \\
\hline Mexico & Estados (32) & Grupos de municipios (209) & - \\
\hline Netherlands & Landsdelen (4) & Provinces (12) & - \\
\hline New Zealand & Groups of regional councils (2) & Regional councils (14) & - \\
\hline Norway & Landsdeler (7) & Fylker (19) & - \\
\hline Poland & Vojewodztwa (16) & Podregiony (66) & - \\
\hline Portugal & $\begin{array}{l}\text { Comissões de coordenaçao e desenvolvimento } \\
\text { regional + regiões autónomas ( } 7)\end{array}$ & Grupos de municipios (30) & - \\
\hline Slovak Republic & Zoskupenia krajov (4) & Kraj (8) & - \\
\hline Slovenia & Kohezijske regije (2) & Statistične regije (12) & - \\
\hline Spain & Comunidades autonomas (19) & Provincias $(59)$ & - \\
\hline Sweden & Riksomraden (8) & Län (21) & - \\
\hline Switzerland & Grandes regions (7) & Cantons (26) & - \\
\hline Turkey & Regions (26) & Provinces (81) & - \\
\hline \multirow[t]{2}{*}{ United Kingdom } & & $\begin{array}{l}\text { Upper tier authorities or groups of lower tier } \\
\text { authorities or groups of unitary authorities or LECs }\end{array}$ & \\
\hline & Government office regions + counties (12) & or groups of districts (133) & - \\
\hline United States & States $(51)$ & Economic areas (179) & - \\
\hline
\end{tabular}


Table A.2. Territorial grid of the BRICS countries

\begin{tabular}{lll}
\hline Region & Territorial levels 2 & Territorial levels 3 \\
\hline Brazil & Estados and Districto federal (27) & Mesoregiao (137) \\
China & 31 provinces; special administrative region of Hong Kong, & \\
& special administrative region of Macao and Chinese Taipei (33) & \\
India & States and Union territories (35) & \\
Russian Federation & Oblast or okrug (83) & \\
South Africa & Provinces (9) & \\
\hline
\end{tabular}

Table A.3. Percentage of national population living in predominantly urban, intermediate and predominantly rural regions (TL3) and number of regions classified as such in each country

\begin{tabular}{|c|c|c|c|c|c|c|}
\hline & \multicolumn{3}{|c|}{ Percentage of population (2008) } & \multicolumn{3}{|c|}{ Number of regions (TL3) } \\
\hline & Rural & Intermediate & Urban & Rural & Intermediate & Urban \\
\hline Australia & 21.95 & 20.88 & 57.18 & 41 & 13 & 6 \\
\hline Austria & 45.66 & 30.87 & 23.47 & 25 & 8 & 2 \\
\hline Belgium & 2.48 & 14.24 & 83.28 & 1 & 2 & 8 \\
\hline Canada & 28.29 & 16.21 & 55.50 & 223 & 35 & 30 \\
\hline Chile & 35.67 & 14.41 & 49.91 & 41 & 7 & 6 \\
\hline Czech Republic & 4.95 & 83.38 & 11.68 & 1 & 12 & 1 \\
\hline Denmark & 42.84 & 27.89 & 29.27 & 5 & 3 & 3 \\
\hline Estonia & 10.46 & 76.81 & 12.73 & 1 & 3 & 1 \\
\hline Finland & 61.67 & 12.13 & 26.20 & 17 & 2 & 1 \\
\hline France & 16.94 & 48.31 & 34.74 & 36 & 46 & 14 \\
\hline Germany & 17.91 & 25.93 & 56.16 & 31 & 30 & 35 \\
\hline Greece & 39.96 & 23.83 & 36.22 & 10 & 2 & 1 \\
\hline Hungary & 40.97 & 42.09 & 16.95 & 11 & 8 & 1 \\
\hline Iceland & 36.96 & 63.04 & & 7 & 1 & 0 \\
\hline Ireland & 72.45 & 0 & 27.55 & 7 & 0 & 1 \\
\hline Italy & 9.22 & 38.27 & 52.51 & 23 & 51 & 33 \\
\hline Japan & 12.45 & 31.88 & 55.67 & 13 & 22 & 12 \\
\hline Korea & 17.19 & 13.08 & 69.73 & 5 & 3 & 8 \\
\hline Luxembourg & 0 & 100.00 & 0 & 0 & 1 & 0 \\
\hline Mexico & 36.15 & 17.12 & 46.73 & 145 & 30 & 34 \\
\hline Netherlands & 0 & 15.02 & 84.98 & 0 & 5 & 7 \\
\hline New Zealand & 0 & 55.76 & 44.24 & 0 & 12 & 2 \\
\hline Norway & 47.99 & 40.18 & 11.83 & 13 & 5 & 1 \\
\hline Poland & 46.37 & 31.13 & 22.50 & 34 & 20 & 12 \\
\hline Portugal & 20.85 & 26.78 & 52.36 & 15 & 8 & 7 \\
\hline Slovak Republic & 25.21 & 63.48 & 11.31 & 2 & 5 & 1 \\
\hline Slovenia & 57.13 & 42.87 & 0 & 8 & 4 & 0 \\
\hline Spain & 13.42 & 38.07 & 48.51 & 22 & 25 & 12 \\
\hline Sweden & 48.86 & 29.91 & 21.23 & 18 & 2 & 1 \\
\hline Switzerland & 8.95 & 49.69 & 41.37 & 7 & 12 & 7 \\
\hline Turkey & 25.59 & 23.82 & 50.59 & 45 & 23 & 13 \\
\hline United Kingdom & 2.03 & 28.43 & 69.54 & 11 & 40 & 82 \\
\hline United States & 37.66 & 20.05 & 42.29 & 132 & 21 & 26 \\
\hline
\end{tabular}


Figure A.1. Extended regional typology

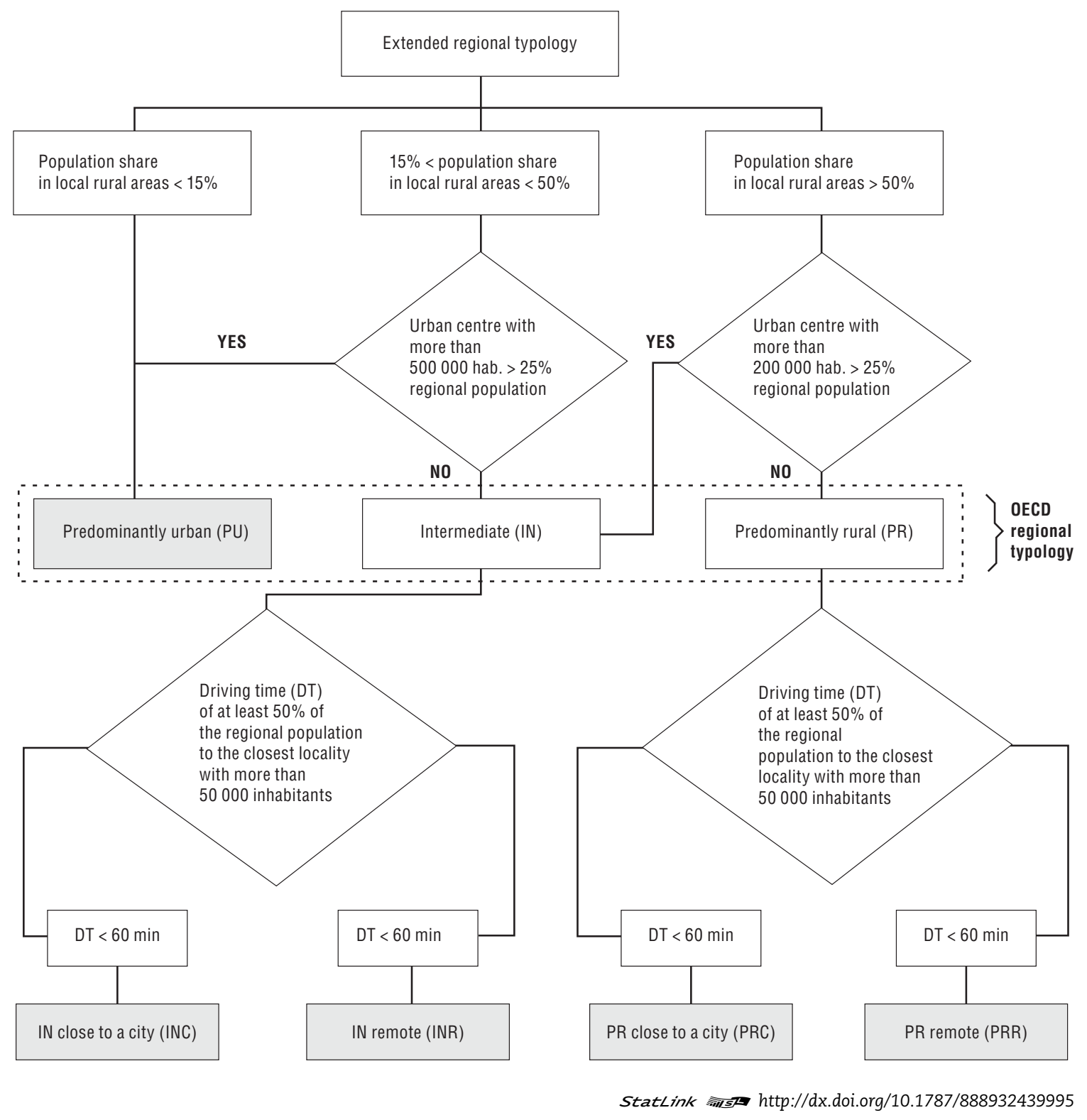


Figure A.2. Extended regional typology: Americas

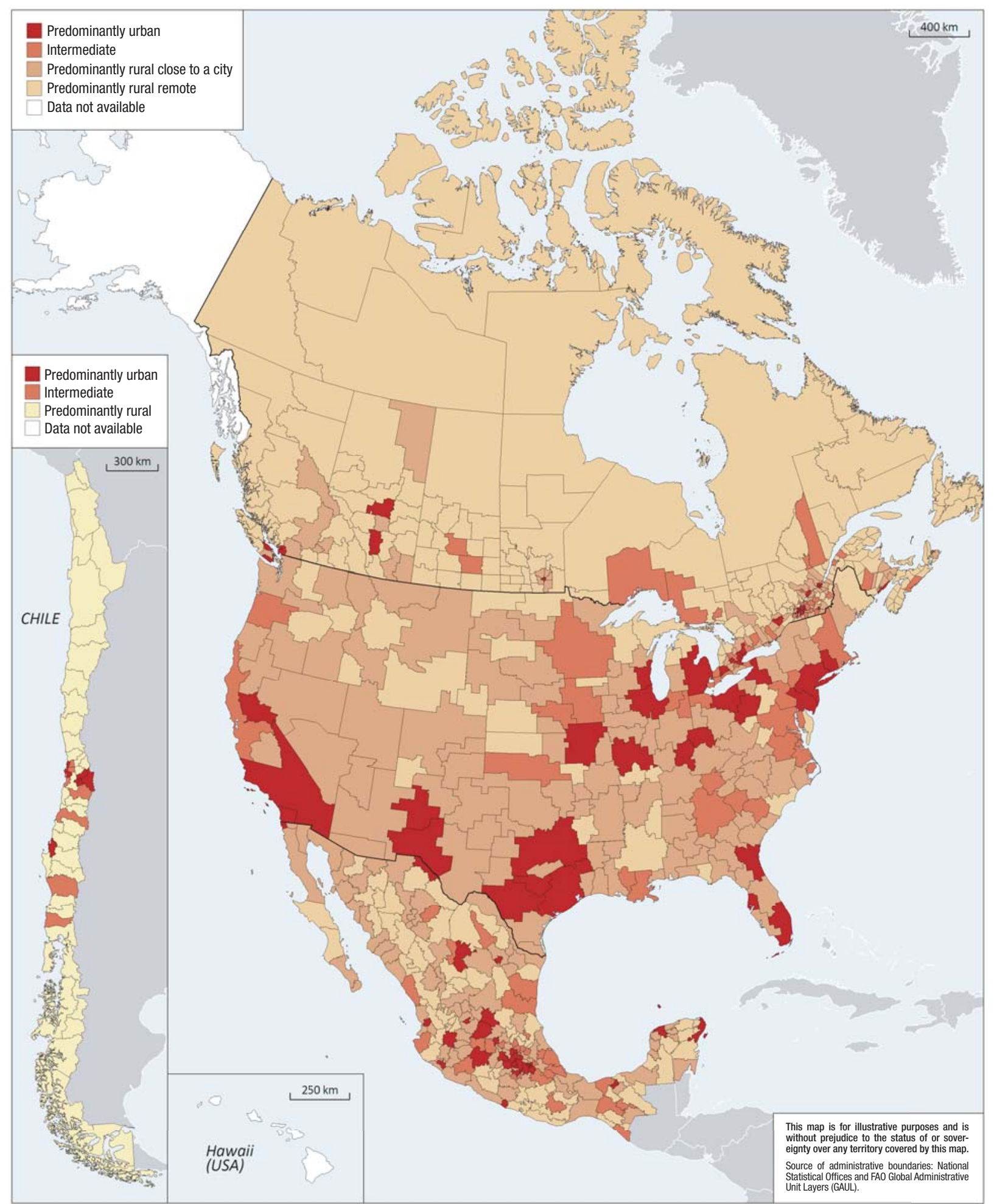


Figure A.3. Extended regional typology: Europe

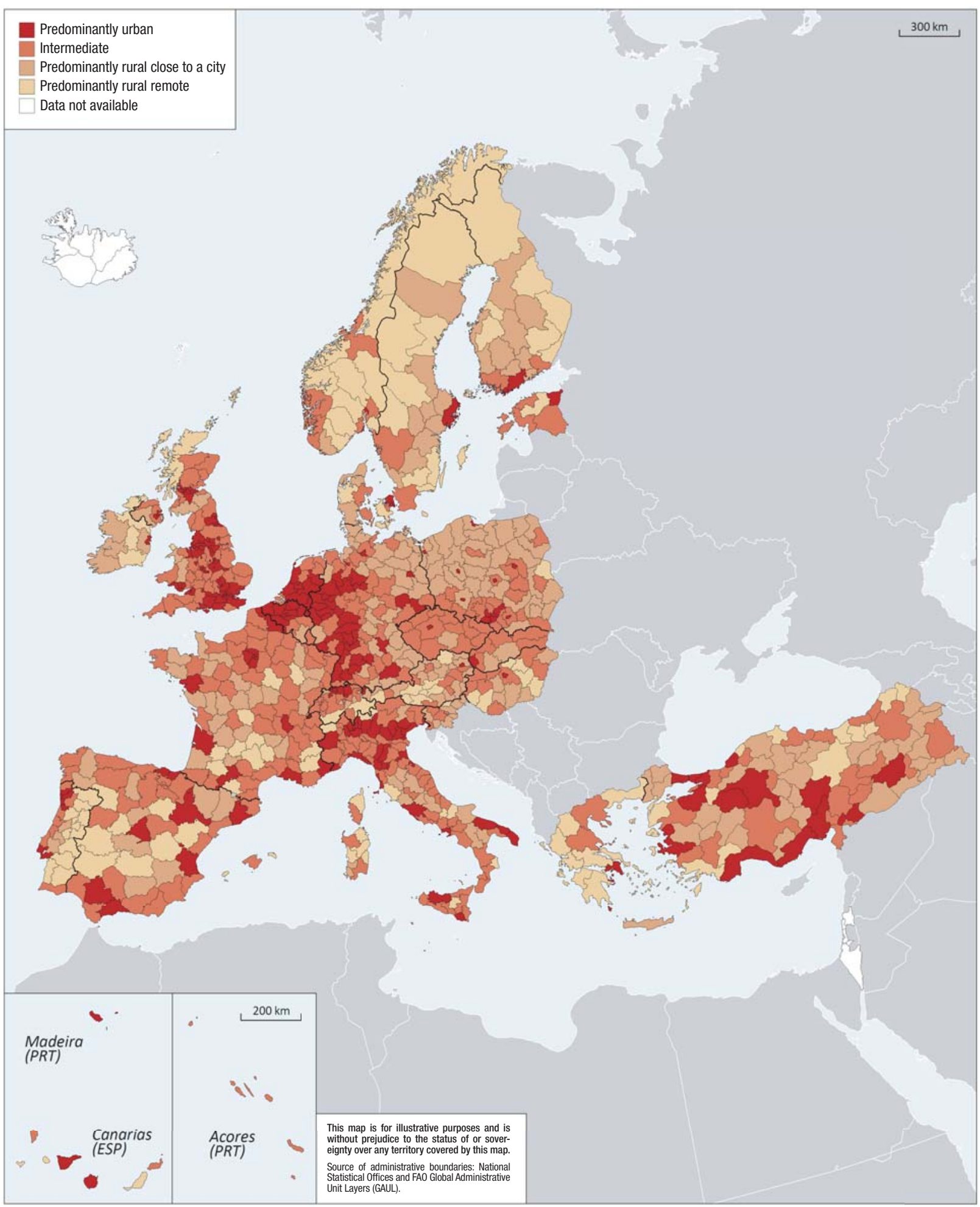


Figure A.4. Regional typology, OECD countries: Asia and Oceania (TL3)

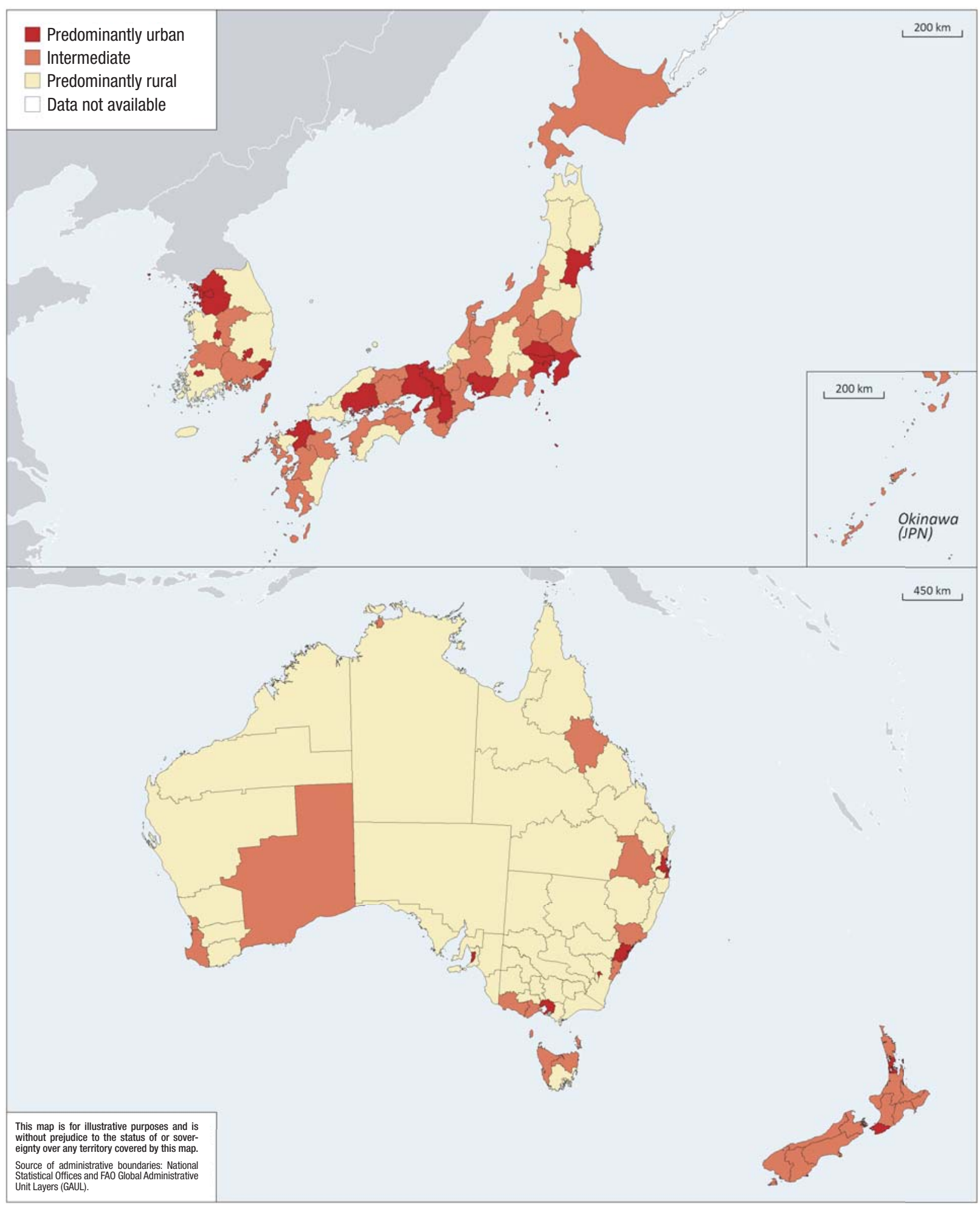




\section{ANNEX B}

\section{Sources and data description}

\section{User guide: List of indicators and variables by chapter}

\begin{tabular}{|c|c|c|c|}
\hline Chapters & Indicator & Variables used & Page \\
\hline Chapter 1 & Regional contribution to population change & Total population; Area & 138 \\
\hline Chapter 2 & Distribution of population and regional typology & Total population; Area; Regional typology & 138 \\
\hline Chapter 3 & Regional contribution to growth & Gross domestic product (GDP); Total population & $138 ; 140$ \\
\hline Chapter 4 & Regional contribution to change in employment & Total employment; Population in age class $15-64$ & 142 \\
\hline Chapter 5 & Labour productivity growth in regions & GDP; Employment by place of work; Total population & $138 ; 139 ; 140$ \\
\hline Chapter 6 & Regional economic disparities & GDP; Total population; Employment by place of work & $138 ; 140$ \\
\hline Chapter 7 & Patterns of growth in regions & GDP; Employment by place of work; Area & $138 ; 140$ \\
\hline Chapter 8 & Impact of the crisis on jobs in regions & Total employment; Population in age class 15-64 & $139 ; 142$ \\
\hline Chapter 9 & Regional disparities in tertiary education & $\begin{array}{l}\text { Educational attainments of labour force; Enrolment in education } \\
\text { institutions by educational level }\end{array}$ & $144 ; 145$ \\
\hline Chapter 10 & Skilled immigration in OECD countries & Foreign- born population by educational attainment & 146 \\
\hline Chapter 11 & Regional disparities in specialisation & $\begin{array}{l}\text { Employment by industry ( } 6 \text { sectors); Gross value added (GVA) by industry } \\
\text { ( } 6 \text { sectors); Employment by detailed industry ( } 20 \text { sectors) }\end{array}$ & $140 ; 141$ \\
\hline Chapter 12 & Regional specialisation in knowledge-oriented sectors & $\begin{array}{l}\text { Employment in high-tech manufacturing; Employment in knowledge- } \\
\text { intensive services; Total employment }\end{array}$ & $142 ; 144$ \\
\hline Chapter 13 & Public investment in regions & General government expenditure; Regional capital expenditure & 146 \\
\hline Chapter 14 & Research and development expenditure in regions & R\&D expenditure by performing sector; GDP; R\&D personnel & $147 ; 148$ \\
\hline Chapter 15 & Public and business research and development expenditure & R\&D expenditure by performing sector; GDP; GVA of industry & $140 ; 148$ \\
\hline Chapter 16 & Patents in regions and among different economic actors & $\begin{array}{l}\text { PCT patents applications; PCT patents applications by type of applicants } \\
\text { (business, public); PCT co-patents applications }\end{array}$ & 148 \\
\hline Chapter 17 & Regional patterns of co-patenting & $\begin{array}{l}\text { PCT patents applications; PCT patents applications by type of applicants } \\
\text { (business, public); PCT co-patents applications }\end{array}$ & 148 \\
\hline Chapter 18 & Regional disparities in household income & Primary and disposable income of households & 149 \\
\hline Chapter 19 & Concentration of elderly population in regions & Total population; Population by age $(0-14 ; 15-64 ; 65+)$ & $138 ; 139$ \\
\hline Chapter 20 & Population mobility among regions & Inter-regional flows of population & 150 \\
\hline Chapter 21 & Immigration trends in OECD countries & Foreign- born population by duration of stay & 146 \\
\hline Chapter 22 & Regional disparities in unemployment & $\begin{array}{l}\text { Unemployment; Long-term unemployment; Labour force; } \\
\text { Youth unemployment rate }\end{array}$ & $142 ; 143$ \\
\hline Chapter 23 & Gender differences in employment opportunities & $\begin{array}{l}\text { Labour force by sex; Population by age }(0-14 ; 15-64 ; 65+) \text { and sex; Female } \\
\text { employment }\end{array}$ & $139 ; 142$ \\
\hline Chapter 24 & Access to education & $\begin{array}{l}\text { Labour force by educational attainment; Early school leavers; PISA scores } \\
\text { in reading }\end{array}$ & $144 ; 151$ \\
\hline Chapter 25 & Access to health & $\begin{array}{l}\text { Number of deaths by five years age; Population by five years age; Number } \\
\text { of physicians; Total population; Disposable income of households }\end{array}$ & $151 ; 152$ \\
\hline Chapter 26 & Access to basic services in developing & Household with access to water, sewage, electricity and telephone & 153 \\
\hline Chapter 27 & The growth of urban land in OECD regions & Land cover and changes & 153 \\
\hline Chapter 28 & Forest, natural vegetation and the carbon footprint of regions & Global forest land cover; Net primary productivity & $153 ; 154$ \\
\hline Chapter 29 & Carbon emissions and air quality in regions & $\begin{array}{l}\text { National values of } \mathrm{CO}_{2} \text { emissions; Gridded concentration of } \\
\text { PM2.5 particles }\end{array}$ & 154 \\
\hline Chapter 30 & Municipal waste & Municipal waste; Total population; recycled waste & $138 ; 155$ \\
\hline Chapter 31 & Regional access to network infrastructure & Percentage of broadband access by households; road network density & 156 \\
\hline Chapter 32 & Green patents in regions & $\begin{array}{l}\text { PCT patent applications by type of applicant (business, non-business); } \\
\text { PCT patent applications in green technologies; Renewable energy; ICT and } \\
\text { biotech }\end{array}$ & 148 \\
\hline
\end{tabular}


Area - Chapters 1, 2 and 7

\begin{tabular}{lcl}
\hline & Notes & Source \\
\hline EU21 countries & $(1)$ & Eurostat: General and regional statistics, demographic statistics, population and area \\
Australia & - & Australian Bureau of Statistics (ABS), summing up SLAs \\
Canada & - & Statistics Canada www12.statcan.ca/english/census01/products/standard/popdwell/Table-CD- \\
& & P.cfm?PR=10\&T=2\&SR=1\&S=1\&O=A \\
Iceland & - & Statistics Iceland \\
Israel & - & Central Bureau of Statistics- Statistical Abstract of Israel. The statistical data for Israel are supplied by and under the \\
& & responsibility of the relevant Israeli authorities. The use of such data by the OECD is without prejudice to the status of the Golan \\
Japan & - & Statistical Office, Area by Configuration, Gradient and Prefecture www.stat.go.jp/English/data/nenkan/1431-01.htm \\
Korea & - & Statistics Korea \\
Mexico & - & Mexican Statistical Office (INEGI) \\
New Zealand & - & Statistics New Zealand, data come from the report "Water Physical Stock Account 1995-2005". www.stats.govt.nz/analytical- \\
& & reports/water-physical-stock-account-1995-2005.htm \\
Norway & - & Statistics Norway, StatBank table: 01402: Area of land and fresh water (km²). (M) (2005-07) \\
Switzerland & - & Office fédéral de la statistique, ESPOP, RFP \\
Turkey & - & Eurostat: General and regional statistics, demographic statistics, population and area \\
United States & - & Census Bureau www.census.gov/population/www/censusdata/density.htmI \\
Brazil & - & Instituto Brasileiro de Geografia e Esta.dística (IBGE) \\
China & - & National Bureau of Statistics of China \\
India & - & Statistics India (Indiastat) \\
Russian Federation & - & Federal State Statistics Service of Russian Federation \\
South Africa & - & Statistics South Africa
\end{tabular}

1. EU21 countries : Austria, Belgium, Czech Republic, Denmark, Estonia, Finland, France, Germany, Greece, Hungary, Ireland, Italy, Luxembourg, Netherlands, Poland, Portugal, Slovak Republic, Slovenia, Spain, Sweden and the United Kingdom.

\section{Population - Chapters 1, 2 and 19}

\begin{tabular}{|c|c|c|c|c|}
\hline & Notes & Source & Years & Territorial level \\
\hline EU21 countries & $(1)$ & Eurostat, Regional demographic statistics, Annual average population & 1995-2009 & 3 \\
\hline Australia & - & Australian Bureau of Statistics, 3201.0 & $1995-2008$ & 3 \\
\hline Canada & - & Statistics Canada, CANSIM Table 051-0036, Estimates of population & 1995-2009 & 3 \\
\hline Chile & - & INE, Chile & $1995-2009$ & 3 \\
\hline Iceland & $(2)$ & Statistics Iceland & 1995-2008 & 3 \\
\hline Israel & - & $\begin{array}{l}\text { Central Bureau of Statistics- Statistical Abstract of Israel. The statistical data for Israel are supplied by } \\
\text { and under the responsibility of the relevant Israeli authorities. The use of such data by the OECD is } \\
\text { without prejudice to the status of the Golan Heights, East Jerusalem and Israeli settlements in the West. }\end{array}$ & 2008 & 2 \\
\hline Japan & (3) & Statistics Bureau, MIC & 1995-2008 & 3 \\
\hline Korea & (4) & Statistics Korea & $1995-2008$ & 3 \\
\hline Mexico & (5) & Secretariat estimates based on Census of population (INEGI) & $1995-2008$ & 3 \\
\hline New Zealand & (6) & Statistics New Zealand, Estimated Resident Population & 1996-2008 & 3 \\
\hline Norway & - & Statistics Norway, StatBank & $1995-2008$ & 3 \\
\hline Switzerland & $(7)$ & Swiss Federal Statistical Office, Statweb & 1995-2009 & 3 \\
\hline Turkey & (8) & Turkish Statistical Institute (TurkStat) & 1995-2009 & 3 \\
\hline United States & (9) & US Census Bureau, Inter censual estimates & 1995-2008 & 3 \\
\hline Brazil & - & Instituto Brasileiro de Geografia e Estadística (IBGE) & $1995-2009$ & 2 \\
\hline China & - & National Bureau of Statistics of China & 2008 & 2 \\
\hline India & - & Statistics India (Indiastat) & 2001-08 & 2 \\
\hline Russian Federation & - & Federal State Statistics Service of Russian Federation & 2000-09 & 2 \\
\hline South Africa & - & Statistics South Africa & $1995-2009$ & 2 \\
\hline
\end{tabular}

1. EU21 countries : Austria, Belgium, Czech Republic, Denmark, Estonia, Finland, France, Germany, Greece, Hungary, Ireland, Italy, Luxembourg, Netherlands, Poland, Portugal, Slovak Republic, Slovenia, Spain, Sweden and the United Kingdom.

Estonia available years: 2005-08.

2. Iceland: Population at 1 December.

3. Japan: Population at 1 October.

4. Korea: Data for 2001-04 are based on population projections.

5. Mexico: Data for 1998 and 2003 are estimated using the exponential growth function based on the period $1995-2000$ and $2000-08$.

6. New Zealand: Population as of 30 June. Population estimates at 30 June 1996-2000 are based on 2001 Regional Council boundaries, whereas estimates from 2001 onwards are based on 2005 Regional Council boundaries.

7. Switzerland: Permanent resident population at the end of the year.

8. Turkey and United States: Mid-year population estimates. 


\section{Population by age and sex - Chapters 4,8 and 19}

\begin{tabular}{|c|c|c|c|c|}
\hline & Notes & Source & Years & Territorial level \\
\hline Australia & - & Australian Bureau of Statistics, 3201.0 & 1996-2008 & 3 \\
\hline Austria & - & Secretariat estimates based on Statistics Austria & 2001-09 & 3 \\
\hline Belgium & (1) & Eurostat, Regional demographic statistics & $1995-2008$ & 3 \\
\hline Canada & - & Statistics Canada, CANSIM Table 051-0036, Estimates of population & 1995-2009 & 3 \\
\hline Chile & & INE, Chile & $1995-2009$ & 2 \\
\hline Czech Republic & (2) & Czech Statistical Office & $1995-2009$ & 3 \\
\hline Denmark & (3) & Statistics Denmark, Statbank & 2005-09 & 3 \\
\hline Estonia & & Eurostat, Regional demographic statistics & 2007-09 & 3 \\
\hline Finland & - & Statistics Finland & $1995-2009$ & 3 \\
\hline France & (1) & INSEE, Local population estimates & $1995-2008$ & 3 \\
\hline Germany & - & Regional statistics Germany, Spatial Monitoring System of the BBR & $1995-2008$ & 3 \\
\hline Greece & (1) & Eurostat, Regional demographic statistics & $1995-2009$ & 3 \\
\hline Hungary & (1) & KSH, Hungarian Statistical Office & 1995-2009 & 3 \\
\hline Iceland & - & Statistics Iceland & $1997-2008$ & 3 \\
\hline Ireland & - & Central Statistics Office, Ireland (Census of population). & 1995-2009 & 3 \\
\hline Israel & - & $\begin{array}{l}\text { Central Bureau of Statistics- Statistical Abstract of Israel. The statistical data for Israel are } \\
\text { supplied by and under the responsibility of the relevant Israeli authorities. The use of } \\
\text { such data by the OECD is without prejudice to the status of the Golan Heights, East } \\
\text { Jerusalem and Israeli settlements in the West. }\end{array}$ & 2008 & 2 \\
\hline Italy & (1) & ISTAT, Intercensal population estimates & 1995-2009 & 3 \\
\hline Japan & (4) & Statistics Bureau, MIC & 1995-2008 & 3 \\
\hline Korea & (5) & Statistics Korea & $1995-2008$ & 3 \\
\hline Luxembourg & (1) & Eurostat, Regional demographic statistics & 1995-2009 & 3 \\
\hline Mexico & - & INEGI, (Census of population) & $1995-2008$ & 3 \\
\hline Netherlands & (1) & Eurostat, Regional demographic statistics & $1995-2009$ & 3 \\
\hline New Zealand & - & Statistics New Zealand (Census of population) & $1995-2008$ & 3 \\
\hline Norway & (1) & Statistics Norway, Statbank & $1995-2008$ & 3 \\
\hline Poland & - & Central Statistical Office, Poland & $2000-09$ & 3 \\
\hline Portugal & - & Statistics Portugal (INE) & $1995-2009$ & 3 \\
\hline Slovak Republic & (2) & Statistical Office of the Slovak Republic & 1996-2009 & 3 \\
\hline Slovenia & & Eurostat, Regional demographic statistics & 2003-09 & 3 \\
\hline Spain & - & National Statistics Institute (INE) & $1995-2009$ & 3 \\
\hline Sweden & (6) & Statistics Sweden & $1995-2009$ & 3 \\
\hline Switzerland & (7) & Swiss Federal Statistical Office, Statweb & $1995-2009$ & 3 \\
\hline Turkey & (8) & Turkish Statistical Institute (TurkStat) & $1995-2008$ & 3 \\
\hline United Kingdom & - & National Statistical Office, population estimates & 1995-2008 & 3 \\
\hline United States & (9) & US Census Bureau, Population Estimates Program & 1995-2008 & 3 \\
\hline Brazil & - & Instituto Brasileiro de Geografia e Estadística (IBGE) & $1995-2009$ & 2 \\
\hline China & - & National Bureau of Statistics of China & 2008 & 2 \\
\hline India & - & Statistics India (Indiastat) & 2008 & 2 \\
\hline Russian Federation & - & Federal State Statistics Service of Russian Federation & $2000-09$ & 2 \\
\hline South Africa & - & Statistics South Africa & 1995-2009 & 2 \\
\hline
\end{tabular}

1. Belgium, France, Greece, Hungary, Italy, Luxembourg, Netherlands, Norway: Population as of 1 January.

2. Czech Republic and Slovak Republic: Population as of 31 December.

3. Denmark: Population as of 1 January. The source of the statistics is Statistic Denmark's population register, which yearly, receives partly an annual outdraw of the total population and partly a weekly outdraw which include information about the weekly events such as removals, emi-/immigrations, births and deaths from the Central Person Register (CPR).

4. Japan: Population as of 10ctober.

5. Korea: Data for 2001-04 are based on population projections.

6. Sweden: Conditions on 31 December 31 for each respective year according to administrative subdivisions of 1 January of the following year.

7. Switzerland: Permanent resident population at the end of the year.

8. Turkey: Mid-year population estimates.

9. United States: Population as of 1 April. 
Gross domestic product - Chapters 3, 5, 6, 7 and 14

\begin{tabular}{|c|c|c|c|c|}
\hline & Notes & Source & Years & Territorial level \\
\hline EU21 countries & (1) & Eurostat, Regional economic accounts & $1995-2007$ & 3 \\
\hline Australia & (2) & Australian Bureau of Statistics, 5220.0 & $1995-2008$ & 2 \\
\hline Canada & - & Statistics Canada, Provincial economic accounts & 1995-2008 & 2 \\
\hline Chile & (3) & Banco central de Chile. Cunetas nacionales de Chile & $1996-2008$ & 2 \\
\hline Iceland & (5) & - & - & - \\
\hline Israel & (5) & - & - & - \\
\hline Japan & (4) & Economic and Social Research Institute, Cabinet Office & $1995-2006$ & 3 \\
\hline Korea & - & Statistics Korea & $1995-2007$ & 3 \\
\hline Mexico & - & INEGI, System of national accounts of Mexico & $1995-2006$ & 2 \\
\hline New Zealand & - & Statistics New Zealand & $2000-03$ & 3 \\
\hline Norway & - & Norwegian Regional Accounts & 1995-2007 & 3 \\
\hline Switzerland & (5) & - & - & - \\
\hline Turkey & - & Turkish Statistical Institute (TurkStat) & 2004-06 & 2 \\
\hline United States & - & Bureau of Economic Analysis & 1997-2008 & 2 \\
\hline Brazil & - & Instituto Brasileiro de Geografia e Estadística (IBGE) & $1995-2007$ & 2 \\
\hline China & - & National Bureau of Statistics of China & $2004-07$ & 2 \\
\hline India & - & Statistics India (Indiastat) & 2001-07 & 2 \\
\hline Russian Federation & - & Federal State Statistics Service of Russian Federation & 1996-08 & 2 \\
\hline South Africa & - & Statistics South Africa & 1995-08 & 2 \\
\hline
\end{tabular}

1. EU21 countries: Austria, Belgium, Czech Republic, Denmark, Estonia, Finland, France, Germany, Greece, Hungary, Ireland, Italy, Luxembourg, Netherlands, Poland, Portugal, Slovak Republic, Slovenia, Spain, Sweden and the United Kingdom.

Poland available years: 1999-2007.

2. Australia: Gross state product. Figures are based on fiscal year (July-June).

3. Chile: Data are not available in two regions.

4. Japan: Figures are based on fiscal year (April-March).

5. Iceland, Israel and Switzerland: Data are not available at the regional level.

\section{Employment at place of work - Chapters 5, 6 and 7}

\begin{tabular}{|c|c|c|c|c|}
\hline & Notes & Source & Years & Territorial level \\
\hline EU21 countries & (1) & Eurostat, Regional economic accounts, Branch accounts, Employment & 1995-2009 & 3 \\
\hline Australia & - & Australian Bureau of Statistics, LFS, Table: 6291.0 .55 .003 & $1995-2009$ & 2 \\
\hline Canada & - & Statistics Canada, Census, Employed labour force by place of work & $1996-2007$ & 2 \\
\hline Chile & - & INE Chile & $1990-2009$ & 2 \\
\hline Iceland & (2) & - & - & - \\
\hline Israel & - & $\begin{array}{l}\text { Central Bureau of Statistics - LFS. The statistical data for Israel are supplied by and } \\
\text { under the responsibility of the relevant Israeli authorities. The use of such data by the } \\
\text { OECD is without prejudice to the status of the Golan Heights, East Jerusalem and } \\
\text { Israeli settlements in the West. }\end{array}$ & 1999-2009 & 2 \\
\hline Japan & - & Statistics Bureau, MIC & $2000 ; 2001-05$ & 2 \\
\hline Korea & - & Statistics Korea & 1996-2009 & 3 \\
\hline Mexico & - & INEGI, LFS (National survey of occupation and employment) & $2000 ; 2004 ; 2009$ & 2 \\
\hline New Zealand & - & Statistics New Zealand, LEED, Annual, Table 3.5: Length of Continuous Job Tenure & 1999-2009 & 3 \\
\hline Norway & - & Statistics Norway, Employees $16-64$ years by region of work by region and period & $1995 ; 1998-2001 ; 2005-07$ & 3 \\
\hline Switzerland & (2) & - & - & - \\
\hline Turkey & - & Turkish Statistical Institute (TurkStat), Census & 2002; $2006-2009$ & 2 \\
\hline United States & - & Bureau of Labour Statistics, State and area employment (sm series) & $2000-09$ & 2 \\
\hline Brazil & - & Instituto Brasileiro de Geografia e Estadística (IBGE) & 2004-08 & 2 \\
\hline China & - & - & - & - \\
\hline India & - & - & - & - \\
\hline Russian Federation & - & Federal State Statistics Service of Russian Federation & $2005 ; 2008$ & 2 \\
\hline South Africa & - & Statistics South Africa & 1995-2009 & 2 \\
\hline
\end{tabular}

1. EU21 countries: Austria, Belgium, Czech Republic, Denmark, Estonia, Finland, France, Germany, Greece, Hungary, Ireland, Italy, Luxembourg, Netherlands, Poland, Portugal, Slovak Republic, Slovenia, Spain, Sweden and the United Kingdom.

2. Iceland and Switzerland: Data are not available at the regional level. 
Employment by industry (six sectors) - Chapter 11

\begin{tabular}{|c|c|c|c|c|}
\hline & Notes & Source & Years & Territorial level \\
\hline EU21 countries & (1) & Eurostat, Regional economic accounts, Branch accounts, Employment & 1995-2008 & 2 \\
\hline Australia & - & Australian Bureau of Statistics, LFS, Table 6291.0.55.003 & $1995-2008$ & 2 \\
\hline Canada & (2) & Statistics Canada, data sent by the delegate & 1995-2007 & 2 \\
\hline Chile & & National Statistical Office (INE) & 1995-2005 & \\
\hline Iceland & - & Statistics Iceland & $1995-2005$ & 2 \\
\hline Israel & & $\begin{array}{l}\text { Central Bureau Statistics (CBS. The statistical data for Israel are supplied by } \\
\text { and under the responsibility of the relevant Israeli authorities. The use of } \\
\text { such data by the OECD is without prejudice to the status of the Golan } \\
\text { Heights, East Jerusalem and Israeli settlements in the West. }\end{array}$ & 1995-2008 & \\
\hline Japan & - & Statistics Bureau, Establishment and Enterprise census & 2005-08 & 2 \\
\hline Korea & - & Statistics Korea - Economically active population survey & 2004-08 & 2 \\
\hline Mexico & - & National Statistical Office (INEGI), Economic Census & $2004 ; 2008$ & 2 \\
\hline New Zealand & - & Statistics New Zealand & $1999-2008$ & 2 \\
\hline Norway & - & Statistics Norway & 2000-08 & 2 \\
\hline Switzerland & - & Federal Statistical Office (FSO), Census of population, table VZ0024KD & $2000-08$ & 2 \\
\hline Turkey & - & $\begin{array}{l}\text { Turkish Statistical Institute, Number of local units and employment by } \\
\text { economic activity branches }\end{array}$ & 2006-08 & 2 \\
\hline United States & - & Bureau of Economic Analysis & 2000-08 & 2 \\
\hline
\end{tabular}

Industries are defined according to the Standard Industrial Classification (ISIC) rev. 3.1. Due to regional data availability, industries from the Eurostat Branch Accounts are aggregated into six sectors: 1) Agriculture, fishing and forestry; 2) Manufacturing, mining and quarrying, electricity, gas and water supply;3) Construction; 4)Trade, hotels and restaurants, transport, storage and communication; 5) Financial intermediation, real estate, renting and business activities; 6) Public administration and defence, health and other public activities.

1. EU21 countries: Austria, Belgium, Czech Republic, Denmark, Estonia, Finland, France, Germany, Greece, Hungary, Ireland, Italy, Luxembourg, Netherlands, Poland, Portugal, Slovak Republic, Slovenia, Spain, Sweden and the United Kingdom.

2. Canada: Data are not available for the regions Yukon Territory and Northwest Territories. 


\section{Labour force, employment at place of residency by sex and unemployment - Chapters 4, 8, 22 and 23} Table B.4. National Data on Employment and Unemployment:
OECD, Annual Labour Force Statistics Database

\begin{tabular}{lcccc}
\hline & Notes & Source & Years & Territorial level \\
\hline EU21 countries & $(1)$ & Eurostat, Regional labour force market statistics, LFS & $1999-2009$ & 3 \\
Australia & $(2)$ & Australian Bureau of Statistics, LFS, Table 6291.0.55.001 & $1999-2009$ & 2 \\
Canada & $(3)$ & Statistics Canada, LFS, CANSIM Table 282-0055 & $1999-2009$ & NOG \\
Chile & - & INE Chile & $1990-2009$ & 2 \\
Iceland & - & Statistics Iceland & $1999-2009$ & 2 \\
Israel & - & Central Bureau of Statistics - LFS. The statistical data for Israel are & $1990-2009$ & 2 \\
& & supplied by and under the responsibility of the relevant Israeli authorities. & & \\
& & The use of such data by the OECD is without prejudice to the status of the & & \\
Japan & & Golan Heights, East Jerusalem and Israeli settlements in the West. & & 3 \\
Korea & - & Statistics Bureau, MIC & $1999-2009$ & 3 \\
Mexico & - & Statistics Korea & $1999-2009$ & 2 \\
New Zealand & $(4)$ & INEGI, LFS (National survey of occupation and employment) & $2000-09$ & 3 \\
Norway & $(5)$ & Statistics New Zealand, LFS & $1999-2009$ & $1999-2008$ \\
Switzerland & - & Statistics Norway, Statbank Table 05613 & $2001-09$ & 3 \\
Turkey & $(6)$ & Secretariat estimates based on Swiss Federal Statistical Office & $2006-09$ & 3 \\
United States & $(7)$ & Turkish Statistical Institute, Census & $1999-2009$ \\
Brazil & $(8)$ & Bureau of Labour Statistics, Labour force data by county & $2004-08$ & 3 \\
China & - & Instituto Brasileiro de Geografia e Estadística (IBGE) & - & 2 \\
India & - & - & - & - \\
Russian Federation & - & - & Federal State Statistics Service of Russian Federation & - \\
South Africa & & Statistics South Africa & $1999-09$ & 2 \\
\hline
\end{tabular}

Data for employment by sex are available only at TL2 level.

1. EU21 countries : Austria, Belgium, Czech Republic, Denmark, Estonia, Finland, France, Germany, Greece, Hungary, Ireland, Italy, Luxembourg, Netherlands, Poland, Portugal, Slovak Republic, Slovenia, Spain, Sweden and the United Kingdom.

1.1. Finland: 2006 Employment data for regions FI191 Satakunta, FI192 Pirkanmaa, FI193 Keski-Suomi, FI194 EteläPohjanmaa and FI195 Pohjanmaa are estimated with data collected at the Statistics Finland website (www.stat.fi/til/ tyti/2008/03/tyti_2008_03_2008-04-22_tau_031_fi.html).

1.2. Germany and Italy: due to changes in the NUTS classification, data have been collected from the delegates (Germany: Statistics of the Federal Agency of Labour Market, Spatial Monitoring System of the BBR, without self-employed).

1.3. Poland: Reference years 2000-06 (PL126 Warszawski and PL127 Miasto Warszawa regions data are missing in 1999).

1.4. Portugal: Labour force data are available only at TL2 level.

1.5. Sweden: data for 2006 at TL3 level are estimated with data from Statistics Sweden (Befolkningen 16-64 år (AKU), 1000tal efter region, arbetskraftstillhörighet, kön) and adjusted with data from Eurostat at TL2.

1.6. United Kingdom: 2006 missing data from Eurostat have been estimated with data from the Office for National Statistics (Nomis) and the Annual Population Survey in Scotland. Data not available for the regions Caithness and Sutherland, Ross and Cromarty, Comhairle Nan Eilan (Western Isles).

2. Australia: Data are based on the Labour Force Dissemination Regions as defined by the Australian Bureau of Statistics.

3. Canada: Data are based on a grouping of TL3 regions according to the Economic Regions as defined in the Guide to the Labour Force Survey, Statistics Canada 2006, (Ottawa: Statistics Canada, Catalogue No. 71-543, www.statcan.ca/bsolc/english/ bsolc?catno=71-543-G).

4. Mexico: Data at TL3 level are available only for the year 2000 from the Census (Censo general de población y vivienda 2000) and employed is for the class age 12 years and over.

5. New Zealand: For regions NZ015-NZ016 and NZ021-NZ021 data are aggregated in the LFS dissemination regions. Data for the merged regions have been estimated on the basis of population share.

6. Switzerland: Data at TL3 are estimated from unemployment at TL2 using the share of labour force as weights.

7. Turkey: Data at TL2 come from the Census of Population for the year 2000 and from Turkstat Household labour survey for the years 2004-06. At TL3 data are available only for the year 2000.

8. United States: US117 New Orleans-Metairie-Bogalusa (Louisiana) figure is estimated for 2006 due to missing values in some Local Area Unemployment Statistics components of this region. Data expressed as annual averages. 
Youth unemployment - Chapter 22

\begin{tabular}{|c|c|c|c|c|c|}
\hline & Notes & Source & $\begin{array}{l}\text { Reference } \\
\text { population }\end{array}$ & Years & Territorial level \\
\hline EU21 countries & (1) & Eurostat, Regional labour market statistics, unemployment & $15-24$ & 1999-2009 & 2 \\
\hline Australia & - & Australian Bureau of Statistics, youth unemployment, cat. 4102.0 & $15-24$ & 1999-2009 & 2 \\
\hline Canada & (2) & Statistics Canada, CANSIM table 109-5304 & $15-24$ & 2001-09 & 2 \\
\hline Chile & (4) & - & - & - & - \\
\hline Iceland & (4) & - & - & - & - \\
\hline Israel & & $\begin{array}{l}\text { Central Bureau of Statistics - LFS. The statistical data for Israel are } \\
\text { supplied by and under the responsibility of the relevant Israeli authorities. } \\
\text { The use of such data by the OECD is without prejudice to the status of the } \\
\text { Golan Heights, East Jerusalem and Israeli settlements in the West. }\end{array}$ & $15-24$ & $1990-2009$ & 2 \\
\hline Japan & - & Statistics Bureau, MIC & $15-24$ & 2006 & 2 \\
\hline Korea & (4) & - & - & - & - \\
\hline Mexico & - & INEGI, Employment and Occupation National Survey & $15-24$ & $2000-09$ & 2 \\
\hline New Zealand & $(4)-$ & - & - & - & - \\
\hline Norway & (3) & $\begin{array}{l}\text { Statistics Norway, Employees } 16-64 \text { years by region of work by region and } \\
\text { period }\end{array}$ & $15-24$ & 2000-09 & 2 \\
\hline Switzerland & (4) & - & - & - & - \\
\hline Turkey & - & Turkish Statistical Institute, LFS & $15-24$ & 2004-09 & 2 \\
\hline United States & & Bureau of Labour Statistics, Local Area Unemployment Statistics & & 1999-2008 & 3 \\
\hline
\end{tabular}

1. EU21 countries: Austria, Belgium, Czech Republic, Denmark, Estonia, Finland, France, Germany, Greece, Hungary, Ireland, Italy, Luxembourg, Netherlands, Poland, Portugal, Slovak Republic, Slovenia, Spain, Sweden and the United Kingdom.

1.1. Italy: Data are not available for the region Valle d'Áosta.

1.2. Netherlands: 1999-2005; Sweden: 1999-2005.

2. Canada: Data are not available for the regions Yukon Territory and Northwest Territories.

3. Norway: Data are not available for the regions Hedmark og Oppland and Trondelag.

4. Chile, Iceland, Korea, New Zealand and Switzerland: Data are not available at regional level.

\section{Long-term unemployment- Chapter 22}

\begin{tabular}{|c|c|c|c|c|}
\hline & Notes & Source & Years & Territorial level \\
\hline EU21 countries & (1) & Eurostat, Regional labour market statistics, Regional unemployment & 1999-2009 & 2 \\
\hline Australia & - & Australian Bureau of Statistics, LFS & 2001-09 & 2 \\
\hline Canada & (2) & Statistics Canada, LFS & 1999-2009 & 2 \\
\hline Chile & (3) & - & - & - \\
\hline Iceland & (3) & - & - & - \\
\hline Israel & & $\begin{array}{l}\text { Central Bureau of Statistics - LFS. The statistical data for Israel are supplied } \\
\text { by and under the responsibility of the relevant Israeli authorities. The use of } \\
\text { such data by the OECD is without prejudice to the status of the Golan } \\
\text { Heights, East Jerusalem and Israeli settlements in the West. }\end{array}$ & $1990-2009$ & 2 \\
\hline Japan & (3) & - & - & - \\
\hline Korea & (3) & - & - & - \\
\hline Mexico & (3) & - & - & - \\
\hline New Zealand & - & - & 1999-2009 & 2 \\
\hline Norway & - & Statistics Norway & 1999-2009 & 2 \\
\hline Switzerland & (3) & - & - & - \\
\hline Turkey & - & Turkish Statistical Institute, LFS & 2004-09 & 2 \\
\hline United States & (3) & - & - & - \\
\hline
\end{tabular}

1. EU21 countries : Austria, Belgium, Czech Republic, Denmark, Estonia, Finland, France, Germany, Greece, Hungary, Ireland, Italy, Luxembourg, Netherlands, Poland, Portugal, Slovak Republic, Slovenia, Spain, Sweden and the United Kingdom.

Denmark: Data are not available at the regional level.

2. Canada: Data are not available for the regions Yukon Territory and Northwest Territories.

3. Chile, Iceland, Japan, Korea, Mexico, Switzerland and United States: Data are not available at regional level. 


\section{Employment in high-tech manufacturing; Employment in knowledge-} intensive services - Chapters 9 and 12

\begin{tabular}{|c|c|c|c|c|}
\hline & Notes & Source & Years & Territorial level \\
\hline EU21 countries & (1) & $\begin{array}{l}\text { Eurostat, Employment in technology and knowledge-intensive sectors at } \\
\text { the regional level (htec_emp_reg) }\end{array}$ & 1995-2008 & 2 \\
\hline Australia & (2) & - & - & - \\
\hline Canada & - & Statistics Canada, special tabulation from the LFS & 1995-2008 & 2 \\
\hline Chile & - & - & - & - \\
\hline Iceland & (2) & - & - & - \\
\hline Israel & - & - & - & - \\
\hline Japan & & Statistics Bureau, MIC & 1995-2006 & - \\
\hline Korea & (3) & $\begin{array}{l}\text { Korean Institute for Industrial Economics and Trade (KIET) - Regional } \\
\text { Statistics and Information Database (RSID) }\end{array}$ & 1995-2008 & 2 \\
\hline Mexico & (2) & - & - & - \\
\hline New Zealand & - & - & - & - \\
\hline Norway & - & $\begin{array}{l}\text { Eurostat, Employment in technology and knowledge-intensive sectors at } \\
\text { the regional level, by gender (htec_emp_reg) }\end{array}$ & $1995-2008$ & 2 \\
\hline Switzerland & - & $\begin{array}{l}\text { Eurostat, Employment in technology and knowledge-intensive sectors at } \\
\text { the regional level, by gender (htec_emp_reg) }\end{array}$ & $1995-2008$ & 2 \\
\hline Turkey & - & $\begin{array}{l}\text { Eurostat, Employment in technology and knowledge-intensive sectors at } \\
\text { the regional level, by gender (htec_emp_reg) }\end{array}$ & $1995-2008$ & 2 \\
\hline United States & - & $\begin{array}{l}\text { Bureau of Labour Statistics (BLS), State and County Employment and } \\
\text { Wages (Quarterly Census of Employment and Wages - QCEW) }\end{array}$ & $1995-2008$ & 2 \\
\hline
\end{tabular}

1. EU21 countries: Austria, Belgium, Czech Republic, Denmark, Estonia, Finland, France, Germany, Greece, Hungary, Ireland, Italy, Luxembourg, Netherlands, Poland, Portugal, Slovak Republic, Slovenia, Spain, Sweden and the United Kingdom.

Poland, Sweden and Slovak Republic, latest available year: 2007.

2. Australia, Iceland, Mexico and New Zealand: Data are not available at the regional level.

3. Korea data on KIS employment are not available at regional level.

\section{Labour force by educational attainment- Chapters 9 and 24}

\begin{tabular}{|c|c|c|c|c|}
\hline & Notes & Source & Year & Territorial level \\
\hline EU21 countries & (1) & Eurostat, Labour force survey & 2008 & 2 \\
\hline Australia & (2) & Australian Bureaus of Statistics, Table 6227.0 Education and Work, LFS & 2005 & 2 \\
\hline Canada & (3) & Statistics Canada, Labour Force Survey & 2006 & 2 \\
\hline Chile & & INE Chile & 2007 & 2 \\
\hline Iceland & (6) & - & - & - \\
\hline Japan & (6) & - & - & - \\
\hline Korea & (2) & KOSIS, Economically Active Population Survey, & 2006 & 2 \\
\hline Mexico & & INEGI, Conteo de Población y Vivienda, 2005 & 2008 & 2 \\
\hline New Zealand & & Statistics New Zealand & 2006 & 2 \\
\hline Norway & & Eurostat, Labour force survey & 2008 & 2 \\
\hline Switzerland & & Federal Statistical Office, Labour Force Survey & 2007 & 2 \\
\hline Turkey & (4) & Turkish Statistical Institute & 2008 & 2 \\
\hline United States & (5) & Census Bureau, American Community Survey (ACS) & 2008 & 2 \\
\hline
\end{tabular}

1. EU21 countries: Austria, Belgium, Czech Republic, Denmark, Estonia, Finland, France, Germany, Greece, Hungary, Ireland, Italy, Luxembourg, Netherlands, Poland, Portugal, Slovak Republic, Slovenia, Spain, Sweden and the United Kingdom.

1.1. Data refer to the labour force aged 15 and over.

1.2. Denmark: Data refer to the labour force aged 25-64. Data obtained from the Register based labour force statistics. Data compiled by the Danish Centre for Studies in Research and Research Policy and Published by Statistics Denmark.

1.3. Sweden: The data obtained from Statistics Sweden.

2. Australia and Korea: Data refer to total labour force.

3. Canada: Data refer to the labour force aged 25-64.

4. Turkey: Data available only for secondary and tertiary education attainments.

5. United States: Data refer to the population aged 18 and over.

6. Iceland and Japan: Data not available at the regional level. 


\section{Enrolment in education institutions by educational level - Chapter 9}

\begin{tabular}{|c|c|c|c|c|}
\hline & Notes & Source & Year & Territorial level \\
\hline EU21 countries & (1) & Eurostat, Regional education statistics & 2005-07 & 2 \\
\hline Australia & - & & & 2 \\
\hline Canada & & & & 2 \\
\hline Iceland & (6) & - & - & - \\
\hline Japan & - & Ministry of Education, Culture, Sports, Science and Technology & 2005-07 & 2 \\
\hline Korea & - & Statistical year book of education & 2005-07 & 2 \\
\hline Mexico & (3) & INEGI, Census 2005. & $2005-07$ & 2 \\
\hline New Zealand & (6) & - & - & - \\
\hline Norway & & Eurostat, Regional education statistics & 2005-07 & 2 \\
\hline Switzerland & (4) & Federal Statistical Office & 2005-07 & 2 \\
\hline Turkey & - & Turkish Ministry of Education & 2005-07 & 2 \\
\hline United States & (5) & Census Bureau, American Community Survey (ACS) & 2005-07 & 2 \\
\hline
\end{tabular}

1. EU21 countries: Austria, Belgium, Czech Republic, Denmark, Estonia, Finland, France, Germany, Greece, Hungary, Ireland, Italy, Luxembourg, Netherlands, Poland, Portugal, Slovak Republic, Slovenia, Spain, Sweden and the United Kingdom.

1.1. Denmark: Data obtained from the Register-based labour force statistics. Data compiled by the Danish Centre for Studies in Research and Research Policy and Published by Statistics Denmark.

1.2. Germany: Data obtained from Regional Statistics Germany, Spatial Monitoring System of the BBR.

2. Canada: ISCED 0-2 include enrolled from junior kindergarden to grade 9 included. ISCED 3-4 include enrolled in grade 10 to 12 included. Data for ISCED 5-6 is the sum of enrolled in public colleges and institutes and enrolled in universities.

3. Mexico: Populations aged five and over by state and educational level.

4. Switzerland: Before beginning tertiary education, ISCED 5-6 students are distributed among regions according to their place of residence. This results in an underestimation of the number of people in this educational level (students living abroad before the beginning of theirs studies are not taken into account).

5. United States: US Census Bureau, Census ACS (American Community Survey). B14001. School enrollment by level of school for the population three years and over - universe: population three years and over. Data are based on a sample and are subject to sampling variability. Data have been translated into ISCED in the following way: Enrolled in nursery school, preschool + Enrolled in kindergarten + Enrolled in grade 1 to grade $4+$ Enrolled in grade 5 to grade $8=$ ISCED 0-2, Enrolled in grade 9 to grade 12 = ISCED 3-4, Enrolled in college, undergraduate years + Graduate or professional school = ISCED 5-6.

6. Australia, Iceland and New Zealand: Data are not available at the regional level. 
Regional capital expenditure - Chapter 13

National Data: OECD, General Government Accounts

\begin{tabular}{|c|c|c|c|c|}
\hline & Notes & Source & Years & Territorial level \\
\hline Australia & - & Australian Bureau of Statistics & $1990-2009$ & 2 \\
\hline Canada & - & Statistics Canada & $1981-2006$ & 2 \\
\hline Chile & - & - & - & - \\
\hline Czech Republic & - & Ministry of Finance (data from the Regional Statistical Bureaus) & 2005-08 & 2 and 3 \\
\hline Finland & - & Statistics Finland & 1980-2007 & 2 and 3 \\
\hline Germany & - & $\begin{array}{l}\text { Federal Office of Statistics (for municipality-level data); Federal Ministry of } \\
\text { Finance (for state-level data) }\end{array}$ & 2001-09 & 2 \\
\hline Hungary & (1) & Statistics Hungary & 2001-05 & 2 \\
\hline Israel & - & - & - & - \\
\hline Italy & - & $\begin{array}{l}\text { Ministry for Economic Development, Department for Development Policy } \\
\text { and Cohesion }\end{array}$ & 1996-2008 & 2 \\
\hline Japan & & System of Prefecture Accounts, Cabinet Office Website & 1996-2007 & 2 and 3 \\
\hline Mexico & 2 & INEGI, National Institute for Statistics and Geography & $1994-2003$ & 2 \\
\hline Norway & - & Statistics Norway & 2003-09 & 2 and 3 \\
\hline Spain & - & Ministry of Finance & $2002-08$ & 2 \\
\hline Sweden & - & Statistics Sweden & $1995-2007$ & 2 \\
\hline Switzerland & (1) & Federal Statistical Office & $2005-07$ & 2 and 3 \\
\hline United Kingdom & (1) & HM Treasury & $2002-08$ & 2 \\
\hline United States & (1) & US Census Bureau & $1991-2008$ & 2 \\
\hline
\end{tabular}

1. Capital expenditure is not broken down into gross fixed capital formation (GFCF) and capital transfers.

2. Data on GFCF by state is derived from states' shares of total national GFCF.

Foreign-born population, by duration of stay and educational attainment Chapters 10 and 21

OECD Database on Immigrants (DIOC)

\begin{tabular}{lllcc}
\hline & Notes & Source & Years & Territorial level \\
\hline Australia & - & Census & 2006 & 3 \\
Austria & - & Microcensus & $2004-06$ & 2 \\
Belgium & - & Labour Force Survey & $2004-06$ & 2 \\
Canada & - & Census & 2006 & 3 \\
Chile & - & - & - & - \\
Czech Republic & - & - & - & - \\
Denmark & - & Population Register & 2005 & 3 \\
Estonia & - & - & - & - \\
Finland & - & Population Register & 2005 & 3 \\
France & - & Census & 2006 & 3 \\
Germany & - & Micro-census & $2005-07$ & 2 \\
Greece & - & - & - & - \\
Hungary & - & Labour Force Survey & $2004-06$ & 2 \\
Iceland & - & - & - & - \\
Ireland & - & Census 2006 & 2006 & 3 \\
Israel & - & - & - & - \\
Italy & - & Labour Force Survey & $2004-06$ & 2 \\
Japan & - & - & - & - \\
Korea & - & - & $2005-07$ & - \\
Mexico & - & Labour Force Survey & $2004-06$ & 2 \\
Netherlands & - & Labour Force Survey & 2006 & 2 \\
New Zealand & - & Census & 2005 & 3 \\
Norway & - & Population Register & - & 2 \\
Poland & - & - & $2005-06$ & 2 \\
Portugal & - & Labour Force Survey & & 2 \\
Slovak Republic & & & & 2 \\
\hline & & & & 2 \\
\end{tabular}


OECD Database on Immigrants (DIOC) (cont.)

\begin{tabular}{lclcc}
\hline & Notes & Source & Years & Territorial level \\
\hline Slovenia & - & - & - & - \\
Spain & - & Labour Force Survey & $2004-06$ & 2 \\
Sweden & - & Population Register & 2005 & 3 \\
Switzerland & - & Labour Force Survey & $2004-06$ & 2 \\
Turkey & - & & - & - \\
United Kingdom & - & Labour Force Survey & 2006 & 2 \\
United States & - & American Community Survey & $2005-07$ & 2 \\
\hline
\end{tabular}

\section{R\&D expenditures by performing sector - Chapters 14 and 15}

\section{National data: OECD, Main Science and Technology Indicators Database}

\begin{tabular}{|c|c|c|c|c|}
\hline & Notes & Source & Years & $\begin{array}{l}\text { Territorial } \\
\text { level }\end{array}$ \\
\hline EU21 countries & (2) & $\begin{array}{l}\text { Eurostat, Regional Science and technology Statistics, R\&D expenditures and personnel, Total } \\
\text { intramural R\&D expenditure (GERD) by sectors of performance and region. }\end{array}$ & 2007 & 2 \\
\hline Australia & (3) & $\begin{array}{l}\text { For the business performing sector: ABS, } 8104.0 \text { Research and Experimental Development, } \\
\text { Business. }\end{array}$ & 2007 & 2 \\
\hline Canada & & $\begin{array}{l}\text { Statistics Canada. www.statcan.ca/english/freepub/88-221-XIE/2008001/tablesectionlist.htm } \\
\text { Table } 2 \text { Provincial Gross Domestic Expenditures on Research and Development, in the total } \\
\text { sciences. }\end{array}$ & 2006 & 2 \\
\hline Chile & (4) & & & \\
\hline Iceland & (4) & - & - & - \\
\hline Israel & & $\begin{array}{l}\text { Central Bureau of Statistics. The statistical data for Israel are supplied by and under the } \\
\text { responsibility of the relevant Israeli authorities. The use of such data by the OECD is without } \\
\text { prejudice to the status of the Golan Heights, East Jerusalem and Israeli settlements in the West. }\end{array}$ & 2007-08 & 2 \\
\hline Japan & (4) & - & - & - \\
\hline Korea & - & Korea Institute of Science and Technology Evaluation and Planning (KISTEP) & 2006 & 2 \\
\hline Mexico & (4) & - & - & - \\
\hline New Zealand & (4) & - & - & - \\
\hline Norway & & $\begin{array}{l}\text { Eurostat, Regional Science and technology Statistics, R\&D expenditures and personnel, Total } \\
\text { intramural R\&D expenditure (GERD) by sectors of performance and region. }\end{array}$ & 2007 & 2 \\
\hline Switzerland & (4) & - & - & - \\
\hline Turkey & (4) & - & - & - \\
\hline United States & (5) & National Science Foundation (NSF)/Division of Science Resources Statistics (SRS) & 2007 & 2 \\
\hline
\end{tabular}

1. Sectors include: business enterprise, government, higher education and private and non-profit. The business enterprise sector is comprehensive of all firms, organisations and institutions whose primary activity is the market production of goods or services (other than higher education) for sale to the general public at an economically significant price. It also includes the private nonprofit institutions mainly serving the above mentioned firms, organisations and institutions (See the Frascati Manual, Section 3.4). The government sector is comprehensive of all departments, offices and other bodies which furnish, but normally do not sell to the community, those common services, other than higher education, which cannot otherwise be conveniently and economically provided, as well as those that administer the state and the economic and social policy of the community. (public enterprises are included in the business enterprise sector). It also includes non-profit institutions controlled and mainly financed by government, but not administered by the higher education sector (see the Frascati Manual, Section 3.5). The higher education sector is comprehensive of all universities, colleges of technology and other institutions of post-secondary education, whatever their source of finance or legal status. It also includes all research institutes, experimental stations and clinics operating under the direct control of or administered by or associated with higher education institutions (see the Frascati Manual, Section 3.7). The private non-profit sector is comprehensive of non-market, private non-profit institutions serving households (i.e. the general public) and private individuals or households (see the Frascati Manual, Section 3.6).

2. EU21 countries: Austria, Belgium, Czech Republic, Denmark, Estonia, Finland, France, Germany, Greece, Hungary, Ireland, Italy, Luxembourg, Netherlands, Poland, Portugal, Slovak Republic, Slovenia, Spain, Sweden and the United Kingdom.

Data for France refer to the year 2004 and Greece 2005.

3. Australia: Values only for business R\&D expenditure.

4. Chile, Iceland, Japan, Mexico, New Zealand, Switzerland and Turkey: Data are not available at the regional level.

5. United States: State totals differ from US totals reported elsewhere for four reasons: (1) some R\&D expenditures cannot be allocated to 1 of 50 states or District of Columbia; (2) non-federal sources of other non-profit R\&D expenditures could not be allocated by state; (3) state-level U\&C data have not been adjusted to eliminate double counting of funds passed through from one academic institution to another; and (4) state-level R\&D data are not converted from fiscal years to calendar years. 


\section{R\&D personnel (headcounts) - Chapter 14}

\begin{tabular}{|c|c|c|c|c|}
\hline & Notes & Source & Years & Territorial level \\
\hline EU21 countries & (1) & Eurostat, Total R\&D personnel by sectors of performance (employment) and region & 2007 & 2 \\
\hline Australia & (3) & - & - & - \\
\hline Canada & $(2)$ & $\begin{array}{l}\text { Statistics Canada, Science Statistics, May } 2008 \text { edition, 88-001-X, www.statcan.ca/english/ } \\
\text { freepub/88-001-XIE/2008001/tablesectionlist.htm }\end{array}$ & 2007 & 2 \\
\hline Chile & (3) & & & \\
\hline Iceland & (3) & - & - & - \\
\hline Israel & (4) & $\begin{array}{l}\text { Central Bureau of Statistics. The statistical data for Israel are supplied by and under the } \\
\text { responsibility of the relevant Israeli authorities. The use of such data by the OECD is without } \\
\text { prejudice to the status of the Golan Heights, East Jerusalem and Israeli settlements in the } \\
\text { West. }\end{array}$ & 2007-08 & 2 \\
\hline Japan & (3) & - & - & - \\
\hline Korea & - & Korea Institute of Science and Technology Evaluation and Planning (KISTEP) & 2007 & 2 \\
\hline Mexico & (3) & - & - & - \\
\hline New Zealand & (3) & - & - & - \\
\hline Norway & - & Eurostat, Total R\&D personnel by sectors of performance (employment) and region & 2007 & 2 \\
\hline Switzerland & (3) & - & - & - \\
\hline Turkey & (3) & - & - & - \\
\hline United States & (3) & - & - & - \\
\hline
\end{tabular}

1. EU21 countries: Austria, Belgium, Czech Republic, Denmark, Estonia, Finland, France, Germany, Greece, Hungary, Ireland, Italy, Luxembourg, Netherlands, Poland, Portugal, Slovak Republic, Slovenia, Spain, Sweden and the United Kingdom.

2. Data for France refer to the year 2004. Greece 2005.

3. Canada: Data are expressed in full-time equivalent.

4. Australia, Chile, Iceland, Japan, Mexico, New Zealand, Switzerland, Turkey and United Kingdom: Data not available at the regional level.

5. Israel: Data available only for business and HEI expenditure. Data are expressed in full-time equivalent.

\section{PCT patents applications - Chapters 16, 17 and 32}

\section{National data: OECD REGPAT Database}

\begin{tabular}{lllll}
\hline & Notes & Source & Years & Territorial level \\
\hline All countries & $(1),(2),(3)$ & OECD REGPAT Database & $1995-2007$ & 2 and 3 \\
\hline
\end{tabular}

1. The OECD REGPAT Database presents patent data that have been linked to regions according to the addresses of the applicants and inventors. For more information on the database, see: www.oecd.org/dataoecd/22/19/40794372.pdf.

2. A patent is generally granted by a national patent office or by a regional office that does the work for a number of countries, such as the European Patent Office and the African Regional Intellectual Property Organization. Under such regional systems, an applicant requests protection for the invention in one or more countries, and each country decides as to whether to offer patent protection within its borders. In this publication the patent data comes from the WIPOadministered Patent Cooperation Treaty (PCT) which provides for the filing of a single international patent application which has the same effect as national applications filed in the designated countries. An applicant seeking protection may file one application and request protection in as many signatory states as needed. More info on PCT can be found here: www.wipo.int/export/sites/www/pct/en/basic_facts/faqs_about_the_pct.pdf.

3. Patent counts are provided for selected technology areas such as information and communication technology (ICT), biotechnology, nanotechnology and for technologies related to the environment. For more information, see www.oecd.org/ dataoecd/5/19/37569377.pdf. For classifications of green and renewable energy patents, see www.oecd.org/environment/ innovation/indicator. 


\section{Primary and disposable income of households - Chapter 18}

\begin{tabular}{|c|c|c|c|c|}
\hline & Notes & Source & Years & Territorial level \\
\hline EU21 countries & (1) & Eurostat, Household income statistics, primary and disposable income & $1995-2007$ & 2 \\
\hline Australia & - & $\begin{array}{l}\text { Australian Bureau of Statistics, Household Income Account and Per Capita, } \\
\text { cat. } 5220.0\end{array}$ & $1990-2010$ & 2 \\
\hline Canada & - & Statistics Canada, CANSIM table 384-0012 & $1990-2009$ & 2 \\
\hline Chile & (3) & Mideplan. Household income data & $\begin{array}{l}1990,1992,1994,1996 \\
1998,2000,2003,2006\end{array}$ & 2 \\
\hline Iceland & $(2)$ & - & - & - \\
\hline Israel & $(3)$ & $\begin{array}{l}\text { Central Bureau of Statistics- Income Survey. The statistical data for Israel } \\
\text { are supplied by and under the responsibility of the relevant Israeli authorities. } \\
\text { The use of such data by the OECD is without prejudice to the status of the Golan } \\
\text { Heights, East Jerusalem and Israeli settlements in the West. }\end{array}$ & $1995-2009$ & 2 \\
\hline Japan & - & Cabinet Office, Government of Japan, Gross Prefectural Products & $1996-2007$ & 2 \\
\hline Korea & $(2)$ & & & \\
\hline Mexico & $(2)$ & & & \\
\hline New Zealand & - & Statistics New Zealand. Household income by region & $1998-2010$ & 2 \\
\hline Norway & - & Statistics Norway & $1995-2007$ & 2 \\
\hline Switzerland & $(2)$ & & & \\
\hline Turkey & $(2)$ & & & \\
\hline United States & - & $\begin{array}{l}\text { Bureau of Economic Analysis. CA30 - Regional economic profiles and CA35 } \\
\text { - Personal current transfer receipts }\end{array}$ & $1990-2008$ & 2 \\
\hline
\end{tabular}

1. EU21 countries: Austria, Belgium, Czech Republic, Denmark, Estonia, Finland, France, Germany, Greece, Hungary, Ireland, Italy, Luxembourg, Netherlands, Poland, Portugal, Slovak Republic, Slovenia, Spain, Sweden and the United Kingdom.

1.1. Denmark: 2000-07.

1.2. Hungary: $2000-07$.

1.3. Spain: From 1995 to 1999 data not available for the regions Ceuta and Melilla.

1.4. France: $1995,2001-07$.

2. Iceland, Korea, Mexico, Switzerland, and Turkey: Data are not available at the regional level.

3. Chile and Israel: Primary income of households are not available at the regional level. 
Interregional flows of population - Chapter 20

\begin{tabular}{|c|c|c|c|c|}
\hline & Notes & Source & Years & Territorial level \\
\hline Australia & (1) & Australian Bureau of Statistics & 1996-2009 & 2 \\
\hline Austria & - & Statistics Austria, Database for population statistics (POPREG) & 1996-2009 & 3 \\
\hline Belgium & - & - & - & - \\
\hline Canada & (2) & Statistics Canada's E-STAT database Table 051-0019. & $1998-2007$ & NOG \\
\hline Chile & - & - & - & - \\
\hline Czech Republic & - & Czech Central Population Register Regional Yearbooks & 2003-08 & 3 \\
\hline Denmark & - & Statistics Denmark, StatBank, table FLY66 & 1990-2009 & 3 \\
\hline Estonia & - & - & - & - \\
\hline Finland & (3) & Statistics Finland & $1997-2008$ & 3 \\
\hline France & (4) & INSEE & 2006 & 3 \\
\hline Germany & - & Regional Statistics Germany & $1996-2007$ & 3 \\
\hline Greece & - & - & - & - \\
\hline Hungary & - & KSH Hungarian Statistical Office & $1996-2008$ & 3 \\
\hline Iceland & - & - & - & - \\
\hline Ireland & - & - & - & - \\
\hline Israel & - & - & - & - \\
\hline Italy & - & ISTAT Demo & $1998-2007$ & 3 \\
\hline Japan & - & Statistics Japan E-STAT & $1991-2008$ & 3 \\
\hline Korea & - & Statistics Korea KOSIS database & $1995-2009$ & 3 \\
\hline Luxembourg & - & - & & 3 \\
\hline Mexico & - & Consejo Nacional de Población CONAPO & $1996-2008$ & 2 \\
\hline Netherlands & - & Statistics Netherlands on Statline & 2002-07 & 3 \\
\hline New Zealand & - & - & - & - \\
\hline Norway & - & Statistics Norway & 1994-2008 & 3 \\
\hline Poland & - & Statistics Poland, Regional Databank & $1995-2008$ & 3 \\
\hline Portugal & (5) & Statistics Portugal (INE) & 1995 and 2001 & 3 \\
\hline Slovak Republic & - & National Statistics Reg-Dat database & 2001-08 & 3 \\
\hline Slovenia & - & - & - & - \\
\hline Spain & - & National Statistics Institute (INE) & 1998-2008 & 3 \\
\hline Sweden & - & Statistics Sweden Population Registers & $1997-2009$ & 3 \\
\hline Switzerland & - & Swiss Federal Statistical Office & 1996-2008 & 3 \\
\hline Turkey & - & - & $1996-2008$ & 3 \\
\hline United Kingdom & - & National Statistical Office, Population Estimates & 1999-2008 & 3 \\
\hline United States & (6) & $\begin{array}{l}\text { IRS Individual Master File system www.irs.gov/taxstats/article/ } \\
0, i d=212695,00 . h t m I\end{array}$ & $2000-08$ & 3 \\
\hline
\end{tabular}

1. Australia: Data are aggregation of quarterly ABS estimates of migration flows, for the six states and two main territories.

2. Canada: Data are inter-censual estimation, see www.statcan.gc.ca/cgi-bin/imdb/p2SV.pl?Function=getSurvey\&SDDS=4101\&lang=en\&db=imdb\&adm=8\&dis=2.

3. Finland: Data from 1990 to 2005 refer to the old regional classification in 16 regions. From 2005 data refer to the current one in 11 TL3 regions.

4. France: France interregional flows, registered in the 2006 census, refer to change of residence with respect to the previous 2001 census, thus covering mobility over five years.

5. Portugal: Data based on 2001 census micro-data. Data for 1995 refer to flows between 31 December 1995 and 12 March 2001 and data for 2000 refer to flows between 31 December 1999 and 12 March 2001.

6. United States: Secretariat's computation of inflows and outflows at TL3 level by aggregating county-to-county bilateral migration data from the IRS Individual Master File system, based on tax filing units. 


\section{Early school leavers - Chapter 24}

\begin{tabular}{lllcc}
\hline & Notes & Source & Year & Territorial level \\
\hline EU-21 countries & (1) (2) & Eurostat, Labour Force Survey statistics & $2008-09$ & 2 \\
\hline
\end{tabular}

Definition: Early school leavers are defined as the young adults (aged 18-24) who have at most attained a lower secondary school diploma and are not currently following any training.

http://epp.eurostat.ec.europa.eu/portal/page/portal/employment_unemployment_lfs/publications/results

1. EU21 countries: Austria, Belgium, Czech Republic, Denmark, Estonia, Finland, France, Germany, Greece, Hungary, Ireland, Italy, Luxembourg, Netherlands, Poland, Portugal, Slovak Republic, Slovenia, Spain, Sweden and the United Kingdom.

2. In some regions data are not available or not reliable due to very small sample size.

\section{Age-adjusted mortality rate - Chapters 25}

\begin{tabular}{|c|c|c|c|c|}
\hline & Notes & Source & Years & Territorial level \\
\hline EU21 countries & (1) & Eurostat, Regional demographic statistics & 2009 & 2 \\
\hline Australia & - & Australian Bureau Statistics, Demographic Summary, Statistical Areas & 2009 & 2 \\
\hline Canada & (2) & Statistics Canada, 2005, Table 102-0503 & 2008 & 2 \\
\hline Denmark & - & Statbank Denmark. & 2009 & 2 \\
\hline Japan & - & Vital Statistics of Japan & 2009 & 2 \\
\hline Korea & - & Statistics Korea. Population and Housing Census & 2009 & 2 \\
\hline Israel & & $\begin{array}{l}\text { Central Bureau of Statistics (CBS). The statistical data for Israel are supplied by and under } \\
\text { the responsibility of the relevant Israeli authorities. The use of such data by the OECD is } \\
\text { without prejudice to the status of the Golan Heights, East Jerusalem and Israeli } \\
\text { settlements in the West. }\end{array}$ & 2009 & 2 \\
\hline Mexico & - & INEGI, Mortality statistics. & 2009 & 2 \\
\hline New Zealand & (3) & Statistics New Zealand & 2008 & 2 \\
\hline Norway & - & Statistics Norway & 2008 & 2 \\
\hline Switzerland & - & Eurostat. Regional demographic statistics & 2009 & 2 \\
\hline Turkey & (3) & - & - & - \\
\hline United States & - & National Centre for Health Statistics. & 2007 & 2 \\
\hline
\end{tabular}

1. EU21 countries : Austria, Belgium, Czech Republic, Denmark, Estonia, Finland, France, Germany, Greece, Hungary, Ireland, Italy, Luxembourg, Netherlands, Poland, Portugal, Slovak Republic, Slovenia, Spain, Sweden and the United Kingdom. Data refer to the age reached during the year.

2. Canada: Death refers to the permanent disappearance of all evidence of life at any time after a live birth has taken place. Stillbirths are excluded. Age attained at the last birthday preceding death.

3. Turkey: Data are not available at the regional level. 
Number of physicians - Chapter 25

National Data: OECD, Health Database

\begin{tabular}{|c|c|c|c|c|}
\hline & Notes & Source & Years & Territorial Level \\
\hline EU21 countries & (1) & Eurostat, Regional health statistics & 2009 & 2 \\
\hline Australia & (2) & AlHW, Medical labour force survey & 2008 & 2 \\
\hline Canada & (3) & Canadian Institute of Health Information (CIHI) & 2008 & 2 \\
\hline Denmark & & Eurostat, Regional health statistics & - & - \\
\hline Iceland & (5) & & & \\
\hline Ireland & (5) & - & - & - \\
\hline Israel & & $\begin{array}{l}\text { Central Bureau of Statistics (CBS). The statistical data for Israel are supplied by and } \\
\text { under the responsibility of the relevant Israeli authorities. The use of such data by the } \\
\text { OECD is without prejudice to the status of the Golan Heights, East Jerusalem and Israeli } \\
\text { settlements in the West. }\end{array}$ & 2009 & 2 \\
\hline Japan & & $\begin{array}{l}\text { Statistics and Information Department, Minister's Secretariat, Ministry of Health, Labour } \\
\text { and Welfare }\end{array}$ & 2008 & 2 \\
\hline Korea & & Statistics Korea & 2009 & - \\
\hline Luxembourg & - & Eurostat, Regional health statistics & 2004 & 2 \\
\hline Mexico & & National Population Council (Conapo) & 2005 & 2 \\
\hline New Zealand & & Medical Council, The New Zealand Medical Force in 2005 & 2005 & 2 \\
\hline Norway & - & Eurostat, Regional health statistics & 2005 & 2 \\
\hline Switzerland & - & OFAS; FSO, Statistics yearbook 2002 & 2002 & 2 \\
\hline Turkey & & Ministry of Health & 2009 & 2 \\
\hline United Kingdom & - & Eurostat, Regional health statistics & 2000 & 2 \\
\hline United States & (4) & American Medical Association & 2005 & 2 \\
\hline
\end{tabular}

1. EU21 countries: Austria, Belgium, Czech Republic, Denmark, Estonia, Finland, France, Germany, Greece, Hungary, Ireland, Italy, Luxembourg, Netherlands, Poland, Portugal, Slovak Republic, Slovenia, Spain, Sweden and the United Kingdom.

2. Australia: The data refers to the number of employed medical practitioners, including clinicians and non-clinicians.

3. Canada: Includes physicians in clinical and/or non-clinical practice. Excludes residents and unlicensed physicians who requested that their information not be published as of 31 December 2005, http://secure.cihi.ca/cihiweb/dispPage.jsp?cw_page=AR_14_E.

4. United States: Excludes doctors of osteopathy, and physicians with addresses unknown and who are inactive. Includes all physicians not classified according to activity status.

5. Iceland and Ireland: Data are not available at the regional level. 
Access to piped water, electricity, sewage and fixed telephone - Chapter 26

\begin{tabular}{|c|c|c|c|c|}
\hline & Notes & Source & Years & Administrative Leve \\
\hline Argentina & (1) & $\begin{array}{l}\text { Data from National Company of Hydraulic and Sewerage Works (ENOHSA) provided by } \\
\text { CEPAL and Census data from National Institute of Statistics and Censuses included in } \\
\text { the Minnesota Population Center Integrated Public Use Microdata Series (IPUMS) }\end{array}$ & $\begin{array}{c}1991, \\
2001,2008\end{array}$ & Department \\
\hline Bolivia & - & $\begin{array}{l}\text { Census data from National Institute of Statistics included in the Minnesota Population Center } \\
\text { Integrated Public Use Microdata Series (IPUMS) }\end{array}$ & 1992,2001 & Province \\
\hline Brazil & (2) & $\begin{array}{l}\text { IBGE, Household Survey data provided by CEPAL and Census data from the Institute of } \\
\text { Geography and Statistics included in the Minnesota Population Center Integrated Public Use } \\
\text { Microdata Series (IPUMS) }\end{array}$ & $\begin{array}{c}1991, \\
2000,2009\end{array}$ & State \\
\hline Chile & (3) & $\begin{array}{l}\text { MIDEPLAN, Socioeconomic Characterization Survey provided by CEPAL and Census data } \\
\text { from the National Institute of Statistics included in the Minnesota Population Center } \\
\text { Integrated Public Use Microdata Series (IPUMS) }\end{array}$ & $\begin{array}{c}1992, \\
2002,2009\end{array}$ & Region \\
\hline Colombia & & $\begin{array}{l}\text { Census data from the National Administrative Department of Statistics provided by CEPAL and } \\
\text { included in the Minnesota Population Center Integrated Public Use Microdata Series (IPUMS) }\end{array}$ & 1993,2005 & Region \\
\hline Costa Rica & - & $\begin{array}{l}\text { Census data from National Institute of Statistics and Censuses included in the Minnesota } \\
\text { Population Center Integrated Public Use Microdata Series (IPUMS) }\end{array}$ & 1984,2000 & Province \\
\hline Ecuador & - & $\begin{array}{l}\text { Census data from National Institute of Statistics and Censuses included in the Minnesota } \\
\text { Population Center Integrated Public Use Microdata Series (IPUMS) }\end{array}$ & 1990, 2001 & Province \\
\hline India & - & $\begin{array}{l}\text { National Sample Survey Report No. 535: Housing Condition and Amenities in India: } \\
\text { July 2008-June } 2009\end{array}$ & 2009 & State \\
\hline Mexico & - & $\begin{array}{l}\text { Census data from National Institute of Statistics, Geography, and Informatics included } \\
\text { in the Minnesota Population Center Integrated Public Use Microdata Series (IPUMS) }\end{array}$ & 1995,2005 & State \\
\hline Panama & - & $\begin{array}{l}\text { Census data from Census and Statistics Directorate included in the Minnesota Population } \\
\text { Center Integrated Public Use Microdata Series (IPUMS) }\end{array}$ & 1990,2000 & Province \\
\hline Peru & - & $\begin{array}{l}\text { Census data from National Institute of Statistics and Informatics provided by CEPAL and included } \\
\text { in the Minnesota Population Center Integrated Public Use Microdata Series (IPUMS) }\end{array}$ & 1993, 2007 & Department \\
\hline South Africa & - & $\begin{array}{l}\text { Census data from Statistics South Africa included in the Minnesota Population Center } \\
\text { Integrated Public Use Microdata Series (IPUMS) }\end{array}$ & 1996, 2007 & Province \\
\hline Venezuela & - & $\begin{array}{l}\text { Census data from National Institute of Statistics included in the Minnesota Population Center } \\
\text { Integrated Public Use Microdata Series (IPUMS) }\end{array}$ & 1990,2001 & State \\
\hline
\end{tabular}

1. Figure 26.1 uses 2008 data provided by the Economic Commission for Latin America and the Caribbean (ECLAC-UN), measuring population with access to drinking water network service. Figure 26.2 uses 2001 IPUMS data. Changes in Figure 26.1 are calculated using 1991 as initial year and 2001 as final year.

2. Figure 26.1 uses 2009 data provided by the Economic Commission for Latin America and the Caribbean (ECLAC-UN), measuring the existence of general network of water supply. Figure 26.2 uses 2000 IPUMS data. Changes in Figure 26.3 are calculated using 1991 as initial year and 2000 as final year.

3. Figure 26.1 uses 2009 data provided by the Economic Commission for Latin America and the Caribbean (ECLAC-UN), measuring the existence of drinking water public network inside dwelling. Figure 26.2 uses 2002 IPUMS data. Changes in Figure 26.3 are calculated using 1992 as initial year and 2002 as final year.

\section{Global urban land cover and changes - Chapters 27 and 28}

\begin{tabular}{|c|c|c|c|c|}
\hline & Notes & Source & Years & $\begin{array}{c}\text { Territorial } \\
\text { level }\end{array}$ \\
\hline All countries & & $\begin{array}{l}\text { MODIS 500m Map of Global Urban Extent, SAGE at University of Wisconsin-Madison, available } \\
\text { at www.sage. wisc.edu/mapsdatamodels.html } \\
\text { Schneider, A., Friedl, M., Potere, D., 2009, A new map of global urban extent from MODIS data. } \\
\text { Environmental Research Letters, Vol. 4, article } 044003 \text {. } \\
\text { Schneider, A., Friedl, M., Potere, D., 2010, Monitoring urban areas globally using MODIS 500m } \\
\text { data: New methods and datasets based on "urban ecoregions". Remote Sensing of } \\
\text { Environment, Vol. 114, p. 1733-1746. }\end{array}$ & 2001 & \\
\hline Europe & (1) & Corine land cover & $2000-2006$ & TL3 \\
\hline United States & (1) & National Land Cover Dataset (NLCD). & 2000-2006 & TL3 \\
\hline Japan & (1) & Japan National Land Service Information data. & $1997-2006$ & $\mathrm{~T} \mid 3$ \\
\hline
\end{tabular}

(1) For the changes in land use, three data set were utilized.

The final classification used to calculate the statistics for regions consists of newly defined six classes: 1) Water (lakes, river, lagoons, etc.); 2) Agriculture (annual crops, rice fields, orchards, pastures, etc.); 3) Forest (coniferous, broad-leaved, mixed, etc.); 4) Other (non-forest) natural vegetation (natural grasslands, shrublands, sparsely vegetated areas, etc.); 5) Urban (residential, industrial, major transportation, green urban areas, etc.); 6) Other (bare lands, wetlands, glaciers).

In Chapter 28, Classes 3 (forest) and 4 (other natural vegetation) are considered together as one class (natural vegetation). Transitions between the two classes are much more extensive than the others as a result of forest harvest and re-growing. Also, because of specificity of the Japanese dataset, the definition of Class 4 is much more narrow in this country than in Europe and the United States. 


\section{Global forest land cover - Chapter 28}

\begin{tabular}{|c|c|c|c|c|}
\hline & Notes & Source & Years & $\begin{array}{c}\text { Territorial } \\
\text { level }\end{array}$ \\
\hline All countries & & $\begin{array}{l}\text { MODIS Land Cover Type (MCD1201) product distributed by the Land Processes Distributed } \\
\text { Active Archive Center (LP DAAC), located at the US Geological Survey (USGS) Earth } \\
\text { Resources Observation and Science (EROS) Center (Ipdaac.usgs.gov). }\end{array}$ & 2008 & 2 \\
\hline
\end{tabular}

This is the latest available version of one of the most detailed global land cover datasets from satellite observation. It is produced at $500 \mathrm{mt}$ spatial resolution. It was overlayed with administrative boundary layers at the territorial level 2 to calculate the share of forest in each region in OECD countries and emerging economies. MODIS Land Cover uses IBGP classification, of which the first five classes were considered as forest for the calculation: 1) Evergreen Needleleaf forest; 2) Evergreen Broadleaf forest; 3) Deciduous Needleleaf forest; 4) Deciduous Broadleaf forest; 5) Mixed forest.

\section{Net primary productivity - Chapter 28}

\begin{tabular}{|c|c|c|c|c|}
\hline & Notes & Source & Years & $\begin{array}{l}\text { Territorial } \\
\text { level }\end{array}$ \\
\hline All countries & & $\begin{array}{l}\text { MODIS GPP/NPP project MOD17, Net primary productivity, } 2000-06 \text { annual mean. } \\
\text { Zhao, M. and S.W. Running (2010), "Drought-Induced Reduction in Global Terrestrial Net } \\
\text { Primary Production from } 2000 \text { Through 2009", Science } 20 \text { August, Vol. 329, No. 5994, } \\
\text { pp. 940-943. } \\
\text { ftp.ntsg.umt.edu/pub/MODIS/Mirror/MOD17A3.305/ } \\
\text { Improved_MOD17A3_C5.1_GEOTIFF_1km }\end{array}$ & 2000-06 & - \\
\hline
\end{tabular}

Net primary production (NPP) quantifies the amount of atmospheric carbon fixed by plants and accumulated as biomass (Zhao et al., 2010). The net primary production is the initial step of the carbon cycle and is a significant factor slowing the $\mathrm{CO}_{2}$ concentration in the atmosphere. The measure of net primary productivity used in Chapter 9 is based on the improved MOD17 collection (improvements over the global MODIS NPP algorithm) produced by Maosheng Zhao and colleagues at the University of Montana. The current version is limited to the period from 2000 to 2006 due to inconsistencies in one data input used for the modelling (daily meteorological driver). Updates are expected for the end of 2011.

\section{Concentration of PM2.5 particles - Chapter 29}

\begin{tabular}{|c|c|c|c|c|}
\hline & Notes & Source & Years & $\begin{array}{l}\text { Territorial } \\
\text { level }\end{array}$ \\
\hline All countries & & $\begin{array}{l}\text { Satellite-Derived Surface PM2.5 concentration dataset, 2001-2006 annual mean. } \\
\text { van Donkelaar, A., et al. (2010), "Global Estimates of Exposure to Fine Particulate Matter } \\
\text { Concentrations from Satellite-based Aerosol Optical Depth", Environmental Health } \\
\text { Perspective 118(6), http://fizz.phys.dal.ca/ atmos/g47.swf. }\end{array}$ & 2001-06 & 2 \\
\hline
\end{tabular}

By combining global datasets estimating surface PM2.5concentrations on the basis of satellite measurements $\left(0.1^{\circ}\right.$ degree grid) and even finer population distribution grid (from LandScan 2009) the average exposure of population to these healththreatening particles was estimated. PM2.5 is defined as particles smaller than 2.5 micrometers in diameter and can be of both artificial and natural origin.

\section{$\mathrm{CO}_{2}$ emissions - Chapter 29}

\begin{tabular}{|c|c|c|c|c|}
\hline & Notes & Source & Years & $\begin{array}{c}\text { Territorial } \\
\text { level }\end{array}$ \\
\hline All countries & & $\begin{array}{l}\text { European Commission, Joint Research Centre (JRC)/Netherlands Environmental } \\
\text { Assessment Agency (PBL). Emission Database for Global Atmospheric Research (EDGAR), } \\
\text { release version 4.1. http://edgar.jrc.ec.europa.eu, } 2010\end{array}$ & 2005 & 2 \\
\hline
\end{tabular}

EDGAR database contains country emission values by compound and sector of origin geographically allocated to grid maps with $0.1^{\circ}$ resolution based on data such as location of energy and manufacturing facilities, road networks, shipping routes, human and animal population density and agricultural land use.

To estimate $\mathrm{CO}_{2}$ emissions for regions, multiple datasets representing different sources of $\mathrm{CO}_{2}$ were combined (ground transport, fuel production, industry combustion, agriculture, etc.; air transport and international navigation were excluded). 
Volume of produced waste - Chapter 30

National Data: OECD Key Environmental Indicators (2008)

\begin{tabular}{|c|c|c|c|c|}
\hline & Notes & Source & Years & $\begin{array}{l}\text { Territorial } \\
\text { Level }\end{array}$ \\
\hline Australia & - & Australian Bureau of Statistics, 8698.0, Waste management survey & 2003 & 2 \\
\hline Austria & - & $\begin{array}{l}\text { Umweltbundesamt (Federal Environment Agency) - Inventory of waste management } \\
\text { in Austria }\end{array}$ & 2008 & 2 \\
\hline Belgium & (1) & - & - & - \\
\hline Canada & - & Statistics Canada & 2006 & 2 \\
\hline Chile & $(1)$ & - & - & - \\
\hline Czech Republic & - & Data provided by the delegate & 2008 & 2 \\
\hline Denmark & (1) & - & - & - \\
\hline Finland & (1) & - & - & - \\
\hline France & - & Data provided by the delegate & 2004 & 2 \\
\hline Germany & - & Regional Statistics Germany, Spatial Monitoring System of the BBSR & 2008 & 2 \\
\hline Greece & - & Ministry of Statistics (EL.STAT) & 2008 & 2 \\
\hline Hungary & - & Central Statistical Office (KSH) & 2007 & 2 \\
\hline Iceland & (1) & - & - & - \\
\hline Ireland & $(1)$ & - & - & - \\
\hline Israel & - & Central Bureau of Statistics (CBS) & 2008 & 2 \\
\hline Italy & & Ministry of Statistics (Istat) & 2008 & 2 \\
\hline Japan & - & Ministry of Environment & 2008 & 2 \\
\hline Korea & - & National Waste Generation and Disposal Statistics 2008 & 2007 & 2 \\
\hline Luxembourg & (1) & - & - & - \\
\hline Mexico & - & $\begin{array}{l}\text { INEGI. Con base en SEDESOL. DGOT. Subdirección de Asistencia Técnica a Organismos } \\
\text { Operadores Urbanos Regionales. }\end{array}$ & 2008 & 2 \\
\hline Netherlands & - & Statistics Netherlands & 2008 & 2 \\
\hline New Zealand & (1) & - & - & - \\
\hline Norway & - & Statistics Norway, Statbank & 2008 & 2 \\
\hline Poland & - & Central Statistical Office, M-09 report & 2008 & 2 \\
\hline Portugal & - & Statistics Portugal (INE) & 2006 & 2 \\
\hline Slovak Republic & - & $\begin{array}{l}\text { Statisical survey of the Statistical Office of the SR. Annual reports on municipality waste } \\
\text { are collected from municipalities. }\end{array}$ & 2008 & 2 \\
\hline Spain & - & Ministerio Economía y Hacienda & 2006 & 2 \\
\hline Sweden & (1) & - & - & - \\
\hline Switzerland & (1) & - & - & - \\
\hline Turkey & - & Data provided by the delegate & 2008 & 2 \\
\hline United Kingdom & - & Data provided by the delegate & 2008 & 2 \\
\hline United States & (1) & - & - & - \\
\hline
\end{tabular}

1. Data not available at the regional level.

\section{Recycled waste - Chapter 30}

\begin{tabular}{llcc}
\hline & Notes Source & Years & $\begin{array}{c}\text { Territorial } \\
\text { Level }\end{array}$ \\
\hline EU21 countries & (1) Eurostat Regional environment statistics & $2008-09$ & 2 \\
& (2) (3) & & \\
\hline
\end{tabular}

1. EU21 countries: Austria, Belgium, Czech Republic, Denmark, Estonia, Finland, France, Germany, Greece, Hungary, Ireland, Italy, Luxembourg, Netherlands, Poland, Portugal, Slovak Republic, Slovenia, Spain, Sweden, and the United Kingdom. Data are available for Austria, Belgium, France, Germany, Hungary, Italy, Netherlands, Norway, Poland, Portugal, Slovenia, and the United Kingdom.

2. Last available data in Austria, Norway and United Kingdom is 2009.

3. Germany and the United Kingdom data are available for nationally defined regions that do not correspond to the OECD Territorial Level 2 or 3. Source of data for Italy: ISTAT Banca dati territoriale per le politiche di sviluppo. 
Access to broadband - Chapters 31

\begin{tabular}{|c|c|c|c|c|}
\hline & Notes & Source & Years & $\begin{array}{c}\text { Territorial } \\
\text { Level }\end{array}$ \\
\hline EU21 countries & (1) & Eurostat. Regional information society statistics & 2009 & 2 \\
\hline Australia & - & ABS: TABLE 8146.0 - Household Use of Information Technology, Australia & 2009 & 2 \\
\hline Canada & (2) & - & - & - \\
\hline Chile & (2) & - & - & - \\
\hline Japan & (2) & - & - & - \\
\hline Korea & (2) & - & - & - \\
\hline Israel & (2) & - & - & - \\
\hline Mexico & (2) & - & - & - \\
\hline New Zealand & (3) & $\begin{array}{l}\text { Statistics New Zealand: The Household Use of Information and Communication Technology } \\
\text { (ICT) Survey }\end{array}$ & 2009 & 2 \\
\hline Norway & - & Statistics Norway & 2009 & 2 \\
\hline Switzerland & (2) & - & - & - \\
\hline Turkey & (2) & - & - & - \\
\hline United States & - & Current Population Survey (CPS) Internet Use 2009 & 2009 & 2 \\
\hline South Africa & - & Statistics South Africa & 2009 & 2 \\
\hline
\end{tabular}

1. EU21 countries: Austria, Belgium, Czech Republic, Denmark, Estonia, Finland, France, Germany, Greece, Hungary, Ireland, Italy, Luxembourg, Netherlands, Poland, Portugal, Slovak Republic, Slovenia, Spain, Sweden, and the United Kingdom.

2. Data not available.

3. Data for New Zealand only available for TL3 regions or groups of TL3 regions: Northland; Auckland; Waikato; Bay of Plenty; Gisborne / Hawke's Bay; Taranaki; Manawatu-Wanganui; Wellington; Nelson/Tasman/Marlborough/West Coast; Canterbury; Otago; and Southland

\section{Road network density - Chapters 31}

\begin{tabular}{|c|c|c|c|c|}
\hline & Notes & Source & Years & $\begin{array}{c}\text { Territorial } \\
\text { Level }\end{array}$ \\
\hline EU21 countries & (1) & Regional Transport Statistics & 2009 & 2 \\
\hline Australia & (2) & - & - & - \\
\hline Canada & - & Road Network File 2010, Statistics Canada & 2009 & 2 \\
\hline Chile & (2) & - & - & - \\
\hline Japan & (2) & - & - & - \\
\hline Korea & (2) & - & - & - \\
\hline Israel & (2) & - & - & - \\
\hline Mexico & - & National Institute of Statistics and Geography (INEGI) & 2009 & 2 \\
\hline New Zealand & (2) & - & - & - \\
\hline Norway & - & Regional Transport Statistics & 2009 & 2 \\
\hline Switzerland & - & Regional Transport Statistics & 2009 & 2 \\
\hline Turkey & - & Regional Transport Statistics & 2009 & 2 \\
\hline United States & - & National Transportation Atlas Database, 2010 & 2009 & 2 \\
\hline
\end{tabular}

1. EU21 countries: Austria, Belgium, Czech Republic, Denmark, Estonia, Finland, France, Germany, Greece, Hungary, Ireland, Italy, Luxembourg, Netherlands, Poland, Portugal, Slovak Republic, Slovenia, Spain, Sweden, and the United Kingdom.

2. Data not available. 
Sources of administrative and regional boundaries - Maps

\begin{tabular}{ll}
\hline & Source \\
\hline European regions & Eurostat GISCO reference geodata OEurogeographics \\
Australia & Australian Bureau of Statistics \\
Brazil & The Brazilian Institute of Geography and Statistics (IBGE) \\
Canada & Geography division, Statistics Canada \\
Japan & Japan Statistics Bureau (www.e-stat.go.jp) \\
Korea & Statistics Korea (KOSTAT) \\
Mexico & Mexican National Institute of Statistics and Geography (INEGI) \\
New Zealand & New Zealand Bureau of Statistics \\
United States & US Census Bureau, TIGER database \\
Russian Federation, China, India, Chile, South Africa and Israel regions & FAO Global administrative unit layers (GAUL) \\
International boundaries & FAO Global administrative unit layers (GAUL) \\
\hline
\end{tabular}




\section{ANNEX C}

\section{Indexes and formulas}

\section{Gini index}

Definition: Regional disparities are measured by an unweighted Gini index. The index is defined as:

$$
G I N I=\frac{2}{N-1} \sum_{i=1}^{N-1}\left|F_{i}-Q_{i}\right|
$$

where $N$ is the number of regions, $F_{i}=\frac{i}{N}, \quad Q_{i}=\frac{\sum_{j=1}^{i} y_{j}}{\sum_{i=1}^{n} y_{i}}$ and $y_{i}$ is the value of variable $y$ (e.g. GDP per capita, unemployment rate, etc.) in region $j$ when ranked from low $\left(y_{1}\right)$ to high $\left(y_{N}\right)$ among all regions within a country.

The index ranges between 0 (perfect equality: $y$ is the same in all regions) and 1 (perfect inequality: $y$ is nil in all region except one).

Interpretation: The index assigns equal weight to each region regardless of its size; therefore differences in the values of the index among countries may be partially due to differences in the average size of regions in each country.

\section{Spearman correlation coefficient}

Definition: The Spearman correlation coefficient is a measure of association between two variables to test whether the two variables covary, that is to say whether as one increases the other tends to increase or decrease. The two variables are converted to ranks and a correlation analysis is done on the ranks. The Spearman correlation coefficient varies between -1 and 1 and the significance of this is tested in the same way as for a regular correlation.

In this publication, for each country three Spearman correlation coefficients are computed between the TL2 regional values of a certain variable (for example, mortality rate, municipal waste, labour force with tertiary educational attainments, etc.) and the share of population in the TL2 regions living, respectively, in predominantly urban (PU), intermediate (IN), or predominantly rural (PR) TL3 regions. 


\section{Specialisation index}

Definition: Specialisation is measured according to the Balassa-Hoover index, which measures the ratio between the weight of an industry in a region and the weight of the same industry in the country:

$$
B H_{i}=\frac{Y_{i j} / Y_{j}}{Y_{i} / Y}
$$

where $Y_{i j}$ is total employment of industry $i$ in region $j, Y_{j}$ is total employment in region $j$ of all industries, $Y_{i}$ is the national employment in industry $i$, and $Y$ is the total national employment of all industries. A value of the index above 1 shows specialisation in an industry and a value below 1 shows lack of specialisation.

Interpretation: The value of the specialisation index decreases with the level of aggregation of industries. Therefore, the specialisation index based on a 1-digit industry (e.g. manufacturing) would underestimate the degree of specialisation in all 2-digit industries belonging to it (e.g. textile, chemistry, etc.).

\section{Age-adjusted mortality rates}

Definition: The age-adjusted mortality rate of a region $i$ is defined as the sum over the age group $g(g=1, \ldots, G)$ of the product of the mortality rate in the age group $g$ and the share of the standard population in the same age group.

$$
M R_{i}=\sum_{g=1}^{G} M_{g, i} * P_{g, S t d}
$$

where $M R_{i}$ is the age-adjusted mortality rate in region $i, M_{g, i}$ is the mortality rate in the $g$-th group of the region, and $\mathrm{P}_{g}$, Std is the share of the standard population in the age group $\mathrm{g}$. 


\section{ORGANISATION FOR ECONOMIC CO-OPERATION AND DEVELOPMENT}

The OECD is a unique forum where governments work together to address the economic, social and environmental challenges of globalisation. The OECD is also at the forefront of efforts to understand and to help governments respond to new developments and concerns, such as corporate governance, the information economy and the challenges of an ageing population. The Organisation provides a setting where governments can compare policy experiences, seek answers to common problems, identify good practice and work to co-ordinate domestic and international policies.

The OECD member countries are: Australia, Austria, Belgium, Canada, Chile, the Czech Republic, Denmark, Estonia, Finland, France, Germany, Greece, Hungary, Iceland, Ireland, Israel, Italy, Japan, Korea, Luxembourg, Mexico, the Netherlands, New Zealand, Norway, Poland, Portugal, the Slovak Republic, Slovenia, Spain, Sweden, Switzerland, Turkey, the United Kingdom and the United States. The European Union takes part in the work of the OECD.

OECD Publishing disseminates widely the results of the Organisation's statistics gathering and research on economic, social and environmental issues, as well as the conventions, guidelines and standards agreed by its members. 


\section{OECD Regions at a Glance 2011}

This fourth edition of OECD Regions at a Glance showcases the contribution of regions to stronger, fairer and cleaner economies, drawing both on the latest comparable data and on past trends across regions in OECD countries. It highlights the persistence of regional disparities, underscores unused resources that can be mobilised to maximise regions' competitive edge, and shows the common characteristics of performing regions. The report presents 32 indicators, grouped under three broad themes:

- Regions as drivers for competitiveness

- Inclusion and equal access to quality services in regions

- Environmental sustainability in regions and metropolitan areas

The report includes data on the four newest OECD member countries: Chile, Estonia, Israel and Slovenia. Where available, data on Brazil, China, India, the Russian Federation and South Africa are also included.

\section{Further reading}

OECD Regional Outlook (2011)

Regions Matter: Economic Recovery, Innovation and Sustainable Growth (2009)

Governing Regional Development Policy: The Use of Performance Indicators (2009)

www.oecd.org/regional/regionsataglance

www.oecd.org/gov/regional/statisticsindicators

http://stats.oecd.org/OECDregionalstatistics/

Please cite this publication as:

OECD (2011), OECD Regions at a Glance 2011, OECD Publishing.

http://dx.doi.org/10.1787/reg_glance-2011-en

This work is published on the OECD iLibrary, which gathers all OECD books, periodicals and statistical databases.

Visit www.oecd-ilibrary.org, and do not hesitate to contact us for more information. 